\title{
STRUCTURE, FUNCTIONING AND CONSERVATION OF COASTAL VEGETATED WETLANDS
}

EDITED BY: Jonathan Richir, Steven Bouillon, Sylvie Gobert, Martin Wiggers Skov and Alberto Vieira Borges

PUBLISHED IN: Frontiers in Ecology and Evolution, Frontiers in Earth Science and Frontiers in Environmental Science
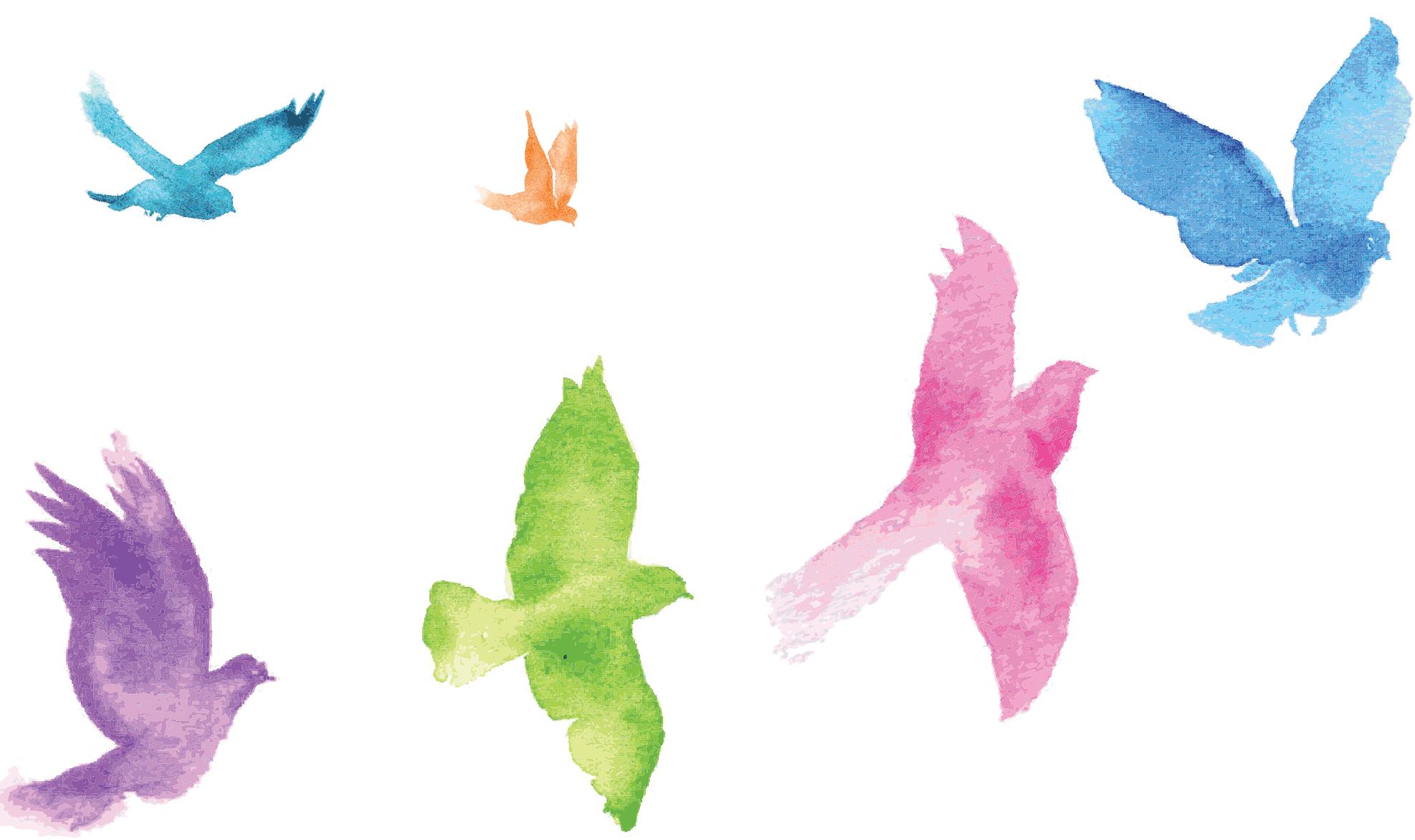


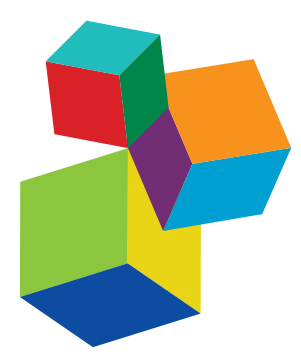

Frontiers eBook Copyright Statement

The copyright in the text of individual articles in this eBook is the property of their respective authors or their respective institutions or funders. The copyright in graphics and images within each article may be subject to copyright of other parties. In both cases this is subject to a license granted to Frontiers.

The compilation of articles constituting this eBook is the property of Frontiers.

Each article within this eBook, and the eBook itself, are published under the most recent version of the Creative Commons CC-BY licence. The version current at the date of publication of this eBook is CC-BY 4.0. If the CC-BY licence is updated, the licence granted by Frontiers is automatically updated to the new version.

When exercising any right under the CC-BY licence, Frontiers must be attributed as the original publisher of the article or eBook, as applicable.

Authors have the responsibility of ensuring that any graphics or other materials which are the property of others may be included in the

CC-BY licence, but this should be checked before relying on the

CC-BY licence to reproduce those materials. Any copyright notices relating to those materials must be complied with.

Copyright and source acknowledgement notices may not be removed and must be displayed in any copy, derivative work or partial copy which includes the elements in question.

All copyright, and all rights therein, are protected by national and international copyright laws. The above represents a summary only.

For further information please read Frontiers' Conditions for Website

Use and Copyright Statement, and the applicable CC-BY licence.

ISSN 1664-8714

ISBN 978-2-88963-843-7

DOI $10.3389 / 978-2-88963-843-7$

\section{About Frontiers}

Frontiers is more than just an open-access publisher of scholarly articles: it is a pioneering approach to the world of academia, radically improving the way scholarly research is managed. The grand vision of Frontiers is a world where all people have an equal opportunity to seek, share and generate knowledge. Frontiers provides immediate and permanent online open access to all its publications, but this alone is not enough to realize our grand goals.

\section{Frontiers Journal Series}

The Frontiers Journal Series is a multi-tier and interdisciplinary set of open-access, online journals, promising a paradigm shift from the current review, selection and dissemination processes in academic publishing. All Frontiers journals are driven by researchers for researchers; therefore, they constitute a service to the scholarly community. At the same time, the Frontiers Journal Series operates on a revolutionary invention, the tiered publishing system, initially addressing specific communities of scholars, and gradually climbing up to broader public understanding, thus serving the interests of the lay society, too.

\section{Dedication to Quality}

Each Frontiers article is a landmark of the highest quality, thanks to genuinely collaborative interactions between authors and review editors, who include some of the world's best academicians. Research must be certified by peers before entering a stream of knowledge that may eventually reach the public - and shape society; therefore, Frontiers only applies the most rigorous and unbiased reviews.

Frontiers revolutionizes research publishing by freely delivering the most outstanding research, evaluated with no bias from both the academic and social point of view. By applying the most advanced information technologies, Frontiers is catapulting scholarly publishing into a new generation.

\section{What are Frontiers Research Topics?}

Frontiers Research Topics are very popular trademarks of the Frontiers Journals Series: they are collections of at least ten articles, all centered on a particular subject. With their unique mix of varied contributions from Original Research to Review Articles, Frontiers Research Topics unify the most influential researchers, the latest key findings and historical advances in a hot research area! Find out more on how to host your own Frontiers Research Topic or contribute to one as an author by contacting the Frontiers Editorial Office: researchtopics@frontiersin.org 


\section{STRUCTURE, FUNCTIONING AND CONSERVATION OF COASTAL VEGETATED WETLANDS}

Topic Editors:

Jonathan Richir, University of Liège, Belgium

Steven Bouillon, KU Leuven, Belgium

Sylvie Gobert, University of Liège, Belgium, STARESO, France

Martin Wiggers Skov, Bangor University, United Kingdom

Alberto Vieira Borges, University of Liège, Belgium

Citation: Richir, J., Bouillon, S., Gobert, S., Skov, M. W., Borges, A. V., eds. (2020). Structure, Functioning and Conservation of Coastal Vegetated Wetlands. Lausanne: Frontiers Media SA. doi: 10.3389/978-2-88963-843-7 


\section{Table of Contents}

05 Editorial: Structure, Functioning and Conservation of Coastal Vegetated Wetlands

Jonathan Richir, Steven Bouillon, Sylvie Gobert, Martin W. Skov and Alberto V. Borges

09 Harnessing Positive Species Interactions to Enhance Coastal Wetland Restoration

Julianna J. Renzi, Qiang He and Brian R. Silliman

23 Increase in Growth and Alteration of C:N Ratios of Avicennia marina and Rhizophora stylosa Subject to Elevated $\mathrm{CO}_{2}$ Concentrations and Longer Tidal Flooding Duration

Adrien Jacotot, Cyril Marchand and Michel Allenbach

34 Intraspecific Root Trait Variability Along Environmental Gradients Affects Salt Marsh Resistance to Lateral Erosion

Davide De Battisti, Mike S. Fowler, Stuart R. Jenkins, Martin W. Skov, Marta Rossi, Tjeerd J. Bouma, Penelope J. Neyland and John N. Griffin

45 The Effects of Tropical Cyclone-Generated Deposition on the Sustainability of the Pearl River Marsh, Louisiana: The Importance of the Geologic Framework

Terrence A. McCloskey, Christopher G. Smith, Kam-biu Liu and Paul R. Nelson

66 Sediment Dynamics of Natural and Restored Bolboschoenus maritimus Saltmarsh

Benjamin W. Taylor, David M. Paterson and John M. Baxter

76 Methane Emissions From the Salt Marshes of Doñana Wetlands: Spatio-Temporal Variability and Controlling Factors

I. Emma Huertas, Mercedes de la Paz, Fiz F. Perez, Gabriel Navarro and Susana Flecha

91 Creek Dynamics Determine Pond Subsurface Geochemical Heterogeneity in East Anglian (UK) Salt Marshes

Alec M. Hutchings, Gilad Antler, Jean V. Wilkening, Anirban Basu, Harold J. Bradbury, Josephine A. Clegg, Marton Gorka, Chin Yik Lin, Jennifer V. Mills, Andre Pellerin, Kelly R. Redeker, Xiaole Sun and Alexandra V. Turchyn

110 No Detectable Broad-Scale Effect of Livestock Grazing on Soil Blue-Carbon Stock in Salt Marshes

Rachel J. Harvey, Angus Garbutt, Stephen J. Hawkins and Martin W. Skov

122 Sowing the Seeds of Seagrass Recovery Using Hessian Bags

Richard K. F. Unsworth, Chiara M. Bertelli, Leanne C. Cullen-Unsworth, Nicole Esteban, Benjamin L. Jones, Richard Lilley, Christopher Lowe, Hanna K. Nuuttila and Samuel C. Rees

129 Light Stress Responses by the Eelgrass, Zostera marina (L)

Chiara M. Bertelli and Richard K. F. Unsworth 
142 A 15-Month Survey of Dimethylsulfoniopropionate and Dimethylsulfoxide Content in Posidonia oceanica

Jonathan Richir, Willy Champenois, Guyliann Engels, Arnaud Abadie,

Sylvie Gobert, Gilles Lepoint, João Silva, Rui Santos, Damien Sirjacobs and Alberto V. Borges

157 Structural Changes of Seagrass Seascapes Driven by Natural and Anthropogenic Factors: A Multidisciplinary Approach

Arnaud Abadie, Jonathan Richir, Pierre Lejeune, Michèle Leduc and Sylvie Gobert

170 Seagrass Removal Leads to Rapid Changes in Fauna and Loss of Carbon Michael N. Githaiga, Anna M. Frouws, James G. Kairo and Mark Huxham 


\title{
Editorial: Structure, Functioning and Conservation of Coastal Vegetated Wetlands
}

\author{
Jonathan Richir ${ }^{1,2 * t}$, Steven Bouillon ${ }^{3 \dagger}$, Sylvie Gobert ${ }^{2,4+}$, Martin W. Skov ${ }^{5 \dagger}$ and \\ Alberto V. Borges ${ }^{1 *+}$ \\ ${ }^{1}$ Chemical Oceanography Unit, FOCUS, University of Liège, Liège, Belgium, ${ }^{2}$ Laboratory of Oceanology, FOCUS, University \\ of Liège, Liège, Belgium, ${ }^{3}$ Department of Earth and Environmental Sciences, KU Leuven, Leuven, Belgium, ${ }^{4}$ Station de \\ Recherches Sous-Marines et Océanographiques (STARESO), Calvi, France, ${ }^{5}$ School of Ocean Sciences, Bangor University, \\ Bangor, United Kingdom
}

Keywords: seagrass, mangrove, saltmarsh, functioning, management, global change, fate of coastal vegetated wetlands

OPEN ACCESS

Edited and reviewed by:

J. Guy Castley,

Griffith University, Australia

${ }^{*}$ Correspondence: Jonathan Richir jonathan.richir@uliege.be Alberto V. Borges alberto.borges@uliege.be

TORCID: Jonathan Richir orcid.org/0000-0001-5890-5724 Steven Bouillon orcid.org/0000-0001-7669-2929 Sylvie Gobert orcid.org/0000-0001-6000-0190 Martin W. Skov orcid.org/0000-0002-7204-3865 Alberto V. Borges orcid.org/0000-0002-5434-2247

Specialty section: This article was submitted to Conservation,

a section of the journal Frontiers in Ecology and Evolution

Received: 19 March 2020 Accepted: 22 April 2020 Published: 29 May 2020

Citation:

Richir J, Bouillon S, Gobert S, Skov MW and Borges AV (2020) Editorial: Structure, Functioning and Conservation of Coastal Vegetated Wetlands. Front. Ecol. Evol. 8:134. doi: 10.3389/fevo.2020.00134

\section{Editorial on the Research Topic}

\section{Structure, Functioning and Conservation of Coastal Vegetated Wetlands}

Coastal vegetated wetlands-mangroves, saltmarshes, and seagrass beds, hereafter called coastal wetlands-are marine ecosystems constituted of rooted macrophytes living intertidally or subtidally (Hopkinson et al., 2012, 2019). They occupy a narrow fringe along the shores of all continents except Antarctica (Duarte et al., 2013; Hopkinson et al., 2019). Their global cover is small, yet they are profoundly important to human livelihoods and the regulation of physical, chemical, and biological processes (Borja et al., 2015), and thus for coastal resilience. Mangroves and saltmarshes contribute 2,000-215,000 US\$ $\mathrm{ha}^{-1} \mathrm{yr}^{-1}$ to coastal economies through the delivery of numerous ecosystem services (Costanza et al., 2014; Gopal, 2016; Macreadie et al., 2019). The equivalent value for seagrass and algae beds is 29,000 US\$ ha ${ }^{-1} \mathrm{yr}^{-1}$ (Costanza et al., 2014; Dewsbury et al., 2016), while climate regulation alone contributes $1,250 \mathrm{US} \mathrm{ha}^{-1}$ to $>90,000$ US\$ ha ${ }^{-1}$ (graphical estimates), with variation depending on the valuation approach and type of coastal wetland (Macreadie et al., 2019). Coastal wetlands have a central role in nature-based flood and erosion protection, much to the interest of mitigative coastal zone planning (Bouma et al., 2014). Up to $10 \%$ of all oceanic carbon passes through coastal wetlands (Jennerjahn and Ittekkot, 2002; Dittmar et al., 2006) and their "blue carbon" burial rates, on a per area basis, exceeds that of most terrestrial forests (Howard et al., 2017). Coastal wetlands are important filters of coastal pollutants and pathogens and provide habitat to a wide array of species, including commercially important fisheries stocks and threatened birds and mammals (Borja et al., 2015; Lamb et al., 2017). Unfortunately, land reclamation, deforestation, eutrophication, and other anthropogenic perturbations threaten coastal wetlands. Although area losses are contextually and geographically variable, with some regions showing gain in wetland cover (Ladd et al., 2019), global declines were 25-50\% over the past five decades (Lotze et al., 2006; Duarte et al., 2013; Telesca et al., 2015) and 54-87\% if including the pre-1900s (Davidson, 2014). The array of functional processes-biological, chemical, physical-which in combination give rise to natural benefits, such as coastal protection and carbon storing, are not always well-understood (Macreadie et al., 2019; Rendón et al., 2019). Nevertheless, ongoing declines in the cover of coastal wetlands will undoubtedly diminish the ecosystem services they provide (Waycott et al., 2009) and could initiate a new source of greenhouse gas emissions through remobilization of carbon they store (Belshe et al., 2017). The current concern is that climate change will affect the functioning and future distribution of coastal wetlands (Wernberg et al., 2016), for instance through poleward 
migration (Sorte et al., 2010), rainfall-driven changes to carbon capturing (Sanders et al., 2016) and shifts in the lateral extent of wetlands due to sea level rise (Pergent et al., 2015; Spencer et al., 2016; Schuerch et al., 2018).

While coastal wetlands were understudied in preceding decades (Orth et al., 2006; Duarte et al., 2008) they are now in vogue and are commonly used as model systems to address globally important research frontiers, such as $\mathrm{CO}_{2}$ emissions after disturbance (Lovelock et al., 2017). Numerous methods and metrics have been used to assess their ecological status (Best et al., 2007; Gobert et al., 2009; Marbà et al., 2013; Faridah-Hanum et al., 2019). Yet, the understanding of their functioning and the use of resultant environmental indices is often inconsistent or not practiced, and/or it is reliant on the knowledge of reference conditions and longterm assessment programs, which may or may not exist (Duarte et al., 2017). Conservation and restoration programs carried out worldwide alongside environmental assessments have yielded both encouraging and disappointing impacts on ecosystem functioning and human welfare (Gittman et al., 2019). Restoration successes depend primarily on the habitat type, site selection and the techniques applied (Bayraktarov et al., 2016). It is essential to have a thorough understanding of the causes for variation in the functioning of coastal wetlands to inform the practices that receive considerable global investment for wetland restoration (Simenstad et al., 2006; Bayraktarov et al., 2016). Lack of research knowledge in many areas of coastal wetland functioning hampers decision-making processes concerning their management and the implementation of successful mitigation programs.

We felt the time was ripe for a special issue to bring together recent research into the functioning of coastal wetlands. The present Research Topic placed particular emphasis on the functioning of seagrasses, saltmarsh plants, and mangrove trees as engineering species, and on processes associated with the ecosystem structure that they constitute. Five main research themes were addressed: (i) biogeochemical fluxes and balances of carbon, nutrients, and chemicals, (ii) coastal and seascape ecology, interspecific relationships, and food webs, (iii) patterns and processes of change in cover and distribution of coastal wetlands, (iv) degradation and resilience to environmental and anthropogenic disturbances, including climate change, and (v) the monitoring, management, and restoration of coastal wetlands. These themes are addressed in this Research Topic e-book by 13 contributions from 67 scientists and 11 countries. Most contributions were made by researchers from the United Kingdom (32), the USA (9), Belgium (8), Spain (5), and France (5), with only two from Africa (Kenya) and Middle East (Israel). All but two of the articles concern seagrass beds and saltmarshes, given the geographic origin of the scientists and research institutes involved. These geographical and system associated biases were unintended and purely a reflection of the manuscript submissions received by the editorial team. The patterns and responses presented in the 13 papers of the Research Topic ebook still provide useful insights for other regions, as well as for other wetland systems.
The Research Topic e-book starts with a review that demonstrates how crucial positive species interactions of mutualism, commensalism, and facilitation are to the restoration and disturbance-recovery of mangroves and saltmarshes (Renzi et al.). Following that is an experimental study on mangrove tree seedling development, which outlines how mangroves could mitigate climate change in the context of rising atmospheric $\mathrm{CO}_{2}$ and increasing tidal flood duration (Jacotot et al.). These first two studies illustrate that successful protection and restoration of coastal wetlands require in-depth knowledge of the biology and dynamics of the species that underpin ecosystem functioning. Sediment dynamics, in particular accretion and erosion, are abiotic processes that greatly influence the distribution and resilience of coastal wetlands, and thus the success of restoration and environmental compensation measures-a point that is exemplified in three saltmarsh papers (De Battisti et al.; McCloskey et al.; Taylor et al.). The spatial complexity of saltmarshes, as an integrated system of vegetated platforms, tidal channels and ponds, gives rise to contextually variable biogeochemistry and resilience to disturbance, as illustrated by two studies (Huertas et al.; Hutchings et al.). Intuitively, one would expect livestock grazing of saltmarshes to have a negative impact on carbon stock; yet a broad-scale study in the UK shows carbon stores were un-affected by variation in the intensity of sheep grazing, probably because grazing has minimal impact on carbon stores relative to the influence of environmental context (Harvey et al.). The Research Topic ebook includes five studies on seagrass beds. These explore an array of topics, from degradation to restoration, at the scale of individual species to whole ecosystems. An experimental, in situ test validates a simple and cost effective method for restoring Zostera marina beds, using seeds packed in hessian bags (Unsworth et al.). In response to water quality degradation, seagrasses exhibit various changes in morphology and physiology. The response of $Z$. marina is tested in controlled laboratory conditions to provide a consistent set of biological response variables to light deprivation and to assign minimum light thresholds for that species (Bertelli and Unsworth). A study shows Posidonia oceanica is the highest marine producer of two organosulfur compounds, dimethylsulfoniopropionate and dimethylsulfoxide, that are central to the marine sulfur cycle and which have mitigating influence on the greenhouse gas effect (Richir et al.). Another study highlights the dichotomous dynamics of seagrass seascapes, as influenced by natural and anthropogenic (anchoring) factors (Abadie et al.). The final paper of the e-book is an 18-month experimental study that demonstrates that seagrass removal in a multi-species tropical meadow causes surface erosion, the diminishing of carbon stock, as well as changes in the local composition of faunal communities (Githaiga et al.).

The novel research findings on the functioning of coastal wetlands published in these 13 studies bring new insights into several research gaps highlighted in this editorial. Although a wide variety of topics have been covered, a common message arises here, which is that we have many shortcomings in our understanding of fundamental ecosystem processes, in particular those associated with ecosystem service delivery. 
This common message is generalisable to all marine and tidal wetlands worldwide. Thus, the e-book underscores the need for continued effort to provide a solid knowledgebase on coastal wetlands, in support of effective management practice, conservation and restoration, and for the benefit of future generations.

\section{REFERENCES}

Bayraktarov, E., Saunders, M. I., Abdullah, S., Mills, M., Beher, J., Possingham, H. P., et al. (2016). The cost and feasibility of marine coastal restoration. Ecol. Appl. 26, 1055-1074. doi: 10.1890/15-1077

Belshe, E. F., Mateo, M. A., Gillis, L., Zimmer, M., and Teichberg, M. (2017). Muddy waters: unintentional consequences of blue carbon research obscure our understanding of organic carbon dynamics in seagrass ecosystems. Front. Mar. Sci. 4:125. doi: 10.3389/fmars.2017.00125

Best, M., Massey, A., and Prior, A. (2007). Developing a saltmarsh classification tool for the European water framework directive. Mar. Pollut. Bull. 55, 205-214. doi: 10.1016/j.marpolbul.2006.08.036

Borja, A., Murillas-Maza, A., Pascual, M., and Uyarra, M. C. (2015). "Marine and coastal ecosystems: delivery of goods and services, through sustainable use and conservation," in Ecosystem Services and River Basin Ecohydrology, eds L. Chicharo, F. Müller, and N. Fohrer (Dordrecht: Springer), 83-105.

Bouma, T. J., Belzen, J., van, Balke, T., Zhu, Z., Airoldi, L., Blight, A. J., et al. (2014). Identifying knowledge gaps hampering application of intertidal habitats in coastal protection: opportunities \& steps to take. Coast. Eng. 87, 147-157. doi: 10.1016/j.coastaleng.2013.11.014

Costanza, R., Groot, R., Sutton, P., van der Ploeg, S., Anderson, S. J., Kubiszewski, I., et al. (2014). Changes in the global value of ecosystem services. Glob. Environ. Change 26, 152-158. doi: 10.1016/j.gloenvcha.2014.04.002

Davidson, N. C. (2014). How much wetland has the world lost? Long-term and recent trends in global wetland area. Mar. Freshw. Res. 65, 934-941. doi: 10.1071/MF14173

Dewsbury, B. M., Bhat, M., and Fourqurean, J. W. (2016). A review of seagrass economic valuations: gaps and progress in valuation approaches. Ecosyst. Serv. 18, 68-77. doi: 10.1016/j.ecoser.2016.02.010

Dittmar, T., Hertkorn, N., Kattner, G., and Lara, R. J. (2006). Mangroves, a major source of dissolved organic carbon to the oceans. Glob. Biogeochem. Cycles 20:GB1012. doi: 10.1029/2005GB002570

Duarte, B., Neto, J. M., Marques, J. C., Adams, J. B., and Caçador, I. (2017). Marine angiosperm indices used to assess ecological status within the Water Framework Directive and South African National Water Act : learning from di ff erences and common issues. Ecol. Indic. 83, 192-200. doi: 10.1016/j.ecolind.2017.07.032

Duarte, C. M., Dennison, W. C., Orth, R. J. W., and Carruthers, T. J. B. (2008). The charisma of coastal ecosystems: addressing the imbalance. Estuar. Coasts 31, 233-238. doi: 10.1007/s12237-008-9038-7

Duarte, C. M., Losada, I. J., Hendriks, I. E., Mazarrasa, I., and Marbà, N. (2013). The role of coastal plant communities for climate change mitigation and adaptation. Nat. Clim. Change 3, 961-968. doi: 10.1038/nclimate1970

Faridah-Hanum, I., Yusoff, F. M., Fitrianto, A., Ainuddin, N. A., Gandaseca, S., Zaiton, S., et al. (2019). Development of a comprehensive mangrove quality index (MQI) in Matang Mangrove: assessing mangrove ecosystem health. Ecol. Indic. 102, 103-117. doi: 10.1016/j.ecolind.2019. 02.030

Gittman, R. K., Baillie, C. J., Arkema, K. K., Bennett, R. O., Benoit, J., Blitch, S., et al. (2019). Voluntary restoration: mitigation's silent partner in the quest to reverse coastal wetland loss in the USA. Front. Mar. Sci. 6:511. doi: 10.3389/fmars.2019.00511

Gobert, S., Sartoretto, S., Rico-Raimondino, V., Andral, B., Chery, A., Lejeune, P., et al. (2009). Assessment of the ecological status of Mediterranean French coastal waters as required by the Water Framework Directive using the Posidonia oceanica Rapid Easy Index: PREI. Mar. Pollut. Bull. 58, 1727-1733. doi: 10.1016/j.marpolbul.2009.06.012

\section{AUTHOR CONTRIBUTIONS}

All authors listed have made a substantial, direct and intellectual contribution to the work, and approved it for publication. JR is a postdoctoral researcher at the Fonds National de la Recherche Scientifique (FNRS) and AVB is a research director at the FNRS.

Gopal, B. (2016). Should 'wetlands' cover all aquatic ecosystems and do macrophytes make a difference to their ecosystem services? Folia Geobot. 51, 209-226. doi: 10.1007/s12224-016-9248-x

Hopkinson, C. S., Cai, W. J., and Hu, X. (2012). Carbon sequestration in wetland dominated coastal systems-a global sink of rapidly diminishing magnitude. Curr. Opin. Environ. Sustain. 4, 186-194. doi: 10.1016/j.cosust.2012.03.005

Hopkinson, C. S., Wolanski, E., Brinson, M. M., Cahoon, D. R., and Perillo, G. M. E. (2019). "Coastal Wetlands: A Synthesis," in Coastal Wetlands, Second Edition: An Integrated and Ecosystem Approach, eds G. M. E. Perillo, E. Wolanski, D. R. Cahoon, and C. S. Hopkinson (Elsevier), 1-75.

Howard, J., Sutton-Grier, A., Herr, D., Kleypas, J., Landis, E., Mcleod, E., et al. (2017). Clarifying the role of coastal and marine systems in climate mitigation. Front. Ecol. Environ. 15, 42-50. doi: 10.1002/fee.1451

Jennerjahn, T. C., and Ittekkot, V. (2002). Relevance of mangroves for the production and deposition of organic matter along tropical continental margins. Naturwissenschaften 89, 23-30. doi: 10.1007/s00114-001-0283-x

Ladd, C. J. T., Duggan-Edwards, M. F., Bouma, T. J., Pagès, J. F., and Skov, M. W. (2019). Sediment supply explains long-term and large-scale patterns in salt marsh lateral expansion and erosion. Geophys. Res. Lett. 46, 11178-11187. doi: 10.1029/2019GL083315

Lamb, J. B., van de Water, J. A., Bourne, D. G., Altier, C., Hein, M. Y., Fiorenza, E. A., et al. (2017). Seagrass ecosystems reduce exposure to bacterial pathogens of humans, fishes, and invertebrates. Science 355, 731-733. doi: $10.1126 /$ science.aal1956

Lotze, H. K., Lenihan, H. S., Bourque, B. J., Bradbury, R. H., Cooke, R. G., Kay, M. C., et al. (2006). Depletion, degradation, and recovery potential of estuaries and coastal seas. Science 312, 1806-1809. doi: 10.1126/science.1128035

Lovelock, C. E., Fourqurean, J. W., and Morris, J. T. (2017). Modeled $\mathrm{CO}_{2}$ emissions from coastal wetland transitions to other land uses: tidal marshes, mangrove forests, and seagrass beds. Front. Mar. Sci. 4:143. doi: $10.3389 /$ fmars.2017.00143

Macreadie, P. I., Anton, A., Raven, J. A., Beaumont, N., Connolly, R. M., Friess, D. A., et al. (2019). The future of Blue Carbon science. Nat. Commun. 10: 3998 doi: 10.1038/s41467-019-11693-w

Marbà N., Krause-Jensen, D., Alcoverro, T., Birk, S., Pedersen, A., Neto, J. M., et al. (2013). Diversity of European seagrass indicators: patterns within and across regions. Hydrobiologia 704, 265-278. doi: 10.1007/s10750-012-1403-7

Orth, R. J., Carruthers, T. J. B., Dennison, W. C., Duarte, C. M., Fourqurean, J. W., Heck, K. L., et al. (2006). A global crisis for seagrass ecosystems. Bioscience 56, 987-996. doi: 10.1641/0006-3568200656987:AGCFSE2.0.CO;2

Pergent, G., Pergent-Martini, C., Bein, A., Dedeken, M., Oberti, P., Orsini, A., et al. (2015). Dynamic of Posidonia oceanica seagrass meadows in the northwestern Mediterranean: could climate change be to blame? C. R. Biol. 338, 484-493. doi: 10.1016/j.crvi.2015.04.011

Rendón, O. R., Garbutt, A., Skov, M., Möller, I., Alexander, M., Ballinger, R et al. (2019). A framework linking ecosystem services and human well-being: saltmarsh as a case study. People Nat. 1, 486-496. doi: 10.1002/pan3.10050

Sanders, C. J., Maher, D. T., Tait, D. R., Williams, D., Holloway, C., Sippo, J. Z., et al. (2016). Are global mangrove carbon stocks driven by rainfall? J. Geophys. Res. Biogeosci. 121, 2600-2609. doi: 10.1002/2016JG003510

Schuerch, M., Spencer, T., Temmerman, S., Kirwan, M. L., Wolff, C., Lincke, D., et al. (2018). Future response of global coastal wetlands to sea-level rise. Nature 561, 231-234. doi: 10.1038/s41586-018-0476-5

Simenstad, C., Reed, D., and Ford, M. (2006). When is restoration not? Incorporating landscape-scale processes to restore self-sustaining ecosystems in coastal wetland restoration. Ecol. Eng. 26, 27-39. doi: 10.1016/j.ecoleng.2005.09.007 
Sorte, C. J. B., Williams, S. L., and Carlton, J. T. (2010). Marine range shifts and species introductions: comparative spread rates and community impacts. Glob. Ecol. Biogeogr. 19, 303-316. doi: 10.1111/j.1466-8238.2009. 00519.x

Spencer, T., Schuerch, M., Nicholls, R. J., Hinkel, J., Lincke, D., Vafeidis, A. T., et al. (2016). Global coastal wetland change under sea-level rise and related stresses: the DIVA Wetland Change Model. Glob. Planet. Change 139, 15-30. doi: 10.1016/j.gloplacha.2015.12.018

Telesca, L., Belluscio, A., Criscoli, A., Ardizzone, G., Apostolaki, E. T., Fraschetti, S., et al. (2015). Seagrass meadows (Posidonia oceanica) distribution and trajectories of change. Sci. Rep. 5:12505. doi: 10.1038/srep 12505

Waycott, M., Duarte, C. M., Carruthers, T. J., Orth, R. J., Dennison, W. C., Olyarnik, S., et al. (2009). Accelerating loss of seagrasses across the globe threatens coastal ecosystems. Proc. Natl. Acad. Sci. U.S.A. 106, 12377-12381. doi: $10.1073 /$ pnas. 0905620106
Wernberg, T., Arenas, F., Olabarria, C., Thomsen M. S., and Mohring, M. B. (2016). "Threats to ecosystem engineering macrophytes: climate change," in Marine Macrophytes as Foundation Species, ed E. Ólafsson (Science Boca Raton, FL: Publisher/CRC Press), 201-225.

Conflict of Interest: The authors declare that the research was conducted in the absence of any commercial or financial relationships that could be construed as a potential conflict of interest.

Copyright (๑) 2020 Richir, Bouillon, Gobert, Skov and Borges. This is an open-access article distributed under the terms of the Creative Commons Attribution License (CC BY). The use, distribution or reproduction in other forums is permitted, provided the original author(s) and the copyright owner(s) are credited and that the original publication in this journal is cited, in accordance with accepted academic practice. No use, distribution or reproduction is permitted which does not comply with these terms. 


\section{OPEN ACCESS}

Edited by:

Martin Wiggers Skov,

Bangor University, United Kingdom

Reviewed by:

Julien Pétillon

University of Rennes 1, France

Anna R. Armitage,

Texas A\&M University, United States

*Correspondence:

Julianna J. Renzi

julianna.renzi@duke.edu

Specialty section:

This article was submitted to Conservation,

a section of the journa

Frontiers in Ecology and Evolution

Received: 30 September 2018 Accepted: 01 April 2019 Published: 18 April 2019

Citation:

Renzi JJ, He Q and Silliman BR (2019)

Harnessing Positive Species Interactions to Enhance Coastal

Wetland Restoration

Front. Ecol. Evol. 7:131 doi: 10.3389/fevo.2019.00131

\section{Harnessing Positive Species Interactions to Enhance Coastal Wetland Restoration}

\author{
Julianna J. Renzi*, Qiang He and Brian R. Silliman \\ Division of Marine Science and Conservation, Duke University, Beaufort, NC, United States
}

Coastal wetlands are among the most productive ecosystems in the world. They generate critical services for humans including shoreline protection, carbon storage, pollution mitigation, and fisheries production. Restoration of coastal wetlands has historically been viewed as a secondary conservation strategy, but recently-given the continued loss of wetlands worldwide-many non-governmental and governmental organizations have elevated habitat restoration to be a primary method for wetland conservation. The long-held paradigm in coastal wetland restoration has been to restore target habitats by reducing physical stressors and avoiding competition among outplants, such as mangrove saplings or Spartina plugs. Recent ecological research, however, reveals that positive species interactions, such as facilitation, are critical to wetland recovery after disturbance. Here, we review the scientific evidence for the importance of positive species interactions in the recovery of salt-marsh and mangrove ecosystems and assess the extent to which they have been integrated into restoration studies. We found that only a small proportion of studies of marsh and mangrove restoration examined the effects of positive species interactions, despite the important role they play in the regrowth of coastal wetlands. We outline how positive species interactions can be systematically incorporated into future restoration work and discuss how this incorporation can help the reestablishment of coastal wetland biota through: (1) trophic facilitation, (2) stress reduction, and (3) associational defenses. The absence of positive interactions in restoration designs may partially explain the significant disparities between the functioning of natural and restored coastal plant ecosystems.

Keywords: salt marshes, mangroves, restoration, positive interactions, facilitation, coastal wetlands

\section{THE IMPORTANCE OF COASTAL WETLANDS AND THE THREATS THEY FACE}

Coastal wetlands are among the most productive ecosystems on Earth and generate vital services that benefit human societies around the world. Sediment-stabilization by wetlands such as salt marshes and mangroves serves to protect coastal communities from storm-waves, flooding, and land erosion (Gedan et al., 2011). Coastal wetlands also reduce pollution from human waste (Kadlec and Wallace, 2008; Yang et al., 2008), remove excess nutrients from the water column (Ouyang and Guo, 2016), trap pollutants (Gambrell, 1994), and sequester carbon (Mcleod et al., 2011). Further, near-shore wetlands act as both essential nursery habitats and feeding grounds for game fish, supporting a diverse group of economically important species (Lipcius et al., 2005; Mumby, 2006; Aburto-Oropeza et al., 2008; Nagelkerken et al., 2008). 
Despite their immense ecological and economic importance, coastal wetland ecosystems are in decline. In this review, we focus on salt marshes and mangroves, which, like many other coastal wetlands, are facing serious threats from coastal development, a rapidly changing climate, pollution, invasive species, and overfishing. North American salt marshes, for instance, have decreased by 30-90\% (Gedan and Silliman, 2009a). Similarly, in 2001 scientists estimated that over $35 \%$ of mangroves had been lost worldwide, which surpasses habitat losses in other ecosystems such as rainforests (Valiela et al., 2001). Furthermore, mangrove deforestation is not halting; the Food and Agriculture Organization of the United Nations estimates that $1-3 \%$ of the remaining area of mangroves is lost each year (FAO, 2007).

Increased physical stress resulting from coastal development, climate change, and pollution is one of the key mechanisms underlying coastal wetland degradation and loss. Dredging, for example, can alter marsh hydrologic regimes that are vital for determining marsh function (Crain et al., 2009) and economic development can lead to the degradation of coastal ecosystems (He et al., 2014). Climate change and pollution also cause wetland loss by increasing drought, toxicity, and nutrient stress (Bertness et al., 2002; Gedan et al., 2009). Human-induced sea level rise poses a drowning threat to coastal wetlands (Ellison and Stoddart, 1991; Nicholls et al., 1999; Craft et al., 2009), particularly where shoreline development impedes plant migration to higher ground (Schuerch et al., 2018). Similarly, subsidence as a result of sediment starvation is a serious threat to salt marshes around the world (Gedan et al., 2009). On a regional and local level, oil spills frequently harm marsh-associated animals (Zengel et al., 2016); can kill salt-marsh plants, which causes erosion and further ecosystem loss (Silliman et al., 2016); and are responsible for the loss of $\sim 120,000$ ha of mangrove forests (Duke, 2016).

In most coastal wetlands, these physical forces do not act alone; biotic forces also contribute to coastal wetland loss and degradation. An increasingly recognized biotic mechanism of coastal wetland degradation is trophic downgrading (i.e., loss of high trophic-level consumers) as well as its associated interactions with climate stress. Overfishing of consumers, for example, can damage coastal wetlands by releasing grazers from top-down control. Particularly in salt marshes, overfishing of predators has been shown to drive coastal wetland loss by increasing grazing on salt-marsh plants which leads to the development of expansive salt and mudflats (Silliman and Bertness, 2002; Altieri et al., 2012; Silliman et al., 2013; He et al., 2017). In China, Argentina, Canada, and the southern U.S., drought stress has been shown to interact with top-down effects, which can lead to wetland loss (Silliman et al., 2005; Costa et al., 2009; Henry and Jefferies, 2009; He et al., 2017). During droughts, salts build up in the soils and make plants more susceptible to grazing. Once plants die-off and mud flats are formed, elevated salt concentrations in soils and intensified grazing pressure can prevent marsh recovery, resulting in the emergence of a stable alternate mud flat state (Henry and Jefferies, 2009; He et al., 2017). Similarly, reduced habitat complexity, which can be a feature of restored marshes (Lawrence et al., 2018), can affect biological interactions that hasten marsh decline. Finke and Denno (2006) found that marsh habitat complexity increases the beneficial impacts of predatory arthropods that control Spartina consumers, while in simplified habitats the beneficial effects of these predators are weakened. In these two cases, both biotic (i.e., grazing, predation) and abiotic (i.e., drought, complexity) factors interact to drive ecosystem change.

Invasive species have also altered the structure and functioning of coastal wetlands. A meta-analysis of aquatic biotic invasions revealed that invasive species decrease native species abundances as well as alter nutrient cycling across diverse ecosystems, including coastal wetlands (Gallardo et al., 2016). In eastern U.S. salt marshes, for instance, invasive species such as Phragmites australis can alter trophic structure (Gratton and Denno, 2005, 2006) and outcompete native species, reducing ecosystem diversity (Silliman and Bertness, 2004; Minchinton et al., 2006). In Chinese, western U.S., Australian, and Mediterranean salt marshes, Spartina species and their hybrids are outcompeting native species and taking over mudflats (Nieva et al., 2005; An et al., 2007; Strong and Ayres, 2009). Although less studied, mangroves are also affected by species invasions (Biswas et al., 2007), which likely influences community functioning. In many cases, these invasions can be exacerbated by human-induced changes, such as eutrophication, which have the potential to facilitate the spread of non-native species (e.g., Tyler et al., 2007). Additionally, younger ecosystems may be more susceptible to species invasions (e.g., native invasion in Veeneklaas et al., 2013) and estuarian wetlands are particularly susceptible to invasions (Byers, 2009), making a thorough understanding of species interactions particularly relevant to coastal wetland restoration projects.

\section{THE ROLE OF RESTORATION IN THE FUTURE OF COASTAL WETLANDS}

Given the current state of coastal wetlands, immediate action is needed to slow the loss of these systems and bolster the services they provide. Although preservation is typically seen as the best way to conserve ecosystems, in some cases restoration may be a better or key supplemental option (Possingham et al., 2015) and vital to the future of natural habitats (Dobson et al., 1997). Particularly if sea level rises faster than shoreline wetlands can migrate, if migration is impeded by coastal development, or if environmental disturbances increase, restoration that facilitates wetland migration and/or re-colonization after die off may be essential to ensure wetland functional longevity. Indeed, major non-governmental and governmental organizations are beginning to discuss whether restoration at large scales (10$1,000 \mathrm{~s} \mathrm{~km}^{2}$ ) can be an effective way to not only halt decline, but actually increase total wetland coverage, and the United Nations declared the upcoming 10 years the decade of restoration.

Many restored ecosystems, however, fail to completely achieve the structure and functioning of natural communities. Recovering wetland diversity through restoration can take decades (Borja et al., 2010) and many projects never achieve the desired state, which can limit the ecosystem services they provide. A global meta-analysis across a variety of ecosystems revealed that restored sites consistently have lower biodiversity 
than natural sites (Rey Benayas et al., 2009). A study in western India found that restored mangroves contributed only $22 \%$ of what natural forests contribute to associated fisheries (Das, 2017) and a study in southeast England found that even after 100 years most restored salt marshes failed to replicate natural species richness (Garbutt and Wolters, 2008). In addition to having lower supporting and regulating services (Meli et al., 2014), restored ecosystems may have altered levels of biogeochemical function. Even decades after restoration is initiated, important nutrients like carbon and nitrogen may be dramatically lower. A 2012 meta-analysis of coastal and inland wetlands by Moreno-Mateos et al. (2012) found that restored sites had 26\% lower functioning in terms of structural services and $23 \%$ lower functioning in terms of biogeochemical services.

In addition to ecological challenges, restoration can be costly and impractical at large scales, particularly if restored areas are slow to become self-sustaining. In 2010 the median reported restoration cost was $\$ 8,961$ for one hectare of mangrove and $\$ 67,128$ for one hectare of salt marsh (Bayraktarov et al., 2016). If restoration is going to be a primary mechanism for wetland recovery, as conservation organizations have proposed, we need to improve restoration efficiency (e.g., the cost to amount of restored habitat ratio) and implement restoration designs that support the rapid creation of natural, highfunctioning wetlands. Although restoration ecology often draws from ecological theory and understanding (Palmer et al., 1997; Young et al., 2005), marine managers often do not integrate important ecological concepts (e.g., positive species interactions) into restoration projects, which may mean coastal wetland restoration is underperforming (e.g., Shaver and Silliman, 2017; Zhang et al., 2018).

\section{IMPORTANCE OF POSITIVE INTERACTIONS IN COASTAL WETLANDS}

Positive interactions are interactions between organisms where at least one partner benefits and no partners are adversely impacted (e.g., mutualism, commensalism, facilitation). Over the past few decades, ecological experiments have shown that positive interactions are critical to the success and recovery of ecosystems (Stachowicz, 2001; Bruno et al., 2003; Hay et al., 2004). For example, oysters recruit to other oyster shells, which offer predator protection (O'Beirn et al., 2000); seagrass can reduce desiccation stress for other seagrasses (Tsai et al., 2010); and adult sea urchins protect urchin larvae (Quinn et al., 1993).

Recolonization and succession processes, which are integral to restoration, are influenced by positive interactions. In the case of seagrass, facultative rhyizophytic algae can help plants overcome nutrient limitations, which facilitates the recolonization of nutrient-limited seagrasses (Williams, 1990). In the rocky intertidal zone, coralline algae and understory species can facilitate kelp recruitment and canopy cover (Barner et al., 2016). Similarly, in mangroves and salt marshes, neighboring plants can reduce both soil salt and low oxygen stress, while aboveground plant structure can create habitat that facilitates biodiversity by lowering predation and insolation stress for associated species
(Figures 1, 2). These interactions often create positive feedback loops, where the establishment of new species is aided by the addition of another species-a process that can and should be harnessed in restoration and recolonization. When these interactions are missing, communities may struggle to recover and the development of biodiversity and ecosystem functioning may be hindered.

A recent multi-ecosystem meta-analysis (He et al., 2013) revealed that positive interactions are particularly important in stressful environments (i.e., the Stress Gradient Hypothesis) such as tidal flats, which experience extreme salinity and tidal fluctuations. These results also revealed that positive interactions are critical for plant community diversity and function during ecosystem recovery from disturbance (e.g., large scale plant mortality due to drought). To elucidate the potential importance of positive species interactions to coastal wetland restoration efforts, we first examine how positive interactions are crucial to salt marsh and mangrove recovery from disturbance via (1) stress amelioration, (2) associational defenses, and (3) trophic facilitation (Figures 1, 2) and then outline how these positive interactions can be systematically incorporated into coastal wetland restoration plans.

\section{Stress Amelioration}

Natural clumping of foundation species such as oysters, mussels, or mangroves is common in stressful environments where survivorship of individuals is higher in groups than when found alone. Clumped organisms can reduce both physical (e.g., low oxygen) and biological (e.g., predation) stress, which facilitates conspecifics as well as other associated species, allowing for community development. For instance, oxygen stress in mudflats is often alleviated through positive interactions among clumped marsh plants and mangrove saplings. Salt-marsh grasses and mangroves planted closely together benefit from oxygen leaking out of the roots of nearby plants (Howes et al., 1986; Gedan and Silliman, 2009b) and plants in clumps can grow 2-3x faster (Silliman et al., 2015). Similarly, mangroves can lessen sedimentation and salinity stress for other mangroves or other foundation species such as oysters (Aquino-Thomas and Proffitt, 2014). Species that benefit from the establishment of these foundation species can generate further positive feedbacks through reciprocal facilitation. For instance, fiddler crabs benefit from the conditions provided by foundation species and in turn increase oxygen availability for marsh plants through burrowing (Bertness, 1985); detritivores recycle nutrients in mangrove ecosystems (Nagelkerken et al., 2008); and mangrove crabs reduce anoxic conditions in sediments (Stieglitz et al., 2000), improving conditions for associated species.

Positive interactions can also ameliorate nutrient stress in coastal wetlands. For example, sponges on mangrove roots provide nitrogen to and receive carbon from mangroves, which promotes the growth of both species (Ellison et al., 1996). Similarly, mutualistic mussels can augment Spartina success and resilience after disturbance by reducing sulfide and nutrient stress (Derksen-Hooijberg et al., 2018) and marsh crabs can slow soil nitrogen depletion, promoting the growth of marsh plants (Zhang et al., 2013). Although less visually apparent, 


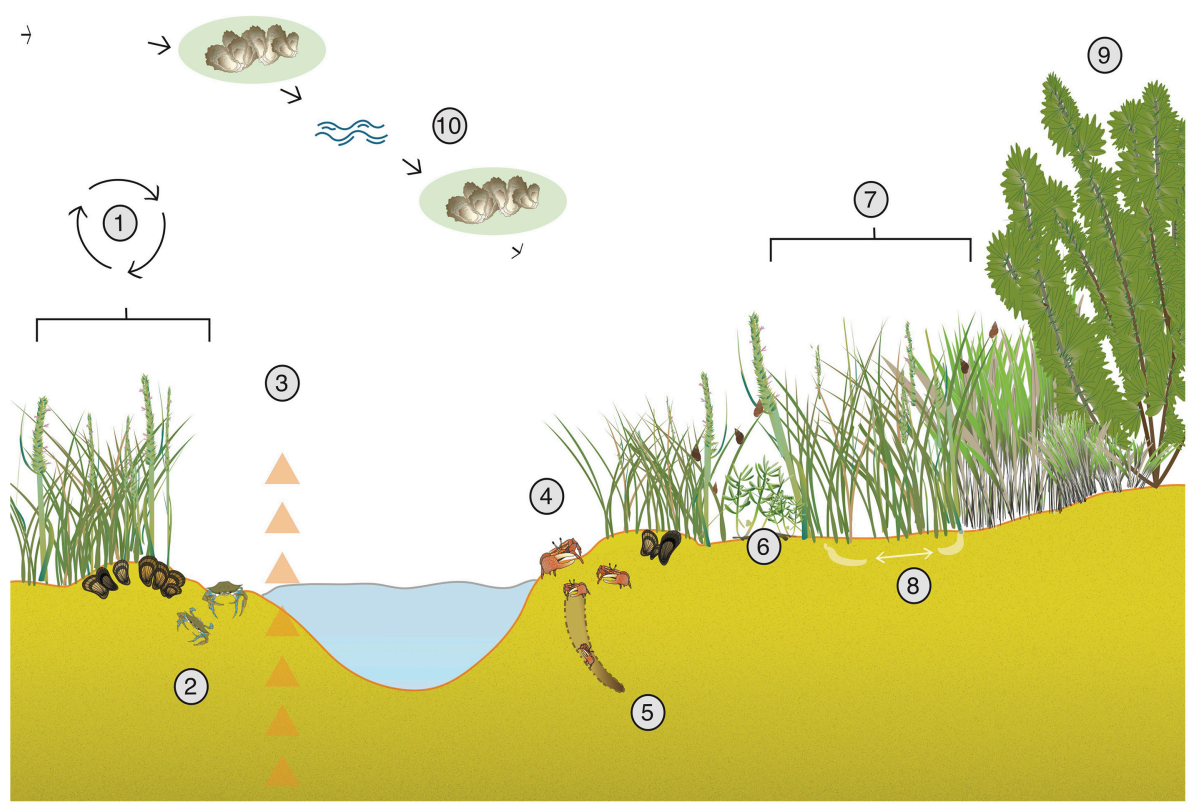

FIGURE 1 | Examples of positive interactions in salt-marsh ecosystems. (1) Mussels provide nutrients to marsh grasses, reduce sulfide stress (Derksen-Hooijberg et al., 2018), enhance biodiversity (Angelini et al., 2015), and increase marsh resistance to drought (Angelini et al., 2016). Cordgrass facilitates mussel establishment (Bertness and Grosholz, 1985) and reduces heat stress (Angelini et al., 2015). (2) Predators such as blue and green crabs act as important top-down controls on herbivores and help prevent run-away grazing on marsh grasses (Silliman and Bertness, 2002; Bertness and Coverdale, 2013). (3) High densities of salt-marsh plants increase wave attenuation, promote sedimentation, and thus increase sediment accumulation (Borsje et al., 2011). (4) Fiddler crabs can mitigate stress caused by snail grazing (Gittman and Keller, 2013) and the facultative effect of mussels and fiddler crabs can be increased when present together (Hughes et al., 2014). (5) Fiddler crab burrowing can increase oxygen in marsh sediments (Bertness, 1985). Further, crab burrowing can faciliate mycorrhizal fungi, which can account for $\sim 35 \%$ of plant growth (Daleo et al., 2007). (6) Biodiverse assemblages increase biomass and nitrogen accumulation (Callaway et al., 2003). (7) Marsh grasses mixed with other plants can provide a refuge for snails from predators and indirectly protect grasses from grazing (Hughes, 2012). (8) Close by marsh grasses can help reduce communal stress as they provide shade (Whitcraft and Levin, 2007) and oxygen to sediments (Howes et al., 1986). (9) Spartina alterniflora can act as a nurse plant for other species (Egerova et al., 2003). (10) Salt marshes provide nutrients to neighboring ecosystems (van de Koppel et al., 2015) and long-distance facilitation from nearby systems such as oyster reefs can reduce wave stress (Meyer et al., 1997). See acknowledgments for vector credits.

microorganisms living symbiotically with marsh plants or mangroves in natural communities can also promote plant growth and aid in restoration yields (Bashan and Holguin, 2002; Daleo et al., 2007; Bledsoe and Boopathy, 2016). In these cases, proximity to other macro- or micro- organisms helps ameliorate the stress of living in a highly dynamic environment. Given that we are discovering an increasing number of positive interactions among organisms that may be pivotal to long-term ecosystem functioning, these examples of stress-reducing, positive species interactions are likely only the beginning of our understanding of facilitation in coastal wetlands.

\section{Associational Defenses}

Wetland species can benefit from the associational defenses of co-occurring organisms. For example, sponges and ascidians on mangrove roots protect mangroves from isopods that impede root growth (Ellison and Farnsworth, 1990). Between plants, mixed stands of mangroves defend trees from crab herbivory (Erickson et al., 2012) and co-occurring marsh plants can reduce snail herbivory on Spartina (Hughes, 2012). Although largely unexplored, there may also be facilitation among different genotypes of coastal wetland plant species. For example, different Spartina genotypes have different morphologies [e.g., heights and stem lengths: (Proffitt et al., 2003)] as well as different interactions with herbivores (Zerebecki et al., 2017). In other plants, genotype has been shown to affect plant interactions with associated species (e.g., ants and aphids on milkweed: Mooney and Agrawal, 2008), which-if present in wetlandsmay provide associational defenses to clumps of foundation species. Associated species can also facilitate non-foundation species, leading to greater ecosystem diversity. For instance, mangrove sponges can encourage growth of other sponge species in return for protection from predators (Engel and Pawlik, 2005).

\section{Trophic Facilitation}

Historically, coastal wetland research focused on how "bottomup" factors, such as nutrient and hydrologic regimes, controlled communities. However, research over the past 15 years has shown that consumer or "top-down" controls on plants are also important (He and Silliman, 2016). Indeed, grazer control of salt-marsh and mangrove plants has been found on every continent where coastal wetlands occur ( $\mathrm{He}$ and Silliman, 2016). Top-down control in food webs can lead to trophic cascades, which indirectly affect plant success. In these cascades predators control grazers, which facilitates plant growth and has positive impacts on coastal wetland structure and function. 


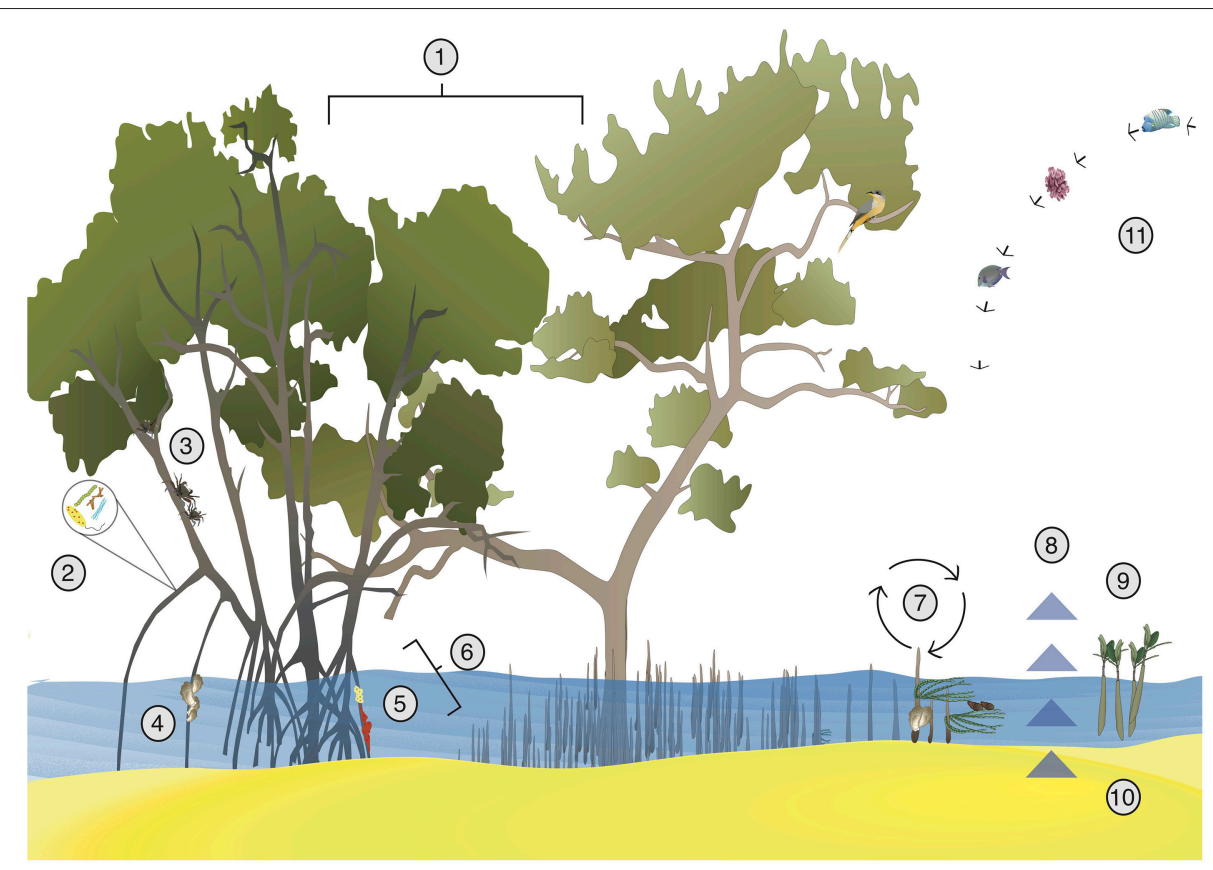

FIGURE 2 | Examples of positive interactions in mangrove ecosystems. (1) Multi-species plantations can sequester more carbon in sediments (Chen et al., 2012) and can increase root yields (Lang'at et al., 2013). (2) Microbial communities receive food from mangrove root exudates and can help recycle nutrients (Bashan and Holguin, 2002). (3) Mixed stands of mangroves can provide association defense against herbivory (Erickson et al., 2012). (4) Mangrove roots allow for oyster recruitment and reduce sedimentation stress, and the presence of oysters in turn supports other species (Aquino-Thomas and Proffitt, 2014). (5) Mangroves provide carbon to sponges and sponges provide nitrogen to mangroves (Ellison et al., 1996). (6) Mangrove roots provide habitat for sponges and tunicates, which protect mangrove roots from harmful isopods (Ellison and Farnsworth, 1990). (7) In a facilitation cascade, mangrove pneumatophores trap algae and oysters, which act as secondary foundation species and support diverse mollusk communities (Bishop et al., 2012). (8) Mangrove plantations sequester carbon in sediments (Mcleod et al., 2011), which is affected by planting density and may be facilitated by top predators (Atwood et al., 2015). (9) Other plant species can increase recruitment of mangroves by trapping seeds and ameliorating abiotic stress (McKee et al., 2007). (10) Higher densities of mangroves can increase seedling success and sediment accumulation, which may allow for more resilience to sea level rise (Huxham et al., 2010). (11) Nearby coral reefs protect mangroves from wave action, while mangroves reduce sedimentation stress and increase reef fish biomass on reefs (van de Koppel et al., 2015). See acknowledgments for vector credits.

The exact species operating in these trophic cascades vary geographically, but generally consist of a top predator that controls an intermediate species, which in turn influences a foundation species (Figure 3). Because foundation species are critical to ecosystem functioning, decreases in top predatorswhich lead to increases in intermediate species and decreases in foundation species-can have ricocheting effects on the entire ecosystem (Figure 3).

In U.S. salt marshes, consumers such as predatory crabs and fish regulate grazers that can decimate cordgrass populations. Overfishing of blue crabs and fish has been linked to marsh vegetation loss through reduced consumer pressure on grazing snails and crabs (Silliman and Bertness, 2002). Trophic cascades are less well-documented in mangrove systems, but are likely important (He and Silliman, 2016). Traditional competition alone does not explain large scale patterns of phytophagous insects and the incorporation of facilitation may improve our understanding of the insects that exert top-down control on plant communities (Kaplan and Denno, 2007), such as those in mangroves.

Ants have been shown to indirectly facilitate mangroves by removing insect herbivores, which in turn makes tree leaves less susceptible to crab herbivory (Offenberg et al., 2006) and predator presence may facilitate carbon sequestration (Atwood et al., 2015). Beyond trophic facilitation via direct consumption, predators can facilitate communities through fear, which can alter herbivore behavior and help maintain important foundation species (Kimbro, 2012).

In addition to protecting coastal wetlands from overgrazing, recent research has shown predators may also facilitate wetland recovery. In New England, for instance, invasive green crabs were found to compensate for native predator declines and facilitate marsh vegetation recovery on Cape Cod by reducing herbivory (Bertness and Coverdale, 2013). Similarly, in seagrass ecosystems Hughes and co-authors found that sea otters could help seagrass resilience by promoting epigrazers (Hughes et al., 2016) and sea otter presence could reduce the impacts of eutrophication on seagrass populations (Hughes et al., 2013). Species that consume fruits may also play an under-appreciated role in ecosystem functions such as seed dispersal. Mangrove-associated birds are important seed dispersers and may facilitate invertebrate dispersal through wading (Buelow and Sheaves, 2015). Similarly, other grazing vertebrates can facilitate marsh seed dispersal by moving uneaten seeds (Shanholtzer, 2012). 


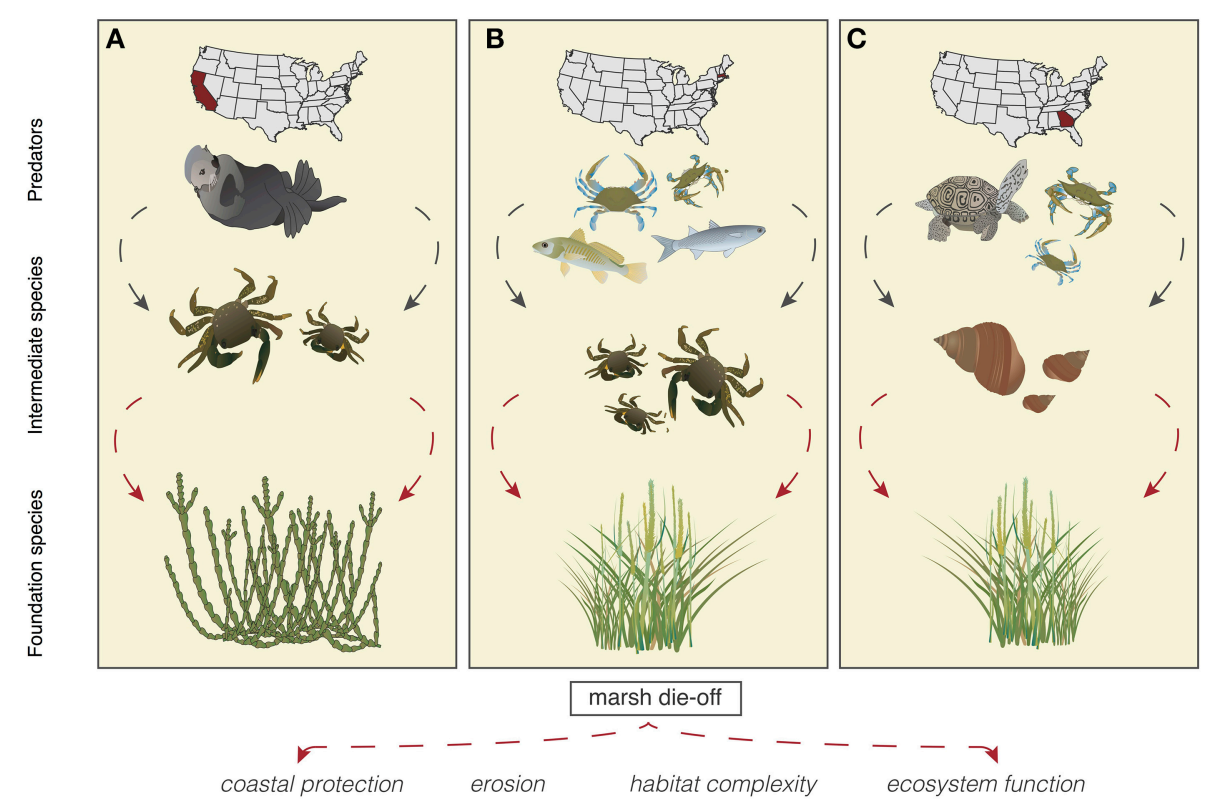

FIGURE 3 | Demonstrated trophic cascades in United States salt marshes. (A) In the western U.S. sea otters control herbivorous crabs, which can cause erosion and loss of salt marshes (Hughes et al., in personal communication). (B) In New England Blue crabs control herbivorous crabs, which can cause runaway grazing on cordgrasses (Altieri et al., 2012). (C) In the Southeast U.S. blue crabs and terrapins control periwinkle snails, which graze on marsh grasses (Silliman and Bertness, 2002). See acknowledgments for vector credits.

The importance of predators in facilitating plants is likely to become more extreme as abiotic stressors increase in coastal wetlands worldwide. For instance in a Chinese salt marsh, He et al. (2017) showed that drought conditions led to complete ecosystem loss in the presence of herbivorous crabs, whereas marsh plants survived drought in areas protected from crabs. Similarly Silliman et al. (2013) found that grazers had a disproportionately large negative impact on marsh cover in declining marshes because grazers flocked to remaining marsh grasses, increasing the relative top-down pressure on surviving grasses. Related research found that wolf spiders can be effective in controlling important Spartina consumers (Prokelisia dolus and Prokelisia marginata), but that the strength of this topdown control was mediated by nutrients and vegetation structure (Denno et al., 2002). Restoration groups that do not address the top-down pressures, as well as bottom-up pressures, on revegetated marshes can suffer significant losses and be forced to continually replant (e.g., He et al., 2017). Robust intact predator assemblages are vital to coastal wetlands as they mediate the effect of primary consumers on foundation species. Through the introduction of predator species, trophic cascades can likely be leveraged to promote restoration.

\section{POSITIVE INTERACTIONS ARE UNDERREPRESENTED IN CURRENT COASTAL WETLAND RESTORATION}

The coastal wetland restoration paradigm is in part borrowed from plantation methodology and forest restoration, which center on the idea that plant populations are limited by physical stress and negative species interactions, such as competition. Accordingly, managers generally disperse outplants and focus on ameliorating abiotic stresses, such as unnatural hydrologic regimes (Silliman et al., 2015). To examine whether the scientific research in coastal wetland restoration reflects these paradigms, we conducted a literature review of relevant articles since 1980. We searched Web of Science for English articles using the search terms: "TS $=$ (restoration) $\mathrm{AND} \mathrm{TS}=$ (salt marsh OR mangrove)" from 1980 to 2017, which yielded 1,415 results. We reviewed abstracts and only included studies about coastal salt marshes and mangroves that were about restoration or conducted in a restored area, which reduced the number of studies to 605 . Of those, only 22 examined positive interactions. The vast majority of studies did not examine biotic interactions, instead focusing on other topics (e.g., physical factors such as hydrologic regimes, policy/management structures) (Figure 4), which may help explain the lag in incorporating facilitation into restoration projects.

There were fewer studies conducted in mangrove than in salt-marsh ecosystems. Of the 605 relevant studies, 395 were about salt marshes, 177 were about mangroves, and 33 looked at both systems. The disproportionately low number of mangrove studies (less than half the number of salt-marsh studies) could partially explain why there are fewer documented trophic cascades and positive interactions in the current body of mangrove research. However, over the past few decades the proportion of mangrove relative to salt-marsh research has increased (Figure 5). The number of new relevant studies was relatively consistent from 1984 to 1995 , with only a few 


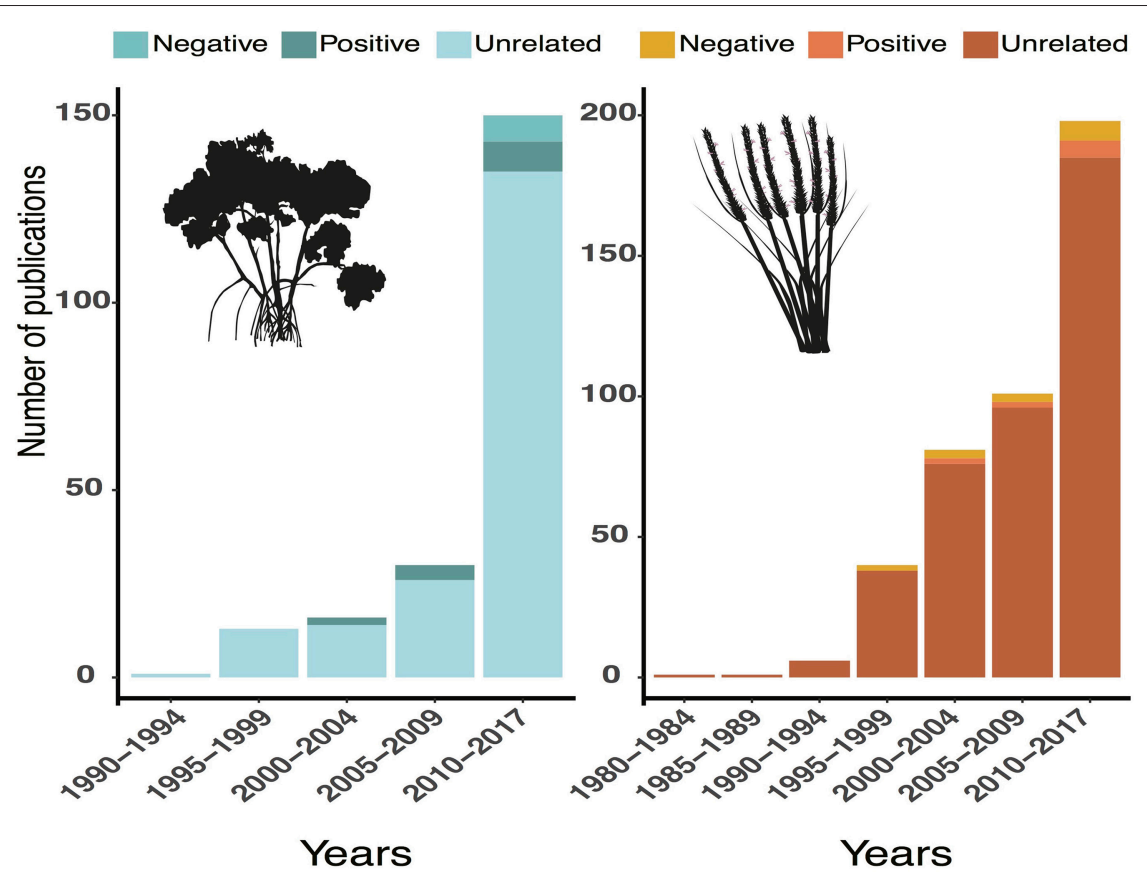

FIGURE 4 | Results from a Web of Science literature review for articles about salt-marsh and mangrove restoration from 1980 to 2017 . See acknowledgments for vector credits.

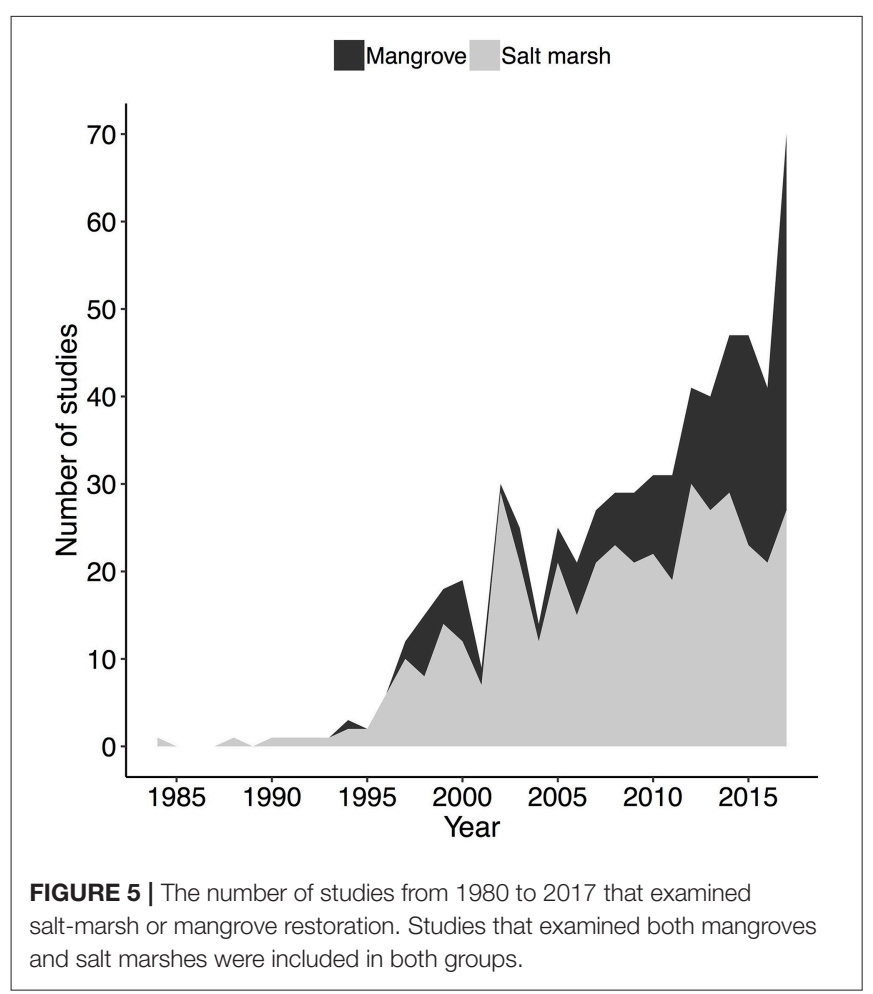

studies coming out each year. Beginning around 1995, however, the annual number of new studies began increasing, with over 60 mangrove and salt-marsh restoration studies published in 2017 (Figure 5).
Over the past decade, in response to primary research showing the importance of positive species interactions in aquatic communities, there have been multiple calls to expand the traditional, abiotic- and competition-centric view of coastal wetland restoration in order to take advantage of positive interactions (Halpern et al., 2007; Silliman et al., 2015; Shaver and Silliman, 2017). Our review, however, suggests that positive interaction research and implementation is lacking in coastal wetland restoration science. Below we outline potential methods for harnessing positive interactions to increase coastal wetland efficiency and success.

\section{Context-Dependent Clumping Design: Moving Away From a Past Paradigm to Reduce Physical Stress}

According to the stress-gradient hypothesis (Bertness and Callaway, 1994), positive interactions are more prevalent, and more important, in stressful environments. In the case of high physical stress, positive interactions help lessen abiotic factors by making the local habitat more suitable. In the case of high consumer pressure, positive interactions become important in the form of associational defenses. At medium levels of stress, competitive interactions tend to dominate. This ecological theory can be translated into restoration practice by implementing a planting design that changes relative to abiotic stresses.

Some of the most prominent stressors in coastal wetlands come from tidal fluctuations. Organisms that live in the intertidal zone must be adapted to deal with an extreme range of temperature, moisture, oxygen, and salinity. For the 


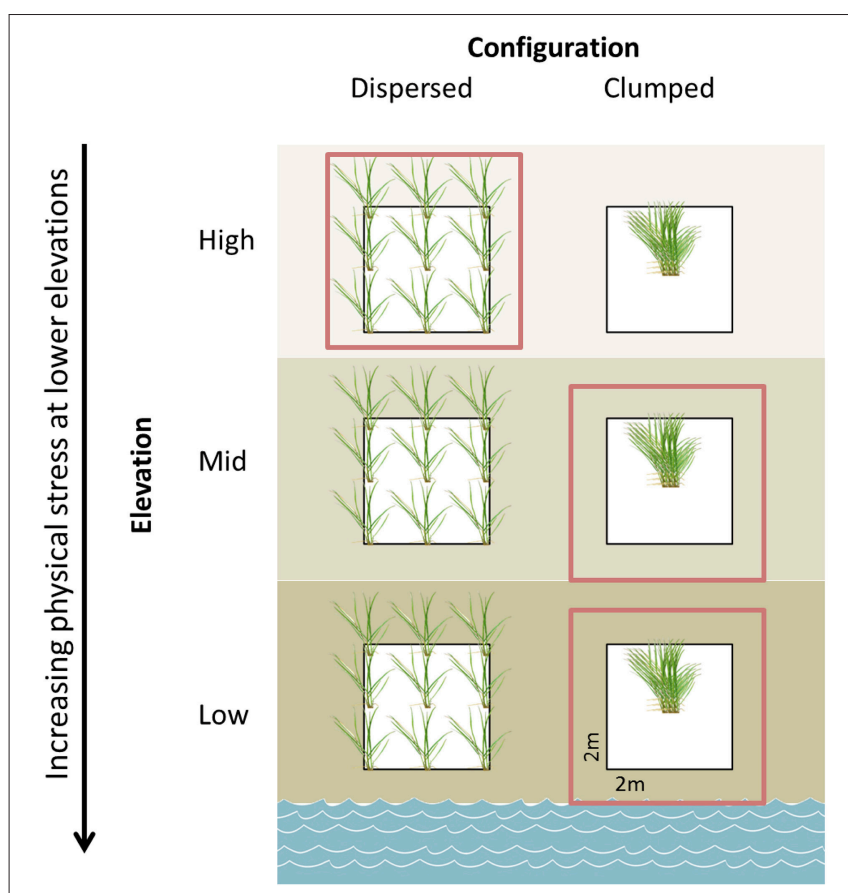

FIGURE 6 | Visual depiction of clumped vs. dispersed restoration designs in a salt marsh with increasing physical stress along an elevation gradient. Red boxes indicate the more efficient method of planting. Created by Amanda Sonti.

purposes of restoration, stress can be approximated by tidal changes, with outplants planted more closely together where the environment is most stressful and outplants planted farther apart where competitive interactions are more likely to be important (Figure 6).

In the intertidal zone, a dense restoration design fosters positive interactions between neighboring conspecifics. For example, clumped planting designs in salt marshes at small scales $\left(1 \mathrm{~m}^{2}\right)$ nearly doubled restoration success (Silliman et al., 2015), and mangrove restoration with a clumped design can result in significantly lower mortality when compared with a uniform design (Sofawi et al., 2017). Clumps of foundation species, such as cordgrass and mangroves, trap sediment, share oxygen, and reduce evaporation through shading. Bare ground can hamper restoration by lowering the redox potential of marsh soils (Mossman et al., 2012), which can be alleviated by denser clumping patters that promote sedimentation and allow colonization by other species (Castellanos et al., 1994). Dispersed designs, which have been prevalent in restoration, lose these benefits because these interactions act on such a local scale (e.g., oxygen leaking from the roots of one plant is only available to a close neighbor). Although less-studied, clumped designs may also allow outplants to reap the benefits of neighbors with different genotypes and promote resilience in periods of stress [e.g., in seagrasses: (Hughes and Stachowicz, 2009)]. However, where competitive interactions dominate, such as in the high intertidal zone where salt and oxygen stress tend to be lower, these interactions become more competitive. Competition for resources then outweighs the benefits provided by conspecifics and a clumped design could result in higher outplant mortality due to limited resources (Silliman et al., 2015). In this case, outplants should be planted in the traditional dispersed design. Therefore, a context-dependent clumping plan that changes dispersal distance with physical and consumer stress (Figure 6) has the potential to increase restoration yields as well as reduce restoration costs.

\section{Holistic, Community-Level Restoration Design: Co-introducing Predators and Biodiverse Assemblages}

In addition to restoring the physical and hydrologic regimes needed to sustain coastal wetlands, managers should restore biotic regimes that support critical foundation species in salt marshes and mangroves. Top predators often have disproportionate impacts on ecosystems (Duffy, 2003) and mediate many of the aforementioned trophic cascades. Although restoration managers have traditionally focused on bottom up controls on restoration (e.g., hydrologic regime, nutrient loading, etc.), top-down controls are vital to coastal wetland ecosystems (He and Silliman, 2016). Loss of predators from coastal wetlands may be one reason for the initial degradation, such as in salt marshes, where overfishing of predatory fish and crabs can lead to marsh die-off through a trophic cascade that facilitates runaway grazing on cordgrass. In these cases, restored coastal wetlands are unlikely to be able to fully recover without predator restoration or restoring wetlands in areas where predators are protected.

In other marine ecosystems, species richness has been shown to improve restoration outcomes (Williams et al., 2017), highlighting the importance of biodiverse assemblages in restoration. Passive restoration designs that rely on dispersal from nearby wetlands can limit restoration projects (e.g., river floodplain: (Bischoff, 2002); freshwater marsh: Neff and Baldwin, 2005) because of the relatively short dispersal distance of species, unless there is a close, well-developed wetland. By introducing a multifarious community of plants and animals along with the focal foundation species, managers introduce diverse services to the ecosystem, which support community development. This introduction leverages documented associational defenses in salt marshes and mangroves, while potentially also leveraging undocumented interactions. Given that positive interactions such as associational defenses are under-studied, introducing an array of organisms similar to the natural community allows for undescribed positive interactions to support wetland functioning. Further, dispersal from these species could potentially "spill-over" into neighboring communities and support populations outside of the restoration area-a phenomenon noted in marine reserves (Halpern and Warner, 2003).

Positive interactions among a suite of community members are likely important to wetland establishment and restoration success. Large-scale meta-analyses suggest that, even in highly diverse marine environments, there is little redundancy (Micheli and Halpern, 2005; Worm et al., 2006), and most organisms provide unique services in an ecosystem. For example, herbaceous plant species can facilitate mangrove restoration after a disturbance, with different species performing different functions, such as trapping propagules, providing abiotic stress 


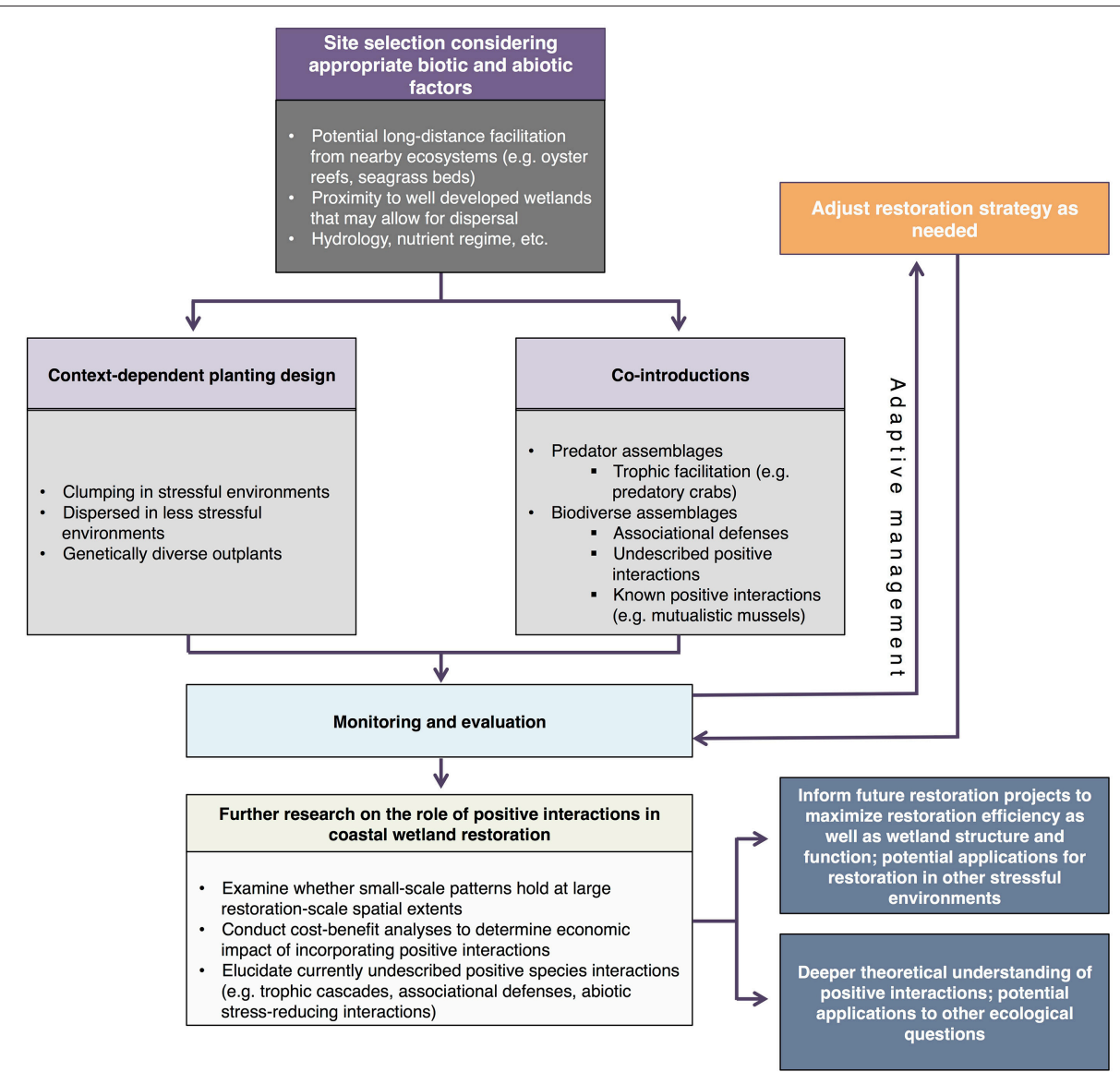

FIGURE 7 | Theoretical diagram describing a potential workflow for systematically incorporating positive species interactions into restoration design.

ameliorations, and creating structural support (McKee et al., 2007). Along the same train of thought, positive interactions are not necessarily linear and some associated species may increase facilitation by other species. For example, the interactive effect of ribbed mussels and fiddler crabs on Spartina is greater when the two species are together than either alone (Hughes et al., 2014). Similarly, organisms associated with foundation species may only have observable positive effects when present together (e.g., Stachowicz and Whitlatch, 2005) and protective animals may be most effective in the presence of other codefenders (e.g., McKeon et al., 2012). If biodiverse assemblages of associated species are co-introduced with focal foundation species, these positive interaction networks can be used to restore damaged ecosystems.

\section{Systematic Incorporation of Positive Species Interactions Into Coastal Wetland Restoration}

Positive interactions can be coupled with traditional restoration strategies to create a more efficient strategy for restoring coastal wetlands (Figure 7). When selecting a site, land managers should continue to consider abiotic factors, such as hydrologic and nutrient regimes, but also consider the proximity of a site to other wetlands that can help a developing community through dispersal and long-distance facilitation. Restoration groups can implement a context-dependent clumping design, where clumped designs are used in the most stressful parts of the site and dispersed designs are used in less stressful areas. Introducing both genetically diverse outplants and diverse species assemblages as part of the restoration plan should allow for a suite of positive interactions among wetland organisms and help facilitate the development of a natural community (see Table 1 for examples). Similarly, cointroducing predators, or choosing a site with healthy predator populations, may help increase the resilience of the ecosystem. Although co-introduction of all species would be ideal from an ecological perspective, it is financially prohibitive in many cases. Restoration managers will ultimately need to choose which species to introduce and there will need to be additional research on what introduction combinations are most effective for restoration goals. Beyond initial introductions, consistent monitoring and evaluation of restoration progress (biodiversity, ecosystem function, etc.) is vital to effective restoration. Results from monitoring should be leveraged to adapt restoration strategies as needed, can be used to develop accurate cost-benefit analyses for species co-introductions, and will further inform our understanding of how positive interactions influence coastal wetland restoration. 
TABLE 1 | Examples of positive species interactions in salt marshes and mangroves that may be useful for restoration managers.

\begin{tabular}{|c|c|c|}
\hline Interaction & Species involved & Associated research \\
\hline Reduced oxidative stress for conspecifics & Marsh grass: Marsh grass, Mangrove: Mangrove & Howes et al., 1986; Gedan and Silliman, 2009b \\
\hline Reduced oxidative stress for associated species & Fiddler crab: Marsh grass & Bertness, 1985 \\
\hline Reduced carbon and nitrogen stress & Mangrove: Sponge & Ellison et al., 1996 \\
\hline Reduced wave stress, increased sedimentation & Marsh grass: Marsh grass & Borsje et al., 2011 \\
\hline Reduced long-distance wave stress & Salt marsh: Oyster reef, Mangrove: Coral reef & Meyer et al., 1997; van de Koppel et al., 2015 \\
\hline Promote plant growth & Mangrove: Bacteria, Marsh grass: Bacteria & $\begin{array}{l}\text { Bashan and Holguin, 2002; Bledsoe and Boopathy, } \\
2016\end{array}$ \\
\hline $\begin{array}{l}\text { Promote growth of associated species by acting as a } \\
\text { nurse plant }\end{array}$ & Marsh grass: Associated marsh plants & Egerova et al., 2003 \\
\hline Reduced grazer pressure via top down control & Predatory crabs: Marsh grass & $\begin{array}{l}\text { Silliman and Bertness, 2002; Bertness and Coverdale, } \\
2013\end{array}$ \\
\hline Aid in re-establishment & Mangrove: Associated mangrove plants & McKee et al., 2007 \\
\hline Increase drought resistance & Marsh grass: Mussels & Angelini et al., 2016 \\
\hline Promote biodiversity & Mangrove: Oysters and algae & Bishop et al., 2012 \\
\hline Facilitate recruitment & Associated plant species: Mangrove & McKee et al., 2007 \\
\hline
\end{tabular}

\section{AVENUES FOR FURTHER INVESTIGATION}

Despite mounting evidence of the importance of positive interactions in coastal wetlands, surveys show that the negative interactions model is still an entrenched view in restoration organizations (Silliman et al., 2015). One potential reason for this lag is scale. Although studies on small scales have shown the potential benefit of positive interactions to restoration, there is no guarantee that these results will scale up to whole-wetlandsized projects. More experiments are needed at scales that are relevant to real-world restoration projects, both to better inform managers and to see whether new, unpredicted patterns emerge at larger experimental areas. For example, although many benefits of a clumped planting design are noticeable at small scales (e.g., oxygen benefits), others (e.g., wave attenuation) may be more evident with large experimental units. Largescale experiments would also allow for a cost-benefit analysis that quantifies money saved-or lost-by incorporating positive interactions into restoration. These cost benefits could come in the form of labor reductions or resource reductions (e.g., fewer plants planted). Concrete numbers on potential economic savings could prove persuasive for restoration organizations considering incorporating facilitation into foundation species restoration projects.

Coastal wetlands are valued for their ability to sequester carbon, which is largely unparalleled in other ecosystems. Although carbon sequestration by wetlands is studied around the world, we have not quantified how positive interactions may change the ability of coastal wetlands to sequester carbon.
This quantification could act as an economic mechanism for restoration, particularly when carbon incentives are in place. Given that positive interactions can alter plant productivity, plants may sequester more carbon through growth and given the heightened sediment-trapping abilities of closely planted species, higher planting densities can be related to higher sediment organic carbon levels (e.g., Chen et al., 2017). Facilitation in the form of predator reintroduction could also positively benefit blue carbon stocks (Atwood et al., 2015), which further emphasizes the importance of holistic, community-scale restoration designs for both ecosystem services (e.g., carbon sequestration) and community development.

Despite these gaps, there is a large body of evidence that supports the importance of positive interactions in coastal wetland functioning. While we focus on three categories of positive interactions, there are many instances of positive interactions present in wetlands (e.g., Figures 1,2) and likely still more to be discovered, such as hitherto undescribed instances of long-distance facilitation and undescribed facilitation cascades. Harnessing the current research on positive interactions, along with insights from future research, to improve restoration is an untapped opportunity that could dramatically improve the outlook of wetland restoration-and the future of the vital ecosystem services they provide.

\section{AUTHOR CONTRIBUTIONS}

BS conceived of the idea for the manuscript. JR wrote the initial draft, conducted the literature review, and created 
Figures 1-5 as well as Figure 7. QH and BS helped develop the concepts presented here, and supervised the project. All authors contributed to the fundamental ideas presented in and reviewing of the manuscript.

\section{FUNDING}

Funding was provided by the Lenfest Ocean Program Grant and JR was supported by a National Science Foundation Graduate Research Fellowship (NSF Grant DGE-1644868).

\section{REFERENCES}

Aburto-Oropeza, O., Ezcurra, E., Danemann, G., Valdez, V., Murray, J., and Sala, E. (2008). Mangroves in the Gulf of California increase fishery yields. Proc Natl Acad Sci U.S.A. 105, 10456-10459. doi: 10.1073/pnas.0804601105

Altieri, A. H., Bertness, M. D., Coverdale, T. C., Herrmann, N. C., and Angelini, C. (2012). A trophic cascade triggers collapse of a salt-marsh ecosystem with intensive recreational fishing. Ecology 93, 1402-1410. doi: 10.1890/11-1314.1

An, S. Q., Gu, B. H., Zhou, C. F., Wang, Z. S., Deng, Z. F., Zhi, Y. B., et al. (2007). Spartina invasion in China: implications for invasive species management and future research. Weed Res. 47, 183-191. doi: 10.1111/j.1365-3180.2007.00559.x

Angelini, C., Griffin, J. N., van de Koppel, J., Lamers, L. P., Smolders, A. J., DerksenHooijberg, M., et al. (2016). A keystone mutualism underpins resilience of a coastal ecosystem to drought. Nat. Comm. 7:12473. doi: 10.1038/ncomms12473

Angelini, C., van der Heide, T., Griffin, J. N., Morton, J. P., DerksenHooijberg, M., Lamers, L. P., et al. (2015). Foundation species' overlap enhances biodiversity and multifunctionality from the patch to landscape scale in southeastern United States salt marshes. Proc. R. Soc. B. 282:1811. doi: 10.1098/rspb.2015.0421

Aquino-Thomas, J., and Proffitt, C. E. (2014). Oysters Crassostrea virginica on red mangrove Rhizophora mangle prop roots: facilitation of one foundation species by another. Mar. Ecol. Prog. Ser. 503, 177-194. doi: 10.3354/meps10742

Atwood, T. B., Connolly, R. M., Ritchie, E. G., Lovelock, C. E., Heithaus, M. R., Hays, G. C., et al. (2015). Predators help protect carbon stocks in blue carbon ecosystems. Nature Clim. Chan. 5, 1038-1045. doi: 10.1038/nclimate2763

Barner, A. K., Hacker, S. D., Menge, B. A., and Nielsen, K. J. (2016). The complex net effect of reciprocal interactions and recruitment facilitation maintains an intertidal kelp community. J. Ecol. 104, 33-43. doi: 10.1111/1365-2745.12495

Bashan, Y., and Holguin, G. (2002). Plant growth-promoting bacteria: a potential tool for arid mangrove reforestation. Trees 16, 159-166. doi: 10.1007/s00468-001-0152-4

Bayraktarov, E., Saunders, M. I., Abdullah, S., Mills, M., Beher, J., Possingham, H. P., et al. (2016). The cost and feasibility of marine coastal restoration. Ecol. App. 26, 1055-1074. doi: 10.1890/15-1077

Bertness, M. D. (1985). Fiddler crab regulation of Spartina alterniflora production on a New England salt marsh. Ecology 66, 1042-1055. doi: 10.2307/1940564

Bertness, M. D., and Callaway, R. (1994). Positive interactions in communities. Trends Ecol. Evol. 9, 191-193. doi: 10.1016/0169-5347(94)90088-4

Bertness, M. D., and Coverdale, T. C. (2013). An invasive species facilitates the recovery of salt marsh ecosystems on Cape Cod. Ecol. 94, 1937-1943. doi: $10.1890 / 12-2150.1$

Bertness, M. D., Ewanchuk, P. J., and Silliman, B. R. (2002). Anthropogenic modification of New England salt marsh landscapes. Proc. Natl. Acad. Sci. U.S.A. 99, 1395-1398. doi: 10.1073/pnas.022447299

Bertness, M. D., and Grosholz, E. (1985). Population dynamics of the ribbed mussel, Geukensia demissa: the costs and benefits of an aggregated distribution. Oecologia 67, 192-204. doi: 10.1007/BF00384283

Bischoff, A. (2002). Dispersal and establishment of floodplain grassland species as limiting factors in restoration. Bio. Conserv. 104, 25-33. doi: 10.1016/S0006-3207(01)00151-3

Bishop, M. J., Byers, J. E., Marcek, B. J., and Gribben, P. E. (2012). Density-dependent facilitation cascades determine epifaunal community

\section{ACKNOWLEDGMENTS}

Non-original vector graphics for Figures 1-4 were adapted from Tracey Saxby, Dieter Tracey, Kim Kraeer, Lucy Van Essen-Fishman, Sally Bell, Jane Thomas, Chip Chenery, and Joanna Woerner. Integration and Application Network, University of Maryland Center for Environmental Science (http://ian.umces.edu/imagelibrary/). We would also like to thank the two reviewers that provided helpful feedback on the manuscript.

structure in temperate Australian mangroves. Ecology 93, 1388-1401. doi: 10.1890/10-2296.1

Biswas, S. R., Choudhury, J. K., Nishat, A., and Rahman, M. M. (2007). Do invasive plants threaten the Sundarbans mangrove forest of Bangladesh? Forest Ecol. Manag. 245, 1-9. doi: 10.1016/j.foreco.2007.02.011

Bledsoe, R., and Boopathy, R. (2016). Bioaugmentation of microbes to restore coastal wetland plants to protect land from coastal erosion. Internat. Biodeter. Biodeg. 113, 155-160. doi: 10.1016/j.ibiod.2016.02.010

Borja, Á., Dauer, D. M., Elliott, M., and Simenstad, C. A. (2010). Medium-and long-term recovery of estuarine and coastal ecosystems: patterns, rates and restoration effectiveness. Est. Coast. 33, 1249-1260. doi: 10.1007/s12237-010-9347-5

Borsje, B. W., van Wesenbeeck, B. K., Dekker, F., Paalvast, P., Bouma, T. J., van Katwijk, M. M., et al. (2011). How ecological engineering can serve in coastal protection. Ecol. Eng. 37, 113-122. doi: 10.1016/j.ecoleng.2010.11.027

Bruno, J. F., Stachowicz, J. J., and Bertness, M. D. (2003). Inclusion of facilitation into ecological theory. Trends Ecol. Evol. 18, 119-125. doi: 10.1016/S0169-5347(02)00045-9

Buelow, C., and Sheaves, M. (2015). A birds-eye view of biological connectivity in mangrove systems. Est. Coast. Shelf Sci. 152, 33-43. doi: $10.1016 /$ j.ecss.2014.10.014

Byers, J. E. (2009). "Invasive animals in marshes" in Human Impacts on Salt Marshes: A Global Perspective, eds B. R. Silliman, E. Grosholz, and M. D. Bertness (Berkeley, CA: University of California Press), 41-56.

Callaway, J. C., Sullivan, G., and Zedler, J. B. (2003). Species-rich plantings increase biomass and nitrogen accumulation in a wetland restoration experiment. Ecol. App. 13, 1626-1639. doi: 10.1890/02-5144

Castellanos, E. M., Figueroa, M. E., and Davy, A. J. (1994). Nucleation and facilitation in saltmarsh succession: interactions between Spartina maritima and Arthrocnemum perenne. J. Ecol. 82, 239-248. doi: 10.2307/2261292

Chen, L., Zeng, X., Tam, N. F., Lu, W., Luo, Z., Du, X., et al. (2012). Comparing carbon sequestration and stand structure of monoculture and mixed mangrove plantations of Sonneratia caseolaris and S. apetala in Southern China. Forest Ecol. Manag. 284, 222-229. doi: 10.1016/j.foreco.2012.06.058

Chen, W., Ge, Z. M., Fei, B. L., Zhang, C., Liu, Q. X., and Zhang, L. Q. (2017). Soil carbon and nitrogen storage in recently restored and mature native Scirpus marshes in the Yangtze Estuary, China: implications for restoration. Ecol. Eng. 104, 150-157. doi: 10.1016/j.ecoleng.2017.04.027

Costa, C. B., Iribarne, O. O., and Farina, J. M. (2009). "Human impacts and threats to the conservation of South American salt marshes" in Human Impacts on Salt Marshes: a Global Perspective, eds. B. R. Silliman, E. Grosholz, and M. D.Bertness (Berkeley, CA: University of California Press), 337-359.

Craft, C., Clough, J., Ehman, J., Joye, S., Park, R., Pennings, S., et al. (2009). Forecasting the effects of accelerated sea-level rise on tidal marsh ecosystem services. Front. Ecol. Env. 7, 73-78. doi: 10.1890/070219

Crain, C. M., Gedan, K. B., and Dionne, M. (2009). "Tidal restrictions and mosquito ditching in New England marshes" in Human Impacts on Salt Marshes: a Global Perspective, eds. B. R. Silliman, E. Grosholz, and M. D. Bertness (Berkeley, CA: University of California Press), 149-69.

Daleo, P., Fanjul, E., Mendez Casariego, A., Silliman, B. R., Bertness, M. D., and Iribarne, O. (2007). Ecosystem engineers activate mycorrhizal mutualism in salt marshes. Ecol. Lett. 10, 902-908. doi: 10.1111/j.1461-0248.2007.01082.x 
Das, S. (2017). Ecological restoration and livelihood: contribution of planted mangroves as nursery and habitat for artisanal and commercial fishery. World Dev. 94, 492-502. doi: 10.1016/j.worlddev.2017.02.010

Denno, R. F., Gratton, C., Peterson, M. A., Langellotto, G. A., Finke, D. L., and Huberty, A. F. (2002). Bottom-up forces mediate natural-enemy impact in a phytophagous insect community. Ecol. 83, 1443-1458. doi: 10.1890/00129658(2002)083[1443:BUFMNE]2.0.CO;2

Derksen-Hooijberg, M., Angelini, C., Lamers, L. P., Borst, A., Smolders, A., Hoogveld, J. R., et al. (2018). Mutualistic interactions amplify saltmarsh restoration success. J. App. Ecol. 55, 405-414. doi: 10.1111/1365-2664.12960

Dobson, A. P., Bradshaw, A. D., and Baker, A. Á. (1997). Hopes for the future: restoration ecology and conservation biology. Science 277, 515-522. doi: 10.1126/science. 277.5325 .515

Duffy, J. E. (2003). Biodiversity loss, trophic skew and ecosystem functioning. Ecol. Lett. 6, 680-687. doi: 10.1046/j.1461-0248.2003.00494.x

Duke, N. C. (2016). Oil spill impacts on mangroves: recommendations for operational planning and action based on a global review. Mar. Poll. Bullet. 109, 700-715. doi: 10.1016/j.marpolbul.2016.06.082

Egerova, J., Proffitt, C. E., and Travis, S. E. (2003). Facilitation of survival and growth of Baccharis halimifolia L. by Spartina alterniflora Loisel. in a created Louisiana salt marsh. Wetlands 23, 250-256. doi: 10.1672/4-20

Ellison, A., and Farnsworth, E. (1990). The ecology of Belizean mangroveroot fouling communities. I. Epibenthic fauna are barriers to isopod attack of red mangrove roots. J. Exp. Mar. Bio. Ecol. 142, 91-104. doi: 10.1016/0022-0981(90)90139-4

Ellison, A. M., Farnsworth, E. J., and Twilley, R. R. (1996). Facultative mutualism between red mangroves and root-fouling sponges in Belizean mangal. Ecology 77, 2431-2444. doi: 10.2307/2265744

Ellison, J. C., and Stoddart, D. R. (1991). Mangrove ecosystem collapse during predicted sea-level rise: holocene analogues and implications. J. Coast. Res. $7,151-165$.

Engel, S., and Pawlik, J. R. (2005). Interactions among Florida sponges. II. Mangrove habitats. Mar. Ecol. Prog. Ser. 303, 145-152. doi: $10.3354 /$ meps 303145

Erickson, A. A., Bell, S. S., and Dawes, C. J. (2012). Associational resistance protects mangrove leaves from crab herbivory. Acta Oecol. 41, 46-57. doi: 10.1016/j.actao.2012.04.002

FAO (2007). “The World's mangroves 1980-2005," in FAO Forestry Paper 153. (Rome: Forest Resources Division, Food and Agriculture Organization of the United Nations), 77.

Finke, D. L., and Denno, R. F. (2006). Spatial refuge from intraguild predation: implications for prey suppression and trophic cascades. Oecologia 149, 265-275. doi: 10.1007/s00442-006-0443-y

Gallardo, B., Clavero, M., Sánchez, M. I., and Vilà, M. (2016). Global ecological impacts of invasive species in aquatic ecosystems. Glob. Change Bio. 22, 151-163. doi: $10.1111 / \mathrm{gcb} .13004$

Gambrell, R. P. (1994). Trace and toxic metals in wetlands-a review. J. Env. Q. 23:883. doi: 10.2134/jeq1994.00472425002300050005x

Garbutt, A., and Wolters, M. (2008). The natural regeneration of salt marsh on formerly reclaimed land. App. Veg. Sci. 11, 335-344. doi: 10.3170/20 08-7-18451

Gedan, K. B., Kirwan, M. L., Wolanski, E., Barbier, E. B., and Silliman, B. R. (2011). The present and future role of coastal wetland vegetation in protecting shorelines: answering recent challenges to the paradigm. Clim. Change 106, 7-29. doi: 10.1007/s10584-010-0003-7

Gedan, K. B., and Silliman, B. R. (2009a). "Patterns of salt marsh loss within coastal regions of North America: Presettlement to present." in Human Impacts on Salt Marshes: A Global Perspective, eds B. R. Silliman, E. D. Grosholz, and M. D. Bertness (Los Angeles, CA: University of California Press), 253-266.

Gedan, K. B., and Silliman, B. R. (2009b). Using facilitation theory to enhance mangrove restoration. Ambio 38:109. doi: 10.1579/0044-7447-38.2.109

Gedan, K. B., Silliman, B. R., and Bertness, M. D. (2009). Centuries of humandriven change in salt marsh ecosystems. Ann. Rev. Mar. Sci. 1, 117-141. doi: 10.1146/annurev.marine.010908.163930

Gittman, R. K., and Keller, D. A. (2013). Fiddler crabs facilitate Spartina alterniflora growth, mitigating periwinkle overgrazing of marsh habitat. Ecology. 94, 2709-2718. doi: 10.1890/13-0152.1
Gratton, C., and Denno, R. F. (2005). Restoration of arthropod assemblages in a Spartina salt marsh following removal of the invasive plant Phragmites australis. Restorat. Ecol. 13, 358-372. doi: 10.1111/j.1526-100X.2005.00045.x

Gratton, C., and Denno, R. F. (2006). Arthropod food web restoration following removal of an invasive wetland plant. Ecol. App. 16, 622-631. doi: 10.1890/10510761(2006)016[0622:AFWRFR]2.0.CO;2

Halpern, B. S., Silliman, B. R., Olden, J. D., Bruno, J. P., and Bertness, M. D. (2007), Incorporating positive interactions in aquatic restoration and conservation. Front. Ecol. Env. 5, 153-160. doi: 10.1890/1540-9295(2007)5[153:IPIIAR]2.0. $\mathrm{CO} ; 2$

Halpern, B. S., and Warner, R. R. (2003). Matching marine reserve design to reserve objectives. Proc. R. Soc. B. 270, 1871-1878. doi: 10.1098/rspb.2003.2405

Hay, M. E., Parker, J. D., Burkepile, D. E., Caudill, C. C., Wilson, A. E., Hallinan, Z. P., et al. (2004). Mutualisms and aquatic community structure: the enemy of my enemy is my friend. Ann. Rev. Ecol. Evo. Syst. 35, 175-197. doi: 10.1146/annurev.ecolsys.34.011802.132357

He, Q., Bertness, M. D., and Altieri, A. H. (2013). Global shifts towards positive species interactions with increasing environmental stress. Ecol. Lett. 16, 695-706. doi: 10.1111/ele.12080

He, Q., Bertness, M. D., Bruno, J. F., Li, B., and Chen, G., Coverdale, et al. (2014). Economic development and coastal ecosystem change in China. Sci. Rep. 4:5995. doi: 10.1038/srep05995

He, Q., and Silliman, B. R. (2016). Consumer control as a common driver of coastal vegetation worldwide. Ecol. Mono. 86, 278-294. doi: 10.1002/ecm.1221

He, Q., Silliman, B. R., Liu, Z., and Cui, B. (2017). Natural enemies govern ecosystem resilience in the face of extreme droughts. Ecol. Lett. 20, 194-201. doi: 10.1111/ele.12721

Henry, H. A. L., and Jefferies, R. L. (2009). "Opportunistic herbivores, migratory connectivity, and catastrophic shifts in Arctic coastal systems" in Human Impacts on Salt Marshes: a Global Perspective, eds. B. R. Silliman, E. Grosholz, and M. D. Bertness (Berkeley, CA: University of California Press), 85-102.

Howes, B. L., Dacey, J. W. H., and Goehringer, D. D. (1986). Factors controlling the growth form of Spartina alterniflora: feedbacks between above-ground production, sediment oxidation, nitrogen and salinity. J. Ecol. 74, 881-898. doi: $10.2307 / 2260404$

Hughes, A. R. (2012). A neighboring plant species creates associational refuge for consumer and host. Ecology 93, 1411-1420. doi: 10.1890/11-1555.1

Hughes, A. R., Moore, A. F., and Piehler, M. F. (2014). Independent and interactive effects of two facilitators on their habitat-providing host plant, Spartina alterniflora. Oikos 123, 488-499. doi: 10.1111/j.1600-0706.2013.01035.x

Hughes, A. R., and Stachowicz, J. J. (2009). Ecological impacts of genotypic diversity in the clonal seagrass Zostera marina. Ecology 90, 1412-1419. doi: 10.1890/07-2030.1

Hughes, B. B., Eby, R., Van Dyke, E., Tinker, M. T., Marks, C. I., Johnson, K. S., et al. (2013). Recovery of a top predator mediates negative eutrophic effects on seagrass. Proc. Natl. Acad. Sci. U.S.A. 110, 15313-15318. doi: $10.1073 /$ pnas. 1302805110

Hughes, B. B., Hammerstrom, K. K., Grant, N. E., Hoshijima, U., Eby, R., and Wasson, K. (2016). Trophic cascades on the edge: fostering seagrass resilience via a novel pathway. Oecologia 182, 231-241. doi: 10.1007/s00442-016-3652-z

Huxham, M., Kumara, M. P., Jayatissa, L. P., Krauss, K. W., Kairo, J., Langat, J., et al. (2010). Intra-and interspecific facilitation in mangroves may increase resilience to climate change threats. Philosoph. Transact. R. Soc. Lond. Bio. Sci. 365:2127. doi: 10.1098/rstb.2010.0094

Kadlec, R. H., and Wallace, S. (2008). Treatment Wetlands. Boca Raton, FL: CRC press.

Kaplan, I., and Denno, R. F. (2007). Interspecific interactions in phytophagous insects revisited: a quantitative assessment of competition theory. Ecol. Lett. 10, 977-994. doi: 10.1111/j.1461-0248.2007.01093.x

Kimbro, D. L. (2012). Tidal regime dictates the cascading consumptive and nonconsumptive effects of multiple predators on a marsh plant. Ecology 93 , 334-344. doi: 10.1890/11-0596.1

Lang'at, J. K., Kirui, B. K., Skov, M. W., Kairo, J. G., Mencuccini, M., and Huxham, M. (2013). Species mixing boosts root yield in mangrove trees. Oecologia 172, 271-278. doi: 10.1007/s00442-012-2490-x

Lawrence, P. J., Smith, G. R., Sullivan, M. J., and Mossman, H. L. (2018). Restored saltmarshes lack the topographic diversity found in natural habitat. Ecol. Eng. 115, 58-66. doi: 10.1016/j.ecoleng.2018.02.007 
Lipcius, R. N., Seitz, R. D., Seebo, M. S., and Colón-Carrión, D. (2005). Density, abundance and survival of the blue crab in seagrass and unstructured salt marsh nurseries of Chesapeake Bay. J. Exp. Mar. Bio. Ecol. 319, 69-80. doi: 10.1016/j.jembe.2004.12.034

McKee, K. L., Rooth, J. E., and Feller, I. C. (2007). Mangrove recruitment after forest disturbance is facilitated by herbaceous species in the Caribbean. Ecol. App. 17:1678. doi: 10.1890/06-1614.1

McKeon, C. S., Stier, A. C., McIlroy, S. E., and Bolker, B. M. (2012). Multiple defender effects: synergistic coral defense by mutualist crustaceans. Oecologia 169, 1095-1103. doi: 10.1007/s00442-012-2275-2

Mcleod, E., Chmura, G. L., Bouillon, S., Salm, R., Björk, M., Duarte, C. M., et al. (2011). A blueprint for blue carbon: toward an improved understanding of the role of vegetated coastal habitats in sequestering $\mathrm{CO}_{2}$. Front. Ecol. Env. 9, 552-560. doi: 10.1890/110004

Meli, P., Rey Benayas, J. M., Balvanera, P., and Martínez Ramos, M. (2014). Restoration enhances wetland biodiversity and ecosystem service supply, but results are context-dependent: a meta-analysis. PLoS ONE. 9:e93507. doi: 10.1371/journal.pone.0093507

Meyer, D. L., Townsend, E. C., and Thayer, G. W. (1997). Stabilization and erosion control value of oyster cultch for intertidal marsh. Restorat. Ecol. 5:93. doi: 10.1046/j.1526-100X.1997.09710.x

Micheli, F., and Halpern, B. S. (2005). Low functional redundancy in coastal marine assemblages. Ecol. Lett. 8, 391-400. doi: 10.1111/j.1461-0248.2005.00731.x

Minchinton, T. E., Simpson, J. C., and Bertness, M. D. (2006). Mechanisms of exclusion of native coastal marsh plants by an invasive grass. J. Ecol. 94, 342-354. doi: 10.1111/j.1365-2745.2006.01099.x

Mooney, K. A., and Agrawal, A. A. (2008). Plant genotype shapes ant-aphid interactions: implications for community structure and indirect plant defense. Am. Nat. 171:E195. doi: 10.1086/587758

Moreno-Mateos, D., Power, M. E., Comín, F. A., and Yockteng, R. (2012). Structural and functional loss in restored wetland ecosystems. PLoS Bio. 10:e1001247. doi: 10.1371/journal.pbio.1001247

Mossman, H. L., Brown, M. J., Davy, A. J., and Grant, A. (2012). Constraints on salt marsh development following managed coastal realignment: dispersal limitation or environmental tolerance? Restorat. Ecol. 20, 65-75. doi: 10.1111/j.1526-100X.2010.00745.x

Mumby, P. J. (2006). Connectivity of reef fish between mangroves and coral reefs: algorithms for the design of marine reserves at seascape scales. Bio. Conserv. 128, 215-222. doi: 10.1016/j.biocon.2005.09.042

Nagelkerken, I. S. J. M., Blaber, S. J. M., Bouillon, S., Green, P., Haywood, M., Kirton, L. G., et al. (2008). The habitat function of mangroves for terrestrial and marine fauna: a review. Aquat. Bot. 89, 155-185. doi: 10.1016/j.aquabot.2007.12.007

Neff, K. P., and Baldwin, A. H. (2005). Seed dispersal into wetlands: techniques and results for a restored tidal freshwater marsh. Wetlands 25, 392-404. doi: $10.1672 / 14$

Nicholls, R. J., Hoozemans, F. M., and Marchand, M. (1999). Increasing flood risk and wetland losses due to global sea-level rise: regional and global analyses. Glob. Env. Chan. 9:S69. doi: 10.1016/S0959-3780(99)00019-9

Nieva, F. J. J., Castellanos, E. M., Castillo, J. M., and Figueroa, M. E. (2005). Clonal growth and tiller demography of the invader cordgrass Spartina densiflora Brongn. at two contrasting habitats in SW European salt marshes. Wetlands 25, 122-129. doi: 10.1672/0277-5212(2005)025[0122:CGA TDO]2.0.CO;2

O'Beirn, F. X., Luchenbach, M. W., Nestlerode, J. A., and Coates, G. M. (2000). Toward design criteria in constructed oyster reefs: oyster recruitment as a function of substrate type and tidal height. J Shellfish Res. 19, 387-395.

Offenberg, J., Macintosh, D. J., and Nielsen, M. G. (2006). Indirect antprotection against crab herbivory: damage-induced susceptibility to crab grazing may lead to its reduction on ant-colonized trees. Funct. Ecol. 20, 52-57. doi: 10.1111/j.1365-2435.2005.01059.x

Ouyang, X., and Guo, F. (2016). Paradigms of mangroves in treatment of anthropogenic wastewater pollution. Sci. Tot. Env. 544, 971-979. doi: 10.1016/j.scitotenv.2015.12.013

Palmer, M. A., Ambrose, R. F., and Poff, N. L. (1997). Ecological theory and community restoration ecology. Restorat. Ecol. 5, 291-300. doi: 10.1046/j.1526-100X.1997.00543.x
Possingham, H. P., Bode, M., and Klein, C. J. (2015). Optimal conservation outcomes require both restoration and protection. PLOS Bio. 13:e1002052. doi: 10.1371/journal.pbio.1002052

Proffitt, C. E., Travis, S. E., and Edwards, K. R. (2003). Genotype and elevation influence Spartina alterniflora colonization and growth in a created salt marsh. Ecol. App. 13, 180-192. doi: 10.1890/1051-0761(2003)013[0180:GAEISA]2.0. $\mathrm{CO} ; 2$

Quinn, J. F., Wing, S. R., and Botsford, L. W. (1993). Harvest refugia in marine invertebrate fisheries: models and applications to the red sea urchin, Strongylocentrotus franciscanus. Amer. Zool. 33, 537-550. doi: 10.1093/icb/33.6.537

Rey Benayas, J. M., Newton, A. C., Diaz, A., and Bullock, J. M. (2009). Enhancement of biodiversity and ecosystem services by ecological restoration: a meta-analysis. Science 325, 1121-1124. doi: 10.1126/science.1172460

Schuerch, M., Spencer, T., Temmerman, S., Kirwan, M. L., Wolff, C., Lincke, D., et al. (2018). Future response of global coastal wetlands to sea-level rise. Nature 561, 231-234. doi: 10.1038/s41586-018-0476-5

Shanholtzer, G. F. (2012). "Relationship of Vertebrates to Salt Marsh Plants" in Ecology of Halophytes, ed R. J. Mold (New York, NY: Elsevier), 463-474.

Shaver, E. C., and Silliman, B. R. (2017). Time to cash in on positive interactions for coral restoration. PeerJ. 5:e3499. doi: 10.7717/peerj.3499

Silliman, B. R., and Bertness, M. D. (2002). A trophic cascade regulates salt marsh primary production. Proc. Natl. Acad. Sci. U.S.A. 99:10500. doi: 10.1073/pnas.162366599

Silliman, B. R., and Bertness, M. D. (2004). Shoreline development drives invasion of Phragmites australis and the loss of plant diversity on New England salt marshes. Conserv. Bio. 18, 1424-1434. doi: 10.1111/j.1523-1739.2004.00112.x

Silliman, B. R., Dixon, P. M., Wobus, C., He, Q., Daleo, P., Hughes, B. B., et al. (2016). Thresholds in marsh resilience to the Deepwater Horizon oil spill. Sci. Rep. 6:32520. doi: 10.1038/srep32520

Silliman, B. R., McCoy, M. W., Angelini, C., Holt, R. D., Griffin, J. N., and van de Koppel, J. (2013). Consumer fronts, global change, and runaway collapse in ecosystems. Ann. Rev. Ecol. Evol. Syst. 44, 503-538. doi: 10.1146/annurev-ecolsys-110512-135753

Silliman, B. R., Schrack, E., He, Q., Cope, R., Santoni, A., van der Heide, T., et al. (2015). Facilitation shifts paradigms and can amplify coastal restoration efforts. Proc. Natl. Acad. Sci. U.S.A. 112:14295. doi: 10.1073/pnas.1515297112

Silliman, B. R., Van De Koppel, J., Bertness, M. D., Stanton, L. E., and Mendelssohn, I. A. (2005). Drought, snails, and large-scale die-off of southern US salt marshes. Science 310, 1803-1806. doi: 10.1126/science.1118229

Sofawi, A. B., Rozainah, M. Z., Normaniza, O., and Roslan, H. (2017). Mangrove rehabilitation on Carey Island, Malaysia: an evaluation of replanting techniques and sediment properties. Mar. Bio. Res. 13, 390-401. doi: 10.1080/17451000.2016.1267365

Stachowicz, J. J. (2001). Mutualism, facilitation, and the structure of ecological communities: positive interactions play a critical, but underappreciated, role in ecological communities by reducing physical or biotic stresses in existing habitats and by creating new habitats on which many species depend. AIBS Bull. 51, 235-246. doi: 10.1641/0006-3568(2001)051[0235:MFATSO]2.0.CO;2

Stachowicz, J. J., and Whitlatch, R. B. (2005). Multiple mutualists provide complementary benefits to their seaweed host. Ecology 86, 2418-2427. doi: 10.1890/04-0819

Stieglitz, T., Ridd, P., and Müller, P. (2000). Passive irrigation and functional morphology of crustacean burrows in a tropical mangrove swamp. Hydrobiology 421, 69-76. doi: 10.1023/A:1003925502665

Strong, D. R., and Ayres, D. R. (2009). “Spartina Introductions and Consequences in Salt Marshes" in Human Impacts on Salt Marshes: A Global Perspective, eds B. R. Silliman, E. Grosholz, and M. D. Bertness (Berkeley, CA: University of California Press), 3-22.

Tsai, C., Yang, S., Trimble, A. C., and Ruesink, J. L. (2010). Interactions between two introduced species: Zostera japonica (dwarf eelgrass) facilitates itself and reduces condition of Ruditapes philippinarum (Manila clam) on intertidal flats. Mar. Bio. 157, 1929-1936. doi: 10.1007/s00227-010-1462-0

Tyler, A. C., Lambrinos, J. G., and Grosholz, E. D. (2007). Nitrogen inputs promote the spread of an invasive marsh grass. Ecol. App. 17, 1886-18898. doi: 10.1890/06-0822.1

Valiela, I., Bowen, J. L., and York, J. K. (2001). Mangrove forests: one of the World's threatened major tropical environments: at least $35 \%$ of the area of mangrove 
forests has been lost in the past two decades, losses that exceed those for tropical rain forests and coral reefs, two other well-known threatened environments. AIBS Bull. 51, 807-815. doi: 10.1641/0006-3568(2001)051[0807:MFOOTW]2. $0 . \mathrm{CO} ; 2$

van de Koppel, J., van der Heide, T., Altieri, A. H., Eriksson, B. K., Bouma, T. J., Olff, H., et al. (2015). Long-distance interactions regulate the structure and resilience of coastal ecosystems. Ann. Rev. of Mar. Sci. 7, 139-158. doi: 10.1146/annurev-marine-010814-015805

Veeneklaas, R. M., Dijkema, K. S., Hecker, N., and Bakker, J. P. (2013). Spatiotemporal dynamics of the invasive plant species Elytrigia atherica on natural salt marshes. App. Veg. Sci. 16:205. doi: 10.1111/j.1654-109X.2012.01228.x

Whitcraft, C. R., and Levin, L. A. (2007). Regulation of benthic algal and animal communities by salt marsh plants: impact of shading. Ecology 88, 904-917. doi: 10.1890/05-2074

Williams, S. L. (1990). Experimental studies of Caribbean seagrass bed development. Ecol. Mono. 60, 449-469. doi: 10.2307/1943015

Williams, S. L., Ambo-Rappe, R., Sur, C., Abbott, J. M., and Limbong, S. R. (2017). Species richness accelerates marine ecosystem restoration in the Coral Triangle. Proc. Natl. Acad. Sci. U.S.A. 114, 11986-11991. doi: 10.1073/pnas.1707962114

Worm, B., Barbier, E. B., Beaumont, N., Duffy, J. E., Folke, C., Halpern, B. S., et al. (2006). Impacts of biodiversity loss on ocean ecosystem services. Science 314, 787-790. doi: 10.1126/science.1132294

Yang, Q., Tam, N. F., Wong, Y. S., Luan, T. G., Su, W. S., Lan, C. Y., et al. (2008). Potential use of mangroves as constructed wetland for municipal sewage treatment in Futian, Shenzhen, China. Mar. Poll. Bullet. 57, 735-743. doi: 10.1016/j.marpolbul.2008.01.037
Young, T. P., Petersen, D. A., and Clary, J. J. (2005). The ecology of restoration: historical links, emerging issues and unexplored realms. Ecol. Lett. 8, 662-673. doi: 10.1111/j.1461-0248.2005.00764.x

Zengel, S., Pennings, S. C., Silliman, B., Montague, C., Weaver, J., Deis, D. R., et al. (2016). Deepwater Horizon oil spill impacts on salt marsh fiddler crabs (Uca spp.). Estu. Coas. 39, 1154-1163. doi: 10.7266/N7FF3Q9S

Zerebecki, R. A., Crutsinger, G. M., and Hughes, A. R. (2017). Spartina alterniflora genotypic identity affects plant and consumer responses in an experimental marsh community. J. Ecol. 105, 661-673. doi: 10.1111/1365-2745.12703

Zhang, X. D., Jia, X., Chen, Y. Y., Shao, J. J., Wu, X. R., Shang, L., et al. (2013). Crabs mediate interactions between native and invasive salt marsh plants: a mesocosm study. PLoS ONE 8: e74095. doi: 10.1371/journal.pone.0074095

Zhang, Y., Cioffi, W., Cope, R., Daleo, P., Heywood, E., Hoyt, C., et al. (2018). A global synthesis reveals gaps in coastal habitat restoration research. Sustainability 10:1040. doi: 10.3390/su10041040

Conflict of Interest Statement: The authors declare that the research was conducted in the absence of any commercial or financial relationships that could be construed as a potential conflict of interest.

Copyright (C) 2019 Renzi, He and Silliman. This is an open-access article distributed under the terms of the Creative Commons Attribution License (CC BY). The use, distribution or reproduction in other forums is permitted, provided the original author(s) and the copyright owner(s) are credited and that the original publication in this journal is cited, in accordance with accepted academic practice. No use, distribution or reproduction is permitted which does not comply with these terms. 
OPEN ACCESS

Edited by:

Alberto Vieira Borges,

University of Liège, Belgium

Reviewed by:

Joshua L. Breithaupt, University of Central Florida,

United States

Lu Zhai,

Los Alamos National Laboratory

(DOE), United States

Mohammad Basyuni,

University of North Sumatra,

Indonesia

*Correspondence:

Cyril Marchand

cyril.marchand@unc.nc

Specialty section:

This article was submitted to

Conservation,

a section of the journal

Frontiers in Ecology and Evolution

Received: 04 November 2018

Accepted: 11 March 2019

Published: 10 April 2019

Citation:

Jacotot A, Marchand $C$ and Allenbach M (2019) Increase in Growth and Alteration of C:N Ratios of Avicennia marina and Rhizophora stylosa Subject to Elevated $\mathrm{CO}_{2}$ Concentrations and Longer Tidal

Flooding Duration.

Front. Ecol. Evol. 7:98.

doi: 10.3389/fevo.2019.00098

\section{Increase in Growth and Alteration of C:N Ratios of Avicennia marina and Rhizophora stylosa Subject to Elevated $\mathrm{CO}_{2}$ Concentrations and Longer Tidal Flooding Duration}

\author{
Adrien Jacotot ${ }^{1,2,3}$, Cyril Marchand ${ }^{1,2 *}$ and Michel Allenbach ${ }^{2}$ \\ 1 MPMC, Institut de Recherche pour le Développement (IRD), UPMC, CNRS, MNHN, Nouméa, New Caledonia, ${ }^{2}$ ISEA, EA \\ 7484, BPR4, Université de la Nouvelle-Calédonie, Nouméa, New Caledonia, ${ }^{3}$ CNRS, ISTO, Université d'Orléans, BRGM, \\ UMR 7327, Orléans, France
}

We investigated the effects of elevated $\mathrm{CO}_{2}$ concentrations and longer tidal flooding duration on two-year-old Avicennia marina and Rhizophora stylosa seedlings for a full year. The seedlings were grown in greenhouses for ambient $\mathrm{CO}_{2}$ (400 ppm) and in enclosed $\mathrm{CO}_{2}$-controlled chambers, which were installed inside the greenhouses for elevated $\mathrm{CO}_{2}(800 \mathrm{ppm})$. The tidal flooding duration was set-up according to the species distribution in the intertidal zone in New Caledonia for the controlled treatment and was increased by $1 \mathrm{~h} 45 \mathrm{~min}$ for the experimental treatment. A total of $400 \mathrm{~A}$. marina and 720 R. stylosa were monitored during this experiment. We measured heights and basal diameters of all seedlings every 90 days, and we determined the above and below ground biomass at the end of the experiment. Our results showed that elevated $\mathrm{CO}_{2}$ increased the growth rates of both $A$. marina and $R$. stylosa, for which the final biomass was, respectively, 46 and $32 \%$ higher than in the ambient $\mathrm{CO}_{2}$ treatment. We suggest that this increase was driven by a stimulation of photosynthesis under elevated $\mathrm{CO}_{2}$, as demonstrated in a previous study. Considering the tidal flooding duration treatment, we observed a contrasted effect between the species. Longer tidal flooding increased the growth of $A$. marina, whereas it reduced the growth of $R$. stylosa in comparison to the controlled treatment. This result may be related to the specific ecosystem zonation in this semi-arid climate, which limits water inputs into the Avicennia zone that increases the salt concentration in the soil, whereas Rhizophora is regularly submerged by tides due to its lower position in the intertidal zone. As a result, the combination of both treatments had a positive cumulative effect on the growth of $A$. marina. Although it was not the case for $R$. stylosa, the negative effect of longer tidal flooding on this species did not suppress the enhancement of growth resulting from elevated $\mathrm{CO}_{2}$ concentrations. At the end of the experiment, elevated $\mathrm{CO}_{2}$ increased the $\mathrm{C}: \mathrm{N}$ ratios of the seedlings, thereby producing a more refractory organic matter, which will potentially result in lower decomposition rates 
and thus may increase carbon accumulation in mangrove soils. These results suggest that future climate changes may enhance the productivity of mangrove seedlings by increasing their growth, which may in turn increase the carbon storage potential of mangroves in their biomass.

Keywords: mangrove, elevated $\mathrm{CO}_{2}$, sea-level rise, growth, biomass, climate changes

\section{INTRODUCTION}

The steady increase in anthropogenic greenhouse gas emissions since the preindustrial age resulted in a substantial atmospheric $\mathrm{CO}_{2}$ concentrations augmentation, from $280 \mathrm{ppm}$ to over 400 ppm currently (Betts et al., 2016). This increase is strongly inducing global warming (Cook et al., 2016), which, in turn, leads to an augmentation of the global mean sea-level. Projections agree that atmospheric $\mathrm{CO}_{2}$ concentrations will continue to rise in the future, and are predicted to range from 794 to $1,150 \mathrm{ppm}$ by the end of the 21st, depending on simulation models (Collins et al., 2014). As a result, the global mean sea-level is expected to increase from 0.26 to $0.98 \mathrm{~m}$ by 2,100 (Church et al., 2013).

Mangroves are forested ecosystem that develop along tropical and subtropical coastlines and are mainly composed of halophytic C3 trees. Due to their high primary productivity

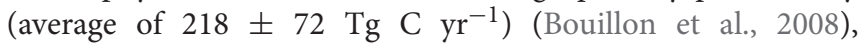
mangroves are considered as major ecosystems in the coastal carbon cycle, and have therefore been recently named "blue carbon" sinks (Mcleod et al., 2011). Many studies have investigated the response of $\mathrm{C} 3$ terrestrial plants to elevated $\mathrm{CO}_{2}$ concentrations, which mainly results in photosynthesis stimulation and higher productivity (Norby et al., 2005; Prior et al., 2011). However, only a few studies have focused on the response of mangroves to elevated $\mathrm{CO}_{2}$ concentrations. These studies showed that that the response of mangroves plants is similar to other C3 plants with an increase in photosynthesis and productivity (Farnsworth et al., 1996; Ball et al., 1997; McKee and Rooth, 2008; Luo et al., 2010; Reef et al., 2016; Jacotot et al., 2018), highlighting their valuable role in climate change mitigation. However, the effects of elevated $\mathrm{CO}_{2}$ concentrations may be strongly dependent of other biotic and abiotic factors such as temperature, nutrient availability, or flooding (Alongi, 2015).

Due to their position at the interface between land and sea, increase in global mean sea-level may be a major threat to mangroves (Ellison, 2015; Ward et al., 2016). Mangrove ecosystems have the ability to cope with sealevel rise through surface elevation change processes (Krauss et al., 2014), however, this capacity is influenced by several factors (Ward et al., 2016) and may be specific to each mangrove forest. In fact, (Lovelock et al., 2015) reported that $69 \%$ of mangroves surveyed in the IndoPacific region were not building surface elevation at rates that equal or exceed sea-level rise and, consequently, will experience major changes in their tidal flooding duration if their landward migration is prevented by human activities (Gilman et al., 2008).
A handful studies have examined the response of mangroves plants with climate changes and they mainly focused on elevated $\mathrm{CO}_{2}$ in interaction with salinity (Reef et al., 2015), nutrient availability (McKee and Rooth, 2008; Reef et al., 2016), or species competition (McKee and Rooth, 2008). However, to our knowledge, no studies have focused on the effects of elevated $\mathrm{CO}_{2}$ in interaction with an increase in tidal flooding duration on mangrove seedlings before, thus, the present study is the first to have investigated this interaction.

During one complete year, between 2016 and 2017, we conducted, in New Caledonia, a greenhouses experiment in which $720 \mathrm{R}$. stylosa and $400 \mathrm{~A}$. marina were grown at two $\mathrm{CO}_{2}$ concentrations ( 400 vs. $800 \mathrm{ppm}$ ) over two tidal flooding durations (one typical of Neo Caledonian mangroves, and a longer one). In a previous paper concerning this experiment (Jacotot et al., 2018), we were mainly interested in the variability of leaf-gas exchange parameters of both species, and our main results were: (i) elevated $\mathrm{CO}_{2}$ concentrations affected seedlings physiology, notably by increasing photosynthesis by more than 37 and $45 \%$ for A. marina and R. stylosa, respectively, (ii) higher mean temperature during the warm season further enhanced this photosynthesis increase, and (iii) longer tidal flooding duration slightly reduced photosynthesis but not enough to offset the carbon gain induced by the elevated $\mathrm{CO}_{2}$ concentrations. In the present complementary study, we now focus on seedlings growth and tissues quality (using C:N ratio as a proxy). Measurements presented herein were conducted at the same time, and thus, on the same seedlings as in Jacotot et al. (2018). In the present study, the questions we wanted to answer were: (i) does atmospheric $\mathrm{CO}_{2}$ enrichment, which increased photosynthesis, lead to a stimulation of growth and biomass? (ii) is the growth response to tidal flooding duration reduced due to waterlogging variations? (iii) what will be the effects of these two parameters on the plant tissues quality, and notably on $\mathrm{C}: \mathrm{N}$ ratios?

\section{MATERIALS AND METHODS}

\section{Greenhouses and Closed Chambers Experiments \\ Description of the Facility}

The study was conducted in New Caledonia $\left(22^{\circ} 13^{\prime} 49^{\prime \prime} \mathrm{S}\right.$, $\left.166^{\circ} 31^{\prime} 09^{\prime \prime} \mathrm{E}\right)$ from June 2016 to May 2017, a period encompassing the two main seasons (i.e., the cool season from June to November, and the warm season from November to June). Experiments were realized in three semi-open greenhouses (Figure 1a) $\left(12 \times 6 \mathrm{~m}, 6 \mathrm{~m}\right.$ height, $72 \mathrm{~m}^{2}$ each $)$, following a splitplot design with $\mathrm{CO}_{2}$ atmospheric concentrations as the whole-plot (Ambient, $400 \mathrm{ppm}$ vs. Elevated, $800 \mathrm{ppm}$ ) and 

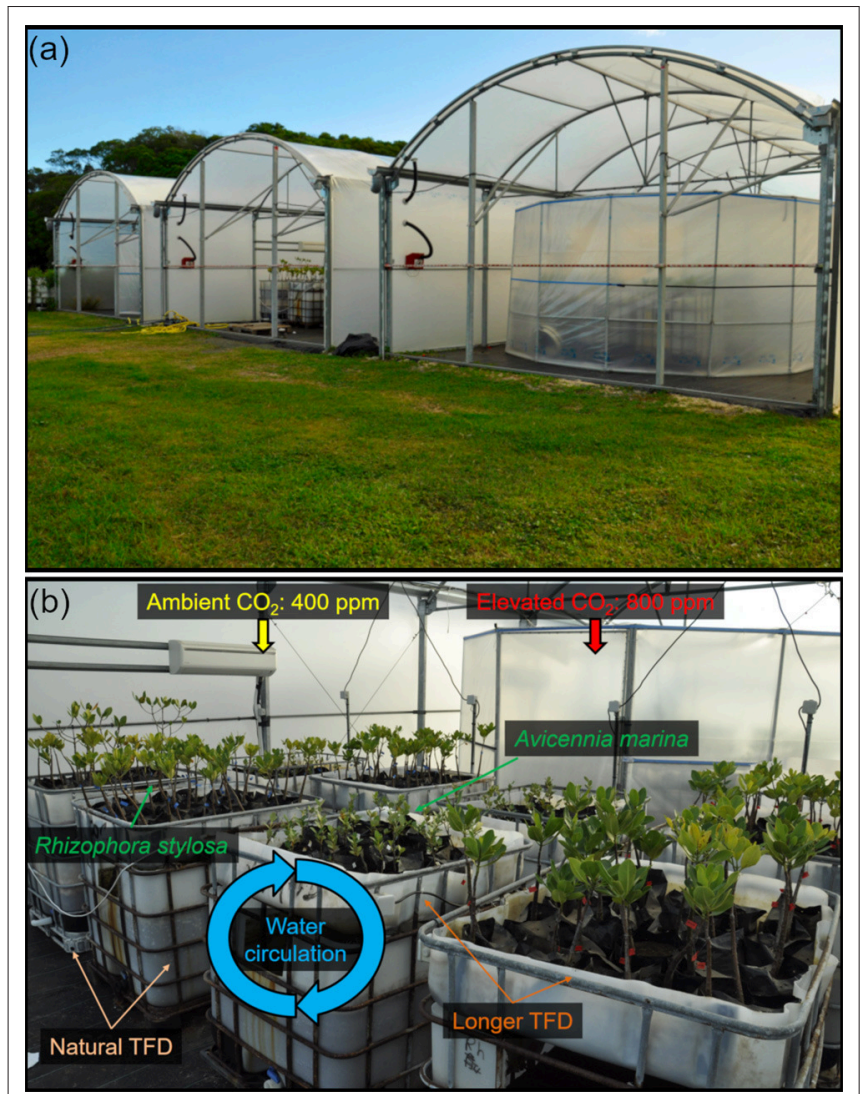

FIGURE 1 | Illustrations of the exterior (a) and interior (b) of the $\mathrm{CO}_{2}$ facility.

tidal flooding duration (TFD) as the split-plot nested within $\mathrm{CO}_{2}$ (Natural vs. Longer). Inside each greenhouse, a circular closed chamber of $36 \mathrm{~m}^{2}$ (2.4 m height) was constructed to maintain elevated atmospheric $\mathrm{CO}_{2}$ concentrations (Figure $\mathbf{1 b}$ ). To control the tidal duration treatment, custom-designed tidal tables were built (Figure 1b). The tidal tables consisted of a 700 liters polypropylene tank ( $1 \mathrm{~m}^{2}$ area over $0.7 \mathrm{~m}$ height) serving as a water reserve, surmounted by a 300 liters planting tray ( $1 \mathrm{~m}^{2}$ area over $0.3 \mathrm{~m}$ height). Each tidal table worked as an individual unit. Every 2 weeks throughout the studied period, the water reserves were renewed with fresh seawater pumped into the adjacent lagoon $(20 \mathrm{~m})$. To simulate high tide periods, an aquarium pump placed in each tank sent the water to the planting trays. During low tide periods, a siphon pipe allowed the planting tray to drain the water back into the reserve. To control the tidal treatment assigned to each tank, the aquarium pumps were connected to three custom-build current controllers (one per greenhouse). The controllers were built from open source Arduino plans freely available under public licenses and were programmed according to the needs of the experiment. Water quality ( $\mathrm{pH}$, salinity, DO) in the tanks was checked periodically using YSI probes.

Air temperature and humidity were recorded every $5 \mathrm{~min}$ inside the greenhouses and the closed chambers with HOBO sensors (Onset, Cape Cod, Massachusetts, USA). The temperature and humidity could fluctuate naturally inside the greenhouses, however, air cooling units have been installed in the closed chambers to prevent large temperature fluctuations. During the experimental period, average temperatures were, for inside the greenhouses and the closed chambers respectively, 23.1 \pm 2.6 and $22.3 \pm 3.0^{\circ} \mathrm{C}$ during the cool season and $26.4 \pm 3.2$ and $26.7 \pm 3.5^{\circ} \mathrm{C}$ during the warm season. The relative humidity was, for inside the greenhouses and the closed chambers respectively, $85.8 \pm 12.6$ and $78.4 \pm 12.2 \%$ during the cool season and $80.7 \pm$ 14.2 and $80.8 \pm 12.8 \%$ during the warm season.

\section{Plant Materials}

A total of 720 R. stylosa and 400 A. marina propagules were collected from multiple trees in the pristine mangrove of Oundjo, in New Caledonia $\left(21^{\circ} 4^{\prime} 8^{\prime \prime} \mathrm{S}, 164^{\circ} 42^{\prime} 51^{\prime \prime} \mathrm{E}\right)$. They were collected between February and March 2014, during the optimal fruiting period. They were then individually planted in 2.5liters polyethylene bags in a 1:1 mixture of mangrove peat and sand and grown for two complete years before being used in the experiment.

The mangrove seedlings were randomly allocated between the tidal tables, with $25 \mathrm{~A}$. marina or $30 \mathrm{R}$. stylosa on each tidal table, resulting in $100 \mathrm{~A}$. marina (4 tidal tables) and $180 \mathrm{R}$. stylosa (6 tidal tables) for each of the four treatments (Figure 1b). The tidal tables were then distributed between the three greenhouses as true experimental replicates, and then either inside or outside the closed chambers according to their $\mathrm{CO}_{2}$ treatment. During the experiment, mangrove seedlings were regularly rotated within each tidal table and were rotated three times between the greenhouses to minimize positional effect.

\section{$\mathrm{CO}_{2}$ Enrichment}

Pure $\mathrm{CO}_{2}$ was supplied into each of the three closed chambers between 5:00 a.m. to 7:00 p.m. and the concentrations were maintained between 780 and 820 ppm throughout this period. The $\mathrm{CO}_{2}$ concentrations inside the chambers were continuously monitored using $\mathrm{CO}_{2}$ probes connected to a central unit that controlled the entire system (MAXICLIM NG 08/3Z, Anjou Automation). In addition, $\mathrm{CO}_{2}$ concentrations were periodically checked using two different infrared portable $\mathrm{CO}_{2}$ analyzers (a G2131- $i$ CRDS analyzer from Picarro Inc., Santa Clara, USA; and a Li-8100A from LI-COR Biosciences, Lincoln, USA).

\section{Tidal Flooding Duration Treatment}

The natural tidal flooding duration (TFD) was set up according to the average flooding duration measured in New Caledonian mangroves for both species (unpublished data). These tidal durations may be different and variable according to the geographical position of the studied mangrove (e.g., Van Loon et al., 2007). In New Caledonia, mangroves develop in semiarid conditions with a specific zonation of the vegetative species: Rhizophora spp. colonizes the sea side, while Avicennia marina develops at higher elevations. Previous studies have suggested that the main factor controlling this distribution of mangrove species in New Caledonia is soil salinity, which in turn is controlled by the duration of tidal inundation, and thus, by the soil elevation (Marchand et al., 2011b, 2012). As a result, the flooding duration for Rhizophora trees is higher than for 
Avicennia. Consequently, in the experiment, natural TFD was $3 \mathrm{~h}$ $15 \mathrm{~min}$ for A. marina and $6 \mathrm{~h} 00 \mathrm{~min}$ for $R$. stylosa for each high tide. Simulated tidal cycles were semi-diurnal, meaning that there were two high tides each day, separated by a low tide period of $8 \mathrm{~h}$ $30 \mathrm{~min}$ and $5 \mathrm{~h} 45 \mathrm{~min}$ for $A$. marina and $R$. stylosa, respectively.

We hypothesized that an increase in mean sea-level would similarly affect the flooding duration of both species; thus, in the experiment, longer TFD was simulated by increasing the natural times by $1 \mathrm{~h} 45 \mathrm{~min}$, which corresponded to a high tide of $5 \mathrm{~h} 00 \mathrm{~min}$ and $7 \mathrm{~h} 45 \mathrm{~min}$ for A. marina and R. stylosa, respectively. Consequently, low tides periods were reduced to $6 \mathrm{~h}$ $45 \mathrm{~min}$ and $4 \mathrm{~h}$ for $A$. marina and $R$. stylosa, respectively. This increase in flooding duration has been randomly defined but remains realistic given the projected sea-level rise at the end of the century. Although we have chosen a similar increase in flooding duration for both species, we are aware that this may be not the case, and that the flooding duration may increase differently in both stands in the natural system. Nevertheless, an increase of $1 \mathrm{~h} 45 \mathrm{~min}$ of tidal duration will have different implications for both species, as it corresponds to an increase of $45 \%$ of the natural tidal duration of $A$. marina, whereas it is only $25 \%$ for R. stylosa. During high tide, the water level in the planting trays was identical for all tidal tables, $5 \mathrm{~cm}$ above sediment surface to completely submerge the root system.

\section{Measurements}

\section{Growth and Biomass}

All mangrove seedlings were measured for their height and basal diameter. Height measurements were made along the main axis, from the soil for A. marina, and from the top of the hypocotyl for $R$. stylosa. Basal diameters were taken at $0.5 \mathrm{~cm}$ above these two limitations. The measurements were realized five times during the experimental period: at the beginning, after 90, 180, 260 days, and at the end of the experiment, when the seedlings were three-years old.

Biomass was measured at the beginning and at the end of the experiment. For each species and treatment, 30 seedlings were randomly selected and separated into below (root system) and above (leaves and stems) ground parts. All plant components were then thoroughly washed with deionized water. Then, all plant materials were dried at $60^{\circ} \mathrm{C}$ during $72 \mathrm{~h}$ before being weighted for dry mass (g). Relative growth rates (RGR) were calculated as the difference between final and initial mass over the duration of the experiment. In addition, the leaf mass area (LMA, $\mathrm{g} \mathrm{cm}^{-2}$ ) was calculated as the inverse of the surface leaf area (SLA), which was previously determined on the same trees and during the same experiment (Jacotot et al., 2018).

\section{Carbon and Nitrogen Content}

Carbon and nitrogen contents were measured at the end of the experiment. For each species and treatment, 30 individuals were randomly selected and separated in three batches of 10 individuals. Within each batch, all seedlings were separated into leaves, stems and roots. All plants materials were then dried at $60^{\circ} \mathrm{C}$ for $72 \mathrm{~h}$, and then ground using a ball mill, to finally obtain three batches of leaves, stems and roots for each species and treatment, each one constituted by 10 individuals. Three subsamples ( $\sim 2 \mathrm{mg}$ ) of each lot of leaves, stems and roots were then analyzed for total carbon $(\mathrm{C})$ and nitrogen $(\mathrm{N})$ contents (\%) using an elemental analyzer (Integra2, Sercon, UK). All the analyses were performed at the French National Institute for Sustainable Development (IRD) of Noumea, New Caledonia (France). The analytical precision of the analyzer was checked using IAEA-600 caffeine standard (IAEA Nucleus) and was less than $0.3 \%$ for $\mathrm{C}$ and $0.15 \%$ for $\mathrm{N}$. All C:N ratios in this study were calculated on the mass basis.

\section{Statistical Analysis}

Final heights, basal diameters, final above and below ground biomasses, below to above ground ratios and $\mathrm{C}: \mathrm{N}$ ratios were analyzed for significant differences $(p<0.05)$ between the four treatments. Both species were analyzed independently. We used a Linear Mixed-Effects model (LMER) in which we set the $\mathrm{CO}_{2}$ treatment (whole-plot) and the TFD treatment (subplot) as fixed effects. Multiple pairwise comparisons were then realized using a Tukey test for above and below ground biomasses, below to above ground ratios and C:N ratios, and a Scheffe post-hoc test was used for heights and basal diameters. All statistical analyzes were performed using $\mathrm{R}$ software version 3.5.1 (R Development Core Team, 2008). All results in the manuscript are reported by their mean \pm standard error (SEM).

\section{RESULTS}

\section{Basal Diameters and Heights}

Changes in basal diameters and heights of A. marina and $R$. stylosa subjected to the four different treatments along the year of experiment are presented in Figure 2. The $\mathrm{CO}_{2}$ enrichment resulted in a strong stimulation of seedlings growth from the start of the experiment (Figure 2); however, this effect was significant only 6 months after the beginning of the enrichment. For A. marina, final basal diameters and heights were significantly higher at elevated $\mathrm{CO}_{2}$ than at ambient $\mathrm{CO}_{2}$ concentrations (Figures 2A,C and Table 1), either with normal or longer tidal flooding duration (TFD). In addition, within each $\mathrm{CO}_{2}$ treatment, the longer TFD significantly increased final basal diameters and heights (Figures 2A,C and Table 1). For $R$. stylosa, elevated $\mathrm{CO}_{2}$ significantly increased final basal diameters and heights for both natural and longer TFD treatments (Figures 2B,D and Table 1); however, no significant effect was observed for longer TFD within each $\mathrm{CO}_{2}$ treatment (Table 1).

\section{Biomass, Below to Above Ground Ratios and Relative Growth Rates}

Results of final above and below ground biomass are presented in Figure 3. For A. marina, elevated $\mathrm{CO}_{2}$ significantly increased final above and below ground biomass, either under natural or longer TFD (Figure 2A and Table 1). However, the increase of the above ground biomass was higher (140 and 126\% for natural and longer TFD) than the augmentation of the below ground biomass (78 and 74\% for natural and longer TFD), which resulted in a significant decrease of the below to above ground ratio (Figure 2C). In addition, no significant effect of the TFD treatment was observed within each $\mathrm{CO}_{2}$ treatment (Figure 2A 

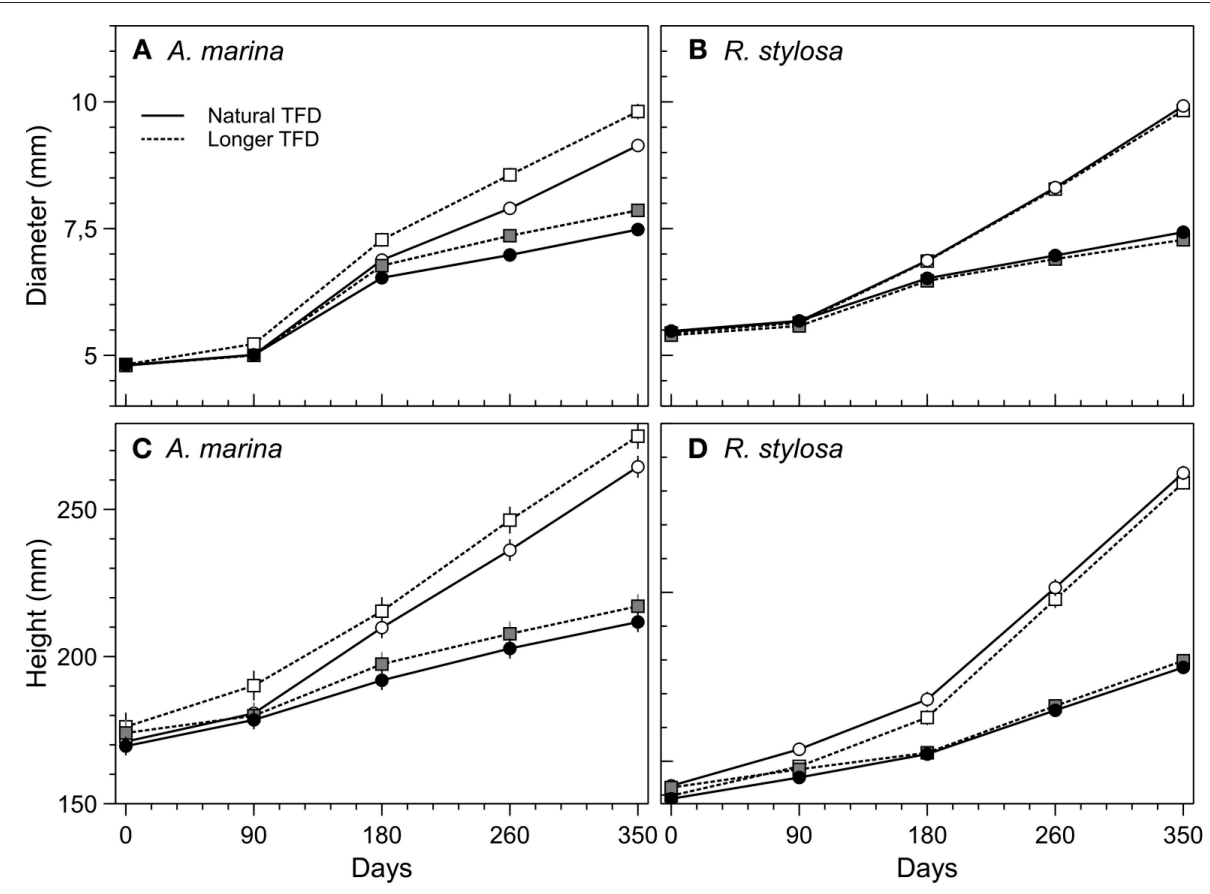

FIGURE 2 | Changes in basal stem diameters and heights of $A$. marina (A,C) and $R$. stylosa (B,D) grown in ambient (closed symbols) and elevated (open symbols) $\mathrm{CO}_{2}$, and two lengths of tidal flooding: normal (solid lines) and longer (dotted lines). Values are means $\pm \mathrm{SEM}(A . \mathrm{marina} n=125 ; R$. stylosa $n=180)$.

TABLE 1 | Significance values reported after a Linear Mixed-Effects model.

\begin{tabular}{|c|c|c|c|c|c|c|}
\hline & \multicolumn{3}{|c|}{ Avicennia marina } & \multicolumn{3}{|c|}{ Rhizophora stylosa } \\
\hline & $\mathrm{CO}_{2}$ & TFD & Interaction & $\mathrm{CO}_{2}$ & TFD & Interaction \\
\hline Height & $2.015^{\star}$ & $4.124^{*}$ & $0.422^{\mathrm{NS}}$ & $117.178^{\star \star \star *}$ & $0.040^{\mathrm{NS}}$ & $2.376^{\mathrm{NS}}$ \\
\hline Diameter & $204.141^{\star \star \star}$ & $17.151^{\star \star \star}$ & $1.303^{\mathrm{NS}}$ & $23.877^{\star \star *}$ & $3.841^{\mathrm{NS}}$ & $0.289^{N S}$ \\
\hline \multicolumn{7}{|l|}{ BIOMASS } \\
\hline Above ground & $376.099^{* * *}$ & $0.825^{\mathrm{NS}}$ & $0.0596^{\mathrm{NS}}$ & $298.433^{\star \star \star}$ & $6.961^{* *}$ & $3.044^{\mathrm{NS}}$ \\
\hline Below ground & $112.676^{\star * *}$ & $4.695^{\star}$ & $0.168^{N S}$ & $75.337^{\star \star \star}$ & $4.653^{*}$ & $0.062^{N S}$ \\
\hline $\mathrm{BG} / \mathrm{AG}$ ratio & $44.228^{* \star \star}$ & $1.584^{\mathrm{NS}}$ & $0.149^{N S}$ & $54.142^{\star \star \star}$ & $0.332^{\mathrm{NS}}$ & $3.221^{\mathrm{NS}}$ \\
\hline \multicolumn{7}{|l|}{ C:N } \\
\hline Leaves & $2.434^{*}$ & $0.007^{N S}$ & $0.446^{\mathrm{NS}}$ & $3.727^{\mathrm{NS}}$ & $10.806^{*}$ & $14.352^{\star *}$ \\
\hline Stems & $4.161^{\mathrm{NS}}$ & $22.057^{* *}$ & $4.033^{\mathrm{NS}}$ & $26.955^{\star \star \star}$ & $4.288^{\mathrm{NS}}$ & $0.896^{N S}$ \\
\hline Roots & $22.418^{* *}$ & $3.243^{\mathrm{NS}}$ & $6.096^{\star}$ & $1.371^{* \star *}$ & $0.281^{N S}$ & $0.0744^{N S}$ \\
\hline
\end{tabular}

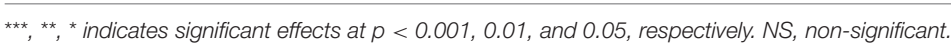

and Table 1). For R. stylosa, elevated $\mathrm{CO}_{2}$ concentrations also significantly increased the final above and below ground biomass (Figure 3B and Table 1). As for A marina, the increase was higher for the above ground biomass ( 84 and $78 \%$ for natural and longer TFD) in comparison to the below ground biomass ( 37 and $50 \%$ for natural and longer TFD), which resulted in a significant decrease of the below to above ground ratio (Figure 3D). Concerning TFD, a significant reduction was observed for the above ground biomass under elevated $\mathrm{CO}_{2}$ (Figure 3B).

Concerning the whole period of the experiment, relative growth rates (RGR) of A. marina were, under ambient $\mathrm{CO}_{2}$ concentrations $18.19 \pm 1.33$ and $20.36 \pm 0.96 \mathrm{~g} \mathrm{yr}^{-1}$, and under elevated $\mathrm{CO}_{2}$ concentrations $35.56 \pm 0.69$ and $38.38 \pm 1.46 \mathrm{~g}$ $\mathrm{yr}^{-1}$, for natural and longer TFD, respectively. For R. stylosa,
RGR were $42.87 \pm 1.89$ and $37.39 \pm 1.33 \mathrm{~g} \mathrm{yr}^{-1}$ under ambient $\mathrm{CO}_{2}$ concentrations, and $63.23 \pm 1.85$ and $58.44 \pm 1.99 \mathrm{~g}$ $\mathrm{yr}^{-1}$ under elevated $\mathrm{CO}_{2}$ concentrations, for natural and longer TFD, respectively.

\section{C:N Ratios}

Results of C:N ratios in the leaves, stems and roots of $A$. marina and $R$. stylosa at the end of the experiment are presented in Table 2. Elevated $\mathrm{CO}_{2}$ concentrations significantly increased the $\mathrm{C}: \mathrm{N}$ ratios in the leaves and roots of A. marina, as well as in the stems and roots of $R$. stylosa (Tables 1, 2). In addition, TFD significantly decreased the C:N ratios in the stems of both species (Tables 1, 2). 


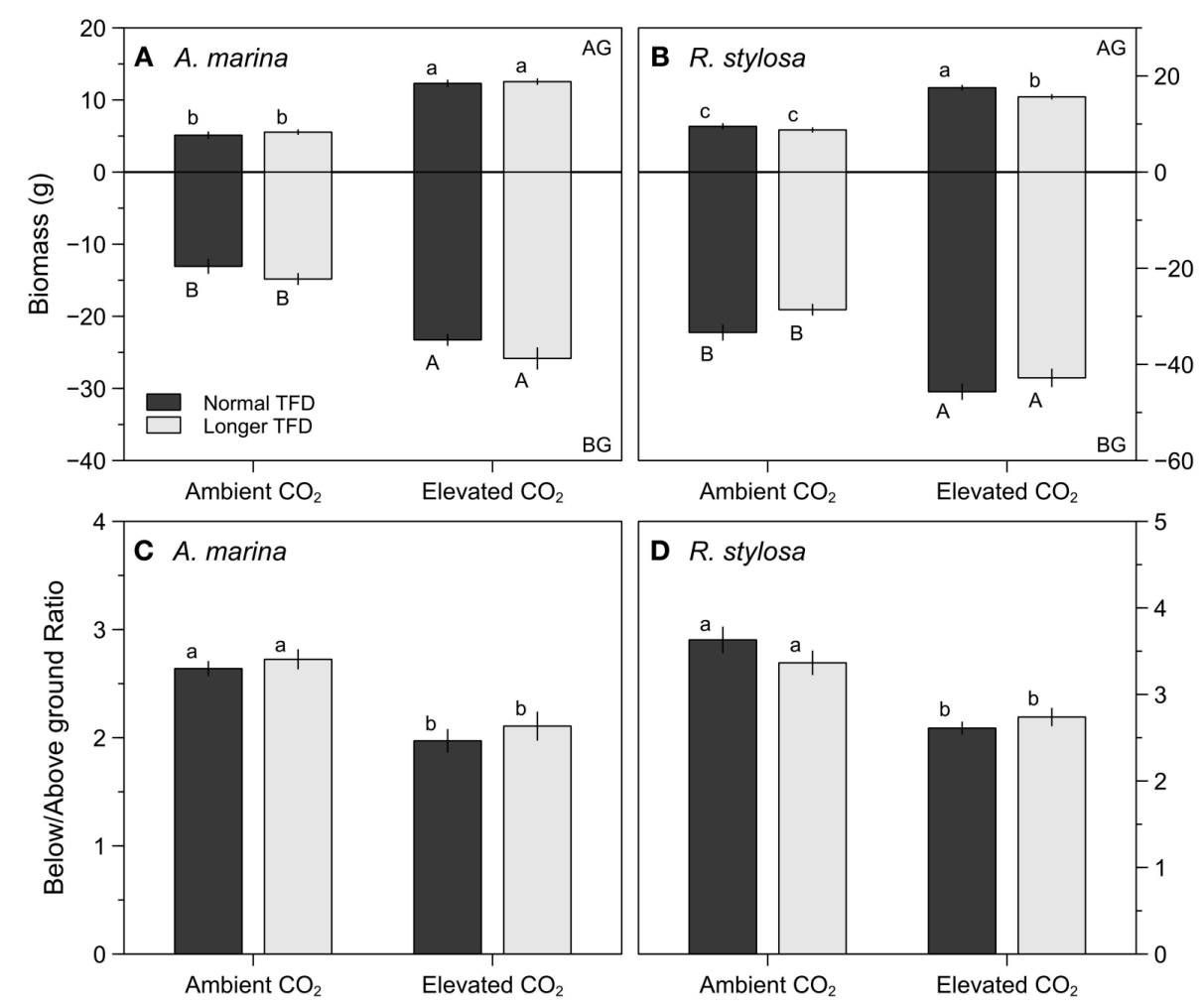

FIGURE 3 | Final above ground (AG) and below ground (BG) biomass (g), and below/above ground biomass ratios of A. marina (A,C) and R. stylosa (B,D) grown in ambient or elevated $\mathrm{CO}_{2}$, and under normal (dark-gray bars) and longer TFD (gray bars), for 12 months. Values are means \pm SEM $(n=30)$. Different letters indicate significant differences $(p<0.05)$.

TABLE 2 | C:N ratios in leaves, stems and roots of $A$. marina and $R$. stylosa grown in ambient and elevated $\mathrm{CO}_{2}$, and under natural $(\mathrm{N})$ and longer $(\mathrm{L}) \mathrm{TFD}$, for 12 months.

\begin{tabular}{|c|c|c|c|c|}
\hline \multirow[t]{2}{*}{ C:N } & \multicolumn{2}{|c|}{ Ambient $\mathrm{CO}_{2}(400$ ppm) } & \multicolumn{2}{|c|}{ Elevated $\mathrm{CO}_{2}(800 \mathrm{ppm})$} \\
\hline & N TFD & L TFD & N TFD & L TFD \\
\hline \multicolumn{5}{|c|}{ Avicennia marina } \\
\hline Leaves & $36.53 \pm 1.89$ & $35.41 \pm 2.05$ & $41.30 \pm 1.02$ & $42.18 \pm 0.33$ \\
\hline Stems & $76.10 \pm 0.30$ & $71.27 \pm 0.42$ & $72.45 \pm 2.13$ & $62.02 \pm 2.12$ \\
\hline Roots & $52.56 \pm 0.39$ & $53.20 \pm 0.75$ & $61.22 \pm 0.87$ & $57.14 \pm 1.48$ \\
\hline \multicolumn{5}{|c|}{ Rhizophora stylosa } \\
\hline Leaves & $61.75 \pm 0.56$ & $69.94 \pm 1.05$ & $70.06 \pm 0.92$ & $69.47 \pm 1.76$ \\
\hline Stems & $132.20 \pm 0.39$ & $119.26 \pm 2.84$ & $172.26 \pm 7.47$ & $167.61 \pm 2.06$ \\
\hline Roots & $101.57 \pm 2.06$ & $100.02 \pm 4.20$ & $159.64 \pm 3.39$ & $154.80 \pm 10.58$ \\
\hline
\end{tabular}

Values are means \pm SEM. $(n=3)$.

\section{DISCUSSION}

\section{Elevated $\mathrm{CO}_{2}$ Will Enhance Mangrove Productivity, Carbon Storage, and Seedlings Establishment}

Our results clearly confirmed that rise in atmospheric $\mathrm{CO}_{2}$ concentrations would affect the growth of mangrove seedlings. In this experiment, doubling $\mathrm{CO}_{2}$ concentrations for one year resulted in an increase of RGR of more than 89 and $47 \%$ for A. marina and $R$. stylosa, respectively. These strong raises in RGR may be partly related to an increase in the photosynthetic activity of both species under elevated $\mathrm{CO}_{2}$ concentrations. Indeed, the present study was performed concomitantly with another one that focused on the photosynthetic response of the seedlings (Jacotot et al., 2018), and both were conducted during the same time period and on the same seedlings. In this related study, we observed that $\mathrm{CO}_{2}$ enrichment enhanced the mean photosynthetic response of both species (Jacotot et al., 2018). However, a $89 \%$ increase in RGR for A. marina and $47 \%$ for $R$. stylosa was surprising as it was much higher than the increase of photosynthesis that rose by more than $37 \%$ for A. marina (from $6.25 \pm 2.24$ to $10.52 \pm 3.24 \mu \mathrm{mol} \mathrm{m}^{-2} \mathrm{~s}^{-1}$ ) and by more than $45 \%$ for R. stylosa (from $6.247 \pm 1.63$ to $11.35 \pm 2.91 \mu \mathrm{mol} \mathrm{m}^{-2}$ $\mathrm{s}^{-1}$ ). In fact, Kirschbaum (2011) reported a RGR augmentation of $10 \%$ for a $30 \%$ increase in photosynthesis, which is a reverse ratio in comparison to our study and we should have expected a lower increase in RGR, but no clear explanation was found to clarify this result. However, Kirschbaum (2011) suggested that excess carbohydrates produced by the enhancement of photosynthesis might not be converted into plant tissues due to other resource limitations. In this case, carbohydrates may accumulate in leaves as sugars and starches, resulting in an increase in the leaf mass area ratio (Poorter and Navas, 2003). In fact, a decrease in the leaf mass per area was observed for both species under elevated $\mathrm{CO}_{2}$ 
concentrations (Jacotot et al., 2018), by more than 33 and $21 \%$ for A. marina and R. stylosa, respectively (Figures 5C,D). This development of seedlings leaves suggests that they have not been affected by nutrient limitations during the experiment, which have been sufficiently provided by the frequent water renewal that was operated in the greenhouses.

RGRs were higher during the last 180 days of the experiment than during the first 180 days (Figure 2), i.e., during the warm season rather than during the cool season. Inside the greenhouses, the mean monthly temperature raised from 22.3 to $26.7^{\circ} \mathrm{C}$ during the warm season. This raise in temperature is thought to be responsible for the increase in productivity of both species. In fact, photosynthetic activity of A. marina and $R$. stylosa under elevated $\mathrm{CO}_{2}$ increased by 40 and $45 \%$ during the warm season, whereas it was only enhanced by 32 and $38 \%$, respectively, during the cool season (Figure 4) (Jacotot et al., 2018), which confirms our hypothesis. Photosynthesis of tropical C3 species, such as A. marina and R. stylosa, can operate between 15 and $45^{\circ} \mathrm{C}$, however, there is a temperature optimum for which photosynthesis is maximal. Gilman et al. (2008) reported a temperature optimum for photosynthesis of $28-32^{\circ} \mathrm{C}$ for mangroves species, but lower temperatures were reported for specific species, such as $24.5^{\circ} \mathrm{C}$ for Avicennia germinans (Reef et al., 2016), or $26.8^{\circ} \mathrm{C}$ for A. marina in New Caledonia (Leopold et al., 2016). The temperature reached during the warm season in our study was closer to the temperature optimum for photosynthesis than the one reached during the cold season, therefore, we suggested that seasonal variations in temperature drove the RGRs throughout the year of experiment. With future climate change, the global temperatures are expected to rise by $0.3-4.8^{\circ} \mathrm{C}$ (Stocker et al., 2013), and our results suggest that elevated $\mathrm{CO}_{2}$ concentrations and increased temperatures could further promote productivity, and thus carbon storage, at least in biomass, of mangrove forests.

Elevated $\mathrm{CO}_{2}$ reduced the below to above ground ratio due to a higher increase of the above ground biomass than of the below ground biomass (Figures 3C,D). This allocation of carbon under elevated $\mathrm{CO}_{2}$ with more carbon invested in the above ground parts has previously been observed for A. germinans by Reef et al. (2016). This newly acquired carbon investment reveals a strategy of light capture and photosynthesis optimization that suggests a lack of limitations of the availability of soil resources. This result was consistent with our previous study (Jacotot et al., 2018), in which we observed, for both species, an increase in the specific leaf area with elevated $\mathrm{CO}_{2}$ (Figure 5), which leads to a higher potential for light interception. Although more carbon was invested in above ground parts, a significant increase in the below ground biomass was also observed for both species (Figures 3A,B). This result may lead to several beneficial implications in the response of mangroves ecosystems to climate change: (i) the soil carbon storage potential of the ecosystem may increase, (ii) the increase in root development may facilitate seedlings establishment in intertidal sediments (Balke et al., 2011), which could in turn promote ecosystem expansion, and (iii) the capacity of mangrove ecosystems to face sea-level rise could be improved, as higher root density will increase soil volume and soil organic matter content, two important factors contributing to the vertical accretion of mangrove soils (Cahoon et al., 2006; McKee et al., 2007; McKee, 2011; Krauss et al., 2014, 2017).

In addition to increases in growth and biomass, we also observed a significant change in plant composition, and notably an increase in the C:N ratios in roots and leaves of $A$. marina and in stems and roots of $R$. stylosa under elevated $\mathrm{CO}_{2}$ (Tables 1, 2). The effects of elevated $\mathrm{CO}_{2}$ on $\mathrm{C}: \mathrm{N}$ ratios have been extensively examined in natural ecosystems, however, the available literature shows contrasting results (e.g., Gifford et al., 2000; Luo et al., 2006). C:N ratios may increase, decrease or be unaffected under elevated $\mathrm{CO}_{2}$ but, in general, a $15 \%$ of increase is observed (Gifford et al., 2000). In our study, the increase in C:N ratios was mainly due to a decrease in nitrogen content $(\mathrm{N})$ in plant tissues. Such a decrease of $\mathrm{N}$ with elevated $\mathrm{CO}_{2}$ has often been observed in terrestrial plants (Cotrufo et al., 1998; Yin, 2002; Ainsworth and Long, 2005; de Graaff et al., 2006), including mangroves (McKee and Rooth, 2008), but remains poorly understood (Taub and Wang, 2008; Lotfiomran et al., 2016). Some authors have shown a general decrease in the specific $\mathrm{N}$ uptake rates by the roots under elevated $\mathrm{CO}_{2}$ (McDonald et al., 2002; Taub and Wang, 2008; Lotfiomran et al., 2016). These authors have suggested that this decrease results from both a decrease in $\mathrm{N}$ demand by shoots and from a reduction of the soil-root system ability to supply N. They also suggested that the bestsupported mechanism for decreased $\mathrm{N}$ supply is a decrease in transpiration-driven mass flow of $\mathrm{N}$ in soils due to decreased stomatal conductance at elevated $\mathrm{CO}_{2}$. In fact, such a decrease in stomatal conductance has effectively been observed for $A$. marina and $R$. stylosa grown under elevated $\mathrm{CO}_{2}$ (Jacotot et al., 2018), which adds to this last hypothesis. Higher C:N ratios may have an important implication, as it may be negatively correlated with lower rates of organic matter decomposition in soils (Hättenschwiler and Gasser, 2005; Zhang et al., 2008; Zimmermann et al., 2009; Jacob et al., 2010), which may lead to a reduction in the greenhouse gas production, and, in turn, to a higher carbon storage capacity. However, this reasoning must be nuanced considering that OM quality is not the only driver of GHG production and emissions in mangrove soils, other parameters influence these biogeochemical processes and will also vary with climate changes and must be taken into account. For example, the increase in soil organic matter decomposition rates with increasing temperature has been widely described in the literature for different ecosystems (Segers, 1998; Fang and Moncrieff, 2001; Fierer et al., 2005; Davidson and Janssens, 2006; Conant et al., 2011; Inglett et al., 2012), including mangroves (Mackey and Smail, 1996; Barroso Matos et al., 2012). Conversely, the increase in tidal flooding duration may lead to a lower renewable of the electron acceptors pool within the soil and to a more anoxic environment, which may limit the organic matter decomposition processes.

\section{Contrasting Effects of the Increase in Tidal Flooding Duration Between A. marina and R. stylosa}

According to our initial hypothesis, growth and biomass of R. stylosa were reduced under longer tidal flooding duration (Figures 2B,D, 3B) although this effect was not significant 

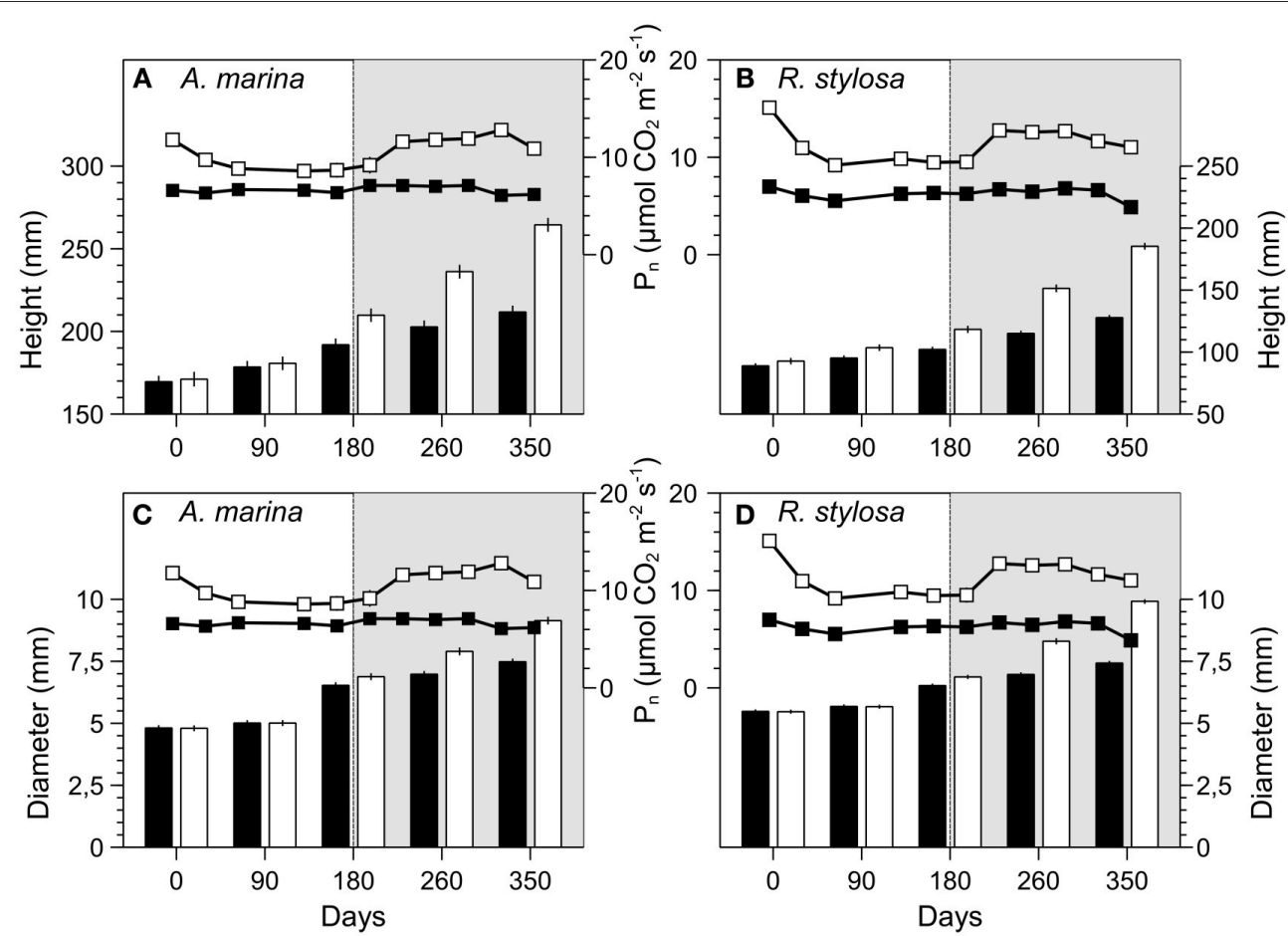

FIGURE 4 | Heights (mm), diameters (mm) and photosynthesis ( $\mu$ mol $\mathrm{CO}_{2} \mathrm{~m}^{-2} \mathrm{~s}^{-1}$ ) of $A$. marina (A,C) and $R$. stylosa (B,D) grown in ambient (black bars and markers) or elevated $\mathrm{CO}_{2}$ (white bars and markers) for 12 months. Values are means $\pm \mathrm{SEM}$ (Heights and diameters: $A$. marina $n=125 ; R$. stylosa $n=180$; photosynthesis: $n=30$ ). The white and shaded area correspond respectively to the cool and the warm seasons. Photosynthesis data are from Jacotot et al. (2018).

(Table 1). Under longer TFD, basal diameters decreased by 13 and by $5 \%$, and seedlings heights decreased by 6 and $11 \%$ for ambient and elevated $\mathrm{CO}_{2}$, respectively. Consequently, final biomass of $R$. stylosa was reduced by 11 and $4 \%$ for ambient and elevated $\mathrm{CO}_{2}$, respectively, in comparison to the controlled TFD treatment. Although we agree that the effect of longer TFD was not significant, we suggest that the reduction in the seedlings growth should not be ignored. We also suggest that the lack of significance in the present work may be due to the limited duration of the experiment and that a longer study could highlight a significant effect of increased TFD on mangrove seedlings. This result may be explained by the $3 \%$ reduction in photosynthesis that we observed for $R$. stylosa seedlings growing under longer tidal duration (Jacotot et al., 2018). However, this slight decrease might be related to other factors. For instance, longer tidal flooding will have probably induced a deficit in oxygen in the soil due to roots and micro-organisms respiration, as well as a reduction of air penetration in the soil from the atmosphere (Naidoo et al., 1997). Although no oxygen measurements have been performed in our experiment, we can expect such a decrease after the longer tidal flooding applied, as it was previously reported in similar experiments (Hovenden et al., 1995; Skelton and Allaway, 1996). In anoxic mangrove sediments, rich in organic matter and in sulfates brought at each tide, organic matter may be oxidized through sulfate reducing processes, leading to sulfide production (Kristensen et al., 2008; Balk et al., 2016). Sulfide compounds, including $\mathrm{H}_{2} \mathrm{~S}$, are highly toxic to plants (Lamers et al., 2013), and inhibit the growth of mangrove seedlings (Holguin et al., 2001; Lyimo and Mushi, 2005; Reef et al., 2010). The presence of sulfide in the longer TFD treatment was assumed due to the dark color of the sediment and because of the strong rotten egg odor typical of $\mathrm{H}_{2} \mathrm{~S}$, therefore, we suggest that sulfides were possibly responsible for the seedlings growth inhibition.

In contrast to $R$. stylosa, final biomass of $A$. marina increased with longer TFD by 11 and $8 \%$ under ambient and elevated $\mathrm{CO}_{2}$ concentrations, respectively (Figures 2A,C, 3A). Natural TFD were based on our field observations and measurements (unpublished data) and were therefore representative of the natural conditions, in which both species develop along the intertidal gradient in New Caledonia, with A. marina growing at a higher elevation than $R$. stylosa. This position in the intertidal area, combined to the semi-arid climate of New Caledonia, implies A. marina suffer from elevated salt concentrations due to high evaporation processes, low freshwater inputs either by rains or river discharges and low frequency of tidal submersions (Marchand et al., 2011a, 2012). We suggest that longer tidal flooding in our experiment increased water availability that in turn decreased soil salinity, which are two stressing factors affecting growth and biomass, and therefore promoted the growth of $A$. marina seedlings. With climate changes, due to its positive response to both longer TFD to elevated $\mathrm{CO}_{2}$ concentrations, we can expect that colonization abilities and productivity of $A$. marina seedlings will be enhanced in the future in this context of a semi-arid climate, where A. marina develops behind Rhizophora spp. 

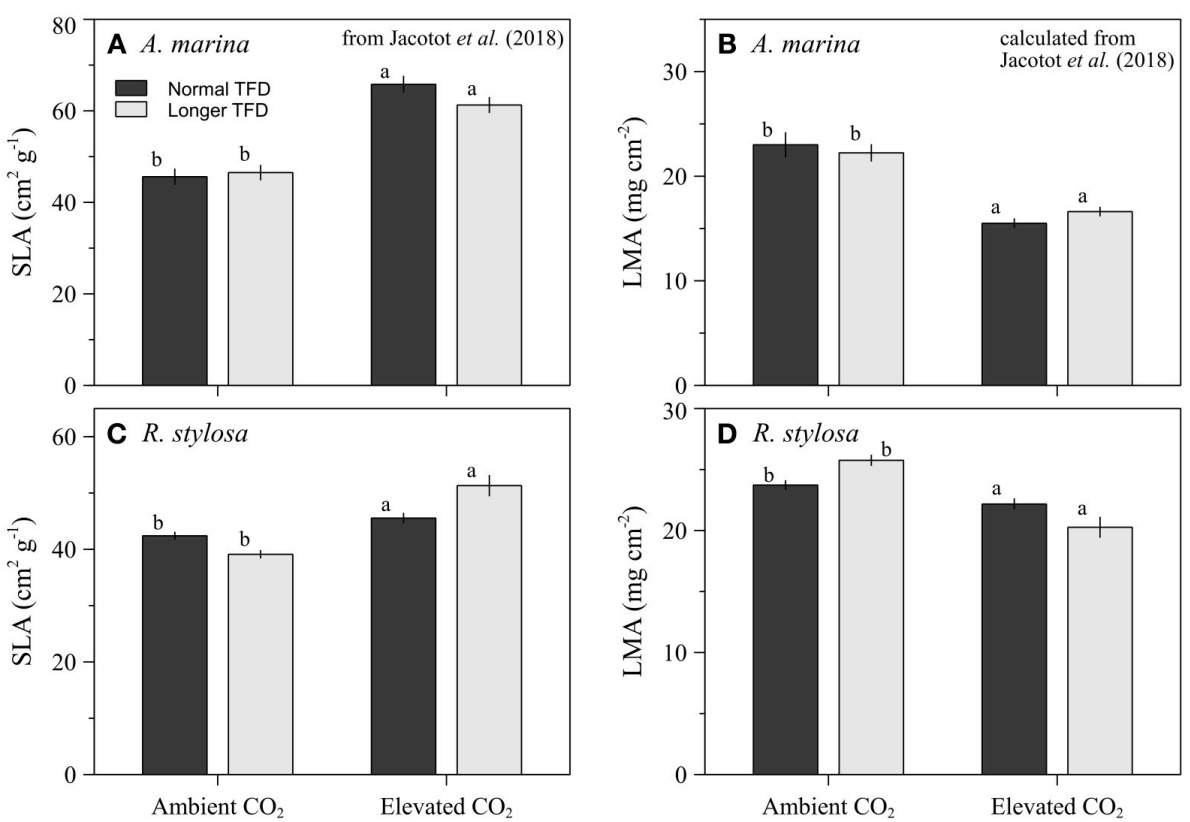

FIGURE 5 | Specific Leaf Area (A,C) and Leaf Mass Area (B,D) of $A$. marina and $R$. stylosa grown in ambient or elevated $\mathrm{CO}_{2}$, and under normal (dark-gray bars) and longer TFD (gray bars), for 12 months. Values are means \pm SEM $(n=30)$. Different letters indicate significant differences $(p<0.05)$. Data are from Jacotot et al. (2018).

Eventually, to fully understand the response of A. marina and R. stylosa to future climate changes, other parameters should be taken into account such as competition between species (McKee and Rooth, 2008). In New Caledonia, the mangrove ecotone is composed of a succession of different mangrove species, including a saltmarsh C4 grass, Sarcocornia quinqueflora, which competes for suitable spaces for expansion, and future climate may change their specific distribution.

\section{CONCLUSION}

Our results suggest that future climate changes, and specifically the increase in atmospheric $\mathrm{CO}_{2}$ concentrations and tidal flooding duration, will affect $A$. marina and $R$. stylosa seedlings physiology. Elevated $\mathrm{CO}_{2}$ concentrations enhanced growth and biomass, with an increase of the relative growth rates of $89 \%$ for A. marina and of $47 \%$ for R. stylosa, for a $100 \%$ increase of atmospheric $\mathrm{CO}_{2}$ concentrations. These results are suggested to be related to photosynthesis enhancement, measured for the same seedlings in a previous study. Elevated $\mathrm{CO}_{2}$ concentrations also increased below-ground biomass, which can lead to soil vertical accretion, thus helping mangroves to face sea-level rise. The increase in below-ground biomass could also favor seedling establishment and mangrove colonization of new available spaces resulting from sea-level rise. Future increase in surface temperature will further stimulate trees development, as seasons affected seedlings productivity with higher relative growth rates during the warmer period. Additionally, $\mathrm{C}: \mathrm{N}$ ratios of seedlings tissues were increased under elevated $\mathrm{CO}_{2}$, which may lower organic matter degradation in mangrove soils, and thus reduce greenhouse gas emissions while increasing carbon sequestration.
When increasing tidal flooding duration, the growth of R. stylosa was slightly reduced, but this effect did not significantly affect the initial enhancement of growth and biomass resulting from elevated $\mathrm{CO}_{2}$ concentrations. Conversely, growth of $A$. marina was further enhanced by $8 \%$ under longer tidal flooding duration in comparison to the control treatment. This result suggests that this species develops in a constraining position along the intertidal gradient in New Caledonia, probably suffering from the lack of water and from high salt concentrations in the soil pore waters. Therefore, the future rise in mean sea level will promote the development of A. marina by a favorable modification of the conditions in the intertidal area under semi-arid climate, which will also affect the recruitment of seedlings and the expansion of mangroves. This study provides complementary information about the productivity of mangrove seedlings with future climate changes. We now suggest that research efforts focus on the impact of climate change on the mineralization processes in mangrove soils to better understand the role of mangroves in climate change mitigation.

\section{AUTHOR CONTRIBUTIONS}

$\mathrm{CM}, \mathrm{AJ}$, and MA performed the experimental design. AJ performed data collection and statistical analyses. AJ and CM performed the data interpretation. $\mathrm{AJ}, \mathrm{CM}$, and MA wrote the paper.

\section{ACKNOWLEDGMENTS}

This study was funded by the Province Sud of New Caledonia, the City of Mont Dore, KNS Koniambo Nickel SAS and 
Vale NC. We are very grateful to the IFRECOR Committee for having attributed to this study the IFRECOR Palme National Distinction. We thank Eric Gay, the mayor of the city of Mont-Dore, for his continuous support during the

\section{REFERENCES}

Ainsworth, E. A., and Long, S. P. (2005). What have we learned from 15 years of free-air $\mathrm{CO}_{2}$ enrichment (FACE)? A meta-analytic review of the responses of photosynthesis, canopy properties and plant production to rising $\mathrm{CO}_{2}$. New Phytol. 165, 351-371. doi: 10.1111/j.1469-8137.2004.01224.x

Alongi, D. M. (2015). The impact of climate change on mangrove forests. Curr. Clim. Change Rep. 1, 30-39. doi: 10.1007/s40641-015-0002-x

Balk, M., Keuskamp, J. A., and Laanbroek, H. J. (2016). Potential for sulfate reduction in mangrove forest soils: comparison between two dominant species of the Americas. Front. Microbiol. 7:1855. doi: 10.3389/fmicb.2016.01855

Balke, T., Bouma, T. J., Horstman, E. M., Webb, E. L., Erftemeijer, P. L., and Herman, P. M. (2011). Windows of opportunity: thresholds to mangrove seedling establishment on tidal flats. Mar. Ecol. Prog. Ser. 440, 1-9. doi: 10.3354/meps09364

Ball, M. C., Cochrane, M. J., and Rawson, H. M. (1997). Growth and water use of the mangroves Rhizophora apiculata and R. stylosa in response to salinity and humidity under ambient and elevated concentrations of atmospheric $\mathrm{CO}_{2}$. Plant Cell Environ. 20, 1158-1166. doi: 10.1046/j.1365-3040.1997.d01-144.x

Barroso Matos, T., Bernini, E., and Rezende, C. E. (2012). Decomposition of mangrove leaves in the estuary of Paraiba do Sul River Rio de Janeiro, Brazil. Lat. Am. J. Aquat. Res. 40, 398-407. doi: 10.3856/vol40-issue2-fulltext-14

Betts, R. A., Jones, C. D., Knight, J. R., Keeling, R. F., and Kennedy, J. J. (2016). El Nino and a record $\mathrm{CO}_{2}$ rise. Nat. Clim. Change 6, 806-810. doi: $10.1038 /$ nclimate 3063

Bouillon, S., Borges, A. V., Castañeda-Moya, E., Diele, K., Dittmar, T., Duke, N. C., et al. (2008). Mangrove production and carbon sinks: a revision of global budget estimates. Glob. Biogeochem. Cycles 22, 1-12. doi: 10.1029/2007GB 003052

Cahoon, D. R., Hensel, P. F., Spencer, T., Reed, D. J., McKee, K. L., and Saintilan, N. (2006). "Coastal wetland vulnerability to relative sea-level rise: wetland elevation trends and process controls," in Wetlands and Natural Resource Management Ecological Studies. (Heidelberg: Springer), 271-292.

Church, J. A., Clark, P. U., Cazenave, A., Gregory, J. M., Jevrejeva, S., Levermann, A., et al. (2013). "Sea level change," in Climate Change 2013: The Physical Science Basis. Contribution of Working Group I to the Fifth Assessment Report of the Intergovernmental Panel on Climate Change, eds T. F. Stocker, D. Qin, G. -K. Plattner, M. Tignor, S. K. Allen, J. Boschung, A. Nauels, Y. Xia, V. Bex, and P.M. Midgley (Cambridge; New York, NY: Cambridge University Press).

Collins, M., Arblaster, J., Dufresne, J.-L., Fichefet, T., Friedlingstein, P., Gao, X., et al. (2014). "Long-term climate change: projections, commitments and irreversibility pages 1029 to 1076," in Climate Change 2013 - The Physical Science Basis Working Group I Contribution to the Fifth Assessment Report of the Intergovernmental Panel on Climate Change (Cambridge: Cambridge University Press), 1029-1136. doi: 10.1017/CBO9781107415324.024

Conant, R. T., Ryan, M. G., Ågren, G. I., Birge, H. E., Davidson, E. A., Eliasson, P. E., et al. (2011). Temperature and soil organic matter decomposition rates - synthesis of current knowledge and a way forward. Glob. Change Biol. 17, 3392-3404. doi: 10.1111/j.1365-2486.2011. 02496.x

Cook, J., Oreskes, N., Doran, P. T., Anderegg, W. R. L., Verheggen, B., Maibach, E. W., et al. (2016). Consensus on consensus: a synthesis of consensus estimates on human-caused global warming. Environ. Res. Lett. 11:048002. doi: 10.1088/1748-9326/11/4/048002

Cotrufo, M. F., Ineson, P., and Scott, A. (1998). Elevated $\mathrm{CO}_{2}$ reduces the nitrogen concentration of plant tissues. Glob. Change Biol. 4, 43-54. doi: 10.1046/j.1365-2486.1998.00101.x

Davidson, E. A., and Janssens, I. A. (2006). Temperature sensitivity of soil carbon decomposition and feedbacks to climate change. Nature 440, 165-173. doi: $10.1038 /$ nature 04514 study. We also thank Jacky Mermoud and Diana Burns for their help in managing the facilities. Eventually, we are thankful to Tracy Rolland and Inès Gayral for their help in fieldwork.

de Graaff, M.-A., van Groenigen, K.-J., Six, J., Hungate, B., and van Kessel, C. (2006). Interactions between plant growth and soil nutrient cycling under elevated $\mathrm{CO}_{2}$. Interactions betwGlob. Change Biol. 12, 2077-2091. doi: 10.1111/j.1365-2486.2006.01240.x

Ellison, J. C. (2015). Vulnerability assessment of mangroves to climate change and sea-level rise impacts. Wetl. Ecol. Manag. 23, 115-137. doi: 10.1007/s11273-014-9397-8

Fang, C., and Moncrieff, J. B. (2001). The dependence of soil $\mathrm{CO}_{2}$ efflux on temperature. Soil Biol. 33, 155-165. doi: 10.1016/S0038-0717(00)00125-5

Farnsworth, E. J., Ellison, A. M., and Gong, W. K. (1996). Elevated $\mathrm{CO}_{2}$ alters anatomy, physiology, growth, and reproduction of red mangrove (Rhizophora mangle L.). Oecologia 108, 599-609. doi: 10.1007/BF00329032

Fierer, N., Craine, J. M., McLauchlan, K., and Schimel, J. P. (2005). Litter quality and the temperature sensitivity of decomposition. Ecology 86, 320-326. doi: 10.1890/04-1254

Gifford, R. M., Barrett, D. J., and Lutze, J. L. (2000). The effects of elevated $\left[\mathrm{CO}_{2}\right]$ on the C:N and C:P mass ratios of plant tissues. Plant Soil 224, 1-14. doi: 10.1023/A:1004790612630

Gilman, E. L., Ellison, J., Duke, N. C., and Field, C. (2008). Threats to mangroves from climate change and adaptation options: a review. Aquat. Bot. 89, 237-250. doi: 10.1016/j.aquabot.2007.12.009

Hättenschwiler, S., and Gasser, P. (2005). Soil animals alter plant litter diversity effects on decomposition. Proc. Natl. Acad. Sci. U. S. A. 102, 1519-1524. doi: 10.1073/pnas.0404977102

Holguin, G., Vazquez, P., and Bashan, Y. (2001). The role of sediment microorganisms in the productivity, conservation, and rehabilitation of mangrove ecosystems: an overview. Biol. Fertil. Soils 33, 265-278. doi: $10.1007 / \mathrm{s} 003740000319$

Hovenden, M. J., Curran, M., Cole, M. A., Goulter, P. F. E., Skelton, N. J., and Allaway, W. G. (1995). Ventilation and respiration in roots of one-year-old seedlings of grey mangrove Avicennia marina (Forsk.) Vierh. Hydrobiologia 295, 23-29. doi: 10.1007/BF00029107

Inglett, K. S., Inglett, P. W., Reddy, K. R., and Osborne, T. Z. (2012). Temperature sensitivity of greenhouse gas production in wetland soils of different vegetation. Biogeochemistry 108, 77-90. doi: 10.1007/s10533-011-9573-3

Jacob, M., Viedenz, K., Polle, A., and Thomas, F. M. (2010). Leaf litter decomposition in temperate deciduous forest stands with a decreasing fraction of beech (Fagus sylvatica). Oecologia 164, 1083-1094. doi: 10.1007/s00442-010-1699-9

Jacotot, A., Marchand, C., Gensous, S., and Allenbach, M. (2018). Effects of elevated atmospheric $\mathrm{CO}_{2}$ and increased tidal flooding on leaf gasexchange parameters of two common mangrove species: Avicennia marina and Rhizophora stylosa. Photosynth. Res. 138, 249-260. doi: $10.1007 /$ s11120-018-0570-4

Kirschbaum, M. U. (2011). Does enhanced photosynthesis enhance growth? Lessons learned from $\mathrm{CO}_{2}$ enrichment studies. Plant Physiol. 155, 117-124. doi: $10.1104 /$ pp.110.166819

Krauss, K. W., Cormier, N., Osland, M. J., Kirwan, M. L., Stagg, C. L., Nestlerode, J. A., et al. (2017). Created mangrove wetlands store belowground carbon and surface elevation change enables them to adjust to sea-level rise. Sci. Rep. 7:1030. doi: 10.1038/s41598-017-01224-2

Krauss, K. W., McKee, K. L., Lovelock, C. E., Cahoon, D. R., Saintilan, N., Reef, R., et al. (2014). How mangrove forests adjust to rising sea level. New Phytol. 202, 19-34. doi: 10.1111/nph.12605

Kristensen, E., Bouillon, S., Dittmar, T., and Marchand, C. (2008). Organic carbon dynamics in mangrove ecosystems: a review. Aquat. Bot. 89, 201-219. doi: 10.1016/j.aquabot.2007.12.005

Lamers, L. P., Govers, L. L., Janssen, I. C. J. M., Geurts, J. J. M., Van der Welle, M. E. W., Van Katwijk, M. M., et al. (2013). Sulfide as a soil phytotoxin-a review. Front. Plant Sci. 4:268. doi: 10.3389/fpls.2013.00268 
Leopold, A., Marchand, C., Renchon, A., Deborde, J., Quiniou, T., and Allenbach, M. (2016). Net ecosystem CO 2 exchange in the "Coeur de Voh" mangrove, New Caledonia: Effects of water stress on mangrove productivity in a semi-arid climate. Agric. For. Meteorol. 223, 217-232. doi: 10.1016/j.agrformet.2016.04.006

Lotfiomran, N., Köhl, M., and Fromm, J. (2016). Interaction effect between elevated $\mathrm{CO}_{2}$ and fertilization on biomass, gas exchange and $\mathrm{C} / \mathrm{N}$ ratio of European beech (Fagus sylvatica L.). Plants 5:38. doi: 10.3390/plants5030038

Lovelock, C. E., Cahoon, D. R., Friess, D. A., Guntenspergen, G. R., Krauss, K. W., Reef, R., et al. (2015). The vulnerability of Indo-Pacific mangrove forests to sea-level rise. Nature 526, 559-563. doi: 10.1038/nature15538

Luo, Y., Hui, D., and Zhang, D. (2006). Elevated $\mathrm{CO}_{2}$ stimulates net accumulations of carbon and nitrogen in land ecosystems: a meta-analysis. Ecology 87, 53-63. doi: 10.1890/04-1724

Luo, Z., Sun, O. J., Wang, E., Ren, H., and Xu, H. (2010). Modeling productivity in mangrove forests as impacted by effective soil water availability and its sensitivity to climate change using biome-BGC. Ecosystems 13, 949-965. doi: 10.1007/s10021-010-9365-y

Lyimo, T. L., and Mushi, D. (2005). Sulfide concentration and redox potential patterns in mangrove forests of Dar es Salaam: effects on Avicennia Marina and Rhizophora Mucronata seedling establishment. West. Indian Ocean J. Mar. Sci. 4, 163-174. doi: 10.4314/wiojms.v4i2.28485

Mackey, A. P., and Smail, G. (1996). The decomposition of mangrove litter in a subtropical mangrove forest. Hydrobiologia 332, 93-98. doi: 10.1007/BF00016688

Marchand, C., Allenbach, M., and Lallier-Vergès, E. (2011a). Relationships between heavy metals distribution and organic matter cycling in mangrove sediments (Conception Bay, New Caledonia). Geoderma 160, 444-456. doi: 10.1016/j.geoderma.2010.10.015

Marchand, C., Fernandez, J.-M., Moreton, B., Landi, L., Lallier-Vergès, E., and Baltzer, F. (2012). The partitioning of transitional metals (Fe, Mn, Ni, Cr) in mangrove sediments downstream of a ferralitized ultramafic watershed (New Caledonia). Chem. Geol. 300-301, 70-80. doi: 10.1016/j.chemgeo.2012.01.018

Marchand, C., Lallier-Vergès, E., and Allenbach, M. (2011b). Redox conditions and heavy metals distribution in mangrove forests receiving effluents from shrimp farms (Teremba Bay, New Caledonia). J. Soils Sediments 11, 529-541. doi: 10.1007/s11368-010-0330-3

McDonald, E. P., Erickson, J. E., and Kruger, E. L. (2002). Research note: can decreased transpiration limit plant nitrogen acquisition in elevated $\mathrm{CO}_{2}$ ? Funct. Plant Biol. 29, 1115-1120. doi: 10.1071/FP02007

McKee, K. L. (2011). Biophysical controls on accretion and elevation change in Caribbean mangrove ecosystems. Estuar. Coast. Shelf Sci. 91, 475-483. doi: 10.1016/j.ecss.2010.05.001

McKee, K. L., Cahoon, D. R., and Feller, I. C. (2007). Caribbean mangroves adjust to rising sea level through biotic controls on change in soil elevation. Glob. Ecol. Biogeogr. 16, 545-556. doi: 10.1111/j.1466-8238.2007.00317.x

McKee, K. L., and Rooth, J. E. (2008). Where temperate meets tropical: multifactorial effects of elevated $\mathrm{CO}_{2}$, nitrogen enrichment, and competition on a mangrove-salt marsh community. Glob. Change Biol. 14, 971-984. doi: $10.1111 / j .1365-2486.2008 .01547 . x$

Mcleod, E., Chmura, G. L., Bouillon, S., Salm, R., Björk, M., Duarte, C. M., et al. (2011). A blueprint for blue carbon: toward an improved understanding of the role of vegetated coastal habitats in sequestering $\mathrm{CO}_{2}$. Front. Ecol. Environ. 9, 552-560. doi: 10.1890/110004

Naidoo, G., Rogalla, H., and von Willert, D. J. (1997). Gas exchange responses of a mangrove species, Avicennia marina, to waterlogged and drained conditions. Hydrobiologia 352:39. doi: 10.1023/A:1003088803335

Norby, R. J., DeLucia, E. H., Gielen, B., Calfapietra, C., Giardina, C. P., King, J. S., et al. (2005). Forest response to elevated $\mathrm{CO}_{2}$ is conserved across a broad range of productivity. Proc. Natl. Acad. Sci. U. S. A. 102, 18052-18056. doi: 10.1073/pnas.0509478102
Poorter, H., and Navas, M.-L. (2003). Plant growth and competition at elevated $\mathrm{CO}_{2}$ : on winners, losers and functional groups. New Phytol. 157, 175-198. doi: 10.1046/j.1469-8137.2003.00680.x

Prior, S. A., Runion, G. B., Marble, S. C., Rogers, H. H., Gilliam, C. H., and Torbert, H. A. (2011). A review of elevated atmospheric $\mathrm{CO}_{2}$ effects on plant growth and water relations: implications for horticulture. HortScience 46, 158-162. doi: 10.21273/HORTSCI.46.2.158

R Development Core Team, Vienna (2008). R: A Language and Environment for Statistical Computing. Vienna: R Foundation for Statistical Computing. Available online at: http://www.R-project.org (accessed March 24, 2019).

Reef, R., Feller, I. C., and Lovelock, C. E. (2010). Nutrition of mangroves. Tree Physiol. 30, 1148-1160. doi: 10.1093/treephys/tpq048

Reef, R., Slot, M., Motro, U., Motro, M., Motro, Y., Adame, M. F., et al. (2016). The effects of $\mathrm{CO}_{2}$ and nutrient fertilisation on the growth and temperature response of the mangrove Avicennia germinans. Photosynth. Res. 129, 159-170. doi: 10.1007/s11120-016-0278-2

Reef, R., Winter, K., Morales, J., Adame, M. F., Reef, D. L., and Lovelock, C. E. (2015). The effect of atmospheric carbon dioxide concentrations on the performance of the mangrove Avicennia germinans over a range of salinities. Physiol. Plant. 154, 358-368. doi: 10.1111/ppl.12289

Segers, R. (1998). Methane production and methane consumption: a review of processes underlying wetland methane fluxes. Biogeochemistry 41, 23-51. doi: 10.1023/A:1005929032764

Skelton, N. J., and Allaway, W. G. (1996). Oxygen and pressure changes measured in situ during flooding in roots of the grey mangrove Avicennia marina (Forssk.) Vierh. Aquat. Bot. 54, 165-175. doi: 10.1016/0304-3770(96)01043-1

Stocker, T. F., Qin, D., Plattner, G.-K., Tignor, M., Allen, S. K., Boschung, J., et al. (2013). "IPCC, 2013: climate change 2013: the physical science basis," in Contribution of Working Group I to the Fifth Assessment Report of the Intergovernmental Panel on Climate Change. Cambridge University Press.

Taub, D. R., and Wang, X. (2008). Why are nitrogen concentrations in plant tissues lower under elevated $\mathrm{CO}_{2}$ ? A critical examination of the hypotheses. J. Integr. Plant Biol. 50, 1365-1374. doi: 10.1111/j.1744-7909.2008.00754.x

Van Loon, A. F., Dijksma, R., and Van Mensvoort, M. E. F. (2007). Hydrological classification in mangrove areas: a case study in Can Gio, Vietnam. Aquat. Bot. 87, 80-82. doi: 10.1016/j.aquabot.2007.02.001

Ward, R. D., Friess, D. A., Day, R. H., and MacKenzie, R. A. (2016). Impacts of climate change on mangrove ecosystems: a region by region overview. Ecosyst. Health Sustain. 2:e1211. doi: 10.1002/ehs2.1211

Yin, X. (2002). Responses of leaf nitrogen concentration and specific leaf area to atmospheric $\mathrm{CO}_{2}$ enrichment: a retrospective synthesis across 62 species. Glob. Change Biol. 8, 631-642. doi: 10.1046/j.1365-2486.2002.00497.x

Zhang, D., Hui, D., Luo, Y., and Zhou, G. (2008). Rates of litter decomposition in terrestrial ecosystems: global patterns and controlling factors. J. Plant Ecol. 1, 85-93. doi: 10.1093/jpe/rtn002

Zimmermann, M., Meir, P., Bird, M., Malhi, Y., and Ccahuana, A. (2009). Litter contribution to diurnal and annual soil respiration in a tropical montane cloud forest. Soil Biol. Biochem. 41, 1338-1340. doi: 10.1016/j.soilbio.2009. 02.023

Conflict of Interest Statement: The authors declare that the research was conducted in the absence of any commercial or financial relationships that could be construed as a potential conflict of interest.

Copyright $\odot 2019$ Jacotot, Marchand and Allenbach. This is an open-access article distributed under the terms of the Creative Commons Attribution License (CC BY). The use, distribution or reproduction in other forums is permitted, provided the original author(s) and the copyright owner(s) are credited and that the original publication in this journal is cited, in accordance with accepted academic practice. No use, distribution or reproduction is permitted which does not comply with these terms. 


\section{OPEN ACCESS}

Edited by:

Alberto Vieira Borges,

University of Liège, Belgium

Reviewed by:

Guillaume Cyril Goodwin,

University of Edinburgh,

United Kingdom

Vishnu Prahalad,

University of Tasmania, Australia

${ }^{*}$ Correspondence:

Davide De Battisti

d.de-battisti.844312@swansea.ac.uk; davide.de85@gmail.com

Specialty section:

This article was submitted to

Conservation,

a section of the journal

Frontiers in Ecology and Evolution

Received: 27 September 2018 Accepted: 16 April 2019 Published: 08 May 2019

Citation:

De Battisti D, Fowler MS, Jenkins SR

Skov MW, Rossi M, Bouma TJ,

Neyland PJ and Griffin JN (2019) Intraspecific Root Trait Variability Along Environmental Gradients Affects Salt Marsh Resistance to Lateral Erosion.

Front. Ecol. Evol. 7:150

doi: 10.3389/fevo.2019.00150

\section{Intraspecific Root Trait Variability Along Environmental Gradients Affects Salt Marsh Resistance to Lateral Erosion}

\author{
Davide De Battisti ${ }^{*}$, Mike S. Fowler ${ }^{1}$, Stuart R. Jenkins ${ }^{2}$, Martin W. Skov ${ }^{2}$, Marta Rossi ${ }^{3}$, \\ Tjeerd J. Bouma ${ }^{4}$, Penelope J. Neyland ${ }^{1}$ and John N. Griffin ${ }^{1}$ \\ 1 Department of Biosciences, Swansea University, Swansea, United Kingdom, ${ }^{2}$ School of Ocean Sciences, Bangor University, \\ Bangor, United Kingdom, ${ }^{3}$ Department of Neuroscience, University of Sussex, Brighton, United Kingdom, ${ }^{4}$ Department of \\ Estuarine and Delta Systems, Royal Netherlands Institute for Sea Research (NIOZ), Utrecht University, Yerseke, Netherlands
}

Recent studies in salt marshes have demonstrated the role of plant roots in sediment stabilisation, and hence the importance of marshes in providing coastal protection. However, the relative role of root traits and environmental factors in controlling sediment stability, and how intraspecific variability of root traits vary within and among marshes, remain poorly understood. In this study, we investigated which root trait(s) drive sediment stability (resistance to lateral erosion) in two marsh species with an important role in coastal protection (Spartina anglica and Atriplex portulacoides) and how the environment affects the expression of these traits. We sampled three marshes along salinity gradients in each of two estuaries in Wales (UK), establishing replicate plots in the respective dominant zones of each species. In all plots we sampled abiotic variables (sand, redox potential, $\mathrm{pH}$, salinity) and root traits (root density, specific root density, root volume, root length density); in a subset of these plots (three per species in each marsh) we extracted soil-plant cores and assessed their erosion resistance in a flume. Sediment stability was enhanced by increases in root density and reductions in sand content. Abiotic variables affected root density in different ways depending on species: in $S$. anglica, redox was the only significant factor, with a positive, linear effect on root density; in A. portulacoides, redox had a non-linear ( $U$-shaped) effect on root density, while sand had a negative effect. Collectively, these results show that (i) intraspecific variability in root density can influence sediment stability in salt marshes, and (ii) sediment properties not only influence sediment stability directly, but also indirectly via root density. These results shed light on spatial variability in the stability of salt marshes to lateral erosion and suggest that root density should be incorporated into coastal vegetation monitoring programs as an easy-to-measure root trait that links the environment to sediment stability and hence to the function and services provided by marshes.

Keywords: resilience, sediment stability, response-effect framework, functional root traits, environmental gradients, root density 


\section{INTRODUCTION}

Salt marshes are coastal ecosystems that provide humans with valuable services such as carbon storage, forage for livestock, buffers against eutrophication and coastal protection from storms (Barbier et al., 2008; Shepard et al., 2011; Nelson and Zavaleta, 2012; Möller et al., 2014). Several studies demonstrate the ability of salt marsh vegetation to effectively decrease wave energy and stabilise the shoreline (Möller and Spencer, 2002; Bouma et al., 2009, 2010; Shepard et al., 2011; Möller et al., 2014) indicating that marshes are highly beneficial in terms of coastal protection (Costanza et al., 2008; Foster et al., 2013). At the same time, however, researchers have shown the susceptibility of salt marshes to lateral erosion (Mariotti and Fagherazzi, 2010; Marani et al., 2011; Fagherazzi et al., 2013; Leonardi et al., 2016). An increased understanding of what drives the stability of the sediment in salt marshes is a fundamental requirement to the effective integration of salt marshes into coastal management schemes (Feagin et al., 2010; Bouma et al., 2014).

The capacity of salt marshes to resist lateral erosion has received attention recently, with studies establishing that sediment sand content and plant roots are the main drivers of sediment stability (Feagin et al., 2009; Ford et al., 2016; Lo et al., 2017; Wang et al., 2017). In particular, studies in European marshes have demonstrated that increasing root biomass strongly reduces the negative effect of sand on sediment stability (Ford et al., 2016; Wang et al., 2017). Furthermore, variability in root biomass has been shown to affect sediment stability within Spartina spp. (Lo et al., 2017), suggesting that intraspecific variability may play an important role in sediment stabilisation. Yet, little is known about the mechanism by which roots bind the sediment or how the environment drives intraspecific root variability. The response-effect framework of functional traits is a powerful approach for understanding the mechanistic link between the response of organisms to environmental factors and, in turn, the effect on ecosystem functions (Lavorel and Garnier, 2002; Suding et al., 2008; Lavorel et al., 2013). In this framework, variability in environmental factors can modify plant traits (e.g. root length) and, in turn, these changes can affect ecosystem functions (e.g., sediment stability). Thus, understanding the cascade effect from abiotic factors to sediment stability in salt marshes is fundamental to gain insights on marsh lateral resistance to erosion.

In salt marshes, recent studies have investigated only the role of root biomass on sediment stability (Ford et al., 2016; Lo et al., 2017; Wang et al., 2017), while in terrestrial systems wider exploration of a range of traits has shown that root traits underpinning a denser and finer root system reduce soil erosion rates (De Baets et al., 2006; Baets et al., 2007; Burylo et al., 2012; Bardgett and van der Putten, 2014). In particular, studies in terrestrial systems highlight that fine roots are mainly responsible for sediment stabilisation (e.g., Burylo et al., 2012). Furthermore, both work in terrestrial systems and salt marshes has also illustrated the potential for environmental factors to affect root traits that are important for sediment stability. For example, in nutrient poor soils plants invest more biomass in the root system and have higher specific root length (Freschet et al., 2015), which could have a positive effect on soil stability. Similarly, experimental studies in salt marshes have shown that an increasing nutrient load corresponds with a decrease in root biomass and length of first order roots in some species (Bouma et al., 2001a,b; Deegan et al., 2012), which could decrease sediment stability. However, in salt marshes it is unknown how root traits, and fine roots in particular, vary along other key environmental gradients and the consequences for sediment stability. Therefore, understanding the effect of the environment on key root traits has the potential to enhance our ability to predict the stability of marshes to lateral erosion.

Salinity, redox potential (a proxy for anoxia in the sediment) and sand content in soils (a proxy for nutrient levels in the sediment) are known to be strong environmental stressors for salt marsh plants (Armstrong et al., 1985; Olff et al., 1997; Tyler and Zieman, 1999; Crain et al., 2004; Watson and Byrne, 2009), yet how variation in these abiotic factors affects root traits in salt marshes remains largely unknown. Plants show a range of morphological and physiological adaptations to cope with these factors (Naidoo et al., 1992; Colmer and Flowers, 2008; Flowers and Colmer, 2008). For instance, plants can produce glands for salt extrusion in high salinity environments (Tabot and Adams, 2014) and aerenchyma and adventitious roots to allow oxygen transport to the root tips in sediment with low redox (Armstrong, 2000; Nishiuchi et al., 2012). Furthermore, the low nutrient status of sandy soils and their mobility could also affect root development (Olff et al., 1997; Tyler and Zieman, 1999; Schutten et al., 2005; Fourcaud et al., 2008; Freschet et al., 2017). Therefore, when environmental conditions are far from a plant's optimum they can directly reduce overall root growth and induce metabolically expensive adaptations that may affect root trait expression (e.g., fewer fine roots) at the intraspecific level. In this way, adaptations to environmental stresses can have detrimental effects on sediment stability.

We investigated how abiotic factors along environmental gradients directly and indirectly affect the stability of saltmarsh sediment through regulating plant root traits. We tested the stability of extracted cores in a flume system and hypothesised first (H1), that root traits associated with a finer root system will be better predictors of sediment stability than other traits (e.g., root density) because they indicate root biomass is more evenly distributed throughout the sediment, which determines that, second (H2), fine roots will be more important for sediment stability than other below-ground compartments (rhizomes, coarse roots). Furthermore, we also considered the effects of sediment properties on erosion and hypothesised (H3) that increasing sand content would reduce sediment stability. Finally, we investigated the potential for environmental factors to indirectly affect sediment stability via their effects on root traits. We hypothesised (H4) that reduced below-ground plant growth and investment in roots would be associated with stressful sediment conditions (e.g., low redox), indirectly reducing sediment stability. We sampled marshes along two estuaries in South Wales (UK) to encompass natural salinity and redox gradients. We focused on Spartina anglica (C.E. Hubb.) and Atriplex portulacoides (L.) (hereafter Spartina and 
Atriplex, respectively) because in the UK, both species form large monospecific stands at the marsh edge (Spartina) and along marsh creeks (Atriplex) (Rodwell et al., 2000), thus being directly involved in stabilising sediment against lateral erosion. We analysed the two species separately to understand the importance of intraspecific trait variability for sediment stability in salt marshes.

\section{MATERIALS AND METHODS \\ Site Description}

Six salt marshes were selected along a salinity gradient in two estuaries in South Wales (UK), the Loughor and the Taf (Figure 1). These marshes showed some variation in community characteristics, but all shared the common feature of extensive monostands of the two target species. In the Loughor estuary, Pembrey Burrows (PB), Penrhyn Gwyn (PNR), and Loughor (LOG) marshes were situated at the mouth, middle, and head of the estuary, respectively. Pembrey contains several zones, with Spartina dominating the pioneer zone and Atriplex occupying the low-mid marsh. Penrhyn Gwyn is characterised by the presence of Spartina and Atriplex, which constitute almost the entire marsh, except for the grazed portion at the landward side; no signs of grazing (browsing marks) were found in the sampling area. Loughor marsh is part of a farm, but no grazing from cattle was observed in the sampled area. Spartina dominates the pioneer zone and Atriplex is present at the low-mid marsh along the creeks; landward of these zones a mixed community is present.

Laugharne South (LS), Laugharne Castle (LC), and Laugharne North (LN) are the marshes at the mouth, middle, and head of the Taf estuary, respectively. Laugharne South is dominated by Atriplex although in the pioneer zone Spartina is dominant (with some Salicornia spp. and Suaeda marina). In Laugharne Castle, Spartina is the main species in the pioneer zone with Atriplex present in the low-mid marsh, as a small strip of patchy vegetation. Laugharne North is characterised almost entirely by Atriplex, with the pioneer zone dominated by Spartina.

\section{Study Design}

At the end of July 2016, in the areas where Spartina and Atriplex were dominant we established seven $1 \times 1 \mathrm{~m}$ plots for each species in each salt marsh and recorded GPS positions. Plots were separated by roughly $30 \mathrm{~m}$, except in the Spartina zone in

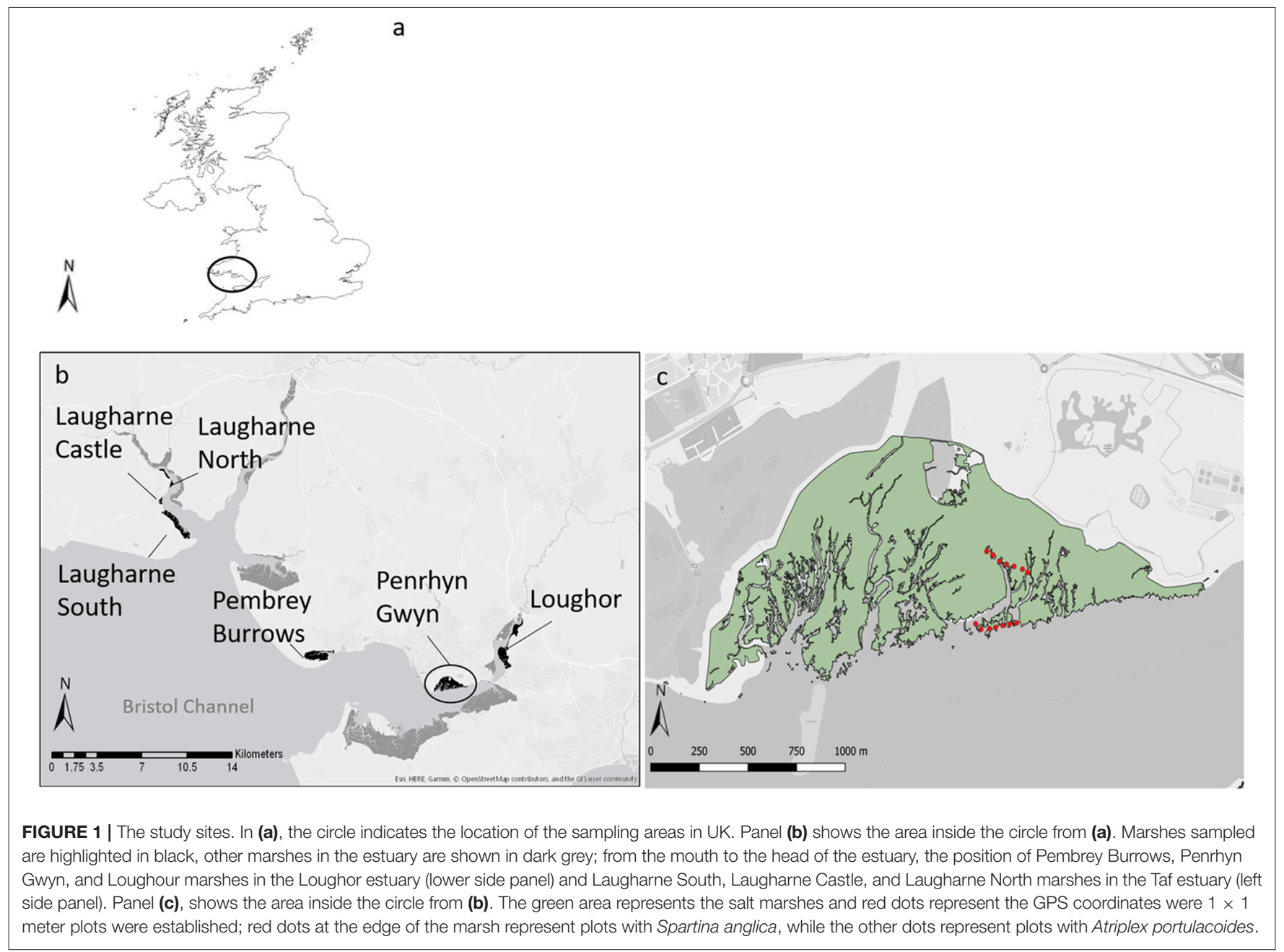


Pembrey where they were $10-15 \mathrm{~m}$ apart due to the limited area covered by this species. Plots were positioned to ensure that only the two targeted species were represented with $100 \%$ cover and, thus, excavated roots belonged to the species under study. Thus, for a suite of abiotic and root trait parameters (Table A1) we obtained a total of 42 replicates per species ( 6 marshes $\times 7$ plots per species). In each marsh and for each species, we collected a core of $16 \mathrm{~cm}$ in diameter and $30 \mathrm{~cm}$ depth from three of the seven plots for a total of 36 cores. Plots were chosen so as to maximise the distance between cores.

\section{Root Traits}

In October 2016, sediment samples of $500 \mathrm{~cm}^{3}$ volume $(5 \times$ $5 \mathrm{~cm}$ surface area and $20 \mathrm{~cm}$ depth) were collected adjacent to where the core was extracted for root traits measurements. In plots where cores were not collected, we excavated a piece of marsh to simulate the core extraction and collected the sediment sample as described above. Sediment samples were washed over a sieve (mesh size, $1 \mathrm{~mm}$ ) to minimise root loss and roots were collected and divided into rhizome, coarse roots (roots $>1 \mathrm{~mm}$ in diameter) and a mixture of fine roots (roots $<1 \mathrm{~mm}$ in diameter; Freschet and Roumet, 2017) and dead plant material. Rhizomes and coarse roots were distinguished based on their morphology. Note that, although Atriplex is a dicotyledonous with a tap root system lacking true rhizomes, its shoots have a prostrate growth form and are often buried in the sediment, forming adventitious roots. Thus, from a sediment stability perspective these buried shoots would play a similar role as rhizomes and, for ease of discussion, here are grouped in the rhizome category. The fine roots present in the samples were calculated based of the proportion of fine roots present in three subsamples of $\sim 1 \mathrm{~g}$ fresh material.

Root traits were measured on representative subsamples of rhizome, coarse and fine root sub-samples. We placed the root material into a petri dish, scanned all the material (black and white at 1,200 dpi of resolution; Epson Perfection, V550 Photo) and analysed the root length in the scanned images with Rootnav software (Pound et al., 2013). All root and rhizome material was dried at $70^{\circ} \mathrm{C}$ for $48 \mathrm{~h}$ (Pérez-Harguindeguy et al., 2013) and the total specific root length (SRLt) was measured as the sum of the length of all roots (rhizome, coarse roots, and fine roots) divided by the sum of their dry weight. We used SRLt as a proxy of the investment of the plant in rhizome/coarse roots vs. fine roots (Burylo et al., 2012; Freschet and Roumet, 2017). The diameter of ten roots in each image were measured with ImageJ software (Schindelin et al., 2012) and used to calculate total root volume as $\left(\mathrm{r}^{2} \cdot \pi\right) \cdot$ ERL, assuming the root is a cylinder; ERL is the estimated length of the entire root system based on the weighted length of scanned roots over the total root weight [(root length/scanned root weight) - total root weight]. Root length density (RLD) and root density $(\mathrm{RD})$ are, respectively, the length and the weight of the entire root system divided by the $500 \mathrm{~m}^{3}$ soil volume sampled (De Baets et al., 2006; Baets et al., 2007). Also, we measured root density for rhizomes (RD.R), coarse roots (RD.C), and fine roots (RD.F) as the weight of each root compartment divided by the $500 \mathrm{~m}^{3}$ soil volume.

\section{Sediment Erosion Rate}

Cores (36 in total) were collected in the middle of plots according to Ford et al. (2016) at the end of the growing season (late October 2016). We tested the cores in a flume facility at Bangor University using the methods of Ford et al. (2016), except cores were eroded at only one flow strength $(146 \mathrm{~Pa})$. Each core was weighed on a scale, eroded for $5 \mathrm{~min}$ and weighed again; we repeated this process five times for a total of $30 \mathrm{~min}$ of erosion for each core (examples of eroded cores in Figure A2). This temporal pattern of erosion and measurement allowed us to detect weight loss of clay cores (Atriplex) while avoiding complete erosion of sandy cores (Spartina).

\section{Abiotic Variables}

We sampled sediment abiotic variables (Table A1) in plots on three spring tides over July-September 2016 to minimise the influence of variation in tide heights and weather, and plot averages were used for analysis. We inserted Macrorhizones (www.rhizosphere.com) at $15 \mathrm{~cm}$ depth, extracted the porewater, and sampled for salinity and $\mathrm{pH}$ (Hanna instrument, HI98129). Redox potential was measured at $5 \mathrm{~cm}$ soil depth (Hanna instruments, HI 98120). We sampled for sediment in two of the spring tides, using a $10 \mathrm{~cm}$ deep, $2.5 \mathrm{~cm}$ diameter core; samples were oven dried for $72 \mathrm{~h}$ at $70^{\circ} \mathrm{C}$ and consequently we quantified: sediment moisture content, bulk density, and organic matter content (loss on ignition, $18 \mathrm{~h}$ at $440^{\circ} \mathrm{C}$ ) (Feagin et al., 2009). Combusted sediments were sieved to separate the clay-silt fraction $(<53 \mu \mathrm{m})$, fine sand $(53-250 \mu \mathrm{m})$, coarse sand $(250-1,000 \mu \mathrm{m})$, and very coarse sand $(>1,000 \mu \mathrm{m})$ (Denef et al., 2001).

\section{Statistical Analysis}

The core erosion data was described by a mixed effects model (Bates, 2010) with time of erosion ( $\mathrm{min}$ ) both as a fixed explanatory variable and a random effect nested in core; core was a random intercept nested within marsh. This model structure allowed individual cores to vary in their initial mass and erosion rate; it also accounted for the hierarchical nature of the sampling. The response variable (loss of core mass) was log-transformed to account for the non-linear decrease in erosion over time (see

TABLE 1 | Summary results of mixed-effect models of the effect of sand content and root density (RD) on sediment stability for Spartina and Atriplex.

\begin{tabular}{|c|c|c|c|c|c|c|c|}
\hline & & $\begin{array}{c}\text { Coefficient } \\
\text { estimate }\end{array}$ & $\begin{array}{c}\text { Standard } \\
\text { error }\end{array}$ & $t$-value & $P$ & $m R^{2}$ & $\mathrm{cR}^{2}$ \\
\hline \multicolumn{8}{|l|}{ Spartina anglica } \\
\hline \multirow[t]{3}{*}{ Sediment stability $\sim$} & Sand & -0.0016 & 0.00022 & -4.84 & $<0.001$ & 0.72 & 0.72 \\
\hline & $\mathrm{RD}$ & 8.96 & 2.845 & 3.15 & 0.010 & & \\
\hline & $\mathrm{RD}^{2}$ & -463.3 & 186.4 & 2.49 & 0.032 & & \\
\hline \multicolumn{8}{|c|}{ Atriplex portulacoides } \\
\hline \multirow[t]{3}{*}{ Sediment stability $\sim$} & Sand & -0.00056 & 0.00032 & -1.743 & 0.105 & 0.18 & 0.63 \\
\hline & $\mathrm{RD}$ & 3.291 & 3.316 & 0.992 & 0.345 & & \\
\hline & $\mathrm{RD}^{2}$ & -368.8 & 438.9 & -0.840 & 0.420 & & \\
\hline
\end{tabular}

$R D$, root density. Sample size: $N=16$ in Spartina and $N=17$ in Atriplex. The random effect of Marsh has been omitted for clarity. Values in bold indicates $p<0.05$. 
example in Figure A2). After fitting the models (one for each species), we extracted the slopes for each core and we used these slopes as a metric of sediment stability (loss of mass/unit of time).

First, a set of a priori mixed-effect models (full models: Table A2) were used to identify root traits that affected sediment stability. Models included parameters for sediment grain size (e.g., sand) and root character (e.g., RLD) because previous studies showed their importance for sediment stabilisation (Ford et al., 2016; Lo et al., 2017; Wang et al., 2017) and marsh as a random factor. Models were ranked with the corrected Akaike Information Criteria (AICc; Akaike, 1973; Burnham et al., 2011) using the MuMIn R package (Barton, 2016). Second, we designed a set of a priori mixed-effect models (Table A3) using $\mathrm{RD}$, the trait selected in the best model from the previous analysis, to understand which root compartment (Rhizome, Coarse roots, and Fine roots) was more important for sediment stability. Because these models were based on the best model selected in the first part of the analysis, results from this model selection has to be considered more exploratory. Third, a priori mixed-effect models (Table A4) were used to understand the effect of the physical environment on the expression of $\mathrm{RD}$, which was the best-model root trait identified in step 1 for both species. As abiotic predictors we included four well-known stressors for salt marsh plants: sand content in the sediment, sediment redox potential, $\mathrm{pH}$, and salinity. Models were designed on expected effects of abiotic variables. We standardised abiotic variables to zero mean and unit variance and fitted these variables as fixed factors and marsh as a random factor. Models were again ranked with AICc and the explanatory power of the best model was evaluated comparing the marginal $R^{2}$ (hereafter, $\mathrm{mR}^{2}$ ) with the conditional $\mathrm{R}^{2}$ (hereafter, $\mathrm{cR}^{2}$ ). Where necessary, we $\log$ transformed the response variable to meet the model assumptions. Quadratic terms were included in candidate models to provide a general and flexible approximation of possible nonlinear relationships. Because of great differences in sediment characteristics between the two species (Figure A1), we decided to split the analysis. Plots were generated with the visreg package (Breheny and Burchett, 2013). All the analyses were carried out in $R$ ( $R$ core team 2015).
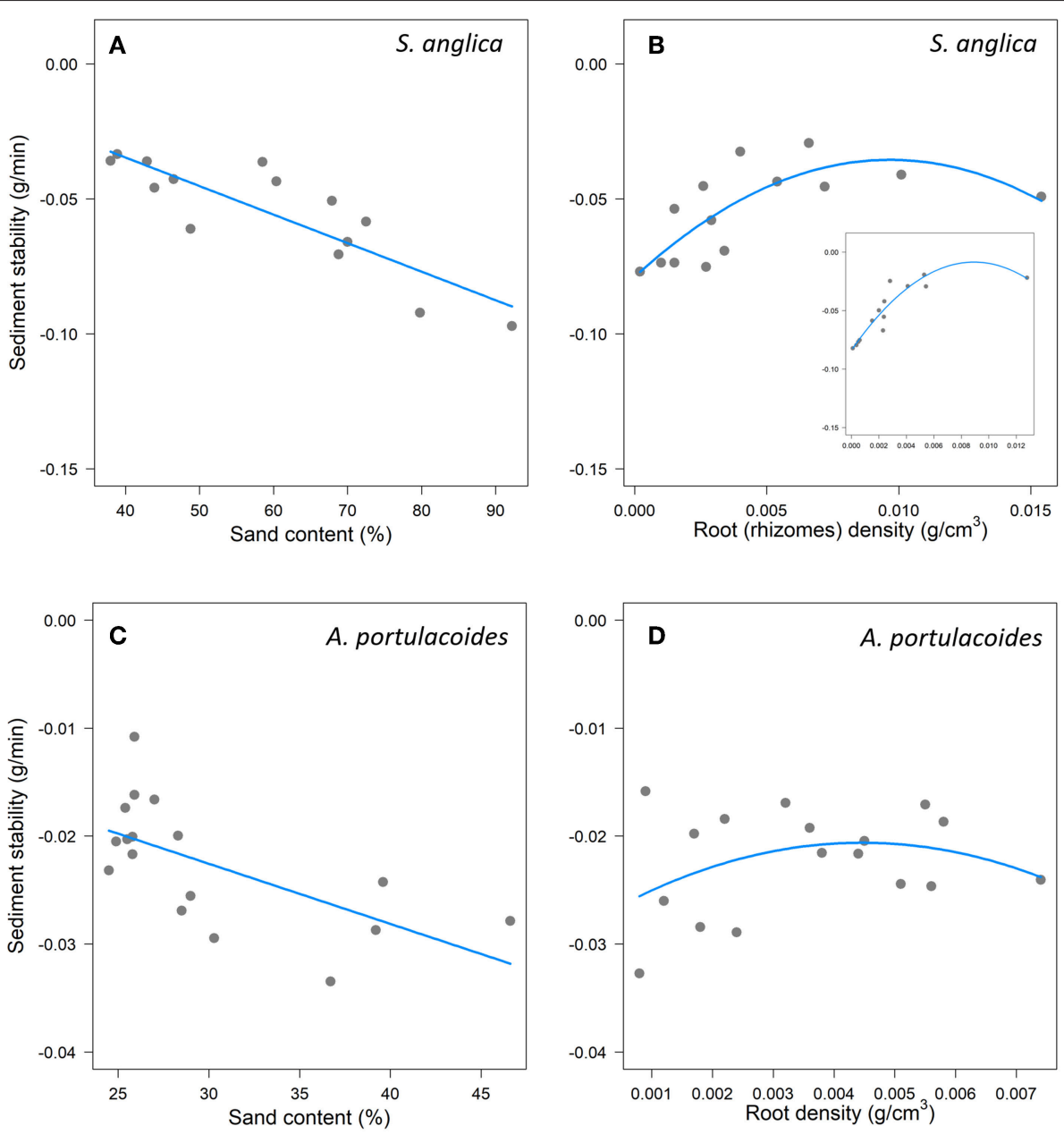

FIGURE 2 | Effects of sand content and root density on marsh resistance to erosion (sediment stability represents a change in the slope of sediment loss; more negative values indicates greater sediment loss,) in experimental erosion cores from Spartina (A,B) and Atriplex (C,D) marshes. In (B), the insert represents marsh resistance to erosion in experimental erosion cores from Spartina when only rhizomes are considered. In (A,C) points indicate partial residuals when root density (RD) was held constant (median). In (B,D), and the insert in (B), points indicate partial residuals when Sand was held constant (median). 


\section{RESULTS}

\section{Effect of Root Traits and Sediment Grain Size on Core Erosion}

The erosion trial was able to account for a high portion of variability in erosion rates in both Spartina and Atriplex (respectively, $\mathrm{cR}^{2}$ : 0.96 and 0.99 ).

We first examined the role of root traits, alongside sediment properties, in explaining sediment stability. For both species, the best model included sand content and a quadratic effect of root density (RD) (Table 1) (Table A5). In Spartina, increasing sand content significantly reduced sediment stability (Table 1, Figure 2A), while $\mathrm{RD}$ had a stabilising, though non-linear, effect (Table 1, Figure 2B; model: $\mathrm{mR}^{2}=0.72, \mathrm{cR}^{2}=0.72$ ). In Atriplex, neither sand content nor $\mathrm{RD}$ had significant effects on sediment stability (Table 1, Figures 2C,D), consistent with the low explanatory ability of the fixed effects in this model $\left(\mathrm{mR}^{2}=\right.$ $0.18, \mathrm{CR}^{2}=0.63$ ). Beyond $\mathrm{RD}$, there was no support for a role of other root traits (e.g., SRLt) in determining sediment stability in either species (Table A5).

We next examined the contributions of different root compartments to sediment stability. In Spartina, the best model included sand content and non-linear effects of both rhizomes and coarse roots $\left(\mathrm{mR}^{2}=0.79, \mathrm{cR}^{2}=0.79\right.$; Figure $2 \mathrm{~B}$, Table A6). This model revealed significant effects of sand content and rhizomes, but not of coarse roots (Table 2). The same analysis for Atriplex showed that the two best, similarly ranked, models had low explanatory ability and none of the parameters included in these models had significant effects on sediment stability (Table 2, Table A7).

\section{Effect of the Environment on Root Density}

Since RD was the only trait included in the best models explaining sediment stability, we investigated the effect of environmental factors on this trait (Note that correlations between RD and other root traits are reported in Figure A3). Redox potential and sand content were the main abiotic factors that affected $\mathrm{RD}$, with both retained in the best models, although there were again differences between species (Tables A8, A9). In Spartina, there was no significant effect of sand content (Table 3, Figure 3B), while increasing redox values were significantly associated with increased RD (Table 3, Figure 3A). In Atriplex, sand content had a significant negative effect, while redox had a non-linear, quadratic, effect (Table 3, Figures 3C,D). In the upper half of the redox range, $\mathrm{RD}$ increased with increasing redox; in the lower half of the redox range $\mathrm{RD}$ appeared to decrease with increasing redox. However, the scarcity of samples calls for a cautious interpretation of the lower half of the relationship. In both species the marginal $\mathrm{R}^{2}$ was relatively low with respect to the conditional $\mathrm{R}^{2}$ (Tables A8, A9), indicating that other factors that vary among marshes are likely to be important for explaining RD variability.

\section{DISCUSSION}

Our results show that: (i) plant roots increased sediment stability (reduced erosion), particularly in the Spartina zone; (ii)
TABLE 2 | Summary results of mixed-effect models of the effect of sand and root density (RD) on sediment stability for Spartina and Atriplex.

\begin{tabular}{|c|c|c|c|c|c|c|c|}
\hline & & $\begin{array}{c}\text { Coefficient } \\
\text { estimate }\end{array}$ & $\begin{array}{l}\text { Standard } \\
\text { error }\end{array}$ & $t$-value & $P$ & $\mathrm{mR}^{2}$ & $\mathrm{cR}^{2}$ \\
\hline \multicolumn{8}{|l|}{ Spartina anglica } \\
\hline \multirow[t]{5}{*}{ Sediment stability $\sim$} & Sand & -0.0011 & 0.00002 & -5.680 & 0.001 & 0.79 & 0.79 \\
\hline & $\mathrm{RD} \cdot \mathrm{R}$ & 16.87 & 4.345 & 3.882 & 0.005 & & \\
\hline & $\mathrm{RD} \cdot \mathrm{R}^{2}$ & -944.2 & 296.3 & -3.187 & 0.013 & & \\
\hline & RD.C & -13.18 & 26.13 & 0.504 & 0.627 & & \\
\hline & $\mathrm{RD} \cdot \mathrm{C}^{2}$ & -395.4 & 1802 & 0.219 & 0.832 & & \\
\hline \multicolumn{8}{|c|}{ Atriplex portulacoides } \\
\hline \multirow[t]{5}{*}{ Sediment stability } & Sand & 0.00076 & 0.00036 & -2.081 & 0.071 & 0.23 & 0.88 \\
\hline & RD.C & -38.21 & 27.30 & -1.399 & 0.2120 & & \\
\hline & RD. $\mathrm{C}^{2}$ & 50210 & 54740 & 0.917 & 0.3925 & & \\
\hline & RD.F & 9.265 & 8.012 & 1.156 & 0.2894 & & \\
\hline & $\mathrm{RD} \cdot \mathrm{F}^{2}$ & -983.8 & 179 & -0.550 & 0.601 & & \\
\hline \multirow[t]{5}{*}{ Sediment stability } & Sand & 0.00086 & 0.00039 & -2.203 & 0.054 & 0.24 & 0.77 \\
\hline & $\mathrm{RD} \cdot \mathrm{R}$ & 11.117 & 5.521 & 2.023 & 0.083 & & \\
\hline & $\mathrm{RD} \cdot \mathrm{R}^{2}$ & -2458 & 1257 & -1.956 & 0.093 & & \\
\hline & RD.C & -38.27 & 45.90 & -0.834 & 0.435 & & \\
\hline & $\mathrm{RD} \cdot \mathrm{C}^{2}$ & 44870 & 79790 & 0.562 & 0.594 & & \\
\hline
\end{tabular}

$R D . R$, rhizome root density; RD.C, coarse root density; RD.F, fine root density. Sample size: $N=16$ in Spartina and $N=17$ in Atriplex. The random effect of Marsh has been omitted for clarity. Values in bold indicates $p<0.05$.

root density (RD) and the fraction of coarse roots/rhizomesrather than the proportion of fine roots or associated traits, as hypothesized-were responsible for enhanced stability in the Spartina zone; and (iii) root density was greater in sediment with higher redox potential (both species) and was either lower (Atriplex) or unaffected (Spartina) in sediment with higher sand content. Collectively, these results deepen our understanding of the consequences and drivers of variability in belowground traits of salt marsh plants.

\section{Effect of Root Traits on Sediment Stability}

Salt marsh lateral erosion is a complex phenomenon regulated by different mechanisms. Marsh lateral erosion depends both on blocks failure, where wave action and water pressure lead to cracks in the sediment and/or subsequent fall of entire marsh blocks (Francalanci et al., 2013; Bendoni et al., 2016), and loss of sediment by sediment erosion, where sediment particles detach from the marsh under wave and water flow action (Bouma et al., 2002, 2009, 2010). At the local scale, field and mesocosm experiments showed that sediment particle erosion well-correlated with lateral marsh retreat and that root biomass played a key role (Wang et al., 2017). Our study strengthens this case and shows that plant roots can increase sediment stability, contributing to reduction in lateral erosion in salt marshes. In Spartina, where evidence of a positive effect of $\mathrm{RD}$ was stronger, the non-linear relationship between $\mathrm{RD}$ and erosion indicates that small changes in this root trait greatly increase sediment stability until a plateau is reached. This is in accordance with flume studies in terrestrial systems, where roots maximally reduced soil detachment rate at similar values 
TABLE 3 | Summary table of linear mixed-effect models of the effect of Sand and Redox on Root density (RD) for both Spartina and Atriplex.

\begin{tabular}{rccccccc}
\hline & $\begin{array}{c}\text { Coefficient } \\
\text { estimate }\end{array}$ & $\begin{array}{c}\text { Standard } \\
\text { error }\end{array}$ & & -value & $\boldsymbol{P}$ & $\mathbf{m R}^{\mathbf{2}}$ & $\mathbf{c R}^{\mathbf{2}}$ \\
\hline Spartina anglica & & & & & & \\
$\mathrm{RD} \sim \quad$ Sand & 0.0003 & 0.0007 & 0.463 & 0.646 & & \\
Redox & 0.002 & 0.0008 & 2.343 & $\mathbf{0 . 0 2 5}$ & 0.13 & 0.61 \\
Atriplex portulacoides & & & & & & \\
$\log (\mathrm{RD}) \sim \quad$ Sand & -0.255 & 0.117 & -2.184 & $\mathbf{0 . 0 3 6}$ & & \\
& Redox & 0.423 & 0.181 & 2.363 & $\mathbf{0 . 0 2 3}$ & & \\
Redox $^{2}$ & 0.241 & 0.080 & 2.998 & $\mathbf{0 . 0 0 5}$ & 0.20 & 0.52 \\
\hline
\end{tabular}

Coefficients are standardised. Sample size, $N=40$ in Spartina and $N=42$ in Atriplex. The random effect of Marsh has been omitted for clarity. Values in bold indicates $p<0.05$.

of RD (De Baets et al., 2006; Baets et al., 2007). Interestingly, terrestrial studies look at top soil instead of lateral erosion (e.g., De Baets et al., 2006). Thus, considering that similar RD values lead to comparable erosion reduction in our and their study, suggests that RD effect on sediment erosion is a general mechanism regardless of the flow direction. Spartina is a species wide spread worldwide (Adam, 2002) at the edge of the marsh, thus, the stabilising effect of RD in this species further confirms the importance of roots for sediment stabilisation in salt marshes demonstrated recently at intraspecific (Lo et al., 2017), species (Wang et al., 2017) and community (Ford et al., 2016) levels.

Yet, the lack of strong evidence of a sediment stabilising effect of roots in the Atriplex zone underlines the context dependency of these processes. Sediment composition might be an important factor explaining this result; when sand content is relatively low, as in the Atriplex zone, roots might play a weaker role for sediment stabilisation and sediment cohesiveness is more important (Schutten et al., 2005; Feagin et al., 2009). Indeed, previous studies also showed that root biomass better explained core erosion rates when sand content in the sediment was high (Ford et al., 2016; Lo et al., 2017). In our study, divergent root architecture of the two-focal species (fibrous, rhizomatous root system in Spartina vs. tap root system in Atriplex) may have also contributed to the differences in root effects on sediment stability. Finally, it is possible that cores with low sand content (Atriplex) needed a longer period of erosion to show statistically detectable effects of both sand content and RD. More studies are required to fully elucidate the role of roots in sediment stabilisation in salt marshes across diverse sediment types and plant rooting architectures.

Our results further suggest that sediment stability in the sandy Spartina zone is mainly determined by coarse roots and rhizomes, rather than by fine roots, as argued in terrestrial studies (De Baets et al., 2006; Burylo et al., 2012). In our study, the primary role of coarse roots/rhizomes is suggested by: (i) RD, the trait that we found drove sediment stability, is mainly determined by these compartments; and (ii) rhizomes and coarse roots best explained erosion rates, while fine roots were consistently not included among predictors for sediment stabilisation. Sand content in the Spartina zone reached levels (up to $90 \%$ ) considerably greater than in analogous terrestrial studies ( 50\%: Vannoppen et al., 2017). Thus, it is possible that coarser roots become more important for sediment stabilisation in environments with high sand content. However, because model selection of the best root compartments involved in sediment stabilisation was more an exploratory analysis and because of methodological differences in defining root classes between our and terrestrial studies, we cannot generalise these results. In our study the root diameter across the entire root system ranged from 0.5 to $3 \mathrm{~mm}$ (rhizomes included), which would be considered either as fine roots (Baets et al., 2007) or coarse roots (Burylo et al., 2012) depending on the terrestrial study considered. Future studies should include a wider sand content gradient and range of root diameters to further elucidate the mechanisms involved in sediment stabilisation (e.g., fine vs. coarse roots) thus allowing reconciliation of the apparent discrepancy between salt marshes and terrestrial systems.

\section{Effect of the Environment on Root Traits and Sediment Stability}

Across the two species, root density showed similarities and differences in its responses to environmental factors, and thus the potential for indirect effect of abiotic factors on sediment stabilisation. First, RD in both species appeared invariant to salinity. This indicates that, while high salinities are known to suppress biomass production in salt marsh plants (Cooper, 1982; Crain et al., 2004; Flowers and Colmer, 2008), these dominant, halophytic, salt marsh plants are able to sustain $\mathrm{RD}$, and therefore associated sediment stabilisation, across sites spanning a range of salinities in our study system. Second, notwithstanding the non-linear pattern in Atriplex, both species showed evidence that declining redox, a proxy for low oxygen in the sediment, could suppress RD. This can probably be explained by the metabolic costs associated with mechanisms to cope with low redox (Armstrong, 1979), reviewed in Colmer (2003) and Nishiuchi et al. (2012). While release of oxygen from plant roots (Pezeshki, 2001) may have contributed to the observed relationships, we assume the direction of causality to flow from the abiotic environment to $\mathrm{RD}$ given previous experimental evidence in salt marsh plants that: (i) waterlogging can directly reduce growth of salt marsh plants (Cooper, 1982; Bouma et al., 2001a); and (ii) the impact of oxygen release from roots on sediment oxygenation is limited (Koop-Jakobsen et al., 2018). Therefore, factors that influence sediment redox potential, including bioturbation, tidal inundation (and sea-level rise) and livestock grazing, may indirectly affect the stability of salt marsh sediments by altering RD. Third, the species differed in their responses to sand content, and thus nutrient availability. The resistance of RD of Spartina to high sand content might be explained by its ability to acquire resources directly from the water column (Bouma et al., 2002), or a greater capacity for compensatory investment in belowground biomass under low soil nutrients, a mechanism known for terrestrial plants (Freschet et al., 2015). Spartina therefore sustains an important erosion buffering function even where sand content, and thus the erosion vulnerability of the marsh platform, is at its highest. Indeed, the sandier sites at the mouth of the estuaries (Figure A1) did not erode more quickly than those at the heads. Finally, although we investigated a suite of well-known stressors for plant growth (redox, salinity, sand, and $\mathrm{pH}$ ), in both species the 

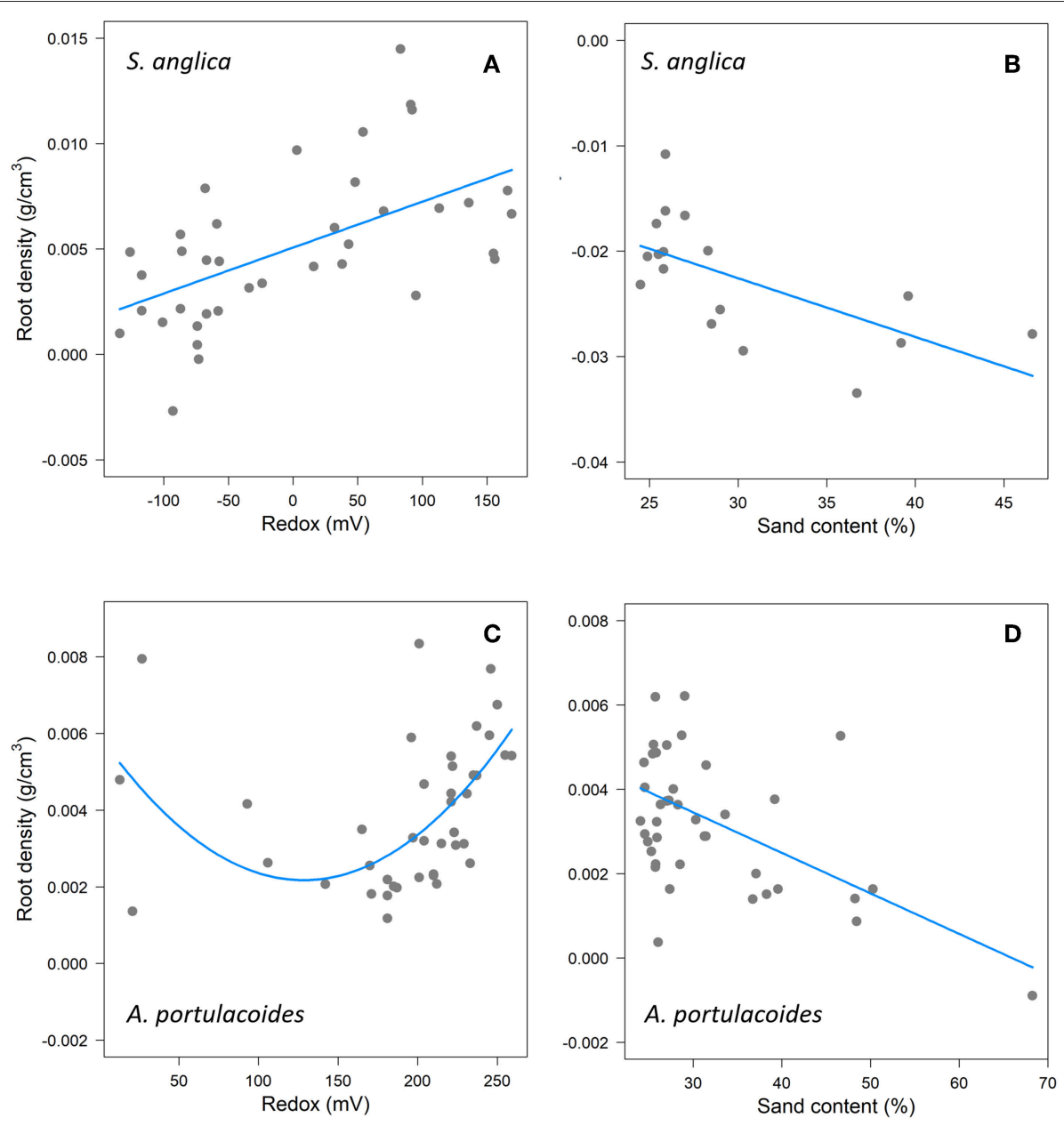

FIGURE 3 | The effects of Redox (left panels) and Sand (right panels) on root density in Spartina (A,B) and Atriplex (C,D). In Atriplex the response variable RD has been log transformed to meet model assumptions, but (C,D) show non-transformed data to allow better comparison between species. Points indicate partial residuals when other abiotic variables are held constant.

modest portion of variability accounted for by the best models suggest that other factors may drive RD. For instance, variation in wave exposure that exists within and between marshes might affect plants' investment in roots (Coops et al., 1996). Further developing our understanding of the belowground responses of salt marsh plants to environmental factors will be an important task if the future vulnerability of salt marshes to lateral erosion under climate change are to be predicted.

\section{Global Significance and Limitations}

Spartina is a pioneer species with a cosmopolitan global distribution (Adam, 2002), thus results of our study highlight the importance of vegetation for reducing lateral erosion in salt marshes. We showed here that marshes with higher sand content in the sediment erode faster, but $\mathrm{RD}$ can effectively counteract this negative effect of sand content. Interestingly, despite the differences found here between Spartina and Atriplex, we showed that RD is a good predictor for sediment stability. Thus, the relatively easy investigation of sediment granulometry and $\mathrm{RD}$ among marshes could allow managers to map marshes vulnerability to later erosion. These maps, could also be employed in management schemes for coastal protection and for understanding how climate change would impact marsh survival in the long term. Yet, more studies are need to expand our results to wider abiotic gradients and type of marshes, such as barrier island marshes, microtidal marshes, or marsh zones with mixed vegetation communities. Moreover, we stress here that our study extrapolates from a flume experiment, but marsh lateral erosion is a complex phenomenon. Several factors contribute to marsh lateral erosion, with wind exposure and foreshore morphology acting at large and intermediate scales, respectively (Wang et al., 2017). Furthermore, block marsh failure is an important mechanism of marsh retreat (Francalanci et al., 2013; Bendoni et al., 2016), which was beyond the scope of investigation of our study. Although plant roots can play a crucial role in reducing block failure (Bendoni et al., 2016), the role of root density in this regard is yet to be investigated. Overall, future studies should aim at understanding how sediment stabilisation by roots relate to other aspects of marsh erosion (e.g., block failure). 


\section{CONCLUSION}

This study shows roots of saltmarsh plants effectively stabilise sediments against erosion, but that root development varies with environmental context, thus generating spatial variation in erosion protection by plants. By addressing both the response of roots to the environment, and, in turn, the effect of roots on sediment stability ("response-effect" approach), we revealed the important role that intraspecific variability plays in marsh resistance to erosion and that environmental factors can propagate through plant traits to influence salt marsh stability. Surprisingly, we found scarce evidence that fine rootsor associated traits-played an important role in sediment stabilisation. Instead, overall root density, and especially the biomass of rhizomes and coarse roots, drove sediment stability. This suggests that different mechanisms of root-sediment stabilisation might exist depending on sand content, and that, in salt marshes, root density can efficiently capture the role of salt marsh plants for sediment stabilisation. More studies are warranted to elucidate the indirect effect of the environment on salt marsh root traits enabling researchers to better forecast salt marsh stability under future climate change and to inform managers on the effective integration of salt marshes into coastal defence schemes.

\section{AUTHOR CONTRIBUTIONS}

DDB and JG developed the idea and led the writing of the manuscript. DDB performed field work, laboratory work, and data analysis. JG, MF, and MR contributed to data analysis. MR contributed to field and laboratory work. MF, SJ, MS,

\section{REFERENCES}

Adam, P. (2002). Saltmarshes in a time of change. Environ. Conserv. 29, 39-61. doi: 10.1017/S0376892902000048

Akaike, H. (1973). "Information Theory and an Extension of the Maximum Likelihood Principle," in Proceedings of the 2nd International Symposium on Information Theory," eds B. N. Petrov and F. Csaki (Budapest: Akademiai Kiado), 267-281.

Armstrong, A. C. (1979). Aeration in higher plants. Adv. Bot. Res. 7, 225-332.

Armstrong, W. (2000). Oxygen distribution in wetland plant roots and permeability barriers to gas-exchange with the rhizosphere: a microelectrode and modelling study with Phragmites australis. Ann. Bot. 86, 687-703. doi: $10.1006 /$ anbo.2000.1236

Armstrong, W., Wright, E. J., Lythe, S., and Gaynard, T. J. (1985). Plant zonation and the effects of the spring-neap tidal cycle on soil aeration in a humber salt marsh. J. Ecol. 73:323. doi: 10.2307/2259786

Baets, S. D., Poesen, J., Knapen, A., and Galindo, P. (2007). Impact of root architecture on the erosion-reducing potential of roots during concentrated flow. Earth Surface Processes Landforms 32, 1323-1345. doi: 10.1002/esp. 1470

Barbier, E. B., Koch, E. W., Silliman, B. R., Hacker, S. D., Wolanski, E., Primavera, J., et al. (2008). Coastal ecosystem-based management with nonlinear ecological functions and values. Science 319, 321-323. doi: 10.1126/science.11 50349

Bardgett, R. D., and van der Putten, W. H. (2014). Belowground biodiversity and ecosystem functioning. Nature 515, 505-511. doi: 10.1038/natur e13855
$\mathrm{TB}$, and PN contributed to write the manuscript. All authors contributed to manuscript revision, read, and approved the submitted version.

\section{FUNDING}

This work was provided by Welsh Government and HEFCW through the 384 Sêr Cymru National Research Network for Low Carbon, Energy and Environment RESILCOAST project. JG was supported by Natural Environment Research Council award NE/N013573/1, CoastWEB: Valuing the contribution which COASTal habitats make to human health and WEllBeing, with a focus on the alleviation of natural hazards.

\section{ACKNOWLEDGMENTS}

We would like to thank The Wildfowl \& Wetlands Trust for access to the Penrhyn Gwyn marsh, Mr. C. Delany for access to marshes on the Taf river, and Mr. D.A. Roberts for access to the Loughor marsh, and Natural Resources Wales for providing authorisation for sampling. We also thank Tom Fairchild, Kate Davidson, Alizée Mauffrey, Laura Cappelatti, Josh Mutter, Olivia Smith, Ella Milne, Gemma Woodhouse, Livius C. Bozga, and Macarius Howard for practical assistance.

\section{SUPPLEMENTARY MATERIAL}

The Supplementary Material for this article can be found online at: https://www.frontiersin.org/articles/10.3389/fevo. 2019.00150/full\#supplementary-material

Barton, K. (2016). MuMIn: Multi-Model Inference. R package version 1.15.6. Available online at: http://CRAN.R-project.org/package $=$ MuMIn

Bates, D. M. (2010). lme4: Mixed-effects Modeling with R. New York, NY: Springer. Bendoni, M., Mel, R., Solari, L., Lanzoni, S., Francalanci, S., and Oumeraci, H. (2016). Insights into lateral marsh retreat mechanism through localized field measurements. Water Resour. Res. 52, 1446-1464. doi: 10.1002/2015WR 017966

Bouma, T., Stapel, J., van der Heiden, J., Koutstaal, B., van Soelen, J., and van IJzerloo, L. (2002). Relative importance of macrophyte leaves for nitrogen uptake from flood water in tidal salt marshes. Marine Ecol. Progr. Ser. 240, 93-104. doi: 10.3354/meps 240093

Bouma, T. J., Friedrichs, M., van Wesenbeeck, B. K., Temmerman, S., Graf, G., and Herman, P. M. J. (2009). Density-dependent linkage of scale-dependent feedbacks: a flume study on the intertidal macrophyte Spartina anglica. Oikos 118, 260-268. doi: 10.1111/j.1600-0706.2008. 16892.x

Bouma, T. J., Koutstaal, B. P., van Dongen, M., and Nielsen, K. L. (2001b). Coping with low nutrient availability and inundation: root growth responses of three halophytic grass species from different elevations along a flooding gradient. Oecologia 126, 472-481. doi: 10.1007/s0044200 00545

Bouma, T. J., Nielsen, K. L., Van Hal, J., and Koutstaal, B. (2001a). Root system topology and diameter distribution of species from habitats differing in inundation frequency. Functi. Ecol. 15, 360-369. doi: 10.1046/j.1365-2435.2001.00523.x

Bouma, T. J., van Belzen, J., Balke, T., Zhu, Z., Airoldi, L., Blight, A. J., et al. (2014). Identifying knowledge gaps hampering application of intertidal habitats 
in coastal protection: opportunities \& steps to take. Coastal Eng. 87, 147-157. doi: 10.1016/j.coastaleng.2013.11.014

Bouma, T. J., Vries, M. D., and Herman, P. M. J. (2010). Comparing ecosystem engineering efficiency of two plant species with contrasting growth strategies. Ecology 91, 2696-2704. doi: 10.1890/09-0690.1

Breheny, P., and Burchett, W. (2013). Visualization of Regression Models Using Visreg. R Package. University of Kentucky.

Burnham, K. P., Anderson, D. R., and Huyvaert, K. P. (2011). AIC model selection and multimodel inference in behavioral ecology: some background, observations, and comparisons. Behav. Ecol. Sociobiol. 65, 23-35. doi: 10.1007/s00265-010-1029-6

Burylo, M., Rey, F., Mathys, N., and Dutoit, T. (2012). Plant root traits affecting the resistance of soils to concentrated flow erosion: plant root traits and soil stability. Earth Surface Processes Landforms 37, 1463-1470. doi: 10.1002/esp.3248

Colmer, T. D. (2003). Long-distance transport of gases in plants: a perspective on internal aeration and radial oxygen loss from roots. Plant Cell Environ. 26, 17-36. doi: 10.1046/j.1365-3040.2003.00846.x

Colmer, T. D., and Flowers, T. J. (2008). Flooding tolerance in halophytes. New Phytol. 179, 964-974. doi: 10.1111/j.1469-8137.2008.02483.x

Cooper, A. (1982). The effects of salinity and waterlogging on the growth and cation uptake of salt marsh plants. New Phytol. 90, 263-275.

Coops, H., Geilen, N., Verheij, H. J., Boeters, R., and van der Velde, G. (1996). Interactions between waves, bank erosion and emergent vegetation: an experimental study in a wave tank. Aquat. Bot. 53, 187-198. doi: 10.1016/0304-3770(96)01027-3

Costanza, R., Pérez-Maqueo, O., Martinez, M. L., Sutton, P., Anderson, S. J., and Mulder, K. (2008). The value of coastal wetlands for hurricane protection. J. Human Environ. 37, 241-248. doi: 10.1579/00447447(2008)37[241:TVOCWF]2.0.CO;2

Crain, C. M., Silliman, B. R., Bertness, S. L., and Bertness, M. D. (2004). Physical and biotic drivers of plant distribution across estuarine salinity gradients. Ecology 85, 2539-2549. doi: 10.1890/03-0745

De Baets, S., Poesen, J., Gyssels, G., and Knapen, A. (2006). Effects of grass roots on the erodibility of topsoils during concentrated flow. Geomorphology 76, 54-67. doi: 10.1016/j.geomorph.2005.10.002

Deegan, L. A., Johnson, D. S., Warren, R. S., Peterson, B. J., Fleeger, J. W., Fagherazzi, S., et al. (2012). Coastal eutrophication as a driver of salt marsh loss. Nature 490, 388-392. doi: 10.1038/nature11533

Denef, K., Six, J., Bossuyt, H., Frey, S. D., Elliott, E. T., Merckx, R., et al. (2001). Influence of dry-wet cycles on the interrelationship between aggregate, particulate organic matter, and microbial community dynamics. Soil Biol. Biochem. 33, 1599-1611. doi: 10.1016/s0038-0717(01)00076-1

Fagherazzi, S., Mariotti, G., Wiberg, P., and McGlathery, K. (2013). Marsh collapse does not require sea level rise. Oceanography 26, 70-77. doi: 10.5670/oceanog.2013.47

Feagin, R. A., Lozada-Bernard, S. M., Ravens, T. M., Möller, I., Yeager, K. M., and Baird, A. H. (2009). Does vegetation prevent wave erosion of salt marsh edges? Proc. Nat. Acad. Sci. 106, 10109-10113. doi: 10.1073/pnas.0901297106

Feagin, R. A., Mukherjee, N., Shanker, K., Baird, A. H., Cinner, J., Kerr, A. M., et al. (2010). Shelter from the storm? Use and misuse of coastal vegetation bioshields for managing natural disasters. Conserv. Lett. 3, 1-11. doi: 10.1111/j.1755-263X.2009.00087.x

Flowers, T. J., and Colmer, T. D. (2008). Salinity tolerance in halophytes. New Phytol. 179, 945-963. doi: 10.1111/j.1469-8137.2008.02531.x

Ford, H., Garbutt, A., Ladd, C., Malarkey, J., and Skov, M. W. (2016). Soil stabilization linked to plant diversity and environmental context in coastal wetlands. J. Veget. Sci. 27, 259-268. doi: 10.1111/jvs.12367

Foster, N. M., Hudson, M. D., Bray, S., and Nicholls, R. J. (2013). Intertidal mudflat and saltmarsh conservation and sustainable use in the UK: a review. J. Environ. Manag. 126, 96-104. doi: 10.1016/j.jenvman.2013.04.015

Fourcaud, T., Ji, J.-N., Zhang, Z.-Q., and Stokes, A. (2008). Understanding the impact of root morphology on overturning mechanisms: a modelling approach. Ann. Bot. 101, 1267-1280. doi: 10.1093/aob/mcm 245

Francalanci, S., Bendoni, M., Rinaldi, M., and Solari, L. (2013). Ecomorphodynamic evolution of salt marshes: experimental observations of bank retreat processes. Geomorphology 195, 53-65. doi: 10.1016/j.geomorph.2013.04.026
Freschet, G. T., and Roumet, C. (2017). Sampling roots to capture plant and soil functions. Funct. Ecol. 31, 1506-1518. doi: 10.1111/1365-2435. 12883

Freschet, G. T., Swart, E. M., and Cornelissen, J. H. C. (2015). Integrated plant phenotypic responses to contrasting above- and below-ground resources: key roles of specific leaf area and root mass fraction. New Phytol. 206, 1247-1260. doi: $10.1111 /$ nph.13352

Freschet, G. T., Valverde-Barrantes, O. J., Tucker, C. M., Craine, J. M., McCormack, M. L., Violle, C., et al. (2017). Climate, soil and plant functional types as drivers of global fine-root trait variation. J. Ecol. 105, 1182-1196. doi: 10.1111/1365-2745.12769

Koop-Jakobsen, K., Mueller, P., Meier, R. J., Liebsch, G., and Jensen, K. (2018). Plant-sediment interactions in salt marshes-an optode imaging study of $\mathrm{O}_{2}, \mathrm{pH}$, and $\mathrm{CO}_{2}$ gradients in the rhizosphere. Front. Plant Sci. 9:e541. doi: $10.3389 /$ fpls.2018.00541

Lavorel, S., and Garnier, E. (2002). Predicting changes in community composition and ecosystem functioning from plant traits: revisiting the Holy Grail. Funct. Ecol. 16, 545-556. doi: 10.1046/j.1365-2435.2002.00664.x

Lavorel, S., Storkey, J., Bardgett, R. D., de Bello, F., Berg, M. P., Le Roux, X., et al. (2013). A novel framework for linking functional diversity of plants with other trophic levels for the quantification of ecosystem services. J. Veget. Sci. 24, 942-948. doi: 10.1111/jvs.12083

Leonardi, N., Ganju, N. K., and Fagherazzi, S. (2016). A linear relationship between wave power and erosion determines salt-marsh resilience to violent storms and hurricanes. Proc. Natl. Acad. Sci. U.S.A. 113, 64-68. doi: 10.1073/pnas.1510095112

Lo, V. B., Bouma, T. J., van Belzen, J., Van Colen, C., and Airoldi, L. (2017). Interactive effects of vegetation and sediment properties on erosion of salt marshes in the Northern Adriatic Sea. Marine Environ. Res. 131, 32-42. doi: 10.1016/j.marenvres.2017.09.006

Marani, M., D'Alpaos, A., Lanzoni, S., and Santalucia, M. (2011). Understanding and predicting wave erosion of marsh edges. Geophys. Res. Lett. 38:48995. doi: 10.1029/2011GL048995

Mariotti, G., and Fagherazzi, S. (2010). A numerical model for the coupled longterm evolution of salt marshes and tidal flats. J. Geophys. Res. Earth Surface 115:1326. doi: 10.1029/2009JF001326

Möller, I., Kudella, M., Rupprecht, F., Spencer, T., Paul, M., van Wesenbeeck, B. K., et al. (2014). Wave attenuation over coastal salt marshes under storm surge conditions. Nat. Geosci. 7, 727-731. doi: 10.1038/ng eo2251

Möller, I., and Spencer, T. (2002). Wave dissipation over macro-tidal saltmarshes: effects of marsh edge typology and vegetation change. J. Coast. Res. 36, 506-521. doi: 10.2112/1551-5036-36.sp1.506

Naidoo, G., McKee, K. L., and Mendelssohn, I. A. (1992). Anatomical and metabolic responses to waterlogging and salinity in Spartina alterniflora and S. patens (Poaceae). Am. J. Bot. 79:765. doi: 10.2307/2444942

Nelson, J. L., and Zavaleta, E. S. (2012). Salt marsh as a coastal filter for the oceans: changes in function with experimental increases in nitrogen loading and sea-level rise. PLOS ONE 7:e38558. doi: 10.1371/journal.pone. 0038558

Nishiuchi, S., Yamauchi, T., Takahashi, H., Kotula, L., and Nakazono, M. (2012). Mechanisms for coping with submergence and waterlogging in rice. Rice 5:2. doi: 10.1186/1939-8433-5-2

Olff, H., Leeuw, J. D., Bakker, J. P., Platerink, R. J., and van Wijnen, H. J. (1997). Vegetation succession and herbivory in a salt marsh: changes induced by sea level rise and silt deposition along an elevational gradient. J. Ecol. 85:799. doi: $10.2307 / 2960603$

Pérez-Harguindeguy, N., Díaz, S., Garnier, E., Lavorel, S., Poorter, H., Jaureguiberry, P., et al. (2013). New handbook for standardised measurement of plant functional traits worldwide. Aust. J. Bot. 61:167. doi: 10.1071/BT 12225

Pezeshki, S. R. (2001). Wetland plant responses to soil flooding. Environ. Exp. Bot. 46, 299-312. doi: 10.1016/s0098-8472(01)00 107-1

Pound, M. P., French, A. P., Atkinson, J. A., Wells, D. M., Bennett, M. J., and Pridmore, T. (2013). RootNav: navigating images of complex root architectures. Plant Physiol. 162, 1802-1814. doi: 10.1104/pp.113.2 21531 
Rodwell, J. S., Dring, J. C., Averis, A. B. G., Proctor, M. C. F., Malloch, A. J. C., Schaminée, J. N. J., et al. (2000). Review of coverage of the National Vegetation Classification JNCC Report, No. 302.

Schindelin, J., Arganda-Carreras, I., Frise, E., Kaynig, V., Longair, M., Pietzsch, T., et al. (2012). Fiji: an open-source platform for biological-image analysis. Nat. Methods 9, 676-682. doi: 10.1038/nmeth.2019

Schutten, J., Dainty, J., and Davy, A. J. (2005). Root anchorage and its significance for submerged plants in shallow lakes. J. Ecol. 93, 556-571. doi: 10.1111/j.1365-2745.2005.00980.x

Shepard, C. C., Crain, C. M., and Beck, M. W. (2011). The protective role of coastal marshes: a systematic review and meta-analysis. PLoS ONE 6:e27374. doi: 10.1371/journal.pone.0027374

Suding, K. N., Lavorel, S., Chapin, F. S., Cornelissen, J. H. C., DíAz, S., Garnier, E., et al. (2008). Scaling environmental change through the community-level: a trait-based response-and-effect framework for plants. Global Change Biol. 14, 1125-1140. doi: 10.1111/j.1365-2486.2008. 01557.x

Tabot, P. T., and Adams, J. B. (2014). Salt secretion, proline accumulation and increased branching confer tolerance to drought and salinity in the endemic halophyte Limonium linifolium. South Afr. J. Bot. 94, 64-73. doi: 10.1016/j.sajb.2014.05.009

Tyler, A., and Zieman, J. (1999). Patterns of development in the creekbank region of a barrier island Spartina alterniflora marsh. Marine Ecol. Progr. Ser. 180, 161-177. doi: 10.3354/meps 180161
Vannoppen, W., De Baets, S., Keeble, J., Dong, Y., and Poesen, J. (2017). How do root and soil characteristics affect the erosion-reducing potential of plant species? Ecol. Eng. 109, 186-195. doi: 10.1016/j.ecoleng.2017.08.001

Wang, H., Wal, D., van der, Li, X., Belzen, J., van, Herman, P. M. J., Hu, Z., et al. (2017). Zooming in and out: scale dependence of extrinsic and intrinsic factors affecting salt marsh erosion. J. Geophys. Res. Earth Surface 122, 1455-1470. doi: 10.1002/2016JF004193

Watson, E. B., and Byrne, R. (2009). Abundance and diversity of tidal marsh plants along the salinity gradient of the San Francisco Estuary: implications for global change ecology. Plant Ecol. 205, 113-128. doi: 10.1007/s11258-009-9602-7

Conflict of Interest Statement: The authors declare that the research was conducted in the absence of any commercial or financial relationships that could be construed as a potential conflict of interest.

The handling editor and author, MS, declared their involvement as co-editors in the Research Topic, and confirm the absence of any other ongoing collaboration.

Copyright (๑ 2019 De Battisti, Fowler, Jenkins, Skov, Rossi, Bouma, Neyland and Griffin. This is an open-access article distributed under the terms of the Creative Commons Attribution License (CC BY). The use, distribution or reproduction in other forums is permitted, provided the original author(s) and the copyright owner(s) are credited and that the original publication in this journal is cited, in accordance with accepted academic practice. No use, distribution or reproduction is permitted which does not comply with these terms. 
OPEN ACCESS

Edited by:

Steven Bouillon,

KU Leuven, Belgium

Reviewed by:

Kelin $\mathrm{Hu}$,

The Water Institute of the Gulf,

United States

Kevin Yeager,

University of Kentucky, United States

Joe Baustian,

The Nature Conservancy, Australia

${ }^{*}$ Correspondence:

Terrence A. McCloskey tmccloskey@USGS.gov

Specialty section This article was submitted to

Conservation

a section of the journal

Frontiers in Ecology and Evolution

Received: 07 May 2018 Accepted: 19 October 2018

Published: 20 November 2018

Citation:

McCloskey TA, Smith CG, Liu K-B and Nelson PR (2018) The Effects of

Tropical Cyclone-Generated Deposition on the Sustainability of the Pearl River Marsh, Louisiana: The Importance of the Geologic Framework. Front. Ecol. Evol. 6:179. doi: 10.3389/fevo.2018.00179
The Effects of Tropical Cyclone-Generated Deposition on the Sustainability of the Pearl River Marsh, Louisiana: The Importance of the Geologic Framework

\author{
Terrence A. McCloskey ${ }^{1 *}$, Christopher G. Smith ${ }^{2}$, Kam-biu Liu ${ }^{3}$ and Paul R. Nelson ${ }^{4}$ \\ ${ }^{1}$ Cherokee Nation Technology Solutions, U.S. Geological Survey, Wetland and Aquatic Research Center, Baton Rouge, LA, \\ United States, ${ }^{2}$ U.S. Geological Survey, St. Petersburg Coastal and Marine Science Center, St. Petersburg, FL, \\ United States, ${ }^{3}$ Department of Oceanography and Coastal Sciences, Louisiana State University, Baton Rouge, LA, \\ United States, ${ }^{4}$ Independent Researcher, Tampa, FL, United States
}

Shoreline retreat is a tremendously important issue along the coast of the northern Gulf of Mexico, especially in Louisiana. Although this marine transgression results from a variety of causes, the crucial factor is the difference between marsh surface elevation and rising sea levels. In most cases, the primary cause of a marsh's inability to keep up with sea level is the lack of input of inorganic material. Although tropical cyclones provide an important source of such sediment, little effort has been made to determine the point of origin of the deposited material. In this study we use sedimentary, geochemical and biogeochemical data to identify the bed of the Pearl River and/or Lake Borgne as the source of a $\sim 5 \mathrm{~cm}$ thick clastic layer deposited on the surface of the Pearl River marsh on the Louisiana/Mississippi border. Radiochemical chronologies and sedimentary evidence indicate that this layer was associated with the passage of Hurricane Katrina in 2005. As this material would otherwise have been lost to the system, this deposition indicates a net gain to marsh surface elevation. Accretion rates, determined from 137Cs and 14C profiles and the use of the Katrina layer as a stratigraphic marker, indicate that short-term ( $\sim 50$ years) rates are as much as an order of magnitude higher than the long- term (1000s of years) rates. We suggest that the marsh's geologic setting in an incised river valley with steep vertical constraints and a large fluvial discharge, promotes rapid accretion rates, with rates accelerating as the sea moves inland, due to extended hydroperiods and the input of clastic material from both the marine and terrestrial sides. These rates are especially large when compared to accretion occurring in the more common open marshes fringing the Gulf that lack fluvial input. The difference is particularly large when related to marsh recovery/regrowth following the deposition of thick hurricane-generated clastic layers. Given the number of similar incised river valleys along the Gulf Coast, we believe that understanding the processes controlling marsh accretion in such environments is essential in evaluating marsh sustainability on a regional basis.

Keywords: pearl river, hurricanes, bayhead delta, vertical accretion, isotopes, marsh sustainability, X-ray flourescene, incised river valleys 


\section{INTRODUCTION}

Sea level variability is a major concern globally. Along the northern coast of the Gulf of Mexico relative sea level rise (rSLR) has resulted in severe coastal erosion and rapid land loss (Day et al., 2007). Between 1932 and 2010 the state of Louisiana lost $\sim 4,800 \mathrm{~km}^{2}$ of land (Couvillion et al., 2011), with projected loss of up to $\sim 13,500 \mathrm{~km}^{2}$ by 2100 (Blum and Roberts, 2009; Moser et al., 2014). This loss of land has already resulted in significant landward migration of the population and infrastructure (Dalbom et al., 2014; Lam et al., 2016; Cai et al., 2018; Colten et al., 2018), including current government-subsidized resettlement of a threatened community Simms, 2018). The landward migration is characterized by the replacement of coastal marshes with open water. The resulting changes in bathymetric and topographic conditions and increased fetch can significantly increase both the wave power and storm-surge height associated with tropical cyclones, thereby increasing the vulnerability of inland areas (Young and Verhagen, 1996; Marani et al., 2011; Leonardi et al., 2016; Twilley et al., 2016; Karimpour et al., 2017), and a reduction in ecological services (Costanza et al., 2006; Peterson et al., 2008; Craft et al., 2009). Modeling studies generally predict an increase in both the number of intense storms and the maximum intensity of future tropical storms under global warming (Bender et al., 2010; Murakami et al., 2012; Emanuel, 2013; Holland and Bruyere, 2014), highlighting a large potential future increase in the societal costs of coastal erosion.

By accreting upward, coastal marshes can maintain a fairly stable elevation relative to sea level, until the rate of rSLR surpasses their rate of surface elevation increase (accretion rate minus subsidence rate). Vertical accretion in marsh environments is dependent upon both allochthonous sediment input and autochthonous biomass accumulation (Reed, 1990). Biomass-based accretion can track sea level during moderate rates of rSLR; however, there is an upper limit beyond which marshes will not be able to keep up (Morris et al., 2002, 2016). As a result, mitigation schemes aimed at reducing future losses are commonly based on increasing sediment supply, principally inorganic sediments (mud, sand), to the deteriorating marshes (CPRA, 2007, 2012, 2013, 2016; Day et al., 2007). Although a current debate concerns the relative importance of marinegenerated sediment (delivered by tropical cyclones) vs. fluviallydelivered terrestrial material (Turner et al., 2006, 2007; Törnqvist et al., 2007; Tweel and Turner, 2012, 2014; Smith et al., 2015), the value of mineral deposition in mitigating the negative effects of rSLR rise is treated as a given (Delaune et al., 1978; Blum and Roberts, 2009; Allison and Meselhe, 2010; Day et al., 2011; Stralberg et al., 2011; Allison et al., 2012; Kemp et al., 2016).

Mineral sediments delivered to coastal marshes by tropical storms can contribute to marsh sustainability in a number of ways, including increasing surface elevation, providing essential nutrients, and reducing phytotoxicity (Guntenspergen et al., 1995; Turner et al., 2006; McKee and Cherry, 2009; Tweel and Turner, 2012, 2014). However, in open marshes fringing the coast, the sudden increase in surface elevation associated with the deposition of a thick clastic layer by a tropical cyclone may not be entirely positive (Osgood et al., 1995). In coastal marshes, vegetation type and biomass levels are highly dependent on the inundation regime, which is controlled by elevation (Eleuterius and Eleuterius, 1979; Rasser et al., 2013). As a result, not only can the deposition of a thick clastic layer kill vegetation, but it can also retard/prevent subsequent organic accretion, and thereby eliminating/reducing organic accumulation and vertical accretion until sea level rises sufficiently to increase the hydroperiods (Langlois et al., 2001; Stagg and Mendelssohn, 2010, 2011; Walters and Kirwan, 2016).

Incised river valleys are common geologic features along the Gulf of Mexico from Texas through the Florida panhandle. During the last oceanic lowstand Gulf Coast rivers formed braided channels, incising and widening their river valleys long distances upstream from the coast, which was far seaward of its present position. Rising Holocene sea levels then pushed sediments landward, filling and leveling the valleys as the bayhead deltas migrated upstream (Kindinger et al., 1994; Saucier, 1994; Greene, 2006; Yeager et al., 2012; Anderson et al., 2016). Marshes occupying these coast-perpendicular incised valleys are usually wide and flat, constrained by steep topographic gradients along both flanks. They are generally fresher and have a steeper salinity gradient than the more common coast-parallel fringing marshes situated along the coastal plain. Although spatially extensive, these environments have been largely ignored in regards to coastal retreat and their response to tropical cyclone-generated deposition. In this study we investigate accretion rates from the Pearl River (Louisiana) bayhead delta and compare recent ( $\sim$ last 50 years) accretion rates to rates observed throughout much of the Holocene.

\section{Study Site}

The Pearl River, located along the border between Louisiana and Mississippi (USA), is one such valley, which during the Wisconsin glaciation incised a channel $\sim 75 \mathrm{~m}$ below present sea level in a valley $\sim 14 \mathrm{~km}$ wide (Frazier, 1974; Yeager et al., 2012) before entering the sea $\sim 145 \mathrm{~km}$ south of the current mouth (Kindinger et al., 1994). The river currently drains $\sim 22,000 \mathrm{~km}$ 2 in Mississippi and Louisiana; reaching the Gulf of Mexico at the border between those two states (Figure 1). Average daily discharge is $373 \mathrm{~m}^{3} / \mathrm{s}$, the fourth largest volume for the eastern Gulf of Mexico (Ward et al., 2005). Average annual precipitation near the coast is $163 \mathrm{~cm} /$ year (Green, 2000). Approximately $75 \mathrm{~km}$ upstream from the present mouth the river diverges into two main channels, the East and West Pearl rivers, that flow through their respective sides of the $5-12 \mathrm{~km}$ wide valley. The oligohaline Pearl River marsh, which fills the valley floor, is dominated by very diverse, heavily-vegetated swamps, marshes, floodplains and a maze of interconnected channels (Ward et al., 2005). Surface elevations are low, ranging from 24 to $42 \mathrm{~cm}$ NAVD88 for the five CRMS sites (https://lacoast.gov/crms viewer/Map/CRMSViewer), and from 23 to $43 \mathrm{~cm}$ NAVD88, for our marsh sampling sites. Human hydrological modification has been restricted almost entirely to the two major channels. The river drains into Lake Borgne, separated from the main Gulf of Mexico by the remnants of the St. Bernard lobe, an abandoned 
delta of the Mississippi River that was active from $\sim 4,000$ to 1,000 years ago (Otvos and Giardino, 2004; Rodgers et al., 2009).

On August 29, 2005 Hurricane Katrina, a very large tropical cyclone, made landfall in the Pearl River marsh as a category 3 hurricane with a maximum sustained wind speed of 105 knots and a pressure of $928 \mathrm{mb}$. The storm tracked due north across the eastern edge of the marsh (Figure 1), producing a recorded storm surge of $4.87 \mathrm{~m}$ just west of the mouth of the East Pearl River (Knabb et al., 2005).

\section{METHODS}

\section{Field Methods}

We extracted one long $(690 \mathrm{~cm})$ and seven short $(\sim 40 \mathrm{~cm})$ sediment cores and 23 surface sediment samples from the Pearl River marsh. The surface samples were collected along two coordinated coast-perpendicular transects (marsh surface and river/estuary bed) down the salinity gradient, beginning at the upland forest and finishing in Lake Borgne, and a single (marsh surface) coast-parallel transect along the lower edge of the marsh (Figure 1). For both sample types, $\sim 25 \mathrm{~cm}^{3}$ of the surface material was collected in sterile plastic bags, which were then sealed and labeled. Marsh surface samples were obtained by scrapping the top $\sim 1-\mathrm{cm}$ of surface sediments with a spoon. The riverine/estuarine samples similarly represent the top $\sim 1-\mathrm{cm}$ of sediments occurring at the water/sediment, scrapped from the top of materials collected from a ponar grab deployed over the side of the boat.

Five of the short cores (PR102D, PR107D, PR108D, PR109D, PR110D, PR11D) were collected along the same coast-parallel transect as the surface samples, $\sim 1 \mathrm{~km}$ inland. Cores were extracted at the same sites as the surface samples, and received the same numerical designation, with the sample type indicated by the last letter; "S" formarsh surface sample, "D" for short cores and "R" for long cores. For example, surface sample PR102S, short core PR102D and long core PR10R were all extracted within a radius of $2-3 \mathrm{~m}$ at site PR102. Short core PR112D was collected on the coast and PR102D was collected was $\sim 7 \mathrm{~km}$ inland. All seven short cores were collected by a "sharpshooter" shovel as $\sim 40 \mathrm{~cm}$ long slabs, which were then placed horizontally on PVC boards, sliced into rectangular shapes, wrapped in plastic and labeled. The long core (PR102R) was collected within a meter of the short core PR102D by a Eijkelkamp Peat Sampler with a $5.08 \mathrm{~cm}$ (inside diameter) hemispherical barrel. The core consists of Seventeen $50 \mathrm{~cm}$ segments, with a minimum 10$\mathrm{cm}$ overlap between segments. Overlaps between core segments were resolve by a matching of loss-on-ignition values and visual inspection. At all sites photographs were taken in the four cardinal directions, and such salient physical, hydrological and geomorphological features as changes in topography or vegetation, the presence/absence of water bodies or channels, evidence of disturbance, distance to streams or open water, were recorded. Locations and elevations for all sites were determined by Ashtech Proflex differential GPS (dGPS) receivers. All cores were photographed in the field and stored in ice chests during field work and transport, and then stored in temperaturecontrolled core lockers after transport to the laboratory.

\section{Laboratory Analyses}

Water and organic content were determined for all surface samples, and at $1-\mathrm{cm}$ resolution for the long and short cores, following the procedures of Liu and Fearn (2000) (methodology summarized in the Supplementary Material S1). Dry bulk density was determined for all surface samples and at $1-\mathrm{cm}$ resolution for short core PR102D, as described in the associated Data Release (McCloskey et al., 2018b). Elemental concentration data was collected with an Innov-X Delta Premium DP-4000 handheld X-ray fluorescence (XRF) unit on all surface samples, all short cores and long cores PR102D and PR102R at the Global Change and Coastal Paleoecology Laboratory of Louisiana State University. Two readings were taken of each surface sample; these were then averaged. The cores were analyzed at $2-\mathrm{cm}$ resolution, except in locations of interest, where readings were taken at $1-\mathrm{cm}$ resolution. The XRF device analyzes each sample across three frequencies for $30 \mathrm{~s}$ per frequency, recording counts per second (cps) for over 30 elements. CPS are converted to parts per million ( $\mathrm{ppm}$ ) through calibration with certified standards NIST 2710a and 2711a. We report data for S, Cl, K, $\mathrm{Ca}, \mathrm{V}, \mathrm{Cr}, \mathrm{Mn}, \mathrm{Fe}, \mathrm{Co}, \mathrm{Zn}, \mathrm{Br}, \mathrm{Rb}, \mathrm{Sr}, \mathrm{Zr}$, and the $\mathrm{Br} / \mathrm{Cl}$ and $\mathrm{Ti} / \mathrm{Br}$ ratios. We note that $\mathrm{XRF}$ is a semi-quantitative technique, producing relative rather than absolute values unless calibrated with quantitative geochemical techniques (such as ICP-MS). Because the recorded values remain the same relative relationship with absolute values, the shape of the downcore elemental profiles are valid, however, concentration comparison between elements must be used with caution (Brand and Brand, 2014; Young et al., 2016).

Four samples of terrestrial plant material were selected from long core PR102R to develop the multi-millennial chronology. Approximately $1-2 \mathrm{~cm}^{3}$ of bulk sediments were removed from interior locations in the core sections and passed through a 63-micron sieve to remove silt and clay. Plant fragments were selected from the remaining material under a dissecting microscope after being washed in de-ionized water. This material was dried and sent to the National Ocean Sciences Accelerator Mass Spectrometry (NOSAMS) Laboratory at Woods Hole Oceanographic Institution for radiocarbon dating. Radiocarbon dates were calibrated to calendar years, and median dates provided by Calib 7.1 (http://calib.qub.ac.uk/calib/calib.html) based on the Reimer et al. (2013) data set. BACON 2.2 agemodeling software (http://chrono.qub.ac.uk/blaauw/bacon.html) was used to display the results.

Grain size analysis was performed on the short core PR102D using a Coulter LS 200 particle-size analyzer. Two subsamples were prepared from homogenized material taken at $1-\mathrm{cm}$ resolution down the length of the core. After removing organic material with hydrogen peroxide, a minimum of three runs was performed on each subsamples. The GRADISTAT software program (Blott and Pye, 2001) was used to calculate the size distribution, mean grain size, sorting, skewness, and kurtosis for each sample. Classification of sediment texture, automatically generated by GRADISTAT, was based on Folk (1954).

Sediments from the short core PR102D were measured for short-lived, atmospherically-derived radionuclides to provide chronology data (time and accretion rates) for the last 50 to 
100 years. The procedures follow that of Smith et al. (2013) and is detailed in McCloskey et al. (2018b). Briefly, the core was sectioned at $1-\mathrm{cm}(0-28 \mathrm{~cm})$ and $2-\mathrm{cm}(30-40 \mathrm{~cm})$ intervals. The mass of each section was recorded prior to (wet) and after (dry) drying the sample at $60^{\circ} \mathrm{C}$ for 48 to $72 \mathrm{~h}$. The dry samples were homogenized with a porcelain mortar and pestle, packed into air-tight containers, and allowed to age for approximately 30 days to allow daughter $\left({ }^{222} \mathrm{Rn}\right)$ and granddaughter radioisotopes $\left({ }^{214} \mathrm{Po},{ }^{214} \mathrm{Bi}\right)$ to reach secular equilibrium with the parent isotope ${ }^{226} \mathrm{Ra}$. Following the aging procedure, each dried sample (section) was measured for ${ }^{210} \mathrm{~Pb}$ (photopeak $46.5 \mathrm{keV}$ ), ${ }^{226} \mathrm{Ra}$ (via the granddaughter isotopes, photopeaks 295.7, 352.5, and

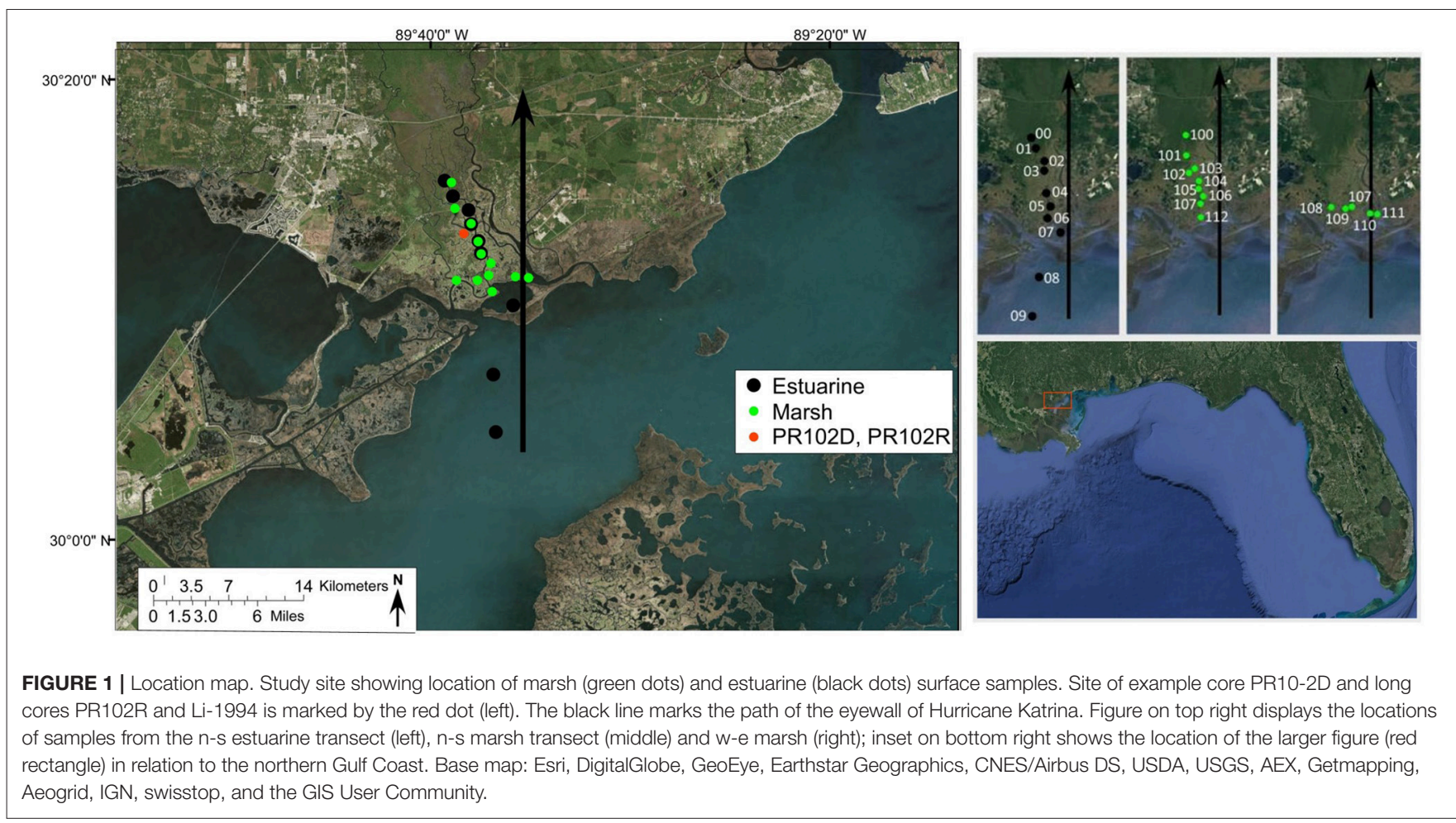

\section{Pearl River Surface Samples}

\section{Elemental concentrations}

$\mathrm{N}-\mathrm{S}$ transects

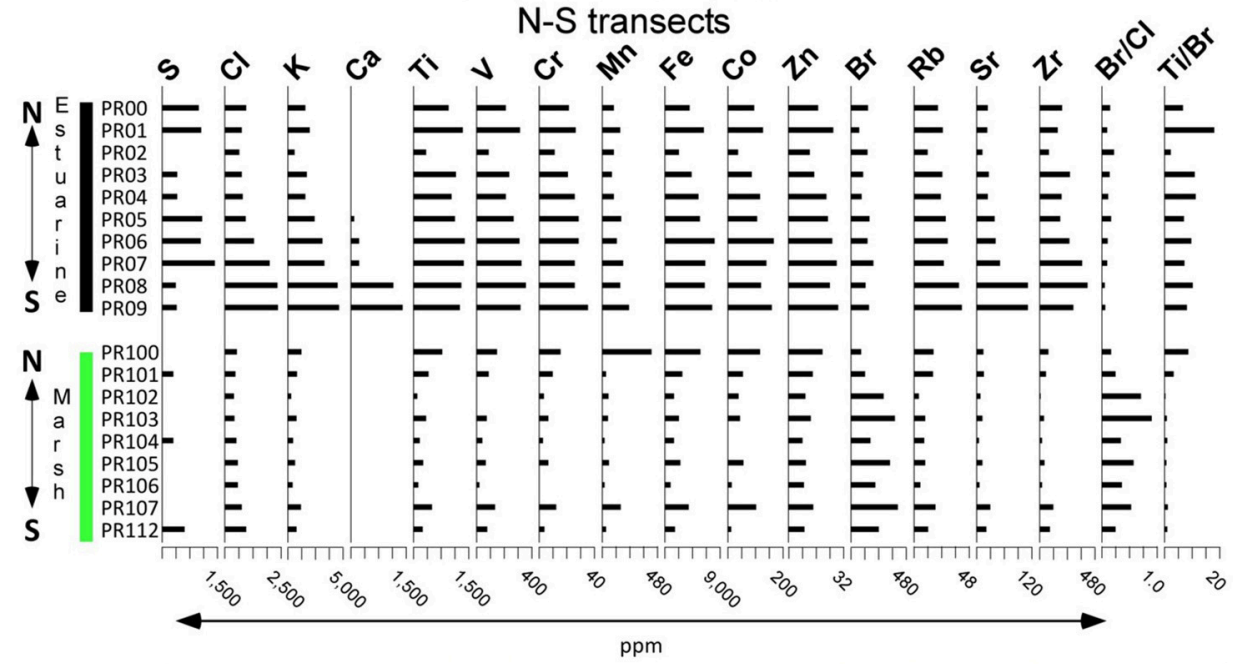

\section{Elemental concentrations PCA}

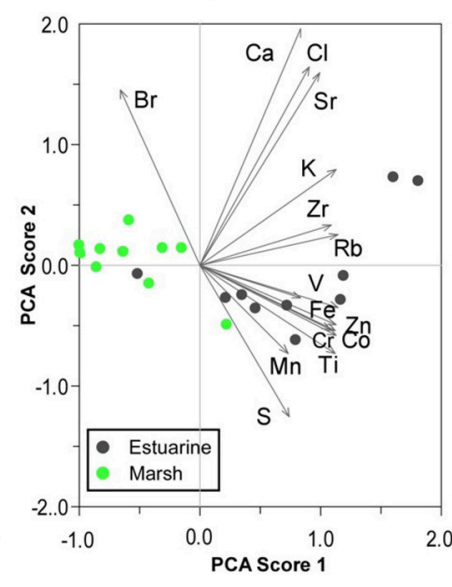

FIGURE 2 | Elemental concentration data. Concentration profiles (left) profiles and PCA biplots (right) are displayed for surface samples. Both estuarine and marsh samples are arranged vertically along their respective north-south transects. Data for the samples along the west-east marsh transect are not shown. 
$609.3 \mathrm{keV}$ ), ${ }^{137} \mathrm{Cs}$ (photopeak $661.7 \mathrm{keV}$ ), and ${ }^{40} \mathrm{~K}$ (photopeak $1460.8 \mathrm{keV}$ ) on a low-energy, planar-style high purity germanium gamma-ray spectrometer (Canberra, Inc). All samples were corrected for self-absorption following the procedure of Cutshall et al. (1983), using a sealed ${ }^{238} \mathrm{U}$ source with unattenuated count rates that are 500, 5000, 22000, 22000, and 25000 times greater than sample count rates for photopeaks 46.5, 63.3, 295.7, 352.5 , and $609.3 \mathrm{keV}$, respectively. Efficiencies for U-Th series radionuclides were determined using the IAEA (International Atomic Energy Agency) RGU-1 standard. Following guidelines by McCurdy et al. (2008), maxima values of sample-specific critical limits for $\left(\mathrm{ssL}_{\mathrm{c}}\right)$ for all samples analyzed for photopeaks $46.5,295.7,352.5,609.3,661.7$, and $1460.8 \mathrm{keV}$, were 4.9, 3.12, $1.77,2.52,1.51$, and $21.7 \mathrm{~Bq} / \mathrm{kg}$, respectively.

Following the guidelines of Swarzenski (2015) and Corbett and Walsh (2015) and references therein (not repeated here), we evaluated the utility of the Constant Rate of Supply (CRS), Constant Flux: Constant Sedimentation (CF:CS), and Constant Initial Concentration (CIC) models to establish chronology from excess ${ }^{210} \mathrm{~Pb}\left({ }^{210} \mathrm{~Pb}_{\mathrm{xs}}\right)$ data. Details of these models and the underpinning assumptions can be found in the reviews by Swarzenski (2015) and Corbett and Walsh (2015). For the CRS and CF:CS models, mass depth $\left(\mathrm{g} / \mathrm{cm}^{2}\right)$ were used to consider autocompaction based on the suggestion of Binford (1990) and Appleby (2001). Additionally, ${ }^{137} \mathrm{Cs}$ occurrence in sediment were compared with historical ${ }^{137} \mathrm{Cs}$ fluxes. ${ }^{137} \mathrm{Cs}$, an artificial nucleotide associated with above-ground nuclear explosions and the release from nuclear reactors (Ferreira et al., 2016), was not detectable in the atmosphere prior to 1954, with atmospheric concentration reaching a maximum $\sim 1963$, after which levels declined rapidly as a result of the Nuclear Test Ban Treaty (Zhang et al., 1990; Walling and He, 1999).

Sediment samples were collected from all surface samples and 18 intervals $(2-\mathrm{cm}$ resolution from 1 to 10,17 to $38 \mathrm{~cm} ; 1-\mathrm{cm}$ resolution 10 to $15 \mathrm{~cm}$ ) down short core PR102D and measured for bulk concentration and stable isotope composition of total organic carbon (TOC, $\left.\delta^{13} \mathrm{C}\right)$ and total nitrogen $\left(\mathrm{TN}, \delta^{15} \mathrm{~N}\right)$. The dried, homogenized samples were divided into two parts, with one portion, placed in small silver capsule and fumigated with hydrochloric acid to remove inorganic carbon, used for the determination of TOC and associated $\delta^{13} \mathrm{C}$, and the untreated, portion used for the determination of TN and associated $\delta^{15} \mathrm{~N}$. These samples were sent to the U.S. Geological Survey (USGS) Reston Stable Isotope Laboratory, where they were processed under the standard protocol described in Révész et al. (2012) (methodology summarized in the Supplementary Material S2). Isotopic abundances are reported as per mil (\%o) and follow standard reporting practice with references for $\delta^{15} \mathrm{~N}$ and $\delta^{13} \mathrm{C}$ being air and VPDB, respectively.

Principal Component Analysis (PCA) was performed on all surface and short core PR102D samples for both the XRF and carbon/nitrogen data. We used standardized and centered variables, entered into the C2 v1.75 software program (https:// www.staff.ncl.ac.uk/stephen.juggins/software/C2Home.htm).

Hurricane tracks were downloaded from the NOAA Historical Hurricane Tracks website (https://coast.noaa.gov/ hurricanes/).

\section{RESULTS}

\section{Surface Samples}

There are significant differences between the sedimentological features of the marsh and river/estuarine sample sets; both wet and dry bulk densities were lower, and water and organic content higher for the marsh than the estuarine samples. Dry bulk densities ranged from 0.09 to $0.31 \mathrm{~g} / \mathrm{cm}^{3}$ for the marsh samples (average $0.18 \mathrm{~g} / \mathrm{cm}^{3}$ ) and from 0.25 to $1.39 \mathrm{~g} / \mathrm{cm}^{3}$ (average 0.71 $\mathrm{g} / \mathrm{cm}^{3}$ ) for the estuarine samples. Water and organic content averaged 4.4 and $36.6 \%$ for the marsh samples and 1.7 and $6.6 \%$ for the estuarine samples (Table S1).

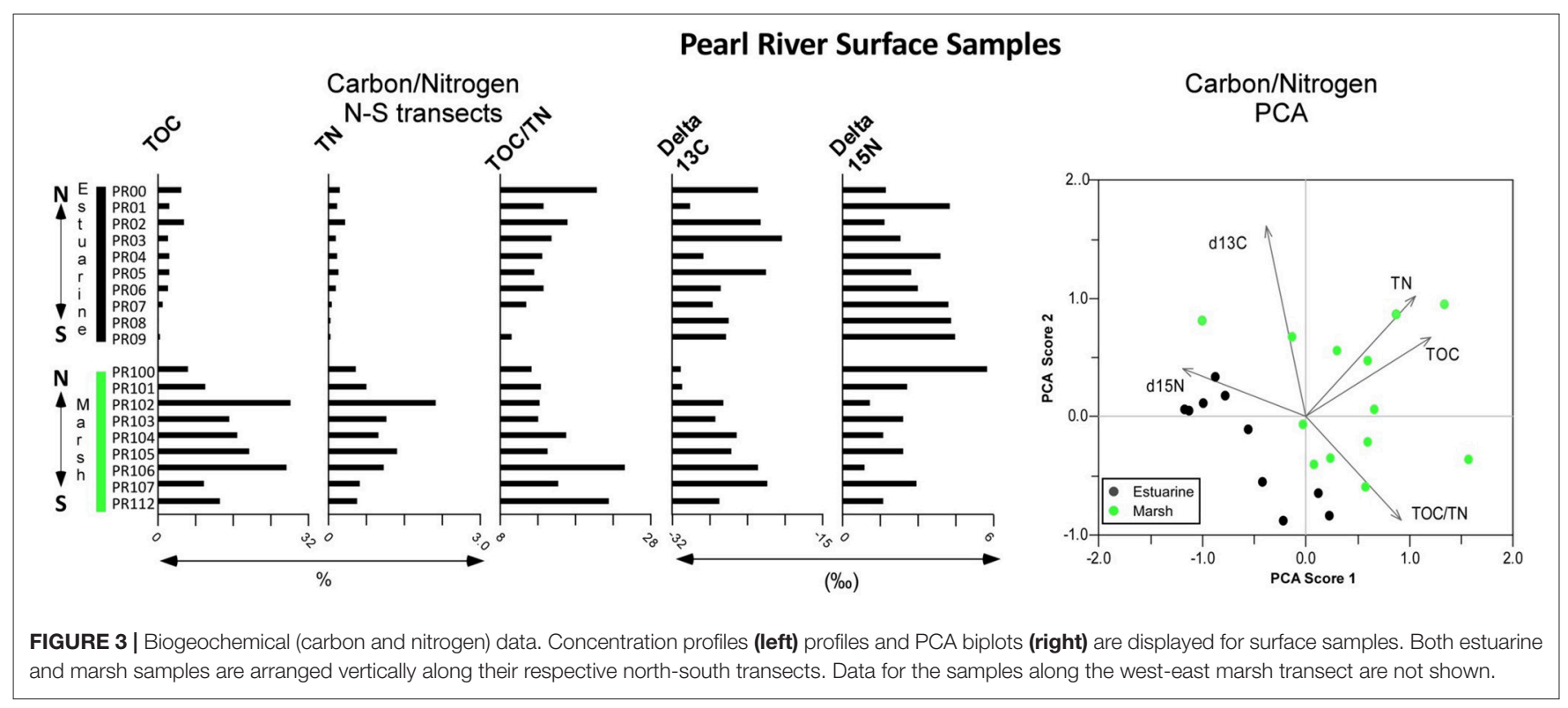


The elemental data exhibit recognizable spatial trends. For the estuarine samples the relative concentrations increase downstream by $>30 \%$, for $\mathrm{K}, \mathrm{Cr}, \mathrm{Fe}, \mathrm{Zn}$, and $\mathrm{Zr}$ and more than $200 \%$ for $\mathrm{Cl}, \mathrm{Ca}, \mathrm{Mn}, \mathrm{Rb}$, and Sr. For the marsh samples, the relative concentrations decrease downstream by $>60 \%$ for $\mathrm{Ti}, \mathrm{Cr}, \mathrm{Mn}, \mathrm{Fe}$, and $\mathrm{Co}$ and $>25 \%$ for $\mathrm{V}$, Co, and $\mathrm{Rb}$, while $\mathrm{Cl}$, $\mathrm{Zr}$, and $\mathrm{Sr}$ increase slightly downstream, and $\mathrm{Br}$ concentrations spike in the middle of the transect (Figure 2). Except for $\mathrm{Br}$, which shows the reverse trend, concentrations are significantly higher for all elements in the estuarine than marsh samples. The PCA biplots of elemental concentrations neatly separates the two sample types along PCA1, the first (primary) component, which explains $72 \%$ of the variance. With the exception of one marsh and one estuarine sample, all estuarine samples exhibit positive values for PCA1 (corresponding to high concentrations of $\mathrm{S}, \mathrm{Cl}, \mathrm{K}, \mathrm{Ca}, \mathrm{Ti}, \mathrm{V}, \mathrm{Cr}, \mathrm{Mn}, \mathrm{Fe}, \mathrm{Co}, \mathrm{Zn}, \mathrm{Rb}, \mathrm{Sr}, \mathrm{Zr}, \mathrm{Pb}$, and low concentrations of $\mathrm{Br}$ ) and all marsh sample exhibit negative values (Figure 2).

The biogeochemical constituents of both the estuarine and marsh sediments vary spatially, yet are distinct from one another. (Figure 3, Table 1). For example, the average TOC and TN percentages are substantially different between marsh (16.38 and 1.03, respectively) and estuarine sediments (2.52 and 0.17 , respectively). Spatially, TOC and TN in estuarine sediment decrease linearly downstream $(5.01$ to $0.58 \%, 0.24$ to $0.06 \%$, respectively), while $\mathrm{TOC}$ and $\mathrm{TN}$ in marsh sediment reach maxima at intermediate sites (28.2 and $2.12 \%$, respectively). For both sediment types, TN has a very strong linear relationship with TOC $\left(r^{2}=0.93\right.$ and 0.69 , for the estuarine and marsh samples respectively). Downstream, the TOC/TN ratio decreases for the estuarine samples (20.88 to 9.67), while increasing for the marsh samples. Isotopically, the $\delta^{13} \mathrm{C}$ signature of estuarine sediments are highly variable along the transect $(-21.34$ to $-24.55 \%$ ), while $\delta^{15} \mathrm{~N}$ generally becomes heavier downstream (1.76 to $4.51 \%$ ). In contrast, $\delta^{13} \mathrm{C}$ signature of marsh sediment tends to become heavier downstream and $\delta^{15} \mathrm{~N}$ has no general trend. Based on PCA analysis, TOC and TN concentration are the biogeochemical variables that most fully distinguish the marsh and estuarine sediment samples (Figure 3).

\section{Cores}

Six of the seven short cores extracted from the southern end of the marsh display a distinct inorganic (low water and organic values) interval several centimeters below the modern marsh surface. The depth and thickness varies among the cores (Figure 4). The top of the layer occurs at an average of $10 \mathrm{~cm}(7,9$, $10,10,12$, and $13 \mathrm{~cm}$ ) in the six cores, and bottom at an average depth of $14 \mathrm{~cm}(12,13,13,15,16$, and $17 \mathrm{~cm})$. This layer has many features that distinguish it from the embedding organic matrix. As displayed by the example core, PR102D (Figure 5), the interval presents visually as a $\sim 6-\mathrm{cm}$ thick gray clay/silt/sand layer, classified as "sandy mud" (Folk, 1954), that completely separates the organic material below from similar material above. Buried grass rhizomes and unsprouted seeds, which do not penetrate the clastic layer, are often encountered immediately below the layer (Figure S1). The clastic layer is marked by heavier (higher wet and dry bulk densities), larger
TABLE 1 | Carbon and nitrogen data for surface samples.

\begin{tabular}{|c|c|c|c|c|c|c|}
\hline Sample & Type & $\delta 13 C$ & TOC & TOC/TN & $\delta 15 \mathrm{~N}$ & TN \\
\hline (name) & & $(\%)$ & $(\%)$ & & (\%) & $(\%)$ \\
\hline PRO0 & Estuarine & -21.34 & 5.01 & 20.88 & 1.76 & 0.24 \\
\hline PR01 & Estuarine & -28.16 & 2.63 & 13.84 & 4.32 & 0.19 \\
\hline PR02 & Estuarine & -21.11 & 5.79 & 17.03 & 1.68 & 0.34 \\
\hline PR03 & Estuarine & -18.94 & 2.39 & 14.94 & 2.36 & 0.16 \\
\hline PR04 & Estuarine & -26.83 & 2.6 & 13.68 & 3.95 & 0.19 \\
\hline PR05 & Estuarine & -20.51 & 2.63 & 12.52 & 2.75 & 0.21 \\
\hline PR06 & Estuarine & -25.1 & 2.22 & 13.88 & 3 & 0.16 \\
\hline PR07 & Estuarine & -25.87 & 1.04 & 11.56 & 4.23 & 0.09 \\
\hline PR08 & Estuarine & -24.29 & 0.33 & 8.25 & 4.35 & 0.04 \\
\hline PR09 & Estuarine & -24.55 & 0.58 & 9.67 & 4.51 & 0.06 \\
\hline Average (estuarine) & & 2.52 & & & 0.17 & \\
\hline PR100 & Marsh & -29.04 & 6.6 & 12.22 & 5.79 & 0.54 \\
\hline PR101 & Marsh & -28.96 & 10.1 & 13.47 & 2.6 & 0.75 \\
\hline PR102 & Marsh & -24.84 & 28.2 & 13.3 & 1.1 & 2.12 \\
\hline PR103 & Marsh & -25.64 & 15.4 & 13.16 & 2.42 & 1.17 \\
\hline PR104 & Marsh & -23.52 & 16.9 & 16.9 & 1.64 & 1 \\
\hline PR105 & Marsh & -24.09 & 19.6 & 14.41 & 2.44 & 1.36 \\
\hline PR106 & Marsh & -21.41 & 27.4 & 24.68 & 0.89 & 1.11 \\
\hline PR107 & Marsh & -20.45 & 9.99 & 15.86 & 2.95 & 0.63 \\
\hline PR112 & Marsh & -25.23 & 13.24 & 22.44 & 1.64 & 0.59 \\
\hline Average (marsh) & & 16.38 & & & 1.03 & \\
\hline
\end{tabular}

(increased mean grain size), better sorted and more finely skewed material (Figure 5), marked by distinct isotopic and geochemical signatures. Isotopically, the material displays positive shifts in the stable isotopes, $\delta^{13} \mathrm{C}$ and $\delta^{15} \mathrm{~N}$, and negative shifts in TOC, TN and the TOC/TN ratio (Figure 6). Chemically, the clastic interval has higher concentrations of $\mathrm{S}, \mathrm{Cl}, \mathrm{K}, \mathrm{Ca}, \mathrm{Ti}, \mathrm{V}, \mathrm{Cr}, \mathrm{Mn}, \mathrm{Fe}, \mathrm{Co}$, $\mathrm{Zn}, \mathrm{Rb}, \mathrm{Sr}$, and $\mathrm{Zr}$, and lower concentrations of $\mathrm{Br}$, resulting in low $\mathrm{Br} / \mathrm{Cl}$ and high $\mathrm{Ti} / \mathrm{Br}$ ratios (Figure 7). Stratigraphic and elemental profiles for the other five cores display extremely similar patterns (Figure S2).

\section{Radiochemistry}

The ages of the four AMS radiocarbon-dated samples from the long core PR102R are in stratigraphic order, with the uppermost, taken from a depth of $75 \mathrm{~cm}$, producing a postmodern (>1950 AD) age. Samples from 196, 389 and $587 \mathrm{~cm}$ produce radiocarbon ages of $1,320 \pm 15,3,130 \pm 20$, and $4,470 \pm 20$ years, respectively, resulting in an extrapolated basal date of $6070 \mathrm{cal} \mathrm{yr} \mathrm{BP.} \mathrm{These} \mathrm{values} \mathrm{and} \mathrm{their}$ calibrated date ranges and median probability age are shown in Table 2.

Gamma-emitting radioisotopes ${ }^{137} \mathrm{Cs},{ }^{210} \mathrm{~Pb}$ and ${ }^{40} \mathrm{~K}$, measured in Becquerels per kilogram (Bq/kg) (Figure 7), were measured in PR012D. Specific activity of ${ }^{137} \mathrm{Cs}$ is quantitatively observed (i.e., above a minimum detection limit of $2.2 \pm 0.9$ $\mathrm{Bq} / \mathrm{kg}$ ) throughout the core, however it reaches a peak of 73.81 $\pm 2.90 \mathrm{~Bq} / \mathrm{kg}$ at $37.5 \mathrm{~cm}$. This falls within the range of peak-1963 ${ }^{137} \mathrm{Cs}$ activities (70 to $84 \mathrm{~Bq} / \mathrm{kg}$ ) recorded from studies conducted in salt marshes along the Louisiana coast (Terrebonne, Barataria, 


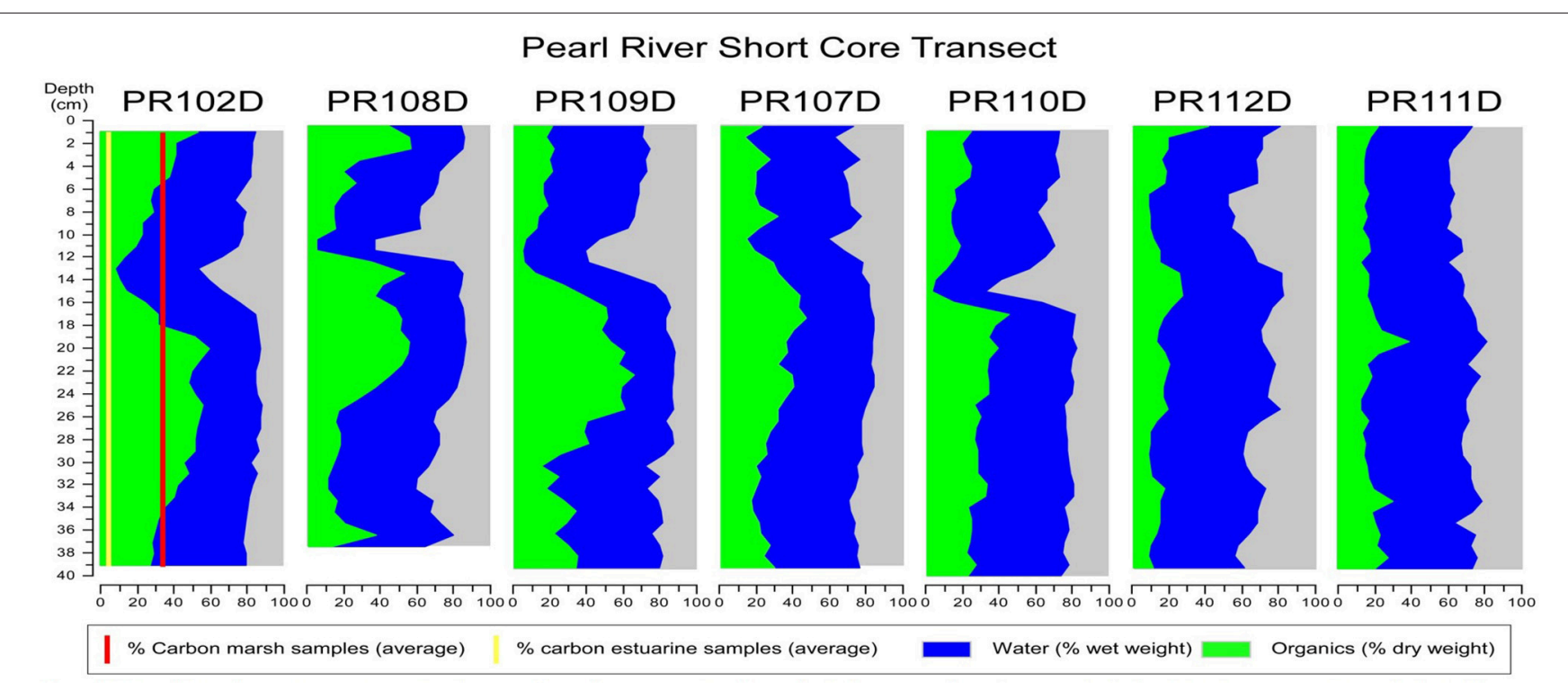

FIGURE 4 | Water (blue) and organic (green) content of the seven short sediment cores. Significant dips in the water and organic content, indicating clastic input, occur $\sim 10 \mathrm{~cm}$ depth in all but core PR11D. Average carbon percentage of the ten estuarine (yellow line) and thirteen marsh surface samples (red line), are superimposed on the graph of PR102D for comparison. Note the close match between organic content values for estuarine samples (yellow line) and clastic intervals (dips), and marsh surface samples (red line) and organic intervals.
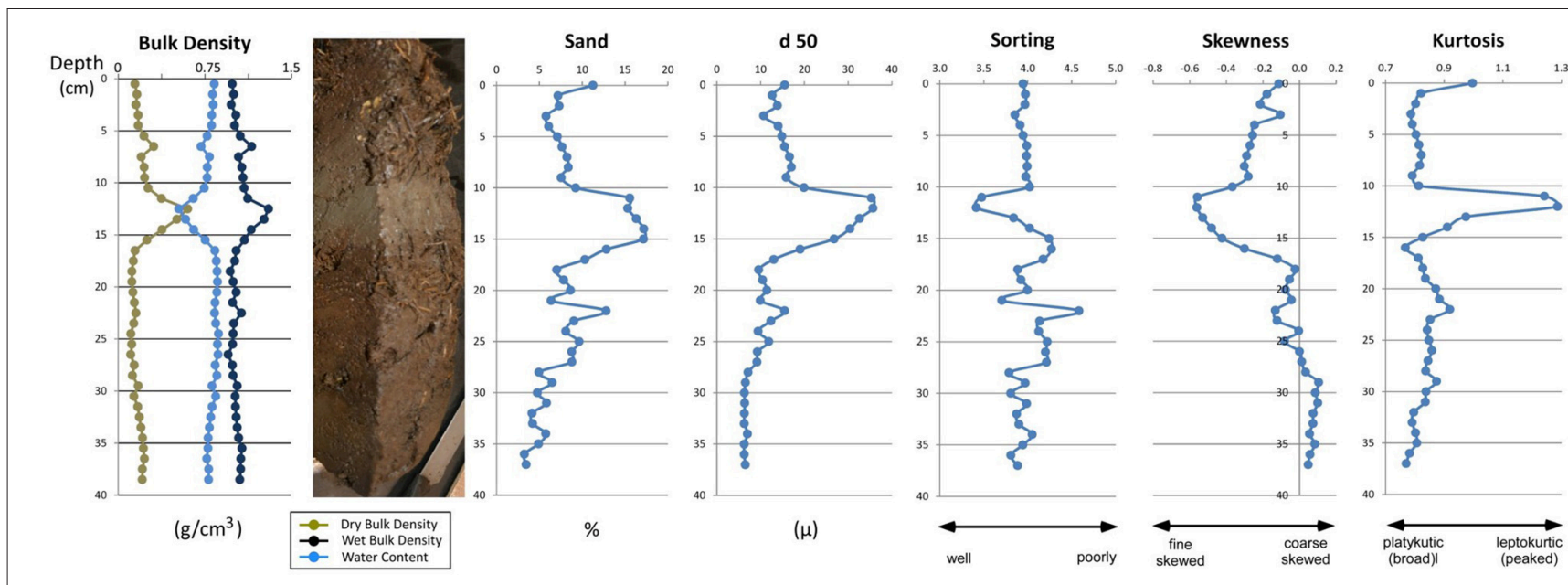

FIGURE 5 | Sedimentary parameters of core PR102D. The light gray band at 10-15 cm of core PR102D corresponds to distinct changes in several sedimentological parameters, including skewness, sorting, and kurtosis, as well as larger mean grain size, and increased density and sand percentage.

and St. Bernard basins) (Milan et al., 1995). This strongly suggests that $37.5 \mathrm{~cm}$ represents the year 1963 .

The ${ }^{210} \mathrm{~Pb}$ profile deviates significantly from an idealized radioactive-decay profile and at the base of the core has total ${ }^{210} \mathrm{~Pb}(63.9 \pm 4.5 \mathrm{~Bq} / \mathrm{kg})$ in excess of supported ${ }^{210} \mathrm{~Pb}(22.2 \pm$ $1.47 \mathrm{~Bq} / \mathrm{kg}$ ). The deviation of the ${ }^{210} \mathrm{~Pb}_{\mathrm{xs}}$ profile is most notable between 9 and $20 \mathrm{~cm}$, with activity in this zone much lower than the overlying and underlying sediment. Below $20 \mathrm{~cm},{ }^{210} \mathrm{~Pb}_{\mathrm{xs}}$ activity demonstrates a quantitative log-linear relationship with both depth $\left(r^{2}=0.989\right)$ and mass-depth $\left(r^{2}=0.968\right)$. Like ${ }^{210} \mathrm{~Pb}_{\mathrm{xs}}$, the ${ }^{40} \mathrm{~K}$ profile has two dominant zones $(0-20 \mathrm{~cm}$ and below $20 \mathrm{~cm}$ ) with gradients at the upper and lower boundaries of each zone. In the lower zone, ${ }^{40} \mathrm{~K}$ is roughly half the activity (mean $203 \mathrm{~Bq} \mathrm{~kg}^{-1}$ ) of the upper zone (mean $=350 \mathrm{~Bq}$ $\mathrm{kg}^{-1}$ ). The zone of high ${ }^{40} \mathrm{~K}$, a commonly-used proxy for clay concentration (Preston et al., 2013), coincides with the zone of low (below the expected values for simple radioactive decay) ${ }^{210} \mathrm{~Pb}_{\mathrm{xs}}$ zone; these zones also roughly correspond to the higher wet and dry bulk density regions of PR102D (Figure 7).

Chronologic results from the CIC or CRS models applied to the ${ }^{210} \mathrm{~Pb}_{\mathrm{xs}}$ data were either unattainable or incomplete due to the complex nature of the ${ }^{210} \mathrm{~Pb}$ distribution, downcore sediment variability (clastic layer), and the incomplete ${ }^{210} \mathrm{~Pb}_{\mathrm{xs}}$ inventory. However, applying the CF:CS model and its 


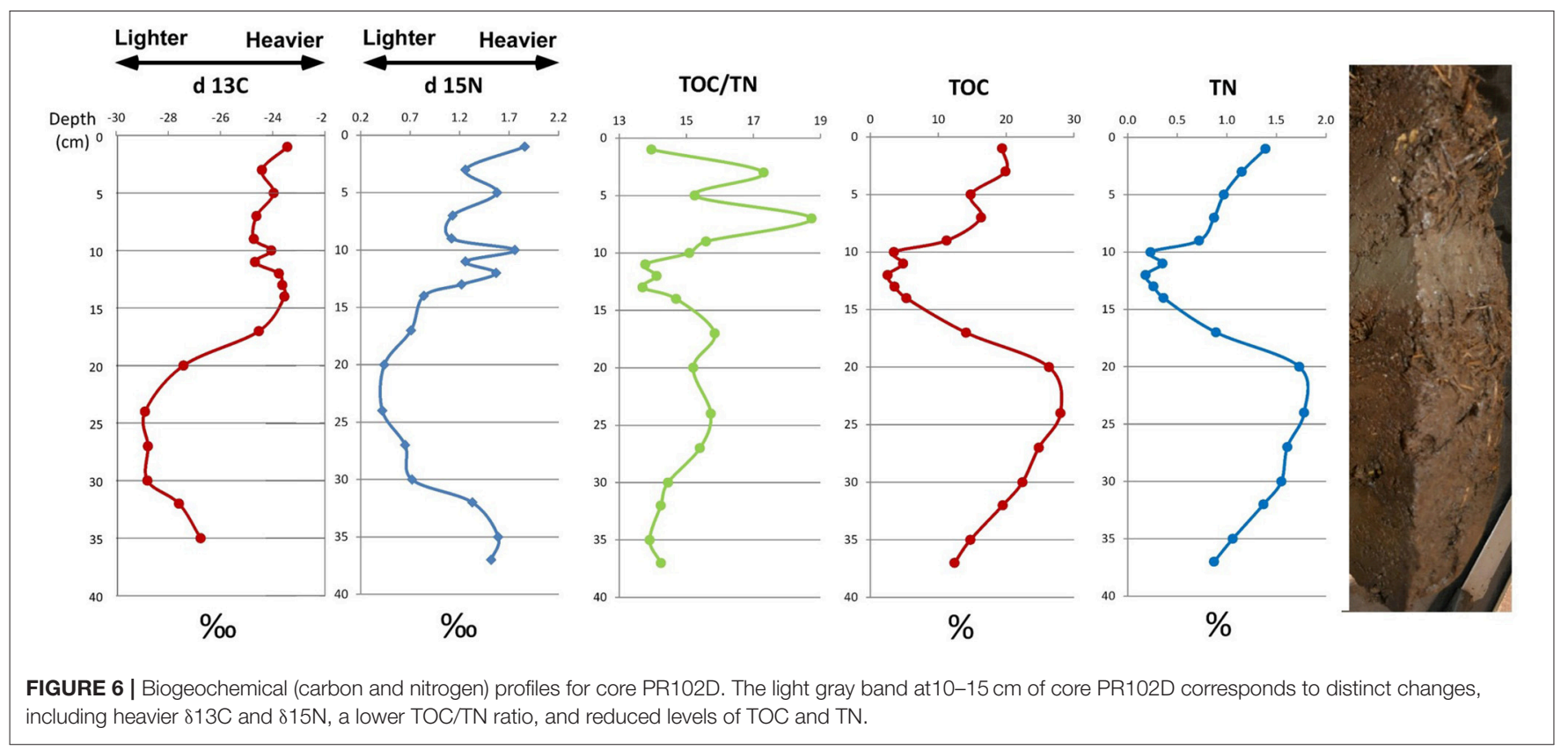

FIGURE 6 | Biogeochemical (carbon and nitrogen) profiles for core PR102D. The light gray band at10-15 cm of core PR102D corresponds to distinct changes, including heavier $\delta 13 \mathrm{C}$ and $\delta 15 \mathrm{~N}$, a lower TOC/TN ratio, and reduced levels of TOC and TN.

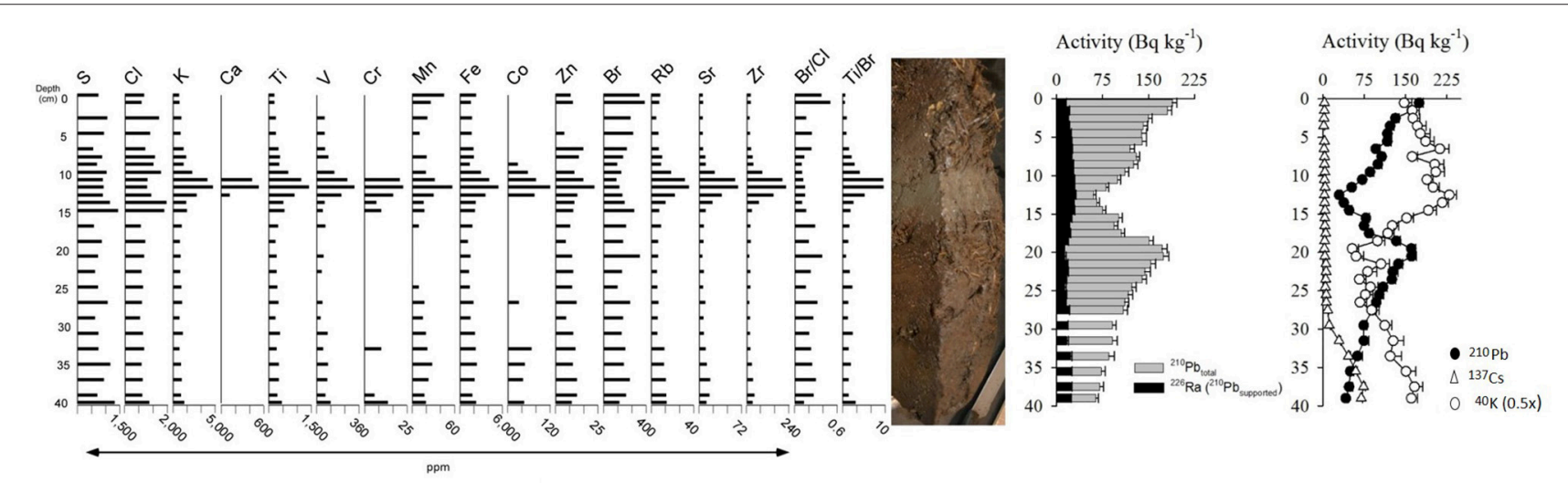

FIGURE 7 | Elemental and radiochemical profiles of core PR102D. The light gray band at 10-15 cm of core PR102D corresponds to distinct changes in both elemental and radiochemical parameters, including increases in the concentration of a range of elements (mostly metals), and a decrease in $\mathrm{Br}$ (left). Within the band, ${ }^{226} \mathrm{Ra}$ (supported ${ }^{210} \mathrm{~Pb}$ ) increases slightly while excess ${ }^{210} \mathrm{~Pb}$ displays a prominent dip (center right). This dip is paralleled by the total ${ }^{210} \mathrm{~Pb}$ curve, and mirrored by the ${ }^{40} \mathrm{~K}$ curve; below $\sim 28 \mathrm{~cm}{ }^{137} \mathrm{Cs}$ steadily increases downcore until peaking at a depth of $37.5 \mathrm{~cm}$ (far right).

assumptions to the ${ }^{210} \mathrm{~Pb}_{\mathrm{xs}}$ profile from $\sim 20 \mathrm{~cm}$ to the base of the core provide a mass accumulation rate of $0.72 \mathrm{~kg} / \mathrm{m}^{2} / \mathrm{y}$ and a corresponding accretion rate of $0.41 \pm 0.10 \mathrm{~cm} / \mathrm{y}$. In comparison and assuming, conservatively, the ${ }^{137} \mathrm{Cs}$ peak corresponds to 1963 , mass accumulation rates post-1963 are $1.5 \mathrm{~kg} / \mathrm{m}^{2} / \mathrm{y}$ and vertical accretion is $0.71 \mathrm{~cm} / \mathrm{y}$.

\section{DISCUSSION}

\section{Clastic Layer}

\section{Distinguishing Features}

The prominent gray clastic layer present in six of the seven short cores clearly represents a depositional environment distinctly different from both the overlying and underlying organic matrix. Visually, the organic material directly beneath this layer, consisting of large, horizontally-oriented, relatively fresh, easily-identifiable marsh plant fragments (Figure S1), closely resembles the organic material that occurs above the clastic interval extending to the mash surface. The sharpness of the clastic layer's bottom contact indicates the rapidity of the change in depositional environments, as does the presence of smothered seeds and grass rhizomes, which suggest that the overlying sediments were deposited over a short enough time span to prevent germination/sprouting (Langlois et al., 2001). The dramatic compositional (organics to clastics) and geochemical changes (increased concentrations of alkali, alkaline and transition metals, and decreased concentrations of bromine) suggest an altered source of the material. This is supported by 
TABLE 2 | Radiocarbon and calibrated dates for cores PR102 and Li-1994.

\begin{tabular}{|c|c|c|c|c|c|c|c|c|c|}
\hline Sample ID & Depth (cm) & Depth (midpoint) & Type & Lab \# & $14 \mathrm{C}$ age & \pm & cal BP & $\begin{array}{l}\text { Probability } \\
\text { distribution }\end{array}$ & Med. prob. \\
\hline PR102R & 75 & 75 & Plant/wood & OS-122840 & >Modern & - & - & - & - \\
\hline \multirow[t]{3}{*}{ PR102R } & 196 & 196 & Plant/wood & OS-122841 & 1320 & 15 & $1187-1203$ & 0.103 & 1275 \\
\hline & & & & & & & $1241-1249$ & 0.027 & \\
\hline & & & & & & & 1255-1293 & 0.87 & \\
\hline \multirow[t]{2}{*}{ PR102R } & 389 & 389 & Plant/wood & OS-123014 & 3,130 & 20 & 3258-3290 & 0.164 & 3361 \\
\hline & & & & & & & 3329-3396 & 0.836 & \\
\hline \multirow[t]{4}{*}{ PR102R } & 587 & 587 & Plant/wood & OS-122842 & 4470 & 20 & 4979-5010 & 0.061 & 5191 \\
\hline & & & & & & & 5035-5083 & 0.191 & \\
\hline & & & & & & & 5102-5139 & 0.117 & \\
\hline & & & & & & & $5162-5282$ & 0.631 & \\
\hline \multirow[t]{3}{*}{ Li-1994 } & $25-26$ & 25.5 & Plant/wood & Beta-65439 & 210 & 60 & $0-43$ & 0.137 & 192 \\
\hline & & & & & & & 58-325 & 0.796 & \\
\hline & & & & & & & $375-429$ & 0.067 & \\
\hline \multirow[t]{3}{*}{ Li-1994 } & $73-74$ & 73.5 & Plant/wood & Beta-65440 & 1050 & 70 & 794-1090 & 0.953 & 968 \\
\hline & & & & & & & $1108-1146$ & 0.033 & \\
\hline & & & & & & & $1159-1172$ & 0.014 & \\
\hline \multirow[t]{2}{*}{ Li-1994 } & $117-132$ & 124.5 & Plant/wood & Beta-60235 & 1240 & 60 & $1007-1025$ & 0.023 & 1173 \\
\hline & & & & & & & 1053-1290 & 0.977 & \\
\hline Li-1994 & $267-275$ & 271 & Plant/Wood & Beta-65441 & 2730 & 70 & 2744-2991 & 1 & 2840 \\
\hline \multirow[t]{3}{*}{ Li-1994 } & $471-472$ & 471.5 & Plant/Wood & Beta-60236 & 4490 & 60 & 4891-4900 & 0.006 & 5145 \\
\hline & & & & & & & $4911-4927$ & 0.012 & \\
\hline & & & & & & & 4959-5313 & 0.982 & \\
\hline \multirow[t]{3}{*}{ Li-1994 } & $736-746$ & 741 & Plant/Wood & Beta-60237 & 5830 & 90 & 6414-6428 & 0.008 & 6637 \\
\hline & & & & & & & 6432-6806 & 0.959 & \\
\hline & & & & & & & 6812-6853 & 0.033 & \\
\hline
\end{tabular}

suppressed ${ }^{210} \mathrm{~Pb}$ activity levels, presumably resulting from the remobilization of previously deposited material or material from where atmospheric ${ }^{210} \mathrm{~Pb}$ is diluted, in either case reflecting an allochthonous source for these sediments (Figure 7). The increase in density and grain size suggests a more energetic transport process. Taken together, these features indicate a rapid deposition of allochthonous clastic material under high-energy conditions. As the isotopic changes (heavier $\delta^{13} \mathrm{C}$ and $\delta^{15} \mathrm{~N}$, decreased TOC/TN ratio, lower TOC and TN) are exactly the changes documented as occurring during marine intrusions along the northern Gulf Coast (Lambert et al., 2008; Das et al., 2013), and the complete burial of plant cover resembles documented effects of hurricanes (Guntenspergen et al., 1995), the most likely source of this anomalous material is transport by a large storm surge associated with a tropical cyclone. As the ${ }^{137} \mathrm{Cs}$ chronology indicates that 1963 correlates approximately a depth of $37.5 \mathrm{~cm}$, the causative storm must have occurred sometime after that year.

\section{Candidate Events}

Twelve tropical storms have passed with $150 \mathrm{~km}$ of the site at hurricane strength since 1963. Their tracks (Figure 8) and important parameters (Table 3 ) are presented below. Because the National Hurricane Center records storm data at $6 \mathrm{~h}$ intervals (https://coast.noaa.gov/hurricanes/) Table 3 provides data from three data points for each storm; the point which occurs closest to our site, and the points immediately preceding it (seaward), and immediately following (landward). Storm surge heights from adjacent coastal areas are listed as reported. Note: locations, measurement units, terminology, and methodology are variable; detailed information can be found in the references. Further, location-specific information was provided by height estimates from storm surge maps created from NOAA's Sea Lake and Overland Surge from Hurricane (SLOSH) model (https://www. nhc.noaa.gov/surge/slosh.php), which recreates storm surge heights for historical storms.

Storm surges recorded along the LA-MS coast for these 12 cyclones can be divided into three groups; Low (Bob, Cindy, Danny, Florence, Frederic, and Georges, with listed maximum surge heights $<6$ feet), Medium (Betsy, Elena, Gustav and Isaac, with heights of 7-12 feet), and High (Camille and Katrina, with heights $>24$ feet). However, large differences in surge heights can occur over short distances. Track location is a very important factor, as the cyclonic nature of hurricanes, tend to drive water in the direction of forward movement in their right front quadrant, and in the opposite direction in the left front quadrant. At Pearl River, this means that for north-moving storms, surge heights will be greater for storms passing to the west than to the east. 


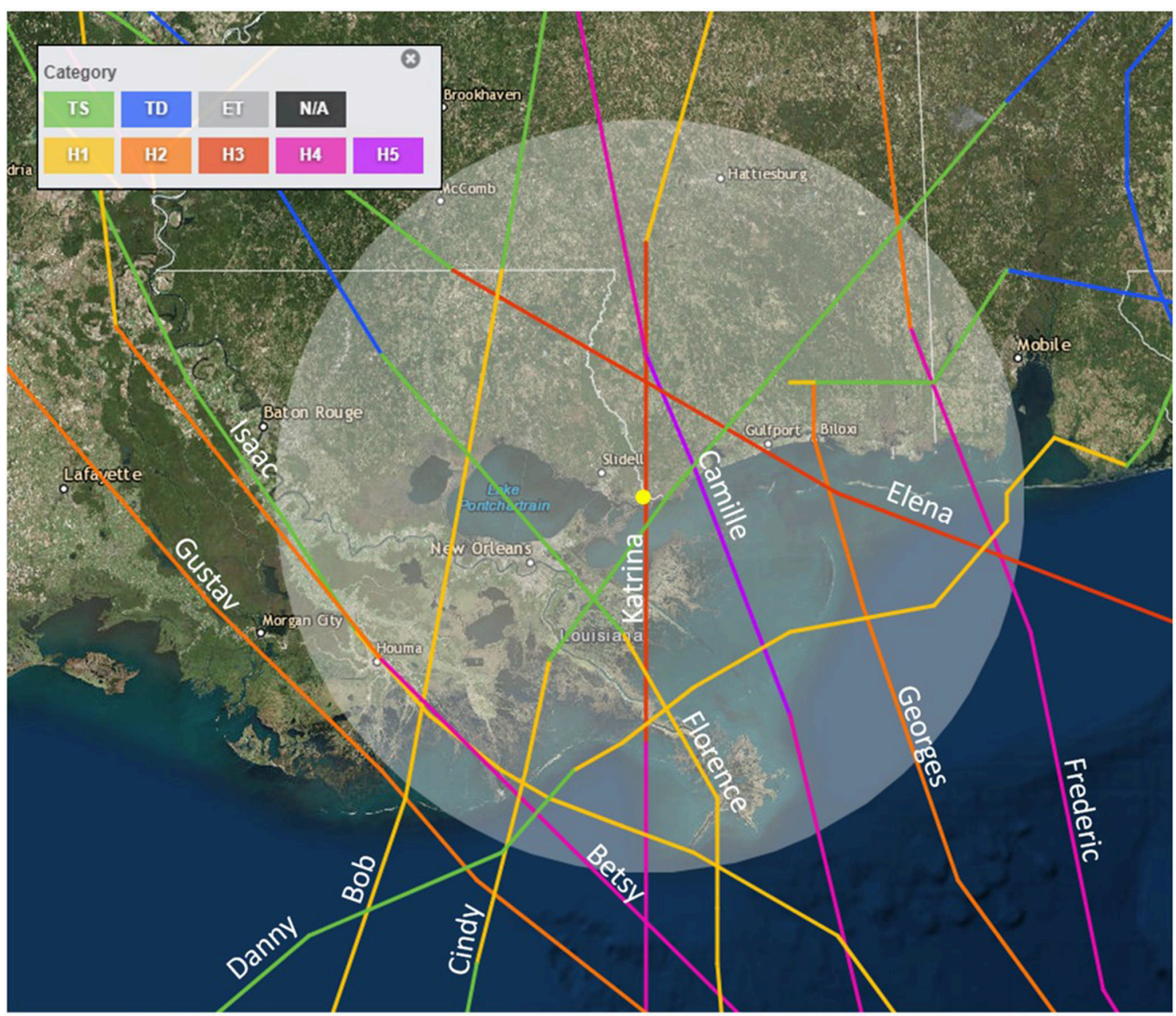

FIGURE 8 | Tracks of all tropical cyclones passing within $150 \mathrm{~km}$ of the study site (yellow dot) since 1963 at hurricane strength (64 knots) or above.

So, although Hurricane Camille and Hurricane Katrina both recorded storm surges $>24$ feet at Pass Christian, MS, SLOSH indicates that storm surge heights at the mouth of the Pearl River were $\sim 8$-10 feet for Camille which passed to the east and $\sim 20$ feet for Katrina which passed to the west (Figure S3). As a result, at our location Hurricane Katrina's storm was by far the largest since 1963. Additionally, Katrina's large extent and duration as a category 5 storm produced large swells for an extended period of time, including the largest significant wave height (55 feet) ever measured up to that time by a National Data Buoy Center buoy (Knabb et al., 2005). It seems likely, therefore, that Hurricane Katrina should have left the largest post-1963 sedimentary signature, and is the event most likely to have generated the clastic layer at $10-15 \mathrm{~cm}$ in PR102D.

\section{Radiochemical Chronology}

That Hurricane Katrina is the causative agent of this clastic layer is supported by the radiochemistry data. Although the maximum ${ }^{137} \mathrm{Cs}$ activity at $37.5 \mathrm{~cm}$ falls within the low end of the range of observed maximum activity documented by
Milan et al. (1995), the depth-integrated $(0-38 \mathrm{~cm})$ inventory of PR102D $\left(\sim 1090 \mathrm{~Bq} / \mathrm{km}^{2}\right)$ is higher than the post-1963 inventory range observed by Milan et al. (1995) (inventory of 1330$1520 \mathrm{~Bq} / \mathrm{km}^{2}$ in $\sim 1995$ or equivalently $850-960 \mathrm{~Bq} / \mathrm{km}^{2}$ in 2015). Restricting ${ }^{137} \mathrm{Cs}$ integration to $20-38 \mathrm{~cm}$ (i.e., below the clastic layer) in PR102D provides an inventory $\left(940 \mathrm{~Bq} / \mathrm{km}^{2}\right)$, much closer to those observed across coastal Louisiana. These observations support our previous assumption that the peak activity at a mid-point depth of $37.5 \mathrm{~cm}$ is conservatively the 1963 peak, and that the inventory below the clastic unit is comparable to regional inventory pre-dating $\sim 1995$, indicating that the sediments starting at the bottom of the clastic layer were deposited by 1995 at the earliest, and that the inventory added to the top of the core $(0-20 \mathrm{~cm})$ was reworked sediment deposited since that time.

Using dates of 1963 for $37.5 \mathrm{~cm}$ and 1995 for $20 \mathrm{~cm}$ yields yields a vertical accretion rate of $0.54 \pm 0.02 \mathrm{~cm} /$ year for the interval. However, this is noticeably higher than the ${ }^{210} \mathrm{~Pb}_{\mathrm{xs}}-$ calculated accumulated rate (log-linear fit with $\mathrm{r}^{2}$ of 0.989 for depth and 0.968 for mass-depth) for the same interval, 
which produces a vertical accretion rate of $0.41 \mathrm{~cm} / \mathrm{year}$, or 2.43 year $/ \mathrm{cm}$. Applying this accumulation rate to the material accumulated starting at $37.5 \mathrm{~cm}(2.44$ year $/ \mathrm{cm} \times 17.5 \mathrm{~cm})$

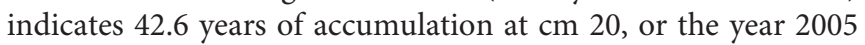
$(1963+42$ year). Therefore, we can confidently say that the placement of the clastic layer at and above $20 \mathrm{~cm}$ in the core post-dates 1995 based on independent measurements in a nearby region, and that internally the closest match would have occurred circa 2005. This, of course, is the year in which Katrina passed over the marsh.

\section{Sedimentary Correlations}

Attributing the clastic layer to Hurricane Katrina is further supported by comparison with sedimentary parameters documented in previously published studies. Both Reese et al. (2008) and McKee and Cherry (2009) collected event layer material from the Pearl River marsh within months of the passage of Katrina, Yeager et al. (2012) extracted cores from the marsh in 2008, and Bera et al. (2018) collected cores from St Louis Bay, $\sim 25 \mathrm{~km}$ to the east, in 2010-2011. Reese et al. (2008) identified the Katrina layer on the basis of clastic content and grain size, classifying the Katrina layer as a silty or medium loam, dominated by silts and fine-grained sands, generally with an organic content of $\sim 10 \%$ or less, marking the most distinctive dip in the LOI curve within the core. All of these characteristics closely match those occurring in the PR102D clastic layer. Both McKee and Cherry (2009) and Bera et al. (2018) identified the Katrina sediments on the basis of elevated sand content, increased grain size, heavier bulk density, and reduced levels of organic carbon, again matching the characteristics of the PR102D clastic layer. Yeager et al. (2012) identified the Katrina layer based on reduced organic content. Significantly, the ${ }^{210} \mathrm{~Pb}$ profiles of a St Louis Bay core (Bera et al., 2018), and core PR102D are remarkably similar, both marked by unexpectedly low values in their respective event layers, below which the values increase to the levels occurring above the event layer, before decreasing in the expected manner (Figure S4).

Due to these previous identifications of the Katrina layer as a readily-recognizable stratigraphic unit, the sedimentary and radioisotope match with the published data and our radiochemical chronology, we feel fully justified in identifying the clastic layer in PR102D, and by stratigraphic inference, the corresponding layers in the other five PR short cores, as having been deposited by Hurricane Katrina.

Published work indicates that organic material was deposited above the event layer, beginning almost immediately post-storm, and continuing thereafter. Reese et al. (2008) found that the Katrina layer was overlaid by a 1-2 cm thick organic clay layer, which they attributed to post-event settling. McKee and Cherry (2009) studied the accumulation of overlying organic marsh material throughout the following year(s), while, Bera et al. (2018) describe a $4 \mathrm{~cm}$ organic layer above the Katrina layer from their marsh core.

The possibility exists that Hurricanes Gustav and Isaac, the two hurricanes that generated medium-sized storm surges, and occurring post-Katrina in 2008 and 2012, respectively, contributed material to the event layer. However, the description of a capping organic layer, already $1-2 \mathrm{~cm}$ thick a few months after the passage of Katrina (Reese et al., 2008), and the continued organic accretion, documented by both Bera et al. and McKee and Cherry, appears to eliminate this possibility, as no organic intervals occur within the event layer. Although erosion from either of the storms could have removed this material, this did not seem to have occurred in the St Louis Bay cores, recovered in 2010-2011, after the passage of Gustav in 2010. Additionally, the smooth bell-shaped curves exhibited by the sedimentary, geochemical and biogeochemical curves representing the event layer argue against the identification of the layer as a mixture of materials deposited by a series of storms. Excursions in the biogeochemical curves, similar to, but smaller than those occurring from 10 to $15 \mathrm{~cm}$, occur at a depth of $5 \mathrm{~cm}$ (Figure 6), matched by dips in the LOI curves in the top ten $\mathrm{cm}$ in several cores (Figure 4)(core PR108D) may, in fact, represent these storms. Given the distance of PR102 inland ( $>6 \mathrm{~km}$ from the small front bay and $>7.5 \mathrm{~km}$ from Lake Borgne), surges from those two storms were likely not capable of leaving significant sedimentary footprints at the site. The same is likely the case for Hurricane Ivan, a powerful storm that crossed the Alabama coast just beyond the $150 \mathrm{~km}$ radius in 2004, the year before Katrina, with a surge height measured at 3.4 feet at Waveland, MS (Stewart, 2004).

\section{Erosion}

Hurricanes, of course, often result in large-scale erosion of marshes (Reed, 1990; Van de Plassche et al., 2006; Howes et al., 2010). However, several lines of evidence suggest that erosion was minimal at our sites, especially PR102. Large unsprouted seeds and grass rhizomes were found just below the bottom of the Katrina layer (Figure S1) in several cores. As it seems likely that the smothering of such seeds and especially rhizomes only affected the near surface zone; seeds and rhizomes deeply buried in the soil should have either sprouted or rotted, suggesting that significant amounts of surface material was not removed. The relative paucity of organic material in the event sediments ( $8 \%$ in the center of the layer, which may include post-depositional root intrusion) (McKee and Cherry, 2009) suggests that little organic material was entrained in the storm surge, at least at this location, Additionally, as within the event layer itself, the smooth form of several of the analytic curves, especially the biogeochemical ones (Figure 6) beginning from $\sim 20 \mathrm{~cm}$ to the bottom of the event layer suggest the completeness of the record (no sudden jumps in the curves). It is possible that the attenuation of wave energy due to the distance inland and the thick vegetation cover at the site (current conditions shown in Figure S5) prevented erosion of the surface sediments, with the main sedimentary effect at the site being burial.

\section{Sediment Provenance Elemental Concentration}

Given the importance of the elevational effects of stormdeposited materials effects on the long-term viability of a marsh, it is important to determine the origin of the material. Along the northern Gulf of Mexico, storm-generation vertical accretion often results from the re-deposition of material eroded from 
TABLE 3 | Storm data for tropical cyclones passing within $150 \mathrm{~km}$ of the study site after hurricane strength or above since 1963.

\begin{tabular}{|c|c|c|c|c|c|c|c|c|}
\hline \multirow[t]{2}{*}{ Name } & \multirow[t]{2}{*}{ Station } & \multirow[t]{2}{*}{ Date } & \multirow{2}{*}{$\begin{array}{l}\text { Pressure } \\
\text { (mb) }\end{array}$} & \multirow{2}{*}{$\begin{array}{l}\text { Wind speed } \\
\text { (kts) }\end{array}$} & \multirow[t]{2}{*}{ Designation } & \multicolumn{3}{|c|}{ Storm surge } \\
\hline & & & & & & (Location) & (Height) & (Reference) \\
\hline \multirow[t]{3}{*}{ Betsy } & Seaward & 9/10/1952 & 941 & 135 & $\mathrm{H} 4$ & Bay St. Louis, MS & 7 feeet above normal & Sugg, 1966 \\
\hline & Closest & 9/11/1952 & 948 & 90 & $\mathrm{H} 2$ & Pascagoula, MS & $\begin{array}{l}7.4 \text { feeet above mean low } \\
\text { water }\end{array}$ & \\
\hline & Landward & 9/12/1952 & 965 & 65 & $\mathrm{H} 1$ & - & - & \\
\hline \multirow[t]{3}{*}{ Bob } & Seaward & 7/11/1979 & 986 & 65 & $\mathrm{H} 1$ & Rigolets, LA & 3.8 feet & Hebert, 1980 \\
\hline & Closest & 7/11/1979 & 992 & 40 & TS & Bay St. Louis & 5.0 feet above normal & \\
\hline & Landward & 7/12/1979 & 998 & 30 & TD & Gulfport, MS & 6.3 feet & \\
\hline \multirow[t]{3}{*}{ Camille } & Seaward & 8/18/1969 & N/A & 140 & H5 & Pass Christian, MS & 24.6 feet & Simpson et al., 1970 \\
\hline & Closest & 8/18/1969 & 900 & 150 & $\mathrm{H} 5$ & Ocean Springs, MS & 15 feet & \\
\hline & Landward & 8/18/1969 & $\mathrm{N} / \mathrm{A}$ & 115 & $\mathrm{H} 4$ & - & - & \\
\hline \multirow[t]{3}{*}{ Cindy } & Seaward & $7 / 6 / 2005$ & 994 & 50 & TS & Rigolets, LA & 4.7 feet above normal & Beven et al., 2008 \\
\hline & Closest & $7 / 6 / 2005$ & 995 & 45 & TS & Gulfport, MS & 5.5 feet above normal & \\
\hline & Landward & $7 / 6 / 2005$ & 998 & 40 & TS & - & - & \\
\hline \multirow[t]{3}{*}{ Danny } & Seaward & 7/17/1997 & 989 & 65 & $\mathrm{H} 1$ & Rigolets, LA & $1.01 \mathrm{~m}$ above NGVD & Rappaport, 1998 \\
\hline & Closest & 7/18/1997 & 990 & 70 & $\mathrm{H} 1$ & - & - & \\
\hline & Landward & 7/18/1997 & 988 & 70 & $\mathrm{H} 1$ & - & - & \\
\hline \multirow[t]{3}{*}{ Elena } & Seaward & 9/2/1985 & 959 & 100 & $\mathrm{H} 3$ & Ocean Springs, MS & $2.4 \mathrm{~m}$ above normal & Case, 1986 \\
\hline & Closest & 9/2/1985 & 959 & 100 & $\mathrm{H} 3$ & Harrison County CD, MS & $1.8 \mathrm{~m}$ above normal & \\
\hline & Landward & 9/2/1985 & 990 & 60 & TS & - & - & \\
\hline \multirow[t]{3}{*}{ Florence } & Seaward & 9/10/1988 & 984 & 70 & $\mathrm{H} 1$ & Rigolets, LA & $0.9 \mathrm{~m}$ above normal & Lawrence and Gross, 1989 \\
\hline & Closest & 9/10/1988 & 988 & 60 & TS & Pass Christian, MS & $1.6 \mathrm{~m}$ above normal & \\
\hline & Landward & 9/10/1988 & 998 & 30 & TD & - & - & \\
\hline \multirow[t]{3}{*}{ Frederic } & Seaward & 9/13/1979 & 946 & 115 & $\mathrm{H} 4$ & Gulfport, MS & $\begin{array}{l}3.0 \text { feet above mean sea } \\
\text { level }\end{array}$ & Hebert, 1980 \\
\hline & Closest & 9/13/1979 & 955 & 95 & $\mathrm{H} 2$ & Pearlington, MS & $\begin{array}{l}3.3 \text { feet above mean sea } \\
\text { level }\end{array}$ & \\
\hline & Landward & 9/13/1979 & 975 & 65 & $\mathrm{H} 1$ & - & - & \\
\hline \multirow[t]{3}{*}{ Georges } & Seaward & 9/28/1998 & 964 & 90 & $\mathrm{H} 2$ & Pass Christian, MS & $2.0 \mathrm{~m}$ above normal & Pasch et al., 2001 \\
\hline & Closest & 9/28/1998 & 964 & 90 & $\mathrm{H} 2$ & Bay St Louis, MS & $1.8 \mathrm{~m}$ above normal & \\
\hline & Landward & 9/28/1998 & 984 & 65 & $\mathrm{H} 1$ & $\begin{array}{l}\text { Lake Borgne-Bayou } \\
\text { Bienvenu, LA }\end{array}$ & $2.3 \mathrm{~m}$ above normal & \\
\hline \multirow[t]{3}{*}{ Gustav } & Seaward & $9 / 1 / 2008$ & 955 & 95 & $\mathrm{H} 2$ & $\begin{array}{l}\text { Lake Borgne-Bayou Dupre, } \\
\text { LA }\end{array}$ & $\begin{array}{l}9.50 \text { feet above normal } \\
\text { (estimated) }\end{array}$ & Brown et al., 2010 \\
\hline & Closest & $9 / 1 / 2008$ & 954 & 95 & $\mathrm{H} 2$ & Rigolets, LA & $\begin{array}{l}5.0 \text { feet above normal } \\
\text { (estimated) }\end{array}$ & \\
\hline & Landward & $9 / 1 / 2008$ & 958 & 85 & $\mathrm{H} 2$ & Waveland, MS & 9.89 feet above normal & \\
\hline \multirow[t]{3}{*}{ Isaac } & Seaward & 8/29/2012 & 968 & 65 & $\mathrm{H} 1$ & Hancock County, MS & 9-11 feet above normal & Berg, 2013 \\
\hline & Closest & 8/29/2012 & 973 & 60 & TS & Pearl River, Highway 90, LA & 9.3 feet above NGVD & \\
\hline & Landward & 8/30/2012 & 977 & 55 & TS & - & - & \\
\hline \multirow[t]{3}{*}{ Katrina } & Seaward & 8/29/2005 & 923 & 110 & $\mathrm{H} 3$ & Pass Christian, MS & 27.8 feet above normal & Knabb et al., 2005 \\
\hline & Closest & 8/29/2005 & 928 & 105 & $\mathrm{H} 3$ & - & - & \\
\hline & Landward & 8/29/2005 & 948 & 80 & $\mathrm{H} 1$ & - & - & \\
\hline
\end{tabular}


the edges of the marsh (either ocean and/or river edges) onto the marsh surface (Goodbred, 1994; Goodbred and Hine, 1995; Barras, 2006; Törnqvist et al., 2007; Turner et al., 2007). In such cases vertical accretion results from landward translation and likely represents net loss.

We have applied PCA analysis to the elemental concentrations of core PR102D in order to elucidate the question of sediment provenance, with the biplot of the first two principle components (which together account for $81.3 \%$ of the variability) providing a means of examining the relationship between chemical composition of the sediments and core depth (Figure 8). Core PR102D can be divided into three stratigraphic units; the prestorm organic material from 40 to $16 \mathrm{~cm}$, the clastic Katrina layer from 15 to $10 \mathrm{~cm}$, and the post-event organic layer from $9 \mathrm{~cm}$ to the surface. The drivers of the first component, which explains $59.8 \%$ of the variability, are high concentrations of $\mathrm{Ti}, \mathrm{K}, \mathrm{Fe}, \mathrm{Sr}$, and $\mathrm{Ca}$ (high scores) and Br (low scores). All samples from both the top and bottom organic units, having low component scores, cluster to the left on the biplot, while the high-score event samples lie to the right. High scores for the second component, which accounts for $21.5 \%$ of the variability, are associated with large concentrations of $\mathrm{Cl}$ and $\mathrm{S}$, while low sores are associated with higher concentrations of $\mathrm{Br}$ and $\mathrm{Ca}$. Because $\mathrm{Cl}$ and $\mathrm{S}$ are marine indicators, higher concentrations can be used to indicate increased marine influence (Goff et al., 2012; Liu et al., 2014; Bianchette et al., 2017; McCloskey et al., 2018a). Notably, there is a large movement in the direction of $\mathrm{S}$ and $\mathrm{Cl}$ at the interface between the underlying organics and the bottom of the event layer (from 17 to $15 \mathrm{~cm}$ ). By the middle of the layer $(11,12 \mathrm{~cm})$ the elemental concentrations (Figure 7 ) and PCA biplot (Figure 9) indicate large concentrations of Ti, $\mathrm{K}$, $\mathrm{Fe}, \mathrm{Sr}$, and $\mathrm{Ca}$ and decreasing concentrations of $\mathrm{S}$ and $\mathrm{Cl}$. The shift back to organics at the top of the event layer (from 10 to $9 \mathrm{~cm}$ ) is marked by a movement toward $\mathrm{Br}$ and away from $\mathrm{Ti}$, $\mathrm{K}, \mathrm{Fe}, \mathrm{Sr}$, and $\mathrm{Ca}$, nearly the reverse of the shift from organics to clastics at the bottom of the event layer. This strong near mirror-image shift in sample position on the biplot occurs across the transect (Figure S6). This not only highlights the anomalous, (allochthonous) nature of the clastic layer, but the movements along the $\mathrm{Cl}$ and $\mathrm{S}$ vectors at the initiation of deposition strongly suggests a marine source. This is further supported by the event layer's low $\mathrm{Br} / \mathrm{Cl}$ ratio (Figure 7), which estimates the relative strength of fresh and marine input, (lower values corresponding to increased marine influence) (Liu et al., 2014; McCloskey et al., 2018a).

Extending the analysis to include the surface sample data and additional cores provides information in regard to sediment provenance (Figure 10). The combined biplots (surface and core data) are nearly identical in terms of both the strength and direction of the defining vectors and the amount of explained variability (76.1, 75.6, and 70.4\% respectively) for PR102D, PR108D, and PR112D. In all three cores, the first component sample scores are positively related to the concentrations of Co, $\mathrm{Zn}, \mathrm{Fe}, \mathrm{Cr}, \mathrm{Pb}, \mathrm{V}, \mathrm{Zr}, \mathrm{Rb}, \mathrm{Sr}, \mathrm{Ca}$, and $\mathrm{K}$ and negatively related to the concentration of $\mathrm{Br}$. Second component sample scores are positively related to the concentration of $\mathrm{Mn}$ and negatively related to the concentrations of and $\mathrm{S}$ and $\mathrm{Cl}$. Samples from the organic sections of the cores cluster with the marsh samples in the second and third quadrants of the biplots, while the event layer samples group with the estuarine samples in the first and fourth quadrants. These patterns are evident across the transect, suggesting that the material deposited by Hurricane Katrina more closely resembles material from the river bed/estuarine bottom than from the marsh surface. Subtler affinities can also be noted. The first component scores for the bottom samples collected in the open water of Lake Borgne (PR08, PR09) (Figure 10) are much higher than the event layer samples scores, which plot closer to the riverbed samples. This suggests that the event material more closely resemble sediments from the river channel than from the open water. Second component scores are generally lower for the event layer samples than for even the open water estuarine samples. Because low values on this component are correlated with high $\mathrm{S}$ and $\mathrm{Cl}$ concentrations, this possibly marks the sediments as more saline than the Lake Borgne samples. Given that the salinity in the open Gulf of Mexico ( 36 ppt) (http://www.ncddc.noaa.gov/website/DataAtlas/atlas. htm?plate=Salinity\%20-\%20Mean), is higher than at PR09 (17. $9 \mathrm{ppt}$ ), our farthest offshore sample, this suggests a possible association with offshore waters.

The marsh and river/estuarine environments appear to have contrasting sources of sediments (Figures 2, 3). For the estuarine samples the concentrations of nearly all elements increase downstream, while TOC, TN and the TOC/TN ratio decrease, suggesting that the source of the inorganic estuarine material is offshore and the source of the organic material is terrestrial. The increase in downstream $\delta^{15} \mathrm{~N}$ values for the estuarine samples likely results from remineralization as nitrogen moves up the food chain. For the marsh samples, elemental concentrations generally decrease downstream, suggesting a terrestrial source of inorganic sediments, likely delivered by fluvial flooding. The exception is $\mathrm{Cl}$, likely derived from marine waters. The high TOC/TN observed throughout the marsh sites (12.2-24.7), especially downstream (15.9-24.7) favor a downstream transition from a C3-dominated environment to one with organic contributions from either $\mathrm{C} 4$ plants or phytoplankton (Cloern et al., 2002), in agreement with the general vegetation gradient observed in the field (decrease in freshwater woody plants and increase in salt-tolerant grasses). These results suggest that the estuarine and marsh sedimentation systems normally operate separately, with the marsh receiving little clastic input from marine sources under normal conditions.

The overlap between the TOC/TN, d13C, and $\mathrm{d} 15 \mathrm{~N}$ values for the marsh and estuarine samples, combined with their sometimes anti-phase spatial relationship, complicates the use of the biogeochemical data as a means of determining provenance. Although the TOC and TN values in the event samples closely resemble estuarine material (while varying markedly from the marsh samples), the $\delta^{13} \mathrm{C}, \delta^{15} \mathrm{~N}$ values and TOC/TN ratios are ambiguous. The PCA biplot of the surface sample and core data (Figure 11) suggests that the event layer samples, although loosely grouped with estuarine samples, likely contains marsh material as well. However, this organic material may result from the post-depositional intrusion of roots as plants recolonize the 


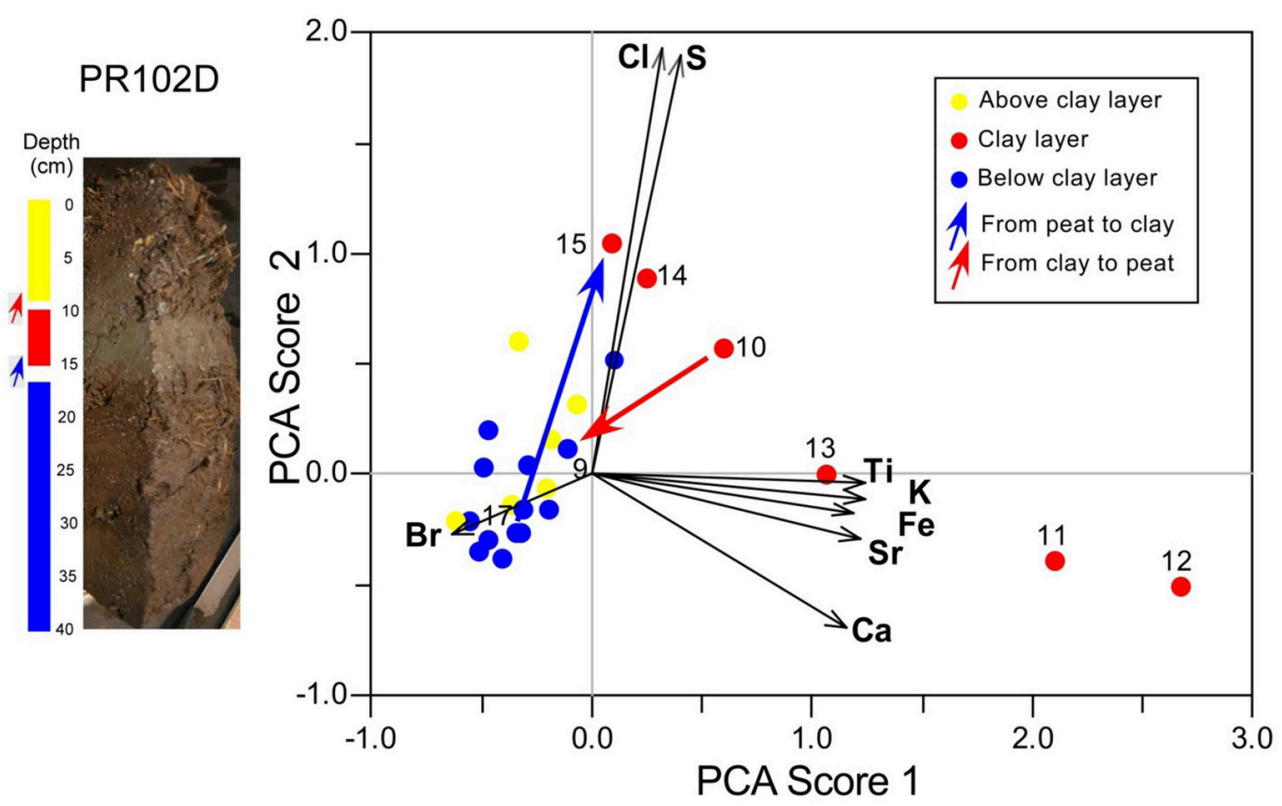

FIGURE 9 | PCA biplot of concentrations of selected elements for core PR102D. Samples from the light brown clastic interval (red dots) plot apart from the organic material that comprises underlying (blue dots) and overlying (yellow dots) material, due primarily to increased concentrations of $\mathrm{Ti}, \mathrm{K}, \mathrm{Fe}, \mathrm{Sr}, \mathrm{Ca}, \mathrm{Cl}$, and $\mathrm{S}$, and decreased concentrations of Br. Arrows mark the vector movement at the bottom (blue) and top (red) of the clastic interval. Numbers indicate the depth of the median point of each sample.
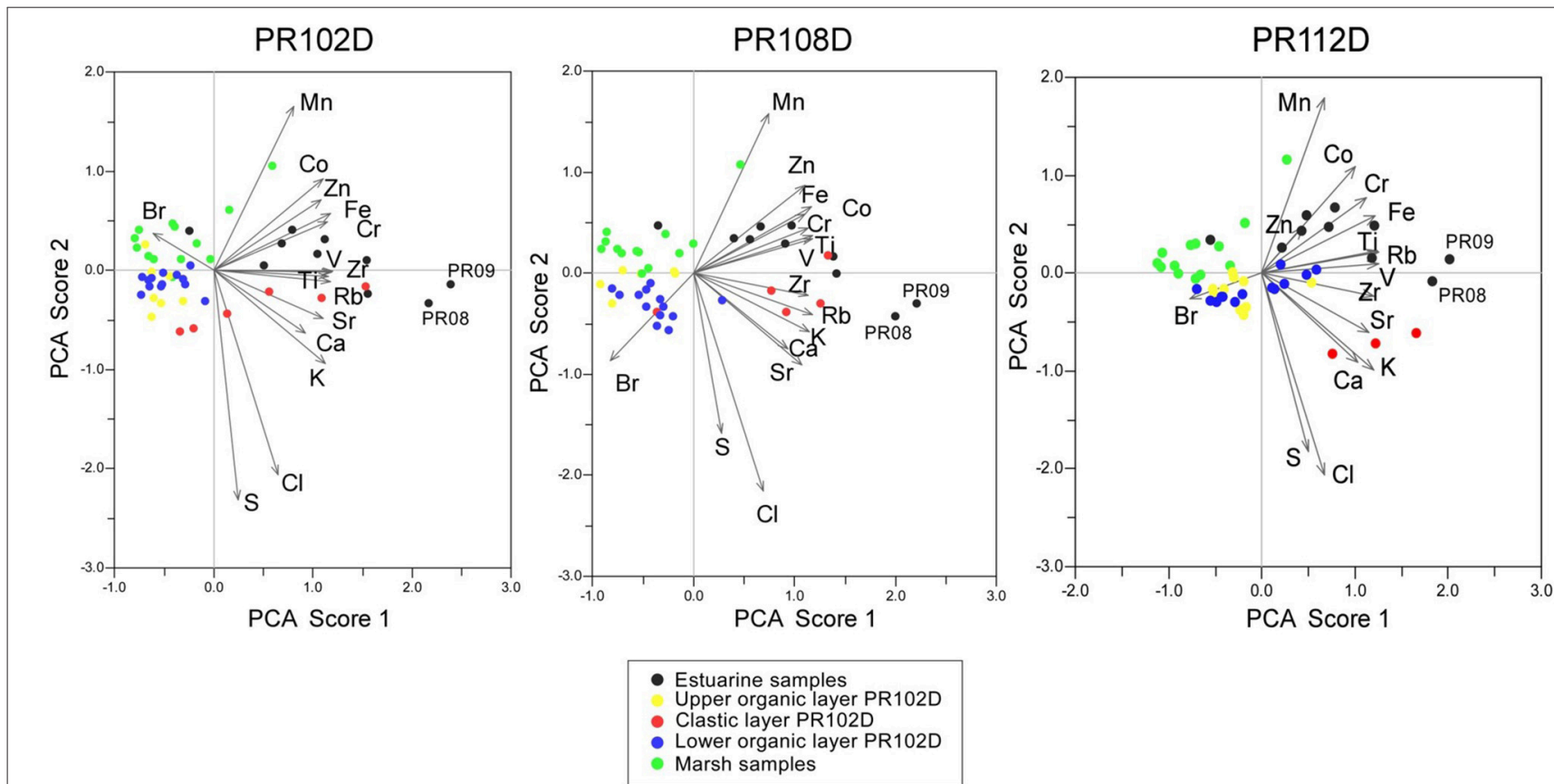

FIGURE 10 | PCA of concentrations of selected elements. PCA biplots for surface samples and cores PR102D, PR108D and PR112D. Note the similarity in ordination space between (1) the elemental concentrations of samples from the clastic layer in cores (red dots) and the estuarine surface samples (black dots), and (2) samples from the organic layer in cores (yellow and blue dots) and the marsh surface samples (green dots). Data from the west-east marsh transect samples are included in the biplots. 

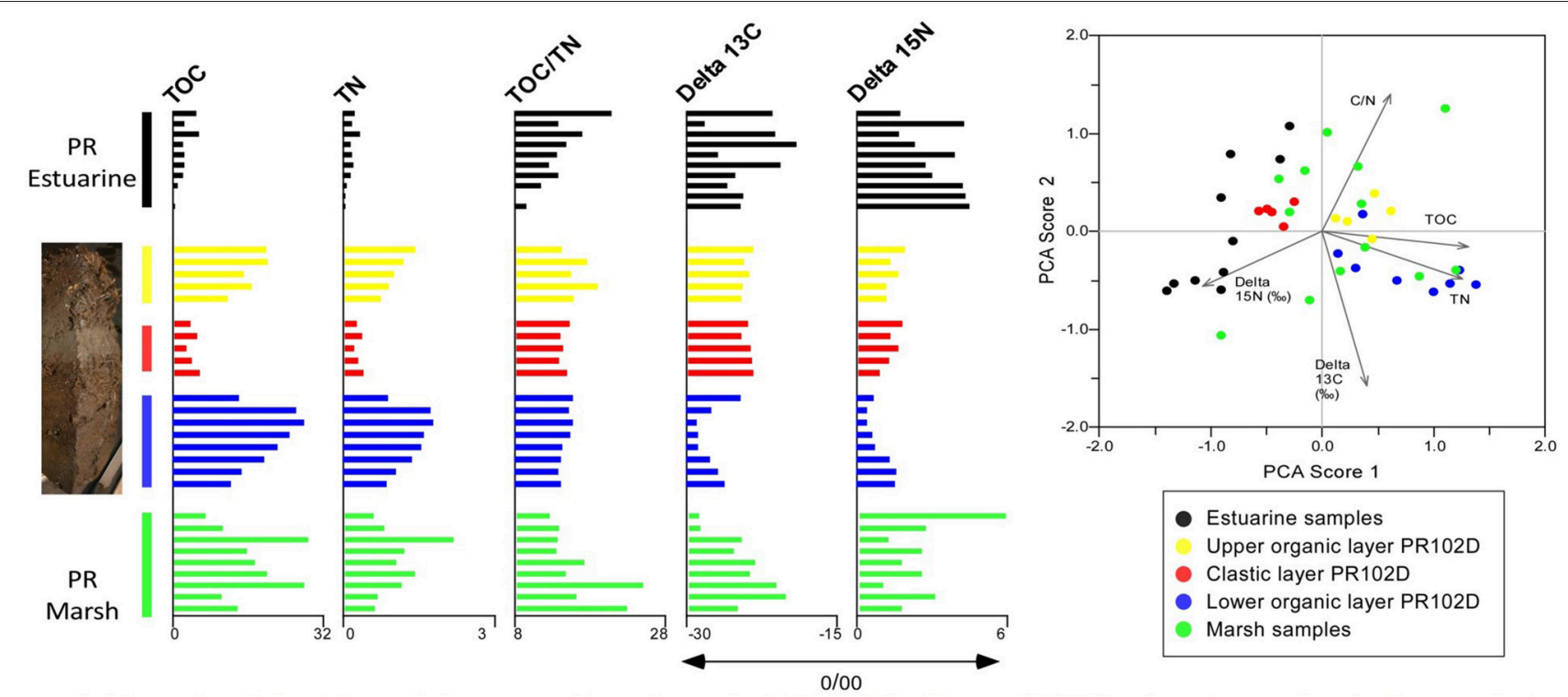

FIGURE 11 | Biogeochemical (carbon and nitrogen) profiles and associated PCA biplots for core PR102D and surface samples. Surface sample data are arranged spatially, as in Figure 2. Similar TOC and TN values drive the grouping of the estuarine samples with the core clastic layer samples in quadrants 3 and 4 , and the marsh samples with the samples from the organic intervals on the core in quadrants 1 and 2 on the PCA biplot. Data from the west-east marsh transect samples are included in the biplot.

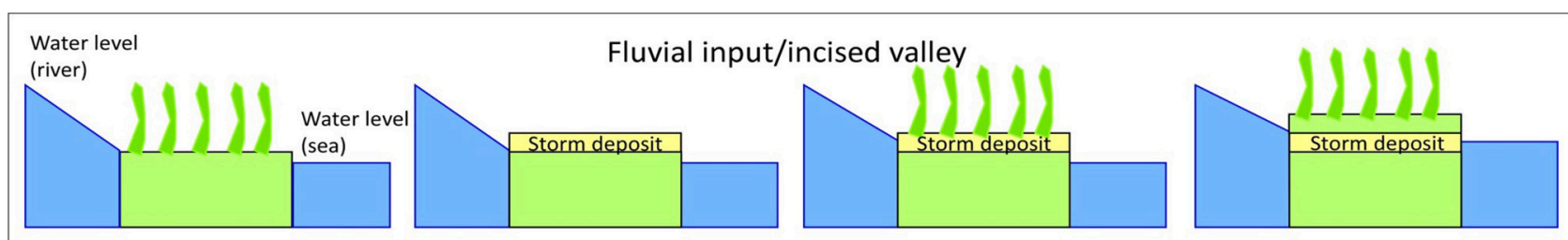

\section{Time}

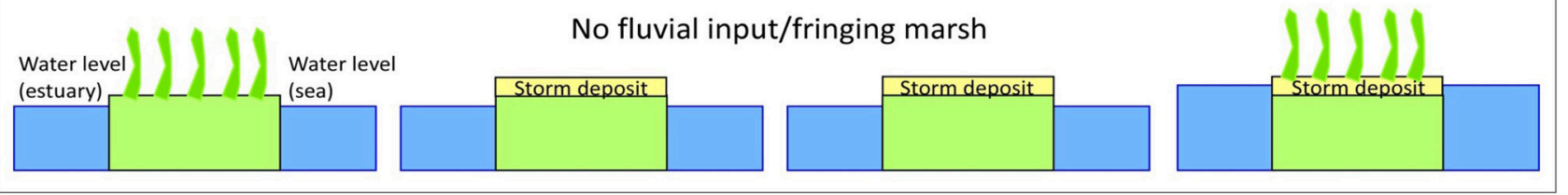

FIGURE 12 | Cartoon of theoretical control exerted by geologic framework over marsh accretion. The bottom displays the potential effect of excessive

hurricane-generated overwash deposits on marsh growth in locations lacking fluvial input (Stagg and Mendelssohn, 2010, 2011; Walters and Kirwan, 2016). In this scenario the increase in platform elevation reduces the hydroperiod enough to prohibit the recovery and regrowth of marsh vegetation. The location remains barren until sea level rises sufficiently to increase hydroperiods beyond the minimum threshold. This process is irrelevant in incised river valleys where fluvial systems with large hydraulic heads can continue to inundate the marsh platform despite thick hurricane-generated overwash deposits (top).

surface, with McKee and Cherry (2009) documenting $25 \mathrm{~g} / \mathrm{m}^{2}$ of root accumulation in the storm layer.

We suggest that the sedimentary, biogeochemical and elemental evidence all indicate that the intermediate unit is allochthonous, composed of large-grained clastic sediments sourced from the river channels or the adjacent estuary.

Combining this information allows us to develop a rather detailed picture of both the deposited material itself and the associated depositional processes. The sediment itself is visually distinct. It is a gray sandy mud, with high concentrations of $\mathrm{S}, \mathrm{Cl}, \mathrm{K}, \mathrm{Ti}, \mathrm{V}, \mathrm{Cr}, \mathrm{Mn}, \mathrm{Fe}, \mathrm{Co}, \mathrm{Zn}, \mathrm{Rb}$, $\mathrm{Sr}$, and $\mathrm{Zr}$, and low levels of $\mathrm{Br}$ heavier $813 \mathrm{C}$ and $815 \mathrm{~N}$ isotopes, and lower TOC, TN, and TOC/TN ratios. The material, although primarily consisting of material resuspended from the nearshore estuarine bottom and/river channels includes low concentrations of marsh material, some of which may have been introduced post-depositionally. The transporting mechanism was the storm surge associated with Hurricane Katrina, possibly including an open marine water component. 


\section{Biogeochemical Effects of the Event Layer}

As with the elemental and sedimentary data, core PR102D can be divided vertically into three distinct units based on the biogeochemical profiles (Figure 6). The upper and lower biogeochemical units are quite similar with respect to TOC and $\mathrm{TN}$ concentration. However, the $\delta^{13} \mathrm{C}$ signature is quite different in the top and bottom sections of the core, with the upper marsh resembling the intermediate clastic unit (Figure 6). Although microbial processing of the organic carbon during burial could explain the difference, the effect is thought to be small (Khan et al., 2015). The dissimilarity between the $\delta^{13} \mathrm{C}$ of the modern marsh and underlying marsh may result from mechanical and/or chemical causes. The TOC, TN, ${ }^{210} \mathrm{~Pb}$, and ${ }^{40} \mathrm{~K}$ (probably representing clay concentration) profiles all show evidence of mixing (gradual secular change), perhaps indicating that the clastic deposit was originally thicker and that sediment has been vertically reworked, probably through bioturbation. Under this scenario, the heavier $\delta^{13} \mathrm{C}$ signature in the near-surface material merely reflects the vertical diffusion of the event layer material. Another possibility is that significant change in the biological assemblage occurred at this site, as occurred in Louisiana marshes following Hurricane Andrew (1992) (Guntenspergen et al., 1995). These changes could be driven either by the vagaries of vegetative recolonization, or as a result of altered edaphic conditions, as the mineral sediment likely increased soil aeration and the availability of essential nutrients. Whatever the cause of the altered isotopic signature, the marsh quickly re-established, and, as evidenced by increasing TOC and TN values, began to again accumulate organic matter, with the allochthonous material driving increased production, as occurred at the adjacent site where standing live biomass and the accretion rates both increased relative to pre-storm values (McKee and Cherry, 2009).

\section{Accretion Rates}

The depth of the Hurricane Katrina layer provides a means of directly determining the accretion that occurred in the 10 years between the passage of the storm (August 2005) and the extraction of the cores (September 2015). The top of the Katrina layer occurs at depths of $7,9,10,10,12$, and $13 \mathrm{~cm}$ in the six cores, or an average of $10 \mathrm{~cm}$, yielding an average accretion rate of $\sim 1 \mathrm{~cm} /$ year, reduced to 0.8 to $0.9 \mathrm{~cm} /$ year if the overlying $1-2 \mathrm{~cm}$ thick organic clay layer, representing post-event settling (Reese et al., 2008) is attributed to the storm. If the Katrina layer itself is included, average accretion since 2005 is $1.4 \mathrm{~cm} /$ year, as the bottom of the layer occur at an average depth of $14 \mathrm{~cm}$. The postmodern radiocarbon date $(>1950 \mathrm{AD})$ at $75 \mathrm{~cm}$ from our long core PR102R yields a minimum accretion rate of 1.15 $\mathrm{cm} /$ year for the last 65 years, while the ${ }^{137} \mathrm{Cs}$ profile for PR102D, which indicates that the oldest possible date at $37.5 \mathrm{~cm}$ is 1963 , produces a minimum accretion rate of $0.71 \mathrm{~cm} /$ year. Accretion rates from a transect of cores extracted in 2008 within a few $100 \mathrm{~m}$ of PR102D are between 0.4 and $0.7 \mathrm{~cm} /$ year (Yeager et al., 2012). Together these rates narrowly bracket the accretion rates recorded from the five Coastwide Reference Monitoring System (CRMS) (Figure S7) stations situated in the Pearl River marsh (https://lacoast.gov/crms/), which range from 0.56 to 1.28 $\mathrm{cm} /$ year (Table S2).
Although these accumulation rates are above the rate of local relative sea level rise $(0.47 \mathrm{~cm} /$ year at $\mathrm{New}$ Canal, La; and $0.41 \mathrm{~cm} /$ year at Bay Waveland, MS) (http://tidesandcurrents. noaa.gov/sltrends/sltrends.html), this does not insure that the Pearl River marsh will maintain its elevation above sea level. Accretion does not directly correspond to surface elevation increase, as subsidence can lower the platform upon which the marsh is accreting. As a result, even marshes with extremely high accretion rates can experience submergence under rapid subsidence (Nyman et al., 1993). Because CRMS station use a rod surface elevation table (RSET), driven to refusal in the underlying substrate (below the marsh sediments), to measure both surface elevation changes and accretion rates, shallow subsidence rates can be calculated. (See Figure S7, or Stagg et al., 2013 for detailed explanation of CRMS operational processes). These records show that all five Pearl River CRMS stations display positive surface elevation changes, with accretion rates surpassing subsidence rates (Table S2). Submerged vulnerability index (SVI) values are also calculated for each station. Index values, based on the relationship between surface elevation change, measured water level and sea level rise rates, project the vulnerability of submergence for each site. Values range from 0 to 100 , representing the percentage of time each site will be above water level during the following five years. All of the Pearl River sites have high SVI values, indicating a high probability for the continued existence of the marsh.

The sustainability of the marsh at our site has been aided by the sediments deposited by Hurricane Katrina. Beyond the immediate benefit of increased surface elevation, the addition of such elements as $\mathrm{Fe}$ and $\mathrm{Mn}$ may aid plant growth over a longer period (Gambrell and Patrick, 1978; McKee and Cherry, 2009). If, as our evidence indicates, this material originated in the river/estuarine bottom, this represents a net gain at our site, as this material would otherwise never have entered the marsh platform. As a marsh as a whole, the overall net gain/loss depends on the balance between deposition and erosion, which we have not assessed, and which will, of course, vary between storms.

\section{Recent Acceleration of Accretion Rates}

This high potential for the long-term survival of the Pearl River marsh is driven by the high current accretion rates. However, we find that long-term sedimentation rates are as much as an order of magnitude lower than current accumulation rates. Sedimentation rates were calculated for both a published core (Li-1994) extracted $\sim 600 \mathrm{~m}$ from PR102 by Li (1994), covering the period from $\sim 200$ to 6700 calendar year before present (BP) and the long core PR102R, with dated material extending to $>5,000 \mathrm{BP}$. Plotting the PR102R data with the postmodern date of $1950 \mathrm{AD}$ as the surface level, the chronologies for the two cores are nearly identical (Figure S8), indicating strong replicability/validity of the data. Sedimentation rates were calculated between each set of radiocarbon dates for both cores. These rates range from 0.06 to $0.25 \mathrm{~cm} /$ year, with an overall average of $0.11 \mathrm{~cm} /$ year for Li-1994, and from 0.9 to $0.11 \mathrm{~cm} /$ year, with an overall average of $0.10 \mathrm{~cm} /$ year for PR102R.

Several possible explanations for the large discrepancy between modern and long-term rates exist. Lithologic changes, 
reflecting significant changes in the depositional environment, can result in vastly different sedimentation rates. However this does not explain the high modern rates for these cores. Although the gross lithologic change from clay to peat occurs at $\sim 450 \mathrm{~cm}$ in Li-1994, the sedimentation rate decreases immediately above that point, with the core's lowest rate $(0.06 \mathrm{~cm} /$ year $)$ occurring in the organic section from $\sim 1100$ to $200 \mathrm{BP}$. The same clay to peat transition occurs $\sim 215 \mathrm{~cm}$ depth in PR102R, with a rate of $0.10 \mathrm{~cm} /$ year between that point (median date 1,275 $\mathrm{BP}$ ) and the postmodern sample.

Anthropogenic activities (deforestation, land clearing, urbanization, construction, etc.) can increase sediment delivery to downstream sites. However, the impact of these processes, although unquantified by us, are likely minor at our site as the Pearl River basin remains relatively undeveloped; 58\% is forested and $12 \%$ is wetlands, with only $25 \%$ agricultural and 2\% urban/suburban (Ward et al., 2005). Agricultural activity, through the release of fertilizer, can potentially increase productivity downstream, thereby leading to an uptick in organic accumulation rates. However, the $\delta^{15} \mathrm{~N}$ profile suggests that this is not occurring here, as the $\delta^{15} \mathrm{~N}$ value for the marsh sites, especially PR100, the most upstream site, and therefore the most likely to be affected by agricultural runoff, has $\delta^{15} \mathrm{~N}$ values higher than those associated with commercial fertilizers, which typically fall within a narrow range around 0 , with $80 \%$ measuring between -2 and 2\%o (Bateman and Kelly, 2007). However, the level and direction of fractionation by the macrophytes is unknown. In any event, the 33,000-acre Ross Barnett Reservoir upstream of the East/West River split has likely reduced both sediment and nutrient supply to the marsh since its construction in the 1960s (Cooper and Knight, 1985).

Growth faults (coast-parallel-extensional faults at continental margins), may have contributed to the increased rate by increasing accommodation space. But, not only has the growth fault adjacent to PR102D been active for at least the last 3,700 years, the recorded slip rates $(0.1 \mathrm{~cm} /$ year over the last 1,300 years, and $0.02 \mathrm{~cm} /$ year over the last 3,700 years) (Yeager et al., 2012) are too low to significantly drive the acceleration of the accretion rate. Autocompaction, the reduction in sediment volume resulting from the weight of the overlying material, is another possible explanation for the low sedimentation rates in the lower sections of the cores. This also seems insufficient to explain the rate changes, as autocompaction rates are generally on the order of $\sim 0.01-0.06 \mathrm{~cm} /$ year (Horton and Shennan, 2009; Brain et al., 2012), with higher rates occurring where thick clastic layers compress the underlying peat (Törnqvist et al., 2008), which is the reverse of the Pearl River stratigraphy. Applying the correction for autocompaction (following the procedures of Bird et al., 2004), to PR102R only increases the overall accretion rate from 0.10 to 0.13 . Due to the lack of detailed lithologic information we were not able to perform autocompaction corrections for Li-1994.

These mitigating processes, even combined, are insufficient to explain the large modern jump in accretion rates, which has likely occurred fairly recently. Both our study and that by Yeager et al. (2012), found that accretion rates were higher when calculated from the $\sim 50$ year ${ }^{137} \mathrm{Cs}$ chronology than when calculated from the $\sim 100$ year ${ }^{210} \mathrm{~Pb}$ chronology, perhaps indicating rate accelerating within very recent times. For PR102R, there has been a notable increase in accretion rates during the last century with rates of 0.1 to $0.13 \mathrm{~cm} /$ year for the period $1,275 \mathrm{BP}$ to early/mid Twentieth century, 0.41 to $0.71 \mathrm{~cm} /$ year for mid to late Twentieth century, and $>1 \mathrm{~cm} / \mathrm{y}$ since roughly the start of the Twenty-First century.

The geologic framework of the Pearl River valley offers a possible explanation for the recent increase in accretion rates. This hypothesis is based on the idea that rising sea levels, combined with high riverine discharge, have increased hydroperiods across the marsh, resulting in lusher vegetation (Nyman et al., 2006), increased biomass and rapid organic deposition. Elevated sea levels have driven increased marine flooding across the marsh, with, due to the lateral topographic constraints and the large hydrological head, no decrease in freshwater flooding from the Pearl River. This bimodal inundation increases marsh accretion in a number of ways. Inorganic deposition is increased due to delivery of mineral sediments from both the up- and down-stream sources, while flocculation spikes as a result of the increased mixing of fresh and marine waters. Plant growth is encouraged by increased hydroperiods, with the fluvial input eliminating/reducing hypersaline conditions.

This hydrological framework is especially important as it relates to the effects of large storms. Studies (Stagg and Mendelssohn, 2010, 2011; Walters and Kirwan, 2016) have shown that thick clastic deposition can negatively affect marsh vegetative growth by reducing hydroperiods. While this is an important control on accretion in marshes located along the open coast, it is irrelevant in incised river valleys such as Pearl River. Fluvial input, and therefore, sufficient soil moisture, will continue in such locations despite large increases in marsh surface elevations, due to the hydrologic head associated with continental watersheds. In such areas, unlike fringing marshes with little or no fluvial input, vertical accretion resulting from the reestablishment, growth and deposition of organic material can continue unabated even after the deposition of thick storm layers. A diagram depicting this process is displayed in Figure 12.

It is likely that similar conditions exist within the numerous incised river valleys intersecting the northern Gulf of Mexico. These sedimentological and hydrological parameters, which differ significantly from those occurring in the more commonly studied fringing coastal marshes, likely result in a unique set of responses to sea level rise. This emphasizes the need to better understand the processes controlling marsh development for such environments and further refine sea-level acceleration thresholds that can result in baywide backstepping (e.g., Rodriguez et al., 2010; Simms and Rodriguez, 2014, 2015).

\section{AUTHOR CONTRIBUTIONS}

TM, CS, and KL designed the project. TM and PN conducted the fieldwork. TM conducted the majority of the laboratory work and wrote the first draft of the manuscript, with major input from CS. All authors contributed to the analysis and synthesis of the data and the development of the conceptual framework and conclusions. 


\section{FUNDING}

This project was supported by the United States Geological Survey's St Petersburg Coastal and Marine Science Center and the Mendenhall Fellowship program.

\section{ACKNOWLEDGMENTS}

The authors would like to thank the staff at Louisiana Department of Wildlife and Fisheries and the Pearl River Wildlife Management Area for their assistance in this project. We would

\section{REFERENCES}

Allison, M. A., Demas, C. R., Ebersole, B. A., Kleiss, B. A., Little, C. D., Meselhe, E. A., et al. (2012). A water and sediment budget for the lower Mississippi-Atchafalaya River in flood years 2008-2010: implications for sediment discharge to the oceans and coastal restoration in Louisiana. J. Hydrol. 432-433, 84-97. doi: 10.1016/j.jhydrol.2012.02.020

Allison, M. A., and Meselhe, E. A. (2010). The use of large water and sediment diversions in the lower Mississippi River (Louisiana) for coastal restoration. J. Hydrol. 3-4, 346-360. doi: 10.1016/j.jhydrol.2010. 04.001

Anderson, J. B., Wallace, D. J., Simms, A., and Rodriguez, A. B. (2016). Recycling sediments between source and sink during a eustatic cycle: systems of late Quaternary northwestern Gulf of Mexico Basin. Ear. Sci. Rev. 153, 111-138. doi: 10.1016/j.earscirev.2015.10.014

Appleby, P. G. (2001). "Chronostratigraphic techniques in recent sediments," in Tracking Environmental Change Using Lake Sediments, eds W. M. Last and J. P. Smol (Dordrecht: Springer), 171-203. doi: 10.1007/0-306-47669-x_9.

Barras, J. A. (2006). Land area changes in coastal Louisiana after the 2005 Hurricanes: a series of three maps. U.S. Geologic Survey Open-File Report 06-1274. doi: 10.3133/ofr20061274

Bateman, A. S., and Kelly, S. D. (2007). Fertilizer nitrogen isotope signatures. Isot. Environ. Healt. S 43, 237-247. doi: 10.1080/10256010701550732

Bender, M. A., Knutson, T. R., Tuleya, R. E., Sirutis, J. J., Vecchi, G. A., Garner, S. T., et al. (2010). Modeled impact of anthropogenic warming on the frequency of intense Atlantic hurricanes. Science 327, 454-458. doi: 10.1126/science.1180568

Bera, G., Yeager, K. M., and Shiller, A. M. (2018). Whether hurricane Katrina impacted trace metal and dioxin depositional histories in marshes of St. Louis Bay, Mississippi. Sci. Total Environ. 624, 517-529. doi: 10.1016/j.scitotenv.2017.12.156

Berg, R. (2013). Tropical Cyclone Report Hurricane Isaac (AL092012) 21 August - 1 September 2012. Available online at: https:/www.nhc.noaa.gov/data/tcr/ AL092012_Isaac.pdf

Beven, J. L., Avila, L. A., Blake, E. S., Brown, D. P., Franklin, J. L., Knabb, R. D., et al. (2008). Annual summary Atlantic hurricane season of 2005. Mon. Weather Rev. 136, 1109-1173. doi: 10.1175/2007MWR2074.1

Bianchette, T. A., McCloskey, T. A., and Liu, K.-B. (2017). A 7000-year history of coastal environmental changes from Mexico's Pacific coast: a multi-proxy record from Laguna Mitla, Guerrero. Holocene 27, 1214-1226. doi:10.1177/0959683616687379

Binford, M. W. (1990). Calculation and uncertainty analysis of ${ }^{210} \mathrm{~Pb}$ dates for PIRLA project lake sediment cores. J. Paleolimnol. 3, 253-267, doi: $10.1007 /$ bf00219461.

Bird, M. I., Fifield, L. K., Chua, S., and Goh, B. (2004). Calculating sediment compaction for radiocarbon dating of intertidal sediments. Radiocarbon 46, 421-435. doi: 10.1017/S0033822200039734

Blott, S. J., and Pye, K. (2001). GRADISTAT: a grain size distribution and statistics package for the analysis of unconsolidated sediments. Earth Surf. Proc. Land. 26, 1237-1248. doi: 10.1002/esp.261

Blum, M. D., and Roberts, H. D. (2009). Drowning of the Mississippi Delta due to insufficient sediment supply and global sea-level rise. Nat. Geosci. 2, 488-491. doi: 10.1038/NGEO553 also like to thank Elsie McBride, Shelby Stoneburner, Ashlyann Morales, Marci Marot, Max Tuten, Catherine Wheaton, and Alysha Ellis for their work in the field and/or the lab. The comments of three reviewers greatly improved the quality of the article.

\section{SUPPLEMENTARY MATERIAL}

The Supplementary Material for this article can be found online at: https://www.frontiersin.org/articles/10.3389/fevo. 2018.00179/full\#supplementary-material

Brain, M. J., Long, A. J., Woodroffe, S. A., Petley, D. N., Milledge, D. G., and Parnell, A. C. (2012). Modelling the effects of sediment compaction on saltmarsh reconstructions of recent sea-level rise. Earth Planet. Sci. Lett. 345-348, 180-193. doi: 10.1016/j.epsl.2012.06.045

Brand, N. W., and Brand, C. J. (2014). Performance comparison of portable XRF instruments. Geochem. Explor. Environ. Anal. 2014, 125-138. doi: 10.1144/geochem2012-172

Brown, D. P., Beven, J. L., Franklin, J. L., and Blake, E. S. (2010). Annual summary Atlantic hurricane season of 2008. Mon. Weather Rev. 138, 1975-2001. doi: 10.1175/2009MWR3174.1

Cai, H., Lam, N. S. N., Zou, L., and Qiang, Y. (2018). Modeling the dynamics of community resilience to coastal hazards using a Bayesian network. Ann. Am. Assoc. Geogr. 108, 1260-1279. doi: 10.1080/24694452.2017. 1421896

Case, R. A. (1986). Annual summary Atlantic hurricane season of 1985. Mon. Weather Rev. 114, 1390-1405.

Cloern, J. E., Canuel, E. A., and Harris, D. (2002). Stable carbon and nitrogen isotope composition of aquatic and terrestrial plants of the San Francisco Bay estuarine system. Limol. Oceanogr. 47, 713-729. doi: 10.4319/lo.2002.47.3.0713

Colten, C. E., Simms, J. R., Grismore, A. A., and Hemmerling, S. A. (2018). Social justice and mobility in coastal Louisiana, U.S.A. Reg. Environ. Change 18, 371-383. doi: 10.1007/s10113-017-1115-7

Cooper, C. M., and Knight, L. A. Jr. (1985). Macrobethos-sediment relationships in Ross Barnett reservoir, Mississippi. Hydrobiologia 126, 193-197. doi: $10.1007 / \mathrm{BF} 00007496$

Corbett, D. R., and Walsh, J. P. (2015). "210 Lead and ${ }^{137}$ Cesium," in Handbook of Sea-Level Research, eds I. Shennan, A. J. Long, and B. P. Horton (Hoboken, NJ: John Wiley and Sons, Ltd), 361-372. doi: 10.1002/9781118452547

Costanza, R., Mitsch, W. J., and Day, J. W. Jr. (2006). A new vision for New Orleans and the Mississippi delta: applying ecological economics and ecological engineering. Front. Ecol. Environ. 4, 465-472. doi: 10.1890/15409295(2006)4[465:ANVFNO]2.0.CO;2

Couvillion, B. R., Barras, J. A., Steyer, G. D., Sleavin, W., Fischer, M., Beck, H., et al. (2011). Land Area Change in Coastal Louisiana From 1932 to 2010: U.S. Geological Survey Scientific Investigations Map 3164, Scale 1:265,000. 12 p. Available online at: http://pubs.usgs.gov/sim/3164/downloads/SIM3164_Map. pdf.

CPRA (2007). Integrated Ecosystem Restoration and Hurricane Protection: Louisiana's Comprehensive Master Plan for a Sustainable Coast. Avaialable online at: http://sonriswww.dnr.state.la.us/dnrservices/redirectUrl.jsp?dID= 4063376.

CPRA (2012). Louisiana's Comprehensive Master Plan for a Sustainable Coast. Aavailable online at: http://sonriswww.dnr.state.la.us/dnrservices/redirectUrl. jsp?dID=4379731.

CPRA (2013). Consistency With the 2012 Coastal Master Plan: Guidelines for Restoration Projects Receiving State Funding. Available online at: http://coastal. la.gov/wpcontent/uploads/2013/12/MPConsistencyGuidelines112013.pdf.

CPRA (2016). 2017 Coastal Master Plan Process. Available online at: http://coastal. la.gov/a-commonvision/2017-master-plan-update/.

Craft, C., Clough, J., Ehman, J., Joye, S., Park, R., Pennings, S., et al. (2009). Forecasting the effects of accelerated sea-level rise on tidal marsh ecosystem services. Front. Ecol. Environ. 7, 73-78. doi:10.1890/070219 
Cutshall, N. H., Larson, I. L., and Olson, C. R. (1983). Direct analysis of ${ }^{210} \mathrm{~Pb}$ in sediment samples: self-absorption corrections. Nucl. Inst. Methods 26, 309-312. doi: 10.1016/0167-5087(83)91273-5

Dalbom, C., Hemmerling, S., and Lewis, J. (2014). Community resettlement prospects in southeast Louisiana: a multidisciplinary exploration of legal, cultural, and demographic aspects of moving individuals and communities. White Paper Tulane Inst. Water Resour. Law Policy. 1-49. Available Online at: https://thewaterinstitute.org/assets/docs/publications/9_23_2014_ Community-Resettlement-Prospects-in-Southeast-Louisiana.pdf

Das, O., Wang, Y., Donoghue, J., Xu, X., Coor, J., Elsner, J., et al. (2013). Reconstruction of paleostorms and paleoenvironment using geochemical proxies archived in the sediments of two coastal lakes in northwest Florida. Quaternary Sci. Rev. 68, 142-153. doi: 10.1016/j.quascirev.2013.02.014

Day, J. W. Jr., Boesch, D. F., Clairain, E. J., Kemp, G. P., Laska, S. B., Mitsch, W. J., et al. (2007). Restoration of the Mississippi Delta: lessons from Hurricanes Katrina and Rita. Science 315, 1679-1684. doi: 10.1126/science. 1137030

Day, J. W. Jr., Kemp, G. P., Reed, D. J., Cahoon, D. R., Boumans, R. M., Suhayda, J. M., et al. (2011). Vegetation death and rapid loss of surface elevation in two contrasting Mississippi delta salt marshes: the role of sedimentation, autocompaction and sea-level rise. Ecol. Eng. 37, 229-240. doi: 10.1016/j.ecoleng.2010.11.021

Delaune, R. D., Patrick, W. H. Jr., and Buresh, R. J. (1978). Sedimentation rates determined by ${ }^{137} \mathrm{Cs}$ dating in a rapidly accreting salt marsh. Nature 275, 532-533. doi: 10.1038/275532a0

Eleuterius, L. N., and Eleuterius, C. K. (1979). Tide levels and salt marsh zonation. Bull. Mar. Sci. 29, 394-400. doi:

Emanuel, K. A. (2013). Downscaling CMIP5 climate models shows increased tropical cyclone activity over the 21 st century. Proc. Natl. Acad. Sci. U.S.A. 110, 12219-12224. doi: 10.1073/pnas.1301293110

Ferreira, P. A. de L., Figueira, R. C. L., Siegle, E., Neto, N. E. A., Martins, C. de, C., Schettini, C. A. F., et al. (2016). Using a cesium-137 (137Cs) sedimentary fallout record in the South Atlantic Ocean as a supporting tool for defining the Anthropocene. Anthropocene 14, 34-45. doi: 10.1016/j.ancene.2016.06.002

Folk, R. L. (1954). The distinction between grain size and mineral composition in sedimentary-rock nomenclature. J. Geol. 62, 344-359.

Frazier, D. E. (1974). Depositional Episodes: Their Relationship to the Quaternary Stratigraphic Framework in the Northwestern Portion of the Gulf Basin. Austin, TX: Texas Bureau of Economic Geology Circular 74-1. 28.

Gambrell, R. P., and Patrick, W. H. Jr. (1978). "Chemical and microbiological properties of anaerobic soils and sediments", in Plant Life in Anaerobic Environments, eds D. D. Hook, and R. M. M. Crawford (Ann Arbor, MI: Ann Arbor Scientific Publishing, Inc.), 375-423.

Goff, J., Chagué-Goff, C., Nichols, S., Jaffe, B., and Dominey-Howes, D. (2012). Progress in paleotsunami research. Sediment. Geol. 243-244, 70-88. doi: $0.1016 /$ j.sedgeo.2011.11.002

Goodbred, S. L. (1994). Geologic Controls on the Holocene Evolution of an OpenMarine Marsh System Fronting a Shallow-Water Embayment: Waccasassa Bay, West-Central Florida. Masters thesis. St. Petersburg, FL: University of South Florida.

Goodbred, S. L., and Hine, A. C. (1995). Coastal storm deposition: salt-marsh response to a severe extratropical storm, March 1993, west-central Florida. Geology 23, 679-682. doi: 10.1130/0091-7613(1995)023<0679:CSDSMR $>2.3$. $\mathrm{CO} ; 2$

Green, A. C. (2000). The Distribution and Speciation of Mercury in the Pearl River Drainage Basin, Mississippi. Master's thesis. Tuscaloosa, AL: University of Alabama.

Greene, D. L. Jr. (2006). Seismic Stratigraphy and Late Quaternary Evolution of Mobile Bay and Mississippi Sound, Alabama-a Record of Large- and Small-Scale Pluvial Systems Through Multiple Sea-Level Cycles. dissertation. Tuscaloosa, AL: University of Alabama.

Guntenspergen, G. R., Cahoon, D. R., Grace, J., Steyer, G. D., Fournet, S., Townson, M. A., et al. (1995). Disturbance and recovery of the Louisiana coastal marsh landscape from the impacts of Hurricane Andrew. J. Coast. Res. SI 21, 324-339.

Hebert, P. J. (1980). Atlantic hurricane season of 1979. Mon. Weather Rev. 108, 973-990. doi: 10.1175/1520-0493(1980)108<0973:AHSO >2.0.CO;2

Holland, G., and Bruyere, C. L. (2014). Recent intense hurricane response to global climate change. Clim. Dynam. 42, 617-627. doi: 10.1007/s00382-013-1713-0
Horton, B. P., and Shennan, I. (2009). Compaction of Holocene strata and the implications for relative sea level change on the east coast of England. Geology 37, 1083-1086. doi: 10.1130/G30042A.1

Howes, N. C., FitzGerald, D. M., Hughes, Z. J., Georgiou, I. Y., Kulp, M. A., Miner, M. D., et al. (2010). Hurricane-induced failure of low salinity wetlands. Proc.. Natl. Acad. Sci. U.S.A. 107, 14014-14019. doi: 10.1073/pnas.09145 82107

Karimpour, A., Chen, Q., and Twilley, R. R. (2017). Wind wave behavior in fetch and depth limited estuaries. Sci. Rep. 7:40654. doi: 10.1038/srep 40654

Kemp, G. P., Day, J. W., Rogers, J. D., Giosan, L., and Peyronnin, N. (2016). Enhancing mud supply from the Lower Missouri River to the Mississippi River Delta USA: dam bypassing and coastal restoration. Estuar. Coast. Shelf S. 183, 304-313. doi: 0.1016/j.ecss.2016.07.008

Khan, N. S., Vane, C. H., and Horton, B. P. (2015). "Stable carbon isotope and $\mathrm{C} / \mathrm{N}$ geochemistry of coastal wetland sediments as a sea-level indicator," in Handbook of Sea-Level Research, First Edn., eds I. Shennan, A. J. Long, and B. P. Horton (Hoboken, NJ: John Wiley and Sons), 295-311.

Kindinger, J. L., Balson, P. S., and Flocks, J. G. (1994). "Stratigraphy of the Mississippi-Alabama shelf and the Mobile river incised-Valley system," in Incised-Valley Systems: Origin and Sedimentary Sequences, eds R. W. Dalrymple, R. Boyd, and B. A. Zaitlin (Tulsa, OK: Society for Sedimentary Geology Special Publication No. 51), 83-95.

Knabb, R. D., Rhome, J. R., and Brown, D. P. (2005). Tropical Cyclone Report Hurricane Katrina 23-30 August 2005. Available online at: www.nhc.noaa.gov/ data/tcr/AL122005_Katrina.pdf

Lam, N. S., Reams, M., Li, K., Li, C., and Mata, L. (2016). Measuring community resilience to coastal hazards along the northern Gulf of Mexico. Nat. Hazards Rev. 17:04015013. doi: 10.1061/(ASCE)NH.1527-6996.0000193

Lambert, W. J., Aharon, P., and Rodriguez, A. B. (2008). Catastrophic hurricane history revealed by organic geochemical proxies in coastal lake sediments: a case study of Lake Shelby, Alabama (USA). J. Paleolimnol. 39, 117-131. doi: 10.1007/s10933-007-9101-6

Langlois, E., Bonis, A., and Bouzillé, J. B. (2001). The response of Puccinellia maritima to burial: a key to understanding its role in salt-marsh dynamics? J. Veg. Sci. 12, 289-297. doi: 10.2307/3236613

Lawrence, M. B., and Gross, J. M. (1989). Annual summaries Atlantic hurricane season of 1988. Mon. Weather Rev. 117, 2248-2259. doi: 10.1175/15200493(1989)117<2248:AHSO >2.0.CO;2

Leonardi, N., Ganju, N. K., and Fagherazzi, S. (2016). A linear relationship between wave power and erosion determines salt-marsh resilience to violent storms and hurricanes. Proc. Natl. Acad. Sci. U.S.A. 113, 64-68. doi: 10.1073/pnas.1510095112

Li, X. (1994). A 6200-Year Environmental History of the Pearl River Marsh, Louisiana. Dissertation. Baton Rouge, LA: Louisiana State University.

Liu, K.-B., and Fearn, M. L. (2000). Reconstruction of prehistoric landfall frequencies of catastrophic hurricanes in northwestern Florida from lake sediment records. Quaternary Res. 54, 238-245. doi: 10.1006/qres. 2000.2166

Liu, K.-B., McCloskey, T. A., Maiti, K., and Ortego, S. (2014). "Sedimentary signature of Hurricane Isaac in a Taxodium swamp on the western margin of Lake Pontchartrain, Louisiana, USA," in Sediment Dynamics From the Summit to the Sea, eds J. Xu, J., M. A. Allison, S. J. Bentley, A. L. Collins, W. D. Erskine, V. Golosov, A. J., Horowitz, and M. Stone (London: IAHS Publication 367), $421-428$.

Marani, M., D'Alpaos, A., Lanzoni, S., and Santalucia, M. (2011). Understanding and predicting wave erosion of marsh edges. Geophys. Res. Lett. 38:L21401. doi: 10.1029/2011GL048995

McCloskey, T. A., Smith, C. G., Liu, K.-B., Haller, C., and Marot, M. (2018a). How could a freshwater swamp produce a XRF chemical signature characteristic of a saltmarsh? Earth Space Chem. 2, 9-20. doi: 10.1021/acsearthspacechem.7b00098

McCloskey, T. A., Smith, C. G., Liu, K.-B., Nelson, P., McBride, E., and Stoneburner, S. (2018b). Sedimentary Data from the Lower Pearl River, USGS Data Release. doi: 10.5066/P9Y2R3LV

McCurdy, D. E., Grarbarino, J. R., and Mullin, A.H., (2008). Interpreting and Reporting Radiological Water-Quality Data: U.S. Geological Survey Techniques and Methods. Reston, VA: U.S. Geological Survey. 33. 
McKee, K. L., and Cherry, J. A. (2009). Hurricane Katrina sediment slowed elevation loss in subsiding brackish marshes of the Mississippi River Delta. Wetlands, 29, 2-15. doi: 10.1672/08-32.1

Milan, C. S., Swensonm, E. M., Turner, R. E., and Lee, J. M. (1995). Assessment of the 137 Cs method for estimating sediment accumulation rates: Louisiana salt marshes. J. Coastal. Res. 11, 296-307.

Morris, J. T., Barber, D. C., Callaway, J. C., Chambers, R., Hagen, S. C., Hopkinson, C. S., et al. (2016). Contributions of organic and inorganic matter to sediment volume and accretion in tidak wetlands at steady state. Earths Fut. 4, 110-121. doi:10.1002/2015EF000334

Morris, J. T., Sundareshwar, P. V., Nietch, C. T., Kjerfve, B., and Cahoon, D. R. (2002). Responses of coastal wetlands to rising sea level. Ecology 83, 2869-2877. doi: 10.1890/0012-9658(2002)083[2869:ROCWTR]2.0.CO;2

Moser, S. C., Davidson, M. A., Kirshen, P., Mulvaney, P., Murley, J. F., Neumann, J. E., et al. (2014). "Ch. 25: coastal zone development and ecosystems. Climate change impacts in the United States: the third national climate assessment," in U.S. Global Change Research Program, eds J. M. Melillo, T.C. Richmond, and G. W. Yohe (Washington, DC: U. S. Global Change Research Program), 79-618. doi:10.7930/J0MS3QNW

Murakami, H., Wang, Y., Yoshimura, H., Mizuta, R., Sugi, M., Shindo, E., et al. (2012). Future changes in tropical cyclone activity projected by the new high-resolution MRI-AGCM. J. Climate 25, 3237-3260. doi: 10.1175/JCLI-D-11-00415.1

Nyman, J. A., DeLaune, R. D., Roberts, H. H., and Patrick, W. H. Jr. (1993). Relationship between vegetation and soil formation in a rapidly submerging coastal marsh. Mar. Ecol. Prog. Ser. 96, 269-279.

Nyman, J. A., Walters, R. J., DeLaune, R. D., and Patrick, W. H. Jr. (2006). Marsh vertical accretion via vegetative growth. Estuar. Coast. Shelf. S 69, 370-380. doi: 10.1016/j.ecss.2006.05.041

Osgood, D. T., Santos, M., and Zieman, J. (1995). Sediment physico-chemistry associated with natural marsh development on a storm-deposited sand flat. Mar. Ecol-Prog. Ser. 120, 271-283.

Otvos, E. G., and Giardino, M. J. (2004). Interlinked barrier chain and delta lobe development, northern Gulf of Mexico. Sediment. Geol. 169, 47-73. doi: 10.1016/j.sedgeo.2004.04.008

Pasch, R. J., Avila, L. A., and Guiney, J. L. (2001). Annual summary Atlantic hurricane season of 1998. Mon. Weather Rev. 129, 3085-3123. doi: 10.1175/ 1520-0493(2001)129<3085:AHSO >2.0.CO;2

Peterson, C. H., Able, K. W., DeJong, C. F., Piehler, M. F., Simenstad, C. A., and Zedler, J. B. (2008). Practical proxies for tidal marsh ecosystem services: application to injury and restoration. Adv. Mar. Biol. 54, 221-266. doi: 10.1016/S0065-2881(08)00004-7

Preston, T., Sojda, R. S., and Gleason, R. A. (2013). Sediment accretion rates and sediment composition in Prairie Pothole wetlands under varying land use practices, Montana, United States. J. Soil Water Conserv. 68, 199-211. doi: 10.2489/jswc.68.3.199

Rappaport, E. N. (1998). Atlantic season of 1997. Mon. Weather Rev. 127, 2012-2026. doi: 10.1175/1520-0493(1999)127<2012:AHSO >2.0.CO;2

Rasser, M. K., Fowler, N. L., and Dunton, K. H. (2013). Elevation and plant community distribution in a microtidal salt marsh of the Western Gulf of Mexico. Wetlands 33, 575. doi:10.1007/s13157-013-0398-9

Reed, D. J. (1990). The impact of sea-level rise on coastal salt marshes. Prog. Phys. Geog. 14, 465-481. doi: 10.1177/030913339001400403

Reese, C. A., Strange, T. P., Lynch, W. D., and Liu, K.-B. (2008). Geologic evidence of Hurricane Katrina recovered from the Pearl River Marsh, MS/LA. J. Coast. Res. 24, 1601-1607. doi: 10.2112/07-0956.1

Reimer, P. J., Bard, E., Bayliss, A., Beck, J. W., Blackwell, P. G., Bronk Ramsey, C., et al. (2013). IntCal13 and MARINE13 radiocarbon age calibration curves 0-50000 years calBP. Radiocarbon 55, 1869-1887. doi: 10.2458/azu_js_rc.55.16947

Révész, K., Qi, H., and Coplen, T. B. (2012). "Chapter 5: determination of the $\delta^{15} \mathrm{~N}$ and $\delta^{13} \mathrm{C}$ of total nitrogen and carbon in solids; RSIL lab code 1832," in Methods of the Reston Stable Isotope Laboratory, eds K. Révész and T. B. Coplen (Reston, VA:USGS Press), Section C, Stable Isotope-ratio Methods Book 10. Available online at: https://pubs.usgs.gov/tm/2006/tm10c5

Rodgers, B. E., Kulp, M. A., and Miner, M. D. (2009). Late Holocene chronology, origin, and evolution of the St. Bernard Shoals, Northern Gulf of Mexico, USA. Geo Mar. Lett. 29, 379-394. doi: 10.1007/s00367-009-0162-6
Rodriguez, A. B., Simms, A. R., and Anderson, J. B. (2010). Bay-head deltas across the northern Gulf of Mexico back step in response to the $8.2 \mathrm{ka}$ cooling event. Q. Sci. Rev. 29, 3983-3993. doi: 10.1016/j.quascirev.2010.10.004

Saucier, R. T. (1994). Geomorphology and Quaternary Geologic History of the Lower Mississippi Valley, Vol. 1. Vicksburg, MS: U.S. Army Engineer Waterways Experiment Station.

Simms, A. R., and Rodriguez, A. B. (2014). Where do coastlines stabilize following rapid retreat? Geophys. Res. Lett. 41, 1698-1703. doi: 10.1002/2013GL0 58984

Simms, A. R., and Rodriguez, A. B. (2015). The influence of valley morphology on the rates of bayhead delta progradation. J. Sediment. Res. 85, 38-44. doi: $10.2110 /$ jsr.2015.02

Simms, J. (2018). "The vanishing Isle de Jean Charles: a resettlement at the community scale," in Annual Meeting, Association of American Geographers (New Orleans, LA).

Simpson, R. H., Sugg, A. L., and Staff (1970). The Atlantic hurricane season of 1969. Mon. Weather Rev. 984, 293-306.

Smith, C. G., Osterman, L. E., and Poore, R. Z. (2013). An examination of historic inorganic sedimentation and organic matter accumulation in several marsh types within the Mobile Bay and Mobile-Tensaw River Delta region. J. Coast. Res. 63, 68-83. doi: 10.2112/SI63-007.1

Smith, J. E., Bentley, S. J., Snedden, G. A., and White, C. (2015). What role do hurricanes play in sediment delivery to subsiding river deltas? Sci. Rep. Nat. 5:17582. doi: 10.1038/srep 17582

Stagg, C. L., and Mendelssohn, I. A. (2010). Restoring ecological function to a submerged salt marsh. Restor. Ecol. 18, 10-17. doi: $10.1111 / j .1526-100 X .2010 .00718 . x$

Stagg, C. L., and Mendelssohn, I. A. (2011). Controls on resilience and stability in a sediment-subsidized salt marsh. Ecol. Appl. 21, 1731-1744. doi: 10.1890/09-2128.1

Stagg, C. L., Sharp, L. A., McGinnis, T. E., and Snedden, G. A. (2013). Submergence Vulnerability Index development and application to Coastwide Reference Monitoring System Sites and Coastal Wetlands Planning, Protection and Restoration Act projects. U. S. Geological Survey Open-File Report 2013-1163.

Stewart, S. R. (2004). Tropical Cyclone Report Hurricane Ivan 2-24 September 2004. Available online at: https://www.nhc.noaa.gov/data/tcr/AL092004_Ivan.pdf.

Stralberg, D., Brennan, M., Callaway, J. C., Wood, J. K., Schile, L. M., Jongsomjit, D., et al. (2011). Evaluating tidal marsh sustainability in the face of sea level rise: a hybrid modeling approach applied to San Francisco Bay. PLoS ONE 6:e27388. doi: 10.1371/journal.pone.0027388

Sugg, A. L. (1966). The hurricane season of 1965. Mon. Weather Rev. 94, 183-191.

Swarzenski, P. W. (2015). " $210 \mathrm{~Pb}$ Dating," in Encyclopedia of Scientific Dating Methods, eds W. J. Rink, and J. W. Thompson (Dordrecht: Springer), 626-632. doi: 10.1007/978-94-007-6304-3_236.

Törnqvist, T. E., Paola, C., Parker, G., Liu, K-B, Mohrig, D., Holbrook, J. M., et al. (2007). Comment on "Wetland Sedimentation from Hurricanes Katrina and Rita”. Science 316, 201. doi: 10.1126/science. 1136780

Törnqvist, T. E., Wallace, D. J., Storms, J. E. A., Wallinga, J., Van Dam, R. L., Blaauw, M., et al. (2008). Mississippi Delta subsidence primarily caused by compaction of Holocene strata. Nat. Geosci. 1, 173-176. doi: 10.1038/ ngeo129

Turner, R. E., Baustian, J. J., Swenson, E. M., and Spicer, J. S. (2006). Wetland sedimentation from Hurricanes Katrina and Rita. Science 314, 449-452. doi: 10.1126/science.1129116

Turner, R. E., Baustian, J. J., Swenson, E. M., and Spicer, J. S. (2007). Response to comment on "Wetland Sedimentation from Hurricanes Katrina and Rita". Science 316, 201. doi: 10.1126/science. 1136869

Tweel, A. W., and Turner, R. E. (2012). Landscape-scale analysis of wetland sediment deposition from four tropical cyclone events. PLoS ONE 7:e50528. doi: 10.137/journal.pone.0050528

Tweel, A. W., and Turner, R. E. (2014). Contribution of tropical cyclones to the sediment budget for coastal wetlands in Louisiana, USA. Landsc. Ecol. 29, 1083-1094. doi: 10.1007/s10980-014-0047-6

Twilley, R. R., Bentley, S. J., Chen, Q., Edmonds, D. A., Hagen, S. C., Lam, N. S.-N., et al. (2016). Co-evolution of wetland landscapes, flooding, and human settlement in the Mississippi River Delta Plain. Sustain. Sci. 11, 711-731. doi: 10.1007/s11625-016-0374-4 
Van de Plassche, O., Erken, G., van Vliet, F., Brandsa, J.,van der Borg, K., and de Jong, A. F. M. (2006). Salt-marsh erosion associated with hurricane landfall in southern New England in the fifteenth and seventeenth centuries. Geology 34, 829-832. doi: 10.1130/G22598.1

Walling, D. E., and He, Q. (1999). Improved models for estimating soil erosion rates from Cesium-137 measurements. J. Environ. Qual. 28, 611-622. doi: 10.2134/jeq1999.00472425002800020027x

Walters, D. C., and Kirwan, M. L. (2016). Optimal hurricane overwash thickness for maximizing marsh resilience to sea level rise. Ecol. Evol. 6, 2948-2956. doi: $10.1002 /$ ece 3.2024

Ward, G. M., Harris, P. M., and Ward, A. K. (2005). "Gulf Coast rivers of the southeastern United States," in Rivers of North America, eds A. C. Benke, and C. E. Cushing (Cambridge, MA: Academic Press), $125-178$.

Yeager, K. M., Brunner, C. A., Kulp, M. A., Fischerd, D., Feagin, R. A., Schindler, K. J., et al. (2012). Significance of active growth faulting on marsh accretion processes in the lower Pearl River, Louisiana. Geomorphology 153-154, 127-143. doi: 10.1016/j.geomorph.2012. 02.018

Young, I. R., and Verhagen, L. A. (1996). The growth of fetch limited waves in water of finite depth. Part 1. Total energy and peak frequency. Coast. Eng. 29, 47-78. doi: 10.1016/S0378-3839(96) 00006-3
Young, K. E., Evans, C. A., Hodges, K. V., Bleacher, J. E., and Graff, T. G. (2016) A review of the handheld X-ray fluorescence spectrometer as a tool for field geologic investigations on earth and in planetary surface exploration. Appl. Geochem. 72, 77-87. doi: 10.1016/j.apgeochem.2016.07.003

Zhang, X. B., Higgit, D. L., and Walling, D. E. (1990). A preliminary assessment of the potential for using caesium-137 to estimate rates of soil erosion in the Loess Plateau of China. Hydrolog. Sci. J. 35, 243-252. doi: $10.1080 / 02626669009492427$

Disclaimer: Any use of trade, firm, or product names is for descriptive purposes only and does not imply endorsement by the U.S. Government.

Conflict of Interest Statement: The authors declare that the research was conducted in the absence of any commercial or financial relationships that could be construed as a potential conflict of interest.

Copyright (c) 2018 McCloskey, Smith, Liu and Nelson. This is an open-access article distributed under the terms of the Creative Commons Attribution License (CC BY).

The use, distribution or reproduction in other forums is permitted, provided the original author(s) and the copyright owner(s) are credited and that the original publication in this journal is cited, in accordance with accepted academic practice. No use, distribution or reproduction is permitted which does not comply with these terms. 


\title{
Sediment Dynamics of Natural and Restored Bolboschoenus maritimus Saltmarsh
}

\author{
Benjamin W. Taylor*, David M. Paterson and John M. Baxter \\ Sediment Ecology Research Group, School of Biology, Scottish Oceans Institute, University of St. Andrews, St. Andrews, \\ United Kingdom
}

\section{OPEN ACCESS}

Edited by:

Martin Wiggers Skov,

Bangor University, United Kingdom

Reviewed by:

Cai Ladd,

Bangor University, United Kingdom Jordi F. Pagès,

University of Barcelona, Spain

*Correspondence:

Benjamin W. Taylor bwt.bentaylor@gmail.com

Specialty section:

This article was submitted to Conservation,

a section of the journal

Frontiers in Ecology and Evolution

Received: 14 December 2018 Accepted: 07 June 2019

Published: 26 June 2019

Citation:

Taylor BW, Paterson DM and Baxter JM (2019) Sediment Dynamics of Natural and Restored Bolboschoenus maritimus Saltmarsh

Front. Ecol. Evol. 7:237. doi: 10.3389/fevo.2019.00237
Saltmarshes are biogeomorphic ecosystems comprising halophytic plant communities typically located on low energy temperate coasts. Their distribution and structure are controlled by several key drivers, including sediment supply, type of vegetation, elevation, and local hydrodynamics. These dynamic systems are highly vulnerable and estimated to be experiencing annual losses of 1-2\% globally. Past restoration efforts have largely implemented managed realignment strategies, however, examples of, and research on, conservation initiatives employing direct transplantation of saltmarsh vegetation into damaged or receding saltmarsh stands is less common. Here an example of transplantation restoration was investigated to understand its influence on sediment dynamics. Sediment settlement, deposition, and accretion rates of natural and restored vegetation (Bolboschoenus maritimus) and adjacent bare mudflats in a small estuary system were studied across consecutive seasons from summer 2015 to spring 2016 to examine the success of transplantation. Natural areas of $B$. maritimus were shown to be most effective at retaining deposited material, although experiencing the least amount of deposition (an average of $48 \mathrm{~g} / \mathrm{m}^{2}$ per day), accreting by nearly $7.5 \mathrm{~mm}$ over the experimental period. Mudflat areas experienced the most deposition (an average of 322 $\mathrm{g} / \mathrm{m}^{2}$ per day) whilst exhibiting the greatest erosion over the study, a decrease in level of $6 \mathrm{~mm}$. Restored areas experience similar rates of deposition as their natural counterparts, however, did not retain this material as efficiently, presenting an erosion of $1.6 \mathrm{~mm}$. The study indicates certain biogeomorphic processes have been altered within the restored area and beginning to reflect those of the natural area. However, the restored vegetation does not yet fully match the functionality of the natural $B$. maritimus stand, specifically where the natural stand displayed a net accretion of material the restored area did not. Such discrepancies may impact on the continued survival of the restoration site, which may have implications for the potential of transplanting to deliver ecosystem services, such as climate change mitigation through carbon burial.

Keywords: saltmarsh, sediment deposition, accretion, seasonal, restoration

\section{INTRODUCTION}

Saltmarshes are biogeomorphic intertidal ecosystems (Thorne et al., 2014; Schwarz et al., 2015, 2018; Baptist et al., 2016) comprised of halophytic plant communities (Burd, 1989) typically located in the low energy zones of temperate coasts (Allen and Pye, 1992). The current global extent of saltmarsh are estimated to be $54,951 \mathrm{~km}^{2}$ (Mcowen et al., 2017). The location of these coastal 
systems within intertidal zones produces a wide range of ecosystem services of value to society (Barbier et al., 2011; Beaumont et al., 2014; Costanza et al., 2014) and the natural world. Benefits such as, the provision of biodiversity, coastal protection (Costanza et al., 2008) through wave attenuation (Koch et al., 2009), the reduction of hard engineered defense costs (King and Lester, 1995) and climate change mitigation through sequestration and storage of carbon (Chmura et al., 2003; Donato et al., 2011; McLeod et al., 2011; Fourqurean et al., 2012; Burden et al., 2013).

However, coastal wetlands are, globally, among the most vulnerable and threatened ecosystems (Boorman, 2003; Craft et al., 2009; McLeod et al., 2011). Annually, it is estimated between 0.7 and 7\% (McLeod et al., 2011) of intertidal wetlands are lost, of which saltmarshes experience 1 to $2 \%$ of loss (Duarte et al., 2008). Losses are driven by various factors, including direct anthropogenic influences, such as coastal development and altered sediment budgets (Boorman, 2003), and changing abiotic factors, such as relative sea-level rise (RSLR) which threatens to drown vegetation (Thorne et al., 2014; Crosby et al., 2016), where increased RSLR threatens to overcome plant tolerances to inundation in the absence of capacity to accrete on an existing marsh platform. However, it is possible accretion could keep pace or exceed RSLR (Reed et al., 1999; Craft et al., 2009; Kirwan et al., 2016) or landward retreat is possible (Schuerch et al., 2018). The loss of these habitats reduces their natural capital assets value and the beneficial services they deliver, as such investment in their conservation should be desired.

The restoration of saltmarshes has historically been achieved through managed realignment. The intentional flooding of previously claimed coastal areas comes with associated conflicts and risks; such as the loss of productive (valuable) land. Various approaches have been employed to facilitate realignment, including managed tidal regimes (Maris et al., 2007; Masselink et al., 2017), channel network design (Zeff, 1999), and sediment subsidization (Schrift et al., 2008). The continued development of restoration strategies to achieve a diverse range of efficient and economical approaches is crucial. The success of all restoration approaches requires a thorough understanding of the biogeomorphic feedbacks, such as between vegetation, sediment and tidal flow, which govern the development and persistence of a marsh area.

Saltmarsh systems are highly dynamic being controlled and influenced by a variety of abiotic (e.g., elevation, tidal flow, sediment supply) and biotic (e.g., vegetation structure, stem density) factors (van Proosdij et al., 2006). The interplay between these factors produce feedbacks which determine the state of the saltmarsh ecosystem at a given point in time-be that a steadystate dynamic equilibrium, or erosional or accreting condition (Baptist et al., 2016); ultimately this balance determine a marshes persistence or not, contributing to their vulnerability. A major factor in this interaction is sediment supply (van Proosdij et al., 2006), namely the erosion-accretion balance. Sediment deposition is governed by the complex interaction between the availability of sediment and the opportunity for this sediment to be deposited (van Proosdij et al., 2006); the interaction of these variables is worthy of further investigation, specifically the effects on sediment deposition resulting from restoration. Coastal vegetation such as mangroves, seagrasses, and saltmarshes encourage deposition to occur (Bos et al., 2007; Chen et al., 2007) by increasing surface roughness and slowing water flow due to presence of stems and leaves (Boorman, 2003; Bouma et al., 2005; Koch et al., 2009; Mudd et al., 2010; Potouroglou et al., 2017), they also decrease sediment resuspension (Boorman et al., 1998). The erosion-deposition balance is an important ecosystem function that determines the elevation of the marsh platform, facilitating successional development. Pioneer vegetation alters the erosiondeposition balance, through increased surface roughness and interception of suspended sediment particles, which encourages the vertical growth of the marsh platform within the tidal frame. The increased diversity of succession (Boorman, 2003) is typically associated with increases in structural complexity and feedbacks (Kirwan and Megonigal, 2013); through increased surface roughness encouraging accretion and lifting of the marsh platform allowing further plant species to colonize.

Restoration can be approached through direct transplanting of a local species (Sullivan, 2001) onto available mudflat or degraded saltmarsh areas, utilizing the "natural" process associated with pioneer establishment and development by altering the erosiondeposition balance. This encourages the spread of new swards and confers protection to existing marshes, relying upon natural lateral and vertical expansion following plantation. Direct transplanting is realistically achievable at a limited scale due to its labor-intensive process. However, transplanting regimes offer the opportunity to (re)vegetate areas of the existing intertidal zone, thus minimizing land-use conflict. The aim of restoration is to produce an ecologically functional area that replicates the natural system and helps to promote the health of an ecosystem under recognized threat. Such restoration through transplantation has taken place since the start of the millennium on the Eden Estuary (east coast of Scotland; Maynard, 2014). Here, Bolboschoenus maritimus plants are harvested from donor stands within the estuary and transplanted onto selected restoration sites (Maynard, 2014).

Here, we compare the potential sedimentation opportunity (quantity of sediment settling out of suspension) with actual sediment deposition and the resulting net elevation change (accretion); capturing tidal and seasonal influence on this relationship. The aim of the study was to assess if successful restoration activities display altered sediment processes then the adjacent un-vegetated mudflat, and further compare how the current processes differ with existing natural saltmarsh extents. It is hypothesized that, (1) restored areas will experience enhanced deposition than adjacent bare mudflats and (2) areas of vegetation, both natural and restored, will experience greater accretion than bare mudflats.

\section{MATERIALS AND METHODS}

\section{Field Location and Sampling Sites}

The Eden Estuary $\left(56^{\circ} 21^{\prime} 52^{\prime \prime} \mathrm{N}, 2^{\circ} 50^{\prime} 27^{\prime \prime} \mathrm{W}\right)$ is a small mesotidal pocket estuary on the east coast of Scotland, located between the larger Firth of Forth to the south and the Tay estuary to the north, and is situated within the Firth of Tay and Eden Estuary SAC 


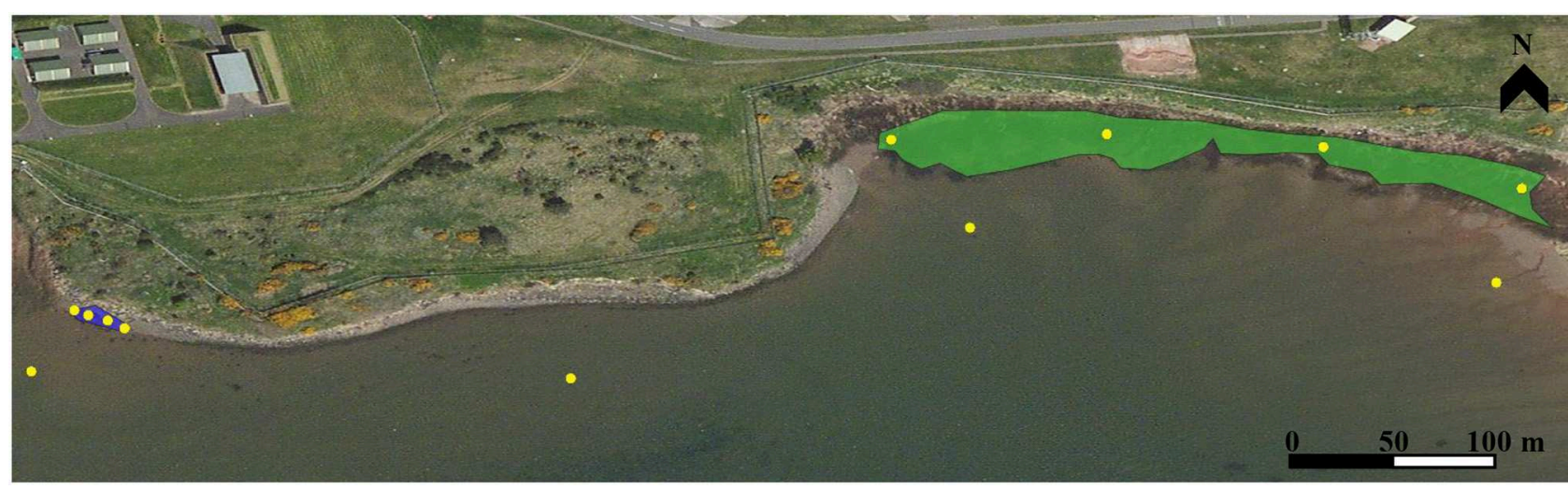

FIGURE 1 | The north shore of the Eden Estuary, Scotland. The green polygon delineates the full extent of the "Natural" saltmarsh, an area of $450 \mathrm{~m}^{2}, \mathrm{made}$ up of a robust bed of $B$. maritimus. The blue polygon delineates the extent of the "Restored" area, a total of $100 \mathrm{~m}^{2}$, consisting of a planted mono-specific stand of B. maritimus. The "Mudflat" area consisted of the entire adjacent fringing edge running along the coast between the extreme ends of the natural and restored vegetated areas. The yellow points are the location of permanent sampling points.

and SPA, it is also designated as a SSSI, Ramsar site and Local Nature Reserve. The sedimentary composition with the estuary is dominated by particles classified as "fine sand" (125 and $250 \mu \mathrm{m}$ ) on the Wentworth scale (Wentworth, 1922), typically ranging between 150 and $200 \mu \mathrm{m}$.

The saltmarshes of the estuary are currently in an unfavorable condition due to coastal erosion and the pressure of extensive coastal defenses (SNH, 2011). Restoration efforts have been implemented to mitigate this degradation and since 2000, Maynard (2014) has been utilizing a "direct transplantation" approach. B. maritimus plants were harvested from donor marshes within the estuary and transplanted onto selected bare upper mudflat sites to encourage the spread of existing marsh as well as produce new swards. In the present study, four permanent sampling points were established in three area types (natural marsh, restored marsh, and natural mudflat; $n=12$, referred to hence as "natural," "restored," and "mudflat") to study the sediment dynamics therein (Figure 1). The study was conducted on the north shore of the estuary, within a confined extent, spanning $\sim 400 \mathrm{~m}$. The "natural" area comprised a robust dense mono-specific stand of $B$. maritimus, at an average elevation of $1.64 \mathrm{~m}$, occupying the upper tidal limits of the intertidal zone. The "restored" area consisted of a mono-specific stand of wellestablished B. maritimus which was planted in 2010 at an average elevation of $1.76 \mathrm{~m}$. The "mudflat" area was an unvegetated area running adjacent to the coast between the two extreme extents of the vegetated areas, at an average elevation of $1.22 \mathrm{~m}$. Tidal inundation was calculated for each area from its known elevation (acquired by relative carrier phase positioning-Leica VIVA GS10 which has $5 \mathrm{~mm}$ horizontal error and $10 \mathrm{~mm}$ vertical error, using $<2 \mathrm{~km}$ baseline) and tide gauge data, contributed by the British Oceanographic Data Center (Leith $-55^{\circ} 59.39^{\prime} \mathrm{N}$, $\left.3^{\circ} 10.902^{\prime} \mathrm{W}\right)$.

\section{Sampling Design}

Sediment deposition and settlement were sampled on 16 occasions over a year period, on each occasion sampling took place at 12 permanent points. Sampling was carried out four times in each season; in summer from 16th to 23rd August 2015, autumn from 13th to 20th November 2015, winter from 10th to 17th February 2016 and spring from 23rd to 30th May 2016. The four sampling occasions in each season spanned across a spring to neap tidal change, beginning on a spring tide. On each occasion, sediment deposition and settlement traps were deployed during low tide and remained exposed for two flood tide events, after which they were retrieved. The next sampling occasion took place the following day at low tide, this was repeated four times each season. Sediment elevation measurements were taken once per season, following the sediment deposition and settlement sampling.

Sampling aimed to capture information on the sediment regime within the study area, where; sediment deposition was actual deposits onto the sediment surface during a sampling period, sediment settlement was the potential amount of sediment which could be deposited during a sampling period and accretion is the expression of the deposition-erosion balance evaluated through measurement of surface elevation change.

\section{Sediment Deposition Measurement}

Deposited sediment was measured using a "sediment trap" as described by Reed (1989), quantifying the passive deposition of material onto the surface of a pre-dry weighted, small pore sized (3-5 $\mu \mathrm{m})$, paper filter disc; paper dried for $24 \mathrm{~h}$ at $\sim 60^{\circ} \mathrm{C}$. The study used a custom designed two-part plastic retaining system (Figure 2) to enhance filter paper retention and facilitate retrieval with minimal risk of sample disturbance. Traps used a $110 \mathrm{~mm}$ filter disc placed between $5 \mathrm{~mm}$ thick PVC base and a $0.25 \mathrm{~mm}$ thick acrylic retention ring with a $90 \mathrm{~mm}$ diameter opening (Figure 2). These were secured into the sediment with four $100 \mathrm{~mm}$ nails through corner holes. Following a $24 \mathrm{~h}$ exposure period, the complete trap was collected, and filter paper removed in the laboratory. Hydrobia sp. were occasionally present on the traps, these were removed using fine forceps, ensuring maximal retention of sediment. Papers were rinsed with distilled water to 

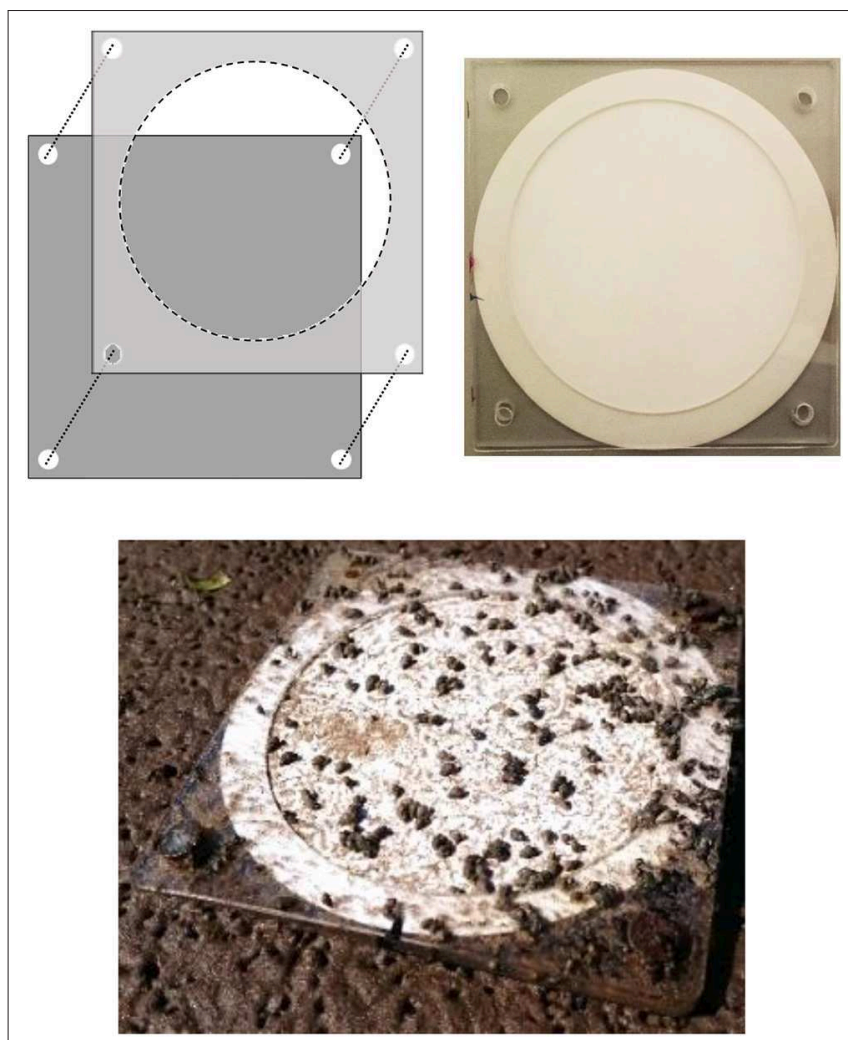

FIGURE 2 | Top left - the deposit trap; upper light gray retention ring holds the filter paper onto the solid dark gray base plate. Four nails are pushed through the corners, affixing to the sediment. Top right - showing trap pre-deployment with filter paper installed. Bottom - showing trap in-situ post exposure with many Hydrobiid snails.

remove salt since initial testing indicated that the presence of salt prevented "ash-less" combustion of the filter paper. Rinsing was completed in two stages; with a first $100 \mathrm{ml}$ wash, followed by a further $50 \mathrm{ml}$ rinse. The filter papers and sediment were transferred to a dried, weighed and labeled aluminum foil dish (57 mm diameter x $13 \mathrm{~mm}$ deep); further distilled water rinsing ensured full sample transfer.

\section{Sediment Settlement Measurement}

Potential sediment for deposition was quantified as the material settling out of suspension during a sampling period, quantified using traps originally designed to measure larval settlement (Todd et al., 2006). Traps were $\sim 300 \mathrm{~mm}$ tall, internally-baffled, tubes with a convex conical top and $10 \mathrm{~mm}$ aperture. At each sample point, a 300 by $68 \mathrm{~mm}$ pipe section was sunk into the sediment, leaving $\sim 50 \mathrm{~mm}$ above of the surface (Figure 3 ). The settlement traps were filled with filtered sea water in the laboratory and affixed with cable ties into the support tubes with the collective aperture positioned $100 \mathrm{~mm}$ above the sediment surface (Figure 3). This placement and design was chosen to reduce disturbance of local hydrodynamics (Nolte et al., 2013), though the low height of the trap and uniform curved surface of the support cage, whilst minimizing the chance of colleting

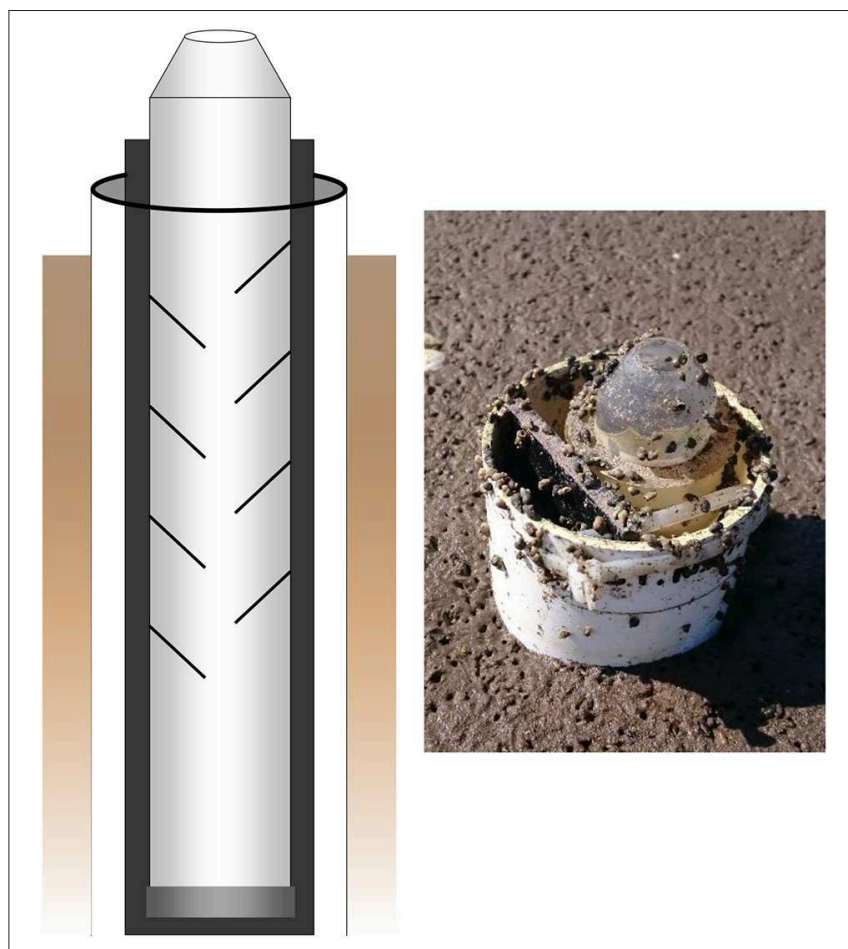

FIGURE 3 | The settlement trap with internal baffles and conical opening. The column is attached to a backing plate (black). In the field this was placed into the sediment, sitting within the illustrated support tube.

resuspended material; thus providing information on sediments settling toward the sediment surface.

Post exposure, tubes were collected and processed in the laboratory. Samples were emptied, by removal of the screwon base. Traps were flushed with distilled water to remove material retained on baffles. Sediment settlement samples were centrifuged at 3,000 rpm for $15 \mathrm{~min}$ and sea water removed using a MORVAC filter pump. The samples were washed twice with distilled water as described above. Once washed, samples were transferred to dried, weighed and labeled aluminum dishes.

\section{Sediment Dry Weight and Organic Content}

Prepared deposit and settlement samples were dried for a minimum of $24 \mathrm{~h}$ at $\sim 60^{\circ} \mathrm{C}$ to remove moisture. Dried samples were placed into a desiccator to cool and then weighed; sediment weight was calculated by removal of aluminum dish weight, and filter paper for deposit samples. Organic content was measured by Loss on Ignition (LOI). Samples were ashed in a muffle furnace at $450^{\circ} \mathrm{C}$ for $6 \mathrm{~h}$, again samples were placed in a desiccator to cool then weighed; remaining sediment weight calculated by removal of aluminum boat weight, for deposit samples it was assumed the filter paper had been fully combusted.

\section{Bed Height Measurements-SEB}

Accretion rate was quantified using a modified Sedimentation Erosion Bar (SEB) (van Wijnen and Bakker, 2001; Nolte et al., 2013), which is based on the Surface Elevation Table as described 
by Boumans and Day (1993). Two $10 \mathrm{~mm}$ reinforced steel bars were sunk $1 \mathrm{~m}$ into the sediment $1.3 \mathrm{~m}$ apart, $\sim 300 \mathrm{~mm}$ above of the surface. The "bar" was a $1.35 \mathrm{~m}$ long, $35 \mathrm{~mm}$ wide, $18 \mathrm{~mm}$ deep metal bar with holes aligned to fit the rods. Along the length of the bar, 11 equally spaced holes provide consistent measurement points. A " $\mathrm{mm}$ " graduated rod was used to measure the distance from the top of the bar to the sediment surface. During measurement trampling near the SEB was avoided so elevation change due natural processes alone were measured.

\section{Elevation to Deposition Conversion}

The possible amount of sediment (gain or loss) which could be expected to result in the measured change in sediment elevation was calculated. To estimate the equivalent sediment weight associated with the change in elevation a conversion was applied using surface layer bulk density values for the study area; vegetated area $=1.45 \mathrm{~g} / \mathrm{cm}^{3}$ and mudflat $=1.30 \mathrm{~g} / \mathrm{cm}^{3}$ (unpublished data, Taylor., 2017). The conversion assumed that the measured elevation change at each sampling point was representative of a $1 \mathrm{~m}^{2}$, applying the bulk density and elevation change to this area provided an estimate of sediment gained or lost.

\section{Statistical Analysis}

Data were analyzed using correlation, linear regression, and analysis of variance (ANOVA) tests to compare relationship between area types and the measured factors and analyses the drivers behind the measured factors.

Tidal inundation period differences between in each area were assessed using linear regression. The influence of tidal inundation on sediment deposition and settlement were then assessed using linear regression.

Correlation between all sediment deposition and settlement quantities at each sampling point for each sampling occasion were assessed. Linear regression was then used to assess how settlement rates and area type influenced measured sediment deposition quantity. The correlation between organic matter content and deposited quantity and settlement quantity were assessed for each sampling point on each sampling occasion.

Further assessment was then made toward understanding deposition rates in the study. ANOVA was used to compare deposition rates found in each area across the study, with Tukey's HSD post-hoc analysis employed to evaluate differences. ANOVA was then used to assess the influence of both area type and season on deposition.

Variables were $\log _{10}$ transformed where statistical tests outcomes breached the required assumptions, primarily nonnormal distribution of test residuals. Deposition and settlement data were standardized to a $1 \mathrm{~m}^{2}$ area, corrected from their 63.62 and $0.78 \mathrm{~cm}^{2}$, respectively.

\section{RESULTS}

\section{Inundation Period}

Over the sampling period there was a significant difference in estimated inundation time between the sites; total inundation times over the sampling period (16 sampling occasions) were, natural $\approx 116 \pm 0.43 \mathrm{~h}$, restored $\approx 109 \pm 0.45 \mathrm{~h}$, and mudflat $\approx 156 \pm 0.24 \mathrm{~h}[F(2,188)=24.87, P<0.001]$.

\section{Tidal Inundation Effect on Deposition and Settlement}

The influence of tidal inundation on the availability of potential sediment for deposition, as measured using the settlement tubes, was compared across the year. The dry weight of sediment and the inundation time for each point was examined to assess the relationship between these variables. Linear regression demonstrated a significant relationship $(p<0.001)$ between inundation period and the amount of settled sediment $\left(r^{2}=\right.$ 0.23 ). There was an average sediment settlement rate of $1.35 \mathrm{~g}$ per hour of inundation $/ \mathrm{m}^{2}$.

Deposition rates were also compared against tidal inundation period, again assessing the total dry weight of sediment deposited and the total inundation period for each sampling point. A linear regression analysis showed there to be a significant relationship $\left(p<0.001, r^{2}=0.17\right)$, as found with settlement rate. There was an average sediment deposition rate of $1.01 \mathrm{~g}$ per hour of inundation $/ \mathrm{m}^{2}$.

\section{Sediment Deposition and Settlement Rates}

In some instances, the sediment deposited on the filter papers was below the level of detection (39 of 512 samples, 7.6\%), and these were assigned a zero-deposition value. One deposit trap of the 194 deployed was lost during the study, due to interference by a wading bird.

There was a significant positive correlation between potential deposition (sediment settlement) and deposited material $\left(r_{\mathrm{s}}=\right.$ $0.672, p<0.001)$. To account for possible sampling area effects (i.e., $1 \mathrm{~cm}$ diameter aperture vs. $9 \mathrm{~cm}$ diameter filter paper) data were standardized to $1 \mathrm{~m}^{2}$, averaged in each area type across each sampling occasion $(n=48)$. These standardized data displayed a similar significant positive correlation between potential (sediment settlement) and deposited material $\left(r_{\mathrm{s}}=\right.$ $0.759, p<0.001)$, where deposition explained $55 \%$ of the variance $\left[F_{(1,46)}=58.57, p<0.0001\right]$, with the relationship $(\log )$ deposited sediment weight per $m^{2}=-3.65+0.9851^{*}(\log )$ settlement weight per $m^{2}$.

This significant relationship between potential deposition and deposited material holds true within each area (Figure 4). A linear regression model assessed the influence of the interaction of settlement quantity, areas type and season on deposition $\left[F_{(23,24)}=5.345, p<0.0001\right]$, which explained $68 \%$ of the variance in deposition; the significant interaction in the model was season:area type $(p=0.0028)$. Across seasons and areas, on average, more material was deposited on traps than collected in settling columns. An average difference of $0.16 \mathrm{~g}$ ( $115 \%$ more), $0.13 \mathrm{~g}$ (33\% more), and $1.44 \mathrm{~g}$ (239\% more) for natural, restored and mudflat areas was found, respectively.

When assessing the organic content (\%) of deposits against the total amount of deposited sediment (dry weight, g) there was a weak positive correlation $\left(r_{\mathrm{s}}=0.195, p=0.0068\right)$, however, for the amount of sediment caught (dry weight, $g$ ) in settlement traps there was a strong negative correlation with organic content (\%) $\left(r_{\mathrm{s}}=-0.48, p<0.001\right)$. The percentage of organic matter present 

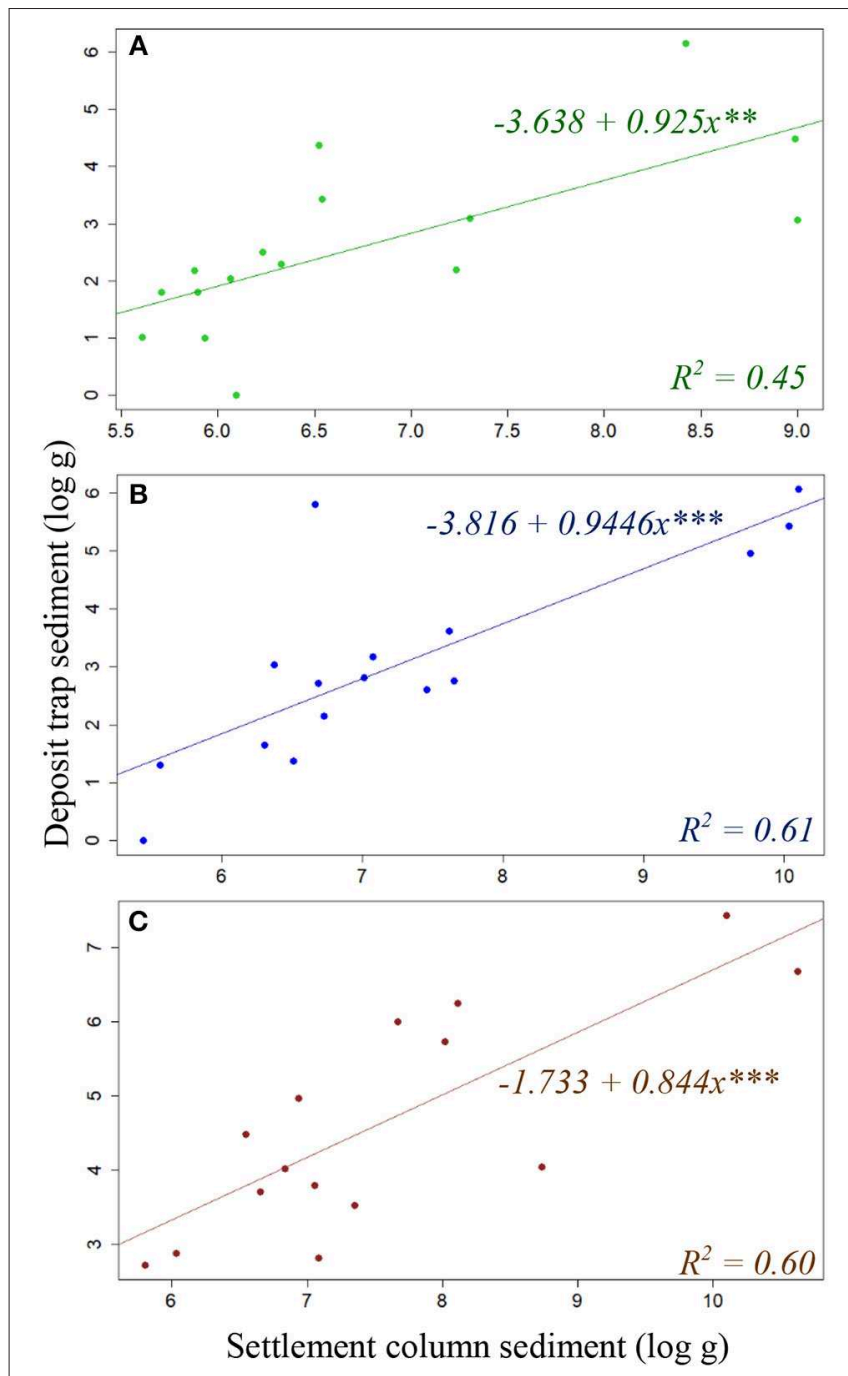

FIGURE 4 | Sediment settlement and deposit dry weights across seasons for each area, corrected to $1 \mathrm{~m}^{2}$ equivalent, each point is averaged value of single sampling occasion. (A) Natural (green), (B) Restored (blue), (C) Mudflat (brown). Displaying linear regression trend line and equations for each area,

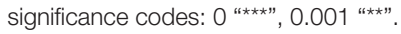

in sediment deposits differed between area and season (Figure 5). The natural area of $B$. maritimus had consistently higher organic content in deposited material than either the restored area or mudflat. The restored area although presenting lower organic content values than the natural vegetation, was generally greater than the adjacent mudflat, with an annual percentage average difference of nearly $3 \%$. All areas displayed the same relationship with the seasons, organic content declining from a peak in summer through to winter then increasing again in spring.

\section{Deposition Rates in Different Areas and Seasons}

The rates of deposition measured between areas were significantly different [ANOVA $F_{(2,189)}=16.67, p<0.001$ ]

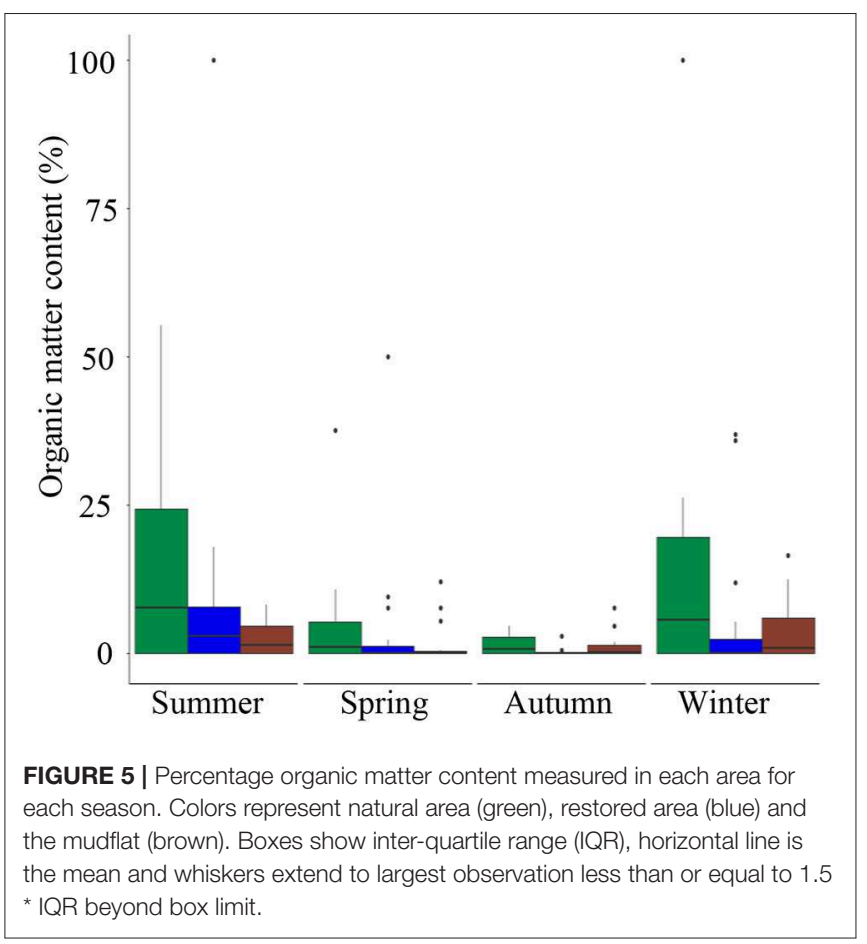

(Figure 6). Tukey's HSD indicated significant differences between deposition rates over the mudflat and natural area (diff. $=3.27, p<0.001$ ) and mudflat and restored vegetation (diff. $=$ 2.87, $p<0.001)$. There was no significant difference between natural and restored area deposition rates $(p=0.792)$. Overall sediment deposition rates between seasons were found to be significantly different $\left[F_{(3,187)}=7.99, p<0.001\right]$. However, a Tukey's HSD indicated that the only significant differences occur between spring and autumn (diff. $=-2.30, p=0.0019$ ) and spring and winter (diff. $=-2.68, p=0.00108$ ); all other comparisons between seasons did not significantly differ in their sediment deposition rates.

The influence of area type and season on deposition rates were assessed together to understand which of these factors was most influential in terms of sediment deposition rates. An ANOVA of deposition rate with season and area type (as independent variables) explained $34 \%$ of the variance in deposition rates measured $\left[F_{(11,179)}=8.31, p<0.001\right]$. The natural stand typically exhibited significantly different deposition rates across seasons (summer $p=0.021$, autumn $p=0.030$, spring $p=$ $0.009)$. The restored site shows significant differences in spring $(p<0.001)$ and winter $(p=0.001)$, and mudflat areas were significantly different in autumn $(p=0.012)$.

\section{Comparison of Sediment Elevation Changes}

The natural area was the only area which displayed a net positive elevation change during the study (Figure 7), an average of $7.5 \mathrm{~mm}$ increase. The restored and mudflat areas both experienced a net lowering in elevation of 1.6 and $6.0 \mathrm{~mm}$, respectively (Figure 7). Measured elevation changes highlighted 


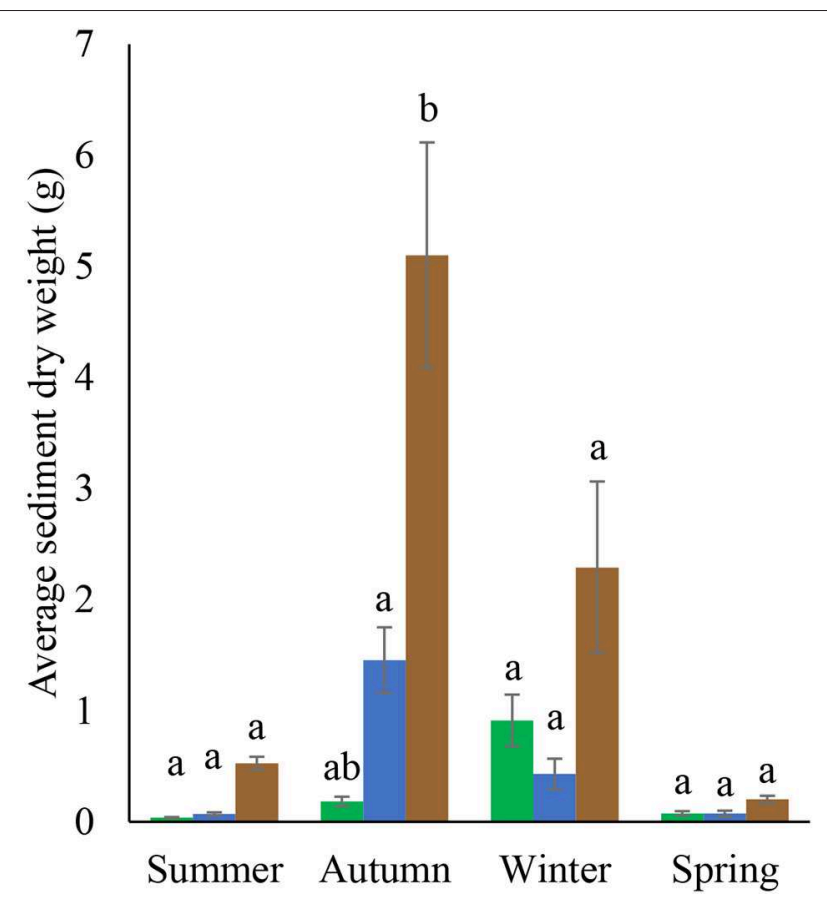

FIGURE 6 | Averaged sediment deposition (dry weight in grams) quantities measured in each area during each season. The average in each area was calculated from samples collected at four points on four occasions ( $n=16$ per area). Letters show significant differences between sediment deposition across each area and season. Colors represent natural area (green), restored area (blue), and the mudflat (brown).

a discontinuity between rates of deposition and accretion. A comparison of potential total dry weight depositional accumulation and converted elevation changes to equivalent sediment weights shows large differences between potential accretion and actual retention (Table $\mathbf{1}$ ). There was a pronounced difference between vegetated and mudflat areas in terms of sediment retention during the study. Mudflats attracted over four times more deposition than the vegetated zones, though mudflat rate of loss was greater than for both vegetated areas (Table 1). The natural areas experienced the least potential accretion input (lowest measured deposition rate) (Figure 6) but retained more material (reduced erosion rates) than other areas; retaining an estimated $6.3 \%$ of deposited material (Table 1). A comparison of the calculated difference between an assumed constant-deposition-no-erosion and converted actual elevation change shows areas of vegetation to be more similar than the unvegetated mudflat area, which displayed the greatest difference of an estimated $118 \mathrm{~kg} / \mathrm{m}^{2}$ discrepancy over the study (Table 1).

\section{DISCUSSION}

Saltmarsh restoration and conservation is of increasing importance under the present threat of loss and increasing future risk (Boorman, 2003; Craft et al., 2009; McLeod et al., 2011). The restoration of saltmarsh areas through direct transplanting offers possible opportunities to diversify conservation initiatives

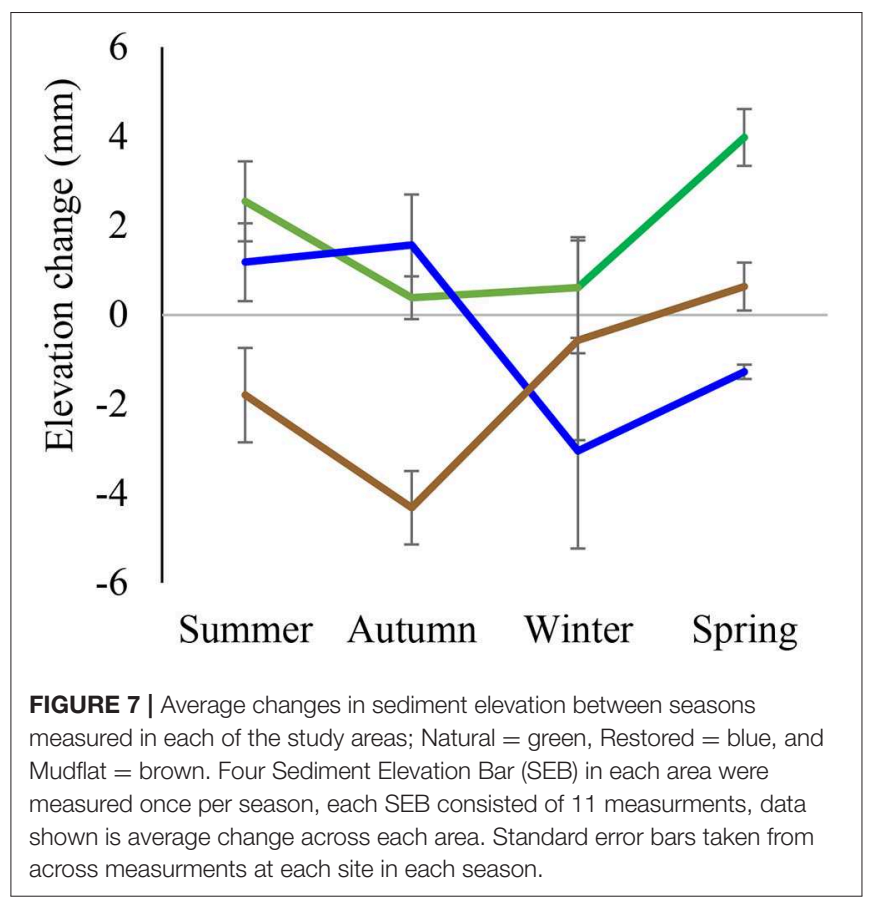

TABLE 1 | Estimate of sediment deposition dry weight taken from deposition rate data (assuming a constant accretion and full sediment retention) and actual elevation change (applying a bulk density conversion to generate a dry weight) and the difference in assumed constant deposited accretion and actual accumulation rates.

\begin{tabular}{|c|c|c|c|}
\hline Area & $\begin{array}{c}\text { Deposition total } \\
\left(\mathrm{kg} / \mathrm{m}^{2}\right)\end{array}$ & $\begin{array}{l}\text { Calculated } \\
\text { retention }\left(\mathrm{kg} / \mathrm{m}^{2}\right)\end{array}$ & $\begin{array}{c}\text { Difference } \\
\left(\mathrm{kg} / \mathrm{m}^{2}\right)\end{array}$ \\
\hline Natural & 17.39 & 1.09 & -16.3 \\
\hline Restored & 29.17 & -0.23 & -29.4 \\
\hline Mudflat & 117.39 & -0.78 & -118.2 \\
\hline
\end{tabular}

beyond typical managed realignment projects. This study shows that restored marshes have the potential to trap sediment as effectively as natural analogs, however restored marshes failed to retain that sediment sufficiently to raise elevation at equivalent rates to natural marshes by the end of the study. It was hypothesized that restored areas would experience enhanced deposition over the adjacent bare mudflat, however, the study showed that this was not the case, with both vegetated (natural and restored) areas experiencing less sediment deposition than the mudflat. It was further hypothesized that the vegetated areas would experience greater rates of accretion, which is partly correct, with the only increase in elevation found in the natural area and the restored area experiencing less elevation loss than the mudflat. The study took advantage of a valuable opportunity to study the effects of saltmarsh restoration as compared to its natural donor marsh within a relatively spatially discreet area. The study was restricted to the estuarine area where restoration and natural stands were present, ideally exposed to similar environmental conditions. However, this restriction limited site availability, so preventing site-level replication and resulting in 
the mudflat being $\sim 40 \mathrm{~cm}$ lower than the vegetated areas which may influence the sediment dynamics studied; these limitations are acknowledged but are not considered to undermine the value of this comparative study.

\section{Deposition and Elevation Trends}

Rates of deposition within vegetated areas (both natural and restored) were shown to be lower than those measured on the mudflat (Figure 6). The similar deposition rates of the restored and natural areas suggest that, although higher in the tidal frame and so experiencing different tidal inundation, the restored area was functionally similar from the perspective of deposition rates and the organic content of deposits. This study focused on deposition onto the sediment platform, but it is possible that sediment intercepted and retained by vegetative structures eventually enhance overall sediment surface deposition and accretion, which is not purposefully measured here. Over the study period the natural stand of vegetation showed an increased sediment elevation (Figure 7), showing a consistent trend of accretion, with the mudflat displaying the greatest loss in elevation of $6.0 \mathrm{~mm}$ (Figure 7); highlighting a discontinuity between deposition rates and the resulting changes in sediment elevation. The studied restored area was well-established and appears to be persisting, but does not appear to have achieved the same sediment retention capacity, possibly a result of the limited size of the sward so reducing the conferred protection to sediment resuspension or a product of its different exposure within the tidal frame. However, the study indicates the restored area has shifted from the more dynamic state of the adjacent mudflats (Bouma et al., 2016), which experienced significantly greater deposition and the greatest net erosion. Vegetated areas were shown to be accretionary or substantially less erosional than the unvegetated mudflat area. The restored site, which previously is assumed to closely reflect the bare mudflat condition, now occupies a "middle ground" between the dynamic mudflat and the accretional natural vegetation.

\section{Settlement, Deposition, and Erosion/Accretion Relationships}

Analysis suggests that area type has limited influence over the settlement-deposition relationship, as indicated by the similar regression relationships for each area; perhaps driven by broader scale forces, such as tidal flow. The two vegetated areas show that higher proportions of the "potential sediment" supply are deposited at any given time point. The slightly lower explained variance in the natural area suggests different factors could influence the relationship between potential deposition and realized deposition in this area. It is likely that characteristics such as elevation (flood height) and vegetative structure should be considered in understanding the settlementdeposition relationship. The link between settlement (potential deposition) and actual deposition is one factor which can influence the persistence saltmarsh system; however, this study suggests that resulting accretion rates could play a greater role.

The deposition-erosion balance reported in the restored area differs from that of the local natural area, such that there was a net loss of material over the study, a trend which may have the greatest adverse effect on the persistence of the restored area. If the trend of elevation loss recorded in this short-term study reflect that of the continued long-term situation of the marsh area, coupled with RSLR, could leave such areas vulnerable to drowning. It will be important to monitor these interactions and feedbacks and assess how these alter as the restoration matures and expands laterally. The differing mechanisms behind sediment accretion acting within the natural and restored area are not readily revealed by this study. Investigation into drivers of sediment retention in each of the areas studied could facilitate improved restoration approaches, to deliver resilient sites which maintain themselves within a tidal frame; such as tidal range (inundation frequency) (van Wijnen and Bakker, 2001; Mudd et al., 2009; Kirwan et al., 2010), suspended sediment concentrations (Kirwan et al., 2010), and elevation (Crooks et al., 2002).

\section{Organic Matter Input Trends}

The data suggested there is little input of organic matter into this benthic system via settling sediment, where the suspended load seems dominated by material lower in organic content, however, the organic content of deposited material was higher. This proportionally greater organic matter content measured in deposits indicates the depositional processes favored the retention of organic matter relative to the potential deposition material. In the case of the natural area, where higher organic content coupled with net vertical accretion, there is potential for such vegetated intertidal areas to act as sites of carbon burial. The study showed the restored area to also retain higher quantities of organic matter in deposits, though experienced a net loss in elevation. If the development of the restored area led to the net accretion of sediment, this would likely deliver ecosystem services, such as carbon sequestration (Burden et al., 2013).

The seasonal relationship with organic matter highlights the possible importance of allochthonous material in the estuary. In the "growing" months of summer and spring there is a larger quantity of organic matter being deposited in all areas; likely a result of increased organic matter availability from plant growth, both within the estuary and from alluvial-terrestrial inputs. However, the change between the seasons is far greater in the vegetated areas, with a maximum difference of $14.2 \%$ in the natural area and $10.3 \%$ in the restored area; compared to a $2.7 \%$ change on the mudflat. This variance illustrates the functional capacity of vegetative structures, which encourage the deposition and retention of finer organic particles through flow retardation. This characteristic may a provide crucial feedback mechanism as the restored area continues to develop, increasing the organic content of the sediment bed during critical growth phases and so enhancing growth capacity.

\section{CONCLUSION}

It is not yet clear how the current sedimentary interactions will affect the long-term survival and evolution of this site, specifically the persistence of the restored area. Although 
the data suggests the site of restoration is experiencing a different biogeomorphic situation compared to the bare mudflat, which is assumed to reflect its previous state, this situation does not yet mirror its natural counterpart. This study illustrates the subtleties of saltmarsh development and feedbacks, highlighting the importance of site selection in restoration activities. The "established" appearance of the restored planted saltmarsh disguises its possible vulnerability in dynamic sedimentary interactions leading to net erosion across the site.

The high cost/effort to size ratio of direct planting makes it important to minimize the risks of failure of any project through a continued improvement of our understanding of interactions between vegetation and sediment resulting from restoration (Maynard, 2014). This study has highlighted the possible vulnerability of restored areas, which may visually appear established, but whose processes do not indicate a robust ecosystem; specifically, net elevation loss during the study. The delay for restoration to achieve comparable ecological functionality to natural areas is important to consider when carrying out restoration projects and may require additional effort once established to ensure their persistence; for example, increased planting effort to continue natural expansion. Such information could advance approaches and maximize the delivery of conservation objectives which are crucial to prevent the loss of these systems.

\section{REFERENCES}

Allen, J. R. L., and Pye, K. (1992). Saltmarshes: Morphodynamics, Conservation and Engineering Significance. Cambridge: Cambridge University Press.

Baptist, M. J., de Groot, A. V., and van Duin, W. E. (2016). Contrasting biogeomorphic processes affecting salt-marsh development of the Mokbaai, Texel, The Netherlands. Earth Surf. Process. Landforms 41, 1241-1249. doi: 10.1002/esp.3949

Barbier, E. B., Hacker, S. D., Kennedy, C., Koch, E. W., Stier, A. C., and Silliman, B. R. (2011). The value of estuarine and coastal ecosystem services. Ecol. Monogr. 81, 169-193. doi: 10.1890/10-1510.1

Beaumont, N. J., Jones, L., Garbutt, A., Hansom, J. D., and Toberman, M. (2014). The value of carbon sequestration and storage in coastal habitats. Estuar. Coast. Shelf Sci. 137, 32-40. doi: 10.1016/j.ecss.2013.11.022

Boorman, L. (2003). Saltmarsh review: an overview of coastal saltmarshes, their dynamic and sensitivity characteristics for conservation and management. JNCC Rep. 334:132.

Boorman, L. A., Garbutt, A., and Barratt, D. (1998). The role of vegetation in determining patterns of the accretion of salt marsh sediment. Sediment. Process. 139, 389-399. doi: 10.1144/GSL.SP.1998.139.01.29

Bos, A. R., Bouma, T. J., de Kort, G. L. J., and van Katwijk, M. M. (2007). Ecosystem engineering by annual intertidal seagrass beds: sediment accretion and modification. Estuar. Coast. Shelf Sci. 74, 344-348. doi: $10.1016 /$ j.ecss.2007.04.006

Bouma, T. J., De Vries, M. B., Low, E., Kusters, L., Herman, P. M. J., Tánczos, I. C., et al. (2005). Flow hydrodynamics on a mudflat and in salt marsh vegetation: identifying general relationships for habitat characterisations. Hydrobiologia 540, 259-274. doi: 10.1007/s10750-004-7149-0

Bouma, T. J., van Belzen, J., Balke, T., van Dalen, J., Klaassen, P., Hartog, A. M., et al. (2016). Short-term mudflat dynamics drive long-term cyclic salt marsh dynamics. Limnol. Oceanogr. 61, 2261-2275. doi: 10.1002/lno.10374

Boumans, R., and Day, J. W. (1993). High precision measurements of sediment elevation in shallow coastal areas using a sedimentation-erosion table. Estuaries 16, 375-380. doi: $10.2307 / 1352509$

\section{AUTHOR CONTRIBUTIONS}

BT carried out collection and analysis of samples used toward completion of this research and completed the written output of this article. DP and JB provided significant input into the planning and design of the research and valuable insight and development during the creation of the manuscript.

\section{FUNDING}

The authors received funding from the MASTS pooling initiative (The Marine Alliance for Science and Technology for Scotland) and Scottish Natural Heritage (SNH), their support is gratefully acknowledged. MASTS is funded by the Scottish Funding Council (grant reference HR09011) and contributing institutions.

\section{ACKNOWLEDGMENTS}

Thanks to the UK Tide Gauge Network for tide date, provided through the British Oceanographic Data Center. Thanks also goes to Dr. Clare Maynard for her past and continuing efforts to restore the saltmarshes of the Eden Estuary, on which this study is based. Finally, thank you to SNH and Fife Coast and Countryside Trust for their helpful input and permissions to carry out the research.

Burd, F. (1989). The Saltmarsh Survey of Great Britain - An Inventory of British Saltmarshes. Nature Conservancy Council, Peterborough. doi: 10.1007/s13398-014-0173-7.2

Burden, A., Garbutt, R., a., Evans, C. D., Jones, D. L., and Cooper, D. M. (2013). Carbon sequestration and biogeochemical cycling in a saltmarsh subject to coastal managed realignment. Estuar. Coast. Shelf Sci. 120, 12-20. doi: 10.1016/j.ecss.2013.01.014

Chen, S.-N., Sanford, L. P., Koch, E. W., Shi, F., and North, E. W. (2007). A nearshore model to investigate the effects of seagrass bed geometry on wave attenuation and suspended sediment transport. Estuar. Coasts 30, 296-310. doi: 10.1007/BF02700172

Chmura, G., Anisfeld, S., Cahoon, D. R., and Lynch, J. (2003). Global carbon sequestration in tidal, saline wetland soils. Global Biogeochem. Cycles 17:1111. doi: 10.1029/2002GB001917

Costanza, R., de Groot, R., Sutton, P., van der Ploeg, S., Anderson, S. J., Kubiszewski, I., et al. (2014). Changes in the global value of ecosystem services. Glob. Environ. Change 26, 152-158. doi: 10.1016/j.gloenvcha.2014.04.002

Costanza, R., Pérez-Maqueo, O., Martinez, M. L., Sutton, P., Anderson, S. J., and Mulder, K. (2008). The value of coastal wetlands for hurricane protection. AMBIO 37, 241-248. doi: 10.1579/0044-7447(2008)37[241:TVOCWF]2.0. $\mathrm{CO} ; 2$

Craft, C., Clough, J., Ehman, J., Joye, S., Park, R., Pennings, S., et al. (2009). Forecasting the effects of accelerated sea-level rise on tidal marsh ecosystem services. Front. Ecol. Environ. 7, 73-78. doi: 10.1890/070219

Crooks, S., Schutten, J., Sheern, G. D., Pye, K., and Davy, A. J. (2002). Drainage and elevation as factors in the restoration of Salt Marsh in Britain. Restor. Ecol. 10, 591-602. doi: 10.1046/j.1526-100X.2002.t01-1-02036.x

Crosby, S. C., Sax, D. F., Palmer, M. E., Booth, H. S., Deegan, L. A., Bertness, M. D., et al. (2016). Salt marsh persistence is threatened by predicted sea-level rise. Estuar. Coast. Shelf Sci. 181, 93-99. doi: 10.1016/j.ecss.2016. 08.018

Donato, D. C., Kauffman, J. B., Murdiyarso, D., Kurnianto, S., Stidham, M., and Kanninen, M. (2011). Mangroves among the most carbon-rich forests in the tropics. Nat. Geosci. 4, 293-297. doi: 10.1038/ngeo1123 
Duarte, C. M., Dennison, W. C., Orth, R. J. W., and Carruthers, T. J. B. (2008). The charisma of coastal ecosystems: addressing the imbalance. Estuar. Coasts 31, 233-238. doi: 10.1007/s12237-008-9038-7

Fourqurean, J. W., Duarte, C. M., Kennedy, H., Marbà, N., Holmer, M., Mateo, M. A., et al. (2012). Seagrass ecosystems as a globally significant carbon stock. Nat. Geosci. 5, 505-509. doi: 10.1038/ngeo1477

King, S. E., and Lester, J. N. (1995). The value of salt marsh as a sea defence. Mar. Pollut. Bull. 30, 180-189. doi: 10.1016/0025-326X(94)00173-7

Kirwan, M. L., Guntenspergen, G. R., D’Alpaos, A., Morris, J. T., Mudd, S. M., and Temmerman, S. (2010). Limits on the adaptability of coastal marshes to rising sea level. Geophys. Res. Lett. 37:L23401. doi: 10.1029/2010GL045489

Kirwan, M. L., and Megonigal, J. P. (2013). Tidal wetland stability in the face of human impacts and sea-level rise. Nature 504, 53-60. doi: 10.1038/nature12856

Kirwan, M. L., Temmerman, S., Skeehan, E. E., Guntenspergen, G. R., and Faghe, S. (2016). Overestimation of marsh vulnerability to sea level rise. Nat. Clim. Change 6, 253-260. doi: 10.1038/nclimate2909

Koch, E. W., Barbier, E. B., Silliman, B. R., Reed, D. J., Perillo, G. M. E., Hacker, S. D., et al. (2009). Non-linearity in ecosystem services: temporal and spatial variability in coastal protection. Front. Ecol. Environ. 7, 29-37. doi: $10.1890 / 080126$

Maris, T., Cox, T., Temmerman, S., De Vleeschauwer, P., Van Damme, S., De Mulder, T., et al. (2007). Tuning the tide: creating ecological conditions for tidal marsh development in a flood control area. Hydrobiologia 588, 31-43. doi: 10.1007/s10750-007-0650-5

Masselink, G., Hanley, M. E., Halwyn, A. C., Blake, W., Kingston, K., Newton, T., et al. (2017). Evaluation of salt marsh restoration by means of selfregulating tidal gate - Avon estuary, South Devon, UK. Ecol. Eng. 106, 174-190. doi: 10.1016/j.ecoleng.2017.05.038

Maynard, C. (2014). Restoring the Degraded Shoreline. St. Andrews; Boca Raton, FL: University of St. Andrews.

McLeod, E., Chmura, G., and Bouillon, S. (2011). A blueprint for blue carbon: toward an improved understanding of the role of vegetated coastal habitats in sequestering $\mathrm{CO}_{2}$. Front. Ecol. 9, 552-560. doi: 10.1890/110004

Mcowen, C. J., Weatherdon, L. V., Bochove, J.-W., Van Sullivan, E., Blyth, S., Zockler, C., et al. (2017). A global map of saltmarshes. Biodivers. Data J. 5:e11764. doi: 10.3897/BDJ.5.e11764

Mudd, S., Howell, S., and Morris, J. (2009). Impact of dynamic feedbacks between sedimentation, sea-level rise, and biomass production on near-surface marsh stratigraphy and carbon accumulation. Estuar. Coast. Shelf Sci. 82, 377-389. doi: 10.1016/j.ecss.2009.01.028

Mudd, S. M., D’Alpaos, A., and Morris, J. T. (2010). How does vegetation affect sedimentation on tidal marshes? Investigating particle capture and hydrodynamic controls on biologically mediated sedimentation. J. Geophys. Res. Earth Surf. 115:F03029. doi: 10.1029/2009JF001566

Nolte, S., Koppenaal, E. C., Esselink, P., Dijkema, K. S., Schuerch, M., De Groot, A. V., et al. (2013). Measuring sedimentation in tidal marshes: a review on methods and their applicability in biogeomorphological studies. J. Coast. Conserv. 17, 301-325. doi: 10.1007/s11852-013-0238-3

Potouroglou, M., Bull, J. C., Krauss, K. W., Kennedy, H. A., Fusi, M., Daffonchio, D., et al. (2017). Measuring the role of seagrasses in regulating sediment surface elevation. Sci. Rep. 7:11917. doi: 10.1038/s41598-017-12354-y

Reed, D. J. (1989). Patterns of sediment deposition in subsiding coastal salt marshes, Terrebonne Bay, Louisiana: the role of winter storms. Estuaries 12, 222-227. doi: 10.1007/BF02689700

Reed, D. J., Spencer, T., Murray, A. L., French, J. R., and Journal, S. (1999). Marsh surface sediment deposition and the role of tidal creeks: implications for created and managed coastal marshes. J. Coast. Conserv. 5, 81-90.
Schrift, A. M., Mendelssohn, I. A., and Materne, M. D. (2008). Salt marsh restoration with sediment-slurry amendments following a droughtinduced large-scale disturbance. Wetlands 28, 1071-1085. doi: 10.1672/ 07-78.1

Schuerch, M., Spencer, T., Temmerman, S., Kirwan, M. L., Wolff, C., Lincke, D., et al. (2018). Future response of global coastal wetlands to sea-level rise. Nature 561, 231-234. doi: 10.1038/s41586-0180476-5

Schwarz, C., Bouma, T. J., Zhang, L. Q., Temmerman, S., Ysebaert, T., and Herman, P. M. J. (2015). Interactions between plant traits and sediment characteristics influencing species establishment and scale-dependent feedbacks in salt marsh ecosystems. Geomorphology 250, 298-307. doi: 10.1016/j.geomorph.2015. 09.013

Schwarz, C., Gourgue, O., van Belzen, J., Zhu, Z., Bouma, T. J., van de Koppel, J., et al. (2018). Self-organization of a biogeomorphic landscape controlled by plant life-history traits. Nat. Geosci. 11, 672-677. doi: 10.1038/s41561-018-0180-y

SNH (2011). Eden Estuary Site of Special Scientific Interest. Cupar: Site Management Statement.

Sullivan, G. (2001). "Establishing vegetation in restored and created coastal wetlands," in Handbook for Restoring Tidal Wetlands, ed B. Zedler (Boca Raton, FL: CRC Press), 119-156.

Thorne, K. M., Elliott-Fisk, D. L., Wylie, G. D., Perry, W. M., and Takekawa, J. Y. (2014). Importance of biogeomorphic and spatial properties in assessing a tidal salt marsh vulnerability to sea-level rise. Estuar. Coasts 37, 941-951. doi: 10.1007/s12237-013-9725-x

Todd, C. D., Phelan, P. J. C., Weinmann, B. E., Gude, A. R., Andrews, C., Paterson, D. M., et al. (2006). Improvements to a passive trap for quantifying barnacle larval supply to semi-exposed rocky shores. J. Exp. Mar. Biol. Ecol. 332, 135-150. doi: 10.1016/j.jembe.2005 11.013

van Proosdij, D., Davidson-Arnott, R. G. D., and Ollerhead, J. (2006) Controls on spatial patterns of sediment deposition across a macro-tidal salt marsh surface over single tidal cycles. Estuar. Coast. Shelf Sci. 69, 64-86. doi: 10.1016/j.ecss.2006.04.022

van Wijnen, H. J., and Bakker, J. P. (2001). Long-term surface elevation change in salt marshes: a prediction of marsh response to future sea-level rise. Estuar. Coast. Shelf Sci. 52, 381-390. doi: 10.1006/ecss. 2000.0744

Wentworth, C. K. (1922). A scale of grade and class terms for clastic sediments. J. Geol. 30, 377-392. doi: 10.1086/6 22910

Zeff, M. L. (1999). Salt marsh tidal channel morphometry: applications for wetland creation and restoration. Restor. Ecol. 7, 205-211. doi: 10.1046/j.1526-100X.1999.72013.x

Conflict of Interest Statement: The authors declare that the research was conducted in the absence of any commercial or financial relationships that could be construed as a potential conflict of interest.

Copyright (c) 2019 Taylor, Paterson and Baxter. This is an open-access article distributed under the terms of the Creative Commons Attribution License (CC BY). The use, distribution or reproduction in other forums is permitted, provided the original author(s) and the copyright owner(s) are credited and that the original publication in this journal is cited, in accordance with accepted academic practice. No use, distribution or reproduction is permitted which does not comply with these terms. 


\section{OPEN ACCESS}

Edited by:

Alberto Vieira Borges,

University of Liège, Belgium

Reviewed by:

Luis Zambrano,

National Autonomous University of

Mexico, Mexico

Damien Troy Maher,

Southern Cross University, Australia

*Correspondence:

1. Emma Huertas

emma.huertas@icman.csic.es

Specialty section This article was submitted to

Conservation,

a section of the journa

Frontiers in Ecology and Evolution

Received: 01 October 2018

Accepted: 28 January 2019

Published: 19 February 2019

Citation:

Huertas IE, de la Paz M, Perez FF, Navarro G and Flecha S (2019)

Methane Emissions From the Salt Marshes of Doñana Wetlands: Spatio-Temporal Variability and

Controlling Factors.

Front. Ecol. Evol. 7:32

doi: 10.3389/fevo.2019.00032

\section{Methane Emissions From the Salt Marshes of Doñana Wetlands: Spatio-Temporal Variability and Controlling Factors}

\author{
I. Emma Huertas ${ }^{1 *}$, Mercedes de la Paz ${ }^{2}$, Fiz F. Perez ${ }^{3}$, Gabriel Navarro ${ }^{1}$ and \\ Susana Flecha ${ }^{4}$
}

${ }^{1}$ Instituto de Ciencias Marinas de Andalucía, CSIC, Puerto Real, Spain, ${ }^{2}$ Centro Oceanográfico de A Coruña, Instituto Español de Oceanografía (IEO), A Coruña, Spain, ${ }^{3}$ Instituto de Investigaciones Marinas, CSIC, Vigo, Spain, ${ }^{4}$ Instituto Mediterráneo de Estudios Avanzados, IMEDEA-CSIC, Esporles, Spain

Coastal wetlands are significant sources of methane in the atmosphere, but emissions in these ecosystems are still poorly quantified, as in situ data are limited. In this study, we present the first assessment of spatio-temporal changes in air-water $\mathrm{CH}_{4}$ fluxes in the salt marshes of the Doñana wetlands (SW Spain), one of the most emblematic protected areas in Europe, due to its high biotic diversity and unique importance for aquatic wildfowl. The marshes are flooded by estuarine waters from the adjacent Guadalquivir River by tidal intrusion, which influences aquatic $\mathrm{CH}_{4}$ dynamics by changing salinity and water chemistry which affects sedimentary methanogenesis. During sixteen samplings, conducted between March 2016 and March 2018, surface water $\mathrm{CH}_{4}$ concentrations were measured using static-head space equilibration gas chromatography in seven sites representing salt marshes located in the land strip close to the estuary. Because of meteorological conditions and tide variations, salinity markedly changed across the salt marshes, although sites located closer to the river mouth could be categorized as polyhaline marshes whereas upstream sites formed a group of mesohaline marshes. The $\mathrm{CH}_{4}$ saturation range was 252-36,735\% (average $5,170 \%$ ) and $374-620,007 \%$ (average 31,541\%) in polyhaline and mesohaline marshes, respectively, suggesting the inhibitory effect of sulfate on methanogenesis, although a linear trend between dissolved $\mathrm{CH}_{4}$ concentration and salinity was not observed. In contrast, water temperature and chlorophyll a were significantly and positively correlated with methane, indicating sedimentary methanogenesis control by temperature, and organic matter availability boosted by primary productivity. This does not exclude the possibility that some $\mathrm{CH}_{4}$ might also come from estuarine inputs. Air-water $\mathrm{CH}_{4}$ fluxes ranged from 2.6 to $720 \mu \mathrm{mol} \mathrm{m}{ }^{-2} \mathrm{~d}^{-1}$ (average $104 \mu \mathrm{mol} \mathrm{m} \mathrm{m}^{-2} \mathrm{~d}^{-1}$ ) in the polyhaline marshes and from 5.6 to $12,715 \mu \mathrm{mol} \mathrm{m}{ }^{-2} \mathrm{~d}^{-1}$ (average $637 \mu \mathrm{mol} \mathrm{m} \mathrm{m}^{-2} \mathrm{~d}^{-1}$ ) in the mesohaline marshes, with higher emissions measured during the summer months in all sites. Even though the strongest environmental drivers of dissolved $\mathrm{CH}_{4}$ accumulation 
seemed to be temperature and productivity, the spatio-temporal patterns observed suggest that methane dynamics in the Doñana salt marshes are controlled by a mosaic of processes rather than by a single environmental force.

Keywords: Doñana, methane, saltmarshes, emissions, Guadalquivir estuary

\section{INTRODUCTION}

Wetlands are the largest global source of the potent greenhouse gas methane, with an estimated annual emission to the atmosphere of 160-210 Tg (Kirschke et al., 2013). In fact, the increase in atmospheric methane concentration measured over the last decade is partially attributed to the rise in the emissions from tropical wetlands, in response to positive rainfall anomalies (Nisbet et al., 2016). If this type of biogenic source continues to grow, the expected rise in atmospheric methane concentration will be beyond the largest events recorded during the last millennium (Nisbet et al., 2016). Therefore, because of their relevant role in the global methane budget, wetlands, and inland waters are likely to drive the methane climate feedback from natural settings in the coming century (Dean et al., 2018). Measuring methane fluxes in these environments is therefore essential to accurately constrain the global methane budget and to understand feedback to the climate system (Kirschke et al., 2013; Dean et al., 2018).

In aquatic systems, methane is mainly generated microbially in anoxic sediments and escapes to the overlying water column where it can be oxidized, thereby reducing the amount of methane that eventually reaches the atmosphere (Dean et al., 2018 and references therein). In estuarine systems $\mathrm{CH}_{4}$ can also be oxidized in the sediment via anaerobic methane oxidation coupled with sulfate reduction (Barnes and Goldberg, 1976; Borges and Abril, 2011).

Particularly in wetlands, air-water $\mathrm{CH}_{4}$ fluxes are affected by several environmental variables, such as the water table level, temperature, and salinity. The water table directly influences methane release through its effect on vascular plant species (Sun et al., 2013) and the redox potential (Yang, 2013). Low temperature negatively affects methane emissions, as both organic matter oxidation and plant photosynthesis decrease in response to reduced temperature (Ding and Cai, 2007). Similarly, high salinity reduces methane generation, as sulfate reducing bacteria compit with methanogens for substrate (Bartlett et al., 1987; Poffenbarger et al., 2011). Therefore, $\mathrm{CH}_{4}$ emissions are routinely higher in freshwater wetlands and inland waters in comparison with coastal salt marshes and mangroves (Ding and Cai, 2007; Sun et al., 2013; Tong et al., 2013). Nevertheless, the influence of salinity on methane production is complicated by local conditions, and methane release in saline marshes still persists despite the inhibitory effects of sulfate (Weston et al., 2011). In addition, site-specific conditions are usually quite variable in coastal wetlands, especially in temperate regions, resulting in a large spatio-temporal heterogeneity of methane fluxes in these ecosystems (Poffenbarger et al., 2011). Therefore, because coastal wetland types vary in methane release and controlling processes, they need to be considered individually

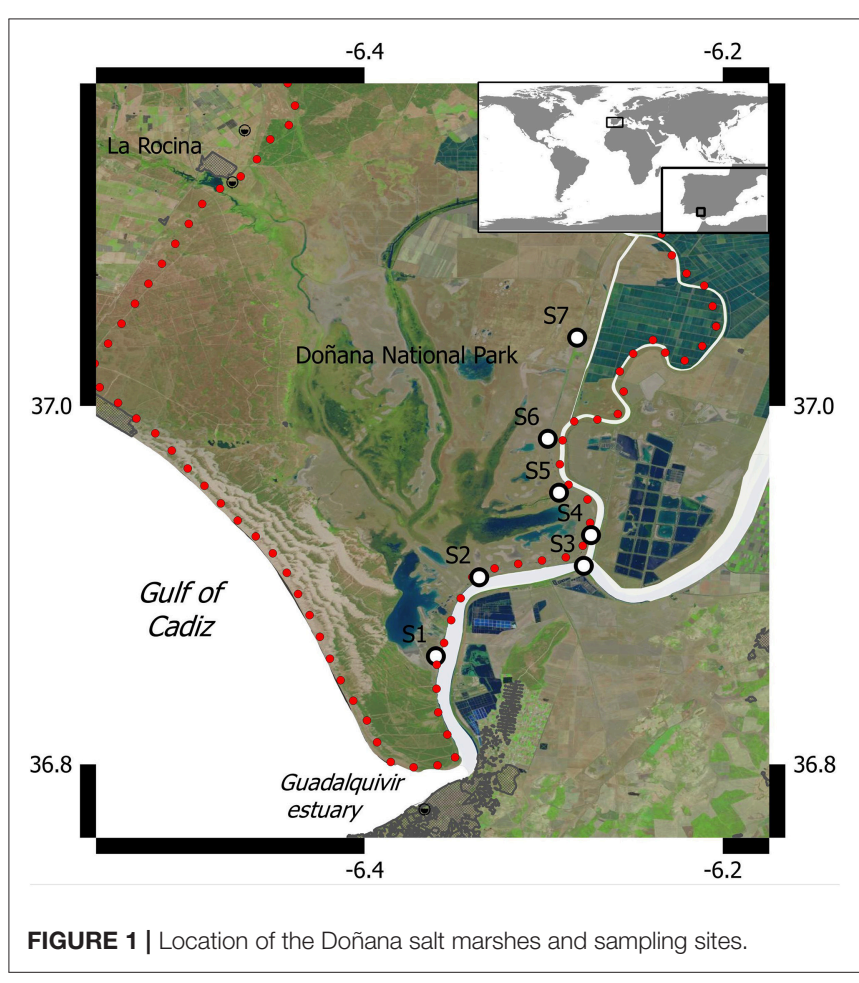

to yield reliable estimates of global wetland methane emissions (Turetsky et al., 2014) and to assess the potential evolution with the advent of environmental stressors.

As a contribution to the Frontiers Research Topic Structure, Functioning, and Conservation of Coastal Wetlands, we report a data set obtained in the salt marshes of the Doñana National Park (DNP, Figure 1) during a number of samplings conducted between March 2016 and March 2018, of biogeochemical variables related to $\mathrm{CH}_{4}$ production pathways in aquatic systems. Located at the mouth of the Guadalquivir River estuary (South Western Iberian Peninsula, Figure 1), the ecosystem complex jointly formed by the Doñana salt marshes and the estuary covers a surface of $3,560 \mathrm{~km}^{2}$, representing the largest coastal wetland in Southern Europe. In particular, DNP (Ramsar Site since 1982 and UNESCO World Heritage Site since 1995) is considered the most relevant sanctuary for migratory birds in Western Europe (Cížková et al., 2013), as it hosts more than 500,000 waterfowl each year during winter and also includes globally threatened water bird species.

Historically, the Doñana salt marshes were flooded by estuarine waters. However, in April 1998, a massive toxic spill from storage ponds at the Aznalcollar mine reached the Guadiamar River (the major tributary of the Guadalquivir) and 
2,650 ha of land adjacent to DNP became contaminated (Taggart et al., 2006). The release of toxic sludge led to the construction of dykes and floodgates in order to protect the marshes against the advance of the contaminated tailings. These prevention actions completely isolated the marshland and impeded any connection with their main draining fluvial basin. Therefore, over almost two decades, hydrology in the Doñana wetlands mostly depended on the annual rainfall regime, small streams situated in the northern side of the Park (e.g., La Rocina, Figure 1) and to a lesser extent, groundwater from the Almonte-Marismas aquifer (Olías et al., 2008). As a result, inundation cycles in the marshland became highly variable (Díaz-Delgado et al., 2016; Huertas et al., 2017). The scientific community and policy-makers designed an ambitious restoration program, the so called Doñana 2005, aimed at restoring partial connectivity between the estuary and the marshes and since 2014, estuarine waters have inundated the Doñana salt marshes again.

Prior to connection, biogeochemistry in aquatic systems of the DNP was examined in relation to the patterns of the variable hydrological cycle occurring in the region (Morris et al., 2013; Huertas et al., 2017). Under wet cycles, prolonged flooding resulted in a marked heterotrophy and a significant $\mathrm{CO}_{2}$ outgassing (Morris et al., 2013) whereas during drynormal hydrological cycles, air-water $\mathrm{CO}_{2}$ fluxes decreased, with permanent floodplains and ponds of the marshland even behaving as mild sinks for atmospheric $\mathrm{CO}_{2}$ for short periods (Huertas et al., 2017). Alternatively, aquaculture lagoons with man-managed water supply from the estuary continuously behaved as carbon sinks, which highlighted the importance of water management in the Doñana, not only for wetland conservation, but also for its role in the atmospheric $\mathrm{CO}_{2}$ exchange. Nevertheless, regardless of the hydroperiod, net primary production of the surrounding terrestrial vegetation largely offset aquatic $\mathrm{CO}_{2}$ effluxes and hence, considering the net ecosystem exchange, the Doñana wetlands were categorized as a large carbon sequestrator (Huertas et al., 2017).

In contrast, previous studies have identified the Guadalquivir estuary as a potent $\mathrm{CO}_{2}$ source in the atmosphere (de la Paz et al., 2007; Flecha et al., 2015). Higher $\mathrm{CO}_{2}$ emissions are mainly associated to the net heterotrophy occurring upstream of the estuary which is less influenced by the tidal intrusion (salinity $<5 \mathrm{psu}$ ) and characterized by a considerable turbidity, which leads to a strong $\mathrm{CO}_{2}$ supersaturation (Flecha et al., 2015). Recent work has also shown that the estuary functions as a small $\mathrm{CH}_{4}$ emitter and as a moderate $\mathrm{N}_{2} \mathrm{O}$ source, with the trace gas dynamics being highly dependent on the tidal-fluvial interaction (Huertas et al., 2018).

To our knowledge, no previous assessment of methane dynamics in the Doñana marshland has been performed, neither during the period of isolation from the estuary, nor after restoring connectivity. The aim of our study was therefore to provide a general description of the current methane dynamics in the salt marshes. Our findings can be used as a base-line to evaluate future trends in response to changes in hydrology, related to direct human management interventions (control of estuarine inputs through dykes and floodgates), or those associated to climate change (draft, sea level rise).

\section{MATERIALS AND METHODS}

\section{Sampling Sites and Strategy}

Samples were taken at seven sites (Figure 1) that represent salt marshes inundated by the Guadalquivir estuary during the 16 field campaigns conducted between March 2016 and March 2018. Sites were selected to account for the salinity gradient present in the estuary, which can range from 34 psu in the river mouth down to near 0 psu in the upper limit of the land strip adjacent to the riverside considered in our study (Huertas et al., 2018). Vegetation in the marshes is characterized by pioneer halophilous species like Sarcocornia fruticosa, Halimione portulacoides (Chenopodiaceae), and Limoniastrum monopetalum (Plumbaginaceae) (García-Murillo et al., 2014). During the monitoring period, we also identified Arthrocnemum macrostachyum, Plantago coronopus, Cotula coronopifolia, Taraxacum spp, Centaurium pulchellum, Polypogon maritimus, and Juncus sp., although plant biodiversity exhibited a marked spatio-temporal variability, which is higher during spring periods (Romagnoli, 2018).

All samplings were carried out when the estuary was under the influence of spring and rising tides. Some studies in marshes and other coastal wetlands, such as mangroves, have shown that there is a strong tidal signal in $\mathrm{CH}_{4}$ and water chemistry (Call et al., 2015). Our sampling design might therefore have affected gas dynamics, as sample collection occurred along with the net water flux into the system. However, those tidal conditions ensured overflow in the mudflat and the presence of a significant water level (a minimum water height of $0.1 \mathrm{~m}$ ) allowing sampling, which was conducted on foot. This strategy may have also had implications for gas distribution due to sediment dynamics disturbance. Nonetheless, it was the only way to access the flooded marshes in certain sites. Considering this caveat, we tried to minimize sediment disturbance as much as possible.

The floodplain is highly variable depending on annual rainfall (Huertas et al., 2017), and is also presently affected by the estuarine intrusion, that in turn is controlled by the tide amplitude. In fact, water levels were too low for sampling during the summer months and early fall. Therefore, data are not available for all sites during the dry season, and temporal variability of aquatic parameters has been examined between periods in which measurements could be performed.

Even though surface water coverage in the marshland changes temporarily, the mudflat is a relatively shallow system. Considering past and current records of wind speed in the area and the average depth of the water column, the Richardson number was calculated, which indicated that at each site, the flooded area was a well-mixed water body (not shown). Due to mixing conditions, methane levels measured at each sampling station were assumed to be representative of each inundated zone.

In all sites, conductivity, temperature and $\mathrm{pH}$ (National Bureau of Standards, NBS scale) were obtained with a Yellow Spring (YSI Incorporate) portable multiparameter probe YS6820v2. The $\mathrm{pH}$ probe was calibrated before samplings using the United States National Bureau of Standards buffer solutions (4 and 7). Discrete surface water samples were taken 
to determine dissolved $\mathrm{CH}_{4}$ concentrations and the rest of the aquatic biogeochemical variables considered in our study such as chlorophyll (Chl $a$ ), dissolved oxygen (DO), total alkalinity (TA), inorganic nutrients $\left(\mathrm{NH}_{4}^{+}, \mathrm{NO}_{2}^{-}, \mathrm{NO}_{3}^{-}, \mathrm{PO}_{4}^{3-}\right.$, and $\left.\mathrm{SiO}_{4}^{4-}\right)$, dissolved organic carbon (DOC), total dissolved nitrogen (TDN), and suspended particulate matter (TSM).

\section{Data}

\section{Meteorology}

Hourly measurements of rainfall $(\mathrm{mm})$, air temperature $\left({ }^{\circ} \mathrm{C}\right)$, humidity and wind speed at height $\mathrm{z}\left(\mathrm{u} z, \mathrm{~m} \mathrm{~s}^{-1}\right)$ were obtained from a meteorological station located in Lebrija $\left(36^{\circ} 58^{\prime} 35^{\prime \prime} \mathrm{N}, 06^{\circ} 07^{\prime} 34^{\prime \prime} \mathrm{W}\right.$ ) which is situated $20 \mathrm{Kms}$ south east of S3 and belongs to the Junta de Andalucía network (www.juntadeandalucia.es/agriculturaypesca/ifapa/ria/ servlet/FrontController).

\section{Aquatic Biogeochemical Variables}

Samples for $\mathrm{CH}_{4}$ measurements were collected in duplicate $120 \mathrm{~mL}$ serum vials, poisoned with $\mathrm{HgCl}_{2}$, sealed and stored upside down in the dark. Analysis was performed by statichead space equilibration gas chromatography (GC) using an Agilent 7890 GC, equipped with a Flame Ionization Detector (FID) for $\mathrm{CH}_{4}$ (de la Paz et al., 2015). Before analysis, $20 \mathrm{~mL}$ of $\mathrm{N}_{2}$ headspace were added to each sample, vigorously shaken and equilibrated for at least $12 \mathrm{~h}$. The gas cromatographer was calibrated using three different standard gas mixtures, a certified NOAA primary standard with composition similar to the atmosphere $\left(1863.4 \pm 0.3 \mathrm{ppb}\right.$ of $\left.\mathrm{CH}_{4}\right)$, and two additional standard gas mixtures of $\mathrm{CH}_{4}$ in a $\mathrm{N}_{2}$ matrix, provided by Air Liquide (France) with certified concentrations (3,000 and 5,000 $\mathrm{ppb}$ of $\mathrm{CH}_{4}$ ). The precision of the method estimated from the coefficient of variation, based on replicate analysis, was $0.6 \%$.

The response of the FID was very stable and highly lineal for $\mathrm{CH}_{4}$ concentrations within the calibration range. Using daily calibrations during the measurement period, a mean regression coefficient was calculated, yielding a value of $0.9997 \pm 0.0002$. For samples above the calibration range, linearity was assumed based on a perturbation test of the calibration equation that gave a relative error of $0.32 \%$. In terms of concentration, the linearity assumption resulted in errors of 0.1 and $3 \mathrm{nmol}^{-1}$ for $\mathrm{CH}_{4}$ concentrations of $50 \mathrm{nmol}$ and $1,000 \mathrm{nmol} \mathrm{l}^{-1}$, respectively, which allowed considering that the uncertainty associated with the measurements was not significant in the overall database.

Saturation values expressed as percentage (\%) of $\mathrm{CH}_{4}$ were computed as the ratio between the gas concentration measured and the calculated equilibrium concentration for the gas. The equilibrium concentration of $\mathrm{CH}_{4}$ was calculated using the solubility expression proposed by (Wiesenburg and Guinasso, 1979) and the annual averaged atmospheric mixing ratio $\mathrm{CH}_{4}$ $\left(\times \mathrm{CH}_{4 \mathrm{~atm}}\right)$ at the nearest station, provided by the World Data Center for Greenhouse Gases (http://ds.data.jma.go.jp/gmd/ wdcgg). As $\mathrm{CH}_{4}$ data at the nearest station were not available for the entire study period, a constant value of 1,866 ppb was used, which corresponds to the last annual averaged value available for 2015 .
Chl $a$ analysis was performed by filtering known volumes of water through Whatman GF/F glass fiber filters, dipping in 90\% acetone overnight in the dark, and measuring by fluorometry using a Turner Designs 10-AU Model fluorometer that was calibrated with a pure standard from Anacystis nidulans (Sigma Chemical Company). DO concentrations were determined by the Winkler method through potentiometric titration using a Metrohm 794 Titroprocessor. Saturation values of DO were calculated according to Benson and Krause (1984) and the Apparent Oxygen Utilization (AOU) was estimated as the difference between the oxygen concentration at saturation and that measured in the samples. Samples for TA determinations were collected in borosilicate bottles $(500 \mathrm{ml})$ preserved with $100 \mu \mathrm{l}$ of a $\mathrm{HgCl}_{2}$ saturated aqueous solution and stored until their analysis in the laboratory by titration according to Mintrop et al. (2000). Accuracy $\left( \pm 5 \mu \mathrm{molkg}^{-1}\right)$ was regularly checked by measurements of Certificate Reference Material provided by Prof. Andrew Dickson, the Scripps Institution of Oceanography, La Jolla, CA, USA (Batch 147). Partial pressure of $\mathrm{CO}_{2}\left(p \mathrm{CO}_{2}\right)$ was calculated from TA and $\mathrm{pH}_{\mathrm{NBS}}$ applying the CO2SYS.xls program (Lewis et al., 1998), with the Cai and Wang (1998) and Dickson (1990) constants for carbon and sulfate, respectively. The propagated error for $p \mathrm{CO}_{2}$ data was $\pm 3 \%$, using an estimated error for $\mathrm{pH}$ measurements of \pm 0.01 $\mathrm{pH}$ units, $\pm 2 \mu \mathrm{molkg}^{-1}$ for TA measurements and $\pm 0.1^{\circ} \mathrm{C}$ for temperature.

Inorganic nutrients were obtained from filtered (Whatman $\mathrm{GF} / \mathrm{F}$ glass fiber filters) and frozen $\left(-20^{\circ} \mathrm{C}\right)$ water samples $(5 \mathrm{~mL})$ that were measured in a Continuous Flow Analyzer, following the protocols described by (Grasshoff et al., 1983). DOC and TDN concentrations were obtained with a Shimadzu TOC-VCPH analyzer, by catalytic oxidation, at high temperature $\left(720^{\circ} \mathrm{C}\right)$ and chemiluminescence, respectively, according to Álvarez-Salgado and Miller (1998). TSM was obtained by the loss on ignition method on known volumes of water filtered through pre-weighed and pre-combusted $450^{\circ} \mathrm{C}$ Whatman $\mathrm{GF} / \mathrm{F}$ glass fiber filters, which were subsequently desiccated at $60^{\circ} \mathrm{C}$ for $48 \mathrm{~h}$ and totally combusted at $450^{\circ} \mathrm{C}$ during $5 \mathrm{~h}$.

\section{Air-Water $\mathrm{CH}_{4}$ Fluxes}

The air-water $\mathrm{CH}_{4}$ flux $\left(\mathrm{F}_{\mathrm{CH} 4}, \mu \mathrm{mol} \mathrm{m} \mathrm{m}^{-2} \mathrm{~d}^{-1}\right)$ was computed as:

$$
\mathrm{F}=\mathrm{k}(\mathrm{Cw}-\mathrm{Ca})
$$

Where $\mathrm{Cw}$ and $\mathrm{Ca}$ are the dissolved gas concentration and the equilibrium concentration in water, based on the molar atmospheric ratio, and $\mathrm{k}\left(\mathrm{cm} \mathrm{h}^{-1}\right)$ is the gas transfer rate as a function of wind speed at $10 \mathrm{~m}$ height, that was calculated from $\mathrm{k}$ and normalized to a Schmidt number $\left(\mathrm{S}_{\mathrm{c}}\right)$ of $600\left(\mathrm{k}_{600}\right)$ according to:

$$
k=k_{600} \sqrt{\frac{600}{S c}}
$$

$\mathrm{S}_{\mathrm{c}}$ was obtained using the formulations given by Wanninkhof (1992) interpolated at the in-situ salinity from the freshwater and 
seawater equations and $\mathrm{k}_{600}$ was calculated from $\mathrm{U}_{10}$ according to Cole and Caraco (1998).

$$
k_{600}=2.07+0.215 \mathrm{U}_{10}^{1.7}
$$

where $\mathrm{U}_{10}$ was calculated from $\mathrm{u} z$ measured at the meteorological station according to Smith (1988).

We acknowledge that the empirical relationship chosen to adjust $\mathrm{k}_{600}$ values may not be ideal for representing windenhancement effects in the flooded marshes (shallow water bodies with substantial variations in extent) but it was proven to be suitable to compute air-water $\mathrm{CO}_{2}$ fluxes in relation to other parameterizations (Morris et al., 2013). Nevertheless, to give an indication of the uncertainty this choice introduces, air-water $\mathrm{CH}_{4}$ fluxes were also predicted considering a 0.67 exponent for the Schmidt number. Despite minor differences obtained at high wind speeds $(<10 \%)$, the mean flux remained unchanged when annual values were averaged.

\section{Statistics}

The program language MATLAB was used to perform statistics analysis. Probability distributions of variables were examined through a Shapiro-Wilk test. Pearson's product-moment correlation (PPMC) was used to test for significant correlations between variables. Significance levels were set at $p<0.05$.

All data contained in this work are available for download from Digital.CSIC, the Institutional Repository of the Spanish National Research Council (CSIC), http://hdl.handle.net/10261/ 173204, http://dx.doi.org/10.20350/digitalCSIC/8588).

\section{RESULTS}

\section{Meteorological Conditions}

Monthly averaged air temperature during the samplings ranged between a minimum of about 8 and a maximum of $24.5^{\circ} \mathrm{C}$ in January 2017 and July 2017, respectively (Figure 2A). Rainfall was quite variable during the study period (Figure 2B), typical of the Mediterranean climatic region that is characterized by a rainy season (usually extending from October to March) and a dry season (from June to September) when rainfall is almost absent. The inter-annual precipitation pattern in this geographical area also fluctuates often, which affects the flooding regime in the wetlands (Huertas et al., 2017). Particularly, between March 2016 and March 2018 which corresponds to 3 hydrological years (starting 1 September 2015), total annual rainfall was $493 \mathrm{~mm}$ from September 2015 to August 2016, $539 \mathrm{~mm}$ from September 2016 to August 2017 and $500 \mathrm{~mm}$ from September 2017 to March 2018. These values are very close to the mean annual precipitation in the region, equivalent to $550 \mathrm{~mm}$ (Serrano Martín et al., 2008), thereby representing normal hydrological cycles. Monthly averaged precipitations during the sampling period varied from a minimum of $0 \mathrm{~mm}$, registered during the months of June and September 2017, to maximum of about $150 \mathrm{~mm}$ in spring of 2016 and 2018 and autumn 2016 (Figure 2B). The tidal coefficient at the mouth of the estuary during the sampling dates and defined as the amplitude of the tide forecast, oscillated between 41 and 111, as observed in January 2017 and November 2016, respectively
(Figure 2B). Monthly averaged horizontal wind velocity at $10 \mathrm{~m}$ above the surface ranged between 1.8 in January 2017 and $4.5 \mathrm{~m}$ $\mathrm{s}^{-1}$ in March 2018 with a median value of $2.5 \mathrm{~m} \mathrm{~s}^{-1}$ (Figure 2C).

\section{Biogeochemical Conditions}

Water temperature during samplings oscillated between 11.4 and $32.3^{\circ} \mathrm{C}$ (Figure 2A), with a clear seasonal pattern that was similar at all sites (not shown for sites individually). The range of variation of other aquatic biogeochemical variables is summarized in Table 1.

Because of meteorology and tide variations, salinity markedly changed across the marshes during the study period. It is worth noting that the Guadalquivir estuary is a mesotidal system, in which tidal influence can be noticeable up to $100 \mathrm{~km}$ upstream of the river mouth. Nevertheless, high freshwater discharges from an upstream dam during the rainy season interferes with the tidal effect and causes drastic changes in salinity (Díez-Minguito et al., 2013). Therefore, under heavy and prolonged rainfall events, salinity along the estuary experiences large decreases, although during the dry period ( $70 \%$ of the hydrological year) low discharges regularly occur to compensate for evaporation losses and the estuary is tidally dominated.

Consequently, salt marshes located closer to the river mouth (S1:S4) generally had higher salinities compared to those located on the land strip upstream of the estuary (S5:S7). With the exception of a single value of 33.6 psu in March 2016, salinity always remained below 5 psu in Site 7. Based on salinity, S1:S4 could be considered polyhaline tidal marshes whereas S5:S7 formed a group of oligo-mesohaline marshes. Clear variations for most other variables were also observed in all sites during the different samplings (Table 1).

According to Chl $a$, the salt marshes may be categorized as meso to eutrophic systems, with the higher pigment concentrations mostly found in the mesohaline sites (Table 1). This was also the case for DOC and nutrients $\left(\mathrm{PO}_{4}^{3-}\right.$ and DIN), which appeared at higher levels in S5:S7. Possibly related to the presence of high phytoplankton biomass, the flooded marshes were always well-oxygenated, and hypoxia was not detected during the samplings, with DO levels keeping values above $5 \mathrm{mg}$ $1^{-1}$ (Table 1). Results of the Pearson correlations performed with the complete dataset of the variables measured (Table 2), confirmed that the chlorophyll concentration was negatively and significantly $(p<0.05)$ correlated with AOU and was therefore, directly related to the dissolved oxygen concentration.

Besides direct precipitation, the only water source to the Doñana marshland is the adjacent estuary and thus, the increased salinity in the flooded marshes reflected the effective entry of estuarine waters through the tides. Salinity was significantly ( $p$ $<0.05$ ) and positively correlated with TSM, DOC and TDN, indicating that the dissolved and suspended matter measured in the marshes could partially have a fluvial origin.

\section{Spatio-Temporal Variation in Dissolved $\mathrm{CH}_{4}$} Dissolved methane ranged between 5.7 and 12,290 $\mathrm{nmol}^{-1}$ and generally increased in the mesohaline marshes (S5:S7, Table 1). The spatio-temporal variability of $\mathrm{CH}_{4}$ in all sites is shown in Figure 3 where salinity has also been plotted. Methane values at 


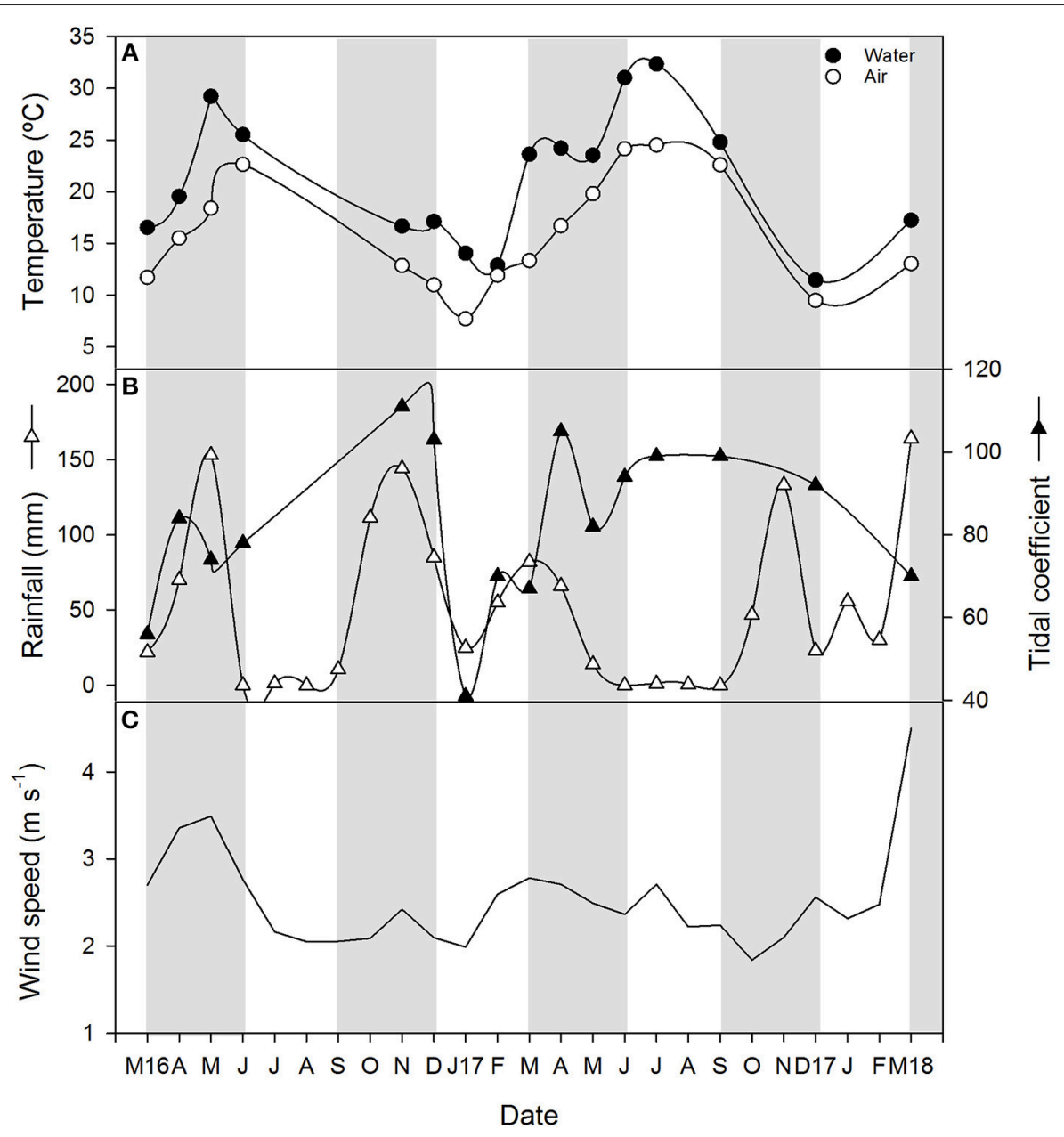

FIGURE 2 | Time series plots of (A) air and water temperature, (B) monthly rainfall and tidal coefficient during the sampling date and (C) monthly mean wind velocity at a height of $10 \mathrm{~m}$. Light and gray shading represent seasons.

site $\mathrm{S} 1$ were below $18 \mathrm{nmol} \mathrm{l}^{-1}$ during the entire sampling period, except for a single value of $22 \mathrm{nmol}^{-1}$ observed in March 2018, coinciding with a drop in salinity $(\sim 4 \mathrm{psu})$ due to heavy monthly precipitations and a moderate estuarine intrusion (marked by the tidal coefficient) during the sampling date (Figure 2B). The highest methane levels in this site were observed when salinity exhibited values below 15 psu, as it occurred in May and December of 2016, March 2017 and March 2018 (Figure 3).

In $\mathrm{S} 2, \mathrm{CH}_{4}$ was invariably higher than in $\mathrm{S} 1$ with a median value of $278 \mathrm{nmol} \mathrm{l}^{-1}$ (Table 1 and Figure 3). A minimum of around $50 \mathrm{nmol}^{-1}$ was measured in March, April and December 2016 when salinity was above 14 psu. A second minimum of 100 nmol $1^{-1}$ was observed in March 2018 despite the low salinity present in the flooded marshes, which may be attributable to a dilution effect caused by the high monthly rainfall (Figure 2B). The maximum concentration of dissolved methane in this site $\left(617 \mathrm{nmol} \mathrm{l}^{-1}\right)$ was detected in the summer of 2017 at a salinity of 19 psu. Therefore, even though salinity was likely to affect methane production, other processes were involved in $\mathrm{CH}_{4}$ dynamics in this particular sector of the marshes.
The range of variation of dissolved methane in S3 decreased with respect to that in S2, oscillating between 13.1 and 319.3 nmol $1^{-1}$ (Table 1) and with an average concentration of 104 nmol $1^{-1}$. Apparent relationship with salinity was not evidenced in this site, as maximum levels of methane were not associated with decreased salinity and vice versa (Figure 3).

In S4, the average concentration of methane during the sampling period was $65 \mathrm{nmol}^{-1}$, with a maximum value of $114 \mathrm{nmol}^{-1}$ found in December 2016 at a salinity of $4 \mathrm{psu}$ (Figure 3). A second maximum was also observed in March 2018 at a similar salinity. However, high $\mathrm{CH}_{4}$ concentrations ( 90) were still measured under significant estuarine intrusions, such as those occurring in June 2016 and May 2017 which can be evidenced by the salinity rises $(\sim 35$ and $\sim 24 \mathrm{psu}$, respectively, Figure 3 ).

In the mesohaline marshes (S5:S7) that were characterized by salinities below 10, except in March 2016, methane concentration clearly increased in relation to the polyhaline sites (Table 1 and Figure 3). Average concentrations of $\mathrm{CH}_{4}$ were 338.5, 261.2, and $431.3 \mathrm{nmol}^{-1}$ in S5, S6, and S7, respectively. However, it must 
TABLE 1 | Range of variation of biogeochemical variables measured in Doñana saltmarshes during the samples conducted between March 2016 and March 2018.

\begin{tabular}{|c|c|c|c|c|c|c|c|}
\hline Range of variation & S1 & s2 & S3 & S4 & S5 & S6 & s7 \\
\hline Methane (nmol I-1) & $5.7-22.4$ & $46.3-675.6$ & $13.1-319.3$ & $12.7-113.5$ & $33.5-12,290$ & $10.9-2,500$ & $9.5-3,069$ \\
\hline Salinity & $3.6-52.6$ & $1.1-21.2$ & $1.4-44$ & $4.4-35.8$ & $1.2-10.4$ & $0.9-16.8$ & $0.7-33.6$ \\
\hline Chl a $\left(\mu \mathrm{gl}^{-1}\right)$ & $1-64$ & $2-49$ & $0.5-34$ & $0.8-53$ & 3.3-815 & $1-342$ & $0.03-457$ \\
\hline $\mathrm{DO}\left(\mathrm{mg} \mathrm{l}^{-1}\right)$ & $6-15$ & $6-20$ & $9-20$ & $8-20$ & $5-17$ & $9-18$ & 8.2-23.3 \\
\hline $\mathrm{pCO}_{2}$ ( $\left.\mu \mathrm{atm}\right)$ & $62-1,003$ & $85-3,526$ & $0.4-225$ & $4-1,700$ & $202-4,427$ & $1-665$ & $41-1,405$ \\
\hline $\mathrm{pH}(\mathrm{NBS})$ & 8.03-9.6 & $7.7-8.9$ & $8.6-10.5$ & $7.8-9.7$ & $7.9-9.0$ & 8.3-10.8 & $7.73-9.52$ \\
\hline $\mathrm{DOC}\left(\mathrm{mg} \mathrm{I}^{-1}\right)$ & $4.9-36.2$ & $2.8-22.3$ & $7.9-44.5$ & $9.6-40.6$ & $6.9-60.9$ & $5.8-65.4$ & $8.5-56.8$ \\
\hline TDN (mg l-1) & $0.4-3.1$ & $0.8-3.9$ & $0.6-3.7$ & $1-3$ & $0.7-4.9$ & $0.4-4.7$ & $0.5-5.6$ \\
\hline $\mathrm{DIN}\left(\mu \mathrm{mol} \mathrm{I}^{-1}\right)$ & $3.4-46.1$ & 29-339 & $6-142$ & $5-67$ & $55.3-277.1$ & $7.8-99$ & $1.8-369.4$ \\
\hline $\mathrm{PO}_{4}^{3-}\left(\mu \mathrm{mol} \mathrm{I}{ }^{-1}\right)$ & $0.03-3.1$ & $0.2-4.5$ & $0-0.8$ & $0-0.4$ & $0-9.3$ & $0.16-17$ & $0.2-8.3$ \\
\hline $\mathrm{TSM}\left(\mathrm{mg} \mathrm{I}^{-1}\right)$ & $52-2013$ & $29-338$ & $18-443$ & $39-706$ & 24-1095 & $17-362$ & $4-460$ \\
\hline
\end{tabular}

TABLE 2 | Pearson correlation matrix for biogeochemical variables measured in Doñana salt marshes.

\begin{tabular}{|c|c|c|c|c|c|c|c|c|c|c|c|c|c|}
\hline & $\mathrm{CH}_{4}$ & Temp. & Salinity & Chl a & TSM & DOC & TDN & $\mathrm{NH}_{4}^{+}$ & $\mathrm{NO}_{2}^{-}$ & $\mathrm{PO}_{4}^{3-}$ & $\mathrm{NO}_{3}^{-}$ & $p \mathrm{CO}_{2}$ & AOU \\
\hline $\mathrm{CH}_{4}$ & & $0.31^{*}$ & 0.05 & $0.46^{\star}$ & $0.36^{*}$ & 0.50 & $0.39^{*}$ & 0.01 & 0.13 & 0.60 & -0.06 & 0.00 & $-0.24^{\star}$ \\
\hline Temp. & & & 0.15 & $0.38^{*}$ & $0.24^{*}$ & 0.45 & $0.27^{\star}$ & -0.14 & -0.04 & $0.35^{\star}$ & -0.13 & -0.01 & $-0.35^{\star}$ \\
\hline Salinity & & & & 0.01 & $0.38^{*}$ & $0.35^{\star}$ & $0.37^{*}$ & -0.09 & -0.06 & -0.08 & 0.01 & -0.19 & -0.03 \\
\hline Chl a & & & & & 0.45 & 0.63 & 0.51 & 0.01 & 0.17 & 0.72 & -0.08 & -0.02 & $-0.27^{\star}$ \\
\hline TSM & & & & & & 0.43 & 0.42 & -0.05 & 0.04 & $0.32^{\star}$ & 0.06 & 0.02 & 0.13 \\
\hline DOC & & & & & & & 0.69 & 0.02 & 0.04 & 0.57 & $-0.30^{*}$ & -0.16 & $-0.30^{\star}$ \\
\hline TDN & & & & & & & & 0.40 & 0.48 & 0.51 & $0.39^{\star}$ & -0.02 & $-0.20^{\star}$ \\
\hline $\mathrm{NH}_{4}^{+}$ & & & & & & & & & $0.76^{\star}$ & 0.07 & $0.22^{\star}$ & 0.04 & 0.03 \\
\hline $\mathrm{NO}_{2}^{-}$ & & & & & & & & & & $0.23^{*}$ & 0.42 & 0.15 & 0.02 \\
\hline $\mathrm{PO}_{4}^{3-}$ & & & & & & & & & & & 0.06 & 0.00 & -0.16 \\
\hline $\mathrm{NO}_{3}^{-}$ & & & & & & & & & & & & $0.36^{\star}$ & 0.18 \\
\hline $\mathrm{pCO}_{2}$ & & & & & & & & & & & & & 0.59 \\
\hline
\end{tabular}

The values were obtained with the complete database collected during the 16 samplings conducted between March 2016 and March 2018 . Abbreviations are indicated in the text.

${ }^{*}$ Correlations significant at $p<0.05$.

be noted that an exceptionally high methane level, equivalent to nearly $12,300 \mathrm{nmol} \mathrm{l}^{-1}$, was found in S5 during July 2017, which has been excluded of the average local computation. As a general trend, methane concentration rose in these marshes during the summer of 2017 when water temperatures reached $32^{\circ} \mathrm{C}$ (Figure 2A).

Overall, the influence of temperature on dissolved $\mathrm{CH}_{4}$ was observed in all sites, as the gas levels increased during the spring and summer months, compared to the levels measured over the winters (Figure 3). The temperature dependence was confirmed by the significant $(\mathrm{p}<0.05)$ and positive correlation obtained between this variable and $\mathrm{CH}_{4}$ (Table 2). When methane concentration was plotted against temperature (Figure 4A), the thermal effect on $\mathrm{CH}_{4}$ levels was especially obvious in the mesohaline marshes, where sulfate inhibition is likely to be suppressed.

In contrast, no statistical correlation between methane and salinity was found (Table 2). Nonetheless, when the relationship between the gas saturation levels in the salt marshes and salinity was more closely examined, separately considering the polyhaline (S1:S4) and mesohaline sites (S5:S7), two different behaviors of $\mathrm{CH}_{4}$ dynamics and their relation to this variable were distinguished (Figure 4B). Polyhaline marshes were characterized by a $\mathrm{CH}_{4}$ saturation range of $252-36,735 \%$ (average 5,170\%) and a scattered distribution with salinity (Figure 4B). On the contrary, mesohaline marshes exhibited a larger $\mathrm{CH}_{4}$ saturation range (374-620,007\%, average $31,541 \%$ ) and a positive relationship with salinity was noticeable (Figure 4B).

In order to better elucidate the effect of ecosystem metabolism on the dynamics of $\mathrm{CH}_{4}$ in the salt marshes, the relationship between $\mathrm{CH}_{4}$ saturation and the oxygen availability was also considered. As shown in Figure $4 \mathrm{C}, \log _{10} \% \mathrm{CH}_{4}$ vs. $\% \mathrm{O}_{2}$ displayed a scattered distribution but a positive relationship, indicating that high levels of $\mathrm{CH}_{4}$ were present in welloxygenated inundated marshes.

Moreover, dissolved $\mathrm{CH}_{4}$ concentration was shown to be strong and significantly $(p<0.05)$ correlated with Chl $a$ (Table 2). The increase of methane with the phytoplankton biomass was evident in both the polyhaline and mesotrophic sites (Figure 5A) and in the mesohaline and eutrophic sites (Figure 5B). The trend found between DOC and Chl $a$ in the salt marshes (Figures 5C,D) suggests that (Figures 5C,D) organic matter in the water column may have originated partially 


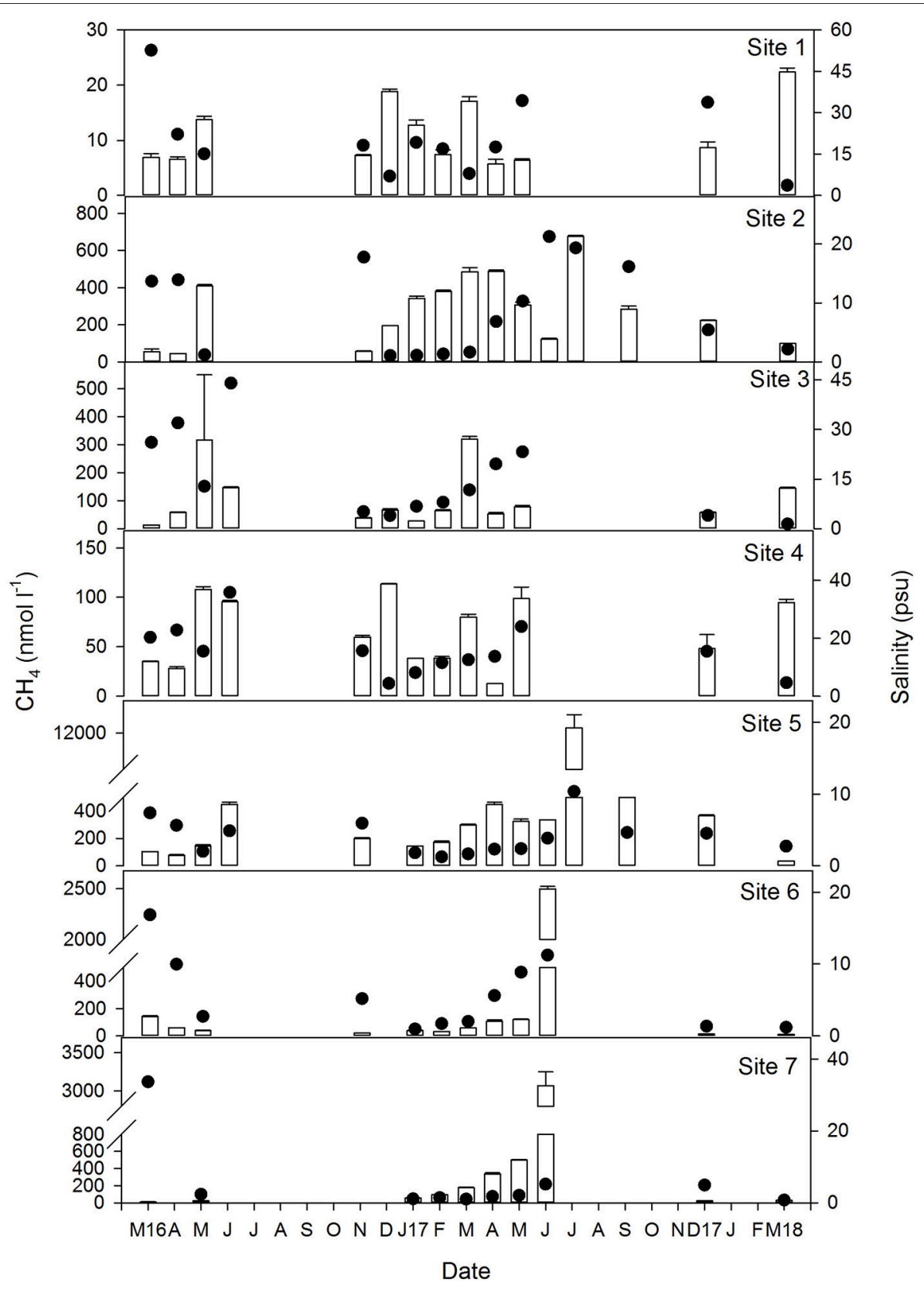

FIGURE 3 | Temporal variation of concentration of dissolved $\mathrm{CH}_{4}$ (vertical bars) and salinity (black circles) at each of the sites between March 2016 and March 2018. Note the $\mathrm{Y}$ axis scale for both parameters varies between sites. Gaps in the data represent periods when water levels were too low (<0.1 $\mathrm{m}$ ) for sampling and therefore, no measurements were taken.

from phytoplankton productivity. Nonetheless, the fact that high values of DOC (>10 $\left.\mathrm{mg} \mathrm{l}^{-1}\right)$ were still present under a low Chl $a$ concentration $\left(<1.5 \mu \mathrm{g} \mathrm{l}^{-1}\right)$ in the two groups of sites, indicate the contribution of external sources to the organic matter content in the marshes. Increases in organic and suspended matter were accompanied by rises in dissolved $\mathrm{CH}_{4}$ (Figures $5 \mathrm{E}-\mathbf{H}$ ). Significant and positive correlations with salinity were found for both variables (Table 2) and between salinity and TDN, supporting the hypothesis that estuarine inputs also contribute to organic matter accumulation and suspended matter entry in salt marshes.

The $p \mathrm{CO}_{2}$ levels in the marshes were also well-correlated to the $\log$ of $\% \mathrm{CH}_{4}$ and to $\% \mathrm{O}_{2}$ (Figures $6 \mathbf{A}, \mathbf{B}$ ). $p \mathrm{CO}_{2}$ values spanned three orders of magnitude, ranging between 0.5 and $4,427 \mu \mathrm{atm}$ in S3 and S5, respectively (Table 1). Extremely low $\mathrm{pCO}_{2}$ levels, could be attributed to the high $\mathrm{pH}$ values measured in the marshes $(\sim 10)$. The inundated mudflat remained undersaturated with respect to atmospheric $\mathrm{CO}_{2}$ 

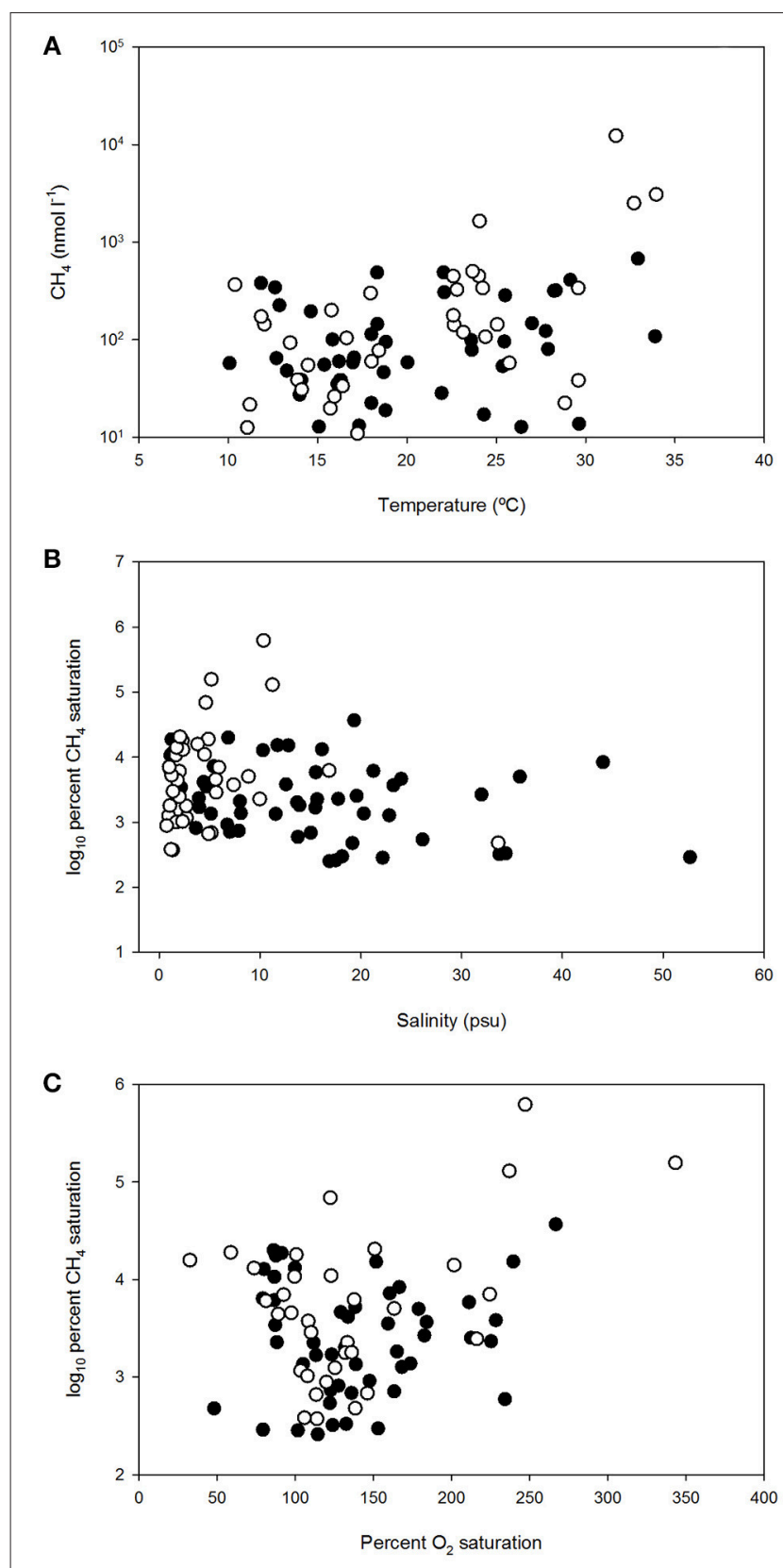

FIGURE 4 | Dissolved methane concentration vs. temperature (A), $\log _{10}$ percent dissolved methane saturation vs. salinity (B) and $\log _{10}$ percent dissolved methane saturation vs. percent dissolved $\mathrm{O}_{2}$ saturation (C) in polyhaline marshes (black symbols) and mesohaline marshes (open symbols) of Doñana National Park.

(average concentration of $\sim 405.4 \mu \mathrm{atm}$ during the sampling period estimated with the Mauna Loa trends, https://www.esrl. noaa.gov/gmd/ccgg/trends/) half of the time. In particular, S3 always behaved as a sink for atmospheric $\mathrm{CO}_{2}$ (Table 2).

\section{$\mathrm{CH}_{4}$ Emission Fluxes}

$\mathrm{CH}_{4}$ emissions exhibited a marked variability during the sampling period in all sites, varying from $\sim 3 \mu \mathrm{mol} \mathrm{m} \mathrm{m}^{-2} \mathrm{~d}^{-1}$ in site 1 in March 2016, to a maximum of $\sim 12,700 \mu \mathrm{mol}$ $\mathrm{m}^{-2} \mathrm{~d}^{-1}$ in site 5 in July 2017 (Figure 7). Overall, a tendency of higher methane effluxes was observed during the summer months, although emissions increased in the mesohaline marshes (from 5.6 to $12,715 \mu \mathrm{mol} \mathrm{m}{ }^{-2} \mathrm{~d}^{-1}$, average $637 \mu \mathrm{mol} \mathrm{m}{ }^{-2} \mathrm{~d}^{-1}$ ) in relation to the polyhaline marshes (from 2.6 to $720 \mu \mathrm{mol}$ $\mathrm{m}^{-2} \mathrm{~d}^{-1}$, average $104 \mu \mathrm{mol} \mathrm{m} \mathrm{m}^{-2} \mathrm{~d}^{-1}$ ).

\section{DISCUSSION}

\section{Sources of $\mathrm{CH}_{4}$ in Doñana Salt Marshes}

Coastal wetlands, and particularly estuarine systems are intense sources of $\mathrm{CH}_{4}$ to the atmosphere (Borges and Abril, 2011; Upstill-Goddard and Barnes, 2016) where emissions are sustained by fluvial inputs and sedimentary methanogenesis, fueled by a high organic matter deposition (Borges et al., 2017; Rosentreter et al., 2018a).

We recently reported a data set of dissolved $\mathrm{CH}_{4}$ concentrations in the Guadalquivir estuary transect that flooded the Doñana salt marshes from March 2016 to March 2017 (Huertas et al., 2018). For this period, that partially encompasses the one used in this study, the $\mathrm{CH}_{4}$ concentration ranged from $14 \mathrm{nmol}^{-1}$ in the river mouth (average salinity during the study $>25$ ) to $750 \mathrm{nmol} \mathrm{l}^{-1}$ upstream to the limit of site 5 (average salinity $\sim 5$ ). These levels of dissolved methane corresponded to a saturation range of 520-30,800\% (average 2,285\%) (Huertas et al., 2018), which is comparable to that measured in the Doñana polyhaline marshes (S1:S4) corresponding to 252$36,735 \%$ (average $5,170 \%$ ) but much lower than that observed in the mesohaline marshes (374-620,007\%, average 31,541\%). This indicates that even though estuarine inputs of $\mathrm{CH}_{4}$ in the salt marshes may occur by lateral transport, through riverine overflow, a local additional source of $\mathrm{CH}_{4}$ must contribute to the observed high $\mathrm{CH}_{4}$ values. The methane over-saturations and concentrations measured in Doñana fall within the range reported in temperate estuarine systems characterized by a salinity gradient (Upstill-Goddard and Barnes, 2016; Borges et al., 2018b) and in mangroves (Rosentreter et al., 2018b and references therein).

The most likely additional source of $\mathrm{CH}_{4}$ to the Doñana tidal flat would be sedimentary methanogenesis. Warm and waterlogged soils provide ideal conditions for methanogenesis (Roehm, 2005). Deep standing water enriched in dissolved organic matter and covered by plant litter creates an anaerobic environment that triggers $\mathrm{CH}_{4}$ production (Ding and Cai, 2007), with this process being favored by temperature increases. Our data show a direct and strong relationship between the levels of dissolved methane, organic matter content and water temperature, as it has been observed in other brackish coastal wetlands (Welti et al., 2017). Methanogenesis is substantially driven by temperature (Martin and Moseman-Valtierra, 2017) and it is therefore the most dominant environmental driver of $\mathrm{CH}_{4}$ emissions in wetlands (Yvon-Durocher et al., 2014) specifically in coastal salt marshes (Abdul-Aziz et al., 2018). The overall pattern found here therefore suggests a methanogenesis control by temperature in the sediment, which has been described as muddy with numerous stems and roots and scarce micro-fauna (Ruiz et al., 2004). In addition, vegetation in the 
Huerta et al.

Methane Emissions From Doñana Marshes

A

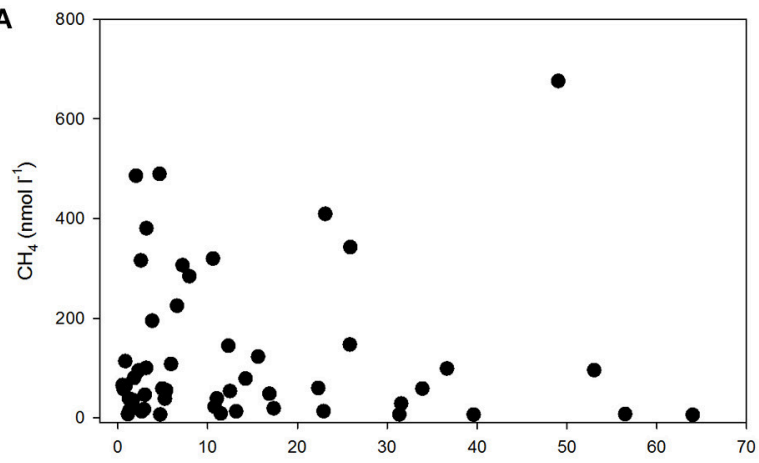

$\mathrm{Chl} a\left(\mu \mathrm{gl}^{-1}\right)$

C

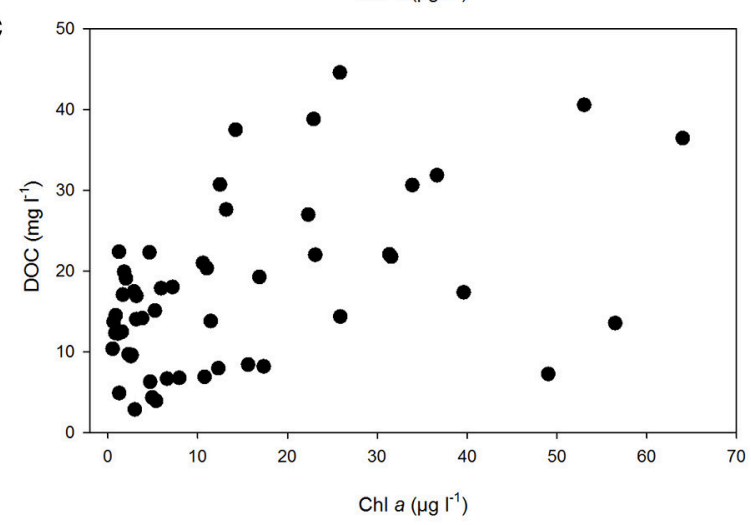

B

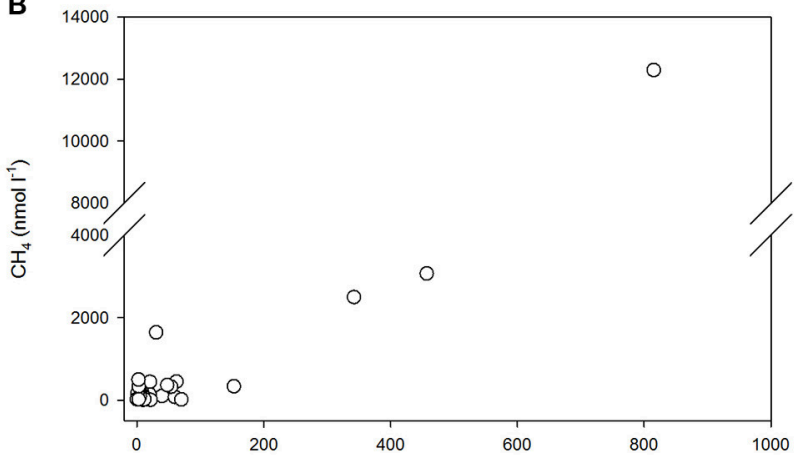

D

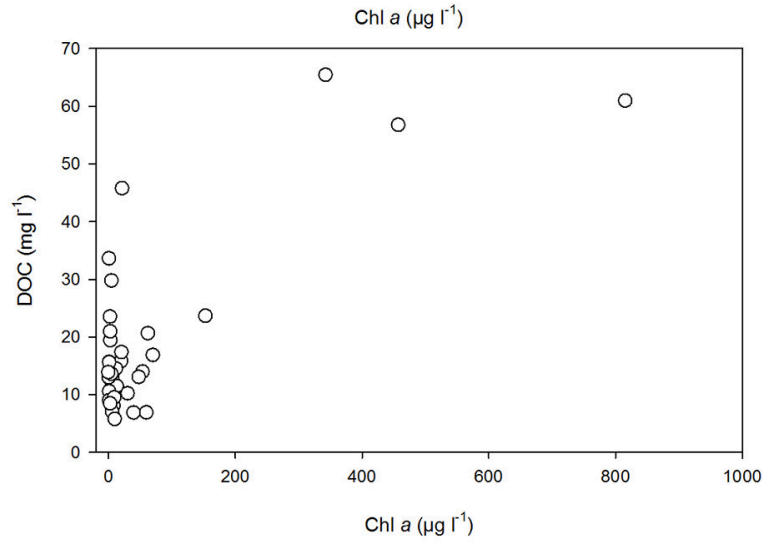

$\mathbf{F}$
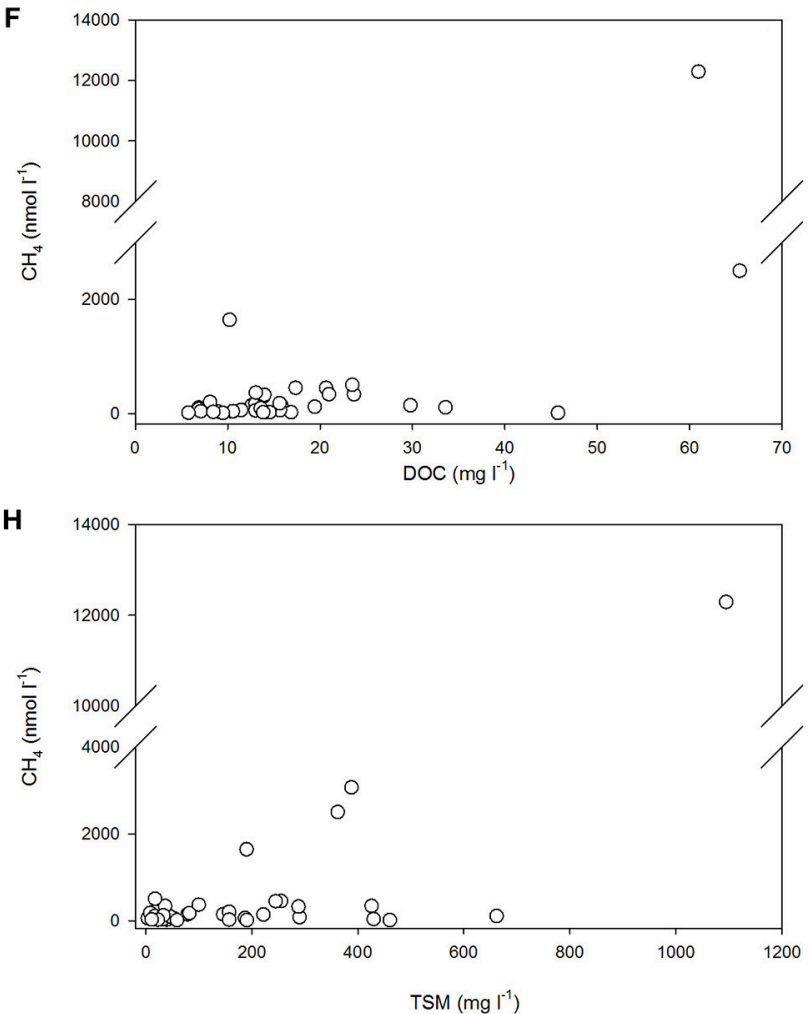

$\operatorname{TSM}\left(\mathrm{mg} \mathrm{l}^{-1}\right)$

G
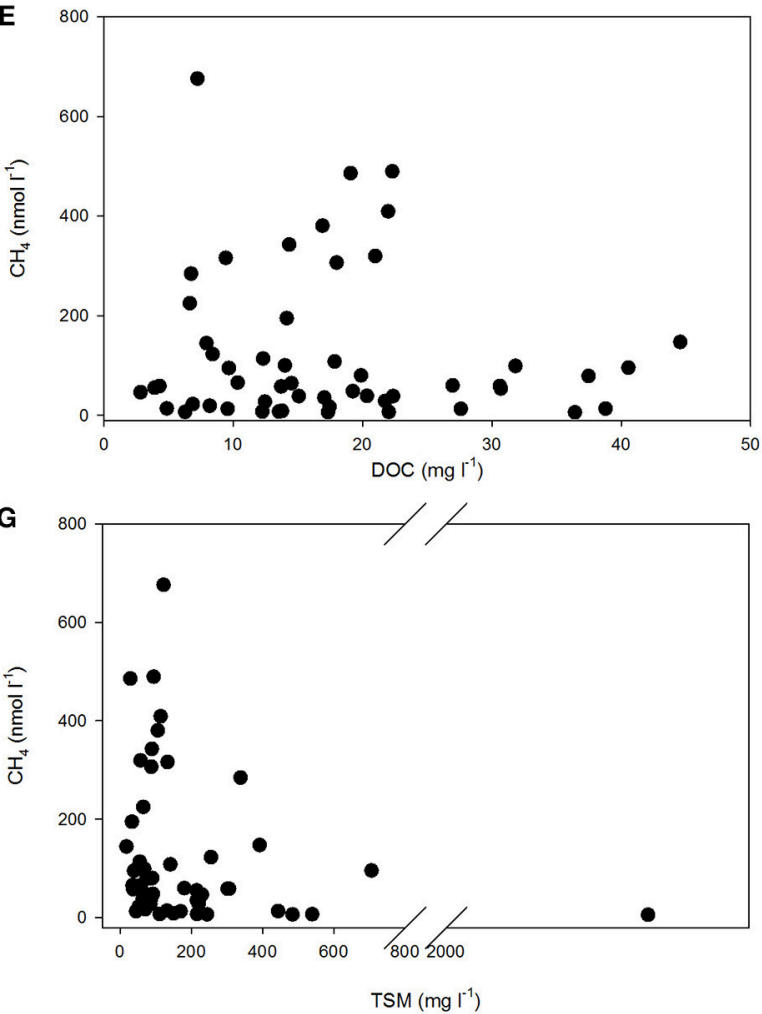

FIGURE 5 | Dissolved methane concentration vs. Ch a (A,B), DOC (E,F), and TSM (G,H) in polyhaline marshes (black symbols) and mesohaline marshes (open symbols) of the Doñana National Park. The relationship between ChI a and DOC in the marshes is also shown in panels (C,D). Abbreviations are indicated in the text.

Frontiers in Ecology and Evolution | www.frontiersin.org

85

February 2019 | Volume 7 | Article 32 

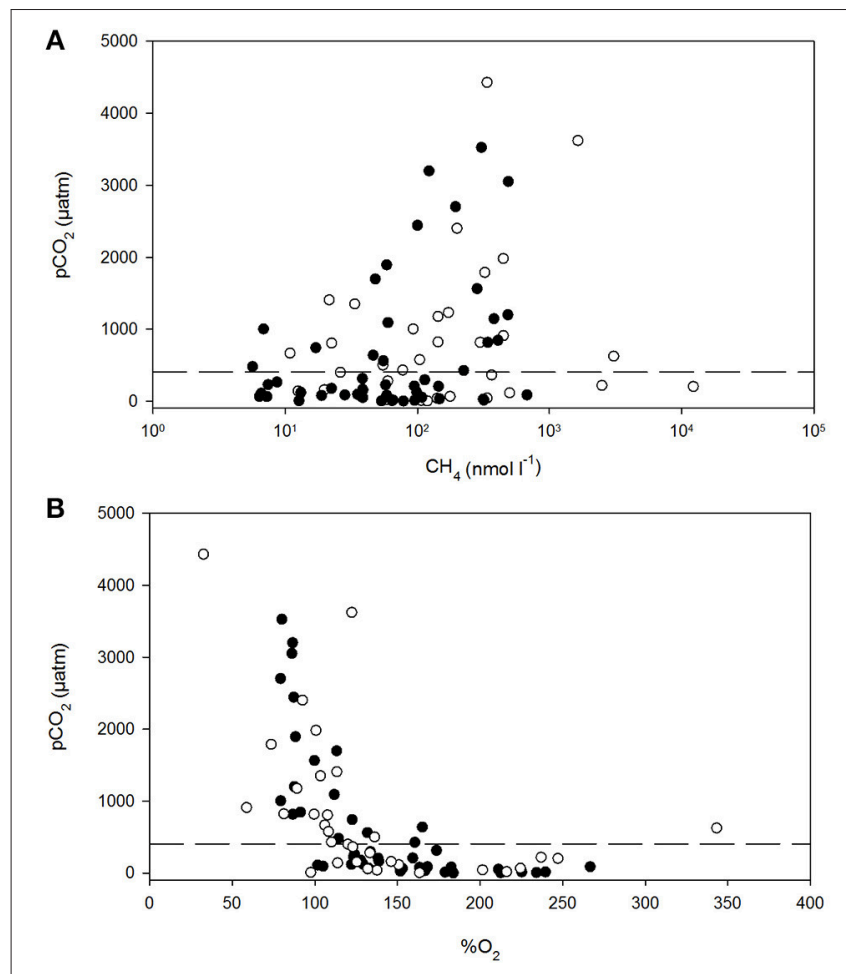

FIGURE 6 | Dissolved carbon dioxide $\left(\mathrm{pCO}_{2}\right)$ vs. dissolved methane (A) and percent dissolved $\mathrm{O}_{2}$ saturation (B) in polyhaline marshes (black symbols) and mesohaline marshes (open symbols) of the Doñana National Park. The dash line is the average atmospheric $\mathrm{pCO}_{2}$ during the sampling period.

marshes may have supported a methanogens population that could contribiute to an increase of $\mathrm{CH}_{4}$ concentrations during warmer conditions, which has been found in Spartina dominated wetlands (Burke et al., 2002; Abdul-Aziz et al., 2018). The organic-matter rich sediment in conjunction with the organic inputs from the heterotrophic Guadalquivir estuary (Flecha et al., 2015) and those generated in situ by the phytoplankton productivity, as indicated by the association found between $\mathrm{Chl} a$ and DOC, provide optimal conditions for sedimentary methanogenesis to proceed, with temperature acting as a major regulating driver. The higher temperatures during the late spring and summer months possibly resulted in increased microbial activity and greater primary productivity (Chl a and temperature were significantly and positively correlated), leading to high organic inputs, sediment carbon contents, and subsequently higher substrate availability. Large suspended matter loads that are characteristic in the turbid Guadalquivir River (Flecha et al., 2015) would also provide higher silt deposition and enhance methane generation, in agreement with what has been observed in shallow coastal areas (Borges et al., 2017). The pattern between TSM and dissolved $\mathrm{CH}_{4}$ in the salt marshes supports this hypothesis, particularly in the mesohaline marshes where very high levels of dissolved methane were measured at a high Chl $a$ concentration, DOC content and TSM.

The couplings between $p \mathrm{CO}_{2}, \mathrm{CH}_{4}, \mathrm{DOC}$, and $\% \mathrm{O}_{2}$ also indicate that the dynamics of dissolved gases in the tidal flat were driven by the oxidation of the organic matter produced by either phytoplankton, as described elsewhere (Borges et al., 2017; Welti et al., 2017) or from allochthonous sources (UpstillGoddard et al., 2017). Here, the relationship observed between $p \mathrm{CO}_{2}$ and $\mathrm{CH}_{4}$ is quite frequent (Borges et al., 2015, 2018a; Rosentreter et al., 2018b) and denotes a common source and similar production dynamics, as both gases are produced through organic matter respiration.

In the polyhaline marshes, large $\mathrm{CH}_{4}$ concentrations were measured when DOC levels were high, but this association was not as clear as in the mesohaline sites. This was probably due to the general inhibitory effects of abundant sulfate electron acceptors and reducing bacteria generally found in saline environments (Alongi et al., 2001; vanDijk et al., 2015). In fact, even though we did not observe a linear relationship between salinity and $\mathrm{CH}_{4}$ levels, coinciding with the trend described in other brackish systems (Chuang et al., 2017; Welti et al., 2017), the lower $\mathrm{CH}_{4}$ levels in the Doñana salt marshes were mainly associated to high salinity values, consistent with existing literature on coastal wetlands (Bartlett et al., 1987; Poffenbarger et al., 2011). Nevertheless, large $\mathrm{CH}_{4}$ levels can still occur in wetlands even when sulfate reduction is relevant (Lee et al., 2008; Alongi and Brinkman, 2011).

Similarly, distinct associations between methane and oxygen have been reported in aquatic systems. It is certain that methanogens are obligate anaerobes, and thus a negative relationship $\% \mathrm{CH}_{4}$ vs. $\% \mathrm{O}_{2}$ would be expected, as previously shown in other coastal wetlands (Livesley and Andrusiak, 2012), including the Guadalquivir estuary (Huertas et al., 2018). But alternatively, positive associations have been described in Amazon floodplain lakes (Devol et al., 1990), in freshwater lakes (Bogard et al., 2014), African savannah rivers (Upstill-Goddard et al., 2017) and shallow coastal zones (Borges et al., 2017). This feature has been attributed to several causes. First, the diffusion of $\mathrm{CH}_{4}$ produced in the underlying sediment into the aerated water column under low levels of turbulence since the $\mathrm{CH}_{4}$ diffusion term in these conditions, exceeds combined $\mathrm{CH}_{4}$ losses via oxidation, and water-to-air exchange (Upstill-Goddard et al., 2017). The contribution of high macrophyte-related productivity has also been suggested as a cause for positive relationships with dissolved oxygen due to direct $\mathrm{CH}_{4}$ production (Stanley et al., 2016). Additionally, methanogens have a higher sensitivity to temperature than methanotrophs do (Dunfield et al., 1993), which leads to higher rates of $\mathrm{CH}_{4}$ production in relation to consumption at elevated temperatures within a certain range of salinity values. Furthermore, methanogenesis in aerobic conditions by methanogen archaea fixed at the surface of phytoplankton cells has also been reported (Grossart et al., 2011). Therefore, peaks of dissolved $\mathrm{CH}_{4}$ that correlate positively with oxygen, phytoplankton biomass, and productivity are a recurrent feature in aquatic ecosystems (Bogard et al., 2014 and references therein).

Considering the shallowness of the tidal flat in the Doñana, it is plausible to assume that benthic productivity could have been decoupled from $\mathrm{CH}_{4}$ production (Borges et al., 2015). Moreover, methane could also have been transported from the creek onto the marshes during the flood tide as it occurs in estuarine systems (Rosentreter et al., 2018b), 


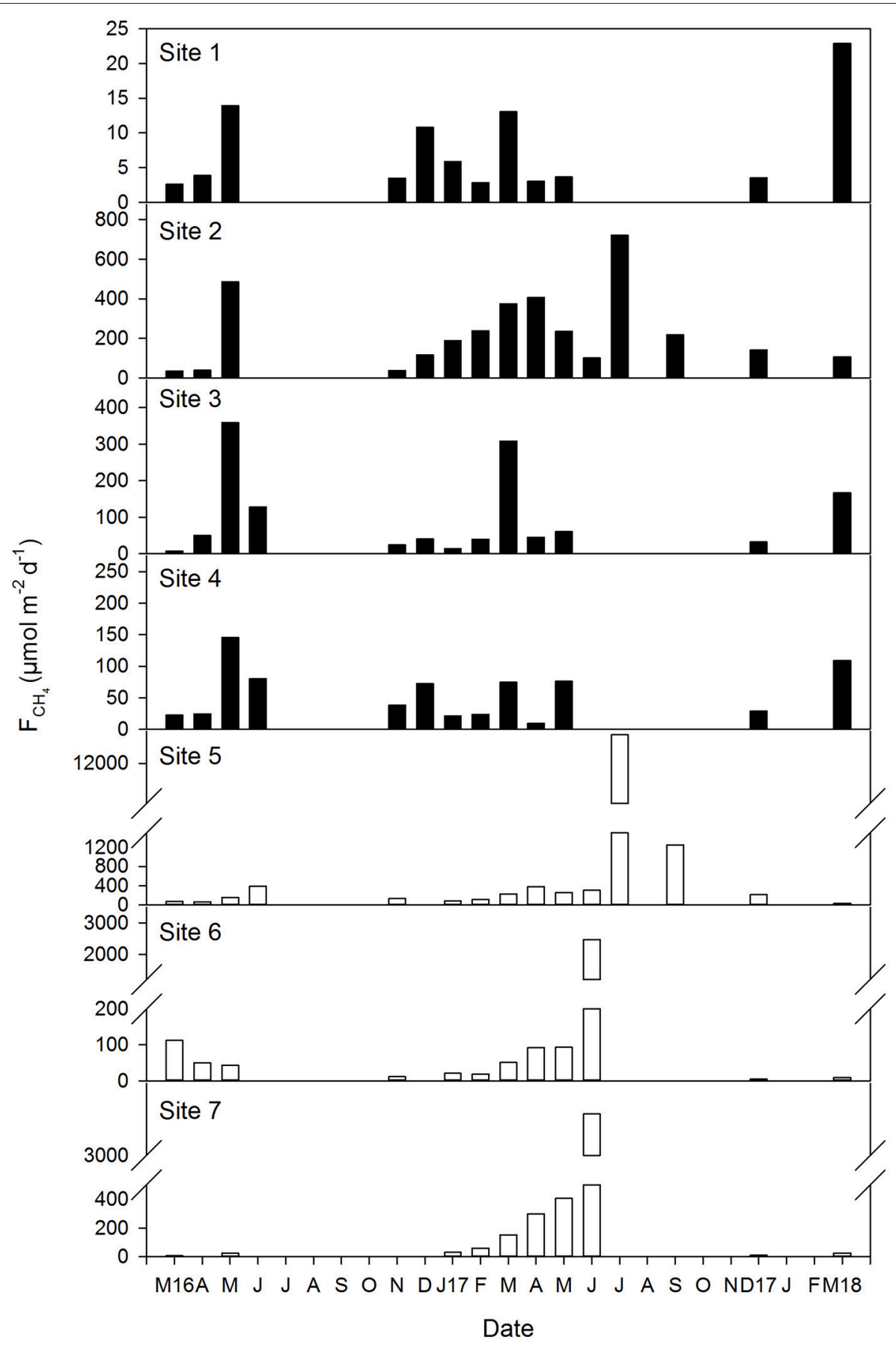

FIGURE 7 | Temporal variation of the air-water $\mathrm{CH}_{4}$ fluxes in the polyhaline marshes (black bars) and mesohaline marshes (open bars) of the Doñana National Park during the sixteen samplings conducted between March 2016 and March 2018. Note that Y axis scale varies between sites. Gaps in the data represent periods when water levels were too low $(<0.1 \mathrm{~m})$ for sampling and therefore, no measurements were taken.

whereas the DO signal would be related to the primary productivity occurring in the mudflat. Unfortunately, tidal pumping cannot be evaluated due to the lack of measurements in the creek, but it could be an important mechanism for $\mathrm{CH}_{4}$ import to the marshes (Rosentreter et al., 2018b). The correlation of methane with a Chl a concentration may support a strong benthic $\mathrm{CH}_{4}$ source, fueled by sinking phytoplankton material (Borges et al., 2017) rather than an aerobic $\mathrm{CH}_{4}$ production.

Therefore, according to the patterns found in our study, temperature, and phytoplankton activity seem to be the main drivers of $\mathrm{CH}_{4}$ formation when salinity does not exceed $17 \mathrm{psu}$ (see for instance temporal changes in methane levels in site 5 and the overall relationship \%sat $\mathrm{CH}_{4}$ vs. salinity). Above this salinity 
threshold, sulfate inhibition would constrain methane formation in the marshes.

Nevertheless, our findings also indicate that besides sedimentary methanogenesis, inflowing estuarine inputs would provide an additional source of methane to the salt marshes. Offsetting these sources, losses by microbial oxidation, lateral advection towards the estuary and dilution by heavy rain events, must also be incorporated as mechanisms affecting temporal variability of methane in the system. Unfortunately, the relative importance of all sources and sinks of dissolved methane cannot presently be estimated.

\section{$\mathrm{CH}_{4}$ Emissions From the Doñana Salt Marshes}

The mean air-water $\mathrm{CH}_{4}$ flux during the sampling period was 324 $\mu \mathrm{mol} \mathrm{m} \mathrm{m}^{-2} \mathrm{~d}^{-1}$, although a high variation in the emissions was observed $\left( \pm 1,394 \mu \mathrm{mol} \mathrm{m} \mathrm{m}^{-2} \mathrm{~d}^{-1}\right)$. This was a consequence of the different ranges of emissions found between the polyhaline and mesohaline marshes, as the methane fluxes were generally lower in the former compared to the latter, in agreement with what has been observed in systems characterized by marked salinity gradients (Poffenbarger et al., 2011; Welti et al., 2017). Nevertheless, the mean flux provided here falls within the ranges of $\mathrm{CH}_{4}$ emissions reported in European estuarine zones (UpstillGoddard and Barnes, 2016), in temperate fluvial catchments (Upstill-Goddard et al., 2017) and in mid-latitude mangroves (Rosentreter et al., 2018a). Few studies have quantified and investigated air-water $\mathrm{CH}_{4}$ exchange and dynamics in tidal flats (Dean et al., 2018). The fluxes measured in our study are slightly lower than those observed in subtropical tidal wetlands (Tong et al., 2013; Welti et al., 2017), coherent with a temperature control on methanogenesis (Abdul-Aziz et al., 2018). Lower emissions can therefore be expected from temperate coastal wetlands compared to tropical and subtropical coastal wetlands. In fact, the higher methane fluxes in the Doñana were found during the summer months in all sites, as increasing temperature increases microbial activity. Nevertheless, methane emissions from the Doñana salt marshes are still of the same order of magnitude than those measured in Indian and Australian mangroves (Linto et al., 2014; Call et al., 2015; Rosentreter et al., 2018b).

The average air-water $\mathrm{CH}_{4}$ flux estimated here is almost 5fold higher than the mean value computed in the Guadalquivir estuary transect that floods Doñana and equivalent to 66.2 $\mu \mathrm{mol} \mathrm{m} \mathrm{m}^{-2} \mathrm{~d}^{-1}$ (Huertas et al., 2018). The biogeochemistry in the estuary is totally different than that in the marshes where large loads of inorganic suspended particulate matter cause a considerable turbidity that limits phytoplankton growth (Ruiz et al., 2013). The low primary productivity in the estuarine waters would constrain labile organic matter supply for sedimentary methanogenesis, whereas in the shallow and lower turbulent salt marshes organic inputs from in situ photosynthesis, or from external sources, would fuel the process. This hypothesis however, remains to be tested.

The Doñana salt marshes behaved as a moderate $\mathrm{CH}_{4}$ emitter under the environmental conditions present during the sampling period, which corresponds to a normal hydrological cycle for this geographical area. Cycles characterized by heavy precipitations, which are not so uncommon (Díaz-Delgado et al., 2016; Huertas et al., 2017), are expected to affect methane dynamics and increase the emissions due to the overall reduction in salinity over the inundated marshes. This effect has been observed in tropical mangrove-dominated estuaries (Rosentreter et al., 2018b). Moreover, it is important to acknowledge that the approach used here to compute methane fluxes, does not quantify $\mathrm{CH}_{4}$ ebullition fluxes, whose contribution to total $\mathrm{CH}_{4}$ emissions may be significant (Baulch et al., 2011), particularly during low water periods. Furthermore, our sampling regime did not account for the potential importance of lateral tidal pumping as a source of $\mathrm{CH}_{4}$ and higher concentrations (and fluxes) during low tide, as it has been reported in other intertidal systems (Call et al., 2015; Maher et al., 2015). In fact, tidal differences may account 5 -fold in the estimated $\mathrm{CH}_{4}$ diffusive water to air fluxes (Maher et al., 2015). $\mathrm{CH}_{4}$ may also be transferred directly from sediments to the atmosphere (Borges and Abril, 2011). At low tide, this can take place through diffusion or ebullition and in vegetated tidal flats, such as Doñana, plants may act as both active and passive conduits of the $\mathrm{CH}_{4}$ (Foster-Martinez and Variano, 2016). All these pathways were not determined in our study and total $\mathrm{CH}_{4}$ emissions must be seen as a lower limit.

Our study is, however, foundational because it underlines the drivers controlling $\mathrm{CH}_{4}$ dynamics in the Doñana marshes. These wetlands are threatened by climate change and many local stressors associated to anthropogenic activities (Green et al., 2017). In the Mediterranean climatic region, higher minimum temperatures, more extreme high temperature events in summer and less precipitation are projected to occur by the end of the 21st century (Giorgi and Lionello, 2008). How the expected warming will affect methane dynamics in the ecosystem complex formed by the estuary and the marshes cannot be anticipated. Increased temperatures can cause methane to be produced at a faster rate but a rise in the saline intrusion associated to the projected sea level rise may offset methane release. Sustained observations would then be required to constrain the gas budget in this iconic coastal wetland.

\section{AUTHOR CONTRIBUTIONS}

IEH conceived the study, contributed to data analysis and interpretation, and drafted the manuscript. GN and FFP contributed to data analysis and interpretation, and critical discussion. SF and MdP contributed to the analytical design, data calculation and discussion.

\section{FUNDING}

This research was funded by the Spanish Ministry for Agriculture, Food and Environment, project 1539/2015. Mercedes de la Paz would like to acknowledge the support of the Spanish Ministry of Economy and Competitiveness (CTM2015-74510-JIN).

\section{ACKNOWLEDGMENTS}

The authors are indebted to María Ferrer-Marco, Marta Riera and Antonio Moreno for their support in the field work and samples analysis and Manuel Arjonilla for nutrient analysis. 


\section{REFERENCES}

Abdul-Aziz, O. I., Ishtiaq, K. S., Tang, J., Moseman-Valtierra, S., Kroeger, K. D.,Gonneea, M. E., et al. (2018).Environmental controls, emergent scaling, and predictions of greenhouse gas (GHG) fluxes in coastal salt marshes. J. Geophys. Res. 123, 2234-2256. doi: 10.1029/2018JG004556

Alongi, D. M., and Brinkman, R. (2011). "Hydrology and Biogeochemistry of Mangrove Forests,"in Forest Hydrology and Biogeochemistry, eds D. F. Levia, D. Carlyle-Moses, and T. Tanaka (Dordrecht, Springer), 203-219. doi: 10.1007/978-94-007-1363-5_10

Alongi, D. M., Wattayakorn, G., Pfitzner, J., Tirendi, F., Zagorskis, I., Brunskill, J., et al. (2001).Organic carbon accumulation and metabolic pathways in sediments of mangrove forests in southern Thailand. Mar. Geol. 179, 85-103. doi: 10.1016/S0025-3227(01)00195-5

Álvarez-Salgado, X. A., and Miller, A. E. J. (1998). Simultaneous determination of dissolved organic carbon and total dissolved nitrogen in seawater by high temperature catalytic oxidation: conditions for precise shipboard measurements. Mar. Chem. 62, 325-333. doi: 10.1016/S0304-4203(98) 00037-1

Barnes, R. O., and Goldberg, E. D. (1976). Methane production and consumption in anoxic marine sediments. Geology 4, 297-300. doi: 10.1130/0091-7613(1976)4<297:MPACIA >2.0.CO;2

Bartlett, K. B., Bartlett, D. S., Harriss, R. C., and Sebacher, D. I. (1987), Methane emissions along a salt-marsh salinity gradient. Biogeochem 4,183-202. doi: $10.1007 / \mathrm{BF} 02187365$

Baulch, H. M., Schiff, S. L., Maranger, R., and Dillon, P. J. (2011), Nitrogen enrichment and the emission of nitrous oxide from streams. Glob. Biogeochem. Cycle, 25. doi: 10.1029/2011JG001656

Benson, B. B., and Krause, D. (1984). The concentration and isotopic fractionation of oxygen dissolved in freshwater and seawater in equilibrium with the atmosphere1. Limnol. Oceanogr. 29, 620-632. doi: 10.4319/lo.19 84.29.3.0620

Bogard, M. J., del Giorgio, P. A., Boutet, L., Chaves, M. C., Merante, A., Prairie, Y. T., et al. (2014). Oxic water column methanogenesis as a major component of aquatic $\mathrm{CH}_{4}$ fluxes. Nat. Commun. 5:5350. doi: 10.1038/ncomms6350

Borges, A., and Abril, G. (2011). "Carbon Dioxide and Methane Dynamics in Estuaries," in Treatise on Estuarine and Coastal Science, Vol. 5, eds E. Wolanski and D. S. McLusky (Waltham, MA: Academic Press), 119-161. doi: 10.1016/B978-0-12-374711-2.00504-0

Borges, A., Darchambeau, F., Teodoru, C. R., Marwick, T. R., Tamooh, F., Geeraert, N., et al. (2015) Globally significant greenhouse-gas emissions from African inland waters. Nat. Geosci. 8. doi: 10.1038/NGEO2486

Borges, A. V., Abril, G., and Bouillon, S. (2018b). Carbon dynamics and $\mathrm{CO}_{2}$ and $\mathrm{CH}_{4}$ outgassing in the Mekong delta. Biogeochem. 15, 1093-1114. doi: 10.5194/bg-15-1093-2018

Borges, A. V., Darchambeau, F., Lambert, T., Bouillon, S., Morana, C., Brouyère, S., et al. (2018a). Effects of agricultural land use on fluvial carbon dioxide, methane and nitrous oxide concentrations in a large European river, the Meuse (Belgium). Sci. Total Environ. 610-611, 342-355. doi: 10.1016/j.scitotenv.2017.08.047

Borges, A. V., Speeckaert, G., Champenois, W., Scranton, M. I., and Gypens, N. (2017). Productivity and temperature as drivers of seasonal and spatial variations of dissolved methane in the southern bight of the North Sea. Ecosystems 21, 583-599. doi: 10.1007/s10021-017-0171-7

Burke, D. J., Hamerlynck, E. P., and Hahn, D. (2002). Interactions among plant species and microorganisms in salt marsh sediments. App. Environ. Microbiol. 68, 1157-1164. doi: 10.1128/AEM.68.3.1157-1164.2002

Cai, W. J., and Wang, Y. (1998). The chemistry, fluxes, and sources of carbon dioxide in the estuarine waters of the satilla and altamaha rivers, Georgia. Limn. Oceanog. 43, 657-668. doi: 10.4319/lo.1998.43.4.0657

Call, M., Maher, D. T., Santos, I. R., Ruiz-Halpern, S., Mangion, P., Sanders, C. J., et al. (2015). Spatial and temporal variability of carbon dioxide and methane fluxes over semi-diurnal and spring-neap-spring timescales in a mangrove creek. Geochim Cosmochim Acta. 150, 211-225. doi: 10.1016/j.gca.2014.11.023

Chuang, P. C., Young, M. B., Dale, A. W., Miller, L. G., Herrera-Silveira, J. A., and Paytan, A. (2017). Methane ?uxes from tropical coastal lagoons surrounded by mangroves, Yucatán, Mexico. J. Geophys. Res. Biogeosci. 122, 1156-1174. doi: 10.1002/2017JG003761
Cížková, H., Květ, J., Comín, F. A., Laiho, R., Pokorný, J., and Pithart, D. (2013). Actual state of European wetlands and their possible future in the context of global climate change.Aqu. Sci. 75, 3-26. doi: 10.1007/s00027-011-0233-4

Cole, J. J., and Caraco, N. F. (1998). Atmospheric exchange of carbon dioxide in a low wind oligotrophic lake measured by the addition of SF6. Limnol. Oceanog. 43, 647-656. doi: 10.4319/lo.1998.43.4.0647

de la Paz, M., Gomez-Parra, A., and Forja, J. (2007). Inorganic carbon dynamic and air-water $\mathrm{CO}_{2}$ exchange in the guadalquivir estuary (SW Iberian Peninsula). J. Mar. Sys. 68, 265-277. doi: 10.1016/j.jmarsys.2006.11.011

de la Paz, M., Huertas, I. E., Flecha, S., Ríos, A. F., and Pérez, F. F. (2015). Nitrous oxide and methane in atlantic and mediterranean waters in the strait of gibraltar: air-sea fluxes and inter-basin exchange. Prog. Oceanog. 138, 18-31. doi: 10.1016/j.pocean.2015.09.009

Dean, J. F.,Middelburg, J. J., Röckmann, T., Aerts, R., Blauw, L. G., Egger, M., et al. (2018). Methane feedbacks to the global climate system in a warmer world. Rev. Geophys. 56, 207-250. doi: 10.1002/2017RG000559

Devol, A. H., Richey, J. E., Forsberg, B. R., and Martinelli, L. A. (1990) Seasonal dynamics in methane emissions from the Amazon River floodplain to the troposphere. J. Geophys. Res. 95, 16417-16426. doi: 10.1029/JD095iD10p16417

Díaz-Delgado, R., Aragonés, D., Afán, I., and Bustamante, J. (2016). Long-term monitoring of the flooding regime and hydroperiod of Doñana marshes with landsat time series (1974-2014). Remote Sens. 8, 1-19. doi: 10.3390/rs8090775

Dickson, A. G. (1990). Standard potential of the reaction: $\mathrm{AgCl}(\mathrm{s})+12 \mathrm{H} 2(\mathrm{~g})$ $=\mathrm{Ag}(\mathrm{s})+\mathrm{HCl}(\mathrm{aq})$, and the standard acidity constant of the ion $\mathrm{HSO} 4-$ in synthetic sea water from 273.15 to $318.15 \mathrm{~K}$. J. Chem. Therm. 22, 113-127. doi: 10.1016/0021-9614(90)90074-Z

Díez-Minguito, M., Contreras, E., Polo, M. J., and Losada, M. A. (2013). Spatiotemporal distribution, along-channel transport, and post-riverflood recovery of salinity in the Guadalquivir estuary (SW Spain). J. Geophys. Res. 118, 2267-2278. doi: 10.1002/jgrc.20172

Ding, W. X., and Cai, Z. C. (2007). Methane emission from natural wetlands in China: summary of years 1995-2004 studies. Pedosphere 17, 475-486. doi: 10.1016/S1002-0160(07)60057-5

Dunfield, P., Dumont, R., and Moore, T. R. (1993). Methane production and consumption in temperate and subarctic peat soils: response to temperature and pH. Soil Biol. Biochem. 25, 321-326. doi: 10.1016/0038-0717(93)90130-4

Flecha, S., Huertas, I. E., Navarro, G., Morris, E., and Ruiz, J. (2015).Air-Water $\mathrm{CO}_{2}$ fluxes in a highly heterotrophic estuary. Est Coasts. 38, 2295-2309. doi: 10.1007/s12237-014-9923-1

Foster-Martinez, M. R., and Variano, E. A. (2016). Air-water gas exchange by waving vegetation stems. J. Geophys. Res. 121, 1916-1923. doi: 10.1002/2016JG003366

García-Murillo, P., Bazo, E., and Fernández-Zamudio, R. (2014). The plants of doñana national park's marisma (Spain): a key element for conservation of an emblematic European wetland. Cienc UAT 9, 60-75. doi: 10.29059/cienciauat.v9i1.620

Giorgi, F., and Lionello, P. (2008). Climate change projections for the mediterranean region. Glob. Plan Change 63, 90-104. doi: 10.1016/j.gloplacha.2007.09.005

Grasshoff, K., Erhardt, M., and Kremling, K. (1983). Methods of seawater analysis. 2. Acta Hydrochim Hydrobiol. 14, 79-80. doi: 10.1002/aheh.19860140112

Green, A. J., Alcorlo, P., Peeters, E. T. H. M., Morris, E. P., Bravo-Utrera M. A., Bustamante, J., et al. (2017). Creating a safe operating space for wetlands in a changing climate. Front. Ecol. Environ. 15, 99-107. doi: 10.1002/fee.1459

Grossart, H. P., Frindte, K., Dziallas, C., Eckert, W., and Tang, K. W. (2011). Microbial methane production in oxygenated water column of an oligotrophic lake. PNAS 108, 19657-19661. doi: 10.1073/pnas.1110716108

Huertas, I. E., Flecha, S., Figuerola, J., Costas, E., and Morris, E. P. (2017), Effect of hydroperiod on $\mathrm{CO}_{2}$ fluxes at the air-water interface in the Mediterranean coastal wetlands of Doñana. J. Geophys. Res. 122, 1615-1631. doi: 10.1002/2017JG003793

Huertas, I. E., Flecha, S., Navarro, G., Pérez, F. F., and de la Paz, M. (2018). Spatio-temporal variability and controls on methane and nitrous oxide in the Guadalquivir Estuary, Southwestern Europe. Aqu. Sci. 80:29. doi: 10.1007/s00027-018-0580-5

Kirschke, S., Bousquet, P., Ciais, P., Saunois, M., Canadell, J. G., Dlugokencky, E. J., et al. (2013). Three decades of global methane sources and sinks. Nat. Geos. 6, 813-823. doi: 10.1038/ngeo1955 
Lee, R. Y., Porubsky, W. P., Feller, I. C., McKee, K. L., and Joye, S. B. (2008). Porewater biogeochemistry and soil metabolism in dwarf red mangrove habitats (Twin Cays, Belize). Biogeochem 87, 181-198. doi: 10.1007/s10533-008-9176-9

Lewis, E., Wallace, D., and Allison, L. J. (1998). Program Developed for $\mathrm{CO}_{2}$ System Calculations. Carbon Dioxide Information Analysis Center managed by Lockheed Martin Energy Research Corporation for the US Department of Energy.

Linto, N., Barnes, J., Ramachandran, R., Divia, J., Ramachandran, P., and Upstill-Goddard, R. C. (2014). Carbon dioxide and methane emissions from mangrove-associated waters of the Andaman Islands, Bay of Bengal. Est. Coasts 37, 381-398. doi: 10.1007/s12237-013-9674-4

Livesley, S. J., and Andrusiak, S. M. (2012). Temperate mangrove and salt marsh sediments are a small methane and nitrous oxide source but important carbon store. Est. Coast Shelf. Sci. 97, 19-27.doi: 10.1016/j.ecss.2011.11.002.

Maher, D. T., Cowley, K., Santos, I. R., Macklin, P., and Eyre, B. D. (2015) Methane and carbon dioxide dynamics in a subtropical estuary over a diel cycle: insights from automated in situ radioactive and stable isotope measurements. Mar. Chem. 168, 69-79. doi: 10.1016/j.marchem.2014.10.017

Martin, R. M., and Moseman-Valtierra, S. (2017). Different short-term responses of greenhouse gas fluxes from salt marsh mesocosms to simulated global change drivers. Hydrobiology 802, 71-83. doi: 10.1007/s10750-017-3240-1

Mintrop, L., Pérez, F. F., González-Dávila, M., Santana-Casiano, J. M., and Körtzinger,A. (2000).Alkalinity determination by potentiometry: intercalibration using three different methods. Cienc Mar. 26, 23-27. doi: $10.7773 / \mathrm{cm} . v 26 i 1.573$

Morris, E. P., Flecha, S., Figuerola, J., Costas, E., Navarro, G., Ruiz, J., et al. (2013). Contribution of Doñana wetlands to carbon sequestration. PLoS ONE 8:e71456. doi: 10.1371/journal.pone.0071456

Nisbet, E.,Dlugokencky, E., Manning, M., Lowry, D., Fisher, R., France, J., et al. (2016). Rising atmospheric methane: 2007-2014 growth and isotopic shift. Glob. Biogeochem Cycles 30, 1356-1370. doi: 10.1002/2016GB005406

Olías, M.,González, F., Cerón, J. C., Bolívar, J. P., González-Labajo, J., and García-López, S. (2008).Water quality and distribution of trace elements in the Doñana aquifer (SW Spain). Environ. Geol. 55, 1555-1568. doi: 10.1007/s00254-007-1106-y

Poffenbarger, H. J., Needelman, B. A., and Megonigal, J. P. (2011).Salinity influence on methane emissions from tidal marshes. Wetlands 31, 831-842.doi: 10.1007/s13157-011-0197-0

Roehm, C. (2005). "Respiration in wetland ecosystems," in Respiration in Aquatic Ecosystems, ed P. del Giorgio and P. le B Williams (Oxford: Oxford University Press), 83-102. doi: 10.1093/acprof:oso/9780198527084.003.0006

Romagnoli, B. (2018).Influence of Guadalquivir Estuary on Aquatic Biogeochemistry and Isotopic Signature of the Saltmarshes of Donana National Park (SW Spain). [dissertation/master's thesis]: University of Bologna.

Rosentreter, J. A., Maher, D. T., Erler, D. V., Murray, R., and Eyre, B. D. (2018b) Factors controlling seasonal $\mathrm{CO}_{2}$ and $\mathrm{CH}_{4}$ emissions in three tropical mangrove-dominated estuaries in Australia. Est. Coast Shelf. Sci. 215, 69-82. doi: 10.1016/j.ecss.2018.10.003

Rosentreter, J. A., Maher, D. T., Erler, D. V., Murray, R. H., and Eyre, B. D. (2018a). Methane emissions partially offset "blue carbon" burial in mangroves. Sci. Adv. 4:eaao4985. doi: 10.1126/sciadv.aao4985

Ruiz, F., Rodriguez-Ramirez, A., Caceres, L. M., Rodriguez-Vidal, J., Carretero, M. I., Clemente, L., et al. (2004).Late Holocene evolution of the southwestern Doñana National Park (Guadalquivir Estuary, SW Spain): a multivariate approach. Palaeogeog. Palaeoclim. Palaeoecol. 204, 47-64. doi: 10.1016/S0031-0182(03)00721-1

Ruiz, J., Macias, D., Losada, M. A., Diez-Minguito, M., and Prieto, L. (2013). A simple biogeochemical model for estuaries with high sediment loads: application to the Guadalquivir River (SW Iberia). Ecol. Model. 265, 194-206. doi: 10.1016/j.ecolmodel.2013.06.012

Serrano Martín, L., Esquivias Segura, M. P., and Zunzunegui, M. (2008). Longterm hydrological changes over a seventeen-year period in temporary ponds of the Doñana NP (SW Spain). Limnetica 27, 65-77.
Smith, S. D. (1988). Coefficients for sea surface wind stress, heat flux, and wind profiles as a function of wind speed and temperature. J. Geophys. Res. 93, 15467-15472. doi: 10.1029/JC093iC12p15467

Stanley, E. H., Casson, N. J., Christel, S. T., Crawford, J. T., Loken, L. C., and Oliver, S. K. (2016). The ecology of methane in streams and rivers: patterns, controls and global significance. Ecol. Monograph. 86, 146-171 doi: 10.1890/ $15-1027$

Sun, L., Song, C., Miao, Y., Qiao, T., and Gong, C. (2013).Temporal and spatial variability of methane emissions in a northern temperate marsh. Atmos. Environ.81, 356-363. doi: 10.1016/j.atmosenv.2013.09.033

Taggart, M. A., Figuerola, J., Green, A. J., Mateo, R., Deacon, C., Osborn, D., et al. (2006). After the Aznalcollar mine spill: arsenic, zinc, selenium, lead and copper levels in the livers and bones of five waterfowl species. Environ. Res. 100, 349-361. doi: 10.1016/j.envres.2005.07.009

Tong, C., Huang, F. J., Hu, Z. Q., and Jin, Y. F. (2013).Diurnal variations of carbon dioxide, methane, and nitrous oxide vertical fluxes in a subtropical estuarine marsh on neap and spring tide days. Est. Coast. 36, 633-642. doi: 10.1007/s12237-013-9596-1

Turetsky, M. R., Kotowska, A., Bubier, J., Dise, N. B., Crill, P., Hornibrook, E. R., et al. (2014). A synthesis of methane emissions from 71 northern, temperate, and subtropical wetlands. Glob. Change Biol. 20, 2183-2197. doi: $10.1111 / \mathrm{gcb} .12580$

Upstill-Goddard, R. C., and Barnes, J. (2016). Methane emissions from UK estuaries: re-evaluating the estuarine source of tropospheric methane from Europe. Mar Chem. 180, 14-23. doi: 10.1016/j.marchem.2016.01.010

Upstill-Goddard, R. C., Salter, M. E., Mann, P. J., Barnes, J., Poulsen, J., Dinga, B., et al. (2017). The riverine source of $\mathrm{CH} 4$ and N 2 O from the Republic of Congo, western Congo Basin. Biogeoscience 14, 2267-2281. doi: 10.5194/bg-14-2267-2017

vanDijk, G., Smolders, A. J. P., Loeb, R., Bout, A., Roelofs, J. G. M., and Lamers, L. P. M. (2015). Salinization of coastal freshwater wetlands; effects of constant versus fluctuating salinity on sediment biogeochemistry. Biogeochem 126, 71-84. doi: 10.1007/s10533-015-0140-1

Wanninkhof, R. (1992). Relationship between wind speed and gas exchange. J. Geophys. Res. 97, 7373-7382. doi: 10.1029/92JC00188

Welti, N., Hayes, M., and Lockington, D. (2017). Seasonal nitrous oxide and methane emissions across a subtropical estuarine salinity gradient. Biogeochem 132, 55-69. doi: 10.1007/s10533-016-0287-4

Weston, N. B., Vile, M. A., Neubauer, S. C., and Velinsky, D. J. (2011). Accelerated microbial organic matter mineralization following salt-water intrusion into tidal freshwater marsh soils. Biogeochem 102, 135-151. doi: 10.1007/s10533-010-9427-4

Wiesenburg, D. A., and Guinasso, N. L. Jr. (1979). Equilibrium solubilities of methane, carbon monoxide, and hydrogen in water and sea water. J. Chem. Eng. Data 24, 356-360. doi: 10.1021/je60083a006

Yang (2013). Methane emissions from rice fields under continuous straw return in the middle-lower reaches of the Yangtze River. J. Environ. Sci. 25, 1874-1881. doi: 10.1016/S1001-0742(12)60273-3

Yvon-Durocher, G., Allen, A. P., Bastviken, D., Conrad, R., Gudasz, C., St-Pierre, A., et al. (2014). Methane fluxes show consistent temperature dependence across microbial to ecosystem scales. Nature 7, 488-491. doi: 10.1038 /nature13164

Conflict of Interest Statement: The authors declare that the research was conducted in the absence of any commercial or financial relationships that could be construed as a potential conflict of interest.

Copyright () 2019 Huertas, de la Paz, Perez, Navarro and Flecha. This is an openaccess article distributed under the terms of the Creative Commons Attribution License (CC BY). The use, distribution or reproduction in other forums is permitted, provided the original author(s) and the copyright owner(s) are credited and that the original publication in this journal is cited, in accordance with accepted academic practice. No use, distribution or reproduction is permitted which does not comply with these terms. 


\section{OPEN ACCESS}

Edited by:

Alberto Vieira Borges,

University of Liège, Belgium

Reviewed by:

Filip Meysman,

University of Antwerp, Belgium

Perran Cook

Monash University, Australia

*Correspondence:

Alec M. Hutchings

amh220@cam.ac.uk

Specialty section: This article was submitted to

Biogeoscience,

a section of the journal

Frontiers in Earth Science

Received: 14 November 2018

Accepted: 20 February 2019

Published: 14 March 2019

Citation:

Hutchings AM, Antler $G$, Wilkening JV, Basu A, Bradbury HJ, Clegg JA, Gorka M, Lin CY, Mills JV, Pellerin A, Redeker KR, Sun X and Turchyn AV (2019) Creek Dynamics

Determine Pond Subsurface Geochemical Heterogeneity in East Anglian (UK) Salt Marshes.

Front. Earth Sci. 7:41 doi: 10.3389/feart.2019.00041

\section{Creek Dynamics Determine Pond Subsurface Geochemical Heterogeneity in East Anglian (UK) Salt Marshes}

\author{
Alec M. Hutchings ${ }^{1 *}$, Gilad Antler ${ }^{2,3}$, Jean V. Wilkening ${ }^{4}$, Anirban Basu ${ }^{5}$, \\ Harold J. Bradbury ${ }^{1}$, Josephine A. Clegg ${ }^{1}$, Marton Gorka ${ }^{1}$, Chin Yik Lin ${ }^{1,6}$, \\ Jennifer V. Mills ${ }^{7}$, Andre Pellerin ${ }^{8}$, Kelly R. Redeker ${ }^{9}$, Xiaole Sun $^{10}$ and \\ Alexandra V. Turchyn ${ }^{1}$
}

\begin{abstract}
${ }^{1}$ Department of Earth Sciences, University of Cambridge, Cambridge, United Kingdom, ${ }^{2}$ Department of Geological and Environmental Sciences, Ben-Gurion University of the Negev, Beersheba, Israel, ${ }^{3}$ The Interuniversity Institute for Marine Sciences in Eilat, Eilat, Israel, ${ }^{4}$ Department of Civil and Environmental Engineering, University of California, Berkeley, Berkeley, CA, United States, ${ }^{5}$ Department of Earth Sciences, Royal Holloway, University of London, Egham, United Kingdom, ${ }^{6}$ Department of Geology, Faculty of Science, University of Malaya, Kuala Lumpur, Malaysia, ${ }^{7}$ Department of Environmental Science, Policy, and Management, University of California, Berkeley, Berkeley, CA, United States, ${ }^{8}$ Department of Bioscience - Microbiology, University of Aarhus, Aarhus, Denmark, ${ }^{9}$ Department of Biology, The University of York, York, United Kingdom, ${ }^{10}$ Baltic Sea Center, Stockholm University, Stockholm, Sweden
\end{abstract}

Salt marshes are complex systems comprising ephemerally flooded, vegetated platforms hydraulically fed by tidal creeks. Where drainage is poor, formation of saline-water ponds can occur. Within East Anglian (UK) salt marshes, two types of sediment chemistries can be found beneath these ponds; iron-rich sediment, which is characterized by high ferrous iron concentration in subsurface porewaters (up to $2 \mathrm{mM}$ in the upper $30 \mathrm{~cm}$ ); and sulfide-rich sediment, which is characterized by high porewater sulfide concentrations (up to $8 \mathrm{mM}$ ). We present 5 years of push-core sampling to explore the geochemistry of the porewater in these two types of sediment. We suggest that when organic carbon is present in quantities sufficient to exhaust the oxygen and iron content within pond sediments, conditions favor the presence of sulfide-rich sediments. In contrast, in pond sediments where oxygen is present, primarily through bioirrigation, reduced iron can be reoxidised and thus recycled for further reduction, favoring the perpetuation of iron-rich sedimentary conditions. We find these pond sediments can alter significantly over an annual timescale. We carried out a drone survey, with ground-truthed measurements, to explore the spatial distribution of geochemistry in these ponds. Our results suggest that a pond's proximity to a creek partially determines the pond subsurface geochemistry, with iron-rich ponds tending to be closer to large creeks than sulfide-rich ponds. We suggest differences in surface delivery of organic carbon, due to differences in the energy of the ebb flow, or the surface/subsurface delivery of iron may control the distribution. This could be amplified 
if tidal inundations flush ponds closer to creeks more frequently, removing carbon and flushing with oxygen. These results suggest that anthropogenic creation of drainage ditches could shift the distribution of iron- and sulfide-rich ponds and thus have an impact on nutrient, trace metal and carbon cycling in salt marsh ecosystems.

Keywords: biogeochemistry, salt marsh, iron-sulfur, carbon, redox, diagenesis

\section{INTRODUCTION}

Salt marshes are highly productive coastal wetlands that serve a critical role in carbon sequestration and nutrient trapping (Valiela et al., 1978; Barbier et al., 2011; Mcleod et al., 2011). As a marginal environment poised between the terrestrial and marine realms, salt marshes are extremely vulnerable to changes in environmental conditions such as anthropogenic eutrophication/drainage, climate change and sea level rise (Deegan et al., 2012; Kirwan and Megonigal, 2013; Kennish, 2016). The delicate interplay between the redox cycles of sulfur, carbon and iron present in salt marsh sediments could potentially become unbalanced through anthropogenic change (Koretsky et al., 2006). This could have consequences for the overall storage of carbon in marginal marine environments; the production and release of methane from these environments; and the efficiency of nutrient capture which impacts the overall productivity of these ecosystems (Mcleod et al., 2011).

Salt marsh surfaces are highly heterogeneous; a largely vegetated platform is incised by a series of narrow, tidally fed creeks with varying cross sections (Allen, 2000; Lawrence et al., 2004). In the areas furthest from these creeks, where drainage is poor, ponds (also commonly referred to as 'salt pans') exist on the surface. These ponds can exist for long periods of time (1000+ years) (Pethick, 1980) and are sporadically flushed by tidal events which flood the vegetated platforms during high tides or storm surges (Santos et al., 2009). The formation mechanism of these ponds is uncertain, although it has been proposed that either physical processes (e.g., algal debris or heterogeneous development of the salt marsh) or biogeochemical processes (e.g., build-up of salinity in standing water or decay of deposited algal matter) are responsible for the initial formation of primary (wellrounded) ponds and senescence of creeks isolated by vegetation forms secondary (elongate-shaped) ponds, both of which can be present in the same salt marsh (Redfield, 1972; Pethick, 1974; Wilson et al., 2014). Ponds are more common where drainage is poorest (Wilson et al., 2014). As brackish water sits on the surface of these ponds, vegetation is prevented from colonizing, resulting in a set of feedbacks which allow these ponds to remain semi-permanent and respond to sea level change and other larger perturbations (Wilson et al., 2014).

The sediment beneath these ponds, and indeed throughout the salt marsh beneath the rhizosphere, is largely anoxic (Mills et al., 2016). In the ponds, the presence of a standing water column $(1-50 \mathrm{~cm})$ and the lack of surface vegetation limits the supply of oxygen into the sediment. In the absence of processes which would disturb the sediment (e.g., bioturbation or a rhizosphere), aerobic respiration is limited to a small boundary layer at the sediment surface $(<1 \mathrm{~cm})$ (Nealson, 1997). In the absence of sufficient oxygen, microbial life will use other electron acceptors roughly in order of decreasing free energy yield: nitrate, manganese, iron, sulfur; and finally, in the absence of other electron acceptors, organic carbon can be converted to methane through methanogenesis (Froelich et al., 1979). Which redox couple dominates in any anoxic sedimentary environment is not always as simple as the conventional redox ladder would suggest, instead depending on a myriad of environmental conditions such as $\mathrm{pH}$ and the availability and speciation of both electron donors and electron acceptors (Lovley and Chapelle, 1995; Bethke et al., 2011). The convergence of the accessible free energies of iron reduction, sulfate reduction and methanogenesis to similar values at the circumneutral $\mathrm{pH}$ conditions observed in these salt marshes means that small changes in these conditions can alter the dominant microbial community and thus the sediment geochemistry (Postma and Jakobsen, 1996; Bethke et al., 2011). Furthermore, interplay among the three redox cycles-iron, sulfur, and carbon-is common; various iron species can be used to reoxidise sulfide to intermediate valence state sulfur species, allowing for processes such as cryptic sulfur cycling (Holmkvist et al., 2011; Hansel et al., 2015; Mills et al., 2016; Blonder et al., 2017). This geochemical complexity is combined with periodic tidal flushing events which supply a range of different elemental species to the water column and sediment (Santos et al., 2009).

Here we investigate the controls on subsurface geochemistry and redox poising in salt marshes from East Anglia, United Kingdom (Figure 1A). We present data from two geographic areas-north Norfolk salt marshes found along the North Sea coast (Figure 1B) and an estuarine salt marsh on the River Blackwater in Essex named Abbotts Hall Farm (Figure 1F). These salt marsh systems contain two types of pond sediment porewater chemistry; sulfide-rich pond sediments, characterized by high sulfide concentrations (up to $6 \mathrm{mM}$ ); and iron-rich pond sediments, characterized by high ferrous iron concentrations (up to $1.5 \mathrm{mM}$ ) (Antler et al., unpublished). Previous work has shown that iron-rich sediments can be converted to sulfide-rich sediments in the laboratory through the addition of labile organic carbon, such as lactate, implying that the geochemical and redox conditions within these sediments may be susceptible to perturbation (Koretsky et al., 2006; Mills et al., 2016). Understanding the distribution of the different types of ponds will provide insight into the carbon budget in these salt marshes and could illustrate how future changes to these environments (e.g., sea level rise or land use change) might change the sedimentary geochemistry, leading to impacts on regional nutrient and carbon cycling.

We describe the geochemical nature of these pond sediments using multiple push cores taken over a 5-year period and an in situ sampler from which samples were collected over the 

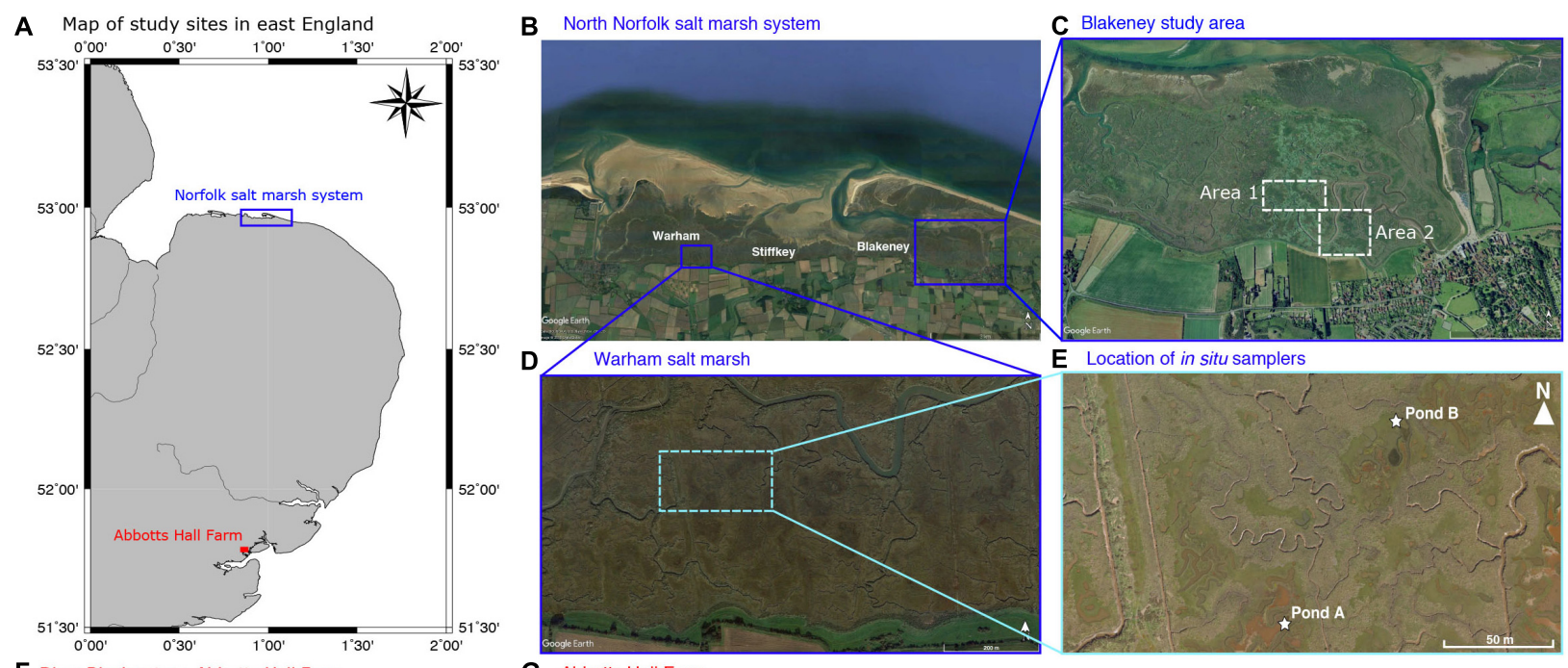

F River Blackwater + Abbotts Hall Farm
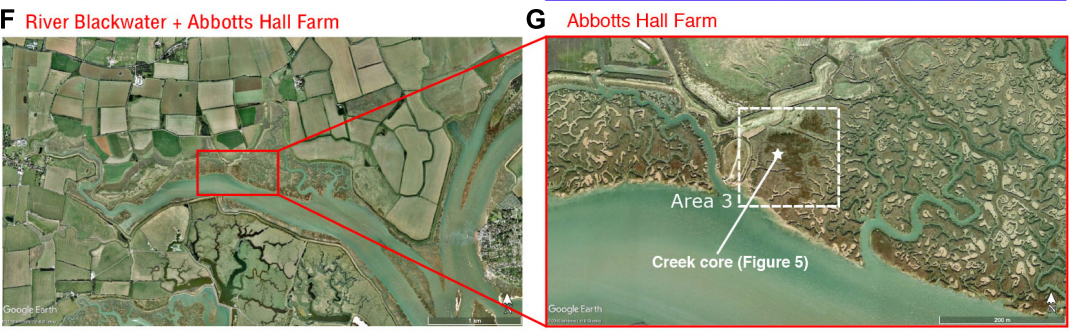

FIGURE 1 | (A) Map of east England showing the Norfolk salt marsh system and Abbotts Hall Farm nature reserve (Essex wildlife trust). Scale from latitude/longitude lines. (B) Google Earth satellite imagery (24-09-17) of the Norfolk salt marsh system comprising Warham marshes, Stiffkey marshes and Blakeney marshes (labeled). Cores in the data compilation were taken throughout this area. The blue box denotes the location of (D). Image credit: Google Earth, Image 2018 DigitalGlobe (C) Google Earth Satellite imagery (31-12-1999) of Blakeney salt marsh. Area 1 and 2 correspond to the mapped areas in Figures 7 and $\mathbf{8}$ respectively. (D) Google Earth satellite imagery (10-01-2019) of the Warham salt marsh area where in situ samplers are installed. Light blue box indicates location of (E). Image credit: Google Earth. (E) Location of in situ samplers (Pond A and B) in Warham salt marsh. (F) Google Earth satellite imagery (06-11-2006) of the River Blackwater and the location of Abbotts Hall Farm nature reserve. Red box denotes the location of (G). Image credit: Google Earth, 2018 Infoterra Ltd \& Bluesky. (G) Google Earth satellite imagery (06-11-1999) of Abbotts Hall Farm salt marsh system. Area 3 corresponds to mapped area in Figure 9. White star denotes location of core taken in Figure 5. Image credit: Google Earth, 2018 Infoterra Ltd \& Bluesky.

course of 1 year. A drone survey was carried out to map the distributions of the types of ponds to understand the mechanisms governing the pond sediment geochemistry. We offer potential hypotheses and areas of investigation for the observed spatial and temporal geochemical patterns. We test the distribution of overlying water depth on the pond sediment, the distribution of carbon within surface sediments and we look for evidence of groundwater fluxes in the salt marsh sediment for preliminary insights into the system.

\section{MATERIALS AND METHODS}

\section{Field Locations}

This study discusses fieldwork undertaken in salt marsh systems across East Anglia, both in Norfolk, United Kingdom and at Abbotts Hall Farm, Essex, United Kingdom (Figure 1). On the Norfolk coastline, protection offered by migrating barrier islands, spits and intertidal sand flats have allowed salt marsh systems to form since the start of the Holocene (Pethick, 1980). In Norfolk, our field locations are three developed areas of stable, upper salt marsh near the small towns of Blakeney, Warham, and Stiffkey (Figure 1B). Areas 1 and 2 for the drone mapping are locations in the Blakeney salt marsh area (Figure 1C). In these sites, the lower marsh is more recent (post-medieval) whereas the upper, stable, marsh is Romano-British (2000+ years) (Pethick, 1980). The upper marsh sediment consists of grayish-brown, silty sands and clayey silts, likely accumulated by vegetative capture of finer grained sediment, which sits upon a northward dipping boulder clay (Pye et al., 1990). Abbotts Hall Farm is a nature reserve on an estuarine portion of the River Blackwater (Figure 1F). Area 3 (Figure 1G) lies on the edge of this tributary (defined as fringed-estuarine) where low energy environments are protected from direct wave action (Allen, 2000). Sediment in this location was previously not well studied; we observe it to be similar to that in the Norfolk marshes, likely reflecting similar provenance of sediment.

\section{Porewater Collection}

Push core liners made of polyvinyl chloride (PVC) were used to extract vertical columns of sediment from ponds at irregular 
intervals over the period 2013-2018. One core, taken in May 2018, was pushed horizontally into the side of a creek at $20 \mathrm{~cm}$ depth. Porewater was extracted from the cores either in the field or within $24 \mathrm{~h}$ of being collected using Rhizons (syringe-based samplers with an inert polymer membrane). Samples for each core were taken at variable depth resolutions (between 1 and $4 \mathrm{~cm}$; see data table in Supplementary Information). Typically, between 2 and $10 \mathrm{~mL}$ of porewater was extracted from each depth sampled, depending on the sediment porosity and what was needed for analysis. Aliquots of porewater $(50-2000 \mu \mathrm{L})$ for ferrous iron analysis were fixed with $100 \mu \mathrm{L}$ ferrozine reagent; the precise amount of porewater depended on the amount of iron present. Aliquots (50-2000 $\mu \mathrm{L})$ for aqueous sulfide were fixed with excess quantities-dependent on sulfide concentration-of either 5 or $20 \%$ zinc acetate.

\section{Analytical Measurements}

All analytical measurements were carried out at the University of Cambridge. Dissolved iron concentrations [Fe(II)] were determined spectrophotometrically (Thermo Aquamate UV-Vis) according to the method described by Stookey (1970) with an error of $0.4 \%$. Dissolved sulfide concentrations were measured spectrophotometrically using the methylene blue method with an error of $2 \%$ and a detection limit of $1 \mu \mathrm{M}$ (Cline, 1969). Samples were diluted with ultrapure water to fit within a calibrated range. Major anion (sulfate and chloride) concentrations were measured by ion chromatography (Thermo Scientific Dionex ICS5000+) with an error up to $2 \%$ based on repeat analysis of standards. Samples measured for alkalinity were filtered using a cellulose nitrate membrane syringe filter $(0.2 \mu \mathrm{M}$, $47 \mathrm{~mm}$ ). Alkalinity was determined using the inflection point method by titrating 1-1.2 mL aliquots of filtered samples with $0.0166 \mathrm{M}$ analytical grade hydrochloric acid $(\mathrm{HCl})$. The $\mathrm{pH}$ was measured at $25^{\circ} \mathrm{C}$ on the NBS scale using an Orion 3 Star meter with a ROSS micro-electrode (ORION 8220 BNWP PerpHect ROSS).

Samples for sulfur isotope analysis were separated into vials and a supersaturated barium chloride solution was added, precipitating barite $\left(\mathrm{BaSO}_{4}\right)$. The barite was cleaned using $10 \% \mathrm{HCl}$, triple washed with ultrapure water, and dried. The $\delta^{34} \mathrm{~S}_{\mathrm{SO} 4}$ was determined through combustion on a Flash Element Analyzer (Thermo Scientific) coupled with continuous helium flow to a Delta V Plus mass spectrometer. Samples were corrected to NBS-127 barite standards $\left(\delta^{34} S=20.3 \% 0\right)$ which were run before and after sets of 20 samples. Based on blind replicates and repeat running of the standard, the data had precision of $0.2 \%$ ( $1 \sigma)$. Sulfur isotopic compositions are reported in standard

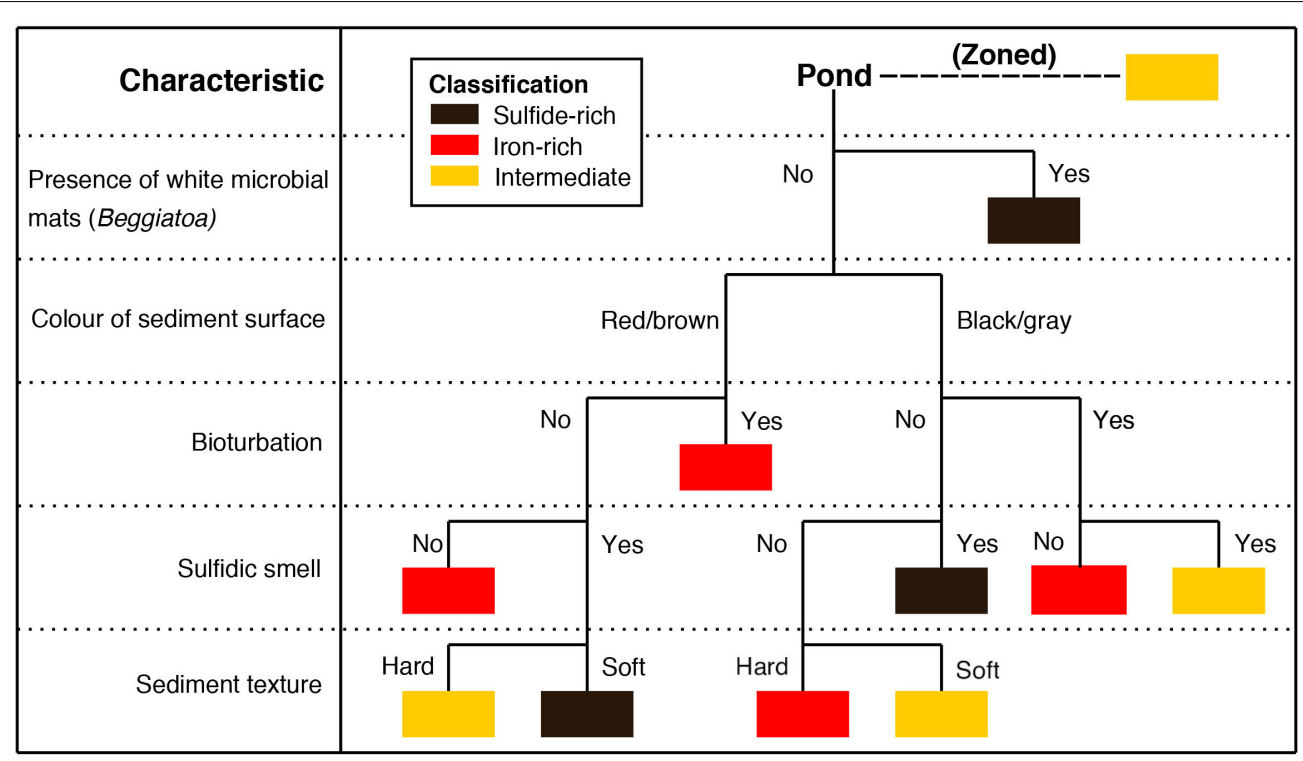

FIGURE 2 | Typical method of characterization of an individual pond based on features visible and/or easily testable from the surface. Flowchart is constructed in order of most diagnostic and most easily characterized (e.g., the presence of Beggiatoaceae and surface color are far quicker to differentiate than the sediment texture). The presence of white microbial mats, presumed to be Beggiatoaceae and resulting oxidized sulfur products present on the sediment surface, was decided to be sufficient enough evidence that sulfate reducing conditions were present in these ponds (Supplementary Figure S3). The color of the sediment surface was typically well differentiated; ponds were either a very dark gray color or had a red/brown tint to them (similar to iron oxide coloration). If the pond sediment surface was a different color to this or was a shade between the classifications, this category would be ignored for the classification. The presence of bioturbation was ascertained by worm casts seen on the sediment surface (Supplementary Figures S1, S2 for evidence). The presence of a single worm cast was deemed sufficient to assign a positive result to this category. The sulfidic smell property relates to a strong sulfidic odor when the sediment was removed from the water and handled. Sediment texture was determined by handling of the top $5 \mathrm{~cm}$ of sediment. When touched, certain sediments were clearly very soft and fluffy at the surface, whilst others had a stiffer clay texture. These would be defined as soft and hard respectively. Some characteristics were occasionally present but in spatially isolated zones on the pond (e.g., signs of bioturbation on one side of the pond and white microbial mats on the other). This is defined as 'zoned' on the diagram and ponds of this nature were classified as intermediate. This method is preferred to geochemical analysis as it is quicker than sampling and allows for rapid characterization of the salt marsh system. 
delta notation as per mil ( $\%$ ) deviations from the Vienna Cañon Diablo Troilite (VCDT).

\section{Mapping of Ponds}

We used a drone (Phantom 3 Standard) to create an aerial survey at a height of $150 \mathrm{~m}$ in May 2018. The orthophotos were assembled using the MapsMadeEasy website and the projection used for uploading to QGIS was WGS $8431 \mathrm{~N}$. We were unable to drone map Area 3, in Abbotts Hall, so we used Google Earth satellite imagery of the area. Two ground-truth campaigns-in May and July 2018-were undertaken to characterize pond sediment types from the drone images. Using the different surface characteristics typical of an iron-rich pond and a sulfide-rich pond (described in results), we were able to classify 350 ponds using the flowchart presented in Figure 2 (see Supplementary Table S1 and Supplementary Figures S1-S5 for full observed attributes and methods of characterization). For each pond visible in the aerial images, we would classify it as an iron-rich pond sediment, a sulfide-rich pond sediment or as 'intermediate' between iron-rich and sulfide-rich. The third category was necessary given that some ponds contained attributes of both iron- and sulfide-rich sediments. We attempted to characterize ponds directly from the drone imagery but this proved impossible given the variable surface colors and the small scale of the distinguishing features. At each pond, we measured the depth of the overlying water column using a tape measure. We also recorded the following characteristics for 267 of the 350 ponds for statistical analysis: the presence of algae (Supplementary Figure S5), signs of bioturbation (worm casts) (Supplementary Figures S1, S2), the presence of sulfur oxidizing bacteria (Beggiatoaceae) (Supplementary Figure S3) and signs of desiccation cracks (Supplementary Figure S6).

\section{In situ Sampling}

In order to monitor geochemical changes in individual pond sediments over time, in situ samplers were designed to allow repeated sampling of pond sediment pore fluids without disturbing the sediment. The submerged samplers consist of plastic frames to which Rhizon filters are attached at $2 \mathrm{~cm}$ intervals starting from the sediment-water interface to a depth of $34 \mathrm{~cm}$ (see Supplementary Figure S7 for construction). Outlets from the Rhizons were connected to sampling ports via airtight, double-walled, $(<60 \mathrm{~cm})$ tubes (polyethylene inner and polyvinylchloride outer, ID $=1 \mathrm{~mm}$ ) to the surface to which $10 \mathrm{~mL}$ syringes were attached for extraction. We selected spacing of $2 \mathrm{~cm}$ so that sampling volume from separate

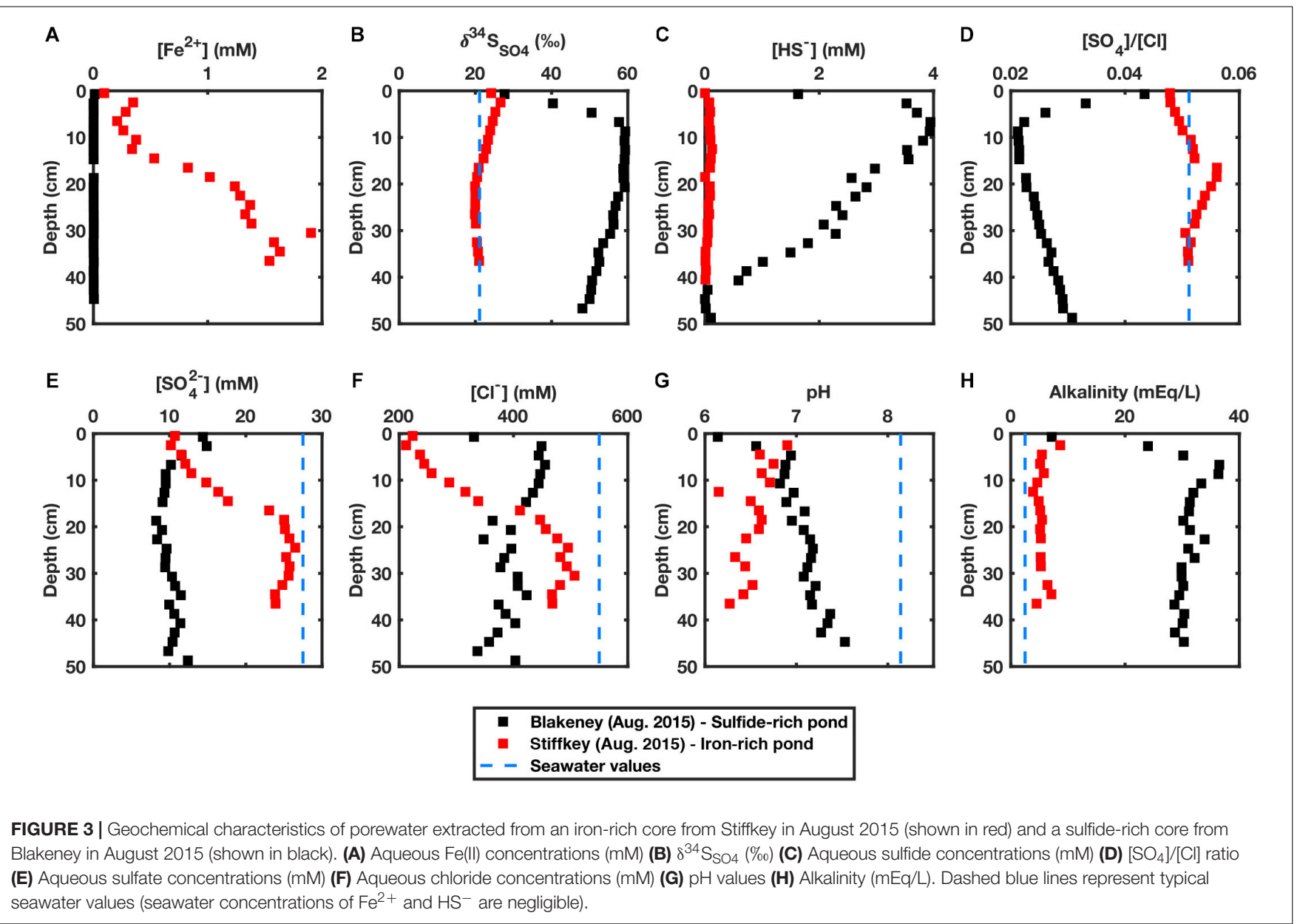


Rhizons remains discrete and does not result in artificial drawdown of surface water, based on tracer and modeling studies (Seeberg-Elverfeldt et al., 2005).

In situ samplers were installed in two Warham salt marsh ponds (termed Pond A and Pond B) in January 2017 (Figures 1D,E). Pond A appeared to contain sulfide-rich pond sediment-using the above criteria-whilst the other, Pond
$B$, an elongate pond in shape, was defined as intermediate. Samples of pore fluids from sediment in both ponds were collected in March, April, May, July, and November 2017, and May 2018. During each sampling, the stagnant fluid in the tubing (roughly $0.6 \mathrm{~mL}$ for $60 \mathrm{~cm}$ of $1 \mathrm{~mm}$ ID tubing) was first removed by extracting and discarding 1-2 $\mathrm{mL}$ of pore fluid from each outlet. Another $4-5 \mathrm{~mL}$ of pore fluid
A

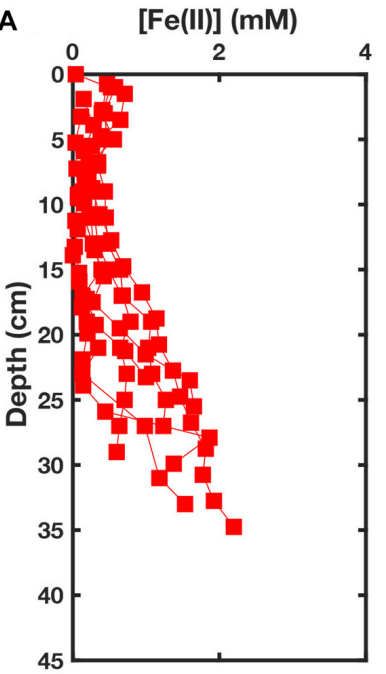

E

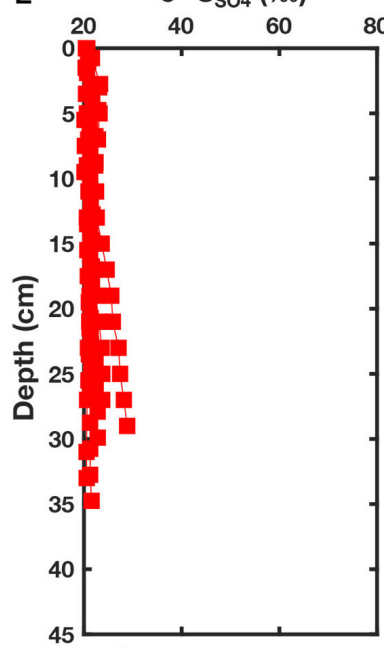

B

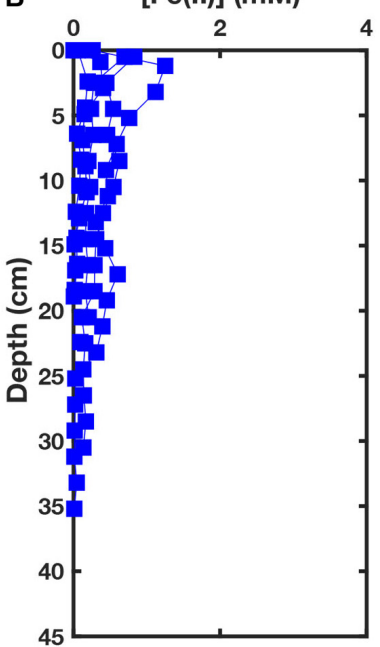

$\mathrm{F}$

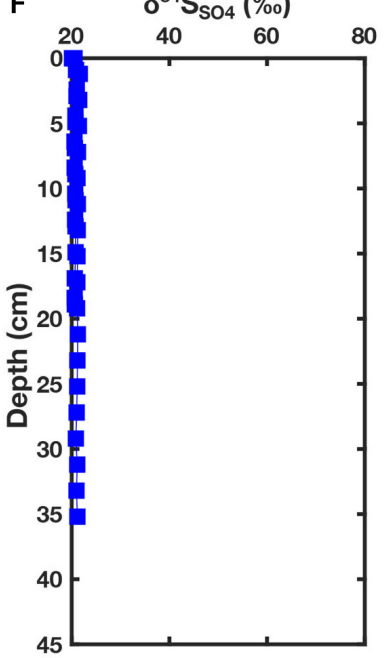

C

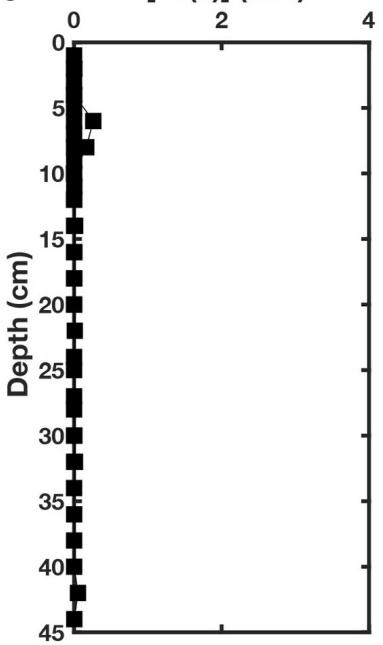

D $[\mathrm{Fe}(\mathrm{II})](\mathrm{mM})$

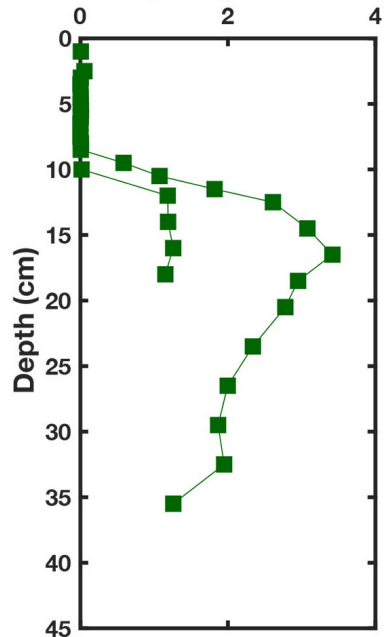

G

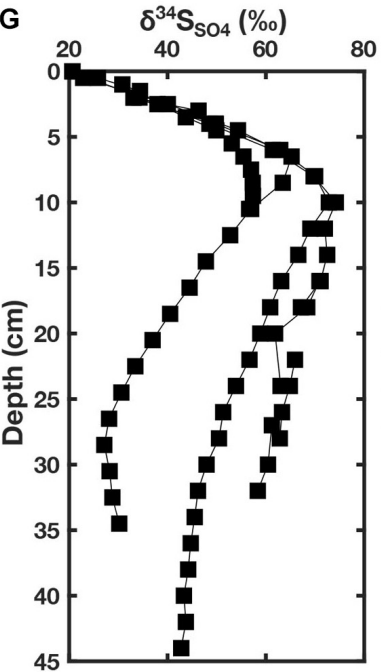

H
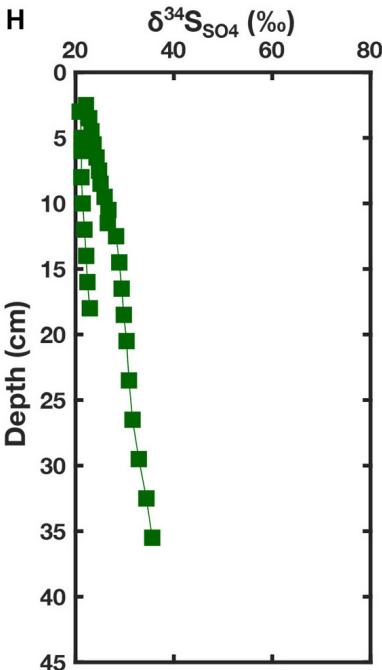

FIGURE 4 | (A) Fe(II) concentrations in iron-rich pond sediment porewaters, with increasing Fe(II) with depth, sampled in November 2013 (Warham), November 2013 (Stiffkey), January 2014 (Warham), May 2014 (Warham), October 2015 (Antler et al., unpublished), October 2015 (Stiffkey) and October 2017 (Blakeney). (B) Fe(II) concentrations in iron-rich sediment porewaters, with decreasing Fe(II) with depth, sampled in November 2013 (Stiffkey), November 2013 (Stiffkey), March 2014 (Warham), December 2017 (Blakeney) and December 2017 (Blakeney). (C) Fe(II) concentrations in sulfide-rich pond sediment porewaters. Only three cores [October 2015 (Antler et al., unpublished), October 2015 (Blakeney) and December 2017 (Blakeney)] are presented here since Fe(II) concentrations are typically below detection limit using our analytical method. (D) Fe(II) concentrations in sediment porewaters in cores taken from the vegetated platform in November 2013 (Warham) and October 2015 (Warham). (E) ${ }^{34} S_{\text {SO }}$ profiles in iron-rich pond sediment porewaters sampled in November 2013 (Warham), November 2013 (Stiffkey), January 2014 (Warham), May 2014 (Warham), October 2015 (Antler et al., unpublished) and October 2015 (Stiffkey) (Note: Not all cores present in subplot A are present here). (F) $\delta^{34} S_{S O 4}$ profiles in iron-rich pond sediment porewaters sampled in November 2013 (Stiffkey), November 2013 (Stiffkey) and March 2014 (Warham) (Note: Not all cores present in subplot B are present here). (G) $\delta^{34} S_{S O 4}$ profiles taken from sulfide-rich cores sampled in November 2013 (Blakeney), November 2013 (Blakeney), November 2013 (Blakeney), October 2015 (Antler et al., unpublished) and October 2015 (Blakeney). (H) $8^{34}$ Sso4 profiles from cores taken from vegetated platforms in November 2013 (Warham) and October 2015 (Warham). Vegetated cores are taken from the sediment surface whereas iron-rich and sulfide-rich pond cores have an undefined column of water on the surface. 
was then extracted for geochemical analysis. All depths were sampled simultaneously.

\section{Carbon Content Analysis}

In May 2018, sediment was taken from the surface of 30 ponds in Abbotts Hall (Area 3 on Figure 1G) using a $1 \mathrm{~mL}$ syringe with a cut edge. Sediments were dried and analyzed for total carbon content using a Costech element analyzer coupled via continuous flow to a Delta V mass spectrometer. Five samples were tested for the presence of carbonate minerals using a duplicate washed in $0.1 \mathrm{M} \mathrm{HCl}$ and subsequently triple washed with ultrapure water. As there were no carbonate minerals found, total carbon content is assumed to come from the organic carbon fraction.

\section{RESULTS}

\section{Sediment Cores Taken Over the 2013-2018 Period}

The subsurface geochemistry of ponds in the East Anglian salt marshes is reflected in characteristics observed at the sediment surface; iron-rich pond sediments are often stained red at the surface, contain worm casts and iron-oxide films are occasionally visible on the water surface; whereas sulfide-rich pond sediments are typically gray/black, commonly contain sulfide oxidizing bacteria on the sediment surface (Beggiatoaceae) and exude a strong sulfidic odor. Sulfide-rich pond sediments have a higher porewater methane concentration, in contrast, iron-rich pond sediments have no methane present (Mills et al., 2016).

Figure 3 shows porewater data collected from two cores; an iron-rich core taken from Stiffkey, August 2015, and a sulfide-rich core taken from Blakeney, August 2015. We note the key features of iron-rich versus sulfide-rich pond sediment porewater in Figure 3. In the iron-rich sediment there are high concentrations of ferrous iron, little change in the $\delta^{34} \mathrm{~S}_{\mathrm{SO} 4}$, near-zero aqueous sulfide, near seawater $\left[\mathrm{SO}_{4}\right] /[\mathrm{Cl}]$ ratios, lower overall $\mathrm{pH}$ and low alkalinity (Figure 3, red). In contrast, in the sulfide-rich pond sediment there is no measurable ferrous iron, an increase in $\delta^{34} \mathrm{~S}_{\mathrm{SO} 4}$ by $40 \%$, sulfide concentrations above $4 \mathrm{mM}$, lower $\left[\mathrm{SO}_{4}\right] /[\mathrm{Cl}]$ ratios relative to seawater, higher $\mathrm{pH}$ and higher pore fluid alkalinity (Figure 3, black). The concentration of both chloride and sulfate in the overlying pond water are lower than typical seawater. In particular, the surface $20 \mathrm{~cm}$ of the ironrich pond contains very low porewater chloride concentrations (200-400 mM, 30-60\% lower than seawater) (Figures 3E,F). We present these cores, collected in August 2015, separately (Figure 3) as they were the only two cores on which $\mathrm{pH}$ and alkalinity were measured in addition to other geochemical parameters. Figure 4 presents a more limited geochemical dataset collected from far more cores taken over the three field sites shown in Figure 1B between 2013 and 2017. Cores taken through the vegetated platform surrounding these ponds are included (denoted as 'vegetated') for an understanding of the porewater profiles in the rest of the marsh where there is an absence of ponds. In one case, we took multiple cores from the same sulfiderich pond and found near identical geochemistry across the pond (Supplementary Figure S8), thus we conclude each core accurately represents the geochemistry of the whole pond from which it was sampled.

Dissolved ferrous iron $\left(\mathrm{Fe}^{2+}\right)$ concentrations of porewater in our compilation of cores indicate that there are two broad types of pond sediments (Figures 3A, 4A,B). Ferrous iron in ironrich sediment porewater is present at millimolar concentrations, whereas concentrations are below the detection limit $(3 \mu \mathrm{M})$ in sulfide-rich sediment porewater (Figures 3A, 4C). We find, however, that there are variations in the general pattern of ferrous iron concentrations within pond sediments broadly classified as 'iron-rich.' In some cores, porewater ferrous iron concentrations increase with depth, sometimes reaching as high as $2 \mathrm{mM}$ at $35 \mathrm{~cm}$ depth (Figure $\mathbf{4 A}$ ). In these cores, lower ferrous iron concentrations are observed from 5 to $15 \mathrm{~cm}$, but iron and manganese oxides are visible, giving the sediments an orange hue in the core within this depth range. Conversely, in the other subset of 'iron-rich cores' there is a decrease in ferrous iron concentration with depth (Figure 4B). Ferrous iron concentrations in cores taken from the vegetated platform in Warham are near zero up to $8-10 \mathrm{~cm}$ from the surface (this coincides with the depth of root penetration) (Figure 4D). Below this rooting zone, porewater ferrous iron concentrations increase up to $3 \mathrm{mM}$-the highest observed in any of the cores.

Both types of iron-rich core have similar porewater $\delta^{34} \mathrm{~S}_{\mathrm{SO} 4}$, either a minor increase with depth or a constant $\delta^{34} \mathrm{~S}_{\mathrm{SO} 4}$ near that of seawater (Figures 3B, 4E,F). In sulfide-rich cores (Figures 3B, $4 \mathbf{C , G}), \delta^{34} \mathrm{~S}_{\mathrm{SO} 4}$ increases up to $70 \%$ by $15-25 \mathrm{~cm}$ depth below the sediment-water interface. This is coincident with an increase in sulfide concentrations and decrease in sulfate concentrations (Figures 3C,D). In vegetated cores (Figure $4 \mathbf{H}$ ), there is an increase of approximately $5-15 \%$ in $\delta^{34} \mathrm{~S}_{\mathrm{SO} 4}$ from 0 to $35 \mathrm{~cm}$.

It should be noted that absolute depths cannot be accurately compared among the sampled ponds because water depth was not always recorded in ponds where sediment cores were taken and we do not have elevation data for the salt marsh platforms. For the full compilation of geochemical data acquired on cores from 2013 to 2018, see the Supplementary Material.

In the core extracted from the creek wall edge, all geochemical measurements show large changes within $5 \mathrm{~cm}$ from the creeksediment boundary (Figure 5). In this zone, a threefold decrease in iron concentration is observed toward the creek edge. This is accompanied by higher concentrations of chlorine and sulfate and lower ${ }^{34} \mathrm{~S}_{\mathrm{SO} 4}$. From $5 \mathrm{~cm}$ inward, the geochemistry is much more stable. Ferrous iron concentrations are significantly higher $(6 \mathrm{mM})$ than those seen in the other cores taken.

\section{In situ Sampling From March 2017 - May 2018}

Two ponds were sampled using in situ samplers over the year from March 2017 - May 2018. Pond A (sulfide-rich pond) shows small seasonal variations in $\delta^{34} \mathrm{~S}_{\mathrm{SO} 4}$ of porewater sulfate with higher $\delta^{34} \mathrm{~S}_{\mathrm{SO} 4}$ observed in the summer and autumn months (Figure 6A). These variations are more pronounced in the upper $15 \mathrm{~cm}$ and values become more uniform (within 10\%) below this. Changes in $\delta^{34} \mathrm{~S}_{\mathrm{SO} 4}$ in Pond B (an intermediate pond) are far greater (Figure 6B); in March 2017, the $\delta^{34} S_{\mathrm{SO} 4}$ is constant with 
A

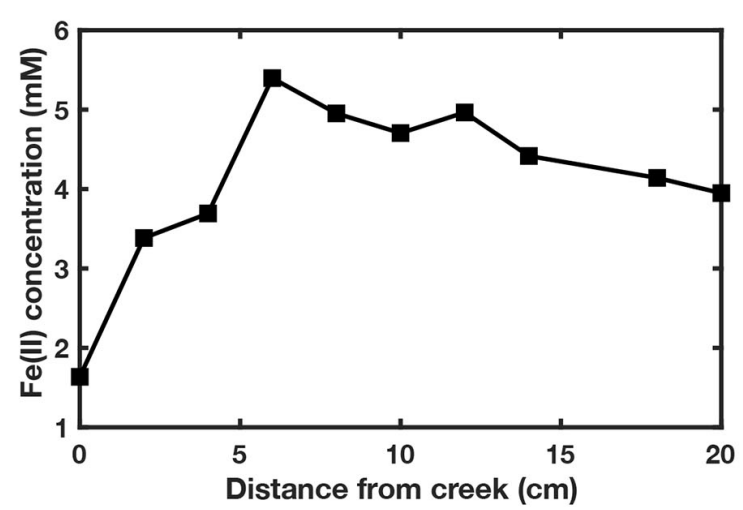

C

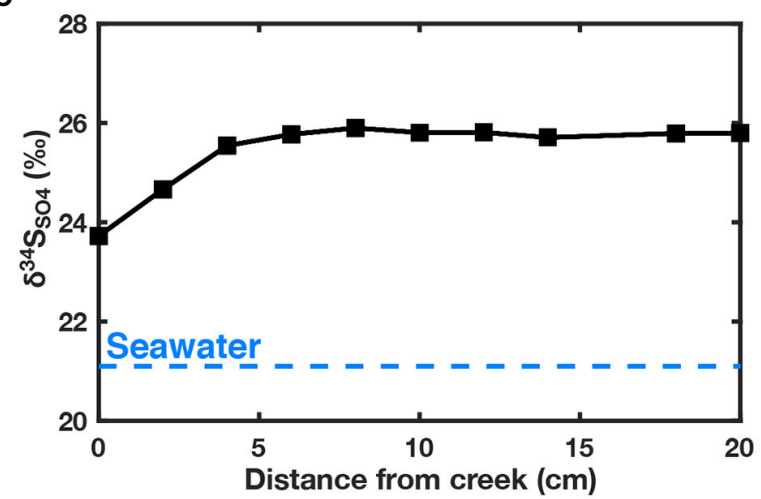

B

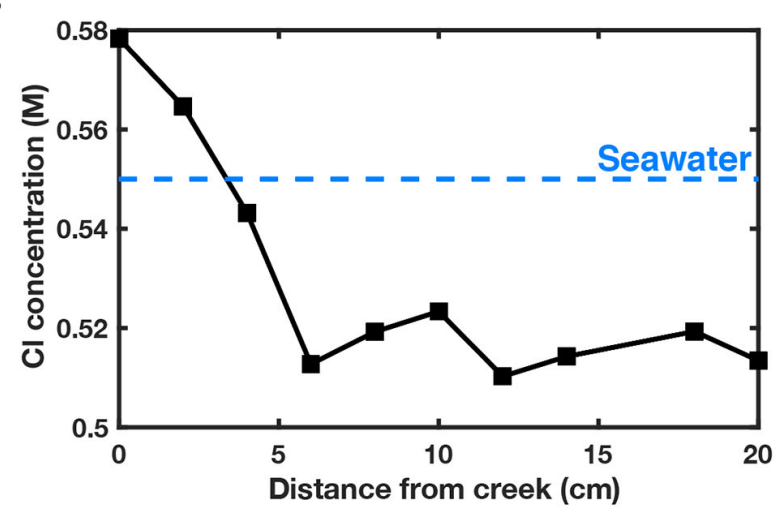

D

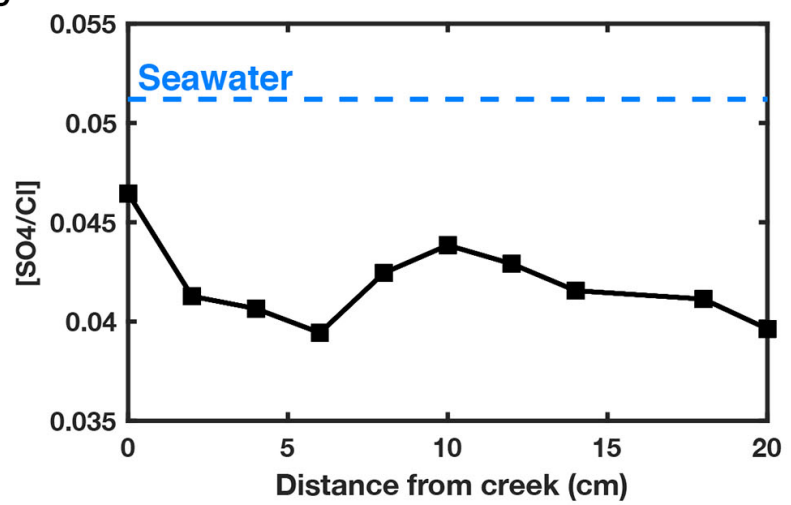

FIGURE 5 | Core horizontally extracted from creek wall (see Figure 1 for location). Depth is $20 \mathrm{~cm}$ from the surface of the salt marsh. (A) Fe(II) concentrations (mM) (B) $\mathrm{Cl}$ concentrations (M) (C) $\delta^{34} \mathrm{~S}_{\mathrm{SO}_{4}}$ (D) $\left[\mathrm{SO}_{4}\right] /[\mathrm{Cl}]$. Blue dashed line corresponds with seawater values. Location shown in Figure 1.

A

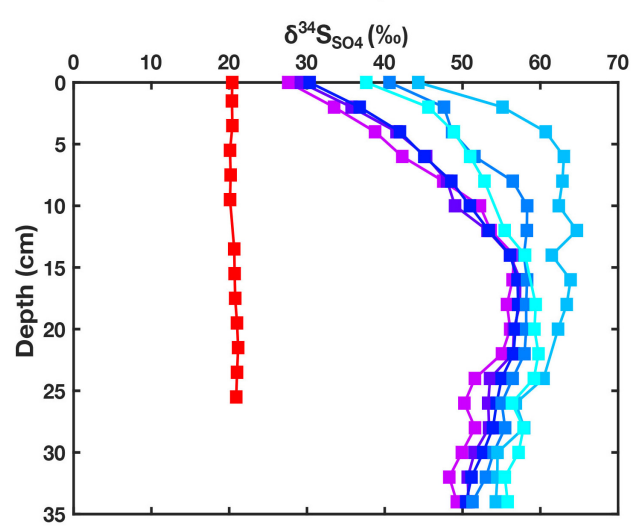

B Intermediate pond

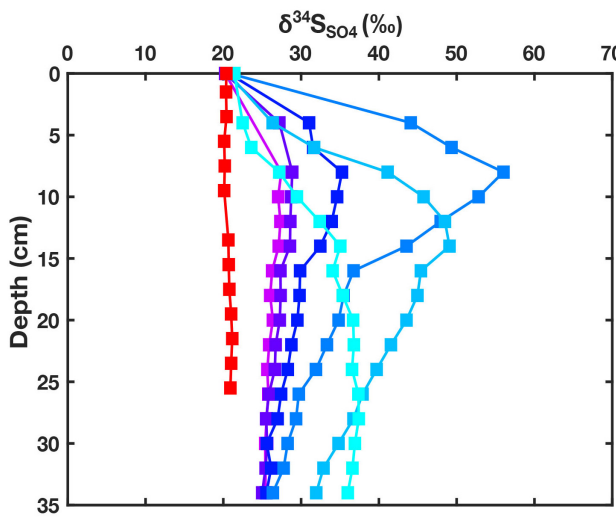

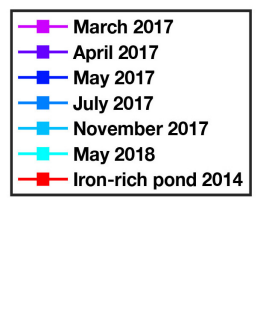

FIGURE 6 | (A) $\delta^{34} \mathrm{~S}_{\mathrm{SO}}$ measured in porewater samples over a 14-month period for pond A (sulfide-rich pond). Data from an iron-rich pond sampled in 2014 is added for comparison. Analytical uncertainty is $0.2 \%$. (B) $\delta^{34} S_{S O 4}$ measured in porewaters over a 14-month period for pond B (intermediate pond). Data from an iron-rich pond from 2014 is added for comparison. Analytical uncertainty is $0.2 \%$.

depth and only slightly elevated from the values seen in a 'typical' iron-rich pond. Ferrous iron concentrations were negligible in both ponds for months March-July and aqueous sulfide is present in both ponds in May 2018, albeit it at higher concentrations in Pond A (Supplementary Figure S9).
Whilst the pond sediment appears to become more sulfiderich with time, there is a decoupling between the shallow $(<20 \mathrm{~cm})$ and the deep zone $(>20 \mathrm{~cm})$. The shallow zone displays greatest ${ }^{34} \mathrm{~S}$ enrichment $-\delta^{34} \mathrm{~S}_{\mathrm{SO} 4}$ up to $55 \% 0$-during July 2017 before falling to lower $\delta^{34} \mathrm{~S}_{\mathrm{SO} 4}$ in November 2017 and May 2018. 


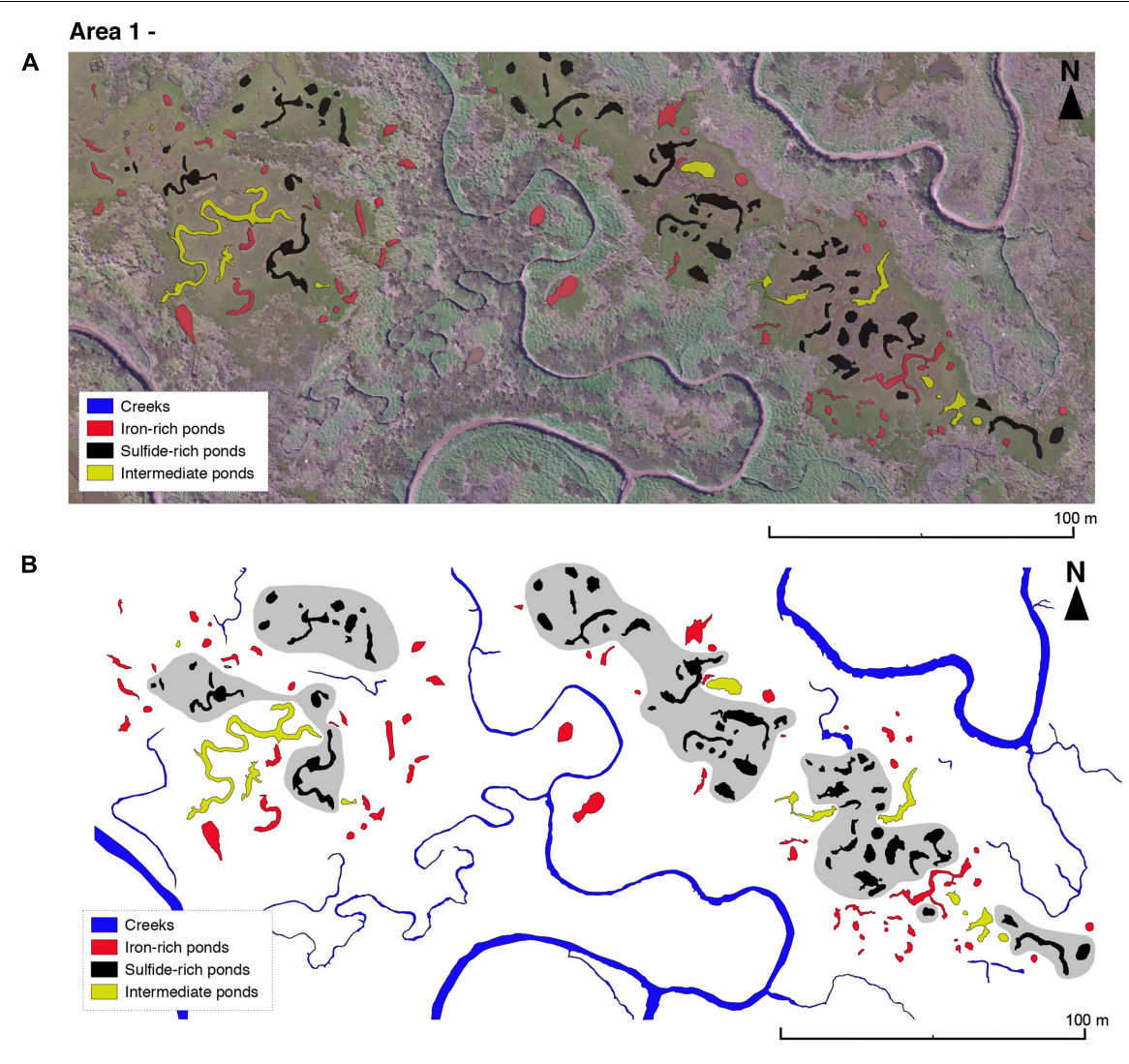

FIGURE 7 | (A) Drone imagery taken on 03/05/18 of two aggregates in Blakeney salt marsh area 1 (see Figure 1C) overlain by geochemical classification observed over the period from May and July 2018. We changed the classification of only two ponds between May and July 2018-both were changed from sulfide-rich to intermediate. (B) Geochemical classification of ponds sediments. Hypothetical, hand-drawn zones of sulfide-rich pond clustering shown in gray.

In contrast, the deep zone shows a consistent increase in $\delta^{34} \mathrm{~S}_{\mathrm{SO}}$ through time-up to $35 \%$ in May 2018.

\section{Mapping of Pond Distributions}

Two areas from the Blakeney salt marsh system were mapped using an aerial drone survey and an area in the Abbotts Hall salt marsh system (Figures 1F,G) was mapped using Google Earth satellite imagery (Figures 7-9). Area 1, from Blakeney (Figure 7) consists of two groups of ponds separated by a tidal creek. Ponds containing sulfide-rich sediment tend to be situated further from large creek networks than ponds containing iron-rich sediment (Figure 7B). The presence of sulfide-rich ponds is often accompanied by a region of standing water on the surrounding vegetated platform (visible in Figure 7A). Ponds of a similar geochemical and geomorphological nature appear to cluster in groups. Intermediate ponds, displaying neither or both criteria for iron-rich or sulfide-rich ponds, often lie at the boundary between iron-rich and sulfide-rich pond clusters. There are also clear differences in the vegetation over the marsh. The center of the platform is characterized by salt marsh 'lawn' species (typically some combination of Puccinellia spp., Salicornia spp., and Sesuvium portulacastrum) whereas the areas closest to the creek have larger species (Atriplex spp. and Suaeda spp.).
In an area of upper marsh (the oldest, most inland marsh) (Figure 1C), ponds with sulfide-rich sediment concentrate at the point furthest inland and iron-rich or intermediate ponds are located more toward the littoral zone (Figure 8). Drone imagery shows vegetation debris on the vegetated platform with sulfide-rich ponds (south of Figure 8A) and larger vegetation (likely Spartina patens) around the edges of sulfide-rich ponds (seen as gray patches surrounding ponds in south of Figure 8A). Proximity to larger creeks appears to favor the presence of ponds with iron-rich sediment (north in Figure 8A).

At Abbotts Hall, we observe a similar pattern of internal salt marsh ponds being more sulfide-rich (Figure 9B), albeit with more exceptions than in Areas 1 and 2 (from Norfolk). Ironrich vs. sulfide-rich pond sediment distribution does not seem to correlate with the type of vegetation observed on satellite imagery (Figure 9A). An artificial drainage ditch (north east of area) is proximal to an area of what we have defined as 'intermediate ponds.'

\section{Pond Characteristics and Water Depths}

There is a correlation between water depth and the type of pond sediment geochemistry; the average pond water depth in sulfidic pond sediments is deeper than that of iron-rich pond sediments [Area $1-$ mean iron-rich pond water depth $=20.2 \pm 5.0 \mathrm{~cm}$ 


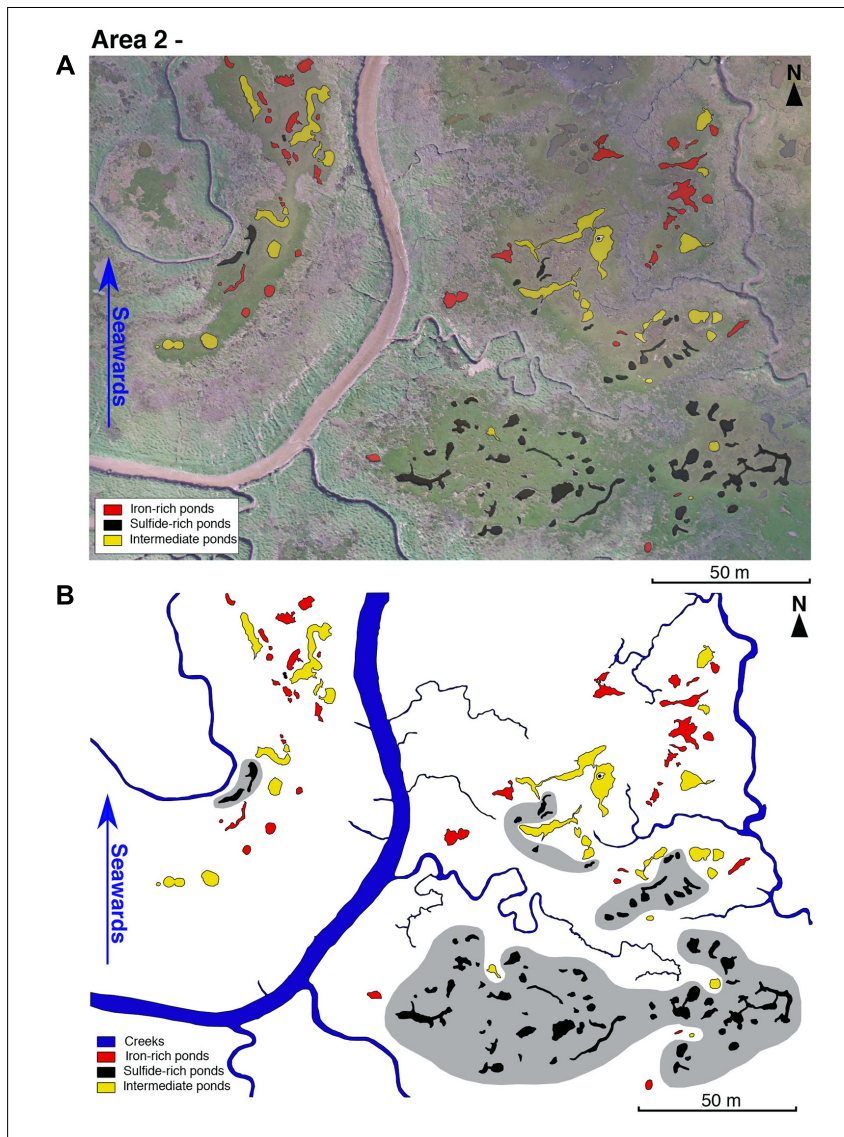

FIGURE 8 | (A) Drone imagery taken on 03/05/18 of an aggregate in Blakeney salt marsh area 2 (see Figure 1C) overlain by geochemical classification observed over period from May 2018. (B) Geochemical classification with hypothetical, hand-drawn zones of sulfide-rich pond clustering shown in gray.

( $n=60)$, mean sulfide-rich pond water depth $=24.1 \pm 4.7 \mathrm{~cm}$ $(n=50)$ (two sample $t$-test, $p<0.05$ ); Area 2-mean iron-rich pond water depth $=19.1 \pm 5.6 \mathrm{~cm}(n=40)$, mean sulfide-rich pond water $=22.4 \pm 5.5 \mathrm{~cm}(n=64)$ (two sample $t$-test, $p<0.05)$; Area 3-mean iron-rich pond water depth $=11.8 \pm 4.0 \mathrm{~cm}$ $(n=40)$, mean sulfide-rich pond water depth $=15.2 \pm 4.6 \mathrm{~cm}$ $(n=40)$ (two sample $t$-test, $p<0.05)$ (Figures 10B-E)].

After identifying the presence of certain features notable from the pond surface, (bioturbation evidence, presence of algae in the surface water, presence of Beggiatoaceae and the presence of desiccation cracks) we observe that cracks, evidence of a transient drying effect, are less prevalent in sulfide-rich ponds compared to iron-rich ponds and intermediate ponds (Figure 10A). This is consistent with the observation that sulfide-rich ponds in general have greater water depths and thus dry out less frequently (Figure 10E). Conversely, the presence of algae is common in sulfide-rich (90\%) and intermediate ponds (80\%) and yet is only present in $30 \%$ of iron-rich ponds. Since we used both the presence of white microbial mats (Beggiatoaceae) and bioturbation as tools for characterizing ponds, it is unsurprising that we find bioturbation to be common in iron-rich ponds and sulfide oxidizing bacteria to be negligible. Intermediate ponds contain any combination of characteristics; in particular, the presence of both algae and bioturbation was common (>70\%).

\section{DISCUSSION}

\section{Salt Marsh Pond Geochemistry}

In the absence of microbial data on the pond sediments, we use the porewater geochemistry, that is the concentrations of various redox-sensitive species, to infer the biogeochemical processes occurring within the sedimentary environment. For example, the presence of ferrous iron [Fe(II)] suggests that reduction of ferric iron is occurring, either through bacterial iron reduction (Equation 1) or the reduction of ferric iron coupled to sulfide oxidation (Equation 2). Similarly, the presence of aqueous sulfide would suggest the presence of either microbial sulfate reduction (Equation 3) or dissolution of sulfide-containing minerals in the environment. The $\delta^{34} \mathrm{~S}_{\mathrm{SO} 4}$ of the porewater sulfate allows us to identify the occurrence of microbial sulfate reduction because during microbial sulfate reduction, bacteria preferentially utilize sulfate with the lighter ${ }^{32} \mathrm{~S}$ isotope over the heavier ${ }^{34} \mathrm{~S}$ isotope. This leads an isotopically lower sulfide pool and a residual porewater sulfate pool enriched in the heavier isotope; the opposite would be true if there were dissolution of sulfide minerals. In this way we use the geochemistry that we have measured to infer the microbially driven processes that are occurring in the salt marsh sediment.

$$
\begin{gathered}
4 \mathrm{Fe}(\mathrm{OH})_{3}+7 \mathrm{H}^{+}+\mathrm{CH}_{2} \mathrm{O} \rightarrow \mathrm{HCO}_{3}^{-}+4 \mathrm{Fe}^{2+}+10 \mathrm{H}_{2} \mathrm{O} \\
\mathrm{HS}^{-}+2 \mathrm{Fe}(\mathrm{OH})_{3}+5 \mathrm{H}^{+} \rightarrow 2 \mathrm{Fe}^{2+}+\mathrm{S}^{\circ}+6 \mathrm{H}_{2} \mathrm{O} \\
2 \mathrm{CH}_{2} \mathrm{O}+\mathrm{SO}_{4}^{2-} \rightarrow \mathrm{H}_{2} \mathrm{~S}+2 \mathrm{HCO}_{3}^{-}
\end{gathered}
$$

Our data, along with $\mathrm{pH}$ and alkalinity, demonstrate that there are two broad classifications of pond sediment in the studied East Anglian salt marshes. Some pond sediments contain porewater with high $\delta^{34} \mathrm{~S}_{\mathrm{SO}}$, high quantities of aqueous sulfide and declining $\mathrm{SO}_{4} / \mathrm{Cl}$ ratios indicative of sulfate consumption; these pond sediments are interpreted to sustain high levels of microbial sulfate reduction. The other group of pond sediments contain porewater with near seawater $\delta^{34} \mathrm{~S}_{\mathrm{SO}}$, seawater $\mathrm{SO}_{4} / \mathrm{Cl}$ and high quantities of ferrous iron. These ponds are likely dominated by bacterial iron reduction, potentially in addition to a cryptic sulfur cycle in which reduced sulfur species are nearly quantitatively recycled back to sulfate (Mills et al., 2016). These pond sediments are referred to as sulfide-rich and iron-rich, respectively.

This broad dichotomy arises due to the titration reaction between sulfide and ferrous iron or iron monosulfides (Equations 4 and 5) which means only one of the species (the one in excess) can be present in significant quantities (Drobner et al., 1990). The pond sediment 'type' therefore reflects environmental conditions which favor production of either reduced iron or aqueous sulfide. The aim of this study is to understand why such contrasting sediment redox states can be seen separated by less than five meters and yet two sulfide-rich ponds, for 


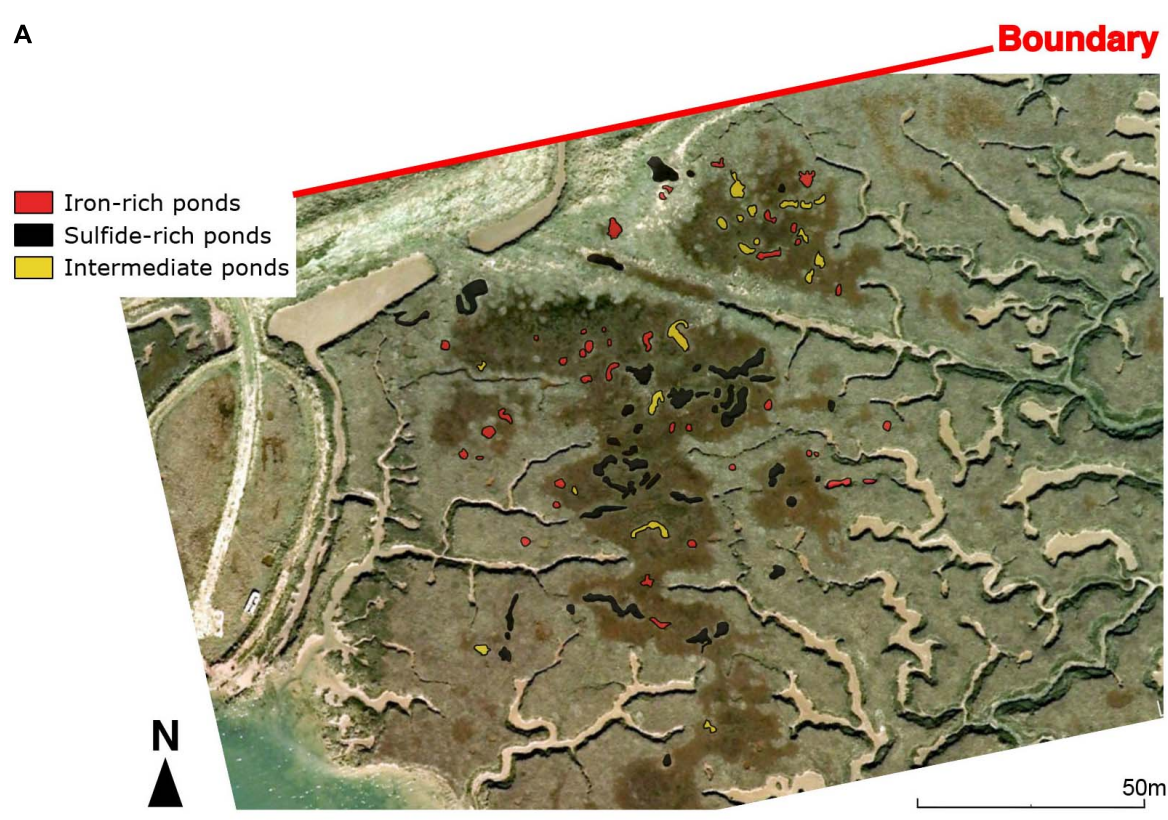

B

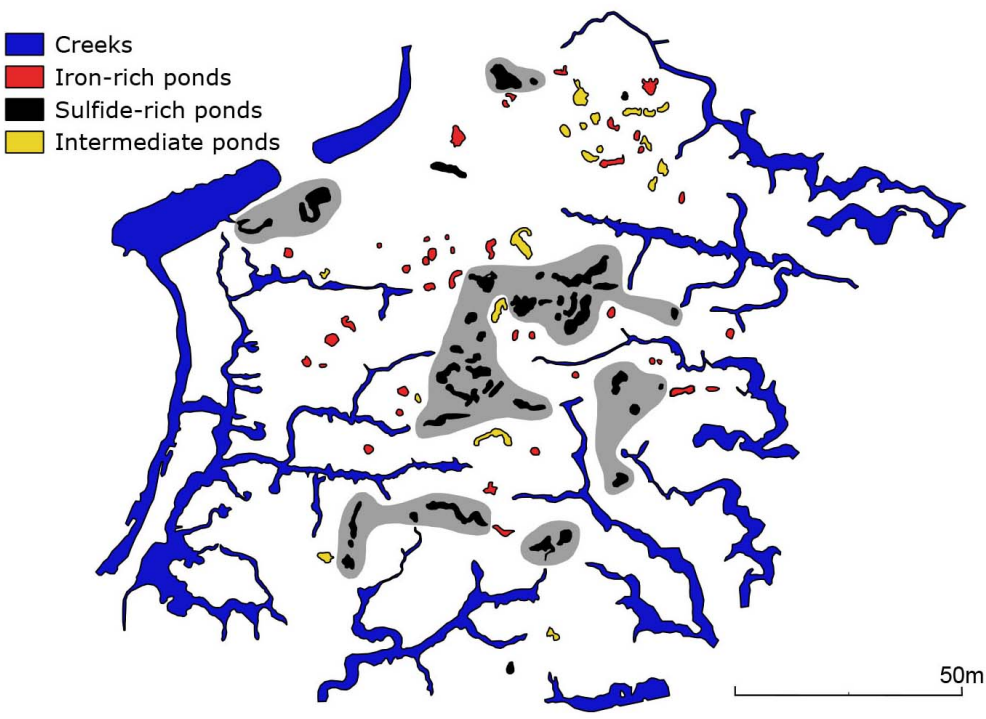

FIGURE 9 | (A) Google Earth imagery (06/11/2006) of the salt marsh system in Abbotts Hall (Area 3) (Figure 1G) overlain by geochemical classification observed in June 2018. (B) Geochemical classification with hypothetical, hand-drawn zones of sulfide-rich pond clustering shown in gray. Boundary depicted on panel (A) corresponds to landward extent of the salt marsh.

example, can be almost identical across hundreds of kilometers over East Anglia.

$$
\begin{gathered}
\mathrm{Fe}^{2+}+\mathrm{HS}^{-} \rightarrow \mathrm{FeS}+\mathrm{H}^{+} \\
\mathrm{FeS}+\mathrm{H}_{2} \mathrm{~S} \rightarrow \mathrm{FeS}_{2}+\mathrm{H}_{2}
\end{gathered}
$$

The conditions which favor certain microbial metabolisms are complex. In contrast to the canonical view of the redox ladder (Froelich et al., 1979), when $\mathrm{pH}$ is circumneutral there is a convergence of the useable energies for iron reducing bacteria, sulfate reducing bacteria, and even methanogenic bacteria
(Bethke et al., 2011). Furthermore, multiple studies have seen interplay among redox cycles (Mortimer et al., 2011; Hansel et al., 2015; Antler et al., unpublished).

We find evidence of this interplay; despite changes in alkalinity that are more consistent with iron reduction or sulfate reduction dominating a sediment, the fact that $\mathrm{pH}$ decreases with depth in the iron-rich core (Figure $4 \mathrm{E}$ ) is counter-intuitive because bacterial iron reduction consumes protons and thus raises $\mathrm{pH}$ (Soetaert et al., 2007). We suggest other redox reactions are working in tandem with bacterial iron reduction, causing the decrease in $\mathrm{pH}$. One example could be Equation (4) or the regeneration of ferric iron (Soetaert et al., 2007). The net result 


\section{A}

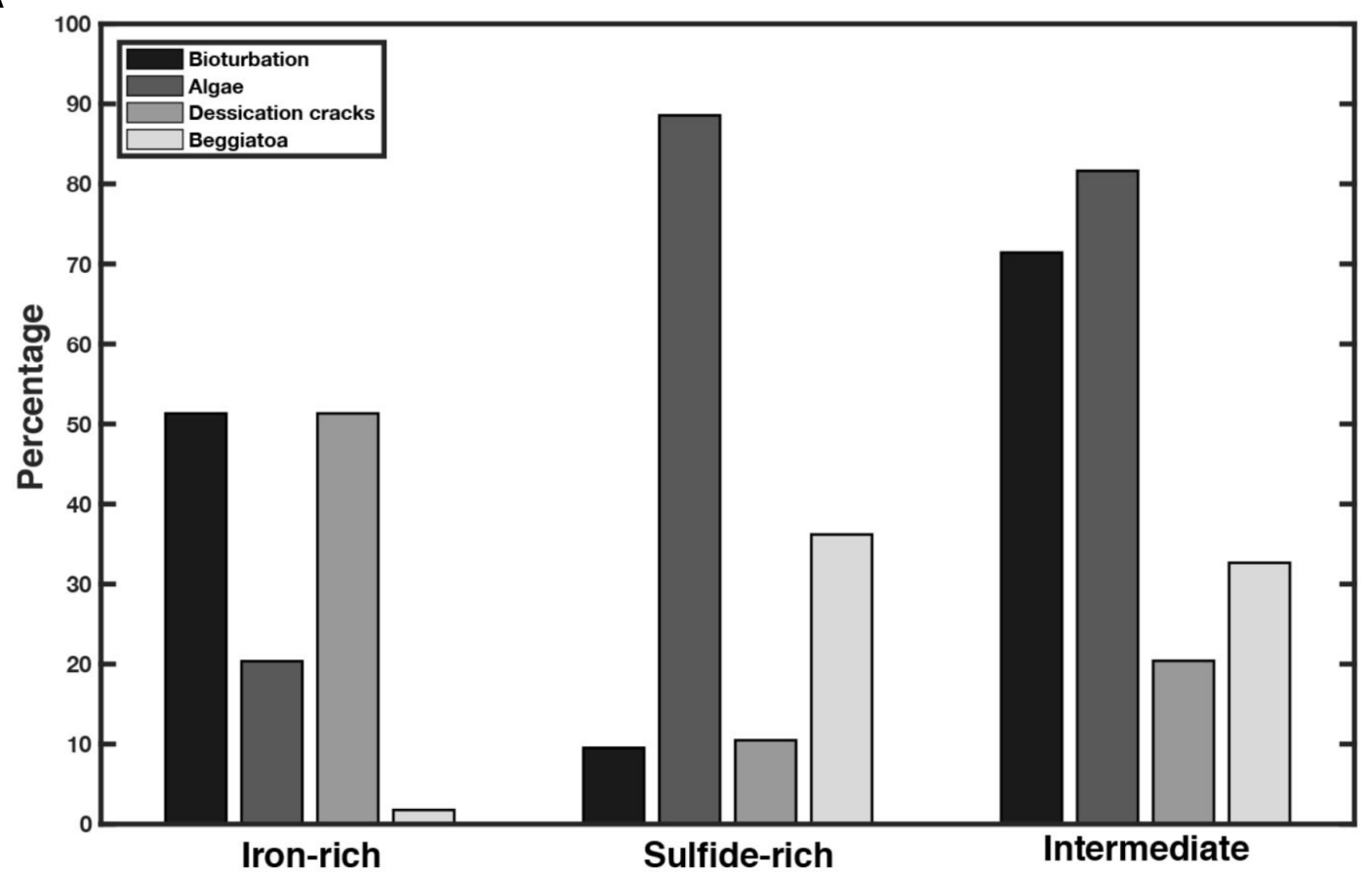

B

\section{Area 1}

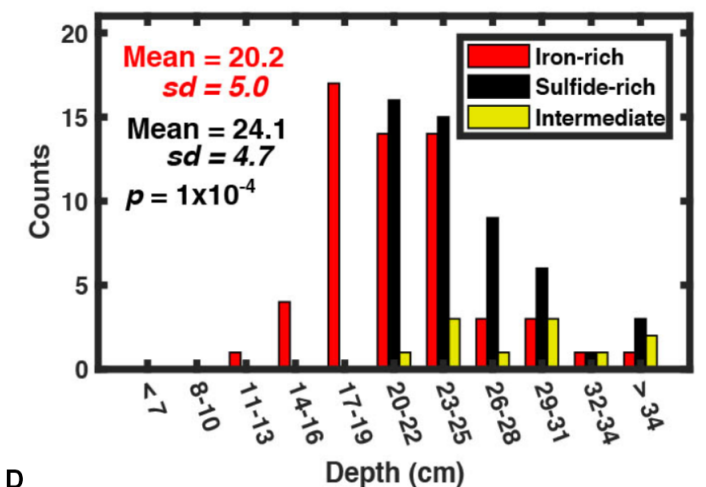

Area 3

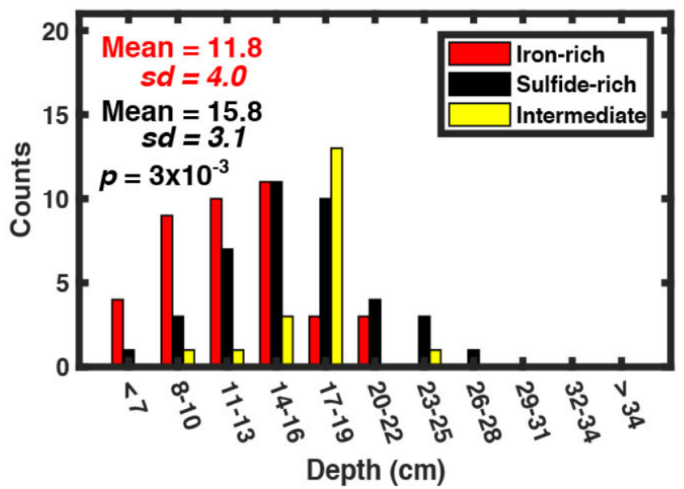

C

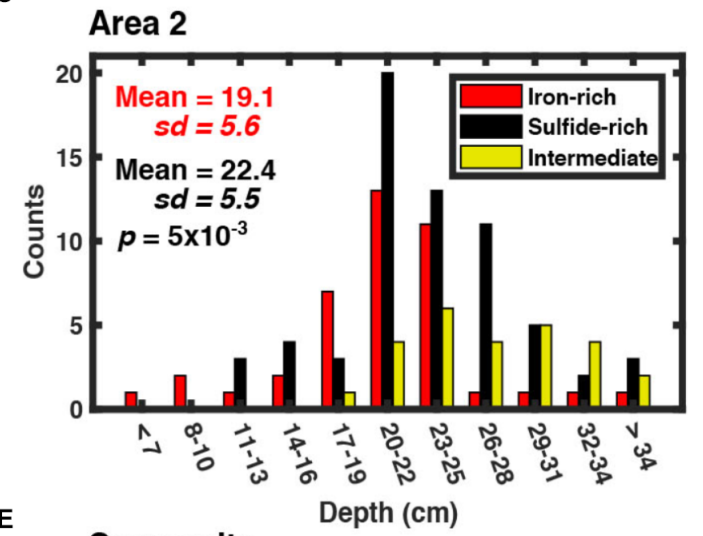

E

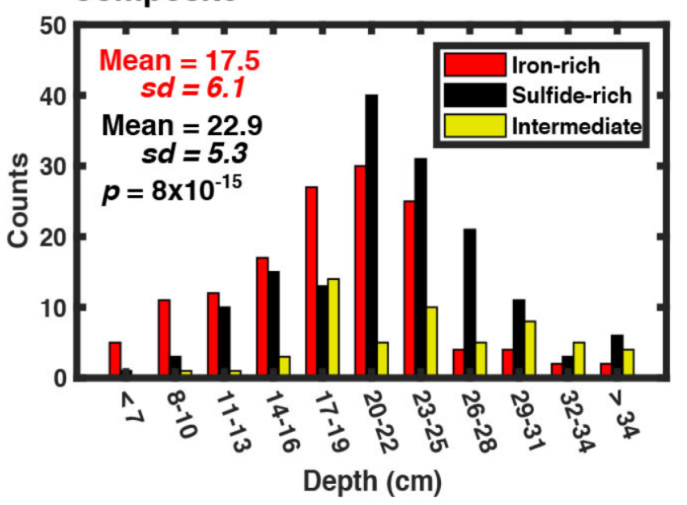

FIGURE 10 | (A) Characteristics [bioturbation, algae, desiccation cracks and sulfide oxidizing bacteria (e.g., Beggiatoaceae)] observed in each category of pond taken in the three areas. (B) Water depth measurements taken in Area 1 for each type of pond (17/05/18). P-value taken from $t$-tests testing the null hypothesis that there is no difference in water depth between pond classfications. (C) Water depth measurements taken in Area 2 for each type of pond (17/05/18). (D) Water depth measurements taken in Area 3 for each type of pond (19/06/18). (E) Composite made of all depth measurements taken from Area's 1, 2, and 3. 
of the reactions present are not well understood currently, and characterization of the fundamental chemical reactions involved is necessary to understand changes in sedimentary $\mathrm{pH}$. This complexity and closeness of energies among metabolisms means even subtle differences in the speciation and quantity of the electron acceptor; the speciation and quantity of the electron donor; and the influence of other redox cycles within the sediment could alter which metabolism, and therefore which geochemistry, dominates.

One observable difference is that $50 \%$ of iron-rich ponds contain evidence of bioturbation on the sediment surface (Supplementary Figures S1, S2), a result of species such as polychaete worms (Nereis spp.) and lugworm (Arenicola spp.) burrowing between 5 and $15 \mathrm{~cm}$ depth (Antler et al., unpublished). The amount of worm casts in iron-rich ponds and worm density in sediment varies substantially, although the $5-15 \mathrm{~cm}$ depth increment contains the highest density of worms (Antler et al., unpublished). This process would introduce pathways for oxic waters into an otherwise diffusion-dominated, anoxic system, potentially providing redox conditions which could regenerate ferric phase minerals [likely poorly ordered iron (oxyhydr)oxides] which become available for further bacterial iron reduction. Although sulfide produced through microbial sulfate reduction, thought to be active in iron-rich sediments due to the presence of reduced sulfide minerals, could titrate some of this iron away (Antler et al., unpublished), the ongoing regeneration of $\mathrm{Fe}$ (III) phases creates favorable conditions for iron reduction over other microbial metabolisms, resulting in high ferrous iron concentrations within the sedimentary porewater. Conversely, in sulfide-rich pond sediment, no worm casts are seen, implying there is no bioturbation. This is likely due to the build-up of aqueous sulfide, generating toxic conditions which preclude the presence of bioturbating organisms. A lack of bioturbation limits mixing of the surface sediment, and hence oxygen penetration within the system. This leads to a positive feedback mechanism where ferrous iron would react with sulfide instead of being regenerated into ferric iron phases. Microbial sulfate reduction would become the dominant reduction pathway, using seawater sulfate as the electron acceptor.

Within the broad categories of iron-rich and sulfide-rich sediment, we find pond sediment chemistry can vary in terms of absolute concentrations of either iron or sulfide. All ironrich cores have a depletion in ferrous iron concentrations from 5 to $15 \mathrm{~cm}$; as suggested above, bioturbation in this region introduces oxygen to the system and reoxidises most aqueous $\mathrm{Fe}(\mathrm{II})$. However, beneath this zone, ferrous iron concentrations in porewaters can either increase from 15 to $35 \mathrm{~cm}$ in some cores (Figure 4A) or continue to decrease to negligible concentrations below $15 \mathrm{~cm}$ (Figure 4B). No major difference is observed in the corresponding $\delta^{34} \mathrm{~S}_{\mathrm{SO} 4}$ (Figures $4 \mathbf{E}, \mathbf{F}$ ). This discrepancy among profiles of ferrous iron could be due to different iron minerals present at depth, though it is not intuitive why there would be significant differences in mineralogy or concentration of iron minerals over a salt marsh platform. Another potential reason for the increase in $\mathrm{Fe}(\mathrm{II})$ is reduction of Fe(III), coupled to deep sulfide oxidation in some cores (Mortimer et al., 2011; Hansel et al., 2015). This would be undetectable in sulfide or sulfate concentrations or $\delta^{34} \mathrm{~S}_{\mathrm{SO} 4}$ if it were near quantitative, implying some kind of 'cryptic' sulfur cycling was occurring (Holmkvist et al., 2011; Mills et al., 2016; Blonder et al., 2017). Further studies of the interconnectedness of the iron and sulfur cycles in these pond sediments are needed to refine this hypothesis.

There are also observed differences among porewater characteristics in sulfide-rich cores (Figure 4G); the maximum concentration of aqueous sulfide varies from 1 to $8 \mathrm{mM}$ among cores. The maximum porewater $\delta^{34} \mathrm{~S}_{\mathrm{SO} 4}$ also varies between sulfide-rich cores, from 50 to $75 \%$. These variations suggest that there are differences in the amount of microbial sulfate reduction compared to the sulfate reservoir or how close to isotopic equilibrium this reduction is occurring (Johnston et al., 2007). Overall, we suggest that, within the two broad groups of the pond sediment geochemistry, there is a continuum on which the pond sediment porewater geochemistry may exist between a concentrated sulfide-rich pond and a concentrated iron-rich pond. Consequently, what we have defined as intermediate ponds' would likely have characteristics consistent with both iron-rich and sulfide-rich porewater geochemistry. For example, if free sulfide is present, but in low quantities or only present in concentrated microenvironments, bioturbation may still be possible, which may drive some reoxidation of aqueous Fe(II).

Furthermore, we suggest that iron-rich pond sediment can transition to sulfide-rich pond sediment over relatively short timescales. In Pond B (Figure 6B), whilst March and April 2017 samples show similar $\delta^{34} \mathrm{~S}_{\mathrm{SO} 4}$ with depth to iron-rich ponds, later months (July 2017 onward) gradually exhibit higher $\delta^{34} \mathrm{~S}_{\mathrm{SO}}$, up to $35 \%$ higher than seawater. This is a phenomenon not observed in the wide array of cores (Figure 4) which either show constant near-seawater $\delta^{34} \mathrm{~S}_{\mathrm{SO} 4}$ (iron-rich cores) or a clear sulfate reducing zone with sulfate up to $75 \%, 55 \%$ over seawater $\delta^{34} \mathrm{~S}_{\mathrm{SO} 4}$ (sulfide-rich cores). Given that we sampled the cores from Figure 4 at different points throughout the year, we would expect at least some iron-rich cores or sulfide-rich cores to show evidence of larger seasonal variations. Furthermore, Pond A (Figure 6A), a sulfide-rich pond, shows seasonal variation of a smaller magnitude. Whilst there is clearly some cyclicity in the $\delta^{34} \mathrm{~S}_{\mathrm{SO} 4}$ profile (for example the two May samples), there is also some longer timescale transition toward more microbial sulfate reduction, particularly at depths greater than $30 \mathrm{~cm}$. Unfortunately, the paucity of longer term data prevents us from drawing conclusions on the speed of these transitions and thus we merely speculate that there are both seasonal and non-seasonal changes taking place. A natural extension also exists that the mechanism determining spatial distribution (as discussed below) may alter how extensive sulfate reduction is within a given pond.

\section{Hypotheses for Spatial Distributions}

Prior to this study, few studies have tried to understand what might drive a pond sediment toward iron- or sulfiderich conditions. Antler et al. (unpublished) proposed the idea that a transient flux of iron may be delivered to certain ponds, stimulating a sulfide-rich to iron-rich transition through bioturbation-related feedbacks. Mills et al. (2016) showed 
that addition of labile organic carbon was able to alter pond sediment geochemistry from iron-rich to sulfide-rich. However, no environmental study has so far attempted to relate the geochemistry of the pond sediments with their spatial distribution on a salt marsh. Of the 350 ponds, we classified 140 as iron-rich, 154 as sulfide-rich and 56 as intermediate. Whilst this suggests a similar number of iron- and sulfiderich ponds in salt marsh systems, we observed no sulfiderich ponds in some areas specifically in the Stiffkey area and we find the quantity of the three types of pond to vary from area to area. Our results suggest that ponds classified as containing sulfide-rich sediment are more likely to be located away from larger creek networks. This result was consistent across two sites; Area 1, in Blakeney (Figure 7), Norfolk; and Area 3, Abbotts Hall, Essex (Figure 9). Given the spatial separation of over $100 \mathrm{~km}$ between these sites, we believe that this correlation is likely not a local phenomenon and instead is a result of more widespread, pervasive, processes. We suggest that Area 2, where iron-rich pond sediments seem to be present moving into the littoral zone, is merely an extension of this creek-pond relationship but on a larger scale. In other words, sulfide-rich pond sediment is more common in areas which we would assume to be less frequently flooded (either further inland or further from the creeks which provide seawater inundation at high tide events). We find that the distribution of pond sediments adheres to this relationship with regards to modern drainage ditches. For example, in Abbotts Hall (Figure 9), pond sediments to the north of a small drainage creek (linear ditch) are all classified as intermediate or iron-rich. This, combined with evidence from our in situ sampling-that pond sediments are capable of geochemical 'switching'-may be an indication that the building of ditches could change pond sediment geochemistry. This observed distribution is not absolute and small-scale exceptions are seen where sulfide-rich pond sediment can be next to a creek. We attribute this to the complex hydrology and geochemistry in these salt marshes.

Almost all ponds appear to exist on lawn vegetation (as described above) as opposed to within the taller vegetation closer to the creeks. This is likely simply because standing water, and subsequent formation of these ponds, is more likely to exist in the lower energy zone where lawn vegetation is present. We have not established if the vegetation type of the adjacent platform surrounding a pond affects pond sediment geochemistry.

We offer three possible hypotheses for the distribution of pond sediment geochemistry in salt marsh ponds we observe: (1) heterogeneity in water depths overlying the pond sediment over a platform could produce differences in the supply of oxygen, relative to other electron acceptors available in the sediment, allowing different metabolisms to dominate; (2) differences in the source or type of organic carbon supplied to the sediment could vary based on a pond's position on a platform; and (3) subsurface water flows could deliver reactants in varying quantities to ponds based on their position on a platform. We will consider each of these in turn.

\section{Water Depth Controls}

The depth of the water column overlying the pond sediments gives an indication of how deep the hollow containing a pond is from the vegetated surface to the sediment-water interface. This is because the major input of water is the tidal inundation events which periodically cover the salt marsh and the output is largely through evaporation. Though there is likely some aspect of groundwater flow contributing water to the salt marsh system, the hydraulic conductivity within this setting is very low; a $2 \mathrm{~m}$ head difference is observed between a pond and a creek horizontally less than $20 \mathrm{~cm}$ apart. As such, unless tidal inundation events vary over a platform (discussed later), the depth of the sediment-water interface compared to the vegetated surface likely controls the water column depth.

The mean water depth of the sulfide-rich ponds is greater than for iron-rich ponds in all three areas $(p<0.05)$. There is, however, no threshold value where it can be said that if a pond is deeper by this amount, it will have a sulfide-rich subsurface geochemistry. We do observe, however, that there is greater disparity when ponds are either very shallow $(<10 \mathrm{~cm})$ or very deep $(>30 \mathrm{~cm}$ ) (Figure 10E). The correlation between water depth and subsurface geochemistry is weaker in the depth range between 16 and $28 \mathrm{~cm}$ (75\% of the classified ponds) in Norfolk (Areas 1 and 2) and between 11 and $19 \mathrm{~cm}(67 \%$ of the classified ponds) in Essex (Area 3)-where the average water depth is shallower. We suggest the relationship between water depth and sediment geochemistry is coincidental. Given that photosynthetic and wind driven sources of oxygen should be largely independent of water depth, small changes in water depth are unlikely to generate large differences in oxygen fluxes to the sediment. Instead, we speculate that ponds further from creeks are simply more likely to be older (as standing water is more likely to exist at this point). The depth of the sediment water interface increases with this increase in the age of a pond because vegetated capture of sediment causes the platform to accrete faster relative to the pond (Spivak et al., 2017) and because continual decomposition of organic matter (which has high porosity) leaves a residual mud layer (which has low porosity), decreasing the volume of sediment (Van Huissteden and van de Plassche, 1998). We suggest, due to the lack of a threshold depth dictating pond chemistry, that some other factor is driving the pond sediment geochemistry distribution.

If, however, ponds are sufficiently shallow that they become perennially exposed to the atmosphere by evaporation, desiccation cracks extending as deep as $15 \mathrm{~cm}$ can form (Supplementary Figure S6). Evidence of desiccation cracks is observed far more in iron-rich pond sediments (50\%) than sulfide-rich pond sediments (5\%)-particularly in Abbotts Hall (Supplementary Figure S10)-which suggests this may be an important 'perturbing' factor capable of favoring iron-rich environments (Figure 10A). We suggest that these cracks act as conduits allowing atmospheric oxygen and, upon re-submergence, oxygen-rich floodwater into a previously anoxic environment. This could regenerate Fe(III) (oxyhydr)oxides and allow bioturbating organisms into the 
sediment (as seen in Supplementary Figures S11, S12)leading to favorable conditions for bacterial iron reduction (Antler et al., unpublished). Conversely, very deep ponds will likely favor sulfide-rich sediment conditions. As the water column is less likely to be fully evaporated, in situ growth of vegetation can provide a larger source of carbon to the sediment (discussed below).

\section{Carbon Controls}

Our second hypothesis suggests differences in the form and quantity of available organic carbon (i.e., the electron donor) delivered to pond sediment may play a significant role in influencing the subsurface heterogeneity. We postulate that the balance of the distribution of oxygen and carbon plays a key role in the redox dynamics of the sediment. It is possible that there is heterogeneity in the delivery of sulfate or iron, however, we dispute this as both are in excess in this local system. There is a high sulfate flux to ponds from the tidal inundation events which periodically flood the platform with seawater. As such, sulfate concentrations in the ponds do not approach zero, even in sulfide-rich pond sediments with extensive sulfate reduction (Figure 3). This suggests that sulfate reduction rate is not limited by sulfate concentration in the water column. The iron content in the fine-grained sediment across East Anglia, as is present in these salt marshes, is supplied by cliff erosion (McCave, 1987). The nearby Crag formation, the likely provenance of the majority of the sediment, contains high iron concentrations (originally from glauconite) which will cause the geochemical composition of the sediment to be iron-rich (Hamblin et al., 1997). This is further supported by the overall high iron content ( $>1 \mathrm{mM}$ ) seen in the vegetated platform sediment porewater (Figure 4D). The majority of the pond sediments, upon formation, are therefore unlikely to be limited by iron or sulfate supply. The supply of organic carbon and dissolved oxygen (DO) over the salt marsh is somewhat more complicated; carbon from organic matter is supplied by a combination of terrestrial inputs, in situ growth, and erosion of the vegetated edges of the ponds. Whilst we do not have water column DO measurements, we would expect large variations over diurnal cycles, from possible supersaturation in the day to significant undersaturation at night.

A higher amount of organic carbon relative to ferrous iron would favor the onset of microbial sulfate reduction in the sediment. The presence of bioturbating organisms introduces oxygen to the system through mixing of the upper $15 \mathrm{~cm}$ of sediment and this reoxidises the reduced Fe(II) pool, keeping the concentration of $\mathrm{Fe}$ (III) high relative to the content of organic carbon. Over time, if random events or organic matter accumulation lead to a condition where the Fe(III) pool is sufficiently exhausted to allow the onset of microbial sulfate reduction, this could cause a switch to sulfide-rich geochemical conditions. This will happen if the sulfide concentration builds up to where it can titrate all $\mathrm{Fe}(\mathrm{II})$ as iron monosulfides, essentially removing the possibility of iron regeneration. Sulfide will then be in excess in the system; the toxicity imparted by free sulfide prevents bioturbation and acts as a positive feedback mechanism which enforces the 'switch.' This also explains the characteristic black color observed in sulfide-rich sediments.

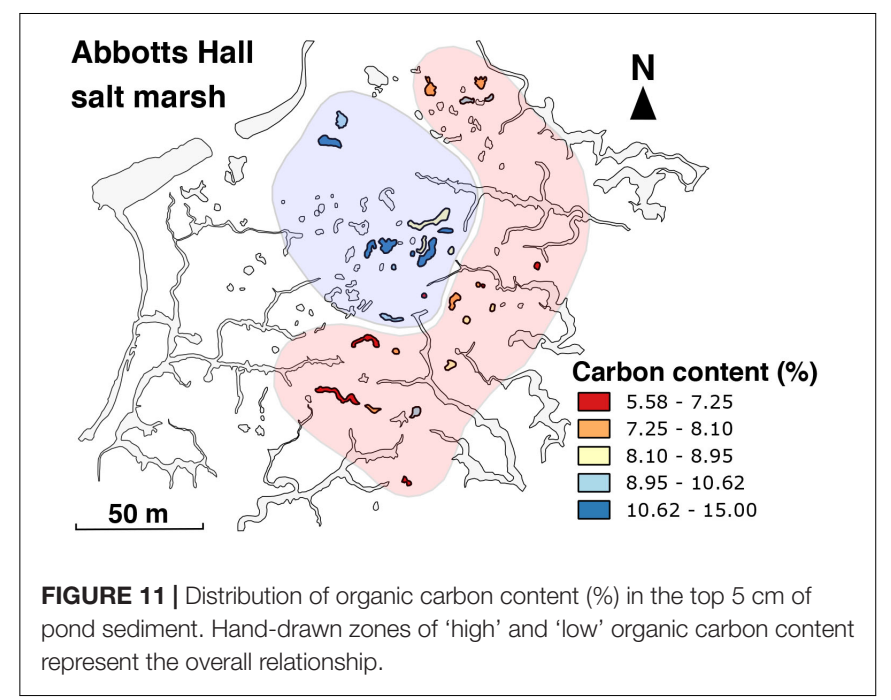

The importance of the amount of organic carbon in 'tipping' the system has been shown previously in laboratory incubations with lactate (Koretsky et al., 2006; Mills et al., 2016). The measurement of organic carbon content in the upper $5 \mathrm{~cm}$ in sediment in ponds at Abbotts Hall (Area 3) allows insight into the quantity of carbon delivered to the ponds. We find sulfide ponds to have significantly greater organic carbon content in the upper $5 \mathrm{~cm}(p<0.05)$ (one outlier was excluded from this which was 2 SD from the mean). We also observe that ponds near the creeks have lower organic carbon content (Figure 11).

We hypothesize that if a pond is proximal to the creeks, it is susceptible to more flooding events and thus any organic carbon, present as dissolved organic carbon, in situ vegetation or marine algae, would be periodically flushed more regularly than ponds located centrally (Spivak et al., 2017). Additionally, the drag imparted by the rough, vegetated surfaces mean that particulate organic carbon is more likely to be deposited in the center of the platform, as the water loses energy during the ebb flow back to the creeks (Figure 12B). This mechanism may help explain why sulfide-rich ponds are located further from creeks (Figures 7, 9). On larger scales, more inland salt marsh areas would also be less affected by these flooding events due to the loss of energy of water as it travels up the platform (Figure 12B). This correlates with what we show in Figure 8, where ponds with sulfide-rich sediment are located further inland. The presence of algal debris on the surface in drone imagery (Figure 8A) reinforces this.

This effect of carbon flushing will likely be convolved with the probability that more frequent flooding events add more oxygenated seawater to ponds proximal to creeks (i.e., oxygenrich water gets added to water which has been stripped of oxygen by aerobic respiration). This would enhance aerobic respiration of organic carbon, lowering the amount of organic carbon available to sustain subsurface microbial activity (Figure 12C). More central ponds, however, are more hydrologically isolated and are less regularly flushed (Figure 12C). This allows for the in situ growth of vegetation, causing a greater organic carbon supply to the sediment (while the oxygen produced through 


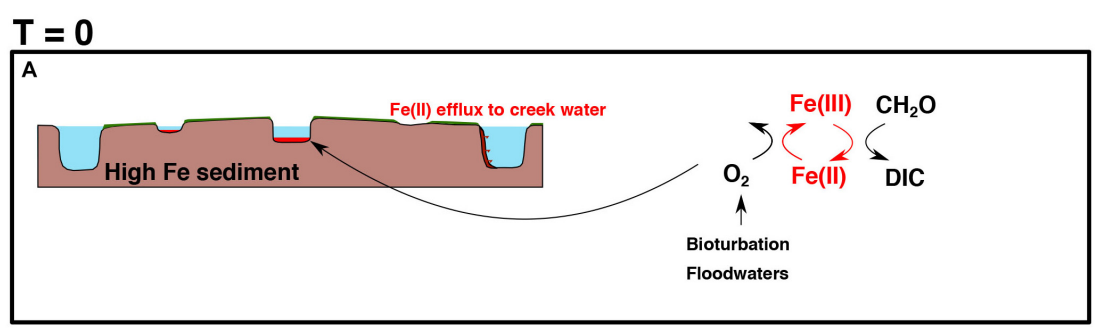

$T>0$

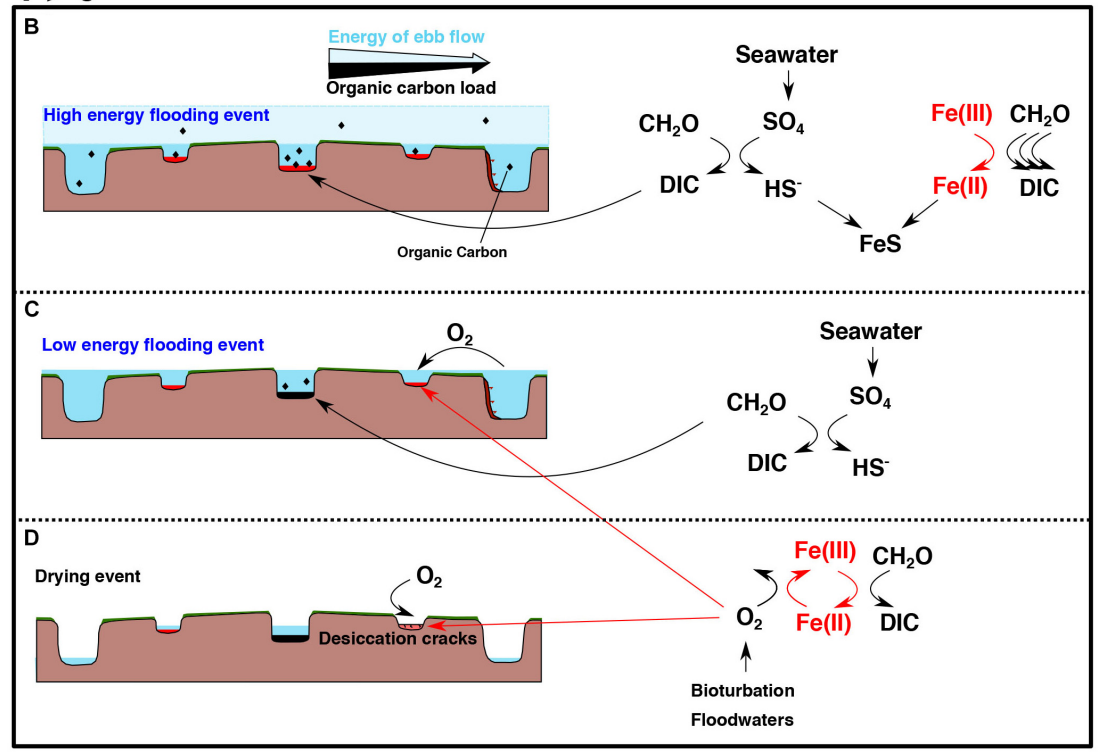

FIGURE 12 | Schematic of potential mechanisms driving pond chemistry heterogeneity over a salt marsh platform. Vertical scale is exaggerated (likely elevation differences are within a meter). (A) Represents an earlier stage of development $[T$ (time) $=0$ ] in a salt marsh platform whereas (B-D) represent changes over time $[T$ (time) $>0]$ (e.g., the effects of deeper, older ponds and the potential transitioning of pond sediment geochemistry). (A) Due to the high iron content of the sediment, all ponds should, in theory, have an iron-rich pond sediment geochemistry. The reaction shows bacterial iron reduction (BIR) reducing organic matter, with oxygen supplied from bioturbative-mixing and oxic flood waters, which acts to regenerate the ferrous iron. Fe(II) efflux to creek demonstrates the unknown diffusive flux at the creek wall boundary (Figure 5). (B) Periods of extremely high flooding (storm events or very high tides) from tidal creeks. All ponds are flushed with seawater and organic carbon will be deposited. As the energy of the ebb flow decreases during retreat (due to friction with the vegetated surface), the suspended organic carbon load will decrease as the flow returns to the creeks. If the central pond has sufficient organic matter to exhaust the ferric iron pool, microbial sulfate reduction can occur (see reaction alongside diagram), using seawater sulfate as the electron acceptor. This will slowly act to titrate ferrous iron as iron monosulfides, possibly acting as a switch to sulfide-rich conditions (C). (C) Low energy flooding events which may only flood ponds closer to the creeks introduces oxic water. The interior pond is assumed to have negligible available ferric iron supply so sulfide-rich pond sediment conditions are achieved. (D) Periods of excessive dry weather on the salt marsh platform (as observed in July 2018). Differential water head is attained due to the low hydraulic conductivity of the clay-rich sediment. More central ponds, having a deeper water column initially, are less susceptible to full evaporation. When the water column is fully evaporated, deep $(<15 \mathrm{~cm})$ desiccation cracks can occur, allowing atmospheric oxygen into the sediment. Further oxygen may be added upon submergence of the pond sediment with oxic seawater and potential bioturbating organisms.

this in situ growth would escape to the atmosphere), favoring sulfide-rich conditions. We suggest that the quantity and type of organic carbon being metabolized in different ponds and temporal studies on carbon input onto the salt marsh platform surface need to be established before we can properly understand this delivery process.

\section{Subsurface and Surface Hydrological Flow Controls}

The final hypothesis to explain the spatial distribution in the pond geochemistry is that subsurface flow, or surface flow, may play a role in distributing reactants, such as ferrous iron, to different parts of the salt marsh (see red arrows on Figure 12). This mechanism is discussed further in Antler et al. (unpublished), whereby a transient flux of ferrous iron might allow for titration of free sulfide and thus allow bioturbation to occur within pond sediments.

The large variation in ferrous iron concentrations among different iron-rich pond sediments, vegetated sediment (Figure 4) and the core taken through the creek wall (Figure 5) indicates there is heterogeneous concentration of ferrous iron over the salt marsh platform. The $3 \mathrm{mM}$ decrease in ferrous iron over the $5 \mathrm{~cm}$ boundary layer in the creek core also suggests there is an efflux of iron out of the sediment, into the creek water. Burrowing of crabs and other organisms appears to intensify 
this effect. The chloride and $\left[\mathrm{SO}_{4}\right] /[\mathrm{Cl}]$ data suggests this is hydrological mixing and not simply a zone of iron reduction. This efflux can be seen in creek water which contains up to $21 \mu \mathrm{M}$ ferrous iron (Supplementary Table S2). From this observation, we believe that there is subsurface movement of ferrous iron over the platform, though we cannot offer insight into the direction of these flows. Hydrological flow paths in salt marshes are complex to predict; a catchment area is typically dictated over long timescales by hydrological equilibrium attained by the flood and ebb tides (Allen, 2000). This complexity could be compounded if the ponds interact with these flow paths. Additionally, surface flow likely plays some role in distributing ferrous iron leached from the sediment and deposited closer to the creeks with ebb tides. Evidence of an iron-oxide rich layer on the surface would suggest that at least some portion of this is captured upon diffusion out, though we cannot quantify this effect. Further work would be needed to test the potential of these fluxes to 'switch' pond sediment.

\section{A Potential Mechanism}

The mechanism which actually causes pond sediment to become sulfide-rich or iron-rich is complex. It is likely some combination of the three effects described above which, together, create conditions favorable for a certain dominant redox condition (Figure 12). Water column depth could play a role, particularly where pond sediments can become sub-aerially exposed, or where the water is so deep that atmospheric oxygen delivery to the sediment surface is greatly curtailed (Figure 12D). The correlation between water depth and classification of the pond could simply be a result of both factors being controlled by creek dynamics independently. If sea level rise causes salt marsh accretion through vegetation-induced sediment capture, then we would expect ponds being impacted by fewer flood tides-the ponds distally located from creeks-to have a lower sedimentation rate to keep pace. As such, depth distribution over the salt marsh favors deeper ponds in the center of the salt marsh platform as the system ages (Figures 12A-D). Since our data suggests a higher organic carbon content in sediments located far from creeks, there is also likely some feedback associated with organic matter degradation and a porosity increase (Spivak et al., 2017). The relative abundance of the surface fluxes of oxygen and carbon compared to the subsurface fluxes of $\mathrm{Fe}$ (II) and other redox available elements is important to understand whether geochemical changes are mainly imparted from the surface water or from the platform. It appears more likely based on the data presented here that the surface coupling of organic carbon and other electron acceptors acts to alter an originally iron-rich pond sediment. This is exemplified by the in situ sampler recording a change from iron-rich conditions to sulfiderich conditions as opposed to the reverse. If this were the only mechanism, we would expect clearer boundaries of iron- and sulfide-rich pond sediment zonation. In view of this, it is likely that other processes are capable of influencing the geochemical characteristics. We suggest spatially heterogeneous transient groundwater and surface water introduction of chemical species and the evaporation of surface water introducing desiccation cracks as such processes for further exploration.
The fact that we see a zonal distribution of pond sediment chemistry implies that the change in pond chemistry is faster than rates of creek migration at present. Whilst it is thought that creek migration is actually quite slow (due to the inability of the flow to carry eroded sediment away) (Allen, 2000), if drainage ditches are emplaced, as in the northern part of Abbotts Hall, the sediment chemistry is likely to be more susceptible to change.

\section{CONCLUSION}

Sulfide-rich and iron-rich sediments are found throughout the East Anglian salt marshes. There is a continuum of observational evidence and porewater geochemical signatures which suggest that these classifications can encapsulate a range of geochemical behaviors. The distribution and in situ sampler data indicate that pond sediment geochemistry can be readily altered in terms of chemical classification over as short a timescale as a year. Drone based mapping of the salt marshes has shown that ponds containing sulfide-rich sediments tend to be congregated in the center of a salt marsh aggregate of ponds, further away from larger creek networks. We hypothesize that this is due to a combination of factors, including delivery of organic carbon across the salt marsh platform, variation in physical characteristics based on the position of the pond (i.e., water depth and the propensity for total evaporation), and a possible sub-surface groundwater flow distributing reactants based on position on the salt marsh. This study suggests that some combination of these effects will result in chemical heterogeneity of salt marsh pond sediment geochemistry and that no single mechanism appears dominant. The results suggest that artificial drainage ditches, common in these East Anglian salt marshes, could alter the geochemistry of these pond sediments on short timescales. This has consequences for the carbon budget, and for nutrient and trace metal capture within salt marsh ecosystems.

\section{DATA AVAILABILITY}

All datasets generated for this study are included in the manuscript and/or the Supplementary Files.

\section{AUTHOR CONTRIBUTIONS}

AH wrote the manuscript. All authors contributed feedback on said manuscript. GA had the initial idea behind the study. GA and CYL collected cores for Figure 3 and provided a number of cores for Figure 4. HB, XS, and JM collected cores for Figure 4 and contributed pioneering fieldwork toward the study. MG, AH, $\mathrm{HB}, \mathrm{AP}$, and GA undertook the drone survey and subsequent characterization. JW and JC provided data for in situ sampling and $\mathrm{AH}$ finished the final 2 months of data analysis. $\mathrm{AB}$ and $\mathrm{AH}$ 
worked in the field collecting cores and undertaking subsequent analysis. KR offered insight into the Essex salt marsh system where he had worked previously. AVT is the supervisor behind all of the work involved in the salt marshes and was the first to suggest work there.

\section{FUNDING}

This work was funded partially by an ERC starting investigator grant (CARBONSINK - 307582) to AVT as well as NERC RG94667 to AVT. Funding for AH was provided by a NERC DTP grant (LBAG/199.02.RG91292).

\section{ACKNOWLEDGMENTS}

The data table for this study is supplied in the Supplementary Material. This work has evolved over the

\section{REFERENCES}

Allen, J. (2000). Morphodynamics of Holocene salt marshes: a review sketch from the Atlantic and Southern North Sea coasts of Europe. Quat. Sci. Rev. 19, 1155-1231. doi: 10.1016/S0277-3791(99)00034-7

Barbier, E. B., Hacker, S. D., Kennedy, C., Koch, E. W., Stier, A. C., and Silliman, B. R. (2011). The value of estuarine and coastal ecosystem services. Ecol. Monogr. 81, 169-193. doi: 10.1890/10-1510.1

Bethke, C. M., Sanford, R. A., Kirk, M. F., Jin, Q., and Flynn, T. M. (2011). The thermodynamic ladder in geomicrobiology. Am. J. Sci. 311, 183-210. doi: 10.2475/03.2011.01

Blonder, B., Boyko, V., Turchyn, A. V., Antler, G., Sinichkin, U., Knossow, N., et al. (2017). Impact of aeolian dry deposition of reactive iron minerals on sulfur cycling in sediments of the Gulf of Aqaba. Front. Microbiol. 8:1131. doi: $10.3389 /$ fmicb. 2017.01131

Cline, J. D. (1969). Spectrophotometric determination of hydrogen sulfide in natural waters. Limnol. Oceanogr. 14, 454-458. doi: 10.4319/lo.1969.14.3.0454

Deegan, L. A., Johnson, D. S., Warren, R. S., Peterson, B. J., Fleeger, J. W., Fagherazzi, S., et al. (2012). Coastal eutrophication as a driver of salt marsh loss. Nature 490, 388-392. doi: 10.1038/nature11533

Drobner, E., Huber, H., Wächtershäuser, G., Rose, D., and Stetter, K. O. (1990). Pyrite formation linked with hydrogen evolution under anaerobic conditions. Nature 346, 742-744. doi: 10.1038/346742a0

Froelich, P. N., Klinkhammer, G. P., Bender, M. L., Luedtke, N. A., Heath, G. R., Cullen, D., et al. (1979). Early oxidation of organic matter in pelagic sediments of the eastern equatorial Atlantic: suhoxic diagenesis. Geochim. Cosmochim. Acta 43, 1075-1090. doi: 10.1016/0016-7037(79)90095-4

Hamblin, R. J. O., Moorlock, B. S. P., Booth, S. J., Jeffery, D. H., and Morigi, A. N. (1997). The Red Crag and Norwich Crag formations in eastern Suffolk. Proceedings of the Geologists'. Association 108, 11-23. doi: 10.1016/S00167878(97)80002-8

Hansel, C. M., Lentini, C. J., Tang, Y., Johnston, D. T., Wankel, S. D., and Jardine, P. M. (2015). Dominance of sulfur-fueled iron oxide reduction in low-sulfate freshwater sediments. ISME J. 9, 2400-2412. doi: 10.1038/ismej.2015.50

Holmkvist, L., Ferdelman, T. G., and Jørgensen, B. B. (2011). A cryptic sulfur cycle driven by iron in the methane zone of marine sediment (Aarhus Bay, Denmark). Geochim. Cosmochim. Acta 75, 3581-3599. doi: 10.1016/j.gca.2011. 03.033

Johnston, D. T., Farquhar, J., and Canfield, D. E. (2007). Sulfur isotope insights into microbial sulfate reduction: when microbes meet models. Geochim. Cosmochim. Acta 71, 3929-3947. doi: 10.1016/j.gca.2007.05.008

Kennish, M. J. (2016). “Anthropogenic impacts," in Encyclopedia of Estuaries, ed. M. J. Kennish (Dordrecht: Springer), 29-35. doi: 10.1007/978-94-017-8801-4_ 246 course of many years and has involved the contribution of many students and scientists who have worked in the Turchyn lab and have contributed to data collection. We acknowledge in particular the help of Jiarui Lui, Katherine Halloran, and Paul Hutchings for help with fieldwork, B. Lawrence and F. Llewellyn-Beard who helped with the initial design of the in situ sampler and James Rolfe who performed carbon analysis. We acknowledge Essex Wildlife Trust for their permission for us to sample in Abbotts Hall Farm.

\section{SUPPLEMENTARY MATERIAL}

The Supplementary Material for this article can be found online at: https://www.frontiersin.org/articles/10.3389/feart. 2019.00041/full\#supplementary-material

Kirwan, M. L., and Megonigal, J. P. (2013). Tidal wetland stability in the face of human impacts and sea-level rise. Nature 504, 53-60. doi: 10.1038/nature12856 Koretsky, C. M., Moore, C. M., Meile, C., Dichristina, T. J., and Cappellen, V. (2006). Seasonal oscillation of microbial iron and sulfate reduction in saltmarsh sediments (Sapelo Island, GA, USA). Biogeochemistry 64, 179-203. doi: 10.1023/ A:1024940132078

Lawrence, D. S. L., Allen, J. R. L., and Havelock, G. M. (2004). Salt marsh morphodynamics: an investigation of tidal flows and marsh channel equilibrium. J. Coast. Res. 201, 301-316. doi: 10.2112/1551-5036(2004)20[301: SMMAIO]2.0.CO;2

Lovley, D. R., and Chapelle, F. H. (1995). Deep subsurface microbial processes. Rev. Geophys. 33, 365-381. doi: 10.1029/95RG01305

McCave, I. N. (1987). Fine sediment sources and sinks around the East Anglian Coast (UK). J. Geol. Soc. Lond. 144, 149-152. doi: 10.1144/gsigs.144.1.0149

Mcleod, E., Chmura, G. L., Bouillon, S., Salm, R., Björk, M., Duarte, C. M., et al. (2011). A blueprint for blue carbon: toward an improved understanding of the role of vegetated coastal habitats in sequestering CO 2. Front. Ecol. Environ. 9, 552-560. doi: 10.1890/11 0004

Mills, J. V., Antler, G., and Turchyn, A. V. (2016). Geochemical evidence for cryptic sulfur cycling in salt marsh sediments. Earth Planet. Sci. Lett. 453, 23-32. doi: 10.1016/j.epsl.2016.08.001

Mortimer, R. J. G., Galsworthy, A. M. J., Bottrell, S. H., Wilmot, L. E., and Newton, R. J. (2011). Experimental evidence for rapid biotic and abiotic reduction in salt marsh sediments: a possible mechanism for formation of modern sedimentary siderite concretions: iron reduction in salt marsh sediments. Sedimentology 58, 1514-1529. doi: 10.1111/j.1365-3091.2011.01224.x

Nealson, K. H. (1997). Sediment bacteria: who's there, what are they doing, and what's new? Annu. Rev. Earth Planet. Sci. 25, 403-434. doi: 10.1146/annurev. earth.25.1.403

Pethick, J. S. (1974). The distribution of salt pans on tidal salt marshes. J. Biogeogr. 1, 57-62. doi: $10.2307 / 3038068$

Pethick, J. S. (1980). Salt-marsh initiation during the holocene transgression: the example of the north norfolk marshes, England. J. Biogeogr. 7, 1-9. doi: 10.2307/ 2844543

Postma, D., and Jakobsen, R. (1996). Redox zonation: equilibrium constraints on the Fe(III)/SO4-reduction interface. Geochim. Cosmochim. Acta 60, 3169-3175. doi: 10.1016/0016-7037(96)00156-1

Pye, K., Dickson, J. A. D., Schiavon, N., Coleman, M. L., and Cox, M. (1990). Formation of siderite-Mg-calcite-iron sulphide concretions in intertidal marsh and sandflat sediments, north Norfolk, England. Sedimentology 37, 325-343. doi: 10.1111/j.1365-3091.1990.tb00962.x

Redfield, A. C. (1972). Development of a New England Salt Marsh. Ecol. Monogr. 42, 201-237. doi: 10.2307/1942263 
Santos, I. R., Burnett, W. C., Dittmar, T., Suryaputra, I. G. N. A., and Chanton, J. (2009). Tidal pumping drives nutrient and dissolved organic matter dynamics in a Gulf of Mexico subterranean estuary. Geochim. Cosmochim. Acta 73, 1325-1339. doi: 10.1016/j.gca.2008.11.029

Seeberg-Elverfeldt, J., Schlüter, M., Feseker, T., and Kölling, M. (2005). Rhizon sampling of porewaters near the sediment-water interface of aquatic systems: Rhizon porewater sampling. Limnol. Oceanogr. 3, 361-371. doi: 10.4319/lom. 2005.3.361

Soetaert, K., Hofmann, A. F., Middelburg, J. J., Meysman, F. J. R., and Greenwood, J. (2007). The effect of biogeochemical processes on pH. Mar. Chem. 105, 30-51. doi: 10.1016/j.marchem.2006. 12.012

Spivak, A. C., Gosselin, K., Howard, E., Mariotti, G., Forbrich, I., Stanley, R., et al. (2017). Shallow ponds are heterogeneous habitats within a temperate salt marsh ecosystem: shallow ponds are heterogeneous habitats. J. Geophys. Res. 122, 1371-1384. doi: 10.1002/2017JG003780

Stookey, L. L. (1970). Ferrozine-a new spectrophotometric reagent for iron. Anal. Chem. 42, 779-781. doi: 10.1021/ac60289a016

Valiela, I., Teal, J. M., Volkmann, S., Shafer, D., and Carpenter, E. J. (1978). Nutrient and particulate fluxes in a salt marsh ecosystem: tidal exchanges and inputs by precipitation and groundwater 1: salt marsh nutrient exchange. Limnol. Oceanogr. 23, 798-812. doi: 10.4319/lo.1978.23.4 0798

Van Huissteden, J., and van de Plassche, O. (1998). Sulfate reduction as a geomorphological agent in tidal marshes ('Great Marshes' at Barnstaple, Cape Cod, USA). Earth Process. Landforms 23, 233-236.

Wilson, C. A., Hughes, Z. J., FitzGerald, D. M., Hopkinson, C. S., Valentine, V., and Kolker, A. S. (2014). Saltmarsh pool and tidal creek morphodynamics: dynamic equilibrium of northern latitude saltmarshes? Geomorphology 213, 99-115. doi: 10.1016/j.geomorph.2014.01.002

Conflict of Interest Statement: The authors declare that the research was conducted in the absence of any commercial or financial relationships that could be construed as a potential conflict of interest.

Copyright (C) 2019 Hutchings, Antler, Wilkening, Basu, Bradbury, Clegg, Gorka, Lin, Mills, Pellerin, Redeker, Sun and Turchyn. This is an open-access article distributed under the terms of the Creative Commons Attribution License (CC BY). The use, distribution or reproduction in other forums is permitted, provided the original author(s) and the copyright owner(s) are credited and that the original publication in this journal is cited, in accordance with accepted academic practice. No use, distribution or reproduction is permitted which does not comply with these terms. 


\section{OPEN ACCESS}

Edited by:

Divya Karnad,

Ashoka University, India

Reviewed by:

Peter Mueller,

Universität Hamburg, Germany

Reza Erfanzadeh,

Tarbiat Modares University, Iran

*Correspondence:

Rachel J. Harvey

rachelharvey14@gmail.com

Specialty section:

This article was submitted to

Conservation,

a section of the journal

Frontiers in Ecology and Evolution

Received: 31 October 2018 Accepted: 17 April 2019

Published: 10 May 2019

Citation:

Harvey RJ, Garbutt A, Hawkins SJ and Skov MW (2019) No Detectable

Broad-Scale Effect of Livestock Grazing on Soil Blue-Carbon Stock in Salt Marshes. Front. Ecol. Evol. 7:151.

doi: 10.3389/fevo.2019.00151

\section{No Detectable Broad-Scale Effect of Livestock Grazing on Soil Blue-Carbon Stock in Salt Marshes}

\author{
Rachel J. Harvey ${ }^{1 *}$, Angus Garbutt ${ }^{2}$, Stephen J. Hawkins ${ }^{1,3,4}$ and Martin W. Skov ${ }^{1}$ \\ ${ }^{1}$ School of Ocean Sciences, Bangor University, Bangor, United Kingdom, ${ }^{2}$ Centre for Ecology and Hydrology, Bangor, \\ United Kingdom, ${ }^{3}$ Ocean and Earth Science, National Oceanography Centre Southampton, University of Southampton, \\ Southampton, United Kingdom, ${ }^{4}$ Marine Biological Association, Plymouth, United Kingdom
}

Grassland carbon capturing and storage (CCS) is thought to benefit from regulation of grazing. The impact is likely to depend on livestock density. Yet, few studies have tested this principle or evaluated the consistency of grazer-carbon relationships across multiple sites. We sampled four intertidal zones across 22 salt marshes along a $650 \mathrm{~km}$ stretch of coast in the UK to examine the impact of livestock density on globally important saltmarsh "blue carbon" stocks. Although there were marked impacts of grazing pressure on above ground vegetation composition, structure and biomass, there was no detectable relationship between grazing intensity and soil organic carbon, irrespective of tidal zone in the marsh or soil depth-layer analyzed. A substantial spatial variation in soil carbon was instead explained by contextual environmental variables. There was evidence that compensatory responses by vegetation, such as increased root growth, countered carbon loss from grazing impacts. Our work suggests that grazing effects on carbon stocks are minimal on broader scales in comparison with the influence of environmental context. The benefits of grazing management to carbon stores are likely to be highly context dependent.

Keywords: blue carbon, grazing, saltmarsh, broad-scale, environmental context

\section{INTRODUCTION}

Environmental policies and management seek to optimize natural carbon capture and storage (CCS) across natural landscapes (Richards, 2004; Beaumont et al., 2014). Natural landscapes that are of most interest for carbon storage, such as peat bogs, upland heathland, mangroves and salt marshes, are often subject to livestock grazing that can influence CCS (Reeder and Schuman, 2002; Ostle et al., 2009; Donato et al., 2011; McSherry and Ritchie, 2013). Effective management of CCS relies both on understanding the nature of the relationship between CCS and intensity of land-use, and the consistency of this relationship across environmentally variable landscapes. While there are several ways to enhance the CCS potential of natural landscapes (Wallage et al., 2006; Ostle et al., 2009; Dung et al., 2016), adjustment of livestock grazing pressure is perhaps one of the easiest to manage and implement.

Natural and semi-natural grasslands, such as prairies, steppes and plains provide a valuable insight into the impact of livestock grazing on above- and below-ground processes (Kang et al., 2007). Globally, more than $40 \%$ of grasslands are grazed by livestock (Reid et al., 2008); thus, the regulation of stocking density provides an opportunity to positively influence carbon sequestration 
(Tanentzap and Coomes, 2012). While the sum of direct emissions of carbon dioxide and methane associated with livestock respiration, digestion and fecal decomposition increase with stocking density (Murray et al., 2001; Pinares-Patino et al., 2007), grazers also have strong above ground impacts on vegetation (Figures 1A,B) (McNaughton, 1979; Jensen, 1985; Facelli and Pickett, 1991; Olofsson and Oksanen, 2002; Cao et al., 2004), indirectly linking to below ground processes associated with CCS (De Deyn et al., 2008). The direction and magnitude of the impacts of livestock grazing are dictated by its intensity. Given the relationship between above and below ground processes (Bardgett and Wardle, 2003), it might be expected that an increase in grazing intensity will lead to a decrease in below ground soil carbon stocks. However, plant compensatory responses, such as increased root growth and increased carbon allocation to the roots with elevation of grazing pressure, can sometimes counter the above ground effects of grazers on carbon storage (Sollins et al., 1996; Derner et al., 2006; Tanentzap and Coomes, 2012). For example, light or moderate grazing intensity results in a fast growing, diverse plant community, increased root growth, and increased carbon allocation to the roots. In contrast, heavy grazing intensity results in minimal above ground biomass, low species richness and stunted root growth (Schuster, 1964; McNaughton, 1979; Jensen, 1985; Kiehl et al., 1996).

There is the expectation that regulation of livestock density will benefit below ground carbon stocks (Frank et al., 1995; Conant et al., 2000; Derner et al., 2006; Yu and Chmura, 2010; Ward et al., 2016). Here we employ a multi-site study to explore whether grazing has detectable broad-scale impacts on aboveand below-ground carbon stores in salt marshes, an ecosystem that is reputedly rich in carbon stocks (Duarte et al., 2013). So far, saltmarsh grazer-carbon relationships have only been explored by small scale studies and these have generated conflicting results from increases in soil C (Schuman et al., 1999; Derner et al., 2006; Yu and Chmura, 2010; Elschot et al., 2015a) to decreases in soil C (Morris and Jensen, 1998; Reader and Craft, 1999; Klumpp et al., 2009; Tanentzap and Coomes, 2012; Di Bella et al., 2015) or varied/no impacts (Meyer et al., 1995; Ford et al., 2012; Chen et al., 2015; Schipper et al., 2017) Large-scale studies are needed given that the likely cause for conflicting evidence is that grazing imapct on cabon storage is context dependent as suggested by recent systematic reviews (Conant and Paustian, 2002; McSherry and Ritchie, 2013; Davidson et al., 2017). In this study, we aim to empirically determine whether livestock grazing shows a significant impact on above- and below-ground salt marsh bluecarbon stocks in relation to several environmental parameters across a large biogeographical region.

Salt marshes are characterized by halophytic herbs, grasses and low shrubs that are periodically inundated with saline water, forming distinct plant communities zoned along the vertical stress-gradient of tidal inundation (Adam, 1990a) (Figure 1B). Salt marshes, along with mangroves and seagrass beds, are thought to provide longer-lasting and far denser "blue" carbon stores than most terrestrial systems, although salt marsh carbon stocks do vary considerably with marsh maturity, geomorphology and environmental setting (Sousa et al., 2010; Mcleud et al., 2011; Hayes et al., 2017; Himes-Cornell et al., 2018). Carbon stores are rich and long-lasting in marshes because they have high plant productivity (Middelburg et al., 1997) and sulfate rich, anaerobic sediments with slow organic deposition rates (Howarth, 1984; Valiela et al., 1985; Mueller et al., 2017) The low-energy, depositional characteristics of salt marshes also make them excellent carbon sinks (Chmura et al., 2003; Andersen et al., 2010) as much of the particulate material trapped by marshes is rich in externally produced organic matter (Van de Broek et al., 2018; Mueller et al., 2019).

Globally, many salt marshes are grazed by livestock for meat production and conservation management (Gedan et al., 2009). In un-grazed marshes the main inputs to soil carbon are sedimentation (Stumpf, 1983), degradation of root matter and plant litter deposition (Saunders et al., 2006), while the main outputs are gas emissions of carbon dioxide and methane (Morris and Whiting, 1986; Bartlett et al., 1987; Ford et al., 2012; Kingham, 2013) and sediment loss from wave and tidal erosion (Chalmers et al., 1985; Kingham, 2013). Introducing livestock is likely to have conflicting effects on saltmarsh properties and processes that affect CCS (Figure 1C) (Schuster, 1964; Jensen, 1985; Kiehl et al., 1996; McNaughton et al., 1998; Milotić et al., 2010). For example, above ground biomass and plant litter are likely to decrease under all grazing regimes (Bakker, 1985; Jensen, 1985; Kiehl et al., 1996). Consequently, less sediment, and associated carbon, would be trapped by vegetation during immersion (Neuhaus et al., 1999; Mueller et al., 2017). Conversely, soil compaction by livestock reduces soil pore size and induces anaerobic conditions (Tanner and Mamaril, 1958; Mueller et al., 2017), which in turn diminishes decomposition and carbon dioxide emission rates (Scanlon and Moore, 2000; Hussein and Rabenhorst, 2002; Elschot et al., 2015b). Grazer introduction of terrestrial sources of organic matter in to marshes may alter microbial community composition, which in turn can cause microbially-controlled pathways to allocate more carbon to medium- and long-term storage pools (Olsen et al., 2011; Mueller et al., 2017). In terrestrial wetlands anaerobic conditions result in microbial communities that increase methane emissions (Wang et al., 1996), but in salt marshes methane emissions are limited by abundant sulfate-reducing bacteria (Winfrey and Ward, 1983); therefore soil compaction at high stocking densities would be expected to reduce carbon loss by gas efflux in salt marshes.

We surveyed salt marshes across the west coast of the UK, covering a range of livestock densities, to investigate the broadscale impacts of grazing intensity on salt marsh below-ground carbon stock. We expected grazing would reduce vegetation height and biomass (Figure 1C) and predicted that below ground carbon stock would significantly decrease at the highest stocking density, due to strong coupling between above and below ground processes. The study explored if grazer-induced loss of above-ground carbon input was counteracted by below-ground increased root growth at lower stocking densities (Figure 1C). Light and intense grazing were expected to increase and reduce plant diversity, respectively (Figure 1C). The study collected information on abiotic environmental variables to explore the influence of environmental context on salt marsh soil carbon, and to contrast the relative importance of context against the effects of grazer density. 

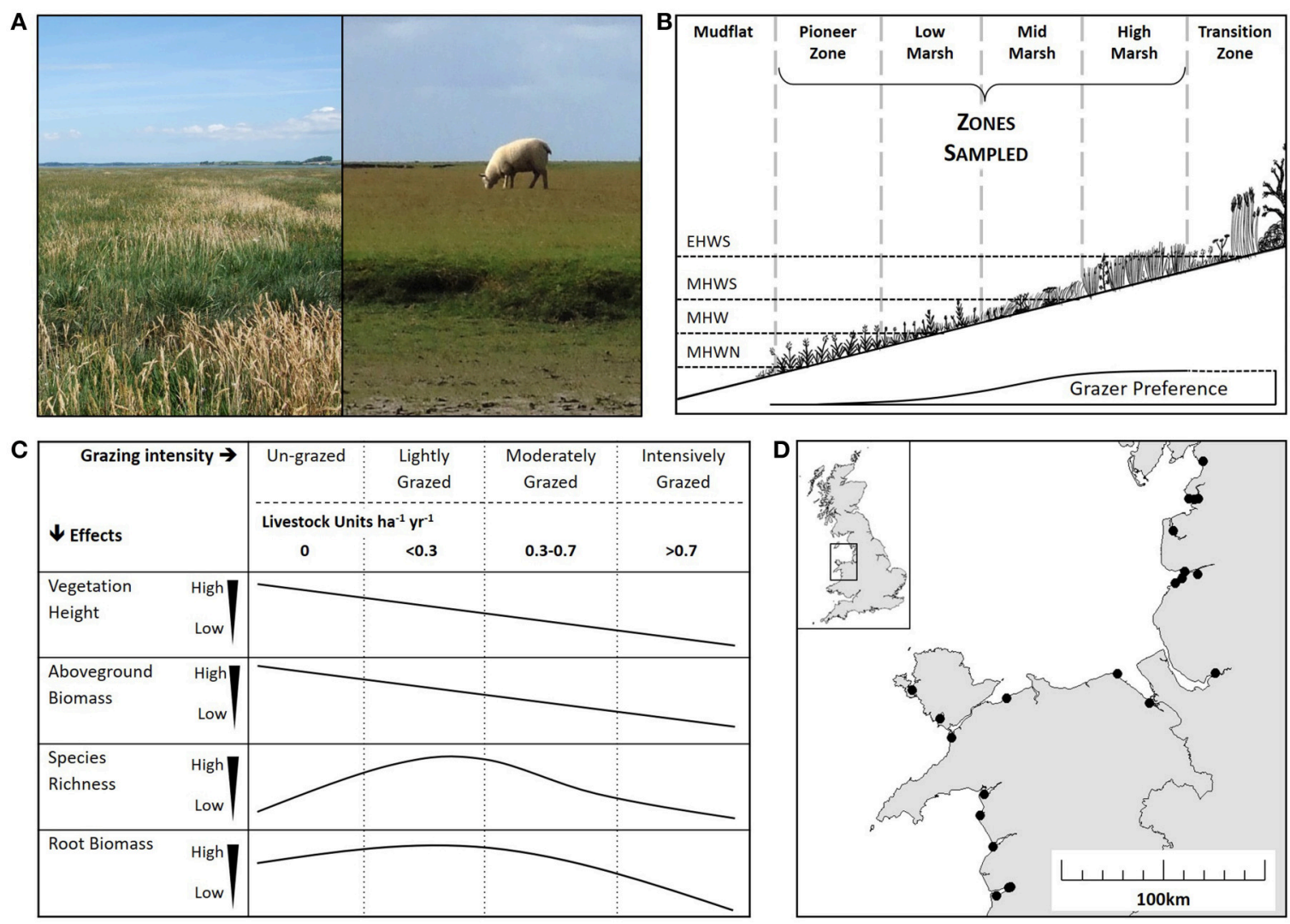

FIGURE 1 | Salt marsh ecology and impacts of grazing. (A) The contrast between an un-grazed marsh (left) and an intensively grazed marsh (right). (B) A diagrammatic representation of a salt marsh showing zonation according to tidal inundation: extreme high-water spring (EHWS), mean high water spring (MHWS), mean high water (MHW) and mean high water neap (MHWN). Only the pioneer, low, mid and high zones were sampled in this study. Grazer preference is indicated showing decreased grazing activity in the lower zones. (C) Predicted effects of a range of grazing intensities on vegetation height, aboveground biomass, species richness and root biomass according to the literature (Stumpf, 1983; Jensen, 1985; Facelli and Pickett, 1991; McNaughton et al., 1998). Grazing is shown as "Grazing Intensity" category classified according to a Welsh Assembly Grazing Management Scheme (un-grazed, lightly grazed, moderately grazed and intensively grazed) and Livestock Units per hectare per year (LSU ha ${ }^{-1} \mathrm{yr}^{-1}$ ). (D) Location of the 22 study sites along the coasts of west Wales and northwest England.

\section{MATERIALS AND METHODS}

\section{Study Sites}

Soil carbon stock was sampled in 22 salt marshes along a $650 \mathrm{~km}$ stretch of the west coast of the United Kingdom (Figure 1D; Table 1). Sites were in a single biogeographical saltmarsh region (Adam, 1990a); they were selected to incorporate a wide range of stocking densities with grazing regimes that were known and had been consistent for the past 30 years or more (Table 1). Although there were around 35-40 salt marshes within this region, marshes that were too small ( $<2$ hectares), had a too much freshwater influence, or those where access was denied by landowners were excluded.

Livestock Units (LSU ha ${ }^{-1} \mathrm{yr}^{-1}$ ) were used as a standardized measure of stocking density, where 1 LSU $=1$ cow/6.6 sheep/33 geese (Almunia, 2009; Welsh Government, 2017). Management schemes in the UK stipulate grazing pressure by categorizing sites into a range of grazing intensities. Thus, sites were categorized into four grazing intensities based on Tir Gofal, an agri-environmental scheme in Wales (un-grazed; lightly grazed: $<0.3 \mathrm{LSU} \mathrm{ha}^{-1} \mathrm{yr}^{-1}$; moderately grazed: $0.3-0.7 \mathrm{LSU} \mathrm{ha}^{-1} \mathrm{yr}^{-1}$; intensively grazed: >0.7 LSU $\mathrm{ha}^{-1} \mathrm{yr}^{-1}$ ). Stocking densities (Table 1) and the Tir Gofal grazing categories were comparable to those observed in grazing studies from other salt marshes (Andresen et al., 1990; Berg et al., 1997; Neuhaus et al., 1999) and terrestrial grasslands (Rauzi and Hanson, 1966; Haveren, 1983; Graff et al., 2007; Proensky et al., 2016).

\section{Sampling Design}

Sampling of each marsh was stratified using the four marsh vegetation zones at different shore elevations classically recognized in the salt marsh literature: pioneer, low, mid, and high marsh (Figure 1B) (Adam, 1990a). Some sites had fewer than four marsh zones due to embankments at the top end and/or erosion at the seaward margin (Table 1). Each zone was sampled in a $100 \mathrm{~m}$ wide area, using 10 randomly located $2 \times 2 \mathrm{~m}$ quadrats. Above-ground plant measurements were sampled in all 10 quadrats and four of the quadrats were additionally sampled below ground. Table 1 shows the total number of quadrats per site. 
TABLE 1 | Site details.

\begin{tabular}{|c|c|c|c|c|c|c|c|c|}
\hline \multirow[t]{2}{*}{ Marsh name } & \multirow[t]{2}{*}{ Grid ref. (BNG) } & \multirow[t]{2}{*}{ Zones present } & \multicolumn{2}{|c|}{ Quadrats sampled } & \multirow[t]{2}{*}{ Grazing intensity } & \multirow{2}{*}{$\begin{array}{c}\text { Stocking rate } \\
\text { (LSU/ha/yr) }\end{array}$} & \multirow{2}{*}{$\begin{array}{l}\text { Livestock } \\
\text { type }\end{array}$} & \multirow{2}{*}{$\begin{array}{l}\text { Historical } \\
\text { grazing }\end{array}$} \\
\hline & & & Vegetation & Core & & & & \\
\hline Dyfi west & SN 6274993642 & $P, L, M$ & 30 & 12 & Intensive & 0.79 & $\begin{array}{l}\text { Sheep } \\
\text { (Geese) }\end{array}$ & As current \\
\hline Ynys Hir & SN 6785797121 & $\mathrm{M}, \mathrm{H}$ & 20 & 8 & Light & 0.26 & $\begin{array}{l}\text { Sheep } \\
\text { (Geese) }\end{array}$ & $\begin{array}{l}\text { Intensive before } \\
2000\end{array}$ \\
\hline Dyfi north & SN 6876197392 & $\mathrm{H}$ & 10 & 4 & Intensive & 3.45 & $\begin{array}{l}\text { Sheep } \\
\text { Cattle (Geese) }\end{array}$ & As current \\
\hline Fairbourne & SH 6147413776 & $P, L, M$ & 30 & 12 & Moderate & 0.70 & Sheep & As current \\
\hline Shell Island & SH 5606526477 & $\mathrm{~L}, \mathrm{M}, \mathrm{H}$ & 30 & 12 & Un-grazed & 0.00 & $\mathrm{~N} / \mathrm{A}$ & As current \\
\hline Morfa harlech & SH 5769035232 & $\mathrm{P}, \mathrm{L}, \mathrm{M}, \mathrm{H}$ & 40 & 16 & Moderate & 0.40 & $\begin{array}{l}\text { Sheep } \\
\text { Cattle }\end{array}$ & As current \\
\hline$Y$ foryd & SH 4448258512 & $\mathrm{P}, \mathrm{L}, \mathrm{M}, \mathrm{H}$ & 40 & 16 & Un-grazed & 0.00 & $\mathrm{~N} / \mathrm{A}$ & As current \\
\hline Malltraeth & SH 3974266134 & $\mathrm{P}, \mathrm{L}, \mathrm{M}, \mathrm{H}$ & 40 & 16 & Un-grazed & 0.00 & N/A & As current \\
\hline Four mile bridge & SH 2814878038 & $P, L, M, H$ & 40 & 16 & Un-grazed & 0.00 & N/A & As current \\
\hline Morfa madryn & SH 6691974629 & $\mathrm{M}$ & 10 & 4 & Moderate & 0.70 & Sheep & As current \\
\hline Talacre & SJ 1255084799 & L, M & 20 & 8 & Un-grazed & 0.00 & $\mathrm{~N} / \mathrm{A}$ & As current \\
\hline Oakenholt & SJ 2566772756 & $L, M$ & 20 & 8 & Light & 0.29 & Sheep & As current \\
\hline Widnes warth & SJ 5274784954 & $\mathrm{H}$ & 10 & 4 & Un-grazed & 0.00 & N/A & $\begin{array}{l}\text { Light cattle } \\
\text { before } 1999\end{array}$ \\
\hline Crossens & SD 3618921676 & $\mathrm{~L}, \mathrm{M}, \mathrm{H}$ & 30 & 12 & Light/Un-grazed & 0.10 & Cattle & As current \\
\hline Banks marsh & SD 3907823861 & $M$ & 10 & 4 & Intensive & 0.82 & Cattle & As current \\
\hline Longton & SD 4537425461 & $\mathrm{H}$ & 10 & 4 & Light & 0.24 & $\begin{array}{l}\text { Sheep } \\
\text { Cattle }\end{array}$ & As current \\
\hline Warton bank & SD 4020826614 & $\mathrm{M}, \mathrm{H}$ & 20 & 8 & Light & 0.19 & Cattle & As current \\
\hline Stannah & SD 3547243247 & L, M & 20 & 8 & Un-grazed & 0.00 & N/A & As current \\
\hline Glasson & SD 4398156127 & $\mathrm{P}, \mathrm{L}, \mathrm{M}, \mathrm{H}$ & 40 & 16 & Intensive & 2.26 & $\begin{array}{l}\text { Sheep } \\
\text { Cattle }\end{array}$ & As current \\
\hline Conder green & SD 4567356416 & $\mathrm{P}, \mathrm{L}, \mathrm{M}, \mathrm{H}$ & 40 & 16 & Un-grazed & 0.00 & N/A & $\begin{array}{l}\text { Light before } \\
1990\end{array}$ \\
\hline Sunderland & SD 4186056333 & $\mathrm{P}, \mathrm{L}, \mathrm{M}, \mathrm{H}$ & 40 & 16 & Intensive & 0.82 & Cattle & As current \\
\hline \multirow[t]{2}{*}{ Carnforth } & SD 4780871776 & $\mathrm{M}, \mathrm{H}$ & 20 & 8 & Intensive & 0.72 & Sheep & As current \\
\hline & & Total: & 570 & 228 & & & & \\
\hline
\end{tabular}

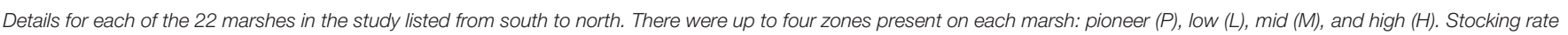

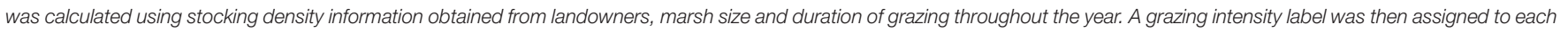

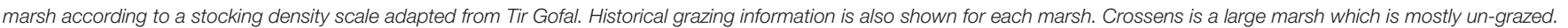

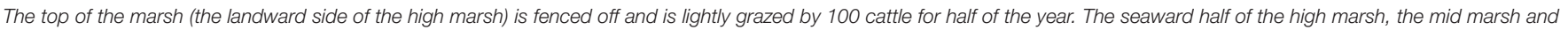
the low marsh zones all remain un-grazed.

\section{Above and Below-Ground Sampling}

Ten quadrats per zone were sampled above-ground for the following. Percentage cover per vegetation species was estimated by eye (Rodwell et al., 2000). Vegetation mean $(n=5)$ and maximum heights $(n=1)$ were observed according to Stewart et al. (2001). Vegetation biomass and litter biomass were sampled in a $25 \times 50 \mathrm{~cm}$ area at the bottom left corner of each quadrat: live vegetation was cut at the soil level and dead litter was collected from the soil surface. Vegetation samples were then dried $\left(80^{\circ} \mathrm{C}, 3 \mathrm{~d}\right)$. Four quadrats per zone were sampled belowground for the following. One soil core $(46 \mathrm{~mm}$ diameter, $46 \mathrm{~cm}$ deep) was taken centrally in the quadrat using a split tube corer with removable PVC liner that held the sediment until analysis. Three bulk density soil samples $(4.8 \mathrm{~cm}$ diameter, $2.5 \mathrm{~cm}$ deep) were taken at the soil surface by each soil core and pooled. The mean $(n=5)$ soil surface compaction and subsurface soil strength were observed using a Geotest pocket penetrometer and a Pilcon shear vane, respectively. In the laboratory, the soil core was split lengthways into two halves: a half-core for root analysis and a half-core for soil organic carbon (SOC) analysis. The root core was divided into $5 \mathrm{~cm}$ depth segments; roots per segment were washed free of sediment over a $0.5 \mathrm{~mm}$ meshed metal sieve and dried $\left(80^{\circ} \mathrm{C}\right.$, for $\left.3 \mathrm{~d}\right)$. Sediment was extracted from the SOC half-core at five depths: 0-2, 5-7, $11-13,22-24$, and $44-46 \mathrm{~cm}$; roots were manually removed and soil organic matter (SOM) was determined by loss on ignition (Ball, 1964; Schumacher, 2002) of $10 \mathrm{~g}$ homogenized sub-samples per depth. SOM was converted to SOC (\%) by a quadratic formula (Craft et al., 1991). Bulk density samples (BD) had large roots and stones removed before being dried $\left(105^{\circ} \mathrm{C}, 16 \mathrm{~h}\right)$, where-after SOC density $\left(\mathrm{g} \mathrm{C} \mathrm{cm}^{-3}\right)$ was calculated (Emmet et al., 2008). 


\section{Observations of Environmental Contextual Predictor Variables}

Data on abiotic indicators of environmental context were collated to examine the influence of environmental context on patterns of SOC. Sediment grain-size samples were taken alongside SOC samples (core depths: 0-2, 5-7, 11-13, 22-24, and 44$46 \mathrm{~cm}$ ) and analyzed in a Malvern Mastersizer 2000 laser particle size analyser after $\mathrm{H}_{2} \mathrm{O}_{2}$ treatment (Robinson, 1927). Marsh geomorphological type was classified according to Allen (2000). Site wave exposure was calculated according to Burrows et al. (2008). Estuarine water quality variables (dissolved inorganic N, Orthophosphate, Silicates, $\mathrm{pH}$, salinity, and suspended solids) were obtained from the June-2009 to May-2012 observational dataset held by the Environment Agency of Wales and northwest England.

\section{Data Analysis}

The study ran separate analyses for each of the four marsh zones (Figure 1B), as well as a single analysis with all zones incorporated. Single-zone analyses were included because substantial between-zone variation in environmental context made it difficult to detect grazing effects in the all-data analysis. Carbon in the top $12 \mathrm{~cm}$ of soils was assumed accumulated over the 30 -years period for which we knew the grazing history of sites (Table 1), given the region's $3-4 \mathrm{~mm} \mathrm{y}^{-1}$ vertical accretion rate (Shi, 1992; French and Spencer, 1993; Cundy and Croudace, 1996; Fox et al., 1999; Van der Wal et al., 2002; Shepherd et al., 2007). The grazing history of soils deeper than $12 \mathrm{~cm}$ was uncertain. The analysis took into consideration this depthdependent variation in the temporal coupling of soil SOC with known grazing regimes: separate analyses were done for soil layers from 0 to 2,0 to 10 , and 0 to $50 \mathrm{~cm}$. The top soil profile $(0-2 \mathrm{~cm})$ was regarded to be indicative of the present flux of material from above ground biomass (e.g., litter) to the below ground carbon pool. This layer was expected to show a tight coupling between above and below ground processes, and to be representative of the current grazing regime. The middle profile $(0-10 \mathrm{~cm})$ encompassed most of the root biomass and reflected the 30-years time scale for which the grazing regimes of marshes were known. This layer was expected to be less representative of the current above ground processes than the $0-2 \mathrm{~cm}$ depth profile, but to still show a weak coupling between above and below ground processes. The deepest profile (0$50 \mathrm{~cm}$ ) was considered a metric of grazing in relation to the broader contextual influences. Some cores lacked the deepest soil layer $(44-46 \mathrm{~cm})$; missing points were estimated using regression techniques based on the remaining real-data points from the core.

Analyses explored the effects of grazing intensity on a categorical scale (un-grazed, light, medium and intense grazing), which are used by grazing management schemes, and on a continuous scale (LSU ha ${ }^{-1} \mathrm{yr}^{-1}$ ) to look for threshold levels in carbon-grazing relationships. Analyses of Variance (ANOVA) or the non-parametric equivalent (Kruskal-Wallis multiple comparisons) were used to assess the impact of grazing as a categorical factor on plant height and biomass and on the individual depth profiles for root biomass and SOC. A $p$-value threshold of 0.05 was used throughout the analysis. A multivariate Permutational Analysis of Variance (PERMANOVA) (Anderson, 2005) was used to analyse the impact of grazing as a categorical factor on root biomass and SOC across all soil depth profiles, and an Analysis of Covariance (ANCOVA) was run on SOC with depth as a covariate to analyse the impact of grazing on the rate of SOC decrease with depth. A series of regression analyses were used to determine the impact of grazing as a continuous variable on both the aboveground plant characteristics and the individual depth profiles for both root biomass and SOC. The effects of factors grazing intensity (four categorical levels) and zone (four levels) on plant community composition was analyzed using 2-way PERMANOVA, followed by a similarity percentage test (SIMPER) to identify species that most strongly characterized compositional differences between grazing intensities (Primer statistical package: Clarke, 1993; Clarke and Warwick, 2001). The PERMANOVA was run with 9,999 permutations on a log transformed Bray-Curtis similarity matrix. False Discovery Rate (FDR) control $p$-values were calculated in Microsot Excel for all analyses to compensate for the large number of tests (Verhoeven et al., 2004) and partial eta squared effect sizes $\left(\eta_{p}^{2}\right)$ were calculated in Microsoft Excel for all results where $\geq 0.0099$ was a small effect, $\geq 0.0588$ was a medium effect, and $\geq 0.1379$ was a large effect (Cohen, 1988; Richardson, 2011). Finally, a mixed effects model was used to analyse the impact of multiple environmental and contextual factors (including grazing measured as LSU) on soil organic carbon (R Core Team, 2012). The model was run on the overall data set, the combined high marsh zone and mid marsh zone data (zones most used by grazers: Sharps et al., 2017), and the combined low zone and pioneer zone data (zones least likely to be influenced by grazers: Sharps et al., 2017).

\section{RESULTS}

Grazing had significant impacts on above ground vegetation, as expected. Plant height (ANOVA, factor Grazing Intensity: $\left.F_{3,9}=17.67, p<0001, \eta_{p}^{2}=0.494\right)$, above ground biomass (ANOVA, factor Grazing Intensity: $F_{3,9}=6.96, p=0.040, \eta_{p}^{2}$ $=0.181$ ) and plant litter biomass (K-WMC: $H_{3}=135.12, p<$ 0001) all significantly decreased with increasing grazing intensity regardless of whether grazing was treated as a categorical (grazing intensity category) or continuous (LSU) variable (Figure 2). There was no significant effect of grazing on plant species richness (ANOVA, factor Grazing Intensity: $F_{3,9}=0.05, p=$ $0.387, \eta_{p}^{2}=0.072$ ), although community composition did change with grazing intensity in the mid marsh [PERMANOVA, factor Grazing Intensity: Pseudo $F_{(3)}=2.071, P($ perm $\left.)=0.029\right]$. A SIMPER analysis found that communities of un-grazed marshes were generally highly variable and dominated by one of several community types (Festuca rubra, Atriplex portulacoides or a diverse Plantago maritima/Puccinellia maritima community). Light and moderately grazed marshes were less variable and were consistently dominated by Puccinellia maritima, a stresstolerant, low marsh species. Intensively grazed marshes were 


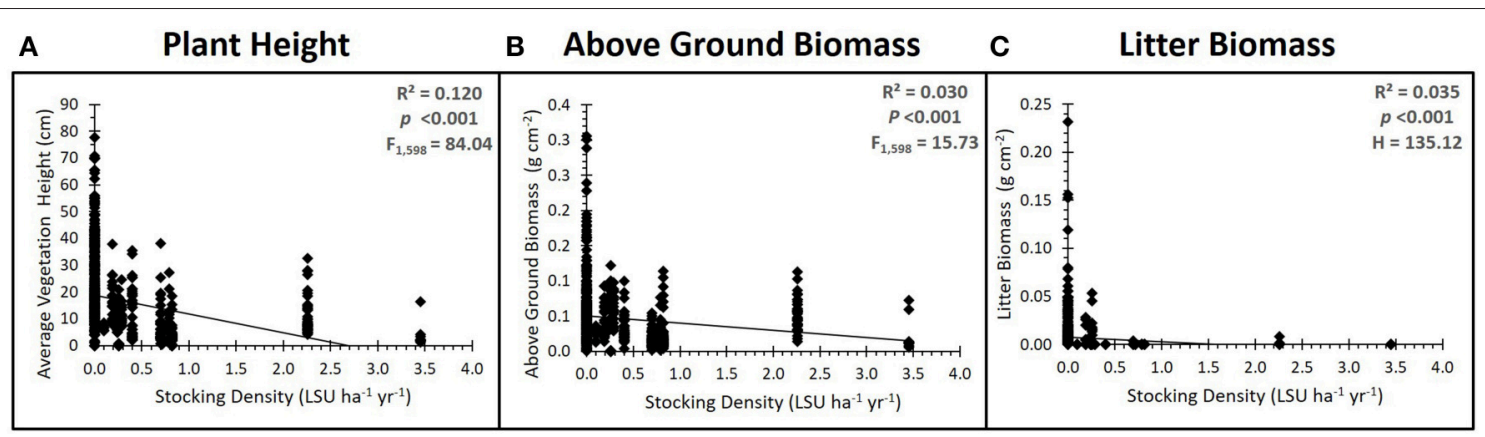

FIGURE 2 | Grazing impacts on above ground vegetation. Results of the regression analysis showing the relationship between grazing intensity (stocking density, $\mathrm{LSU} \mathrm{ha}^{-1}$ ) and $\mathbf{( A )}$ average vegetation height, (B) above ground biomass and (C) litter biomass. All significantly decreased with an increase in stocking density, with litter biomass reducing to almost zero as soon as grazers are introduced.

characterized by a low-diversity Festuca rubra sward, which changed little between each marsh. Grazing also impacted surface soil compaction (ANOVA, factor: Grazing $-\mathrm{F}_{3,18}=6.39, p$ $\left.=0.003, \eta_{p}{ }^{2}=0.355\right)$, with soil compaction increasing with increasing grazing intensity.

Grazing had no single or interactive effects on below ground soil organic carbon (SOC) [PERMANOVA, factor Grazing Intensity: Pseudo $F=1.18, P$ (perm) $=0.327$ ] or root biomass [PERMANOVA, factor Grazing Intensity: Pseudo $F=1.35, P$ (perm) $=0.235]$ for any of the sediment depths analyzed, regardless of whether grazing was treated as a categorical or continuous variable (Figure 3) (Supplementary Information S1: Regression Table). The rate of decline in SOC with soil depth did not vary significantly between grazing intensities (ANCOVA, factor Grazing Intensity: $\left.F_{3,1093}=0.64, p=0.597, \eta_{p}^{2}=0.009\right)$, although SOC did significantly decrease with depth (Figure 4) (ANCOVA, factor Depth: $\left.F_{1,1093}=219.96, p<0.001, \eta_{p}^{2}=0.166\right)$. There was no overall (all zones) relationship between root biomass and stocking density (LSU), except for a significant positive relation of root biomass with LSU in the surface soils of the high marsh, suggesting a possible plant compensatory response in this zone (Supplementary Information S1: regression table).

SOC (ANOVA, factor: Zone- $F_{3,18}=5.09, p<0.001, \eta_{p}{ }^{2}=$ 0.193 ) and root biomass (ANOVA factor: Zone $-F_{3,18}=41.47$, $\left.p<0.001, \eta_{p}^{2}=0.365\right)$ did differ between marsh zones: both were higher in the mid and high zones than in the low marsh and pioneer zone. A Tukey HSD test showed that there was significantly less SOC in the top $10 \mathrm{~cm}$ of soil of the pioneer $(x$ $\pm \mathrm{SD}=0.009 \pm 0.007)$ and low marsh $(0.014 \pm 0.008)$ zones than in the mid $(0.019 \pm 0.008)$ and high $(0.017 \pm 0.008)$ marsh zones. SOC in the top $50 \mathrm{~cm}$ of soils was lower in the pioneer zone $(0.007 \pm 0.005)$ than in the other three zones (low: 0.012 \pm 0.007 ; mid: $0.014 \pm 0.005$; high: $0.012 \pm 0.005)$. A similar pattern was found for root biomass where root biomass in the top $10 \mathrm{~cm}$ was significantly lower in the pioneer zone $(0.003 \pm$ 0.005 ) than in the other three zones (low: $0.011 \pm 0.007$; mid: $0.015 \pm 0.011$; high: $0.021 \pm 0.015)$ and was significantly higher in the high marsh than in the other three zones. This pattern was expected as older, higher marsh zones have had longer to accumulate organic matter.
The substantial spatial variation in SOC (Figure 3) was due to consistent among-marsh differences in SOC (ANOVA, factor Marsh: $\left.F_{18,18}=7.95, p<0.001, \eta_{p}^{2}=0.315\right)$ and root biomass (ANOVA, factor Marsh: $F_{3,18}=7.14, p<0.001, \eta_{p}{ }^{2}=0.392$ ), suggesting that contextual differences among marshes had a greater influence on carbon stocks than grazing. A linear mixed effects model found that SOC in the top $10 \mathrm{~cm}$ of soil had a significant association with plant community composition $\left(F_{16,181}=3.10, p<0.001\right)$, but this relationship generally did not translate down to the deeper soil layers $\left(F_{16,181}=1.17, p=\right.$ 0.292). SOC in the deeper soil profiles of the higher marsh zones showed a significant association with marsh morphology $\left(F_{5,12}\right.$ $=3.92, p=0.024)$, tidal range $\left(F_{1,12}=11.86, p=0.005\right)$ with more SOC in marshes with higher tidal ranges, and wave fetch $\left(F_{1,12}=21.69, p=0.001\right)$ with higher SOC in more sheltered marshes. SOC in the deeper profiles in the lower marsh zones was significantly associated with soil grain size, with less SOC in coarse sediments $\left(F_{1,69}=29.38, p<0.001\right)$ (Table 2).

\section{DISCUSSION}

Our study shows that clear above ground effects of grazing do not necessarily translate to below ground effects on soil carbon stocks on the broad-scale. We found no detectable effect of grazing on

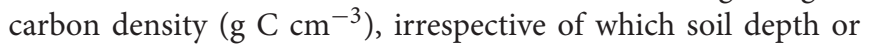
marsh zones were considered, or whether or not grazing was considered a categorical or continuous predictor of carbon. The expectation of coupled above to below-ground effect of grazing negates the many complex interactions that vegetation and carbon may have with livestock. Grazing has complex influences on grassland abiotic (e.g., compaction) and biotic (e.g., vegetation biomass and structure) conditions that influence carbon capture and storage (Andresen et al., 1990; Bardgett and Wardle, 2003; Bhogal et al., 2010). Increased stocking density can also initiate compensatory responses by the vegetation community (Holland et al., 1996; Tanentzap and Coomes, 2012) and Tanentzap and Coomes (2012) showed that a small reduction of soil carbon storing in the early years after grazer addition tailed off to no effect of grazing when study systems had sufficient time to develop compensatory responses to herbivory. We found that livestock grazing weakly stimulated the root content in high 


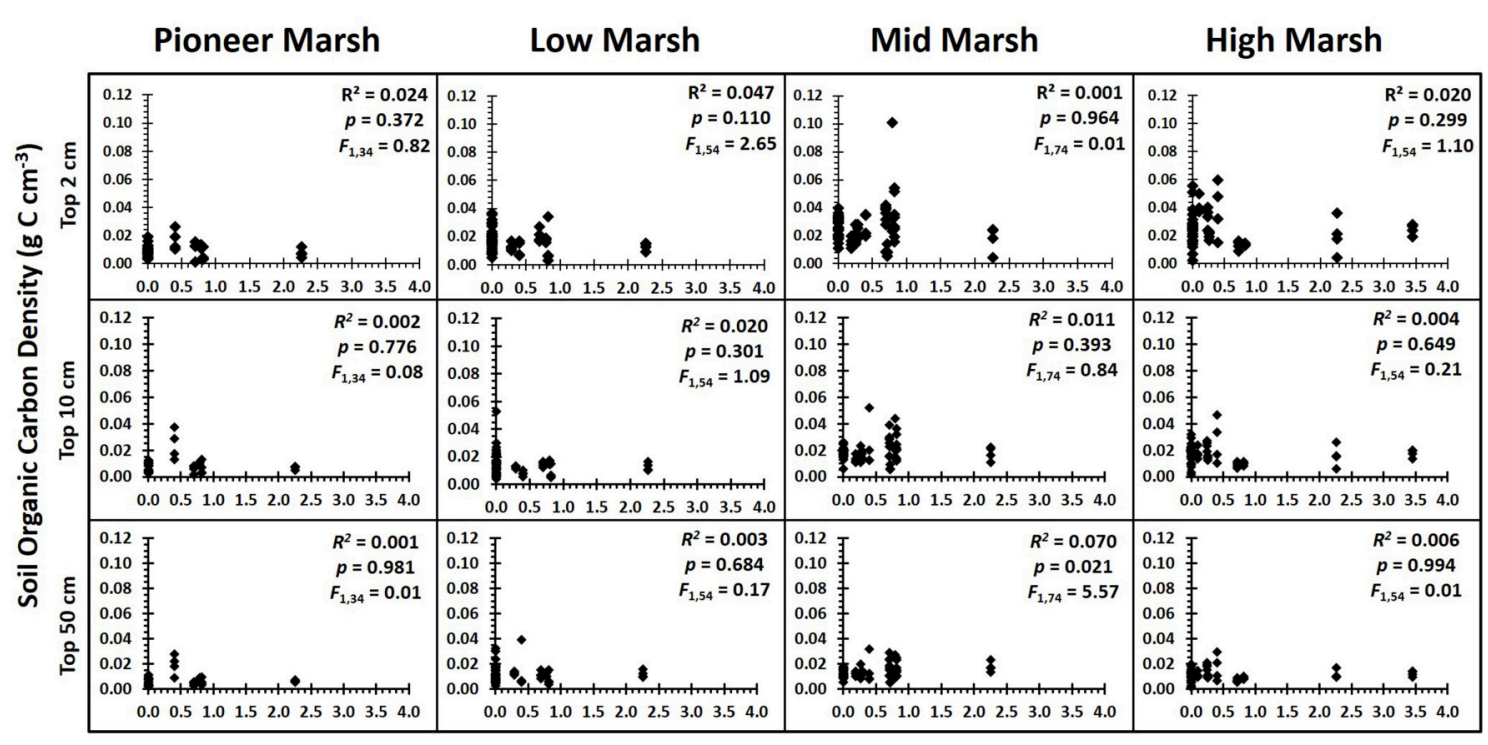

Stocking Density (LSU ha-1 $\mathrm{yr}^{-1}$ )

FIGURE 3 | Soil organic carbon density vs. grazing intensity by zone for each of the depths analyzed. Results of the regression analysis showing the relationship between soil organic carbon density and grazing intensity (stocking density, LSU ha ${ }^{-1}$ ) for each zone and for each of the depth profiles analyzed: top $2 \mathrm{~cm}$, top $10 \mathrm{~cm}$, and top $50 \mathrm{~cm}$. With the false discovery rate corrections (Verhoeven et al., 2004), there were no significant impacts of grazing on soil carbon

(Supplementary Information S1: regression table).

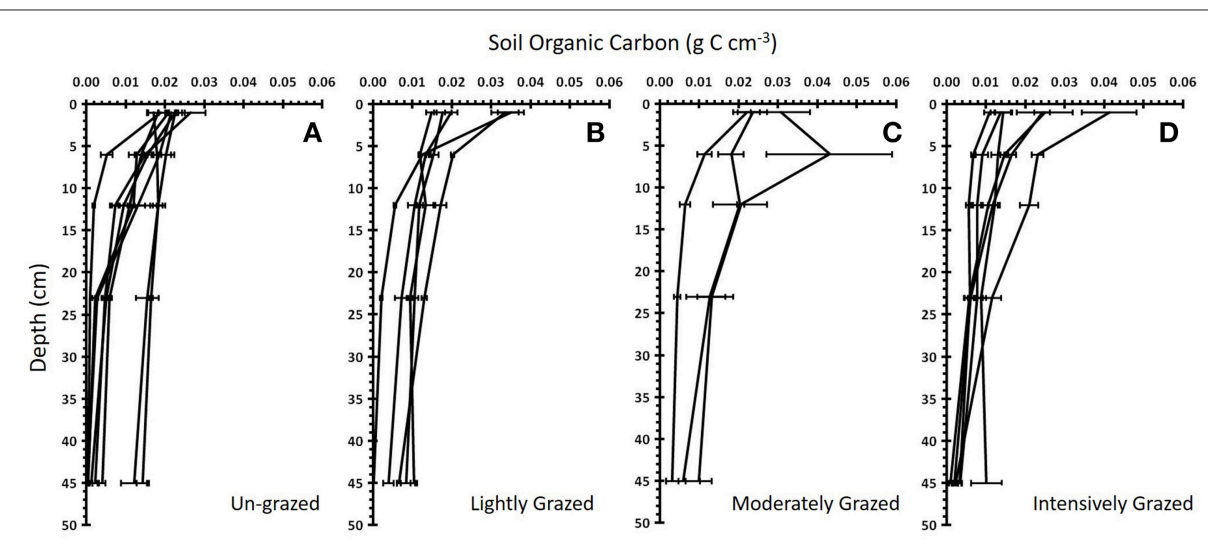

FIGURE 4 | Soil organic carbon with depth for four different grazing intensities. The mean \pm standard error soil organic carbon vs. soil depth for each marsh within each "Grazing Intensity" category: (A) un-grazed ( $n=8$ marshes), (B) lightly grazed $(n=5)$, (C) moderately grazed ( $n=3)$, and (D) intensively grazed $(n=6)$. Each line represents a single marsh.

marsh soils, suggesting that there is some compensation by the species in the vegetation community, thereby mitigating any negative impact of grazing on soil carbon stocks (Tanentzap and Coomes, 2012). Similarly, changes in the microbial communities on grazed marshes may also have increased SOC due to the introduction of terrestrial organic matter from the livestock (Mueller et al., 2017). Alternatively, carbon turnover in microbial communities may have been slower, due to lower redox levels under grazed regimes, resulting in reduced microbial exoenzymes and therefore slower decomposition rates and greater carbon accumulation in medium- and long-term storage pools (Olsen et al., 2011; Mueller et al., 2017).
In salt marshes, above ground plant adaptation to grazing occurs within a few years to a decade of introduction of grazers (Kuijper and Bakker, 2004). Our sites had been exposed to the same grazing regimes for a minimum of 30 years prior to the study-long enough for plant compensation to take place. We do not dismiss that grazers might have diminished the annual carbon storage at some point; for instance, in the early years following grazer introduction, when some studies have found that grazing can impact on carbon storing (Yu and Chmura, 2010; Sammul et al., 2012). However, over time, this early reduction of soil carbon stocks is likely to have been diluted into insignificance 
TABLE 2 | ANOVA output from mixed effects model.

\begin{tabular}{|c|c|c|c|c|c|c|c|c|c|c|}
\hline \multirow[t]{2}{*}{ Effect } & \multirow[t]{2}{*}{$d f$} & \multicolumn{3}{|c|}{$0-2 \mathrm{~cm}$ depth } & \multicolumn{3}{|c|}{$0-10 \mathrm{~cm}$ depth } & \multicolumn{3}{|c|}{$0-50 \mathrm{~cm}$ depth } \\
\hline & & $\boldsymbol{F}$ & $p$ & $m$ & $\boldsymbol{F}$ & $p$ & $m$ & $\boldsymbol{F}$ & $P$ & m \\
\hline \multicolumn{11}{|l|}{ OVERALL } \\
\hline Zone & 3,181 & 28.11 & $<0.001$ & $\star \star \star *$ & 23.58 & $<0.001$ & $\star \star \star *$ & 8.77 & $<0.001$ & $\star \star \star *$ \\
\hline Grazing (LSU) & 1,181 & 2.78 & 0.097 & & 0.44 & 0.505 & & 0.04 & 0.851 & \\
\hline Marsh area (ha) & 1,12 & 9.52 & 0.010 & * & 2.94 & 0.112 & & 1.99 & 0.184 & \\
\hline Tidal range (m) & 1,12 & 12.00 & 0.005 & ** & 1.80 & 0.204 & & 5.58 & 0.036 & * \\
\hline Wave fetch (m) & 1,12 & 0.68 & 0.426 & & 10.15 & 0.008 & $\star * *$ & 11.56 & 0.005 & ** \\
\hline Marsh geomorphology & 5,12 & 1.61 & 0.231 & & 2.99 & 0.056 & & 2.38 & 0.101 & \\
\hline Community composition & 16,181 & 3.10 & $<0.001$ & $\star \star \star$ & 1.67 & 0.057 & & 1.17 & 0.292 & \\
\hline Percent coarse sand & 1,181 & 2.52 & 0.114 & & 0.07 & 0.798 & & 4.95 & 0.027 & * \\
\hline \multicolumn{11}{|l|}{ HIGH AND MID ZONES } \\
\hline Zone & 1,96 & 1.02 & 0.315 & & 0.29 & 0.592 & & 0.06 & 0.800 & \\
\hline Grazing (LSU) & 1,96 & 0.29 & 0.592 & & 0.87 & 0.353 & & 5.51 & 0.021 & * \\
\hline Marsh area (ha) & 1,12 & 8.73 & 0.012 & * & 4.75 & 0.050 & & 2.88 & 0.115 & \\
\hline Tidal range $(\mathrm{m})$ & 1,12 & 7.20 & 0.020 & * & 2.40 & 0.147 & & 11.86 & 0.005 & ** \\
\hline Wave fetch (m) & 1,12 & 0.29 & 0.602 & & 10.71 & 0.007 & $* *$ & 21.69 & 0.001 & ** \\
\hline Marsh geomorphology & 5,12 & 2.42 & 0.098 & & 3.34 & 0.040 & * & 3.92 & 0.024 & * \\
\hline Community composition & 11,96 & 4.15 & $<0.001$ & $\star \star \star ~$ & 3.02 & 0.002 & ** & 2.18 & 0.021 & * \\
\hline Percent coarse sand & 1,96 & 5.05 & 0.027 & * & 0.71 & 0.402 & & 4.95 & 0.029 & * \\
\hline \multicolumn{11}{|c|}{ LOW AND PIONEER ZONES } \\
\hline Zone & 1,69 & 26.83 & $<0.001$ & $\star \star \star$ & 20.81 & $<0.001$ & $\star \star *$ & 35.17 & $<0.001$ & $\star \star \star *$ \\
\hline Grazing (LSU) & 1,5 & 6.97 & 0.046 & * & 1.91 & 0.225 & & 0.07 & 0.799 & \\
\hline Marsh area (ha) & 1,5 & 0.20 & 0.674 & & 0.05 & 0.825 & & 0.37 & 0.570 & \\
\hline Tidal range (m) & 1,5 & 8.50 & 0.033 & * & 2.48 & 0.176 & & 13.53 & 0.014 & * \\
\hline Wave fetch (m) & 1,5 & 0.11 & 0.725 & & 3.00 & 0.144 & & 11.27 & 0.020 & * \\
\hline Marsh geomorphology & 4,5 & 3.21 & 0.117 & & 4.34 & 0.069 & & 14.77 & 0.006 & ** \\
\hline Community composition & 6,69 & 3.90 & 0.002 & ** & 1.55 & 0.175 & & 1.42 & 0.219 & \\
\hline Percent coarse sand & 1,69 & 5.53 & 0.022 & $\star$ & 27.38 & $<0.001$ & $\star \star \star *$ & 19.26 & $<0.001$ & $\star \star \star *$ \\
\hline
\end{tabular}

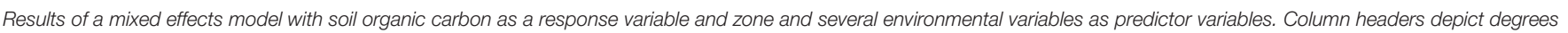

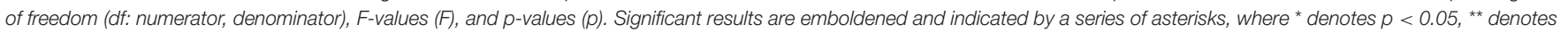
$p<0.01$ and $^{\star \star \star}$ denotes $p<0.001$.

by decades of compensation by the plant community (Tanentzap and Coomes, 2012).

Across a large biogeographical region, variation in environmental drivers had a stronger influence on carbon stocks than livestock density. Salt marshes are at the interface between terrestrial and marine environments (Adam, 1990b) and are subjected to greater spatial and temporal variation in environmental conditions, and hence more disturbance, than many grazed terrestrial grasslands (Adam, 1990c). Environmental context determines much of the external carbon inputs to salt marshes. For instance, sedimentation rates are linked to the local tidal regime (Stumpf, 1983) and allochthonous organic matter, that imported with marine sediment rather than created on the salt marsh, can contribute considerably to SOC stocks where tall vegetation traps sediment (Van de Broek et al., 2018; Mueller et al., 2019). Arguably, the impact of grazing on saltmarsh carbon is comparatively weak relative to the influence of sharp background environmental gradients (Grime, 1974; Nolte et al., 2013). The assumption that carbon capture and storage benefits from management of grazing might well be tenuous in naturally variable and disturbed systems, such as salt marshes.

The observed lack of grazer effects on carbon stock is consistent with the findings of a few smaller-scale grazer presence/absence studies (Meyer et al., 1995; Ford et al., 2012), but it disagrees with studies made in North America (Reader and Craft, 1999; Yu and Chmura, 2010). A recent systematic review showed grazer effects on carbon have only been demonstrated in the USA (Davidson et al., 2017), where marshes are structurally and functionally different too much of the rest of the world (Catterjsse and Hampel, 2006; Bakker et al., 2015). In the USA much of SOC is derived from prolific within-marsh plant production, whilst in Europe the majority of carbon is externally derived through sedimentation (Catterjsse and Hampel, 2006; Bakker et al., 2015). Thus, carbon storing in European type marshes may be more strongly influenced by extrinsic processes that regulate sedimentation than intrinsic processes that influence the vegetation, such as grazing pressure. 
This deduction is corroborated by the observation made here that environmental context explained the majority of spatial variation in carbon stock, whereas the effects of grazing could not be detected.

Our expectations of negative impacts of grazing on soil carbon stocks were based on evidence from a combination of single-site, experimental studies (Schuster, 1964; Klumpp et al., 2009; Yu and Chmura, 2010; Ford et al., 2012) and meta-data analyses from both terrestrial grasslands and coastal wetlands (Chmura et al., 2003; Tanentzap and Coomes, 2012). None of these studies incorporated a full range of grazing intensities, as we did here; nor did they view the influence of grazing in the context of natural variation. Our study does not imply that grazing has no effect on carbon stocks; rather it shows that the effect of grazing was insufficiently strong or consistent to be detectable above the broad-scale influences of environmental variation and compensation by vegetation. This finding implies that management schemes that stipulate grazing regimes across multiple sites are unlikely to generate spatially consistent effects on carbon stocks. Furthermore, our study only looked at carbon stocks and not carbon sequestration rates. The carbon stocks in this study are a product of accumulated inputs and outputs of organic and inorganic carbon from autochthonous and allochthonous sources, and while there was no impact of grazing on the overall carbon stocks, grazing may affect carbon sequestration rates and mechanisms. There are still many good reasons to manage grazing, such as safeguarding the provision of other ecosystem services, including wave attenuation (Möller et al., 1999), sea defense (King and Lester, 1995; Möller et al., 2007); habitat management (Norris et al., 1997) and biodiversity conservation (Adler et al., 2001). It may be that the regulation of grazing intensity is of particular benefit to above-ground functioning of saltmarshes, such as the provisioning of wildlife habitat and the regulation of gaseous fluxes, and less beneficial to below-ground processes, such as carbon storing.

\section{REFERENCES}

Adam, P. (1990a). Saltmarsh Ecology. Cambridge: Cambridge University Press.

Adam, P. (1990b). "General features of saltmarshes and their environment," in Saltmarsh Ecology (Cambridge: Cambridge University Press), 1-71.

Adam, P. (1990c). "Coping with the environment," in Saltmarsh Ecology (Cambridge: Cambridge University Press), 207-308.

Adler, P. B., Raff, D. A., and Lauenroth, W.K. (2001). The effect of grazing on spatial heterogeneity of vegetation. Oecologia. 128:4. doi: $10.1007 /$ s004420100737

Allen, J. R. L. (2000). Morphodynamics of Holocene salt marshes: a review sketch from the Atlantic and Southern North Sea coasts of Europe. Quaternary Sci. Rev. 19:12. doi: 10.1016/S0277-3791(99)00034-7

Almunia, J. (2009). Commission of the European Communities. Commission Regulation (EC): Implementing Regulation (EC) No 1166/2008 of the European Parliament and of the Council on Farm Structure Surveys and the Survey on Agricultural Production Methods, as Regards Livestock Unit Coefficients and Definitions of the Characteristics. Report number: 1200/2009. Brussels: European Union.

Andersen, T. J., Svinth, S., and Prejrup, M. (2010). Temporal variation of accumulation rates on a natural salt marsh in the 20th century - the impact of sea level rise and increased inundation frequency. Mar. Geol. 279:1-4. doi: 10.1016/j.margeo.2010.10.025

\section{AUTHOR CONTRIBUTIONS}

MS, AG, RH, and $\mathrm{SH}$ contributed toward experimental conception design. RH and MS selected the study sites and collected the field data. RH analyzed all laboratory samples and MS and $\mathrm{RH}$ conducted the data analysis with inputs from $\mathrm{SH}$. $\mathrm{RH}$ wrote the first draft of the manuscript and all authors contributed to revisions.

\section{FUNDING}

Funding was provided from Knowledge Economy Skills Scholarships (KESS) as a European Social Fund, and from the Natural Environmental Research Council C-SIDE grant (NERC: NE/RO10846/1 R28R32).

\section{ACKNOWLEDGMENTS}

We thank the Centre for Ecology and Hydrology (CEH), Bangor for providing project support and field and laboratory facilities throughout the project. We would like to thank Inma Roberts, Steve Hughes, Hilary Ford, and Jan Hiddink for help and advice on practical and analytical techniques throughout the project. Thanks for fieldwork assistance: Marc Brouard, Gareth Harvey, Jennifer Harvey, Fred Maier, Damian Smith, Caroline Lucien, Kate Batchelor, Cat Spinney, Dan Hewitt, Vicki Foster, and in particular Matt Lundquist, Aoife Ni Neachtain, and Cai Ladd.

\section{SUPPLEMENTARY MATERIAL}

The Supplementary Material for this article can be found online at: https://www.frontiersin.org/articles/10.3389/fevo. 2019.00151/full\#supplementary-material

Anderson, M. J. (2005). PERMANOVA-Permutational Multivariate Analysis of Variance. Aukland: Department of Statistics, University of Aukland.

Andresen, H., Bakker, J. P., Brongers, M., Heydenmann, B., and Irmler, U. (1990). Long-term changes of salt marsh communities by cattle grazing. Vegetatio. 898:2. 10.1007/BF00032166

Bakker, J. P. (1985). The impact of grazing on plant communities, plant populations and soil conditions on salt marshes. Vegetatio. 62:1-3. doi: $10.1007 / \mathrm{BF} 00044766$

Bakker, J. P., Nielsen, K. J., Alberti, J., Chan, F., Hacker, S. D., Iribarne, O. O., et al. (2015). "Bottom-up and top-down interactions in coastal interface systems," in Trophic Ecology: Bottom-up and Top-Down Interactions Across Aquatic and Terrestrial Systems, eds T. C. Hanley, and K. J. La Pierre (Cambridge, UK: Cambridge University Press), 157-200.

Ball, D. F. (1964). Loss-on-ignition as an estimate of organic matter and organic carbon in non-calcareous soils. J. Soil Sci. 15:1. doi: 10.1111/j.1365-2389.1964.tb00247.x

Bardgett, R. D., and Wardle, D. A. (2003). Herbivore-mediated linkages between aboveground and belowground communities. Ecology. 84:9. doi: 10.1890/02-0274

Bartlett, K. B., Bartlett, D. S., Harriss, R. C., and Sebacher, D. I. (1987). Methane emissions along a salt marsh salinity gradient. Biogeochemistry. 4:3. doi: $10.1007 / \mathrm{BF} 02187365$ 
Beaumont, N. J., Jones, L., Garbutt, A., Hansom, J. D., and Toberman, M. (2014). The value of carbon sequestration and storage in coastal habitats. Estuar. Coast. Shelf Sci. 137, 32-40. doi: 10.1016/j.ecss.201 3.11 .022

Berg, G., Esselink, P., Groeneweg, M., and Kiehl, K. (1997). Micropatterns in Festuca rubra dominated salt-marsh vegetation induced by sheep grazing. Plant Ecol. 132:1. doi: 10.1023/A:1009727804007

Bhogal, A., Nicholson, F. A., Young, I., Sturrock, C., Whitmore, A. P., and Chambers, B. J. (2010). Effects of recent and accumulated livestock manure carbon additions on soil fertility and quality. Eur. J. Soil Sci. 62:1. doi: 10.1111/j.1365-2389.2010.01319.x

Burrows, M. T., Harvey, R., and Robb, L. (2008). Wave exposure indices from digital coastlines and the prediction of rocky shore community structure. Mar. Ecol. Prog. Ser. 353, 1-12. doi: 10.3354/meps07284

Cao, G., Tang, Y., Mo, W., Wang, Y., Li, Y., and Zhao, X. (2004). Grazing intensity alters soil respiration in an alpine meadow on the Tibetan plateau. Soil Biol. Biochem. 36:2. doi: 10.1016/j.soilbio.2003.09.010

Catterjsse, A., and Hampel, H. (2006). European intertidal marshes: a review of their habitat functioning and value for aquatic organisms. Mar. Ecol. Prog. Ser. 324, 293-307. doi: 10.3354/meps324293

Chalmers, A. G., Wiegert, R. G., and Wolf, P. L. (1985). Carbon balance in a salt marsh: interactions of diffusive export, tidal deposition and rainfall-caused erosion. Estuar. Coast. Shelf Sci. 21:6. doi: 10.1016/0272-7714(85)90071-X

Chen, W., Huang, D., Liu, N., Zhang, Y., Badgery, W. B., Wang, X., et al. (2015). Improved grazing management may increase soil carbon sequestration in temperate steppe. Sci. Rep. 5:10892. doi: 10.1038/srep10892

Chmura, G. L., Anisfeld, S. C., Cahoon, D. R., and Lynch, J. C. (2003). Global carbon sequestration in tidal, saline wetland soils. Global Biogeochem. Cy. 17:4. doi: 10.1029/2002GB001917

Clarke, K. R. (1993). Non-parametric multivariate analyses of changes in community structure. Aust. J. Ecol. 18:1. doi: $10.1111 /$ j.1442-9993.1993.tb00438.x

Clarke, K. R., and Warwick, R. M. (2001). Change in Marine Communities: An Approach to Statistical Analysis and Interpratation. 2nd Edn. Plymouth: PRIMER-E.

Cohen, J. (1988). Statistical Power Analysis for the Behavioural Sciences. Hillside, NJ: Lawrence Erlbaum.

Conant, R., Paustian, K., and Elliott, E. T. (2000). Grassland management and conversion into grassland: effects on soil carbon. Ecol. Appl. 11:2. doi: 10.1890/ 1051-0761(2001)011[0343:GMACIG]2.0.CO;2

Conant, R. T., and Paustian, K. (2002). Potential soil carbon sequestration in overgrazed grassland ecosystems. Global Biogeochem. Cy. 16:4. doi: 10.1029/2001GB001661

Craft, C. B., Seneca, E. D., and Broome, S. W. (1991). Loss on ignition and kjeldahl digestion for estimating organic carbon and total nitrogen in estuarine marsh soils: calibration with dry combustion. Estuar. Coast. 14:2. doi: $10.2307 / 1351691$

Cundy, A. B., and Croudace, I. W. (1996). Sediment accretion and recent sealevel rise in the Solent, Southern England: inferences from radiometric and geochemical studies. Estuar. Coast. Shelf Sci. 43:4. doi: 10.1006/ecss.1996.0081

Davidson, K. E., Fowler, M. S., Skov, M. W., Doerr, S. Y., Beaumont, N., and Griffin, J. N. (2017). Meta-analysis reveals livestock grazing alters multiple ecosystem properties and services in salt marshes. J. Appl. Ecol. 54:5. doi: 10.1111/1365-2664.12892

De Deyn, G. B., Cornelissen, J. H. C., and Bardgett, R. D. (2008). Plant functional traits and soil carbon sequestration in contrasting biomes. Ecol. Lett. 11:5. doi: $10.1111 /$ j.1461-0248.2008.01164.x

Derner, J. D., Boutton, T. W., and Briske, D. D. (2006). Grazing and ecosystem carbon storage in the North American great plains. Plant Soil. 280:1-2. doi: 10.1007/s11104-005-2554-3

Di Bella, C. E., Rodríguez, A. M., Jacobo, E., Golluscio, R. A., and Taboada, M. A. (2015). Impact of cattle grazing on temperate coastal salt marsh soils. Soil Use Manage. 31:2. doi: 10.1111/sum.12176

Donato, D. C., Kauffman, J. B., Murditarso, D., Kurnianto, S., Stidham, M., and Kannien, M. (2011). Mangroves among the most carbon-rich forests in the tropics. Nat. Geosci. 4, 293-297. doi: 10.1038/ngeo1123

Duarte, C. M., Losada, I. J., Hendriks, I. E., Mazarrasa, I., and Marbà, N. (2013). The role of coastal plant communities for climate change mitigation and adaptation. Nat. Clim. Change. 3:11. doi: 10.1038/ nclimate 1970

Dung, L. V., Tue, N. T., Nhuan, M. T., and Omori, K. (2016). Carbon storage in a restored mangrove forest in Can Gio Mangrove Forest Park, Mekong Delta, Vietnam. Forest Ecol. Manag. 380, 31-40. doi: 10.1016/j.foreco.2016.08.032

Elschot, K., Bakker, J., Temmerman, S., van de Koppel, J., and Bouma, T. (2015a). Ecosystem engineering by large grazers enhances carbon stocks in a tidal salt marsh. Mar. Ecol. Prog. Ser. 537, 9-21. doi: 10.3354/meps11447

Elschot, K., Bakker, J., Temmerman, S., van de Koppel, J., and Bouma, T. (2015b). "Experimental evidence for top-down control of carbon stocks in a tidal salt marsh," In. Effects of Vegetation Patterns and Grazers on Tidal Marshes. Ph.D. thesis (Groningen: Rijksuiversiteit Groningen).

Emmet, B. A., Frogbrook, Z. L., Chamberlain, P. M., Griffiths, R., Pickup, R., Poskitt, J., et al. (2008). Countryside Survey Technical Report No. 3/07. Centre for Ecology and Hydrology, Natural Environment Research Council.

Facelli, J. M., and Pickett, S. T. A. (1991). Plant litter: its dynamics and effects on plant community structure. Bot. Rev. 57:1. doi: 10.1007/BF02858763

Ford, H., Garbutt, A., Jones, L., and Jones, D. L. (2012). Methane, carbon dioxide and nitrous oxide fluxes from a temperate salt marsh: grazing management does not alter global warming potential. Estuar. Coast. Shelf Sci. 113. doi: $10.1016 /$ j.ecss.2012.08.002

Fox, W. M., Johnson, M. S., Jones, S. R., Leah, R. T., and Copplestone, D. (1999). The use of sediment cores from stable and developing salt marshes to reconstruct the recent historical contamination profiles in the Mersey estuary, UK. Mar. Environ. Res. 47:4. doi: 10.1016/S0141-1136(98)00 123-8

Frank, A. B., Tanaka, D. L., Hofmann, L., and Follett, R. F. (1995). Soil carbon and nitrogen of the northern great plains grasslands as influenced by long-term grazing. J. Range Manage. 48:5. doi: 10.2307/4002255

French, J. R., and Spencer, T. (1993). Dynamics of sedimentation in a tide-dominated backbarrier salt marsh, Norfolk, UK. Mar. Geol. 110:3-4. doi: 10.1016/0025-3227(93)90091-9

Gedan, K. B., Silliman, B. R., and Bertness, M. D. (2009). Centuries of human driven change in salt marsh ecosystems. Annu. Rev. Mar. Sci. 1, 117-141. doi: 10.1146/annurev.marine.010908.163930

Graff, P., Aguiar, M. R., and Chaneton, E. J. (2007). Shifts in positive and negative plant interactions along a grazing intensity gradient. Ecology. 88:1. doi: 10.1890/ 0012-9658(2007)88[188:SIPANP]2.0.CO;2

Grime, J. P. (1974). Vegetation classification by reference to strategies. Nature. 250, 26-31. doi: 10.1038/250026a 0

Haveren, B. P. (1983). Soil bulk density as influenced by grazing intensity and soil type on a shortgrass prairie site. J. Range Manage. 36:5. doi: 10.2307/3898346

Hayes, M. A, Jesse, A., Hawke, B., Baldock, J., Tabet, B., Lockington, D., et al. (2017). Dynamics of sediment carbon stocks across intertidal wetland habitats of Moreton Bay, Australia. Glob. Change Biol. 23:10. doi: 10.1111/gcb.13722

Himes-Cornell, A., Pendleton, L., and Atiyah, P. (2018). Valuing ecosystem services from blue forests: a systematic review of valuation of salt marshes, sea grass beds and mangrove forests. Ecosyst. Serv. 30, 36-48. doi: 10.1016/j.ecoser.2018.01.00

Holland, J. N., Cheng, W., and Crossley, D. A. J. (1996). Herbivore-induced changes in plant carbon allocation: assessment of below-ground C fluxes using carbon-14. Oecologia. 107:1. doi: 10.1007/BF00582238

Howarth, R. W. (1984). The ecological significance of sulfur in the energy dynamics of salt marsh and coastal marine sediments. Biogeochemistry. 1:1. doi: $10.1007 / \mathrm{BF} 02181118$

Hussein, A. H., and Rabenhorst, M. C. (2002). Modelling of nitrogen sequestration in coastal marsh soils. Soil Sci. Soc. Am. J. 66:1. doi: 10.2136/sssaj2002.3240

Jensen, A. (1985). The effect of cattle and sheep grazing on salt-marsh vegetation at Skallingen, Denmark. Vegetatio. 60:1. doi: 10.1007/BF00053910

Kang, L., Han, X., Zhang, Z., and Sun, O. J. (2007). Grassland ecostystems in China: review of current knowledge and research advancement. Philos. Trans. Roy. Soc. B. 362:1482. doi: 10.1098/rstb.2007.2029

Kiehl, K., Eischeid, I. E., Gettner, S., and Walter, J. (1996). Impact of different sheep grazing intensities on salt marsh vegetation in Northern Germany. J. Veg. Sci. 7, 99-106. doi: 10.2307/3236421

King, S. E., and Lester, J. N. (1995). The value of salt marsh as a sea defence. Mar. Pollut. Bull. 30:3. doi: 10.1016/0025-326X(94) 00173-7 
Kingham, R. J. (2013). The Broad-Scale Impacts of Livestock Grazing on Saltmarsh Carbon Stocks. Ph.D. thesis. Bangor: Bangor University.

Klumpp, K., Fontaine, S., Attard, E., Le Roux, X., Gleixner, G., and Soussana, J.-F. (2009). Grazing triggers soil carbon loss by altering plant roots and their control on soil microbial community. J. Ecol. 97:5. doi: 10.1111/j.1365-2745.2009.01549.x

Kuijper, D., and Bakker, J. P. (2004). Large-Scale Effects of a Small Herbivore on SaltMarsh Vegetation Succession, A Comparative Study. Ph.D. thesis. Groningen: University of Groningen.

Mcleud, E., Chmura, G. L., Bouilln, S., Salm, R., Björk, M., Duarte, C. M., et al. (2011). A blueprint for blue carbon: towards an improved understanding of the role of vegetated costal habitats in sequestering $\mathrm{CO}_{2}$. Front. Ecol. Environ. 9:4. doi: $10.1890 / 110004$

McNaughton, S. J. (1979). Grazing as an optimization process: grass-ungulate relationships in the Serengeti. Am. Nat. 113:5. doi: 10.1086/283426

McNaughton, S. J., Banyikwa, F. F., and McNaughton, M. M. (1998). Root biomass and productivity in a grazing ecosystem: the Serengeti. Ecology. 79:2. doi: 10. 1890/0012-9658(1998)079[0587:RBAPIA]2.0.CO;2

McSherry, M. E., and Ritchie, M. E. (2013). Effects of grazing on grassland soil carbon: a global review. Glob. Change Biol. 19:5. doi: 10.1111/gcb.12144

Meyer, H., Fock, H., Haase, A., Reinke, H. D., and Tulowitzki, I. (1995). Structure of the invertebrate fauna in salt marshes of the Wadden Sea coast of Schleswig-Holstein influenced by sheep-grazing. Helgoländer Meeresun. 49, 1-4. doi: $10.1007 / \mathrm{BF} 02368383$

Middelburg, J. J., Nieuwenhuize, J., Lubberts, R. K., and van de Plassche, O. (1997). Organic carbon isotope systematics of coastal marshes. Estuar. Coast. Shelf Sci. 45:5. doi: 10.1006/ecss.1997.0247

Milotić, T., Erfanzadeh, R., Pétillon, J., Maelfait, J.-P., and Hoffman, M. (2010). Short-term impact of grazing by sheep on vegetation dynamics in a newly created salt-marsh site. Grass Forage Sci. 65, 121-132. doi: $10.1111 / j .1365-2494.2009 .00725 . x$

Möller, I., Spencer, T., French, J. R., Legget, D. J., and Dixon, M. (1999). Wave transformation over salt marshes: a field and numerical modelling study from North Norfolk, England. Estuar. Coast. Shelf Sci. 49, 411-426. doi: 10.1006/ecss.1999.0509

Möller, I., Spencer, T., French, J. R., Leggett, D. J., and Dixon, M. (2007). The sea-defence value of salt marshes: field evidence from North Norfolk. Water Environ. J. 15:2. doi: 10.1111/j.1747-6593.2001.tb00315.x

Morris, J. T., and Jensen, A. (1998). The carbon balance of grazed and nongrazed Spartina anglica saltmarshes at Skallingen, Denmark. J. Ecol. 86:2. doi: 10.1046/j.1365-2745.1998.00251.x

Morris, J. T., and Whiting, G. J. (1986). Emission of gaseous carbon dioxide from salt-marsh sediments and its relation to other carbon losses. Estuar. Coast. 9:1. doi: $10.2307 / 1352188$

Mueller, P., Granse, D., Nolte, S., Do, H. T., Weingartner, M., Hoth, S., et al. (2017). Top-down control of carbon sequestration: grazing affects microbial structure and function in salt marsh soils. Ecol. Appl. 27:5. doi: 10.1002/eap.1534

Mueller, P., Ladiges, N., Jack, A., Schmiedl, G., Kutzbach, L., Jensen, K., et al. (2019). Assessing the long-term carbon-sequestraion potential of the semi-natural salt marshes in the European Wadden Sea. Ecosphere. 10:1. doi: $10.1002 /$ ecs 2.2556

Murray, P. J., Gill, E., Balsdon, S. L., and Jarvis, S. C. (2001). A comparison of methane emissions from sheep grazing pastures with different management intensities. Nutr. Cycl. Agroecosys. 60, 1-3. doi: 10.1023/A:1012654928177

Neuhaus, R., Stelter, T., and Kiehl, K. (1999). Sedimentation in salt marshes affected by grazing regime, topographical patterns and regional differences. Senck. Marit. 29:1. doi: 10.1007/BF03043134

Nolte, S., Mueller, F., Schuerch, M., Wanner, A., Esselink, P., Bakker, J. P., et al. (2013). Does livestock grazing affect sediment deposition and accretion rates in salt marshes? Estuar. Coast. Shelf Sci. 135, 296-305. doi: $10.1016 /$ j.ecss.2013.10.026

Norris, K., Cook, T., O’Dowd, B., and Durdin, C. (1997). The density of redshank Tringa totanus breeding on the salt-marshes of the Wash in relation to habitat and its grazing management. J. Appl. Ecol. 34:4. doi: 10.2307/24 05289

Olofsson, J., and Oksanen, L. (2002). Role in litter decomposition for the increased primary production in areas heavily grazed by reindeer: a litterbag experiment. Oikos. 96:3. doi: 10.1034/j.1600-0706.2002.960312.x
Olsen, Y. S., Dausse, A., Garbutt, A., Ford, H., Thomas, D. N., and Jones, D. L. (2011). Cattle grazing drives nitrogen and carbon cylingin a temperate salt marsh. Soil Biol. Biochem. 43:3. doi: 10.1016/j.soilbio.201 0.11 .018

Ostle, N. J., Levy, P. E., Evans, C. D., and Smith, P. (2009). UK land use and soil carbon sequestration. Land Use Policy. 26:1. doi: 10.1016/j.landusepol.2009.08.006

Pinares-Patino, C. S., D’Hpur, P., Jouany, J.-P., and Martin, C. (2007). Effects of stocking rate on methane and carbon dioxide emissions from grazing cattle. Agr. Ecosyst. Environ. 121, 1-2. doi: 10.1016/j.agee.200 6.03 .024

Proensky, L. M., Mueller, K. E., Augustine, D. J., and Derner, J. D. (2016). Thresholds and gradients in a semi-arid grassland: long-term grazing treatments induce slow, continuous and reversible vegetation change. J. Appl. Ecol. 53:4. doi: 10.1111/1365-2664.12630

R Core Team (2012). R: A Language and Environment for Statistical Computing. Vienna: R Foundation for Statistical Computing. Available online at: http:// www.R-project.org/

Rauzi, F., and Hanson, C. L. (1966). Water intake and runoff affected by intensity of grazing. J. Range Manage. 19:6. doi: 10.2307/3895570

Reader, J., and Craft, C. (1999). Comparison of wetland structure and function on grazed and ungrazed salt marshes. J. Elisha Mitch. Sci. Soc. 115, 236-249.

Reeder, J. D., and Schuman, G. E. (2002). Influence of livestock grazing on C sequestration in semi-acid, mixed-grass and short-grass rangelands. Environ. Pollut. 116, 457-463. doi: 10.1016/S0269-7491(01)00223-8

Reid, R.S., Galvin, K.A., and Kruska, R.S. (2008). "Global significance of extensive grazing lands and pastoral societies: an introduction," in Fragmentation in SemiArid and Arid Landscapes, eds K. A. Galvin, R. S. Reid, R. H. J. Behnke, and N. Thompson Hobbs (Heidleberg: Springer Netherlands), 1-24.

Richards, K. R. (2004). A brief overview of carbon sequestration economics and policy. Environ. Manage. 33, 545-558. doi: 10.1007/s00267-003-9111-8

Richardson, J. T. E. (2011). Eta squared and partial eta squared as measures of effect size in educational research. Edu. Res. Rev. 6, 135-147. doi: 10.1016/j.edurev.2010.12.001

Robinson, W.O. (1927). The determination of organic matter in soils by means of hydrogen peroxide. J. Agric. Res. 34, 339-356.

Rodwell, J.S., Pigott, C.D., Ratcliffe, D.A., Malloch, A.J.C., Birks, H.J.B., Proctor, M.C.F., et al. (2000). British Plant Communities. Volume 5: Maritime Communities and Vegetation of Open Habitats. Cambridge: Cambridge University Press.

Sammul, M., Kauer, K., and Köster, T. (2012). Biomass accumulation during reed encroachment reduces efficiency of restoration of Baltic coastal grasslands. Appl. Veg. Sci. 15:2. doi: 10.1111/j.1654-109X.2011.01167.x

Saunders, C. J., Megonigal, J. P., and Reynolds, J. F. (2006). Comparison of belowground biomass in $\mathrm{C}^{3}$ - and $\mathrm{C}^{4}$-dominated mixed communities in a Chesapeake Bay brackish marsh. Plant Soil. 280, 1-2. doi: 10.1007/s11104-005-3275-3

Scanlon, D., and Moore, T. R. (2000). Carbon dioxide production from peatland soil profiles: the influence of temperature, oxic/anoxic conditions and substrate. Soil Sci. 165:2. doi: 10.1097/00010694-200002000-00006

Schipper, L. A., Mudge, P. L., Kirschnaum, M. U. F., Hedley, C. B., Golubiewski, N. E., Smaill, S. J., et al. (2017). A review of soil carbon change in New Zealand's grazed grasslands. New Zeal. J. Agr. Res. 60:2. doi: 10.1080/00288233.2017.1284134

Schumacher, B.A. (2002). United States Environmental Protection Agency. Methods for the Determination of Total Organic Carbon (TOC) in Soils and Sediments. Las Vegas, NV: Ecological Risk Assessment Support Center, Office of Research and Development.

Schuman, G. E., Reeder, D. J., Manley, J. T., Hart, R. H., and Manley, W. A. (1999). Impact of grazing management on the carbon and nitrogen balance of a mixed-grass rangeland. Ecol. Appl. 9:1. doi: 10.1890/10510761(1999)009[0065:IOGMOT]2.0.CO;2

Schuster, J. L. (1964). Root development of native plants under three grazing intensities. Ecology. 45:1. doi: 10.2307/1937107

Sharps, E., Smart, J., Mason, L. R., Jones, K., Skov, M. W., Garbutt, A., et al. (2017). Nest trampling and ground nesting birds: quantifying temporal and spatial overlap between cattle activity and breeding redshank. Ecol Evol. 7:16. doi: 10.1002/ece3.3271 
Shepherd, D., Burgess, D., Jickells, T., Andrews, J., Cave, R., Turner, R. K., et al. (2007). Modelling the effects and economics of managed realignment on the cycling and storage of nutrients, carbon and sediments in the Blackwater estuary UK. Estuar. Coast. Shelf Sci. 73, 3-4. doi: 10.1016/j.ecss.2007. 01.019

Shi, Z. (1992). Recent saltmarsh accretion and sea level fluctuations in the Dyfi Estuary, central Cardigan Bay, Wales, UK. Geo-Mar. Lett. 13:3. doi: 10.1007/BF01593192

Sollins, P., Homann, P., and Caldwell, B. A. (1996). Stabilization and destabilization of soil organic matter: mechanisms and controls. Geoderma. 74, 1-2. doi: 10.1016/S0016-7061(96)00036-5

Sousa, A. I., Lillebo, A. I., Pardal, M. A., and Cacador, I. (2010). The influence of Spartina maritima on carbon retention capacity in salt marshes from warm-temperate estuaries. Mar. Pollut. Bull. 61, 4-6. doi: 10.1016/j.marpolbul.2010.02.018

Stewart,. K. E. J., Bourn, N. A. D., and Thomas, J. A. (2001). An evaluation of three quick methods commonly used to assess sward height in ecology. J. Appl. Ecol. 38:5. doi: 10.1046/j.1365-2664.2001.00658.x

Stumpf, R. P. (1983). The process of sedimentation on the surface of a saltmarsh. Esutar. Coast. Shelf Sci. 17:5. doi. 10.1016/0272-7714(83)90002-1

Tanentzap, A. J., and Coomes, D. A. (2012). Carbon storage in terrestrial ecosystems: do browsing and grazing herbivores matter? Biol. Rev. 87:1. doi: 10.1111/j.1469-185X.2011.00185.x

Tanner, C. B., and Mamaril, C. P. (1958). Pasture soil and compaction by animal traffic. Crop Sci. Soc. Am. 51:6. doi: 10.2134/agronj1959.00021962005100060007x

Valiela, I., Teal, J. M., Allen, S. D., Van Etten, R., Goehringer, D., and Volkmann, S. (1985). Decomposition in salt marsh ecosystems: the phases and major factors affecting disappearance of above-ground organic matter. J. Exp.l Mar. Biol. Ecol. 88:1. doi: 10.1016/0022-0981(85)90080-2

Van de Broek, M., Vandendriessche, C., Poppelmonde, D., Merckx, R., Temmerman, S., and Govers, G. (2018). Long-term organic carbon sequestration in tidal marsh sediments is dominated by old-aged allochthonous inputs in a macrtidal estuary. Glob. Change Biol. 24:6. doi: 10.1111/gcb. 14089
Van der Wal, D., Pye, K., and Neal, A. (2002). Long-term morphological change in the Ribble Estuary, northwest England. Mar. Geol. 189, 3-4. doi: 10.1016/S0025-3227(02)00476-0

Verhoeven, K. J. F., Simonsen, K. L., and McIntyre, L. M. (2004). Implementing false discovery rate control: increasing your power. Oikos. 108:3. doi: 10.1111/j.0030-1299.2005.13727.x

Wallage, Z. E., Holden, J., and McDonald, A. T. (2006). Drain blocking: an effective treatment for reducing dissolved organic carbon loss and water discolouration in a drained peatland. Sci. Total Environ. 367, 2-3. doi: $10.1016 /$ j.scitotenv.2006.02.010

Wang, Z., Zeng, D., and Partrick, W. H. J. (1996). Methane emissions from natural wetlands. Environ. Monit. Assess. 42:1-2. doi: 10.1007/BF00394047

Ward, S. E., Smart, S. M., Quirk, H., Tallowin, J. R. B., Mortimer, S. R., Shiel, R. S., et al. (2016). Legacy effects of grassland management on soil carbon depth. Glob. Change Biol. 22:8. doi: 10.1111/gcb.13246

Welsh Government (2017). Rural Communities. Glastir Advanced 2017, Rules Booklet 1. Cardiff.

Winfrey, M. R., and Ward, D. M. (1983). Substrates for sulfate reduction and methane production in intertidal sediments. Appl. Environ. Mircob. 45, 193-199.

Yu, O. T., and Chmura, G. L. (2010). Soil carbon can be maintained under grazing in a St Lawrence Estuary tidal marsh. Environ. Conserv. 36:4. doi: $10.1017 /$ S0376892910000184

Conflict of Interest Statement: The authors declare that the research was conducted in the absence of any commercial or financial relationships that could be construed as a potential conflict of interest.

Copyright $\odot 2019$ Harvey, Garbutt, Hawkins and Skov. This is an open-access article distributed under the terms of the Creative Commons Attribution License (CC BY). The use, distribution or reproduction in other forums is permitted, provided the original author(s) and the copyright owner(s) are credited and that the original publication in this journal is cited, in accordance with accepted academic practice. No use, distribution or reproduction is permitted which does not comply with these terms. 


\section{OPEN ACCESS}

Edited by:

Jonathan Richir,

Fonds National de la Recherche Scientifique, Belgium

Reviewed by:

Yi Zhou,

Institute of Oceanology (CAS), China Martin Gullström,

Stockholm University, Sweden

Eduardo Infantes,

University of Gothenburg, Sweden

${ }^{*}$ Correspondence:

Richard K. F. Unsworth

r.k.f.unsworth@swansea.ac.uk

Specialty section:

This article was submitted to

Conservation

a section of the journal

Frontiers in Ecology and Evolution

Received: 25 January 2019 Accepted: 05 August 2019

Published: 21 August 2019

Citation:

Unsworth RKF, Bertelli CM, Cullen-Unsworth LC, Esteban N,

Jones BL, Lilley R, Lowe C

Nuuttila HK and Rees SC (2019)

Sowing the Seeds of Seagrass

Recovery Using Hessian Bags.

Front. Ecol. Evol. 7:311

doi: 10.3389/fevo.2019.00311

\section{Sowing the Seeds of Seagrass Recovery Using Hessian Bags}

\author{
Richard K. F. Unsworth ${ }^{1,2 *}$, Chiara M. Bertelli ${ }^{1}$, Leanne C. Cullen-Unsworth ${ }^{2,3}$, \\ Nicole Esteban ${ }^{1}$, Benjamin L. Jones ${ }^{2,4}$, Richard Lilley², Christopher Lowe ${ }^{1}$, \\ Hanna K. Nuuttila ${ }^{1}$ and Samuel C. Rees ${ }^{1}$ \\ ${ }^{1}$ Seagrass Ecosystem Research Group and SEACAMS, College of Science, Swansea University, Swansea, United Kingdom, \\ ${ }^{2}$ Project Seagrass, Cardiff, United Kingdom, ${ }^{3}$ Sustainable Places Research Institute, Cardiff University, Cardiff, \\ United Kingdom, ${ }^{4}$ Department of Ecology, Environment and Plant Sciences, Stockholm University, Stockholm, Sweden
}

Seagrass meadows are an important wetland habitat that have been degraded globally but have an important carbon storage role. In order to expand the restoration of these productive and biodiverse habitats methods are required that can be used for large scale habitat creation across a range of environmental conditions. The spreading of seagrass seeds has been proven to be a successful method for restoring seagrass around the world, however in places where tidal range is large such methods become limited by resultant water movements. Here we describe and test a method for deploying seagrass seeds of the species Zostera marina over large scales using a new, simple method "Bags of Seagrass Seeds Line (BoSSLine)." This method involved planting seeds and sediment using natural fiber hessian bags deployed along strings anchored onto the seabed. When deployed in a suitable environment $94 \%$ of bags developed mature seagrass shoots, unfortunately one site subjected to a large storm event resulted in sediment burial of the bags and no seed germination. Bags were filled with 100 seeds with each leading to the development of $2.37 \pm 2.41$ mature shoots ( $206 \pm 87 \mathrm{~mm}$ in length) 10 months after planting. The method was proven successful however the experiments illustrated the need to ensure habitat suitability prior to their use. Low seed success rate was comparable to other restoration studies, however further trials are recommended to ensure ways to improve this rate. In conclusion, this study provides evidence for an effective, simple method "Bags of Seagrass Seeds Line (BoSSLine)" for deploying seeds of the seagrass Zostera marina over large scales.

Keywords: seagrass, feedbacks (positive/negative), restoration, seagrass (Zostera), macrophytes (aquatic plants)

\section{INTRODUCTION}

Seagrass meadows provide critically important ecosystem services to our planet, including the storage of carbon (Fourqurean et al., 2012; Röhr et al., 2018), supporting world fisheries production (Unsworth et al., 2018), and amongst many other things, helping prevent beach erosion (James et al., 2019). Unfortunately, seagrass meadows are one of the world's most threatened ecosystems and are rapidly disappearing in many parts of the world (Waycott et al., 2009).

Although seagrass meadows have long been considered the "ugly duckling" of marine conservation (Duarte et al., 2008), the urgent and unprecedented changes that are now required to avoid a climate change catastrophe mean that a dual need for conservation of existing meadows, 
and the active restoration of previously extirpated seagrass meadows, are emerging as potentially meaningful climate change mitigation strategies (Duarte et al., 2013). This is due to the high rates at which seagrass meadows store carbon. Under the Paris Climate Accord and the Katowice Climate Package, seagrass restoration can be considered with respect to Nationally Determined Contributions (NDCs) and therefore be part of defined emissions reduction targets or traded for carbon credits (Kuwae and Hori, 2019). With increasing interest in habitat restoration through a rewilding lens, there is now ever more interest in seagrass restoration (Ockendon et al., 2018). Seagrass conservation and restoration practices are coming of age and with it so is the need for improved methods in all potential seagrass environments.

In the UK, seagrass loss has been estimated to have been vast. Of Britain's 155 estuaries, only 20 now contain seagrass: an $85 \%$ decline since the 1920s (Hiscock et al., 2005), with little natural recovery, and continuing losses and degradation in many parts of the country still being observed (Jones and Unsworth, 2016; Unsworth et al., 2017a,b). Poor water quality, primarily driven by excess nutrients, is one of the largest threats faced by seagrass, both in the UK and globally (Grech et al., 2012; Jones et al., 2018). But with increased efforts to improve UK coastal water quality, there is now interest in taking steps to restore associated coastal ecosystems such as seagrass.

Seagrass restoration efforts in the UK have been limited with only a few minor trials ever taking place (RanwelI et al., 1974; Hockings and Tompsett, 2002). However, this field has grown rapidly around the world over the last 30 years, with many successful large-scale projects now documented (Reynolds et al., 2016; van Katwijk et al., 2016). "The field of dreams hypothesis" or the assumption that "if you build it, they will come" (Palmer et al., 1997) is the presumption of that restoration will engender a desirable ecological response. There is now growing evidence that successful seagrass restoration will result in such ecological improvements (Greiner et al., 2013).

These restoration successes are largely down to a plethora of experimental studies as well as the lessons learnt from numerous failed projects (van Katwijk et al., 2016). Arguably the most important finding from past global restoration efforts is that scale matters; large-scale planting increases plant survival. Scaling up spreads the risks, and the resultant increase in population growth rate enhances positive feedbacks, helping the seagrass to self-facilitate a more affable environment (van Katwijk et al., 2016).

Simple and reliable methods are needed for successful seagrass restoration that can be deployed on a large scale, the results of which can lead to meaningful changes to the coastal environment and act as a major component of broader climate change mitigation strategies. The large over production of seeds by some species of seagrass (e.g., Z. marina) creates significant simple, low cost, and potentially effective opportunities for their use in restoration. As such, meta-analysis of global restoration studies indicate that seed based planting may be amongst the most effective methods of restoration (van Katwijk et al., 2016). In the Chesapeake Bay, US, seagrass restoration has largely utilized seed based techniques and has had extensive success
(Marion and Orth, 2010). Additionally, recent successful trials of $Z$. marina restoration in Sweden have also included the use of seeds (Infantes et al., 2016a,b). Projects planting seeds have used a range of methods such as spreading by hand at the water surface, the use of seed buoys (Pickerell et al., 2005), and more recently planting of seeds in coconut matting (Sousa et al., 2017). In many parts of the UK the effectiveness of any technique that involves the loose spreading of seed (e.g., seed buoys) is likely to be compromised by the very large tidal ranges and resultant fast tidal currents that can rapidly move seeds away from their intended location. Thus, a method is required that is both cost effective and simple, yet will still facilitate deployment of seeds on the seabed without dispersal from the intended restoration site. Previous studies describe the use of hessian bags (burlap) for deploying seagrass seeds (Harwell and Orth, 1999; Zhang et al., 2015). Here we adapt, trial and describe their use over a range of sites of high tidal range in West Wales. We name this method "Bags of Seagrass Seeds Line (BoSSLine)" for deploying seeds of the seagrass $Z$. marina over large scales.

\section{METHODS}

\section{Study Sites}

Two pilot Proof of Concept (PoC) studies on seagrass "seed bag" use were conducted, one at Porthdinllaen in North Wales and the other in the Helford River, Cornwall (Figure 4). These PoC studies trialed the use of differing types of seed bags under various deployment methods. Based on the findings from these initial PoC studies a seagrass seed bag experiment was then conducted at a further three sites around Wales. The locations for this experiment were based on the use of a simple habitat suitability model to confirm their potential viability for seagrass growth (Brown, 2015). In addition, the three sites were inspected in May 2017 using dropdown video and hand grabs to confirm suitability of the sediment. These sites were Dale and Longoar in the Milford Haven Waterway, and Freshwater East on the Pembrokeshire Coast. Dale was known to have an unconfirmed record of seagrass (Kay, 1998), and Freshwater East is suspected to have a small patch due to fragments commonly washing up on its beach. Longoar Bay has a small meadow of seagrass, with areas surrounding it likely to be good potential seagrass habitat (similar exposure, depth, and sediment). The sites were all in the range of 1-3 m depth (below low water spring) with a maximum tidal range of $7.68 \mathrm{~m}$. Sediment type varied from fine and very fine sand at Dale and Longoar, to course sand at Freshwater East and all sites are fully marine (Carey et al., 2015). Sea surface temperatures typically range from 8 to 17 degrees C. During this project we confirmed the location of a small patch of seagrass (Zostera marina) previously recorded in 1958 by Martin George (Kay, 1998) in Dale $\left(51.704765^{\circ} \mathrm{N}, 5.159228^{\circ} \mathrm{W}\right)$. This patch was found to still have dense shoots and cover an area of $\sim 5 \mathrm{~m}^{2}$. At these three locations a series of trials were conducted using seed bags to plant the seagrass Zostera marina.

\section{Seed Collection}

During August 2014, for the initial PoC, SCUBA divers were used to collect ripe, seed laden reproductive shoots from 
seagrass meadows at Durgan in the Helford River (Hockings and Tompsett, 2002). Seed-laden shoots were also collected (August 2015) for the second PoC study within an intertidal seagrass meadow at Porthdinllaen in North Wales (Bertelli and Unsworth, 2014). For the main study, ripe seed laden reproductive shoots were collected in August 2017 at Littlewick Bay in Milford Haven Waterway, West Wales.

For the PoC studies and the main experiment all shoots were randomly collected throughout the natural meadows with care taken to cause no damage to the rhizome. They were collected under permit from Natural Resources Wales (and Natural England for the Helford study). Reproductive shoots were transported to Swansea University (except the Helford seeds) where they were placed in aerated flow through aquaria $\left(8-12^{\circ} \mathrm{C}\right)$ within a laboratory. Nylon mesh was used to prevent the loss of seeds and seagrass material. Tanks were regularly maintained and cleaned to reduce algal fouling. Matured seeds were naturally released from the flowering shoots and since seeds are negatively buoyant, they sank to the bottom of the tanks. Seeds were collected from the bottom of the tanks and were sieved to remove dead leaves and larger organic material before further separation in separating funnels (Infantes and Moksnes, 2018). Seeds were then stored in flowing seawater tanks.

\section{Initial Proof of Concept Studies}

For the initial PoC study in Helford, large hessian bags $(80 \times$ $33 \mathrm{~cm}$ ) (of the type used as sand bags) were filled with local sediment (amount unquantified) from the site in August 2014 (by SCUBA divers using shovels) and mature seagrass seeds (still within their reproductive shoots) (10 spathes in each bag). Six bags were placed $1 \mathrm{~m}$ apart from each other in a line at two locations on the edge of an existing seagrass meadow and their location marked with GPS (Figure 4). The bags and their seedling production were monitored using SCUBA divers in April 2015.

For the second PoC study which was conducted during November 2015 at Porthdinllaen, smaller bags of seeds $(13 \times$ $7.5 \mathrm{~cm}$ with $1 \mathrm{~mm}$ holes in the fabric) were deployed. Ten bags were placed on the bare intertidal sediment at Porthdinllaen but weren't secured (see Figure 1A). These were patches of bare sediment within the local seagrass meadow. The bags used in the second PoC study were a much thicker weave hessian than within the Helford PoC pilot and the hessian had a silicon coating. Approximately 100 seeds were placed into each bag together with $100 \mathrm{~cm}^{3}$ of local sediment.

\section{Seed Bag Experiment}

Approximately 100 seeds, were placed into small hessian bags (see Figure 2) along with $100 \mathrm{~cm}^{3}$ of sediment. The uncoated hessian bags were $13 \times 7.5 \mathrm{~cm}$ with $1 \mathrm{~mm}$ holes in the fabric. Surface sediment (top $5 \mathrm{~cm}$ ) was carefully collected avoiding any sulfurous anoxic layers) within $100 \mathrm{~m}$ of an existing seagrass meadow at Littlewick Bay. Due to concerns about the potential for sediment to have low nutrient levels at the recipient site in Dale and to potentially not contain appropriate micro fauna and flora, $50 \mathrm{~cm}^{3}$ of seagrass detritus was added to the sediment bag to assist with microbial inoculation of the seagrass microbiome. The seagrass detritus was the degraded remains of the flowering

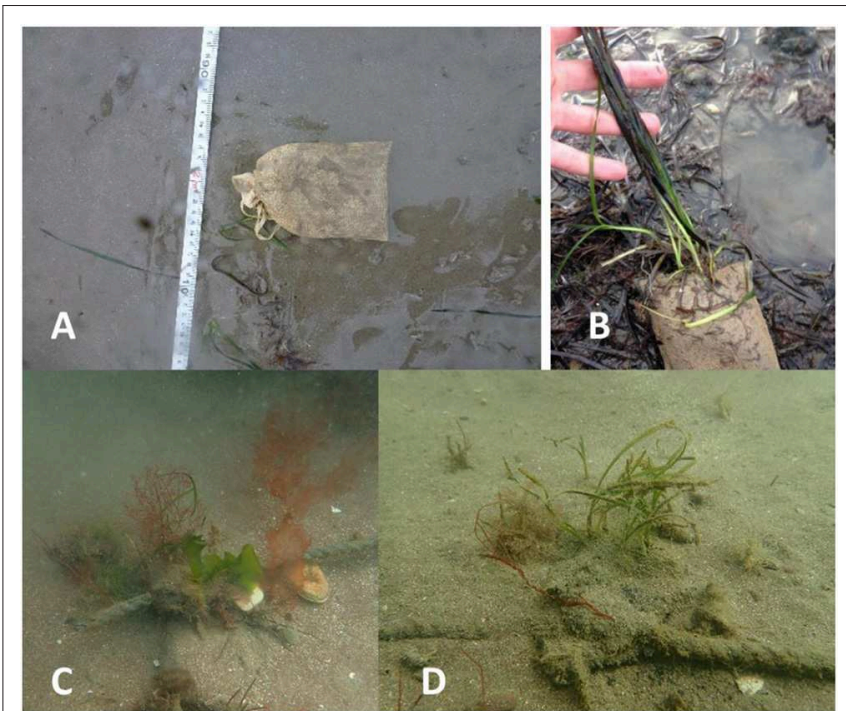

FIGURE 1 | (A) Deployment of PoC seed bags at Porthdinllaen without anchoring. (B) Successful retrieval of 1 of 2 PoC seed bags at Porthdinllaen. (C) Seed bag containing seedlings at Dale with hessian rope degraded at one end. (D) Seed bag at Dale containing an abundance of young seagrass plants.

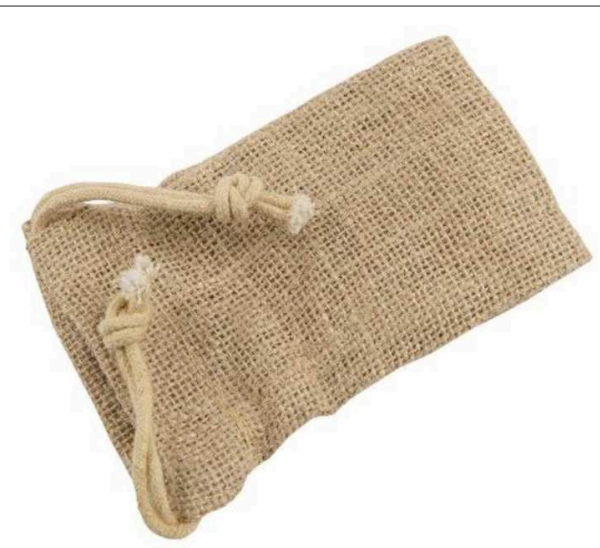

FIGURE 2 | Small hessian bags $(13 \times 7.5 \mathrm{~cm})$ filled with seagrass seeds. Sediment and seagrass detritus were also added. Bags were strung into lines for deployment at potential restoration sites.

shoots from which the seeds were collected. Bags were then tied and fixed along hessian rope at $1 \mathrm{~m}$ intervals. Each line of rope contained six seed bags (Figure 3 ). The process for creating seagrass seed bags is visually described in Figure 3.

\section{Bag Deployment and Monitoring}

Two lines of seed bags were placed at Dale, and one line was placed at both Longoar Bay and Freshwater East. A total of 24 bags were deployed across the three sites. The lines were held down using steel pegs and the ends of the lines marked approximately from the surface using GPS. All seed bags were deployed in November 2017 and then monitored for the shoot 

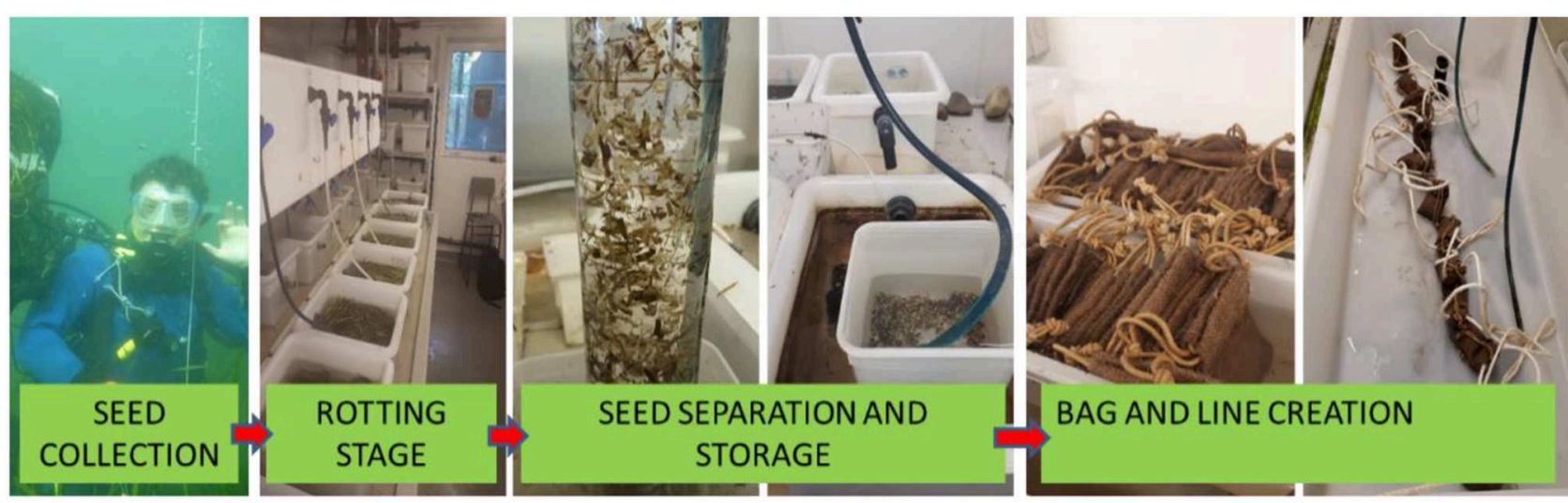

FIGURE 3 | Stages of seed bag creation (1) reproductive shoot collection by SCUBA divers, (2) natural rotting of seagrass to allow for seed dropping, (3) separation of seeds from detritus, and (4) filling of bags with seeds, sediment, and detritus.

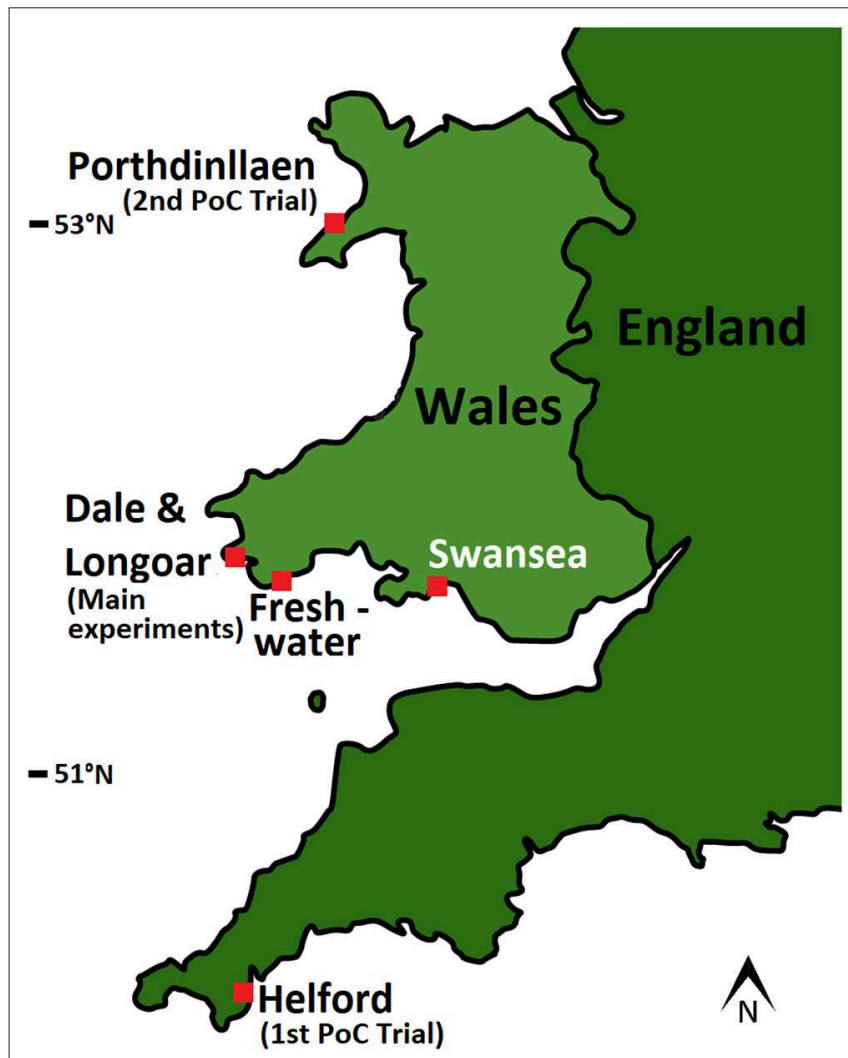

FIGURE 4 | Location of the Proof of Concept (PoC) and main experimental sites used to trial seagrass seed bags.

density and canopy height using SCUBA divers in May and August 2018.

\section{RESULTS}

\section{Proof of Concept Trial}

The initial PoC study conducted in Helford was found to be very time intensive and difficult due to the use of large bags. These were too cumbersome for divers to work with and too large to be deployed from the surface. Assessment of the bags 8 months after deployment revealed that the bags had rapidly broken down and were mostly just observed as fragments. In the areas where the bags were placed, seedling density was determined to be on average $( \pm \mathrm{SD}) 5.2 \pm 3.7$ per $\mathrm{m}^{2}$, this was $\sim 4 \mathrm{x}$ the density of the seedlings in the surrounding area. Based upon these PoC findings further PoC trials were to be conducted using smaller bags.

Ten smaller seed bags were placed in Porthdinllaen in November 2015, but most of these were lost due to a major easterly storm event (the site faced east) just 2 weeks after deployment. Bags had not been secured to the sediment so were susceptible to displacement. After 3 months only three bags were still in situ, but in all, successful germination had taken place, each containing two seedlings. By October 2016 only two bags remained but contained five and six mature shoots, respectively, with mature rhizome present (see Figure 1B). The seagrass in these bags unfortunately hadn't rooted into the surrounding sediment and the bags were largely intact, possibly as a result of the type of hessian of the bags which were made from thick weave with silicon coated hessian. As a result of these trials, the bags in the following experimental study were changed to be of a lighter hessian comprising 100\% natural fibers rather than those with fibers coated in silicon. Bags in the following experimental study were anchored down using pegs and lines.

\section{Seed Bag Experiment}

Twenty-four seed bags were deployed across the three sites (Dale, Longoar, and Freshwater East), and 16 of these were recorded by May 2018 to have developed at least one seedling (Figure 1D). In May 2018, 100\% of bags at Dale were observed to contain seedlings (Figure 1C), whilst $80 \%$ of bags at Longoar contained seedlings (one bag was not observed as the rope had degraded and the bag was lost). All seed bags at Freshwater East failed to develop seedlings, we believe this could have resulted from poor siting of bags leading to sand movement burying them too deep. When the bags were relocated under the sediment, they had become completely anoxic and were blackened by sulfates. 
Density of seedlings in May 2018 was on average $( \pm S D) 2.95 \pm$ 3.22 per bag, of those bags where shoots had developed there was an average $( \pm S D)$ of $3.65 \pm 2.09$ shoots per bag. By August 2018 there was an overall average $( \pm \mathrm{SD})$ density of $2.37 \pm 2.41$ shoots per bag with many of those shoots appearing mature (Figure 5). In May 2018, the average ( \pm SD) shoot length was $41 \pm 11 \mathrm{~mm}$ and by August 2018 this was $206 \pm 87 \mathrm{~mm}$.

In order to calculate a \% seed success rate we excluded data from Freshwater East, based on the assessment that the failure of the seed bags was the result of a poor site choice rather than the seed bag method itself. The average number of seeds in any given bag was 100 and the average $( \pm S D)$ shoot density was 3.6 \pm 2.1 and so we estimate that seed success was 3.6\%. Excluding data from Freshwater East we conclude that seed bags had a $94 \%$ success rate.

The hessian rope used in this detailed experiment broke down quickly and by May 2018 was mostly fragmented, making monitoring individual bags difficult, but illustrating the value of using such material for deployment without creating environmental pollution. Importantly, these small bags and simple metal pegs had withstood winter storm(s) without any damage or movement. The bags had also allowed for germination without potential predators (e.g., Carcinus maenas) consuming the abundant seeds and germinating seeds were able to grow through the hessian fabric. By the end of August 2018 all the hessian bags were now fragmented and had mostly broken down, with evidence of rhizomes growing

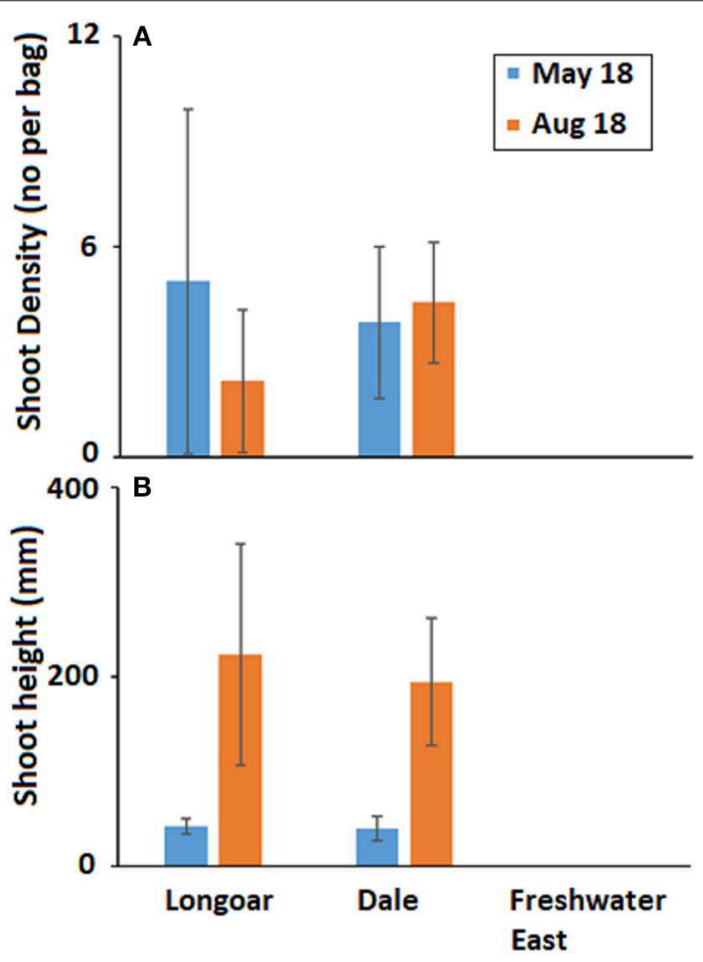

FIGURE 5 | Mean $( \pm S D$ ) (A) seagrass shoot density (no per bag) and (B) shoot height $(\mathrm{mm})$ developing from seed in hessian bags at three locations in South West Wales (UK) on two monitoring visits following deployment of seeds in November 2017. beyond the hessian bags and becoming embedded into the surrounding sediment.

\section{DISCUSSION}

There is increasing need for seagrass restoration to be conducted using simple methods over large scales, high reliability, and a low per unit cost. Here we document for the first time the use of the BOSSline method (Bags of Seagrass Seeds Line) for deploying seeds of the seagrass Zostera marina. Seedling establishment rates (the proportion of seeds generating a surviving seedling) was low (3.5\%) but typical of an $\mathrm{r}$-strategist species and comparable to many rates recorded in other studies and sites (Marion and Orth, 2010; Govers et al., 2016; Sousa et al., 2017). The reasons for such low rates could be local environmental conditions, health of the seeds, or even disease contamination (Govers et al., 2016). Further experiments are required to separate these low germination rates from the use of this BOSSline method. The BOSSline method is simple, in that beyond the initial collection of seeds, very little (if any) diver based work is required reducing costs and the skills required, however the downside is that in contrast to rudimentary seed based methods (e.g., seed buoys) (Pickerell et al., 2005) laboratory processing is required.

We believe that the complete failure of one of the experimental stations reflected a poor site choice rather than a failed method, this location was possibly too close to the intertidal zone and subject to very mobile sandy substrate. This highlights the need to use a high resolution within any habitat suitability model. It is important to be clear that successful restoration projects require suitable environmental conditions (van Katwijk et al., 2016) and only when conditions can be deemed suitable should projects be conducted.

Whilst success has been observed in the use of seed bags for planting seagrass seeds a more mechanistic understanding is still required as to the processes driving the germination and development of Zostera marina seeds. In the present study we speculatively included detritus into the seed bags, such inclusion may have enhanced the nutrient environment or added microbes that could potentially carry out a broad range of functions that potentially support the health and growth of aquatic plants (Ettinger et al., 2017; Crump et al., 2018). Given the rapidly expanding understanding of the seagrass microbiome (Fahimipour et al., 2017) and its potential mutualistic role in seagrass growth and production (Crump et al., 2018) more information is required as to the relative role of this in germination and seedling development.

Feedbacks, both positive and negative within seagrass systems have significant roles at a meadow scale, particularly with respect to restoration (Maxwell et al., 2017). This study doesn't examine these factors, but we recognize that the use of our BOSSline method does have the potential to reduce potential negative feedbacks present from polychaetes and crustaceans. The hessian bag not only keeps the seeds from dispersing due to tidal movements but also protects the seeds from burial or consumption (Infantes et al., 2016a).

In conclusion we present evidence of the effectiveness of a new seagrass seed planting method referred to as BOSSline. Our experiments show this method to be simple to conduct, 
and proven to result in successful germination. However, our low germination rates indicate further experimental studies are required to maximize method efficiency and determine factors influencing germination in these bags. An important benefit of this method is its capacity to be upscaled with ease to the meadow creation scale. In the US, large scale mechanized seed collection has enabled the harvesting of 10's of millions of seeds at a time for restoration. In order to potentially facilitate such large-scale restoration in the UK we present a method that could be used to plant such large seed quantities in conditions where tidal currents and adverse seasonal weather conditions necessitate ensuring seeds are not rapidly washed away from the restoration site.

\section{AUTHOR CONTRIBUTIONS}

RU designed the method, took part in fieldwork, analyzed data, and wrote the paper. $\mathrm{CB}, \mathrm{SR}$, and NE contributed to the design of

\section{REFERENCES}

Bertelli, C. M., and Unsworth, R. K. F. (2014). Protecting the hand that feeds us: seagrass (Zostera marina) serves as commercial juvenile fish habitat. Mar. Pollut. Bull. 83, 425-429. doi: 10.1016/j.marpolbul.201 3.08.011

Brown, G. (2015). Modelling the potential distribution of Zostera marina in Wales (MRes Thesis). Swansea University, Swansea, United Kingdom.

Carey, D. A., Hayn, M., Germano, J. D., Little, D. I., and Bullimore, B. (2015). Marine habitat mapping of the Milford Haven Waterway, Wales, UK: comparison of facies mapping and EUNIS classification for monitoring sediment habitats in an industrialized estuary. J. Sea Res. 100, 99-119. doi: 10.1016/j.seares.2014.09.012

Crump, B. C., Wojahn, J. M., Tomas, F., and Mueller, R. S. (2018). Metatranscriptomics and amplicon sequencing reveal mutualisms in seagrass microbiomes. Front. Microbiol. 9:388. doi: 10.3389/fmicb.2018.00388

Duarte, C. M., Dennison, W. C., Orth, R. J. W., and Carruthers, T. J. B. (2008). The charisma of coastal ecosystems: addressing the imbalance. Estuar. Coasts 31, 233-238. doi: 10.1007/s12237-008-9038-7

Duarte, C. M., Losada, I. J., Hendriks, I. E., Mazarrasa, I., and Marbà N. (2013). The role of coastal plant communities for climate change mitigation and adaptation. Nat. Climate Change 3, 961. doi: 10.1038/nclimate1970

Ettinger, C. L., Voerman, S. E., Lang, J. M., Stachowicz, J. J., and Eisen, J. A. (2017). Microbial communities in sediment from Zostera marina patches, but not the Z. marina leaf or root microbiomes, vary in relation to distance from patch edge. PeerJ 5:e3246. doi: 10.7717/peerj.3246

Fahimipour, A. K., Kardish, M. R., Lang, J. M., Green, J. L., Eisen, J. A., and Stachowicz, J. J. (2017). Global-scale structure of the eelgrass microbiome. Appl. Environ. Microbiol. 83:e03391-03316. doi: 10.1128/aem.03391-16

Fourqurean, J. W., Duarte, C. M., Kennedy, H., Marba, N., Holmer, M., Mateo, M. A., et al. (2012). Seagrass ecosystems as a globally significant carbon stock. Nat. Geosci. 5, 505-509. doi: 10.1038/ngeo1477

Govers, L. L., Man in 't Veld, W. A., Meffert, J. P., Bouma, T. J., van Rijswick, P. C. Heusinkveld, J. H., et al. (2016). Marine Phytophthora species can hamper conservation and restoration of vegetated coastal ecosystems. Proc. R. Soc. B Biol. Sci. 283:20160812. doi: 10.1098/rspb.2016.0812

Grech, A., Chartrand-Miller, K., Erftemeijer, P., Fonseca, M., McKenzie, L., Rasheed, M., et al. (2012). A comparison of threats, vulnerabilities and management approaches in global seagrass bioregions. Environ. Res. Lett. 7:024006. doi: 10.1088/1748-9326/7/2/024006

Greiner, J. T., McGlathery, K. J., Gunnell, J., and McKee, B. A. (2013). Seagrass restoration enhances "blue carbon" sequestration in coastal waters. PLOS ONE 8:e72469. doi: 10.1371/journal.pone.0072469 the method. All authors contributed to fieldwork and helped to write the paper.

\section{FUNDING}

Funding for this research came from the European Union Regional Development Fund to the project SEACAMS2.

\section{ACKNOWLEDGMENTS}

The authors wish to acknowledge the financial support of the European Union Regional Development fund through the SEACAMS and SEACAMS2 projects. We thank the following for their assistance with this work: Max Robinson, Keith Naylor, Evie Furness, Alison Palmer-Hargrave, Laura Hughes, and Mark Milburn.

Harwell, M. C., and Orth, R. J. (1999). Eelgrass (Zostera marina L.) seed protection for field experiments and implications for largescale restoration. Aquat. Bot. 64, 51-61. doi: 10.1016/S0304-3770(99)0 0008-X

Hiscock, K., Selwell, J., and Oakley, J. (2005). The Marine Health Check 2005: A Report to Gauge the Health of the UK's sea life. Godalming: WWF-UK.

Hockings, S., and Tompsett, P. E. (2002). The Location and Conservation of Eelgrass Beds in Cornwall and the Isles of ScillyVols 1 and 2. Project Series Number 5. Truro: ERCCIS Cornwall Wildlife Trust.

Infantes, E., Crouzy, C., and Moksnes, P.-O. (2016a). Seed predation by the shore crab Carcinus maenas: a positive feedback preventing eelgrass recovery? PLoS ONE 11:e0168128. doi: 10.1371/journal.pone.0168128

Infantes, E., Eriander, L., and Moksnes, P. O. (2016b). Eelgrass (Zostera marina) restoration on the west coast of Sweden using seeds. Mar. Ecol. Prog. Ser. 546, 31-45. doi: 10.3354/meps 11615

Infantes, E., and Moksnes, P.-O. (2018). Eelgrass seed harvesting: flowering shoots development and restoration on the Swedish west coast. Aquat. Bot. 144, 9-19. doi: 10.1016/j.aquabot.2017.10.002

James, R. K., Silva, R., van Tussenbroek, B. I., Escudero-Castillo, M., Mariño-Tapia, I., Dijkstra, H. A., et al. (2019). Maintaining tropical beaches with seagrass and algae: a promising alternative to engineering solutions. Bioscience 69, 136-142. doi: 10.1093/biosci/biy154

Jones, B. L., Cullen-Unsworth, L. C., and Unsworth, R. K. F. (2018). Tracking nitrogen source using $\delta 15 \mathrm{~N}$ reveals human and agricultural drivers of seagrass degradation across the British Isles. Front. Plant Sci. 9:133. doi: 10.3389/fpls.2018.00133

Jones, B. L., and Unsworth, R. K. F. (2016). The perilous state of seagrass in the British Isles. R. Soc. Open Sci. 3. doi: 10.1098/rsos.150596

Kay, Q. O. N. (1998). A Review of the Existing State of Knowledge of the Ecology and Distribution of Seagrass Beds Around the Coast of Wales. Science Report 296. Countryside Council for Wales, Bangor.

Kuwae, T., and Hori, M. (2019). "The future of blue carbon: addressing global environmental issues," in Blue Carbon in Shallow Coastal Ecosystems: Carbon Dynamics, Policy, and Implementation, eds T. Kuwae and M. Hori (Singapore: Springer), 347-373.

Marion, S. R., and Orth, R. J. (2010). Innovative techniques for large-scale seagrass restoration using Zostera marina (eelgrass) seeds. Restor. Ecol. 18, 514-526. doi: 10.1111/j.1526-100X.2010.00692.x

Maxwell, P. S., Eklöf, J. S., van Katwijk, M. M., O’Brien, K. R., de la Torre-Castro, M., Boström, C., et al. (2017). The fundamental role of ecological feedback mechanisms for the adaptive management of seagrass ecosystems-'a review. Biol. Rev. 92, 1521-1538. doi: 10.1111/br v.12294 
Ockendon, N., Thomas, D. H. L., Cortina, J., Adams, W. M., Aykroyd, T., Barov, B., et al. (2018). One hundred priority questions for landscape restoration in Europe. Biol. Conserv. 221, 198-208. doi: 10.1016/j.biocon.2018.03.002

Palmer, M. A., Ambrose, R. F., and Poff, N. L. (1997). Ecological theory and community restoration ecology. Restor. Ecol. 5, 291-300. doi: 10.1046/j.1526-100X.1997.00543.x

Pickerell, C. H., Schott, S., and Wyllie-Echeverria, S. (2005). Buoy-deployed seeding: Demonstration of a new eelgrass (Zostera marina L.) planting method. Ecol. Eng. 25, 127-136. doi: 10.1016/j.ecoleng.2005.03.005

RanwelI, D. S., Wyer, D. W., Boorman, L. A., Pizzey, J. M., and Waters, R. J. (1974). Zostera transplants in Norfolk and Suffolk, Great Britain. Aquaculture 4, 185-198.

Reynolds, L. K., Waycott, M., McGlathery, K. J., and Orth, R. J. (2016). Ecosystem services returned through seagrass restoration. Restor. Ecol. 24, 583-588. doi: $10.1111 /$ rec.12360

Röhr, M. E., Holmer, M., Baum, J. K., Björk, M., Chin, D., Chalifour, L., et al. (2018). Blue carbon storage capacity of temperate eelgrass (Zostera marina) meadows. Global Biogeochem. Cycles 32, 1457-1475. doi: 10.1029/2018GB005941

Sousa, A. I., Valdemarsen, T., Lillebø A. I., Jørgensen, L., and Flindt, M. R. (2017). A new marine measure enhancing Zostera marina seed germination and seedling survival. Ecol. Eng. 104, 131-140. doi: 10.1016/j.ecoleng.201 7.04.004

Unsworth, R. K. F., Bertelli, C. M., Robinson, M., and Mendzil, A. F. (2017a). Status Review and Surveillance Recommendations for Seagrass (Zostera spp.) in Milford Haven Waterway. Report for The Milford Haven Waterway Environmental Surveillance Group.

Unsworth, R. K. F., Nordlund, L. M., and Cullen-Unsworth, L. C. (2018). Seagrass meadows support global fisheries production. Conserv. Lett. 12:e12566. doi: $10.1111 /$ conl.12566
Unsworth, R. K. F., Williams, B., Jones, B. L., and Cullen-Unsworth, L. C. (2017b). Rocking the boat: damage to eelgrass by swinging boat moorings. Front. Plant Sci. 8:1309. doi: 10.3389/fpls.2017.01309

van Katwijk, M. M., Thorhaug, A., Marba, N., Orth, R. J., Duarte, C. M., Kendrick, G. A., et al. (2016). Global analysis of seagrass restoration: the importance of large-scale planting. J. Appl. Ecol. 53, 567-578. doi: 10.1111/1365-2664.12562

Waycott, M., Duarte, C. M., Carruthers, T. J. B., Orth, R. J., Dennison, W. C., Olyarnik, S., et al. (2009). Accelerating loss of seagrasses across the globe threatens coastal ecosystems. Proc. Natl. Acad. Sci. U.S.A. 106, 12377-12381. doi: 10.1073/pnas.0905620106

Zhang, P.-D., Fang, C., Liu, J., Xu, Q., Li, W.-T., and Liu, Y.-S. (2015). An effective seed protection method for planting Zostera marina (eelgrass) seeds: implications for their large-scale restoration. Mar. Pollut. Bull. 95, 89-99. doi: 10.1016/j.marpolbul.2015.04.036

Conflict of Interest Statement: The authors declare that the research was conducted in the absence of any commercial or financial relationships that could be construed as a potential conflict of interest.

The reviewer, MG, declared a shared affiliation, with no collaboration, with one of the authors, BJ, to the handling editor at time of review.

Copyright (C) 2019 Unsworth, Bertelli, Cullen-Unsworth, Esteban, Jones, Lilley, Lowe, Nuuttila and Rees. This is an open-access article distributed under the terms of the Creative Commons Attribution License (CC BY). The use, distribution or reproduction in other forums is permitted, provided the original author(s) and the copyright owner(s) are credited and that the original publication in this journal is cited, in accordance with accepted academic practice. No use, distribution or reproduction is permitted which does not comply with these terms. 
OPEN ACCESS

Edited by:

Sylvie Gobert,

University of Liège, Belgium

Reviewed by:

Marcelo Bertellotti

Centro Para el Estudio de Sistemas Marinos (CONICET), Argentina

Jennifer Lesley Silcock,

The University of Queensland,

Australia

${ }^{*}$ Correspondence:

Chiara M. Bertell

c.m.bertell@swansea.ac.uk

Specialty section:

This article was submitted to

Conservation,

a section of the journal

Frontiers in Environmental Science

Received: 23 March 2018

Accepted: 14 May 2018

Published: 06 June 2018

Citation:

Bertelli CM and Unsworth RKF (2018)

Light Stress Responses by the

Eelgrass, Zostera marina (L).

Front. Environ. Sci. 6:39

doi: 10.3389/fenvs.2018.00039

\section{Light Stress Responses by the Eelgrass, Zostera marina (L)}

\author{
Chiara M. Bertelli* and Richard K. F. Unsworth \\ Seagrass Ecosystem Research Group, Department of Biosciences, Swansea University, Swansea, United Kingdom
}

Zostera marina is the dominant seagrass species in the Northern Hemisphere where it grows in sheltered bays and estuaries. As a consequence of its distribution its conservation is commonly threatened by poor coastal water quality. The high minimum light requirements of seagrasses results in water quality degradation (high turbidity and eutrophication) being a significant risk. Bioindicators of light stress can be used to interpret seagrass responses to light limitation and therefore act as sentinels for conservation management. However, there exists limited experimental inter-comparison of the effectiveness of multiple individual bioindicator responses. Meta-analysis suggests that rhizome sugars, shoot C:N, shoot growth, and number of leaves per shoot provide the most consistent response variables to increasing light limitation in seagrass, but this premise remains largely untested at the plant level as a direct comparison of multiple bioindicators. The present study aimed to test the morphological, physiological, and photo-physiological bioindicator responses of $Z$. marina to light stress applied within controlled laboratory conditions. These bioindicators were used to assign minimum light thresholds. Growth rate and photophysiological parameters (alpha, $E_{k}$, and ETR $\max$ ) were rapidly (1st week) and drastically affected by low light shade treatments $(20.12 \mu \mathrm{mol}$ photons $\mathrm{m}^{-2} \mathrm{~s}^{-1}$ and lower). After 3 weeks at low light, significant reductions in maximum leaf length and leaf width were observed. Principal Component Analysis identified leaf length, shoot growth, shoot surface area, ETR max,$E_{k}$, and alpha as having the strongest responses to reduced light. Shoot growth, ETR max,$E_{k}$, and alpha were found to provide the best early warning of light limitation after $5-8$ days. These results provide evidence for bioindicators of light stress in Z. marina and highlights the importance of understanding these responses for the successful management and conservation of this species.

Keywords: bioindicator, light, shading, seagrass, morphology, fluorometry

\section{INTRODUCTION}

Chronic and temporary light reductions caused by reduced water quality are the biggest threat to seagrasses globally (Hemminga, 1998; Biber et al., 2009; Jiang et al., 2013). The sensitivity to light reduction and high nutrient levels defines seagrasses as sentinels of coastal degradation (Orth et al., 2006; McMahon et al., 2013) and in many cases seagrasses are integrated into management plans to assess the ecological status of coastal waters (Dennison et al., 1993; Krause-jensen et al., 2005; Foden and Brazier, 2007). However, poor water quality has resulted in a steady decline in seagrass meadows for decades worldwide and we are at risk of losing the very sentinels of coastal health we have defined (Dennison et al., 1993; Short and Wyllie-Echeverria, 1996; Orth et al., 2006; McMahon et al., 2013). 
Seagrasses have been found to exhibit various changes in morphology and physiology in response to light limitation. These responses can be used as bioindicators of reduced light levels attributed to anthropogenic disturbance or other causes for decline in water quality. Light limitation generally causes a decrease in above ground biomass, enabling plants to reduce the respiratory demand of the shoots, but resulting in a decrease in photosynthetic capacity (Campbell and Miller, 2002; Ralph et al., 2007; Collier et al., 2012b). This is shown in morphological responses exhibited during shading experiments such as decreases in leaf length, leaf width, shoot growth, and fewer leaves per shoot reducing overall plant surface area (Olesen and Sand-jensen, 1993; Biber et al., 2009; Ochieng et al., 2010; Collier et al., 2012b; Yaakub et al., 2013). The photosynthetic performance of seagrasses, measured using chlorophyll fluorescence, has been found to be affected by light stress within a relatively short time-frame from within days to just seconds (Ralph and Gademann, 2005; Bité et al., 2007). The reduction in light availability results in an increase in the light capture efficiency of the photosystems, but an overall decrease in electron transport rates and carbon fixation (Ralph and Gademann, 2005; Bité et al., 2007). Light reduction can also result in an increase in chlorophyll content, with the chlorophyll $a: b$ ratio lowering to increase photosynthetic efficiency (Collier et al., 2008, 2012b; Sharon et al., 2009; Silva et al., 2013). However, some studies have found the opposite effect under very low light conditions (Biber et al., 2009; Collier et al., 2012b). These responses in morphology and physiology indicate that seagrasses are able to acclimate to a changing light environment. However, the ability to adapt and maintain a positive carbon balance will depend upon the stores within the rhizomes which will have been built up in higher light conditions, as well as the strength and length of light attenuating events (Dennison and Alberte, 1985; Yaakub et al., 2013). This can be shown by a reduction in rhizome sugars and reduced carbon uptake indicated by the carbon nitrogen ratio (C:N) in the shoots (Alcoverro et al., 1999; McMahon et al., 2013). If light levels drop below the minimum light requirement (MLR) threshold, plants are unable to maintain this carbon balance and plant mortality follows.

The range of responses and adaptations of seagrasses to changing light environments could be a reason for the variety of methods used in monitoring. In Europe, 49 seagrass indicators and a total of 51 metrics have been identified in a review of monitoring strategies (Marbà et al., 2013). A more consistent approach would prove useful for managers in determining the status of seagrass meadows aided by identifying the best metrics to measure. A detailed meta-analysis by McMahon et al. (2013) revealed a number of consistent and robust bioindicators to light stress from an array of tropical and temperate seagrass species across a geographical range. In particular, rhizome sugars, shoot C:N, shoot growth, and number of leaves per shoot were found to exhibit early responses, with shoot density and above-ground biomass as meadow-scale, long-term responses. However, it should be taken into consideration that response thresholds to light reduction are species-specific and dependent on morphological plasticity, storage products, and growth rates (Olesen et al., 2002; Ralph et al., 2007; Collier et al., 2012b).
Although there exists a number of reviews and meta-analyses of bioindicators (Biber et al., 2005; Lee et al., 2007; Ralph et al., 2007; McMahon et al., 2013), there are limited case study examples that simultaneously compare a plethora of morphological, photophysiological, and biochemical indicators of seagrass response to light availability.

Zostera marina (eelgrass) is a prolific temperate seagrass found growing from the intertidal to depths of around $10 \mathrm{~m}$ depending on water clarity (Dennison and Alberte, 1982; Jackson et al., 2013). Its distribution in temperate and subpolar regions makes $Z$. marina particularly vulnerable to light limitation, with significant reductions in light during winter months (Backman and Barilotti, 1976; Zimmerman et al., 1995; Moore et al., 1997; Alcoverro et al., 1999). The MLR of seagrass is relatively high in comparison to other marine primary producers (Kenworthy and Fonseca, 1996), due in part to the large proportion of nonphotosynthetic tissue that makes up the roots and rhizomes. By using maximal depth limits, the MLR for Z. marina is estimated to be $17.6 \pm 5.3 \%$ SI (Dennison et al., 1993; Erftemeijer and Lewis, 2006; Lee et al., 2007). Surface irradiance (SI) levels vary spatially and temporally with photo-acclimation to local light regimes thought to be responsible for the large within-species variation (Lee et al., 2007). Other studies suggest that eelgrass requires 5$6 \mathrm{~h}$ of irradiance-saturated photosynthesis per day to maintain a positive carbon balance (Zimmerman et al., 1995, 1996; Alcoverro et al., 1999). Nonetheless, the understanding of the MLR threshold of survival has been highlighted as an important component which needs to be integrated into management and monitoring plans (Dennison et al., 1993; Erftemeijer and Lewis, 2006; McMahon et al., 2013; Yaakub et al., 2013; Collier et al., 2016).

The aim of the present study was to test a range of light stress bioindicators simultaneously by systematically monitoring the morphological and physiological responses of $Z$. marina to varying degrees of light stress treatment under experimental conditions. Plants under low and extremely low light treatments were expected to show a rapid change in photosynthetic performance and shoot growth followed by morphological responses as plants become constrained by low light, leading to mortality. Plants under medium light (close to MLRs) were expected to show less extreme responses and better adaptation to lower light conditions to allow survival. By monitoring the rate of numerous responses to light stress over time, this study aimed to identify the most robust bioindicators of light stress specific to $Z$. marina and provide a quantitative estimate for the MLR threshold for this seagrass species.

\section{MATERIALS AND METHODS}

\section{Experimental Design}

Thirty independent $Z$. marina cores $(10 \times 10 \mathrm{~cm}, 15-20 \mathrm{~cm}$ deep $)$ were collected on a low spring tide from across a shallow subtidal seagrass meadow at Durgan, Helford River, UK $\left(50^{\circ} 06^{\prime} 27.19^{\prime \prime} \mathrm{N}\right.$; $\left.5^{\circ} 06^{\prime} 54.70^{\prime \prime} \mathrm{W}\right)$. Care was taken to ensure the plants were extracted with as little damage as possible and that the shoots had substantial rhizome sections and sediment for re-planting. The cores of seagrass were put into separate large plastic bags 
and then transferred to pots and placed in a cool box for transportation to Swansea University, with ice packs and fresh seawater. Extra samples of rhizomes and shoots were taken as site control samples for carbohydrate analysis $(n=4)$, chlorophyll content $(n=4)$ and C:N ratios $(n=5)$ to compare with plants at the end of the experiment. These samples were stored in a freezer at $-20^{\circ} \mathrm{C}$. The individual cores were replanted into tubs $(n=5$ per treatment). Extra sediment collected from the field site was used to ensure natural presence of benthic fauna.

In the laboratory, the plants were left to acclimatize for 10 days before the experiment started in a flow-through system providing fresh filtered seawater. At the start of the experiment, the plants were placed under four different light treatments in a flow-through seawater micrososym providing continuous fresh seawater. Pumps and air stones were provided to ensure circulation and the shade treatments were created using shade cloths. The flow-through system was connected to a cooling unit to ensure maintenance of a temperature of $14 \pm 1^{\circ} \mathrm{C}$, simulating the sea temperature at time of collection. The temperature was monitored in each tank with a Tiny Tag (Aquatic 2, Gemini data loggers, Chester, UK) temperature logger. Frames with LED aquatic lights (AquaBeam 2000HD) were fitted and shades of varying weave put in place above and between the tubs to create independent shade treatments (and high light with no shade). A light meter (ULM-500, with spherical micro quantum Sensor US-SQS/L, Waltz GmbH, Effeltrich, Germany) was used to set up the light treatments by measuring the average PAR (Photosynthetic Active Radiation) in each tank section at the top of the seagrass leaf canopy. The HL treatment was set up to have a level that corresponds to HL treatments in other studies of around $100 \pm 10 \mu \mathrm{mol}$ photons $\mathrm{m}^{-2} \mathrm{~s}^{-1}$ (Olesen and Sandjensen, 1993; Biber et al., 2005; Shafer and Kaldy, 2013) also comparable to highest growth rates found previously (between 100 and $150 \mu \mathrm{mol}$ photons $\mathrm{m}^{-2} \mathrm{~s}^{-1}$, Olesen and Sand-jensen, 1993). The medium light treatment (ML) was set up using $40 \%$ shade cloth which gave an average of $27 \pm 5 \mu \mathrm{mol}$ photons $\mathrm{m}^{-2} \mathrm{~s}^{-1}$ at plant height, to create light levels that correspond to levels of light compensated growth (between 19 and $47 \mu \mathrm{mol}$ photons $\mathrm{m}^{-2} \mathrm{~s}^{-1}$, Olesen and Sand-jensen, 1993). The low light treatment (LL) was created using a $90 \%$ shade cloth, reducing the light to around $7 \pm 3 \mu \mathrm{mol}$ photons $\mathrm{m}^{-2} \mathrm{~s}^{-1}$. The extreme low light treatment (EL) was placed under a $98 \%$ shade cloth found to have a PAR of around $1.8 \pm 0.5 \mu \mathrm{mol}$ photons $\mathrm{m}^{-2} \mathrm{~s}^{-1}$. Lights were fitted on a timer to give a photoperiod of $10 \mathrm{~h}$ of light and $14 \mathrm{~h}$ of dark reflecting the natural daylight hours at time of collection. An Odyssey PAR light logger (Dataflow Systems Ltd), calibrated against a Li-Cor quantum light sensor (LI 192), was deployed at mid-depth of plant canopy under each treatment for 1-2 days logging every 10 mins, to provide an average PAR per day (Table 1). The experiment was set up to run for 6 weeks after acclimation time.

\section{Morphometric Measurements}

Morphometric measurements for each shoot $(n=5$ per treatment) were taken weekly, these included; sheath length, leaf length (taken from top of sheath to tip of leaf), leaf width, and shoot growth. Leaves were wiped clean of epiphytes
TABLE 1 | Total amount of light recorded by Odyssey PAR logger placed within tanks (calibrated with a LI-COR, Li-250A light meter) and temperature range logged for each treatment tank.

\begin{tabular}{|c|c|c|c|}
\hline Treatment & $\begin{array}{l}\text { Amount of light } \\
\text { per day (mol } \\
\text { photons } \\
\mathrm{m}^{-2} \text { day }^{-1} \text { ) }\end{array}$ & $\begin{array}{c}\text { Average PAR per } \\
\text { treatment }(\mu \mathrm{mol} \\
\text { photons } \\
\left.\mathrm{m}^{-2} \mathbf{s}^{-1} \pm \mathrm{SD}\right)\end{array}$ & $\begin{array}{c}\text { Temperature } \\
\text { range }\left({ }^{\circ} \mathrm{C}\right)\end{array}$ \\
\hline High & 5.61 & $\begin{array}{c}155.76 \pm 11.42 \\
(100 \%)\end{array}$ & $13.2-14.0$ \\
\hline Medium & 0.73 & $\begin{array}{c}20.15 \pm 0.36 \\
(12.9 \%)\end{array}$ & $13.2-14.0$ \\
\hline Low & 0.35 & $\begin{array}{c}9.78 \pm 0.57 \\
(6.3 \%)\end{array}$ & $13.4-13.9$ \\
\hline Extreme low & 0.14 & $\begin{array}{c}3.76 \pm 0.41 \\
(2.4 \%)\end{array}$ & $13.4-13.9$ \\
\hline
\end{tabular}

throughout the experiment although older ends of leaves were difficult to clean without causing damage so were left, but these tended to be chlorotic and often dead (Drake et al., 2003). Lengths measurements were taken with a measuring tape to the nearest $\mathrm{mm}$, and the maximum leaf length for each shoot was analysed as a measure that can be attributed to canopy height in seagrass meadows (Longstaff and Dennison, 1999). Leaf width was measured using calipers to the nearest $0.05 \mathrm{~mm}$ at $5 \mathrm{~cm}$ above sheath or in the middle of each leaf $<5 \mathrm{~cm}$ long. Average leaf width was calculated for each shoot. Shoot surface area was calculated from the length and width measurements of all leaves of all shoots to provide potential surface area for photosynthesis. For shoot growth, each plant was marked at the top of its sheath with a needle so the growth of each leaf could be measured using the method outlined by Short and Duarte (2001). If new leaves were found, they were marked at the same location on the sheath. The new growth could then be measured against the mark on the sheath, the outer part of which is usually dead and does not alter. If the outer leaf became detached then the top of the sheath would remain so growth could still be measured from this position. Raw values for maximum leaf length, shoot surface area, shoot growth, and average leaf width per shoot were used for statistical analysis.

\section{Photosynthetic Measurements}

Pulse Amplitude Modulated (PAM) fluorometry using a DivingPAM (Waltz), was used to measure chlorophyll fluorescence weekly, as a non-invasive technique for assessing photosynthetic activity. Photosynthetic parameters were obtained by performing rapid light curves (RLC) using the internal stepwise function of the PAM fluorometer. These were conducted on the midsection of the youngest mature leaf using a leaf clip, enabling the measurement of effective quantum yield $\left(\Phi_{p s I I}=\left(F_{m}{ }^{\prime}-F\right) / F_{m}{ }^{\prime}\right)$, where $F$ is fluorescence yield and $F_{m}{ }^{\prime}$ is maximal fluorescence yield of the light adapted leaf at each irradiance step (Ralph and Gademann, 2005; Collier et al., 2008). Steps ranged from 7 to $1652 \mu \mathrm{mol}$ photons $\mathrm{m}^{-2} \mathrm{~s}^{-1}$ lasting $10 \mathrm{~s}$, with initial saturating pulse $>>2,000 \mu \mathrm{mol}$ photons $\mathrm{m}^{-2} \mathrm{~s}^{-1}$ (Beer et al., 2001) for $0.8 \mathrm{~s}$. All RLCs were carried out between 11a.m. and 
2p.m. Electron Transport Rate (ETR) was worked out using the equation; ETR $=\Phi_{p s I I}{ }^{*} I_{i}{ }^{*} \mathrm{AF}^{*} 0.5$, where $\mathrm{AF}$ is the absorption factor, calculated to be 0.78 ( \pm 0.02 S.D., $n=5$ ) (Beer et al., 2001; Saroussi and Beer, 2007) and $I_{i}$ is the incident irradiance (from the light stages of the light curve programmed into the Dive-PAM). The stepwise RLCs were fitted to the non-linear least-squares regression model by Eilers and Peeters (Eilers and Peeters, 1988) to estimate the $\mathrm{ETR}_{\max }$ (maximum rate of photosynthesis), $\alpha$ (the initial slope of the rapid light curve, a measure of the light harvesting efficiency) and $\mathrm{E}_{\mathrm{k}}$ (the minimum saturating irradiance worked out from the intercept of $\alpha$ and the maximum photosynthetic rate).

\section{Physiological Measurements C:N Content of Seagrass}

At the end of the experiment, leaf material from each shoot was taken to be compared with site control samples taken from the field site at Durgan. Avoiding the older chlorotic leaves, leaf material was scraped free of epiphytes, blotted dry and weighed before being dried at $60^{\circ} \mathrm{C}$ for $48 \mathrm{~h}$. The dried seagrass was ground up with a pestle and mortar to a fine homogenous powder before being weighed (Ohaus balance, max $100 g d=0.1 \mathrm{mg}$, Switzerland). Samples were sent to IBERS (Aberystwyth University) for analysis of the \% composition of $\mathrm{C}$ and $\mathrm{N}$ by weight using a continuous flow isotope ratio mass spectrometer (Anca SL 20-20, Europa Scientific, Crewe, UK).

\section{Rhizome Sugars}

At the end of the experiment the rhizomes from each plant were separated, weighed, and also stored at $-20^{\circ} \mathrm{C}$ to be compared with samples taken from the field site at Durgan. The rhizomes were dried in an oven at $60^{\circ} \mathrm{C}$ for $4-5$ days. The dried rhizome sections were ground up with a pestle and mortar to a fine homogenous powder to enable analysis by HPLC. Samples were sent to IBERS at Aberystwyth University for analysis. Soluble rhizome sugars were extracted based on the method outlined in Cairns and Pollock (1988).

\section{Chlorophyll Pigments}

Samples of $Z$. marina from Durgan were collected from the study site and compared with samples from all of the plants at the end of the experiment. Chlorophyll was extracted in 90\% acetone and quantified using a spectrophotometer (Schimadzu UV-2550 UV VIS Series) based on the methods outlined by Dennison (1990) and Granger and Izumi (2001).

\section{Statistics}

Two-way repeated measures ANOVA was used to analyse time series collected data, with light treatment (betweensubject effects) over time (within-subject effects) using SigmaPlot Version 11 (Systat Software, San Jose, CA). Data did not completely fulfill the assumptions of ANOVA therefore in order to minimize the risk of Type I error, significance was only accepted based on $p$-values of $<0.01$ (Underwood, 1997; Collier et al., 2012b; McDonald, 2014). ANOVA was still performed due to the robust nature of the test and the relative insensitivity of the $\mathrm{F}$ test to departures from normality (Glass et al.,
1972; Lix et al., 1996; McDonald, 2014). Results from the repeated measures ANOVA were interpreted with the HolmŠ́dák pairwise comparisons test in SigmaPlot.

$\mathrm{C}: \mathrm{N}$ ratio, rhizome total water soluble carbohydrate (WSC) content and chlorophyll content were analysed using one-way ANOVA in RStudio ( $R$ version 3.2.2) to compare plants after treatment with site control plants that were taken directly from Durgan (untreated). The Bartlett test for homogeneity was used to test for equal variance (Bartlett, 1937). Tukey's test was used to look at multiple comparisons of means.

Principal Component Analysis (PCA) using Primer6 was used to identify patterns of which morphological and photophysiological factors contributed to the biggest responses of plants to shade treatment over time. Principal components with eigenvalues $>1.0$ were considered, and eigenfactors or variable coefficients $\leq-0.3$, or $\geq 0.3$ were selected.

\section{RESULTS}

At the end of the experiment none of the HL shoots had died but all plants subjected to shade treatment (ML, LL, and EL) showed signs of mortality at the basal meristem (all leaves coming free from within the sheath) by day 43 , with one LL shoot dying after just 4 weeks.

\section{Morphological Characteristics Maximum Leaf Length}

At the start of the experiment all plants exhibited a maximum leaf length within the range of 455 to $727 \mathrm{~mm}$ with an average of $564.00 \pm 18.53 \mathrm{~mm}$. The average max leaf length decreased in all plants throughout the experiment although reduction was lowest in HL plants. All plants under shade treatments showed a significant reduction in average max leaf length in comparison to those under HL from day 15 for ML $(p=0.009)$ and LL plants $(p=0.01)$ and day 22 for EL plants $(p=0.013$, Figure 1). ML plants decreased steadily in length from day 15 resulting in a significant reduction in max leaf length to $391.60 \pm 51.61 \mathrm{~mm}$ by day $43(p<0.001)$. LL plants also decreased steadily from day 15 although the differences in max leaf length were not significant. EL plants decreased in max leaf length from day 22 with a significant reduction shown between day 15 and day 37 $(p=0.002)$. HL plants remained with a max leaf length above $610 \mathrm{~mm}$ until day 43 when average max leaf length had decreased to $489.80 \pm 38.47 \mathrm{~mm}$.

\section{Leaf Width}

The leaf width of all plants at the start of the experiment ranged between 4.6 and $6.85 \mathrm{~mm}$.

All plants decreased in average width throughout the experiment and this reduction was lowest in HL plants. All plants under shade treatments showed significant reductions in width by day 29 with no significant change in leaf width for HL plants throughout the experiment (Figure 1). ML plants decreased steadily from day 0 and showed a significant reduction in width from $5.35 \pm 0.11 \mathrm{~mm}$ to $5.02 \pm 0.12 \mathrm{~mm}$ on day 22 $(p=0.002)$. LL plants decreased significantly in width from 5.93 $\pm 0.35 \mathrm{~mm}$ on day 0 to $5.14 \pm 0.30 \mathrm{~mm}$ on day $43(p<0.001)$ 


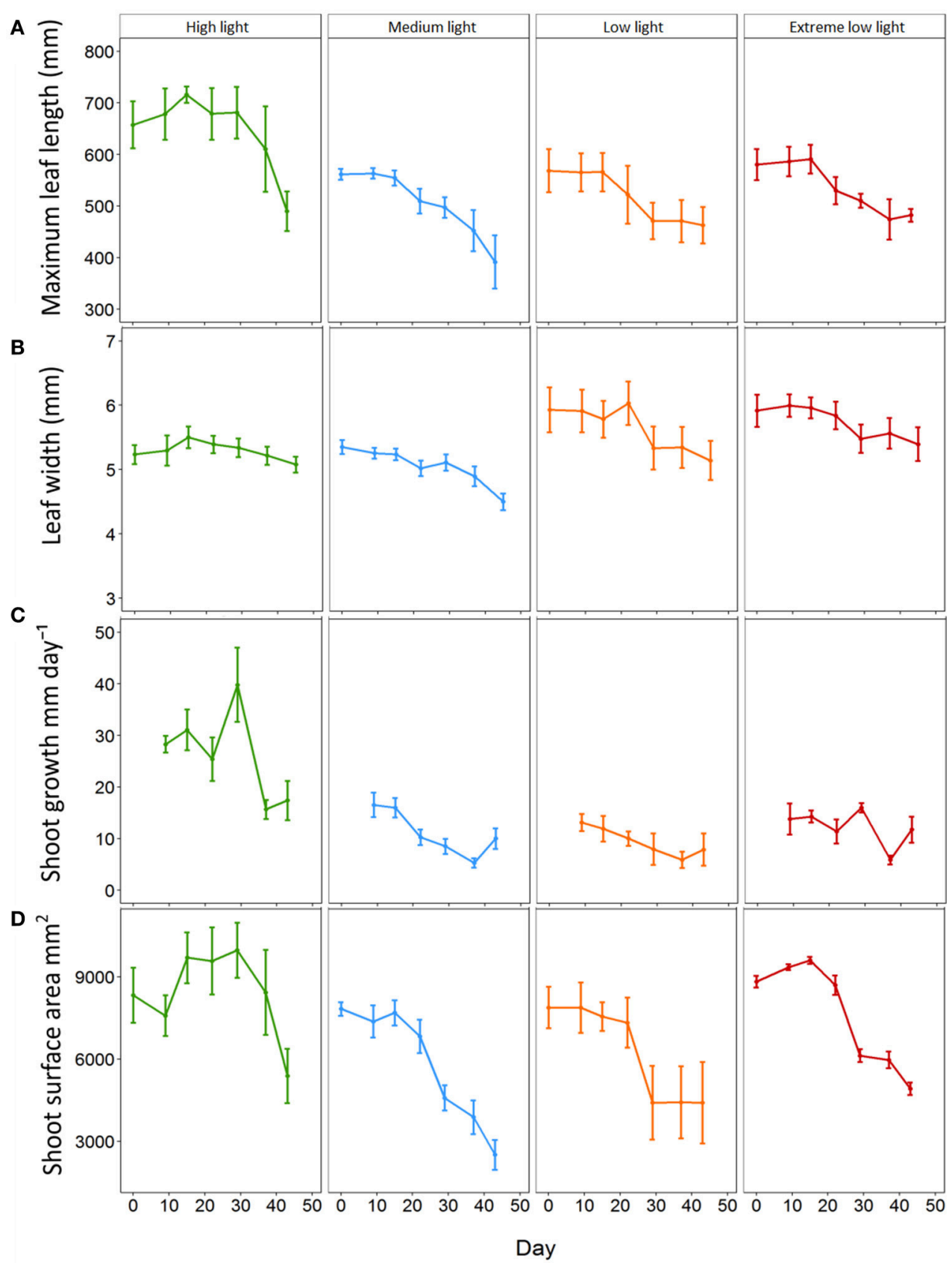

FIGURE 1 | Effect of light shading on the morphological characteristics of Zostera marina over time. Plants were kept in a flow through aquaria using natural filtered seawater under artificial light. (A) Maximum leaf length (B) leaf width, (C) shoot growth and (D) total shoot surface area. Values are means $\pm \mathrm{SE}, n=5$ (except low light plants on days 37 and 45 where $n=4)$.

with the first significant reduction by day $29(5.33 \pm 0.33 \mathrm{~mm}$, $p<0.001)$. For EL plants leaf width decreased significantly from $5.92 \pm 1.25 \mathrm{~mm}$ on day 0 to $5.40 \pm 0.26 \mathrm{~mm}$ on day $43(p<0.001)$ with the first observed significant decrease in width observed on day 29 (5.48 $\pm 0.22 \mathrm{~mm}, p<0.001)$. Results showed there was a significant interaction between light treatment and time on average leaf width $(p \leq 0.001)$ (Table 2$)$.

\section{Shoot Growth}

All plants decreased in average growth rate throughout the experiment, although this reduction was lowest in HL plants. HL plants had significantly higher growth of $28.29 \pm 1.63 \mathrm{~mm} \mathrm{day}^{-1}$ on day 9 in comparison to $16.55 \pm 2.36 \mathrm{~mm}^{\text {day }}{ }^{-1}$ for ML plants $(p=0.001), 13.10 \pm 1.66 \mathrm{~mm} \mathrm{day}^{-1}$ for LL plants $(p \leq 0.001)$ and $13.80 \pm 3.03 \mathrm{~mm} \mathrm{day}^{-1}$ for EL plants $(p<0.001)$ (Figure 1). 
TABLE 2 | Results of two-way repeated measures ANOVA testing for the within-subjects effects of time and treatment on the morphological parameters maximum leaf length, width shoot surface area, and shoot growth rate, and on the photosynthetic parameters Alpha $(\alpha)$, ETRmax and Maximal yield [( $\left.\left.\mathrm{Fm}_{\mathrm{m}}^{\prime}-\mathrm{F}\right) / \mathrm{F}_{\mathrm{m}}{ }^{\prime}\right]$.

\begin{tabular}{|c|c|c|c|c|c|c|c|c|c|c|c|c|c|}
\hline & \multirow[b]{2}{*}{ DF } & \multicolumn{3}{|c|}{ Max leaf length (mm) } & \multicolumn{3}{|c|}{ Leaf width (mm) } & \multicolumn{3}{|c|}{ Shoot surface area $\left(\mathrm{mm}^{2}\right)$} & \multicolumn{3}{|c|}{ Shoot growth rate $\left(\mathrm{mm}\right.$ day $\left.^{-1}\right)$} \\
\hline & & MS & $\mathbf{F}$ & $\boldsymbol{P}$ & MS & $\mathbf{F}$ & $\boldsymbol{P}$ & MS & $\mathbf{F}$ & $p$ & MS & $\mathbf{F}$ & $p$ \\
\hline \% Light & 3 & $1.41 \mathrm{E}+05$ & 4.532 & 0.018 & 3.735 & 2.856 & 0.070 & $5.11 \mathrm{E}+07$ & 3.897 & 0.029 & 1791.182 & 22.496 & $<0.001$ \\
\hline Day & 6 & $5.90 \mathrm{E}+04$ & 17.305 & $<0.001$ & 0.97 & 37.633 & $<0.001$ & $5.11 \mathrm{E}+07$ & 29.086 & $<0.001$ & 367.994 & 12.472 & $<0.001$ \\
\hline$\%$ Light $\times$ Day & 18 & 3660.635 & 1.073 & 0.391 & 0.0907 & 3.519 & $<0.001$ & $5.15 E+06$ & 2.809 & $<0.001$ & 84.04 & 2.848 & 0.001 \\
\hline \multirow[t]{3}{*}{ Significance level } & & & & 0.05 & & & 0.05 & & & 0.05 & & & 0.05 \\
\hline & & \multicolumn{3}{|c|}{ Alpha $(\alpha)$} & \multicolumn{3}{|c|}{ ETR $_{\max }$} & \multicolumn{3}{|c|}{ Ek } & \multicolumn{3}{|c|}{$\left(F_{m^{\prime}}-F\right) / F_{m}{ }^{\prime}$} \\
\hline & DF & MS & $\mathbf{F}$ & $P$ & MS & $\mathbf{F}$ & $P$ & MS & $\mathbf{F}$ & $p$ & MS & $\mathbf{F}$ & $p$ \\
\hline \% Light & 3 & 1.108 & 21.632 & $<0.001$ & 3314.746 & 21.908 & $<0.001$ & 1.92E+04 & 8.71 & 0.001 & 1.108 & 21.632 & $<0.001$ \\
\hline Day & 6 & 0.158 & 7.425 & $<0.001$ & 2256.437 & 43.597 & $<0.001$ & 6373.13 & 16.44 & $<0.001$ & 0.158 & 7.425 & $<0.001$ \\
\hline$\%$ Light $\times$ Day & 18 & 0.040 & 1.878 & 0.027 & 184.494 & 3.565 & $<0.001$ & 1057.88 & 2.73 & 0.001 & 0.040 & 1.878 & 0.027 \\
\hline Significance level & & & & 0.01 & & & 0.01 & & & 0.01 & & & 0.01 \\
\hline
\end{tabular}

No transformations were applied to the data for statistical analysis. Also shown is the p-value that was considered significant (adjusted if variances were not homogenous).

Shoot growth of HL plants remained significantly higher than shade treated plants until day 37 , and continued to remain higher than shaded plants until day 43. ML plants showed a significant decline in growth from day 9 to day $37(p=0.002)$. The growth of LL and EL plants was significantly lower than HL plants from day 9, but not significantly different to ML plants or to each other suggesting growth was already affected by light reduction for shade treated plants between before day 9. Results showed there was a significant interaction between light treatment and time for shoot growth $(p=0.001)$ (Table 2).

\section{Shoot Surface Area}

At the start of the experiment shoot surface area ranged from 4563.3 to $10580.0 \mathrm{~mm}^{2}$ and averaged $8218.6 \pm 326.6 \mathrm{~mm}^{2}$. All plants decreased in average shoot surface area throughout the experiment with the lowest reduction in HL plants. All plants subjected to shade treatments showed a significant decline in surface area by day 29 (Figure 1). HL plants remained significantly larger in surface area than all shade treated plants from day 29 until day 43 ( $p \leq 0.001-0.002)$. ML plants reduced in surface area by $41.5 \%$ (a reduction from $7831.89 \pm 245.9 \mathrm{~mm}^{2}$ to $\left.4584.1 \pm 464.5 \mathrm{~mm}^{2}, p \leq 0.001\right)$ and LL plants were reduced by $44 \%$ by day 29 (from $7883.3 \pm 756.6 \mathrm{~mm}^{2}$ to $4413.8 \pm 1345.7$ $\left.\mathrm{mm}^{2}, p \leq 0.001\right)$. EL plants displayed a reduction of $30.5 \%$ on day $29(p=0.002)$ and had reduced by $44.3 \%$ by day $43(p \leq 0.001)$. For plant surface area there was a significant interaction between light and day $(p \leq 0.001)$ (Table 2).

\section{Photosynthetic Characteristics Alpha}

At the start of the experiment the light harvesting efficiency or alpha $(\alpha)$ ranged from 0.53 to 1.27 with an overall average of 0.87 \pm 0.05 . Alpha responded rapidly (by day 5 ) to shading treatments relative to the HL plants (Figure 2A). There was no significant change in $\alpha$ for HL plants throughout the experiment. ML plants, displayed a significant increase in $\alpha$ from $0.91 \pm 0.07$ on day
0 to $1.19 \pm 0.02$ on day $19(p=0.003)$. EL plants showed a significant increase in $\alpha$ from day 5 from $0.69 \pm 0.08$ to $1.25 \pm$ 0.08 ( $p \leq 0.001)$. LL plants showed no significant change in $\alpha$ over time, although levels remained significantly higher than HL plants throughout the experiment. Results showed there was a significant interaction between light treatment and time for alpha $(p=0.001)$ (Table 2).

\section{ETR $_{\max }$}

The maximum Electron Transport Rate $\left(\mathrm{ETR}_{\max }\right)$ ranged from $26.82 \mu \mathrm{mol}$ electrons $\mathrm{m}^{-2} \mathrm{~s}^{-1}$ to $97.60 \mu \mathrm{mol}$ electrons $\mathrm{m}^{-2} \mathrm{~s}^{-1}$ with an average of $57.98 \pm 4.75 \mu \mathrm{mol}$ electrons $\mathrm{m}^{-2} \mathrm{~s}^{-1}$ at the beginning of the experiment. The $\mathrm{ETR}_{\max }$ was significantly affected in all shading treatments by day 5 (Figure 2B). Not all plants gave a reliable $\mathrm{ETR}_{\max }$ value as some curves did not saturate and these results were omitted. HL plants remained with significantly higher $\mathrm{ETR}_{\max }$ than all shade treated plants ( $p<0.001-0.012)$ with EL plants showing the biggest drop of $76 \%$ from day 0 to day $5(79.39 \pm 9.11$ to $18.96 \pm 0.50 \mu \mathrm{mol}$ photons $\left.\mathrm{m}^{-2} \mathrm{~s}^{-1} ; p<0.001\right)$. ML plants showed a reduction in $\mathrm{ETR}_{\max }$ of $42 \%$ on day $5(55.03 \pm 6.58$ to $31.94 \pm 2.34 \mu \mathrm{mol}$ electrons $\left.\mathrm{m}^{-2} \mathrm{~s}^{-1} ; p<0.001\right)$. LL plants showed a reduction of $57 \%\left(43.66 \pm 5.89 \mu \mathrm{mol}\right.$ electrons $\mathrm{m}^{-2} \mathrm{~s}^{-1}$ to $18.85 \pm 0.24$ $\mu \mathrm{mol}$ electrons $\mathrm{m}^{-2} \mathrm{~s}^{-1} ; p<0.001$ ) on day 5 . On the contrary, HL plants showed a slight increase on day 5 from $60.04 \pm 4.18$ $\mu \mathrm{mol}$ electrons $\mathrm{m}^{-2} \mathrm{~s}^{-1}$ to $69.10 \pm 0.36 \mu \mathrm{mol}$ electrons $\mathrm{m}^{-2} \mathrm{~s}^{-1}$.

$\mathrm{E}_{\mathrm{k}}$

The $\mathrm{E}_{\mathrm{k}}$ of plants at the start of the experiment averaged 75.52 $\pm 11.32 \mu \mathrm{mol}$ photons $\mathrm{m}^{-2} \mathrm{~s}^{-1}$ with a broad range from 24.64 to $183.57 \mu \mathrm{mol}$ photons $\mathrm{m}^{-2} \mathrm{~s}^{-1}$. Not all plants gave a reliable $\mathrm{E}_{\mathrm{k}}$ value as some curves did not saturate and these results were omitted. The $\mathrm{E}_{\mathrm{k}}$ of all shaded plants was significantly affected on day 5 (Figure 2C). HL had a significantly higher $E_{k}$ than shaded plants, $72.42 \pm 20.38$ compared to $33.07 \pm 4.80$ for ML $(p=0.002), 16.17 \pm 0.19$ for LL $(p \leq 0.001)$ and 15.27 


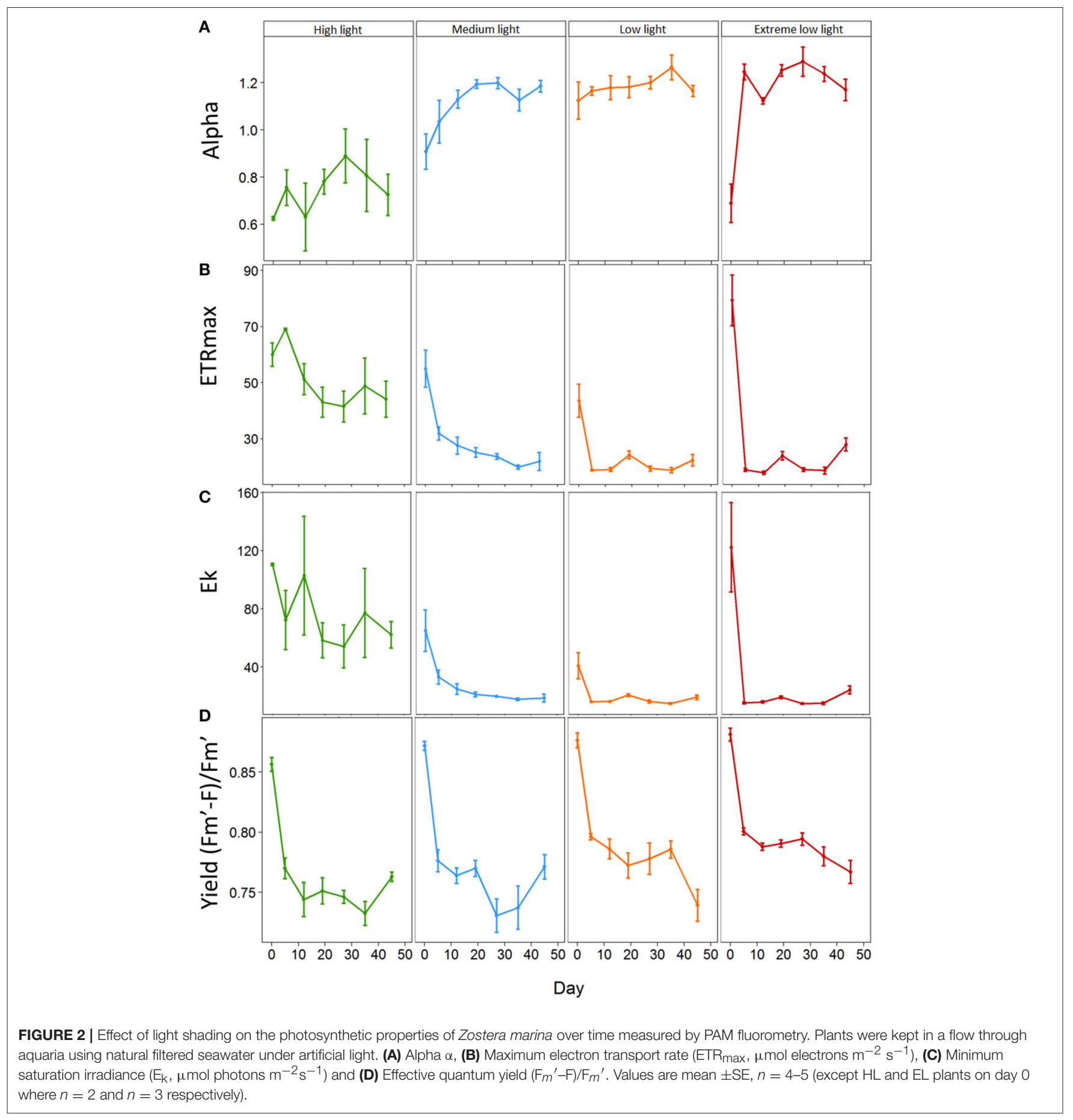

$\pm 0.56 \mu$ mol photons $\mathrm{m}^{-2} \mathrm{~s}^{-1}$ for EL plants $(p \leq 0.001)$. All plants showed a decrease in $\mathrm{E}_{\mathrm{k}}$ throughout the experiment with EL plants showing the biggest reduction of $80.1 \%$ by day 43 $(p \leq 0.001)$.

\section{Effective Quantum Yield}

The effective quantum yield was significantly affected by shading by day 12 where HL plants had significantly $(p<0.001$ and $p=0.001$ respectively) lower yield $(0.74 \pm 0.01)$ than EL plants
$(0.79 \pm 0.003)$ and LL plants $(0.79 \pm 0.01)$. EL light levels resulted in plants having a significantly higher yield than HL until day 43 (Figure 2D).

\section{Physiological Results}

\section{C:N}

Results of the one-way ANOVA with Tukey's post-hoc comparison showed ML plants had a significantly higher C:N (17.56 \pm 0.57$)$ than EL plants (15.04 \pm 0.37$), p \leq 0.006$. 
There were no significant differences in C:N between site control plants $(16.48 \pm 0.55)$ and any of the plants after treatment (Table 3, Figure 3).

\section{Rhizome Sugars-WSC (Water Soluble Carbohydrates)}

Results of the one-way ANOVA with Tukey's post-hoc comparison showed site control plants had significantly higher total WSC content $(52.76 \pm 2.36 \mathrm{mg} / \mathrm{ml})$ than all treatments $(p$ $\leq 0.001)$. There was no significant difference between treatments at the end of the experiment (Table 3, Figure 3).

TABLE 3 | Results of one-way ANOVA testing effects of light manipulation on the physiological parameters $\mathrm{C}: \mathrm{N}$, water soluble carbohydrate content of rhizomes (WSC), and leave chlorophyll content.

\begin{tabular}{lcccc}
\hline & DF & MS & F & $\boldsymbol{P}$ \\
\hline C:N & 4 & 872.8 & 34.27 & $<\mathbf{0 . 0 0 1}$ \\
WSC & 4 & 4.191 & 4.175 & $<\mathbf{0 . 0 5}$ \\
Chlorophyll & 4 & 5.029 & 9.179 & $<\mathbf{0 . 0 0 1}$ \\
Significance level & & & & 0.05
\end{tabular}

All passed Bartlett's test for homogeneity except chlorophyll.

\section{Chlorophyll Content}

Results of the one-way ANOVA with Tukey's post-hoc comparison showed site control samples had significantly higher chlorophyll content $\left(4.13 \pm 0.16 \mu \mathrm{g} \mathrm{Chl} \mathrm{cm}^{-2}\right)$ than ML $\left(2.45 \pm 0.28 \mu \mathrm{g} \mathrm{Chl} \mathrm{cm}^{-2}\right), p \leq 0.001$, and LL plants $(3.14 \pm$ $0.09 \mu \mathrm{g} \mathrm{Chl} \mathrm{cm}^{-2}$ ), $p=0.014$. ML plants were also significantly lower in chlorophyll content than HL plants, $p=0.002$, and EL plants, $p=0.009$ (Table 3, Figure 3).

\section{Bioindicator Analysis}

Principal component analysis was used to show which bioindicators contributed to the most variability between treatments and within treatments over time. The first two principal components (PC1 and PC2) had eigenvalues over 1 making up over $70 \%$ of the variability. PC1 approximately corresponds with the change from high light to low light, whereas the treatments are more evenly spread across PC2. PC1 had an eigenvalue of 3.85 making up $48.1 \%$ of the variability, and showed a correlation (above 0.3 ) between the variables leaf length, shoot surface area, shoot growth, ETR $\mathrm{Eax}_{\text {ax }}$ alpha, and $\mathrm{E}_{\mathrm{k}}$. The first component increases with decreasing leaf length, shoot surface area, shoot growth, $\mathrm{ETR}_{\max }, \mathrm{E}_{\mathrm{k}}$, and an increase in alpha. PC2 has a strong correlation with leaf width and shoot surface area (both above -0.5 ) and also a correlation with effective
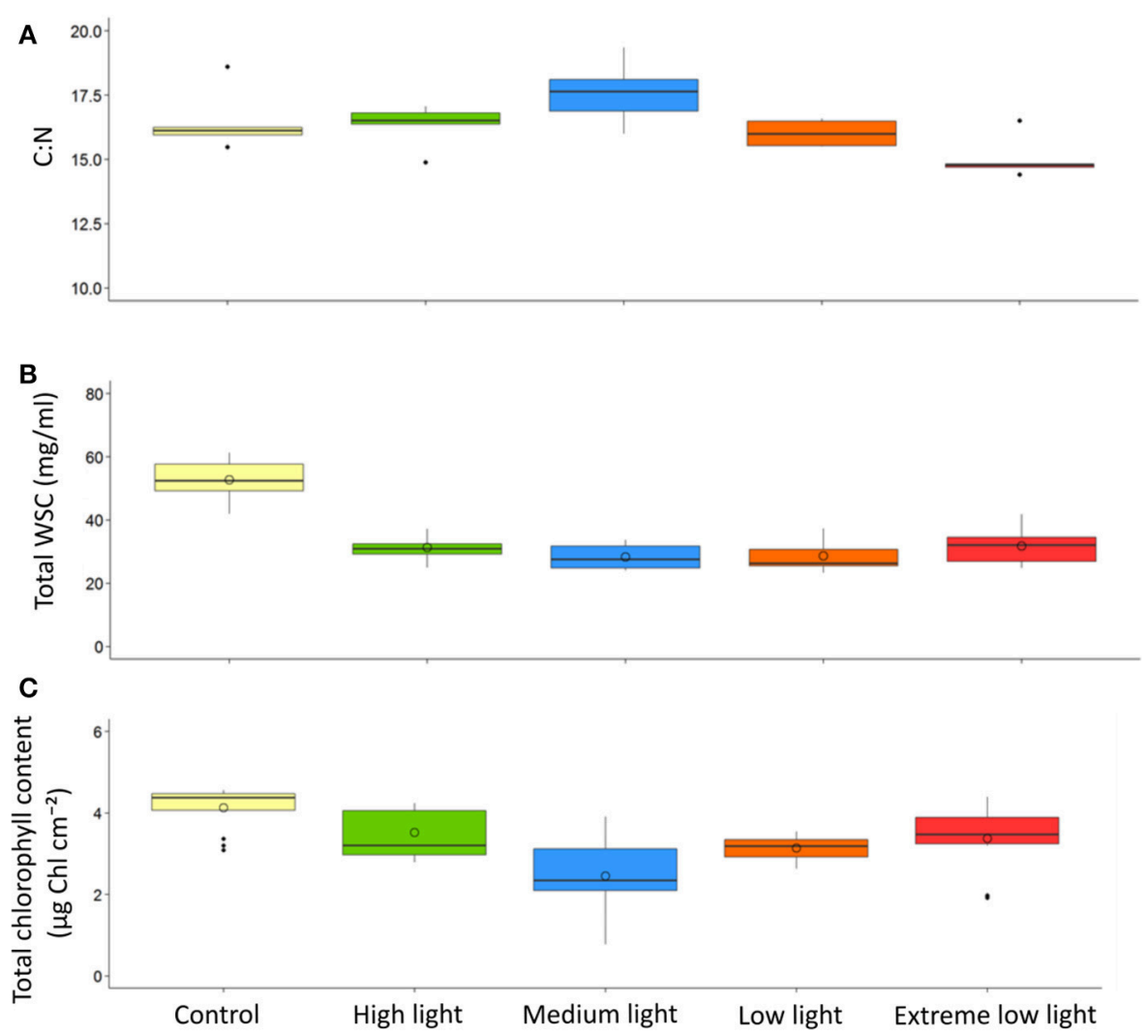

FIGURE 3 | Effect of light shading on physiological properties of $Z$. marina with time. Plants were kept in a flow through aquaria using natural filtered seawater under artificial light. Boxplots show results from control site plants compared with plants at the end of the experiment. (A) C:N (B) Total water soluble carbohydrates(WSC), (C) Total chlorophyll content. Central line is the median, o point is the mean, $n=5$. 
quantum yield $\left.\left(\mathrm{F}_{\mathrm{m}}{ }^{\prime}-\mathrm{F}\right) / \mathrm{F}_{\mathrm{m}}{ }^{\prime}\right)(-0.482)$. PC2 increases with a decrease with these correlating factors. HL plants remain in cluster away from shade treated plants, only moving closer in similarity to shaded plants in week 5 and 6 (Figure 4).

\section{DISCUSSION}

The present study provides an experimental test of the response of multiple photophysiological and morphological bioindicators to light limitation on $Z$. marina. The study provides an experimental insight into timescales and levels of response to light limitation specific to $Z$. marina relative to models of light stress developed through meta-analysis (McMahon et al., 2013). Leaf length, shoot growth rate, $\mathrm{ETR}_{\max }$, alpha, $\mathrm{E}_{\mathrm{k}}$, and shoot surface area showed the strongest responses to light limitation across time suggesting that they act as robust bioindicators of light stress in Z. marina. Leaf width and effective quantum yield were also found to respond consistently to light limitation. Physiological parameters proposed by the metaanalysis (McMahon et al., 2013) to make good bioindicators were not found to be as robust when considered directly against these other variables such as leaf length, alpha, and ETR $\mathrm{max}_{\text {. }}$

Under light limiting conditions, plants exhibited significant reductions in length, width, surface area and growth rate within 3-4 weeks, resulting in a reduction of above ground tissue. This reduction potentially poses a respiratory burden to the plant (Fourqurean and Zieman, 1991; Collier et al., 2012a). Growth rate was significantly reduced in shaded plants by day 8 , suggesting that the response could have been detected even earlier. At a meadow scale, we propose that the plant response to low light would result in a reduction in overall seagrass density with corresponding impacts upon ecosystem resilience (Unsworth et al., 2015; Maxwell et al., 2016). A reduction in canopy density may actually be considered an adaptive mechanism to maximise available light as this allows more ambient light through to reduce self-shading (Collier et al., 2012a).

The present study shows that a reduction in light to 20.12 $\mu \mathrm{mol}$ photons $\mathrm{m}^{-2} \mathrm{~s}^{-1} \quad(10: 14 \mathrm{~h}$ light:dark photoperiod) is enough to cause a significant decrease in leaf length and width resulting in a decrease in plant surface area by $41 \%$ after 29 days, with further light stress in the LL and EL treatments causing similar albeit slightly bigger reductions. Light reductions of this scale would result in significant effects at a meadow scale within weeks, indicating that impacts causing light reductions over a similar time scale would have a substantially damaging effect. These results are comparable to in situ shading experiments conducted on Z. marina (Backman and Barilotti, 1976; Dennison and Alberte, 1985). A decline in shoot surface area results in significant implications on a meadow-scale. A reduced amount of photosynthetic tissue and a decrease in canopy density may affect the ability of the meadow to attenuate the effects of waves and currents. This results in an increase in levels of suspended sediments causing an increase in turbidity, and a reduction in sediment stabilization for the roots and rhizomes (van der Heide et al., 2007). A scenario like this can cause a shift to an alternate state within the meadow system, making it difficult for recovery unless conditions and light levels are restored (van der Heide et al., 2011; Unsworth et al., 2015). Frequent and prolonged
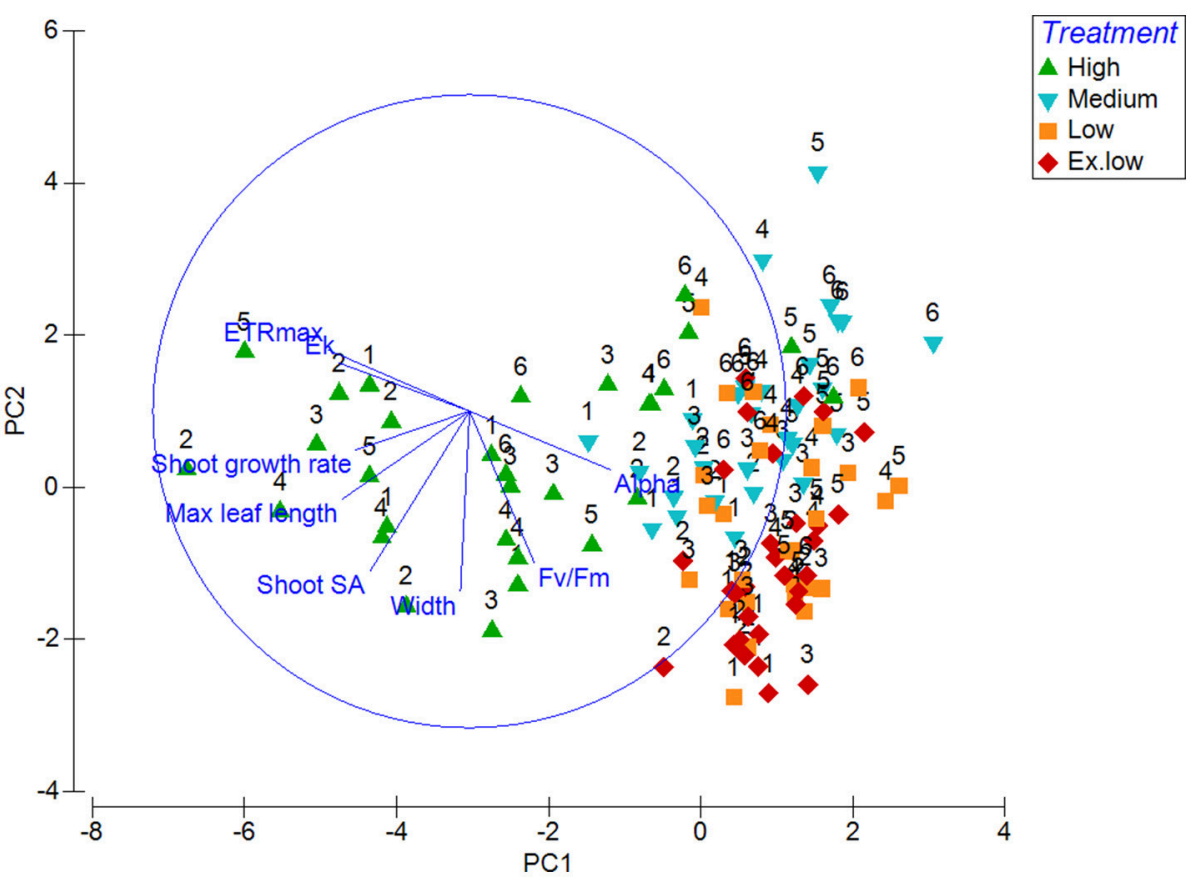

FIGURE 4 | Principal Component Analysis graph of morphological (leaf length, width, shoot surface area and shoot growth) and photophysiological (Alpha, maximum electron transfer rate, minimum saturation irradiance, and effective quantum yield) responses with treatment and week (starting from week 1) as factors. 
periods of reductions in light levels to $20.12 \mu \mathrm{mol}$ photons $\mathrm{m}^{-2} \mathrm{~s}^{-1}$ or below should be cause enough to alert managers to take action to improve water quality.

The meta-analysis by McMahon et al. (2013) did not recommend the morphological characteristics of leaf length, leaf width or shoot surface area as robust bioindicators of light stress for seagrasses overall. However, there is evidence for differences between different genera or species in response to light limitation. For instance, $Z$. muelleri was found to have the most rapid and "plastic" responses in morphology and growth to shading when compared to three other species of differing genus (Collier et al., 2012b). The importance of these differences is also highlighted by contrasting interspecific morphological responses, for example, Posidonia oceanica has been found to increase leaf width whilst Zostera nigricaulis, Halophila ovalis, and Halodule wrightii exhibit an increase in leaf length as a way of increasing light capture (Bulthuis, 1983; Dalla Via et al., 1998; Shafer, 1999; Collier et al., 2007).

Photophysiological responses to shading were exhibited within the first week and results showed trends consistent with other studies (Belshe et al., 2008; Beer et al., 2014). All plants showed high variability in alpha, $\mathrm{ETR}_{\max }$ and $\mathrm{E}_{\mathrm{k}}$ on day 0 , however by day 5 , all shaded plants exhibited significant reductions in $\mathrm{ETR}_{\max }$ and $\mathrm{E}_{\mathrm{k}}$ and significant increases in alpha. HL plants did not show such significant changes in alpha or $\mathrm{ETR}_{\max }$ as would be expected of plants adapted to higher light conditions. In contrast to the meta-analysis the present study identified alpha as a robust indicator of light stress, along with $\mathrm{ETR}_{\max }$ and $\mathrm{E}_{\mathrm{k}}$. The use of PAM fluorometry is useful as a non-invasive monitoring tool as it can detect physiological responses of seagrasses to light stress before morphological changes take place (Belshe et al., 2007). However, photosynthesis measurements using PAM display high levels of seasonal, diurnal and shoot-scale variation which need to be fully understood (Durako and Kunzelman, 2002). Also, chlorophyll fluorescence has been found to be good for assessing recovery in Z. marina, but not for detecting the onset of mortality (Biber et al., 2009). Even so, if the use of PAM fluorometry is feasible, consistent monitoring would give valuable information about the environmental conditions of a $Z$. marina meadow, especially if used alongside morphological bioindicators.

Physiological responses measured in this study showed no significant changes between shaded and HL plants. There were no significant changes in C:N at the end of the experiment when compared to control site samples. This could have been affected by the time of year the samples were taken. The C:N of Z. marina

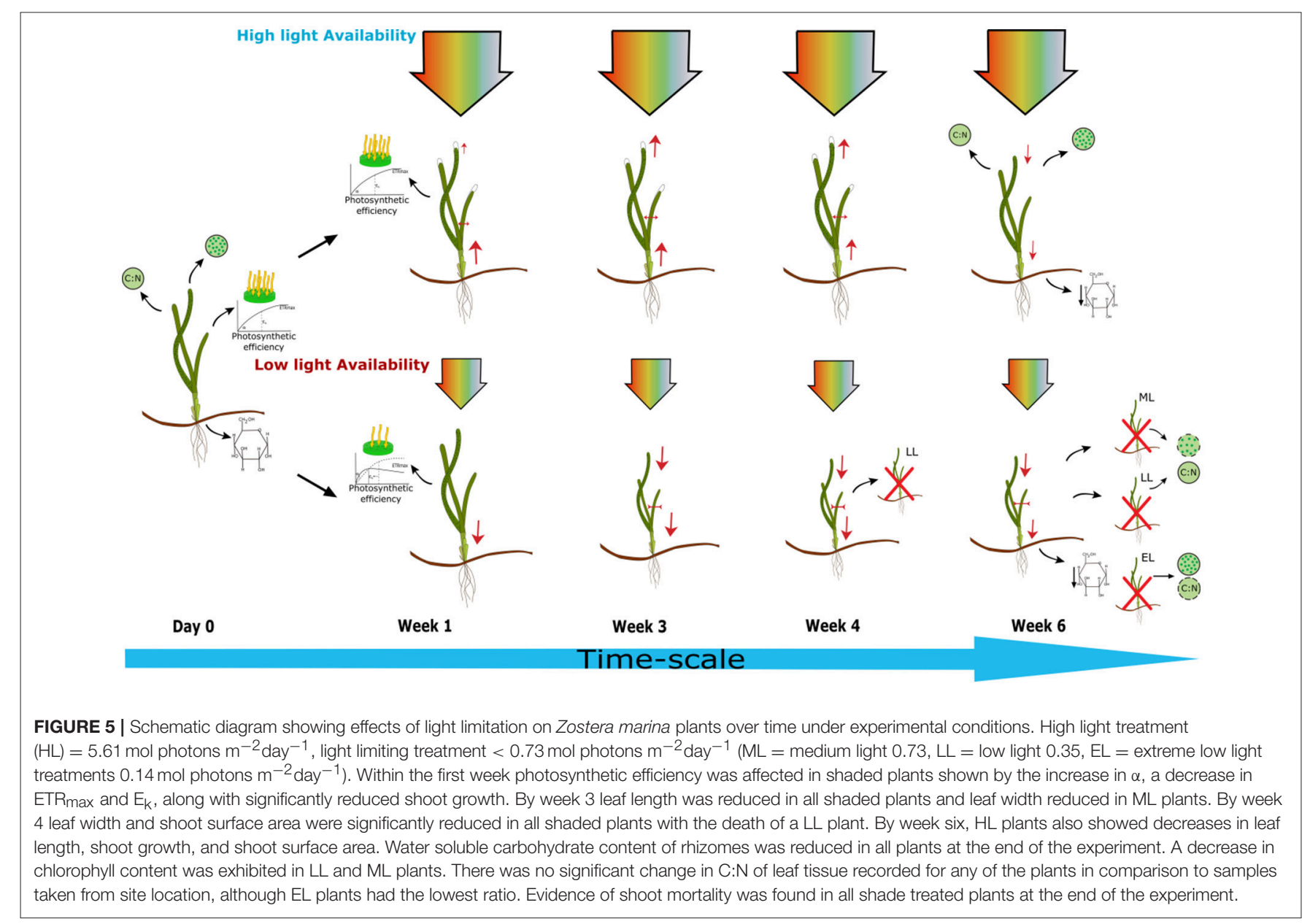


is usually at its highest in summer months and lowest in winter months (Fourqurean et al., 1997) and sampling for the present study took place in late October (autumn in UK). It should also be noted that $\mathrm{C}: \mathrm{N}$ has been identified as a robust bioindicator for Z. marina in a study that used an intensive field sampling strategy providing reliable evidence to this effect (Jones and Unsworth, 2016).

The WSC content of rhizomes did not vary significantly between treatments at the end of the experiment and therefore the present study did not conclusively find WSC to be a robust bioindicator of light stress. The significant seasonal variation in carbohydrate stores of Z. marina (Dawes and Guiry, 1992; Burke et al., 1996; Soissons et al., 2016) suggests sampling time could also have effected this result.

Leaf chlorophyll content did not provide a strong predictor of light limitation. LL and ML plants had the lowest chlorophyll levels, although shaded plants were expected to have higher chlorophyll content than control plants. However, if light stress is too high, plants are unable to respond by producing more chlorophyll. Collier et al. (2012b) also found that chlorophyll levels in very low light treated plants did not increase compared to the HL treated plants. This was thought to be due to the higher level of stress counteracting the energetic benefits of producing more chloroplasts.

Findings from this study indicate that MLR thresholds of Z. marina are between the levels of $\mathrm{HL}$ and ML treatments: between 155.76 and $20.12 \mu \mathrm{mol}$ photons $\mathrm{m}^{-2} \mathrm{~s}^{-1}$ or 5.61 and $0.73 \mathrm{~mol}$ photons $\mathrm{m}^{-2} \mathrm{day}^{-1}$ under experimental conditions. Maximum growth rates of $Z$. marina have previously been found to be at irradiances between 100-150 $\mu$ mol photons $\mu \mathrm{m}^{-2} \mathrm{~s}^{-1}$ (Dennison and Alberte, 1985; Olesen and Sand-jensen, 1993), or 5 mol photons $\mathrm{m}^{-2} \mathrm{day}^{-1}$ (Thom et al., 2008) and the photosynthesis saturating irradiance required for plant growth in situ found to be to be $30-40 \mu \mathrm{mol}$ photons $\mathrm{m}^{-2} \mathrm{~s}^{-1}$ (Alcoverro et al., 1999). As such, HL treatment at $155.76 \mu \mathrm{mol}$ photons $\mathrm{m}^{-2}$ day ${ }^{-1}$ could be considered to be the equivalent of a maximal surface irradiance level and it could therefore be suggested that ML treatment is equivalent to $\sim 12.9 \%$ of SI. This is similar to the MLRs that have been determined for Z. marina in other studies (Olesen and Sand-jensen, 1993; Short et al., 1995; Koch and Beer, 1996). Despite being close to the MLR, the ML treatment in this study is still considerably higher than the light compensation point determined for $Z$. marina in other studies at comparable temperatures; $8.33 \mu \mathrm{mol}$ photons $\mathrm{m}^{-2} \mathrm{~s}^{-1}$ at $15^{\circ} \mathrm{C}$ (Abe et al., 2003), $10 \mu \mathrm{mol}$ photons $\mathrm{m}^{-2} \mathrm{~s}^{-1}$ at $20^{\circ} \mathrm{C}$ (Dennison and Alberte, 1982) and $18.5 \mu \mathrm{mol}$ photons $\mathrm{m}^{-2} \mathrm{~s}^{-1}$ at $15^{\circ} \mathrm{C}$ (Olesen and Sand-jensen, 1993). Consequently, one would expect seagrasses under the ML treatment to be still surviving, although maybe not thriving. However, ML plants showed similar responses to LL and EL plants with the bioindicators not changing in a proportional manner relative to light treatment. This suggests that below a certain light threshold, responses will be consistent. The significant impacts to photosynthetic properties and growth rate within the first week, and significant reductions in leaf length, width and surface area after 4 weeks of shade treatment indicates $12.9 \%$ SI or $20.12 \mu \mathrm{mol}$ photons $\mathrm{m}^{-2} \mathrm{~s}^{-1}$ for $10 \mathrm{~h}$ per day is insufficient for $Z$. marina survival.

\section{CONCLUSIONS}

This study experimentally tests a wide range of bioindicators of light stress on $Z$. marina plants within controlled laboratory conditions (Figure 5). The minimum light threshold for Z. marina was found to be above $20.12 \mu \mathrm{mol}$ photons $\mathrm{m}^{-2} \mathrm{~s}^{-1}$ with photophysiological responses and shoot growth being the first bioindicators to be adversely affected by light stress to this level within the first week. Morphological factors took longer to be affected by light stress; this response was observed between 29 and 39 days. EL plants experienced lowest light levels, but responses were not always as quickly exhibited as in LL or ML plants. This lag in response shows that previous condition, such as larger shoot surface area and rhizomal stores, will slow the effect of light limitation on morphological responses. However, shoot growth, alpha, $\mathrm{E}_{\mathrm{k}}$, and $\mathrm{ETR}_{\max }$ are rapidly effected by light limitation. Environmental monitoring of light levels within $Z$. marina meadows could allow managers to foresee potential risks if light is being attenuated to this level for prolonged periods of time. Using the robust bioindicators identified in this study specifically relevant to $Z$. marina can make it possible to assess whether light limitation has or is occurring. This study shows that light reduction to $20 \mu \mathrm{mol}$ photons $\mathrm{m}^{-2} \mathrm{~s}^{-1}$ or below for $10 \mathrm{~h}$ daily light period causes significant reductions in above ground tissues and photosynthetic performance leading to shoot mortality within 4-6 weeks, under experimental conditions. These results show what the impacts of a light stress event to this level over the time-frame of a few weeks can have on $Z$. marina and its implications at a meadow scale.

\section{AUTHOR CONTRIBUTIONS}

$\mathrm{CB}$ carried out the experiment and data collection. $\mathrm{CB}$ was responsible for the write-up of introduction, methods, results and discussion. RU supervised and advised CB on experimental design and write-up. RU edited and added text to manuscript throughout.

\section{ACKNOWLEDGMENTS}

I would like to thank Max Robinson for help with sample and data collection, and advice with writing R scripts; Mike Fowler for $\mathrm{R}$ tuition, and statistical advice; Prof Rory Wilson for supervision and support. Many thanks to Stuart Gibb and Jason McIlvenny from the University of Highlands and Islands; Richard Webster, Pippa Moore, and Nathan King from Aberystwyth for the kind loan of the Diving-PAM fluorometers for experimental trials, and Naomi Ginnever for advice on PAM fluorometry. In addition, many thanks to Skomer MNR team for allowing collection of samples to trial methods, and to Natural England and Marine Management Organisation for consenting to the collection of samples from Helford River for scientific research. This study was supported and made possible by the EU ERDF funded SEACAMS project. Also thanks to the reviewers who helped improve the article. 


\section{REFERENCES}

Abe, M., Hahimoto, N., Kurashima, A., and Maegwa, M. (2003). Estimation of light requirement for the growth of Zostera marina in central Japan. Fish. Sci. 69, 890-895. doi: 10.1046/j.1444-2906.2003.00704.x

Alcoverro, T., Zimmerman, R. C., Kohrs, D. G., and Alberte, R. S. (1999). Resource allocation and sucrose mobilization in light-limited eelgrass Zostera marina. Mar. Ecol. Prog. Ser. 187, 121-131. doi: 10.3354/meps187121

Backman, T. W., and Barilotti, D. C. (1976). Irradiance reduction: effects on standing crops of the eelgrass Zostera marina in a coastal lagoon. Mar. Biol. 34, 33-40. doi: 10.1007/BF00390785

Bartlett, M. S. (1937). Properties of sufficiency and statistical tests. Proc. R. Soc. Lond. A. Math. Phys. Sci. 160, 268-282. doi: 10.1098/rspa.1937.0109

Beer, S., Bjork, M., and Beardall, J. (2014). Photosynthesis in the Marine Environment. Oxford: John Wiley \& Sons, Ltd.

Beer, S., Bjork, M., Gademann, R., and Ralph, P. J. (2001). "Chlorophyll fluorescence as a measure of photosynthesis," in Global Seagrass Research Methods, eds F. T. Short and R. G. Coles (Amsterdam: Elsevier), 190-198.

Belshe, E. F., Durako, M. J., and Blum, J. E. (2007). Photosynthetic rapid light curves (RLC) of Thalassia testudinum exhibit diurnal variation. J. Exp. Mar. Biol. Ecol. 342, 253-268. doi: 10.1016/j.jembe.2006.10.056

Belshe, E. F., Durako, M. J., and Blum, J. E. (2008). Diurnal light curves and landscape-scale variation in photosynthetic characteristics of Thalassia testudinum in Florida Bay. Aquat. Bot. 89, 16-22. doi: 10.1016/j.aquabot.2008.01.007

Biber, P. D., Kenworthy, W. J., and Paerl, H. W. (2009). Experimental analysis of the response and recovery of Zostera marina (L.) and Halodule wrightii (Ascher.) to repeated light-limitation stress. J. Exp. Mar. Biol. Ecol. 369, 110-117. doi: 10.1016/j.jembe.2008.10.031

Biber, P. D., Paerl, H. W., Gallegos, C. L., Kenworthy, W. J., and Fonseca, M. S. (2005). "Evaluating indicators of seagrass stress to light," in Estuar. Indic., ed S. A. Bortone (Boca Raton, FL: CRC Press), 193-209. doi: $10.1201 / 9781420038187 . c h 13$

Bité, J. S., Campbell, S. J., McKenzie, L. J., and Coles, R. G. (2007). Chlorophyll fluorescence measures of seagrasses Halophila ovalis and Zostera capricorni reveal differences in response to experimental shading. Mar. Biol. 152, 405-414. doi: 10.1007/s00227-007-0700-6

Bulthuis, D. A. (1983). Effects of in situ light reduction on density and growth of the seagrass Heterozostera tasmanica (Martens ex Aschers.) den Hartog in Western Port, Victoria, Australia. J. Exp. Mar. Biol. Ecol. 67, 91-103.

Burke, M. K., Dennison, W. C., and Moore, K. A. (1996). Non-structural carbohydrate reserves of eelgrass Zostera marina. Mar. Ecol. Prog. Ser. 137, 195-201. doi: 10.3354/meps137195

Cairns, A. J., and Pollock, C. J. (1988). Fructan biosynthesis in excised leaves of Lolium temulentum L. New Phytol. 109, 399-405. doi: 10.1111/j.1469-8137.1988.tb03715.x

Campbell, S. J., and Miller, C. J. (2002). Shoot and abundance characteristics of the seagrass Heterozostera tasmanica in Westernport estuary (south-eastern Australia). Aquat. Bot. 73, 33-46. doi: 10.1016/S0304-3770(02)00002-5

Collier, C. J., Adams, M. P., Langlois, L., Waycott, M., O'Brien, K. R., Maxwell, P. S., et al. (2016). Thresholds for morphological response to light reduction for four tropical seagrass species. Ecol. Indic. 67, 358-366. doi: 10.1016/j.ecolind.2016.02.050

Collier, C. J., Lavery, P., Masini, R., and Ralph, P. (2007). Morphological, growth and meadow characteristics of the seagrass Posidonia sinuosa along a depthrelated gradient of light availability. Mar. Ecol. Prog. Ser. 337, 103-115. doi: $10.3354 /$ meps337103

Collier, C. J., Lavery, P. S., Ralph, P. J., and Masini, R. J. (2008). Shade-induced response and recovery of the seagrass Posidonia sinuosa. J. Exp. Mar. Biol. Ecol. 370, 89-103. doi: 10.1016/j.jembe.2008.12.003

Collier, C. J., Waycott, M., and McKenzie, L. J. (2012a). Light thresholds derived from seagrass loss in the coastal zone of the northern Great Barrier Reef, Australia. Ecol. Indic. 23, 211-219. doi: 10.1016/j.ecolind.2012.04.005

Collier, C. J., Waycott, M., and Ospina, A. G. (2012b). Responses of four IndoWest Pacific seagrass species to shading. Mar. Pollut. Bull. 65, 342-354. doi: 10.1016/j.marpolbul.2011.06.017

Dalla Via, J., Sturmbauer, C., Schönweger, G., Sötz, E., Mathekowitsch, S., Stifter, M., et al. (1998). Light gradients and meadow structure in Posidonia oceanica: ecomorphological and functional correlates. Mar. Ecol. Prog. Ser. 163, 267-278.

Dawes, C. J., and Guiry, M. D. (1992). Proximate constituents in the seagrasses Zostera marina and Z. noltii in Ireland: seasonal changes and the effect of blade removal. Mar. Ecol. 13, 307-315.

Dennison, W. C. (1990). "Chlorophyll content," in Seagrass Research Methods, eds R. C. Phillips and C. P. McRoy (Paris: United Nations Educational, Scientific and Cultural Organization (UNESCO)), 83-85.

Dennison, W. C., and Alberte, R. S. (1982). Photosynthetic responses of Zostera marina to in situ manipulations of light intensity. Oecologia 55, 137-144. doi: 10.1007/BF00384478

Dennison, W. C., and Alberte, R. S. (1985). Role of daily light period in the depth distribution of Zostera marina (eelgrass). Mar. Ecol. Prog. Ser. 25, 51-61. doi: 10.3354/meps025051

Dennison, W. C., Orth, R. J., Moore, K. A., Stevenson, J. C., Carter, V., Kollar, S. et al., (1993). Assessing water quality with submersed aquatic vegetation habitat requirements as barometers of Chesapeake Bay health. Bioscience 43, 86-94. doi: $10.2307 / 1311969$

Drake, L. A., Dobbs, F. C., and Zimmerman, R. C. (2003). Effects of epiphyte load on optical properties and photosynthetic potential of the seagrasses Thalassia testudinum Banks ex König and Zostera marina L. Limnol. Oceanogr. 48, 456-463. doi: 10.4319/lo.2003.48.1_part_2.0456

Durako, M. J., and Kunzelman, J. I. (2002). Photosynthetic characteristics of Thalassia testudinum measured in situ by pulse-amplitude modulated (PAM) fluorometry: methodological and scale-based considerations. Aquat. Bot. 73, 173-185. doi: 10.1016/S0304-3770(02)00020-7

Eilers, P. H. C., and Peeters, J. C. H. (1988). A model for the relationship between light intensity and the rate of photosynthesis in phytoplankton. Ecol. Modell. 42, 199-215. doi: 10.1016/0304-3800(88)90057-9

Erftemeijer, P. L. A., and Lewis, R. R. R. (2006). Environmental impacts of dredging on seagrasses: a review. Mar. Pollut. Bull. 52, 1553-1572. doi: 10.1016/j.marpolbul.2006.09.006

Foden, J., and Brazier, D. P. (2007). Angiosperms (seagrass) within the EU water framework directive: a UK perspective. Mar. Pollut. Bull. 55, 181-195. doi: 10.1016/j.marpolbul.2006.08.021

Fourqurean, J. W., Moore, T. O., Fry, B., and Hollibaugh, J. T. (1997). Spatial and temporal variation in C:N:P ratios, $\delta 15 \mathrm{~N}$ and $\delta 13 \mathrm{C}$ of eelgrass Zostera marina as indicators of ecosystem processes, Tomales Bay, California. Mar. Ecol. Prog. Ser. 157, 147-157. doi: 10.3354/meps157147

Fourqurean, J. W., and Zieman, J. C. (1991). Photosynthesis, respiration and whole plant carbon budget of the seagrass Thalassia testudinum. Mar. Ecol. Prog. Ser. 69, 161-170. doi: 10.3354/meps069161

Glass, G. V., Peckham, P. D., and Sanders, J. R. (1972). Consequences of failure to meet assumptions underlying the fixed effects analyses of variance and covariance. Rev. Educ. Res. 42, 237-288. doi: 10.3102/00346543042003237

Granger, S., and Izumi, H. (2001). "Water quality measurement methods for seagrass habitat," in Global Seagrass Research Methods, eds F. T. Short and R. G. Coles (Amsterdam: Elsevier Science, B.V.), 393-404.

Hemminga, M. A. (1998). The root/rhizome system of seagrasses: an asset and a burden. J. Sea Res. 39, 183-196. doi: 10.1016/S1385-1101(98)00004-5

Jackson, E. L., Griffiths, C. A., and Durkin, O. (2013). A Guide to Assessing and Managing Anthropogenic Impact on Marine Angiosperm Habitat - Part 1: Literature Review. Natural England Commissioned Reports Number 111.

Jiang, Z., Huang, X., and Zhang, J. (2013). Effect of nitrate enrichment and salinity reduction on the seagrass Thalassia hemprichii previously grown in low light. J. Exp. Mar. Biol. Ecol. 443, 114-122. doi: 10.1016/j.jembe.2013.02.034

Jones, B. L., and Unsworth, R. K. F. (2016). The perilous state of seagrass in the British Isles. R. Soc. Open Sci. 3:150596. doi: 10.1098/rsos.150596

Kenworthy, W. J., and Fonseca, M. S. (1996). Light requirements of seagrasses Halodule wrightii and Syringodium filiforme derived from the relationship between diffuse light attenuation and maximum depth distribution. Estuaries 19, 740-750. doi: 10.2307/1352533

Koch, E. W., and Beer, S. (1996). Tides, light and the distribution of Zostera marina in Long Island Sound USA. Aquat. Bot. 53, 97-107. doi: 10.1016/0304-3770(95)01015-7

Krause-jensen, D., Greve, T. M., and Nielsen, K. (2005). Eelgrass as a bioindicator under the European Water Framework Directive. Water Resour. Manag. 19, 63-75. doi: 10.1007/s11269-005-0293-0 
Lee, K.-S., Park, S. R., and Kim, Y. K. (2007). Effects of irradiance, temperature, and nutrients on growth dynamics of seagrasses: a review. J. Exp. Mar. Biol. Ecol. 350, 144-175. doi: 10.1016/j.jembe.2007.06.016

Lix, L. M., Keselman, J. C., and Keselman, H. J. (1996). Consequences of assumption violations revisited: a quantitative review of alternatives to the one-way analysis of variance F test. Rev. Educ. Res. 66, 579-619.

Longstaff, B., and Dennison, W. (1999). Seagrass survival during pulsed turbidity events: the effects of light deprivation on the seagrasses Halodule pinifolia and Halophila ovalis. Aquat. Bot. 65, 105-121. doi: 10.1016/S0304-3770(99)00035-2

Marbà, N., Krause-Jensen, D., Alcoverro, T., Birk, S., Pedersen, A., Neto, J. M. et al., (2013). Diversity of European seagrass indicators: patterns within and across regions. Hydrobiologia 704, 265-278. doi: 10.1007/s10750-012-1403-7

Maxwell, P. S., Ekl, J. S., Katwijk, M. M., and Van, B.rien, K.R.O. (2016). The fundamental role of ecological feedback mechanisms for the adaptive management of seagrass ecosystems - a review. Biol. Rev. 92, 1521-1538 doi: $10.1111 /$ brv.12294

McDonald, J. H. (2014). Handbook of Biological Statistics, 3rd Edn. Baltimore, MD: Sparky House Publishing.

McMahon, K., Collier, C. J., and Lavery, P. S. (2013). Identifying robust bioindicators of light stress in seagrasses: a meta-analysis. Ecol. Indic. 30, 7-15. doi: 10.1016/j.ecolind.2013.01.030

Moore, K. A., Wetzel, R. L., and Orth, R. J. (1997). Seasonal pulses of turbidity and their relations to eelgrass (Zostera marina L.) survival in an estuary. J. Exp. Mar. Biol. Ecol. 215, 115-134. doi: 10.1016/S0022-0981(96)02774-8

Ochieng, C. A., Short, F. T., and Walker, D. I. (2010). Photosynthetic and morphological responses of eelgrass (Zostera marina L.) to a gradient of light conditions. J. Exp. Mar. Biol. Ecol. 382, 117-124. doi: 10.1016/j.jembe.2009.11.007

Olesen, B., Enríquez, S., Duarte, C. M., and Sand-Jensen, K. (2002). Depthacclimation of photosynthesis, morphology and demography of Posidonia oceanica and Cymodocea nodosa in the Spanish Mediterranean Sea. Mar. Ecol. Prog. Ser. 236, 89-97. doi: 10.3354/meps236089

Olesen, B., and Sand-jensen, K. (1993). Seasonal acclimatization of eelgrass Zostera marina growth to light. Mar. Ecol. Prog. Ser. 94, 91-99. doi: 10.3354/meps094091

Orth, R. J., Carruthers, T. J. B., Dennison, W. C., Duarte, C. M., Fourqurean, J. W., Heck Jr, K. L., et al. (2006). A global crisis for seagrass ecosystems. Bioscience 56, 987-996. doi: 10.1641/0006-3568(2006)56[987:AGCFSE]2.0.CO;2

Ralph, P. J., Durako, M. J., Enríquez, S., Collier, C. J., and Doblin, M. A. (2007). Impact of light limitation on seagrasses. J. Exp. Mar. Biol. Ecol. 350, 176-193. doi: 10.1016/j.jembe.2007.06.017

Ralph, P. J., and Gademann, R. (2005). Rapid light curves: a powerful tool to assess photosynthetic activity. Aquat. Bot. 82, 222-237. doi: 10.1016/j.aquabot.2005.02.006

Saroussi, S., and Beer, S. (2007). Alpha and quantum yield of aquatic plants derived from PAM fluorometry: uses and misuses. Aquat. Bot. 86, 89-92. doi: 10.1016/j.aquabot.2006.09.003

Shafer, D. J. (1999). The effects of dock shading on the seagrass Halodule wrightii in Perdido Bay, Alabama. Estuaries 22, 936-943. doi: 10.2307/1353073

Shafer, D. J., and Kaldy, J. E. (2013). Comparison of photosynthetic characteristics of the seagrass congeners Zostera marina L. and Zostera japonica Ascher. \& Graeb. Aquat. Bot. 112, 91-97. doi: 10.1016/j.aquabot.2013.09.002

Sharon, Y., Silva, J., Santos, R., Runcie, J., Chernihovsky, M., and Beer, S. (2009). Photosynthetic responses of Halophila stipulacea to a light gradient. II. Acclimations following transplantation. Aquat. Biol. 7, 153-157. doi: $10.3354 / \mathrm{ab} 00148$
Short, F., and Duarte, C. M. (2001). "Methods for the measurement of seagrass growth and production," in Global Seagrass Research Methods, eds F. T. Short, and R. G. Coles (Amsterdam: Elsevier Science B.V.), 473.

Short, F. T., Burdick, D. M., and Kaldy, J. E. I. (1995). Mesocosm experiments quantify the effects of eutrophication on eelgrass, Zostera marina. Limnol. Oceanogr. 40, 740-749. doi: 10.4319/lo.1995.40.4.0740

Short, F. T., and Wyllie-Echeverria, S. (1996). Natural and humaninduced disturbance of seagrasses. Environ. Conserv. 23: 17. doi: $10.1017 / S 0376892900038212$

Silva, J., Barrote, I., Costa, M. M., Albano, S., and Santos, R. (2013). Physiological responses of Zostera marina and Cymodocea nodosa to light-limitation stress. PLoS ONE 8:e81058. doi: 10.1371/journal.pone.0081058

Soissons, L. M., Li, B., Han, Q., van Katwijk, M. M., Ysebaert, T., Herman, P. M. J., et al. (2016). Understanding seagrass resilience in temperate systems: the importance of timing of the disturbance. Ecol. Indic. 66, 190-198. doi: 10.1016/j.ecolind.2016.01.030

Thom, R. M., Southard, S. L., Borde, A. B., and Stoltz, P. (2008). Light requirements for growth and survival of eelgrass (Zostera marina L.) in Pacific northwest (USA) estuaries. Estuaries and Coasts 31, 969-980. doi: 10.1007/s12237-008-9082-3

Underwood, A. J. (1997). Experiments in Ecology: Their Logical Design and Interpretation Using Analysis of Variance. Stony Brook, NY: Cambridge University Press.

Unsworth, R. K. F., Collier, C. J., Waycott, M., Mckenzie, L. J., and Cullenunsworth, L. C. (2015). A framework for the resilience of seagrass ecosystems. Mar. Pollut. Bull. 100, 34-46. doi: 10.1016/j.marpolbul.2015.08.016

van der Heide, T., van Nes, E. H., Geerling, G. W., Smolders, A. J. P., Bouma, T. J., and van Katwijk, M. M. (2007). Positive feedbacks in seagrass ecosystems: implications for success in conservation and restoration. Ecosystems (N. Y.). 10, 1311-1322. doi: 10.1007/s10021-007-9099-7

van der Heide, T., van Nes, E. H., van Katwijk, M. M., Olff, H., and Smolders, A. J. P. (2011). Positive feedbacks in seagrass ecosystems - evidence from large-scale empirical data. PLoS ONE 6:e16504. doi: 10.1371/journal.pone.0016504

Yaakub, S. M., Chen, E., Bouma, T. J., Erftemeijer, P. L. A., and Todd, P. A. (2013). Chronic light reduction reduces overall resilience to additional shading stress in the seagrass Halophila ovalis. Mar. Pollut. Bull. 83, 467-474. doi: 10.1016/j.marpolbul.2013.11.030.

Zimmerman, R. C., Kohrs, D. G., and Alberte, R. S. (1996). Top-down impact through a bottom-up mechanism: the effect of limpet grazing on growth, productivity and carbon allocation of Zostera marina L. (eelgrass). Oecologia 107, 560-567. doi: 10.1007/BF00333949

Zimmerman, R. C., Reguzzonp, J. L., and Alberte, R. S. (1995). Eelgrass (Zostera marina L.) transplants in San Francisco Bay : role of light availability on metabolism, growth and survival. Aquat. Bot. 51, 67-86. doi: 10.1016/0304-3770(95)00472-C

Conflict of Interest Statement: The authors declare that the research was conducted in the absence of any commercial or financial relationships that could be construed as a potential conflict of interest.

Copyright $\odot 2018$ Bertelli and Unsworth. This is an open-access article distributed under the terms of the Creative Commons Attribution License (CC BY). The use, distribution or reproduction in other forums is permitted, provided the original author(s) and the copyright owner are credited and that the original publication in this journal is cited, in accordance with accepted academic practice. No use, distribution or reproduction is permitted which does not comply with these terms. 


\section{OPEN ACCESS}

Edited by:

Mark A. Elgar,

The University of Melbourne, Australia

Reviewed by:

Joseph Daniel Husband,

Florida State College at Jacksonville

United States

Martin Wiggers Skov,

Bangor University, United Kingdom

*Correspondence:

Jonathan Richir jonathan.richir@uliege.be

Alberto V. Borges

alberto.borges@uliege.be

tThese authors have contributed equally to this work

¥ORCID:

Jonathan Richir orcid.org/0000-0001-5890-5724

Willy Champenois orcid.org/0000-0002-4678-175X

Arnaud Abadie

orcid.org/0000-0003-2704-8680

Sylvie Gobert

orcid.org/0000-0001-6000-0190

Gilles Lepoint

orcid.org/0000-0003-4375-0357

João Silva

orcid.org/0000-0002-7211-1661

Rui Santos

orcid.org/0000-0002-7861-4366

Damien Sirjacobs

orcid.org/0000-0002-1770-2063

Alberto V. Borges

orcid.org/0000-0002-5434-2247

Specialty section:

This article was submitted to

Conservation,

a section of the journa

Frontiers in Ecology and Evolution

Received: 17 January 2019

Accepted: 16 December 2019

Published: 31 January 2020

\section{A 15-Month Survey of Dimethylsulfoniopropionate and Dimethylsulfoxide Content in Posidonia oceanica}

\author{
Jonathan Richir ${ }^{1,2 * \neq \neq}$, Willy Champenois ${ }^{1+\neq}$, Guyliann Engels ${ }^{1,3+}$, Arnaud Abadie ${ }^{2,4 \neq}$, \\ Sylvie Gobert ${ }^{2,5 \neq}$, Gilles Lepoint ${ }^{2 \ddagger}$, João Silva ${ }^{6 \neq}$, Rui Santos ${ }^{6 \neq}$, Damien Sirjacobs ${ }^{7 \ddagger}$ and \\ Alberto V. Borges ${ }^{1 * t}$ \\ ${ }^{1}$ Chemical Oceanography Unit, FOCUS, University of Liège, Liège, Belgium, ${ }^{2}$ Laboratory of Oceanology, FOCUS, University \\ of Liège, Liège, Belgium, ${ }^{3}$ Econum, COMPLEXYS Institute, University of Mons, Mons, Belgium, ${ }^{4}$ Seaviews, La Ciotat, \\ France, ${ }^{5}$ STAtion de REcherches Sous-marines et Océanographiques (STARESO), Calvi, France, ${ }^{6}$ Center of Marine \\ Sciences of Algarve, University of Algarve, Faro, Portugal, ${ }^{7}$ Eukaryotic Phylogenomics, InBioS-PhytoSYSTEMS, University of \\ Liège, Liège, Belgium
}

Posidonia oceanica is the only reported seagrass to produce significant amount of dimethylsulfoniopropionate (DMSP). It is also the largest known producer of DMSP among coastal and inter-tidal higher plants. Here, we studied (i) the weekly to seasonal variability and the depth variability of DMSP and its related compound dimethylsulfoxide (DMSO) in P. oceanica leaves of a non-disturbed meadow in Corsica, France, (ii) the weekly to seasonal variability and the depth variability of DMSP to DMSO concentration to assess the potential of the DMSP:DMSO ratio as indicator of stress, and (iii) the relationships between DMSP, DMSO, and the DMSP:DMSO ratio with potential explanatory variables such as light, temperature, photosynthetic activity (effective quantum yield of photosystem II), and leaf size. The overall average concentrations of organosulfured compounds in $P$. oceanica leaves were $130 \pm 39 \mu \mathrm{mol}_{\mathrm{ffw}}^{-1}$ for DMSP and $4.9 \pm 2.1 \mu \mathrm{mol} . \mathrm{g}_{\mathrm{fw}}^{-1}$ for DMSO. Concentrations of DMSP and DMSO in P. oceanica were overall distinctly higher and exhibited a wider range of variations than other marine primary producers such as Spartina alterniflora, phytoplankton communities, epilithic Cyanobacteria and macroalgae. Concentrations of both DMSP and DMSO in P. oceanica leaves decreased from a maximum in autumn to a minimum in summer; they changed little with depth. Potential explanatory variables except the leaf size, i.e., the leaf age were little or not related to measured concentrations. To explain the seasonal pattern of decreasing concentrations with leaf aging, we hypothesized two putative protection functions of DMSP in young leaves: antioxidant against reactive oxygen species and predator-deterrent. The similar variation of the two molecule concentrations over time and with depth suggested that DMSO content in $P$. oceanica leaves results from oxidation of DMSP. The DMSP:DMSO ratio remained constant around a mean value of $29.2 \pm 9.0$ $\mu \mathrm{mol}: \mu \mathrm{mol}$ for the non-disturbed harvested meadow regardless of the time of the year, the depth or the leaf size. As suggested for the salt march plant S. alterniflora, 
we hypothesized the DMSP:DMSO ratio could be considered as indicator of stress in seagrasses exposed to environmental or anthropogenic stressors. More research would now be needed to confirm the functions of DMSP and DMSO in seagrasses and how the DMSP:DMSO ratio will vary under various disturbances.

Keywords: Posidonia oceanica, seagrass, organosulfured compounds, dimethylsulfoniopropionate (DMSP), dimethylsulfoxide (DMSO), DMSP:DMSO ratio, ecology, physiology

\section{INTRODUCTION}

The synthesis and metabolism of dimethylsulfoniopropionate (DMSP) has been studied for 70 years (Challenger and Simpson, 1948). DMSP and related sulfonium compounds dimethyl sulfide (DMS) and dimethylsulfoxide (DMSO) constitute an integral part of the marine sulfur cycle and play an important role in the global sulfur budget (Stefels et al., 2007; Asher et al., 2017). DMS, via transfer from the ocean to the atmosphere, could have a cooling effect on climate and could help to compensate for warming from "greenhouse effect" (Lovelock and Maggs, 1972; Charlson et al., 1987). Although this climatic role has been found to be much more complex than originally thought (Quinn and Bates, 2011), it nevertheless explains the interest of research on the production and fate of these organosulfured compounds in the marine environment.

Among the terrestrial and coastal magnoliophytes studied for DMSP production, only few poaceae and asteraceae have a high DMSP content, e.g., Spartina anglica C.E. Hubbard, 1978 (Van Diggelen et al., 1986) and Spartina alterniflora Loisel (Dacey et al., 1994), Saccharum officinarum L., 1753 (Paquet et al., 1994), and Wollastonia biflora (L.) DC., 1836 (Hanson et al., 1994). Recently, Borges and Champenois (2015) added the seagrass Posidonia oceanica (Linnaeus) Delile, 1813 to this short list. This seagrass is endemic to the Mediterranean Sea and forms dense monospecific meadows from the surface to depths of 40$48 \mathrm{~m}$ (Boudouresque and Meinesz, 1982; Gobert et al., 2006; Boudouresque et al., 2012). P. oceanica beds are major coastal ecosystems (Gobert et al., 2006; Boudouresque et al., 2012), highly productive (Champenois and Borges, 2019b), provide many goods and services (Campagne et al., 2015; Mtwana Nordlund et al., 2016) and have considerable environmental, financial, and heritage value (Vassallo et al., 2013; Campagne et al., 2015).

To our best knowledge only one previous study investigated the occurrence of DMSP in seagrass species other than $P$. oceanica (Dacey et al., 1994). In this study, the DMSP content in the epiphytized leaves of the three seagrasses Halodule wrightii Ascherson, 1868, Syringodium filiforme Kützing, 1860, and Thalassia testudinum K.D. Koenig, 1805 was mostly attributed to their epiphytes (Dacey et al., 1994). Recently, Borges and Champenois $(2015,2017)$ analyzed P. oceanica leaf segments non-epiphytized or carefully cleaned of their epiphytes prior DMSP analysis. In addition epiphyte flora growing on $P$. oceanica leaves is dominated by red coralline algae (Jacquemart and Demoulin, 2006; Piazzi et al., 2016) that have a very low DMSP content of below $0.1 \mu$ mol.g $\mathrm{f}_{\mathrm{fw}}^{-1}$ (Kamenos et al., 2008). For these reasons, it is obvious that DMSP measured in P. oceanica material came from the plant itself. Borges and Champenois (2015) reported depth and seasonal variability of the DMSP content in $P$. oceanica leaves, suggesting a relationship with irradiance. Because these authors followed the sample preparation protocol used in the vast majority of DMSP-related studies dealing with macroalgae, i.e., performing measurements on oven-dried samples, their work and similar are not quantitative. Indeed, most DMSP is lost and/or transformed into DMSO because of the drying treatment, and fresh or frozen tissues of $P$. oceanica have a DMSP content orders of magnitude higher (Borges and Champenois, 2017). Consequently, there is a need to investigate again depth and seasonal variations of DMSP content in $P$. oceanica tissues.

DMSP plays physiological roles in marine autotrophs that has stimulated numerous studies on its production, especially on marine phytoplankton (Challenger and Simpson, 1948; Stefels et al., 2007; Bullock et al., 2017). Briefly, DMSP may act as osmolyte, cryoprotectant, antioxidant, predator deterrent, antibiotic, and overflow metabolite for carbon and nitrogen (reviews in: Otte et al., 2004; Stefels et al., 2007; Van Alstyne, 2008). These functions like, e.g., the role of antioxidant in $S$. alterniflora (Husband and Kiene, 2007; Husband et al., 2012), remain often hypothetical and still require testing. Coastal higher plants further have to deal with toxic sediment-reduced sulfur (Zheng et al., 2017; Apostolaki et al., 2018) and are colonized by epiphytes (Jackson et al., 2006; Piazzi et al., 2016). In Spartina spp., the production of DMSP could allow the plant to excrete excess sulfur (Van Diggelen et al., 1986; Otte and Morris, 1994). DMSP production as an overflow mechanism for excess reduced sulfur and for excess energy was also hypothesized by Stefels (2000) in microalgae. Regarding an hypothetical role of antifouling agent, it seems ruled out from experimental observations in S. alterniflora (Jackson and Stuckey, 2007), but was reported in the brown algae Fucus vesiculosus Linnaeus, 1753 against bacterial attachment (Saha et al., 2012). Studies are to date still too few to fully elucidate the roles DMSP and its related compounds effectively play, in particular in coastal higher plants.

DMSO is present in phytoplankton (Simó and Vila-Costa, 2006) and in intertidal salt marsh plants of the genus Spartina (Husband et al., 2012; McFarlin and Alber, 2013). DMSO is also present in the seagrass $P$. oceanica, as reported in the protocol papers of Borges and Champenois (2017) and Champenois and Borges (2019a). In comparison to DMSP and DMS, DMSO has received less attention (Lee et al., 1999) because of the later discovery of particulate DMSO in the late 90s (Simó et al., 1998) and its importance for the sulfur cycle (Green and Hatton, 2014). DMSO is formed through photochemical oxidation of DMS in seawater (Brimblecombe and Shooter, 1986) and through 
biological oxidation of DMS(P) in cells (Zhang et al., 1991; Simó and Vila-Costa, 2006). The reasons why DMSO is biosynthesized by phytoplankton remain unresolved. Similar to DMSP, DMSO could act as a cryoprotectant, a free-radical scavenger and an osmoregulator (Lee and de Mora, 1999).

The significant correlation between DMSO and DMSP frequently observed in marine phytoplankton indicates that the production of DMSO is closely related to DMSP production (Simó and Vila-Costa, 2006; Hatton and Wilson, 2007). From field (Simó and Vila-Costa, 2006) and experimental (Simó et al., 1998) observations of DMSO and DMSP kinetics in phytoplankton, Simó and Vila-Costa (2006) suggested the ratio of their concentrations would be a rather good indicator for oxidative stress caused by, e.g., nutrient exhaustion and light. Studies on S. alterniflora have further argued the usefulness of this ratio as generic indicator of physiological stress: tissue senescence (Husband and Kiene, 2007) and sudden dieback (McFarlin and Alber, 2013), chemical stress: herbicides (Husband et al., 2012), and mechanical stress: wrack deposition and herbivory (McFarlin and Alber, 2013).

DMSP and its relatives are compounds that clearly deserve attention in higher plants. This consideration, discussed 15 years ago by Otte et al. (2004), is still relevant today. The study of DMSP and DMSO in seagrasses is at its very beginning, the little we currently know being to some extent biased methodologically (DMSP analysis in leaf-epiphyte complex or dried samples; Dacey et al., 1994; Borges and Champenois, 2015). In order to deepen our knowledge on the ecology of these organosulfured compounds in $P$. oceanica, we investigated (i) the weekly to seasonal variability and the depth variability of DMSP and DMSO in $P$. oceanica leaves, (ii) the weekly to seasonal variability and the depth variability of DMSP to DMSO concentration to assess the potential of the DMSP:DMSO ratio as indicator of stress, and (iii) the relationships between DMSP, DMSO, and the DMSP:DMSO ratio with potential explanatory variables such as light, temperature, photosynthetic activity (effective quantum yield of photosystem II), and leaf size. To reach these objectives, we monitored during 15 months the DMSP and DMSO content in $P$. oceanica leaves of a non-disturbed meadow in Corsica, France, in the framework of the STARECAPMED program (Richir et al., 2015).

\section{MATERIALS AND METHODS}

\section{Study Site and Environmental Parameters}

The study was conducted between April 2015 and July 2016 in a dense and healthy $P$. oceanica meadow in the northwestern part of the Revellata Bay in the Gulf of Calvi (Corsica, France; Norie, 1831), close to the STARESO research station $\left(42.580^{\circ} \mathrm{N}\right.$, $8.725^{\circ} \mathrm{E}$ ). The Gulf of Calvi has an area of about $22 \mathrm{~km}^{2}$, opens to the Ligurian Sea on the northeast with a border of about $6 \mathrm{~km}$ and connects to the deep sea by a canyon. STARESO, with a direct access to the sea, boats and diving facilities enables high-frequency scientific observations in all areas of oceanographic research. The Gulf of Calvi is a "reference site" in a very good state of environmental conservation (Gobert et al., 2009; Lopez y Royo et al., 2010, 2011). The sea level to about $38 \mathrm{~m}$ depth benthic ecosystem is dominated by a dense and healthy $P$. oceanica meadow. The four other main benthic communities in the Gulf are shallow rocky substrates covered by photophilic macroalgae, bare coarse sand, Cymodocea nodosa (Ucria) Ascherson, 1870 meadows and heterogeneous muddy sand rich in debris of $P$. oceanica leaves, with sciaphilic macroalgae down to $100 \mathrm{~m}$ depth (Bay, 1984; Champenois and Borges, 2012; Richir et al., 2015). The study site in the present work was identical to that of Borges and Champenois (2015, 2017).

Water temperature and light intensity are parameters recorded continuously by STARESO with probes and loggers deployed in the water column and the $P$. oceanica meadow facing the research station, i.e., where the survey was conducted. The collected environmental data was made accessible via the shared database RACE (Binard, 2017). Photosynthetically active radiation (PAR, $\mu \mathrm{mol}$ photons. $\mathrm{m}^{-2} \cdot \mathrm{s}^{-1}$ ) was recorded (10 or $20 \mathrm{~min}$ interval) at a depth of $10 \mathrm{~m}$ just above the seagrass meadow canopy with an Odyssey logger (Odyssey Submersible Photosynthetic Active Radiation Logger, Dataflow Systems Ltd). The Odyssey logger was calibrated in the air against a LICOR LI190 quantum sensor (LI-COR Inc.). Temperature $\left({ }^{\circ} \mathrm{C}\right)$ and light intensity (lux, cd.sr. ${ }^{-2}$ ) were recorded (10 or 20 min interval) along the depth gradient of distribution of $P$. oceanica, i.e., from the sea level to $36 \mathrm{~m}$ depth, with Hobo loggers (HOBO Pendant ${ }^{\circledR}$ Temperature/Light Data Logger, Onset Computer Corporation). Five Hobo loggers were deployed along the depth transect at 1,8, 18,27 , and $34 \mathrm{~m}$ depth just above the seagrass bed to record light intensity that reached the meadow canopy. Five supplementary Hobo loggers were deployed along the depth transect at 3, 10, 20,29 , and $36 \mathrm{~m}$ depth at the water column-sediment interface to record water temperature within the meadow canopy (and light absorption by the meadow canopy).

Measurements of $P$. oceanica leaf photosynthetic activity and seagrass sampling were performed around midday between 10:25 and 13:33 (Universal Time; see below section Photosynthetic Activity and Sample Collection). Only the temperature and light data corresponding to this 3 -h time window were selected for analysis.

\section{Photosynthetic Activity and Sample Collection}

Measurements of $P$. oceanica leaf photosynthetic activity and seagrass sampling for subsequent biometry and DMSP and DMSO analysis were performed by scuba dives at $10 \mathrm{~m}$ depth at a weekly to fortnightly frequency between April 15, 2015 and July 11, 2016. Between June 23, 2015 and July 13, 2015, measurements of leaf photosynthetic activity and seagrass sampling were additionally performed by scuba dives along the depth transect at $3,10,15,20,25,29$, and $36 \mathrm{~m}$ depth (no leaf sampling for biometry at 15 and $25 \mathrm{~m}$ depth). Measurements of leaf photosynthetic activity and seagrass sampling were performed on orthotropic shoots (i.e., vertical growth, as opposite to plagiotropic-horizontalgrowth; Boudouresque et al., 2012) randomly sampled on a few $\mathrm{m}^{2}$ surfaces. 
During each dive, the chlorophyll fluorescence effective quantum yield of photosystem II (Yield of PSII, or ФPSII) of six $P$. oceanica shoots was recorded using an underwater fluorometer (DIVING-PAM, Heinz Walz GmbH). ФPSII is a measure of the effective photochemical efficiency of the plant, in the conditions of light and temperature at the time of measurement (Silva et al., 2009; Murchie and Lawson, 2013). To obtain reliable and comparable data, the protocol was standardized. The measurement of $\Phi P S I I$ was performed on the convex middle part of the third internal leaf from the inside of the leaf bundle [juveniles leaves $-<5 \mathrm{~cm}$ long (Giraud, 1979)—excluded], around midday, during cloud free and calm weather days. The measurement of $\Phi$ PSII was made on leaves in their natural position in the water column, i.e., at the vertical (measurements are indeed often performed with leaves maintained horizontally, which exposes them de facto to higher light intensities). PAR at half height of the meadow canopy was recorded concomitantly to leaf $\Phi$ PSII in the same vertical position with the Fiber Quantum Sensor DIVING-LI of the DIVING-PAM. The calibration of the DIVING-LI was checked in the air before each dive against a LICOR LI-190 quantum sensor. PAR was recorded close to the spot of the sample where fluorescence was recorded using the Universal Sample Holder DIVING-USH.

Of the six leaves analyzed for $\Phi$ PSII during each dive, three were sampled for DMSP and DMSO analysis. Sampling was performed by cutting the leaf just above the meristem area with a scissor to ensure its post-regrowth (De los Santos et al., 2016). Six supplementary $P$. oceanica complete leaf bundles were sampled with the same method for shoot biometry analysis (concomitantly to sampling for DMSP and DMSO analysis). Leaf bundles were clipped with plastic tongs prior cutting to keep the insertion order of the leaves. Sampled third leaves and leaf bundles were brought back to the STARESO facility in opaque plastic bags.

Quickly after the end of the dive, the first 20 photosynthetic $\mathrm{cm}$ from the base of $P$. oceanica third leaves (i.e., first little pigmented cm excluded) sampled for DMSP and DMSO analysis were dissected, then prepared and stored according to the protocol of Borges and Champenois (2017). Briefly, dissected leaf fragments were cleaned of their epiphytes (when present) with a razor blade (Dauby and Poulicek, 1995), conditioned individually in $20 \mathrm{ml}$ glass vials sealed with polytetrafluoroethylene coated silicone septa stopper and frozen at $-20^{\circ} \mathrm{C}$ until DMSP and DMSO analysis. P. oceanica leaf bundles clipped with plastic tongs were stored individually in plastic bags and frozen at $-20^{\circ} \mathrm{C}$ until biometry measurements. Samples were brought back frozen to the home laboratory in Belgium to avoid DMSP loss during transport (Borges and Champenois, 2017). Samples stored in the home laboratory at $-20^{\circ} \mathrm{C}$ were then analyzed for DMSP and DMSO (see section DMSP and DMSO Analysis) and for biometry according to the method of Giraud (1979) for measuring and counting foliar structures of $P$. oceanica. The third leaf foliar surface $\left(\mathrm{cm}^{2}\right)$ was calculated as: leaf length $\mathrm{x}$ leaf width; the leaf bundle foliar surface was calculated as: (the sum of the lengths of intermediate leaves $\mathrm{x}$ mean width of intermediate leaves) + (the sum of the lengths of adult leaves $\mathrm{x}$ mean width of adult leaves).

In addition to $P$. oceanica sampling and for comparison purpose of DMSP and DMSO analysis between benthic primary producers of the Revellata Bay, 29 species of epilithic Cyanobacteria and macroalgae (Ochrophyta, Chlorophyta, and Rhodophyta) were collected by snorkel dives between surface and $8 \mathrm{~m}$ depth in May 2016 along the shore close to the STARESO research station. Quickly after the end of the dive, the samples were rinsed with running seawater in the STARESO facility, stored in $50 \mathrm{ml}$ polyethylene bottles and kept frozen (storage, transport; Borges and Champenois, 2017) until analysis. Variable amounts of algae biomass (depending on the expected DMSP content based on literature values) were processed for DMSP and DMSO content (three replicates by species-specific pool sample) in a similar fashion as for P. oceanica leaves (see section DMSP and DMSO Analysis).

\section{DMSP and DMSO Analysis}

$P$. oceanica third leaves sampled for DMSP and DMSO analysis were unfrozen, gently dried of water droplets on absorptive paper and cut in $3 \mathrm{~mm}^{2}$ square fragments. About $20 \mathrm{mg}$ of fresh leaf fragments were put in three different pre-weighted $20 \mathrm{ml}$ glass vials for analysis (three pseudoreplicates by leaf, three leaves by sampling; Borges and Champenois, 2017). DMSP and DMSO concentrations were measured after conversion into DMS with the headspace technique with a gas chromatograph (GC) with a flame photometric detector (FPD) (Agilent 7890A, Agilent Technologies Inc.) according to the method of Champenois and Borges (2019a). In brief, the method consists first in digesting $P$. oceanica leaf fragments in their $20 \mathrm{ml}$ closed vials with $\mathrm{NaOH}$ (6M). In the presence of $\mathrm{NaOH}, \mathrm{DMSP}$ cleaves quantitatively into DMS and acrylate. The DMS in the vial headspace is measured by GC-FPD. The $\mathrm{NaOH}$ digestate is then bubbled with ambient air to evacuate the DMS and acidified with $\mathrm{HCl}$. The DMSO present in the digestate is then reduced by $\mathrm{TiCl}_{3}$ in $\mathrm{DMS}$. The DMS in the vial headspace is again measured by GC-FPD. The GC-FPD peaks of DMS are finally converted into DMSP and DMSO concentrations from a series of standards of known concentrations treated in the same way and at the same time as the samples. Sample DMSP and DMSO concentrations are given in $\mu$ mol per $g$ of leaf fresh weight $\left(\mu \mathrm{mol} \cdot \mathrm{g}_{\mathrm{fw}}^{-1}\right)$. The ratio of DMSP to DMSO concentration was further computed.

\section{Statistical Analysis}

The study had two datasets to analyze: (i) a 15-month time series dataset from a fixed depth $(10 \mathrm{~m})$ and (ii) a depth gradient dataset $(3-36 \mathrm{~m})$ of variation in environmental (temperature, light) and biological ( $\Phi$ PSII, foliar surfaces, DMSP and DMSO concentrations, DMSP:DMSO ratio) observations. The statistical analysis of the two datasets was performed in RStudio version 1.1.383 (RStudio Team., 2016). The significance level alpha was set to $1 \%$ to reduce Type I error.

Regarding the 15-month survey dataset (see Supplementary Material Table 1), cross-validated smoothing cubic splines (Pope and Gadh, 1988) were fitted to the mean 
PAR and mean $\Phi P S I I$ recorded with the DIVING-PAM. Crossvalidated smoothing cubic splines were also fitted to $P$. oceanica third leaf and shoot mean foliar surfaces, and to P. oceanica third leaf mean DMSP concentration, mean DMSO concentration, and mean DMSP:DMSO ratio. DMSP and DMSO concentrations, and to a lesser extend the DMSP:DMSO ratio showed breaks during their seasonal evolution at $10 \mathrm{~m}$ depth in late summer and autumn. In $P$. oceanica, the fall of senescent adult leaves is not a continuous process, most remaining in position until being torn off by autumnal storms (Wittmann, 1984). The potential effect of this non-continuous leaf renewal cycle on the dynamics of leaf DMSP and DMSO concentrations and their ratio was identified using segmented linear regression analysis (Muggeo, 2003; Toms and Lesperance, 2003). This semi parametric procedure is useful for assessing if the relationships between explanatory and response variables can be divided into more intervals. Identified linear segments were tested for model assumptions.

Regarding the depth transect performed between June 23, 2015 and July 13, 2015 (see Supplementary Material Table 2), it included four samplings at $10 \mathrm{~m}$ depth (data shared between both the 15-month survey and the depth gradient datasets) and one sampling at, respectively, 3, 15, 20, 25, 29, and $36 \mathrm{~m}$ depth. The four samplings at $10 \mathrm{~m}$ depth were compared for $P$. oceanica biological parameters using one-way ANOVA after testing for assumptions. Because none of the parameters displayed differences at $10 \mathrm{~m}$ depth over the 3 weeks of the depth gradient sampling (results not shown), we could consider that depths were comparable over this short period. Depths were compared for $P$. oceanica biological parameters using oneway ANOVAs after testing for assumptions, followed by Tukey's multiple comparison test of means.

Relationships between response variables: DMSP and DMSO concentrations and the DMSP:DMSO ratio and potential explanatory biological ( $\Phi$ PSII and third leaf foliar surface) and environmental (light and temperature) variables were explored using Spearman's rank correlation coefficient (Pearson, 2001; Schober et al., 2018) and analyzed using Generalized Linear Model (GLM, with gaussian distribution and identity link function; McCullagh and Nedler, 1989). The interpretation of the meaning of the Spearman's rank correlation coefficients was from Fowler and Cohen (1990). From correlation and GLM analyses results (coefficient $p$-values), we modeled linear relationships between $P$. oceanica third leaf foliar surface and third leaf DMSP concentration, DMSO concentration and DMSP:DMSO ratio, for $10 \mathrm{~m}$ depth data. We further modeled the linear relationship between $P$. oceanica third leaf DMSP and DMSO concentrations for all $10 \mathrm{~m}$ depth survey and depth gradient data, after removing from this global dataset two influential observations measured by Cook's distance (Cook, 1977). GLMs and linear regressions were checked for model assumptions.

\section{RESULTS}

\section{Environmental Parameters}

PAR and temperature at $10 \mathrm{~m}$ depth followed a classic annual sinusoidal cycle (Figure 1A), with about 2-month time lag between seasonal extrema of the two parameters. Summer

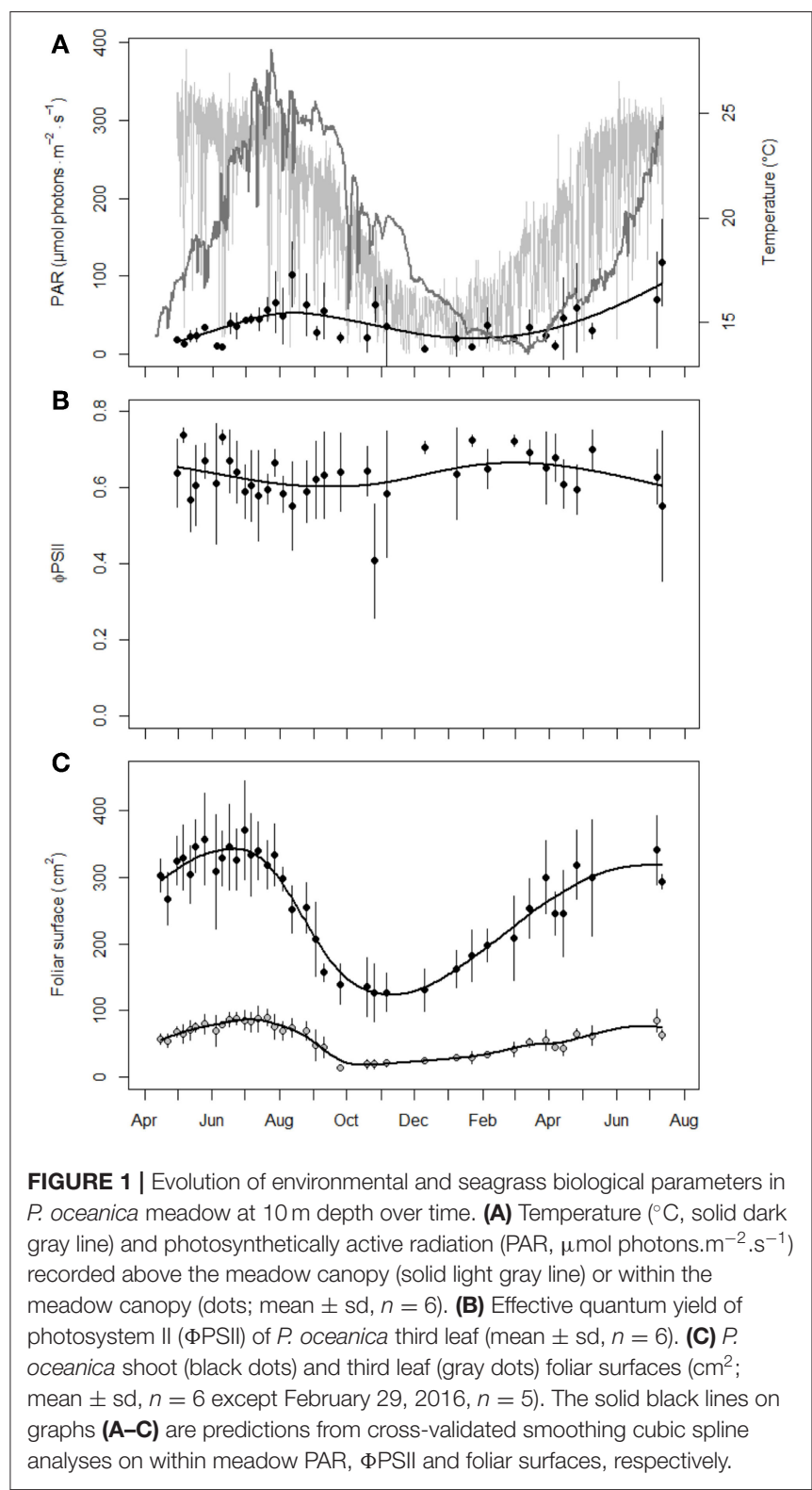

and winter water temperatures were, on average, about $1.2^{\circ} \mathrm{C}$ higher than their respective climatological seasonal mean values averaged over the 1981-2018 period (unpubl. data). The autumnwinter period of the survey was further characterized by a low occurrence of storms (Champenois and Borges, 2019b). The low predicted values of the PAR profile within the meadow canopy resulted from their measurement vertical to the surface and the shading effect of the dense seagrass meadow (Figure 1A). PAR within the meadow canopy peaked with time lag late summer, during the period of large $P$. oceanica leaf decay.

The average lux over the 3 -week sampling period along the depth transect decreased exponentially with depth while the average temperature decreased linearly with depth (results of models not shown; Figure 2A). The more marked decrease 


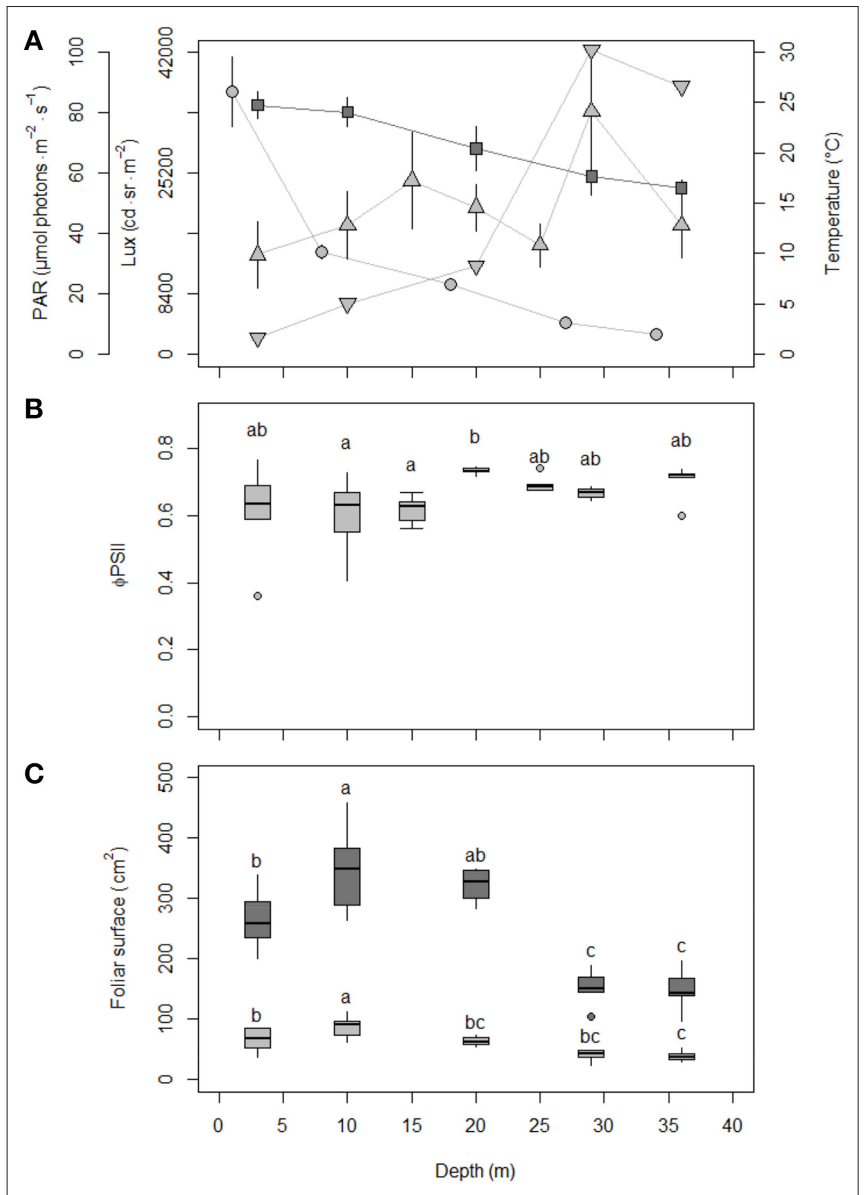

FIGURE 2 | Evolution of environmental and seagrass biological parameters in P. oceanica meadow along the $3-36 \mathrm{~m}$ depth transect. (A) Temperature $\left({ }^{\circ} \mathrm{C}\right.$; dark gray squares; mean $\pm \mathrm{sd}, n=23$ ) and light recorded above the meadow canopy (lux, cd.sr.m ${ }^{-2}$; light gray dots; mean $\pm \mathrm{sd}, n=23$ ) or within the meadow canopy (photosynthetically active radiation (PAR), $\mu \mathrm{mol}$ photons. $\mathrm{m}^{-2} \cdot \mathrm{s}^{-1}$; light gray triangles; $n=6$ at all depths except $10 \mathrm{~m}, n=$ 24). For comparison purpose between depths, mean PAR recorded during dives were normalized by mean lux of corresponding days (flipped light gray triangles, no scale). (B) Boxplot of the effective quantum yield of photosystem II (ФPSII) of $P$. oceanica third leaf. (C) Boxplot of $P$. oceanica shoot (dark gray) and third leaf (light gray) foliar surfaces $\left(\mathrm{cm}^{2}\right)$. Letters on boxplots $(\mathbf{B}, \mathbf{C})$ represent significant differences (one-way ANOVA and Tukey test) in mean $\Phi P S I I$ or mean foliar surfaces between depths, respectively ( $n=6$ at all depths except $10 \mathrm{~m}, n=24$ ).

in temperature below $10 \mathrm{~m}$ depth indicated the progressive installation of the summer thermocline. The random pattern of the PAR profile recorded during sampling scuba dives within the meadow canopy illustrated the day-to-day irradiance variability during the 3-week depth gradient survey (Figure 2A). After normalization of mean PAR within the canopy by mean lux of corresponding days above the canopy, a more structured profile of increase of light in the meadow canopy with depth was obvious. The most consistent increase between 20 and $29 \mathrm{~m}$ depth resulted from the net reduction of $P$. oceanica shoot density and biomass (Gobert et al., 2003), which de facto decreased shading in the meadow canopy at depths where light becomes limiting.

\section{Effective Quantum Yield of Photosystem II and Biometry}

$P$. oceanica third leaf $\Phi$ PSII measured at $10 \mathrm{~m}$ depth showed inter-shoot and inter-date variability (Figure 1B). Globally, $\Phi P S I I$ decreased from late winter to late summer, for an average general value of $0.63 \pm 0.06$ over the survey period. $P$. oceanica third leaf $\Phi P S I I$ changed little with depth (Figure 2B). Mean $\Phi P S I I$ along the $3-36 \mathrm{~m}$ depth gradient was $0.66 \pm 0.05$, i.e., a value close to the mean annual one of $0.63 \pm 0.06$ at $10 \mathrm{~m}$ depth. Globally, ФPSII showed lower mean values at lower 3-15 m depths.

$P$. oceanica shoot and third leaf foliar surfaces displayed at $10 \mathrm{~m}$ depth the same classic annual cycle, with summer maxima and autumn minima after the massive decay of senescent and necrotic adult leaves and the renewing of leaf bundles before winter (Figure 1C). Foliar surfaces along the $3-36 \mathrm{~m}$ depth gradient were maximal at $10 \mathrm{~m}$ depth, decreased close to the surface and with depth and were minimal at $36 \mathrm{~m}$ depth (Figure 2C), i.e., at the lower limit of the meadow with the lowest access to light. The highest Spearman's rank correlation coefficient of the analysis of the leaf foliar surface matrices (results of supplementary analyses not detailed) were observed between the shoot and the third leaf ( $P$. oceanica shoots dissected for biometry had in average $6 \pm 0$ leaves), both at $10 \mathrm{~m}$ depth over time ( $r h o=0.85, p<0.001)$ and along the depth gradient $(r h o=$ $0.88, p<0.001)$. The third leaf from the inside of the leaf bundle (juvenile leaves excluded, see Giraud, 1979) therefore appears to be the best proxy for $P$. oceanica shoot total foliar surface and justifies, by extension, its election as representative tissue to study the plant biology (similar inference for $15 \mathrm{~m}$ depth in: Romero et al., 2007; Luy et al., 2012).

\section{DMSP, DMSO, and DMSP:DMSO Ratio}

Mean DMSP concentrations at $10 \mathrm{~m}$ depth ranged between 62 \pm 17 and $205 \pm 58 \mu$ mol.g $\mathrm{fw}_{\mathrm{fw}}^{-1}$ (reported as preliminary result in Borges and Champenois, 2017), i.e., a ratio of about three between leaf extrema (Figure 3A). The DMSP concentration decreased continuously from autumn to summer, with a clear break in the cycle between the two seasons properly predicted by segmented linear regression analysis unlike spline smoothing (Figure 3A). DMSO differed from DMSP in terms of both absolute concentrations and relative difference between extrema. Mean DMSO concentration at $10 \mathrm{~m}$ depth ranged between 1.5 and $8.6 \pm 2.0 \mu \mathrm{mol} . \mathrm{g}_{\mathrm{fw}}^{-1}$, i.e., a ratio of about six between leaf extrema (Figure 3B). The DMSO concentration also decreased continuously from autumn to summer, with however a smoother break in the cycle between both seasons (Figure 3B); as a result, both spline model and segmented linear regression adequately predicted the cyclic evolution of the DMSO concentration. The DMSP and DMSO concentrations in P. oceanica leaves at $10 \mathrm{~m}$ depth were strongly positively correlated with each other $(r h o=$ $0.74, p<0.001)$. They were, respectively, strongly ( $r h o=-0.75$, $p<0.001$ ) and modestly (rho $=-0.55, p<0.001$ ) negatively correlated with the third leaf foliar surface. Correlations of concentrations were non-significant with $\Phi$ PSII and weak to modest with environmental parameters light $(r h o=-0.59, p$ 

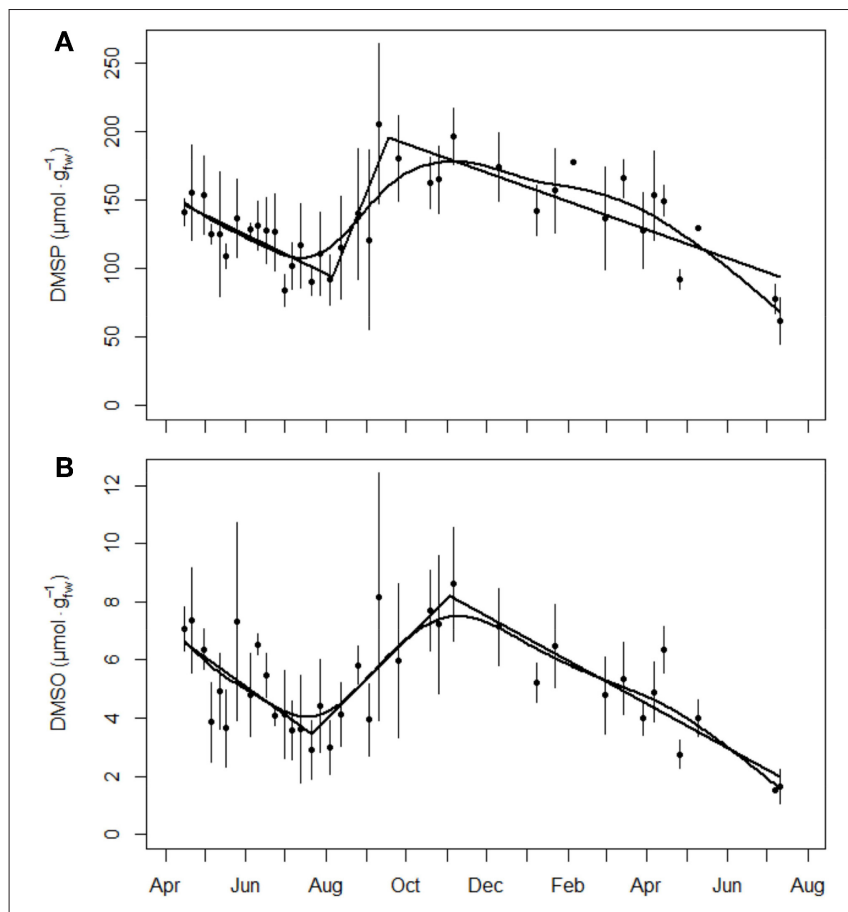

FIGURE 3 | Evolution of $(\mathbf{A})$ the DMSP concentration $\left(\mu \mathrm{mol} \cdot \mathrm{g}_{\mathrm{fw}}^{-1}\right)$ and $\mathbf{( B )}$ the DMSO concentration $\left(\mu \mathrm{mol} . \mathrm{g}_{\mathrm{fw}}^{-1}\right.$ ) in $P$. oceanica third leaf at $10 \mathrm{~m}$ depth (mean \pm sd, $n=3$ except February 5, 2016 for DMSP and DMSO and July 7, 2016 for DMSO, $n=2$ ). The solid black lines are predictions from segmented linear regression and cross-validated smoothing cubic spline analyses on leaf concentrations.

$<0.001$ for DMSP; rho $=-0.38, p=0.025$ for DMSO) and temperature ( $r h o=-0.50, p=0.002$ for DMSP; $r h o=-0.33$, $p=0.041$ for DMSO). Confirming the results of the exploratory correlation analyses, results from the GLM analyses showed an effect of the third leaf foliar surface only on DMSP $(p=0.004)$ and DMSO $(p=0.033)$ concentrations at $10 \mathrm{~m}$ depth. Indeed, DMSP and DMSO concentrations decreased linearly with the increase of the leaf foliar surface $\left(p<0.001, R^{2}=0.53\right.$ for DMSP; $p<0.001, R^{2}=0.34$ for DMSO), i.e., the aging of the leaf (Wittmann et al., 1981; Wittmann and Ott, 1982).

Mean DMSP concentrations along the depth gradient ranged from a minimum of $71 \pm 21 \mu \mathrm{mol}_{\mathrm{fw}}^{-1}$ at $20 \mathrm{~m}$ depth to a maximum of $143 \pm 26 \mu$ mol.g $\mathrm{f}_{\mathrm{fw}}^{-1}$ at $29 \mathrm{~m}$ depth. Depth influence on DMSP concentration was not significant at alpha $1 \%$ (ANOVA- $p=0.042$; Figure 4A). Mean DMSO concentrations remained close to $3.9 \mu \mathrm{mol} . \mathrm{g}_{\mathrm{fw}}^{-1}$ along the depth gradient, except for the lower mean value of $1.8 \pm 0.2 \mu \mathrm{mol} . \mathrm{g}_{\mathrm{fw}}^{-1}$ at $20 \mathrm{~m}$ depth (ANOVA- $p=0.080$; Figure 4B). The positive correlation between the two molecule concentrations was modest (rho $=0.58, p=0.001)$. The DMSP and DMSO concentrations remaining relatively constant with depth, none of the potential explanatory variables that for most showed a clear depth gradient were related to the concentrations of the two molecules, as observed from correlation and GLM analyses. Overall, the general scatterplot of DMSP and DMSO concentrations for all $P$. oceanica leaves sampled at $10 \mathrm{~m}$ depth over time and along the

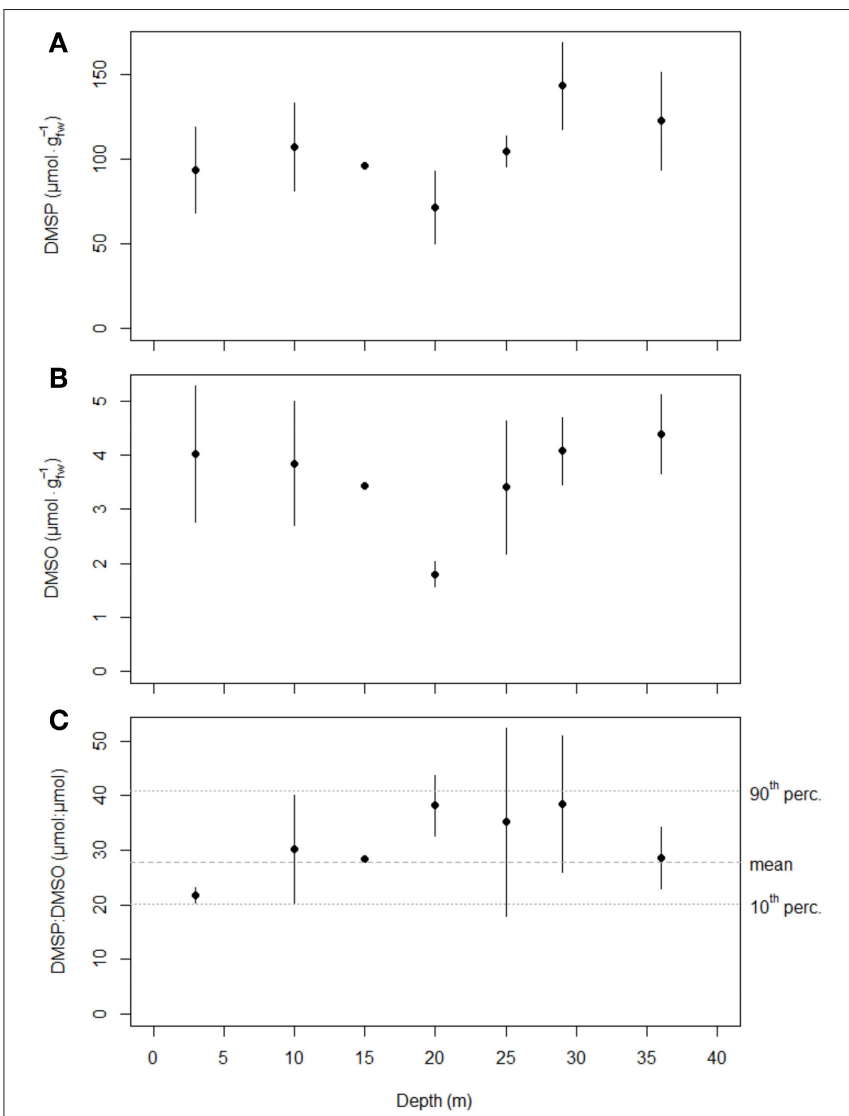

FIGURE 4 | Evolution of $(\mathbf{A})$ the DMSP concentration ( $\mu \mathrm{mol}_{\mathrm{fw}}^{-1}$ ), (B) the DMSO concentration ( $\mu \mathrm{mol} \cdot \mathrm{g}_{\mathrm{fw}}^{-1}$ ) and $\mathbf{( C )}$ and the DMSP:DMSO ratio ( $\mu \mathrm{mol}: \mu \mathrm{mol}$ ) in $P$. oceanica third leaf along the $3-36 \mathrm{~m}$ depth transect (mean \pm $\mathrm{sd}, n=3$ except at depths $15 \mathrm{~m}, n=2$ and $10 \mathrm{~m}, n=12$ ). Tenth and ninetieth percentiles (horizontal dotted gray lines) and the mean ratio value (horizontal dashed gray line) of the interpercentile range for the $10 \mathrm{~m}$ depth survey are reported on the DMSP:DMSO ratio graph $\mathbf{( C )}$.

depth transect showed a clear linear relationship between the two compounds (Figure 5).

Mean DMSP:DMSO ratio values at $10 \mathrm{~m}$ depth ranged between $20.2 \pm 1.0$ and $55.9 \mu \mathrm{mol}: \mu \mathrm{mol}$, i.e., a ratio of about three between leaf extrema (Figure 6A). All mean DMSP:DMSO ratio values except the maximum were distributed in the 10th-90th interpercentile range of leaf ratio values, around a corresponding mean of $27.7 \pm 5.0 \mu \mathrm{mol}: \mu \mathrm{mol}$ (Figure 6A). Segmented linear regression on the 10th-90th interpercentile range predicted, unlike spline smoothing, a slight cycle break around mid-October when DMSP and DMSO concentrations were at high seasonal levels (Figure 3) and foliar surfaces at their lowest (Figure 1C). October thus corresponded to a new physiological cycle for the seagrass. Accordingly, the evolution of the DMSP:DMSO ratio was bounded to the month of October, regardless of the year. October-bounded DMSP:DMSO leaf ratio values in the 10 th-90th interpercentile range showed no significant linear trend (Figure 6B). This was consistent with the absence of significant linear relationship between the DMSP:DMSO ratio and the third leaf foliar surface $(p=0.160$, 


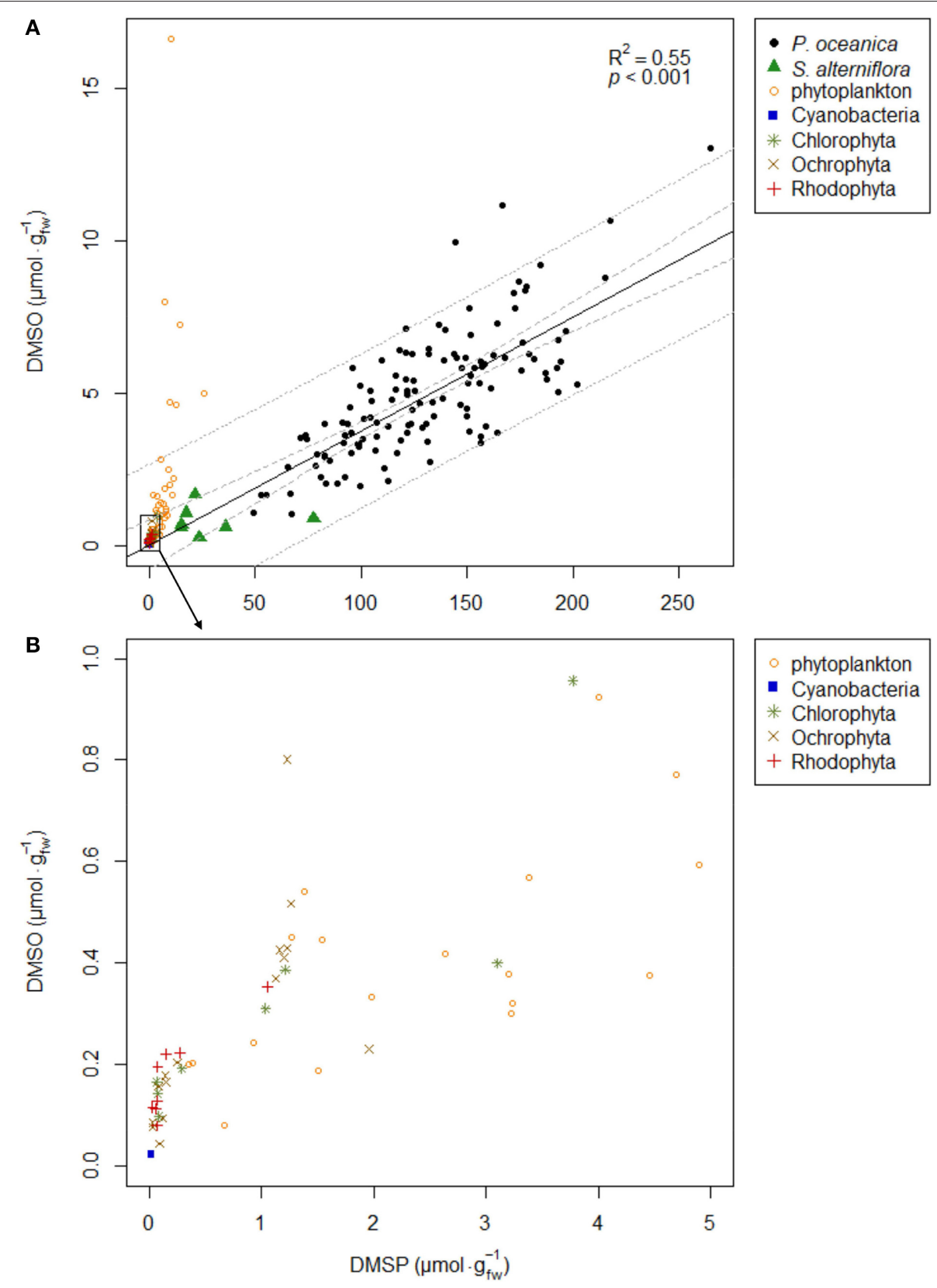

FIGURE 5 | Scatterplot of DMSP and DMSO concentrations ( $\mu$ mol. $\mathrm{g}_{\mathrm{fw}}^{-1}$ ) in $P$. oceanica third leaf, $S$. alterniflora leaves, epilithic Cyanobacteria, macroalgae (Ochrophyta, Chlorophyta, and Rhodophyta), and marine phytoplankton communities. P. oceanica data are for individual leaf samples, all $10 \mathrm{~m}$ depth survey and depth transect observations combined $(n=129)$. S. alterniflora data are mean values from Husband and Kiene (2007), Husband et al. (2012), and McFarlin and Alber (2013). Epilithic Cyanobacteria and macroalgae data are mean species-specific pool sample values. Phytoplankton data are mean values from Simó and Vila-Costa (2006). Graph (B) is a zoom of graph (A) bottom left area framed by a rectangle. The legends of marine primary producer symbols are given next to the graphs. The solid black line on graph (A) is the linear regression modeling the relationship between $P$. oceanica DMSP and DMSO concentrations. Model $R^{2}$ and $p$-value are shown on the graph. 95\% confidence (dashed gray lines) and prediction (dotted gray lines) intervals are plotted.

$\left.R^{2}=0.05\right)$, i.e., the leaf age (Wittmann et al., 1981; Wittmann and Ott, 1982).

Mean DMSP:DMSO ratio values along the depth gradient did not significantly differ between depths (ANOVA- $p=0.356$ ) and were included in the $10 \mathrm{~m}$ depth 10th-90th interpercentile range of leaf ratio values (Figures $4 \mathrm{C}, 6$ ). The DMSP:DMSO ratio general mean of $31.5 \pm 6.1 \mu \mathrm{mol}: \mu \mathrm{mol}$ along the depth gradient was further close to the $10 \mathrm{~m}$ depth value of $27.7 \pm$ $5.0 \mu \mathrm{mol}: \mu \mathrm{mol}$. From these results, we can reasonably conclude that the DMSP:DMSO ratio in P. oceanica third leaves remained constant regardless of the depth, just as it was over time at $10 \mathrm{~m}$ depth. Consequently, none of the potential explanatory 


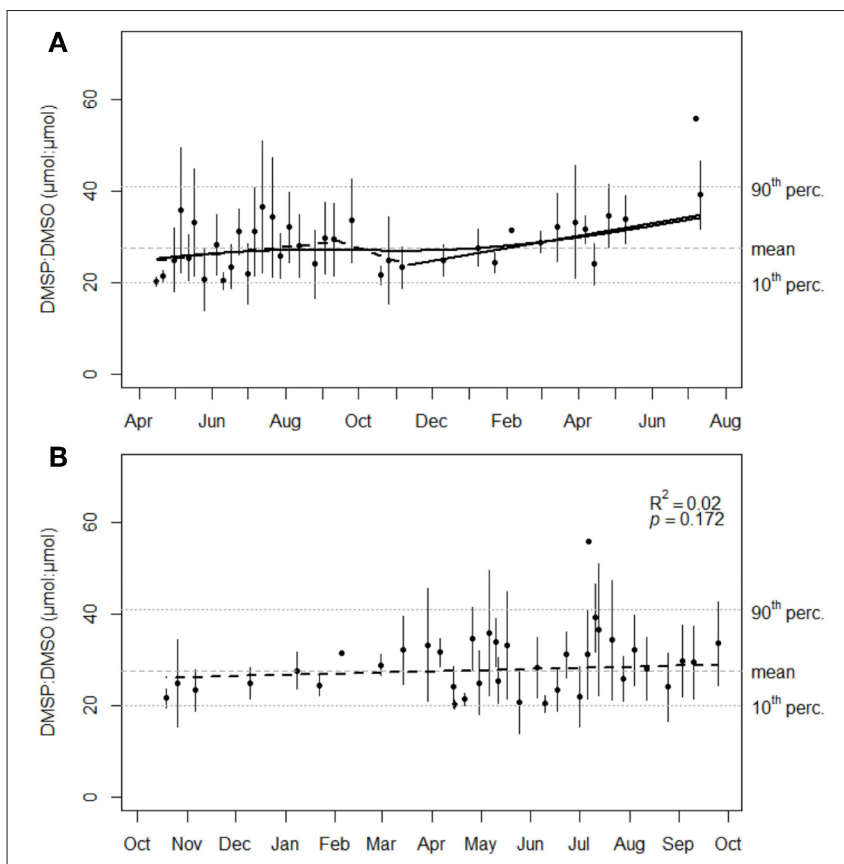

FIGURE 6 | (A) Evolution of the DMSP:DMSO ratio ( $\mu$ mol: $\mu$ mol) in P. oceanica third leaf at $10 \mathrm{~m}$ depth (mean $\pm \mathrm{sd}, n=3$ except February 5, 2016 and July $7,2016, n=2)$. The dashed (non-significant slope at $p=0.01$ ) and solid (significant slope at $p=0.01$ ) segments of the broken black line and the solid black line are predictions from segmented linear regression and

cross-validated smoothing cubic spline analyses, respectively, for the leaf ratio values between 10th and 90th percentiles. (B) DMSP:DMSO ratio values ( $\mu \mathrm{mol}: \mu \mathrm{mol}$ ) bounded to October, regardless of the year. The dashed black line represent the non-significant linear trend of leaf ratio values over the year for data between 10th and 90th percentiles. Model $R^{2}$ and $p$-value are shown on the graph. Tenth and ninetieth percentiles (horizontal dotted gray lines) and the mean ratio value (horizontal dashed gray line) of the interpercentile range are reported on both graphs.

variables that for most showed an annual cycle and/or a depth gradient were related to the DMSP:DMSO ratio, as observed from correlation and GLM analyses.

\section{DISCUSSION}

\section{DMSP}

The maximum mean DMSP concentration measured in this work was $205 \pm 58 \mu \mathrm{mol} . \mathrm{g}_{\mathrm{fw}}^{-1}$, for an overall average in $P$. oceanica leaves of $130 \pm 39 \mu \mathrm{mol} . \mathrm{g}_{\mathrm{fw}}^{-1}$. These values are much higher than the maximum mean DMSP concentration of $33.9 \mu$ mol per $g$ of oven-dried leaf, i.e., $6.8 \mu$ mol.g $_{\mathrm{fw}}^{-1}$ (P. oceanica leaves contain about $80 \%$ water) reported by Borges and Champenois (2015), and of the same order of magnitude as the DMSP concentrations of fresh and frozen leaf samples reported by Borges and Champenois (2017). The present survey thus confirms the quantitative important role played by $P$. oceanica as DMSP producer in Mediterranean coastal environments. The DMSP concentration in P. oceanica leaves showed a continuous decrease over the seagrass physiological year. The scientific literature on the seasonal evolution of DMSP in marine species, and more specifically macrophytes is sparse. Husband (2007) reported that DMSP in S. alterniflora seemed to present a general pattern of increasing concentrations through summer to an autumnal maximum followed by a decrease over winter into early spring. Lyons et al. (2010) observed that DMSP content in Codium fragile subsp. fragile (Suringar) Hariot, 1889 off the Atlantic coast of Nova Scotia were highest in boreal spring, lowest in autumn, and negatively related to temperature. These authors further studied experimentally the DMSP production plasticity by $C$. fragile subsp. fragile. Results indicated it increased with decreasing temperature and with light intensity. Conversely, Karsten et al. (1992) measured a decrease in DMSP concentration in Antarctic green macroalgae acclimated to higher temperatures. Statistical relationships with temperature do not suggest any cryoprotectant function of DMSP in P. oceanica. The species, endemic of the Mediterranean, grows in temperate environmental conditions, must not cope with cold water temperatures (Boudouresque and Meinesz, 1982) but with global warming (Duarte et al., 2018; Darmaraki et al., 2019). According to Sunda et al. (2002), DMSP has the ability to capture free oxygen radicals (known collectively as reactive oxygen species, or ROS) produced especially during the photolysis of water molecules by PSII during photosynthesis (Lesser, 2006). The study did not find any deterministic relationship between light intensity or photosynthetic activity and the DMSP concentration measured in P. oceanica leaves. Our sampling protocol was standardized at around midday, during calm and sunny weather days; this may have partially masked a real effect of light and $\Phi$ PSII on leaf DMSP content. We can therefore not confirm or refute a role of DMSP in $P$. oceanica related to light regime and put forward for macroalgae (Rix et al., 2012) and phytoplankton (Slezak and Herndl, 2003), i.e., to be an antioxidant for ROS and to cope with oxidative stress.

The main significant relationship of DMSP content with potential explanatory variables was with the third leaf foliar surface: the longer, i.e., the older the leaf (Wittmann et al., 1981; Wittmann and Ott, 1982), the less DMSP. DMSP concentration in the first 20 photosynthetic $\mathrm{cm}$ of $P$. oceanica young third leaves was the highest in September, after the decay of senescent leaves and the renewal of the leaf bundle. The plant, with acropetal growth (Boudouresque et al., 2012), will allocate costly defenses to tissues that contribute most to fitness and survival (Rhoades, 1979), that is, the basal segment of newly grown leaves. Two known functions of DMSP production could explain higher concentrations in young growing tissues. First, the protection against grazers. Sarpa salpa (Linnaeus, 1758), the main herbivore on $P$. oceanica, can either feed on any range of leaf ages or select mid-age leaves (Pinna et al., 2009; Steele et al., 2014). Paracentrotus lividus (Lamarck, 1816), the second most important grazer on that species feeds preferentially on the epiphytes, more abundant on older leaves (Traer, 1979; Tomas et al., 2006). Higher DMSP concentration (or related compounds DMSO, DMS, and acrylic acid) in younger tissues could thus reduce, as repulsive, the grazing pressure (Vergés et al., 2007). Predator deterrence by DMSP and its metabolites was indicated by grazing observations by rats on inner tissues of $S$. alterniflora stems depleted in DMSP after nitrogen fertilization (Morris et al., 2002; Sundareshwar et al., 2003; Otte et al., 2004), 
difficulties to experimentally feed rats at high concentrations of DMSP (Nakajima, 1989) and DMSP cleavage to DMS and acrylic acid which deter feeding on algae by some herbivores (Van Alstyne et al., 2001; Van Alstyne and Houser, 2003). Changes in tolerance to grazing and defense allocation against herbivores in aging tissues (Schultz et al., 2013; Martínez-Crego et al., 2015) could then lead to the decrease of the DMSP concentration in $P$. oceanica leaves over time. Second, the protection against ROS as suggested above. Alcoverro et al. (1998) experimentally reported higher primary production from net oxygen release in younger leaf segments, i.e., close to the base. High productivity implies high rate of photosynthesis that leads unavoidably to the production of ROS (Hajiboland, 2014). We observed no relationship between DMSP concentration and $\Phi$ PSII in $P$. oceanica third leaf. Seagrass canopy photosynthetic response is a function of canopy density and light environment (Hedley et al., 2014). Thus, although P. oceanica younger leaf segments analyzed for DMSP and DMSO have the ability to be more productive, the shading effect of the canopy at low to medium depths and poor light availability deeper where the meadow is sparse are probably unfavorable for the production of ROS at deleterious levels for the plant. The possibility of these two DMSP functions (grazer deterrent and protection against ROS from photosynthesis) remains open and will require further testing. However, considering these two potential functions, knowing the dynamics of the meadow canopy and the physiology of the plant, a potential scheme of DMSP production by $P$. oceanica leaves can be established. In late summer early autumn, during the main renewal of the leaf bundles, the old senescent leaves are replaced by young productive leaves whose access to light and grazers (Prado et al., 2007; Pinna et al., 2009) is facilitated by the drastic fall of the leaf biomass. The production of DMSP by these new leaves is, from this moment, maximum. The annual cycle of light and the biology of organisms (predation by grazers, plant productivity and growth cycle) evolved toward a linear decrease in DMSP concentration until next summer. This cycle, evident at $10 \mathrm{~m}$, will have to be investigated along depth transects. The absence of difference observed along the unique depth profile performed in this study, a snapshot at the beginning of the summer period when the DMSP content levels were seasonally very low, does not allow emitting any hypotheses.

\section{DMSO}

The maximum mean DMSO concentration measured in this work was $8.6 \pm 2.0 \mu \mathrm{mol} . \mathrm{g}_{\mathrm{fw}}^{-1}$, for an overall average in $P$. oceanica leaves of $4.9 \pm 2.1 \mu$ mol. $\mathrm{g}_{\mathrm{fw}}^{-1}$. These values are much higher than for the other coastal higher plant S. alterniflora. Husband and Kiene (2007) and Husband et al. (2012) reported DMSO concentrations ranging from 0.25 to $0.88 \mu \mathrm{mol} . \mathrm{g}_{\mathrm{fw}}^{-1}$ (after conversion to fresh weight for Husband et al., 2012 DMSO data-S. alterniflora leaf mean moisture content of $62.5 \%$; Hardisky et al., 1983-since they analyzed fresh samples but published results per $g$ of dry weight), McFarlin and Alber (2013) from 0.57 to $1.66 \mu \mathrm{mol} . \mathrm{g}_{\mathrm{fw}}^{-1}$. The latter argued that differences might result from a high variability of DMSO content across marshes, differences in DMSO to DMS conversion efficiency during analysis (Kiene and Gerard, 1994) and methodological differences, the former estimating DMSO from within the same serum vial (same plant sample) that was used to estimate DMSP, the latter not. Husband and Kiene (2007) collected their samples in summer in Alabama, McFarlin and Alber (2013) in autumn in Georgia. These states are neighbors and sampling locations are at similar latitude. In addition, performing both DMSP and DMSO analyses on the same leaf sample does not lead to any loss of DMSO (Champenois and Borges, 2019a). So presumably, the reasons for the differences observed for S. alterniflora are natural, not methodological. Because Husband (2007) did not measure any consistent seasonal trend of the DMSO concentration in $S$. alterniflora leaves, differences might indeed result mainly from variability across marshes. In contrast to $S$. alterniflora, the DMSO concentration in $P$. oceanica leaves evolved clearly over the seasons (as was for DMSP). The spatial variability across meadows remains however to be investigated, all the current data coming from the same location.

The distribution of DMSO within healthy S. alterniflora tissues and between sampling areas reflected somewhat the distribution of DMSP (Husband and Kiene, 2007; Husband et al., 2012; McFarlin and Alber, 2013). Such a similar distribution between the two molecules within healthy $P$. oceanica leaves was particularly evident in the present study, both over time and with depth. Some evidences suggested that DMSO production in $S$. alterniflora leaves could result both from direct oxidation of DMSP and via cleavage of DMSP to DMS and subsequent oxidation of DMS (Dacey et al., 1987; Husband and Kiene, 2007; Husband et al., 2012). Such information on the metabolic pathway of DMSP to DMSO in seagrasses are for the moment missing. However, DMSO and DMSP concentrations in $P$. oceanica leaves increased concomitantly in late summer when the seagrass leaf bundle was renewed. This period corresponds to maximum potential grazing on shoot inner leaves (Prado et al., 2007; Pinna et al., 2009) and maximum access to light for young productive tissues. Leaf wound and grazing (McDowell et al., 2014a) and photosynthesis (Hajiboland, 2014) lead to the production of ROS, the latter being also predator deterrent (McDowell et al., 2014b). DMSP conversion to DMSO could then be mediated by these ROS because of the hypothesized antioxidant function of DMSP (Sunda et al., 2002; Simó and Vila-Costa, 2006; Husband and Kiene, 2007). Considering the similar distribution of DMSP and DMSO in P. oceanica and a main function of DMSP as antioxidant for ROS, the strong relationship between the two molecules reported in this study is evident. The absence of any other strong relationship with potential explanatory variables except with third leaf foliar surface reinforces the hypothesis of a close link between the concentrations of the two molecules.

Strong relationships between particulate DMSP and DMSO have also been reported within cultured marine phytoplanctonic cells (Hatton and Wilson, 2007) and natural communities in coastal and open surface waters collected in a variety of marine biomes and different seasons (Simó and Vila-Costa, 2006). The scatterplot distribution of DMSP and DMSO for S. alterniflora, for epilithic Cyanobacteria and macroalgae and for most (88\%) natural marine phytoplankton communities fall within the 95\% prediction interval of the regression line of Figure 5A derived 
from the $P$. oceanica data. Their DMSP contents are distinctly lower than in P. oceanica, as well as their DMSO contents. It is particularly the case for epilithic Cyanobacteria and macroalgae (Ochrophyta, Chlorophyta and Rhodophyta) from the Revellata Bay (see Supplementary Material Table 3), with DMSP and DMSO content globally very low compared to other marine primary producers. DMSP and DMSO in macroalgae showed a proportional relationship between their concentrations, all species considered (Figure 5B). The highest DMSP content was reported in the Chlorophyta group, for Ulva intestinalis Linnaeus, $1753\left(3.10 \pm 0.42 \mu \mathrm{mol} . \mathrm{g}_{\mathrm{fw}}^{-1}\right)$ and Codium adhaerens C. Agardh, $1822\left(3.77 \pm 0.34 \mu \mathrm{mol}_{\mathrm{ff}}^{-1}\right)$ in agreement with Van Alstyne and Puglisi (2007) for Ulva spp. and Lyons et al. (2010) for C. fragile subsp. fragile. DMSO data in macroalgae are currently very scarce. The DMSO content in $U$. intestinalis $\left(0.40 \pm 0.02 \mu\right.$ mol. $\left.\mathrm{g}_{\mathrm{fw}}^{-1}\right)$ was in agreement with Deschaseaux et al. (2014) who reported similar value for Ulva lactuca Linnaeus, 1753, but a DMSP content one order of magnitude higher in $U$. lactuca compared to $U$. intestinalis. In contrast to $S$. alterniflora, epilithic Cyanobacteria and macroalgae, some of the average DMSO concentrations of natural marine phytoplankton communities from warm tropical waters are very high (up to $16.67 \mu \mathrm{mol} . \mathrm{g}_{\mathrm{fw}}^{-1}$ ). Simó and Vila-Costa (2006) provided two possible explanations for these high DMSO values: first, the dominance of phytoplankton community by nano- and picophytoplankton in warmer waters supposedly enriched in DMSO relative of DMSP; second, higher solar irradiance in the sampled warmer waters, and higher DMSO content to scavenge ROS.

\section{DMSP:DMSO Ratio}

The monitoring of seagrass biological responses to stressors at the molecular and cellular level is a useful complementary tool in environmental quality evaluation and risk assessment (Ferrat et al., 2003; Hansen, 2003). A multiparametric approach including structural and physiological indicators, indicators of general stress and stress-related specific indicators seems to be required to establish an appreciable ecotoxicological diagnostic using seagrasses (Ferrat et al., 2003; Roca et al., 2016). Considering the source of DMSO in the plant is DMS(P), their ratio represents the degree of oxidation of the DMSP pool (Husband and Kiene, 2007). In our study, DMSO accounted for $3.8 \pm 1.0 \%$ of DMSP in P. oceanica leaves, a value similar to the $4.0 \%$ reported for $S$. alterniflora leaves from a natural population (Husband and Kiene, 2007). In yellowing and experimentally stressed (application of herbicides) S. alterniflora (Husband and Kiene, 2007; Husband et al., 2012) and in plants collected from areas affected by different disturbances (sudden marsh dieback, horse grazing, littorinid snail grazing, wrack deposition; McFarlin and Alber, 2013), DMSP was converted to its oxidation product DMSO resulting in a higher DMSO:DMSP ratio compared to healthy unstressed plants. These studies on S. alterniflora reported evidences that the DMSO:DMSP ratio could be useful as generic indicator of stress in plants, the response being consistent regardless of disturbance type. For obvious reasons of understanding, in order to work with numbers (not just decimals), for stress to result in a decrease in the value of the indicator for monitoring purpose in the framework of
Environmental Directives and as expected by environmental actors and decision-makers, we report the ratio as DMSP:DMSO.

In the present study, the DMSP:DMSO ratio in $P$. oceanica leaves remained constant over time and with depth. The absence of a seasonal trend of the ratio of the two molecules was also observed in S. alterniflora (Husband, 2007). The primary contributor to the evolution over time of DMSP and DMSO concentrations was the elongation, i.e., the aging (Wittmann et al., 1981; Wittmann and Ott, 1982) of the third leaf over the annual growth cycle of the plant. Regardless of the age of the leaf, the DMSP:DMSO ratio remained constant as indicated by the absence of a significant relationship between the two variables. A generic early warning indicator of stress, not subject to the time of year, the depth, the stage of development of the plant would be a real asset for the monitoring of the quality of coastal waters, especially for diffuse stressors such as pollution that are currently difficult to assess. The main biotic indices based on $P$. oceanica for assessing the ecological status of Mediterranean coastal waters reported good to high quality index values for the Gulf of Calvi (Gobert et al., 2009; Lopez y Royo et al., 2010, 2011). Here, the DMSP:DMSO ratio remained constant over time and with depth, in a narrow range of values around a mean of 29.2 $\pm 9.0 \mu \mathrm{mol}: \mu \mathrm{mol}$. This constant ratio for a healthy $P$. oceanica meadow not subject to environmental or direct anthropogenic stressors (except global change) can be considered as reference value for future work (field and laboratory) on the assessment of the DMSP:DMSO ratio as early generic indicator of stress.

\section{CONCLUSIONS}

P. oceanica leaves are important producers of DMSP and DMSO, their concentrations being overall much higher than phytoplankton, epilithic Cyanobacteria, macroalgae, and saltmarsh plants. Concentrations of the two organosulfured compounds varied with time, probably not with depth. Considering the similar distribution of both molecules, we hypothesized DMSO content results from the oxidation of DMS(P). Their concentration dynamics could be an important homeostatic process involved in the maintenance of an internal steady state of the plant. Of all physiological (photosynthetic activity), biometrical (foliar surface) and environmental (light, temperature) parameters monitored, the annual cycle of the plant aging was the main vector of evolution of leaf DMSP and DMSO concentrations. We hypothesized two protective functions of DMSP to explain higher concentrations in young tissues that contribute most to the plant fitness and survival: antioxidant against ROS and predator-deterrent. Finally, we observed a constant DMSP:DMSO ratio in $P$. oceanica leaves for the studied non-disturbed meadow. We hypothesized this ratio, constant for unstressed plants, could be useful as early warning indicator of stress in seagrasses independently of the season, the depth or the age of the leaf bundle. In conclusion, the present study deepened our knowledge on the ecology of DMSP and DMSO in P. oceanica and brought new insights on the concentration dynamics of both molecules in coastal ecosystems overall. More research is now needed to confirm the functions of 
DMSP and DMSO in seagrasses, notably because grazing was not investigated and the relationship with light and photosynthesis was not obvious, and to assess how the DMSP:DMSO ratio would vary under disturbance.

\section{DATA AVAILABILITY STATEMENT}

All datasets generated for this study are included in the article/Supplementary Material.

\section{AUTHOR CONTRIBUTIONS}

JR, WC, SG, GL, JS, RS, and AB elaborated the survey protocol. JR and AA performed seagrass sampling and in situ measurements. DS and WC performed algae sampling and DS identified algae species. WC, GE, and $\mathrm{AB}$ analyzed samples for DMSP and DMSO. JR, JS, and RS analyzed photosynthetic activity data. SG and $A B$ provided access to tools and instruments and provided fundings. JR processed data and performed statistical analysis. JR, $\mathrm{WC}$, and $\mathrm{AB}$ wrote the manuscript. AA, SG, GL, JS, RS, and DS participated to the manuscript revision.

\section{FUNDING}

This work was funded by the Fonds National de la Recherche Scientifique (FNRS) (Fellowship-Grant 1237018F and

\section{REFERENCES}

Alcoverro, T., Manzanera, M., and Romero, J. (1998). Seasonal and agedependent variability of Posidonia oceanica (L.) Delile photosynthetic parameters. J. Exp. Mar. Bio. Ecol. 230, 1-13. doi: 10.1016/S0022-0981(98) 00022-7

Apostolaki, E. T., Holmer, M., Santinelli, V., and Karakassis, I. (2018). Species-specific response to sulfide intrusion in native and exotic Mediterranean seagrasses under stress. Mar. Environ. Res. 134, 85-95. doi: 10.1016/j.marenvres.2017.12.006

Asher, E., Dacey, J. W., Ianson, D., Peña, A., and Tortell, P. D. (2017). Concentrations and cycling of DMS, DMSP, and DMSO in coastal and offshore waters of the Subarctic Pacific during summer, 2010-2011. J. Geophys. Res. Ocean 122, 3269-3286. doi: 10.1002/2016JC012465

Bay, D. (1984). A field study of the growth dynamics and productivity of Posidonia oceanica in Calvi Bay, Corsica, France. Aquat. Bot. 20, 43-64. doi: 10.1016/0304-3770(84)90026-3

Binard, M. (2017). Composantes météorologiques de la base de données océanographique RACE de STARESO (Baie de Calvi - Corse). Bull. Soc. Géogr. Liège 68, 37-47. doi: 10.25518/0770-7576.4517

Borges, A. V., and Champenois, W. (2015). Seasonal and spatial variability of dimethylsulfoniopropionate (DMSP) in the Mediterranean seagrass Posidonia oceanica. Aquat. Bot. 125, 72-79. doi: 10.1016/j.aquabot.2015.05.008

Borges, A. V., and Champenois, W. (2017). Preservation protocol for dimethylsulfoniopropionate and dimethylsulfoxide analysis in plant material of the Mediterranean seagrass Posidonia oceanica, and reevaluation of dimethylsulfoniopropionate leaf content. Aquat. Bot. 143, 8-10. doi: 10.1016/j.aquabot.2017.08.004

Boudouresque, C. F., Bernard, G., Bonhomme, P., Charbonnel, E., Meinesz, A., Pergent, G., et al. (2012). Protection and Conservation of Posidonia oceanica Meadows. Tunis: RAMOGE and RAC/SPA Publisher.

Boudouresque, C. F., and Meinesz, A. (1982). Découverte de l'herbier de posidonie. Cah. Parc. Natl. Port Cros. 4, 1-79. contract 2.4.637.10), the University of Liège (C-10/78 Fonds Spéciaux) and the Territorial Collectivity of Corsica and the Rhone-Mediterranean and Corsica Water Agency (STARECAPMED-Station of reference and research on change of local and global anthropogenic pressures on Mediterranean ecosystem drifts). The Portuguese Foundation for Science and Technology supported this research through the contract program of DL 57/2016 and project UID/Multi/04326/2019.

\section{ACKNOWLEDGMENTS}

Authors thank Nicolas Cimiterra and Jon Lapeyra Martin for their help during fieldwork and Marianadjah Zemmouri for the analysis of the DMSP and DMSO content of the algae samples. Authors also thank Reviewers for their careful consideration and suggestions to improve the manuscript. JR is a postdoctoral researcher at the FNRS, GL is a research associate at the FNRS, and $A B$ is a research director at the FNRS. This paper has the MARE number MARE392.

\section{SUPPLEMENTARY MATERIAL}

The Supplementary Material for this article can be found online at: https://www.frontiersin.org/articles/10.3389/fevo. 2019.00510/full\#supplementary-material
Brimblecombe, P., and Shooter, D. (1986). Photo-oxidation of dimethylsulphide in aqueous solution. Mar. Chem. 19, 343-353. doi: 10.1016/0304-4203(86)90055-1

Bullock, H. A., Luo, H., and Whitman, W. B. (2017). Evolution of dimethylsulfoniopropionate metabolism in marine phytoplankton and bacteria. Front. Microbiol. 8:637. doi: 10.3389/fmicb.2017.00637

Campagne, C. S., Salles, J. M., Boissery, P., and Deter, J. (2015). The seagrass Posidonia oceanica: ecosystem services identification and economic evaluation of goods and benefits. Mar. Pollut. Bull. 97, 391-400. doi: 10.1016/j.marpolbul.2015.05.061

Challenger, F., and Simpson, M. I. (1948). Studies on biological methylation. Part, X. I. I. A precursor of the dimethyl sulphide evolved by Polysiphonia fastigiata. Dimethyl-2-carboxyethylsulphonium hydroxide and its salts. J. Chem. Soc. 3, 1591-1597. doi: 10.1039/jr9480001591

Champenois, W., and Borges, A. V. (2012). Seasonal and interannual variations of community metabolism rates of a Posidonia oceanica seagrass meadow. Limnol. Ocean 57, 347-361. doi: 10.4319/lo.2012.57.1.0347

Champenois, W., and Borges, A. V. (2019a). Determination of dimethylsulfoniopropionate and dimethylsulfoxide in Posidonia oceanica leaf tissue. MethodsX 6, 56-62. doi: 10.1016/j.mex.2018.12.014

Champenois, W., and Borges, A. V. (2019b). Inter-annual variations over a decade of primary production of the seagrass Posidonia oceanica. Limnol. Oceanogr. 64, 32-45. doi: 10.1002/lno.11017

Charlson, R. J., Lovelock, J. E., Andreae, M. O., and Warren, S. G. (1987). Oceanic phytoplancton, atmoshperic sulphur, cloud albedo and climate. Nature 326, 655-661. doi: 10.1038/326655a0

Cook, R. D. (1977). Detection of influential observation in linear regression. Technometrics 19, 15-18. doi: 10.1080/00401706.1977.10489493

Dacey, J. W. H., King, G. M., and Lobel, P. S. (1994). Herbivory by reef fishes and the production of dimethylsulfide and acrylic acid. Mar. Ecol. Prog. Ser. 112, 67-74. doi: 10.3354/meps112067

Dacey, J. W. H., Wakeham, S. G., and Howes, B. L. (1987). Factors controlling emission of dimethylsulphide from salt marshes. Nature 330, 643-645. doi: $10.1038 / 330643 \mathrm{a} 0$ 
Darmaraki, S., Somot, S., Sevault, F., Nabat, P., Narvaez, W. D. C., Cavicchia, L., et al. (2019). Future evolution of marine heatwaves in the Mediterranean Sea. Clim. Dyn. 53, 1371-1392. doi: 10.1007/s00382-019-04661-z

Dauby, P., and Poulicek, M. (1995). Methods for removing epiphytes from seagrasses: SEM observations on treated leaves. Aquat. Bot. 52, 217-228. doi: 10.1016/0304-3770(95)00500-5

De los Santos, C. B., Vicencio-Rammsy, B., Lepoint, G., Remy, F., Bouma, T. J., and Gobert, S. (2016). Ontogenic variation and effect of collection procedure on leaf biomechanical properties of Mediterranean seagrass Posidonia oceanica (L.) Delile. Mar. Ecol. 37, 750-759. doi: 10.1111/maec.12340

Deschaseaux, E. S. M., Kiene, R. P., Jones, G. B., Deseo, M. A., Swan, H. B., Oswald, L., et al. (2014). Dimethylsulphoxide (DMSO) in biological samples: A comparison of the $\mathrm{TiCl} 3$ and $\mathrm{NaBH} 4$ reduction methods using headspace analysis. Mar. Chem. 164, 9-15. doi: 10.1016/j.marchem.2014.05.004

Duarte, B., Martins, I., Rosa, R., Matos, A. R., Roleda, M. Y., Reusch, T. B. H., et al. (2018). Climate change impacts on seagrass meadows and macroalgal forests: An integrative perspective on acclimation and adaptation potential. Front. Mar. Sci. 5:190. doi: 10.3389/fmars.2018.00190

Ferrat, L., Pergent-Martini, C., and Roméo, M. (2003). Assessment of the use of biomarkers in aquatic plants for the evaluation of environmental quality: application to seagrasses. Aquat. Toxicol. 65, 187-204. doi: 10.1016/S0166-445X(03)00133-4

Fowler, J., and Cohen, L. (1990). Practical Statistics for Field Biology. Chichester: John Wiley \& Sons Ltd.

Giraud, G. (1979). Sur une méthode de mesure et de comptage des structures foliaires de Posidonia oceanica (Linnaeus) Delile. Bull. Mus. Hist. Nat. Marseille 39, 33-39.

Gobert, S., Cambridge, M. L., Velimirov, B., Pergent, G., Lepoint, G., Bouquegneau, J. M., et al. (2006). "Biology of posidonia," in Seagrasses: Biology, Ecology and Conservation, eds A. W. D. Larkum, R. J. Orth, and C. M. Duarte (Dordrecht: Springer), 387-408.

Gobert, S., Kyramarios, M., Lepoint, G., Pergent-Martini, C., and Bouquegneau, J. (2003). Variations at different spatial scales of Posidonia oceanica (L.) Delile beds; effects on the physico-chemical parameters of the sediment. Oceanol. Acta 26, 199-207. doi: 10.1016/S0399-1784(02)00009-9

Gobert, S., Sartoretto, S., Rico-Raimondino, V., Andral, B., Chery, A., Lejeune, P., et al. (2009). Assessment of the ecological status of Mediterranean French coastal waters as required by the Water Framework Directive using the Posidonia oceanica Rapid Easy Index: PREI. Mar. Pollut. Bull. 58, 1727-1733. doi: 10.1016/j.marpolbul.2009.06.012

Green, T. K., and Hatton, A. D. (2014). The Claw hypothesis: a new perspective on the role of biogenic sulphur in the regulation of global climate. Oceanogr. Mar. Biol. An. Annu. Rev. 52, 315-336. doi: 10.1201/b17143-7

Hajiboland, R. (2014). "Reactive oxygen species and photosynthesis," in Oxidative Damage to Plants: Antioxidant Networks and Signaling, ed. P. Ahmad (Elsevier Inc.), 1-63. doi: 10.1016/B978-0-12-799963-0.00001-0

Hansen, P. D. (2003). "Biomarkers," in Bioindicators and Biomonitors, eds B. A. Markert, A. M. Breure, and H. G. Zechmeiste (Elsevier Science Ltd.), 203-220. Available online at: https://www.sciencedirect.com/bookseries/tracemetals-and-other-contaminants-in-the-environment/vol/6

Hanson, A. D., Rivoal, J., Paquet, L., and Cage, D. A. (1994). Biosynthesis of 3dimethylsulfoniopropionate in Wollastonia biflora (L.) DC. Plant Physiol. 105, 103-110. doi: 10.1104/pp.105.1.103

Hardisky, M. A., Klemas, V., and Smart, R. M. (1983). The influence of soil salinity, growth form, and leaf moisture on the spectral radiance of Spartina alterniflora canopies. Photogramm. Eng. Remote Sens. 49, 77-83.

Hatton, A. D., and Wilson, S. T. (2007). Particulate dimethylsulphoxide and dimethylsulphoniopropionate in phytoplankton cultures and Scottish coastal waters. Aquat. Sci. 69, 330-340. doi: 10.1007/s00027-007-0891-4

Hedley, J. D., McMahon, K., and Fearns, P. (2014). Seagrass canopy photosynthetic response is a function of canopy density and light environment: a model for Amphibolis griffithii. PLoS ONE 9:e111454. doi: 10.1371/journal.pone.0111454

Husband, J., and Kiene, R. (2007). Occurrence of dimethylsulfoxide in leaves, stems, and roots of Spartina alterniflora. Wetlands 27, 224-229. doi: 10.1672/0277-5212(2007)27[224:OODILS]2.0.CO;2

Husband, J. D. (2007). The role of DMSP in oxidative stress protection in Spartina alterniflora Loisel (PhD thesis). University of South Alabama, Mobile, AL, United States.
Husband, J. D., Kiene, R. P., and Sherman, T. D. (2012). Oxidation of dimethylsulfoniopropionate (DMSP) in response to oxidative stress in Spartina alterniflora and protection of a non-DMSP producing grass by exogenous DMSP+acrylate. Environ. Exp. Bot. 79, 44-48. doi: 10.1016/j.envexpbot.2012.01.006

Jackson, G., and Stuckey, J. (2007). Effects of dimethylsulfoniopropionate (DMSP) produced by the cordgrass Spartina alterniflora on its epiphytic algal community. Aquat. Sci. 69, 419-426. doi: 10.1007/s00027-007-0890-5

Jackson, G., Zingmark, R., Lewitus, A. J., Tymowski, R. G., and Stuckey, J. (2006). Spatial and temporal dynamics of epiphytic microalgae on the cordgrass Spartina alterniflora in North Inlet Estuary, South Carolina. Estuaries Coasts 29, 1212-1221. doi: 10.1007/BF02781821

Jacquemart, J., and Demoulin, V. (2006). Inventaire des macroalgues épiphytes des feuilles de Posidonia oceanica (L.) Delile dans la Baie de la Revellata (Calvi, Corse). Lejeunia Rev Bot 181:71. Available online at: https://popups.uliege.be: 443/0457-4184/index.php?id=464

Kamenos, N. A., Strong, S. C., Shenoy, D. M., Wilson, S. T., Hatton, A. D., and Geoffrey Moore, P. (2008). Red coralline algae as a source of marine biogenic dimethylsulphoniopropionate. Mar. Ecol. Prog. Ser. 372, 61-66. doi: $10.3354 /$ meps 07687

Karsten, U., Wiencke, C., and Kirst, G. O. (1992). Dimethylsulphoniopropionate (DMSP) accumulation in green macroalgae from polar to temperate regions: interactive effects of light versus salinity and light versus temperature. Polar Biol. 12, 603-607. doi: 10.1007/BF00236983

Kiene, R. P., and Gerard, G. (1994). Determination of trace levels of dimethylsulfoxide (DMSO) in seawater and rainwater. Mar. Chem. 47, 1-12. doi: 10.1016/0304-4203(94)90009-4

Lee, P. A., and de Mora, S. J. (1999). Intracellular dimethylsulfoxide (DMSO) in unicellular marine algae: speculations on its origin and possible biological role. J. Phycol. 35, 8-18. doi: 10.1046/j.1529-8817.1999.3510008.x

Lee, P. A., De.Mora, S. J., and Levasseur, M. (1999). A review of dimethylsulfoxide in aquatic environments. Atmos. Ocean 37, 439-456. doi: 10.1080/07055900.1999.9649635

Lesser, M. P. (2006). Oxidative stress in marine environments: biochemistry and physiological ecology. Annu. Rev. Physiol. 68, 253-278. doi: 10.1146/annurev.physiol.68.040104.110001

Lopez y Royo, C., Casazza, G., Pergent-Martini, C., and Pergent, G. (2010). A biotic index using the seagrass Posidonia oceanica ( $\mathrm{BiPo}$ ), to evaluate ecological status of coastal waters. Ecol. Indic. 10, 380-389. doi: 10.1016/j.ecolind.2009.07.005

Lopez y Royo, C., Pergent, G., Alcoverro, T., Buia, M. C., Casazza, G., MartínezCrego, B., et al. (2011). The seagrass Posidonia oceanica as indicator of coastal water quality : experimental intercalibration of classification systems. Ecol. Indic. 11, 557-563. doi: 10.1016/j.ecolind.2010.07.012

Lovelock, E. J., and Maggs, R. J. (1972). Atmospheric dimethyl sulphide and the natural sulfur cycle. Nature 237, 452-453. doi: 10.1038/237452a0

Luy, N., Gobert, S., Sartoretto, S., Biondo, R., Bouquegneau, J. M., and Richir, J. (2012). Chemical contamination along the Mediterranean French coast using Posidonia oceanica (L.) Delile above-ground tissues: a multiple trace element study. Ecol. Indic. 18, 269-277. doi: 10.1016/j.ecolind.2011.11.005

Lyons, D. A., Scheibling, R. E., and Van Alstyne, K. L. (2010). Spatial and temporal variation in DMSP content in the invasive seaweed Codium fragile ssp. fragile: effects of temperature, light and grazing. Mar. Ecol. Prog. Ser. 417, 51-61. doi: $10.3354 /$ meps 08818

Martínez-Crego, B., Arteaga, P., Ueber, A., Engelen, A. H., Santos, R., and Molis, M. (2015). Specificity in mesograzer-induced defences in seagrasses. PLoS ONE 10:e0141219. doi: 10.1371/journal.pone.0141219

McCullagh, P., and Nedler, J. A. (1989). Generalized Linear Models. London: Chapman and Hall/CRC. doi: 10.1007/978-1-4899-3242-6

McDowell, R. E., Amsler, C. D., Dickinson, D. A., McClintock, J. B., and Baker, B. J. (2014a). Reactive oxygen species and the antarctic macroalgal wound response. J. Phycol. 50, 71-80. doi: 10.1111/jpy.12127

McDowell, R. E., Amsler, C. D., McClintock, J. B., and Baker, B. J. (2014b). Reactive oxygen species as a marine grazing defense: $\mathrm{H} 2 \mathrm{O} 2$ and wounded Ascoseira mirabilis both inhibit feeding by an amphipod grazer. J. Exp. Mar. Bio. Ecol. 458, 34-38. doi: 10.1016/j.jembe.2014.04.012

McFarlin, C. R., and Alber, M. (2013). Foliar DMSO:DMSP ratio and metal content as indicators of stress in Spartina alterniflora. Mar. Ecol. Prog. Ser. 474, 1-13. doi: $10.3354 /$ meps 10184 
Morris, J. T., Sundareshwar, P. V., Nietch, C. T., Kjerfve, B., and Cahoon, D. R. (2002). Responses of coastal wetlands to rising sea level. Ecology 83, 2869-2877. doi: 10.1890/0012-9658(2002)083[2869:ROCWTR]2.0.CO;2

Mtwana Nordlund, L., Koch, E. W., Barbier, E. B., and Creed, J. C. (2016). Seagrass ecosystem services and their variability across genera and geographical regions. PLoS ONE 11:e0163091. doi: 10.1371/journal.pone.0163091

Muggeo, V. M. R. (2003). Estimating regression models with unknown breakpoints. Stat. Med. 22, 3055-3071. doi: 10.1002/sim.1545

Murchie, E. H., and Lawson, T. (2013). Chlorophyll fluorescence analysis: a guide to good practice and understanding some new applications. J. Exp. Bot. 64, 3983-3998. doi: 10.1093/jxb/ert208

Nakajima, K. (1989). Effects of High Concentrations of Dimethylthetin, Dimethylb-Propiothetin and Vitamin $U$ on Young Rats. Takarazuka: Memoirs of Koshien University.

Norie, J. W. (Ed.). (1831). "Section, V. I. The Islands of Corsica and Sardinia," in New Piloting Directions for the Mediterranean Sea, the Adriatic, or Gulf of Venice, the Black Sea, Grecian Archipelago, and the Seas of Marmara and Azof (London: S. M’Dowall, Printer), 72-89.

Otte, M. L., and Morris, J. T. (1994). Dimethylsulphoniopropionate (DMSP) in Spartina alterniflora Loisel. Aquat. Bot. 48, 239-259. doi: 10.1016/0304-3770(94)90018-3

Otte, M. L., Wilson, G., Morris, J. T., and Moran, B. M. (2004). Dimethylsulphoniopropionate (DMSP) and related compounds in higher plants. J. Exp. Bot. 55, 1919-1925. doi: 10.1093/jxb/erh178

Paquet, L., Rathinasabapathi, B., Saini, H., Zamir, L., Gage, D., Huang, Z. H., et al. (1994). Accumulation of the compatible solute 3-dimethylsulfoniopropionate in sugarcane and its relatives, but not other gramineous crops. Aust. J. Plant Physiol. 21, 37-48. doi: 10.1071/PP9940037

Pearson, R. K. (2001). Exploring process data. J. Process Control. 11, 179-194. doi: 10.1016/S0959-1524(00)00046-9

Piazzi, L., Balata, D., and Ceccherelli, G. (2016). Epiphyte assemblages of the Mediterranean seagrass Posidonia oceanica: an overview. Mar. Ecol. 37, 3-41. doi: $10.1111 /$ maec. 12331

Pinna, S., Pais, A., Chessa, L., Nicola, S., and Ceccherelli, G. (2009). Leaf partitioning of the seagrass Posidonia oceanica between two herbivores: is Sarpa salpa herbivory underestimated because of Paracentrotus lividus grazing? Estuar. Coast. Shelf Sci. 84, 21-27. doi: 10.1016/j.ecss.2009.05.025

Pope, S. B., and Gadh, R. (1988). Fitting noisy data using cross-validated cubic smoothing splines. Commun. Stat. Simul. Comput. 17, 349-376. doi: 10.1080/03610918808812668

Prado, P., Tomas, F., Alcoverro, T., and Romero, J. (2007). Extensive direct measurements of Posidonia oceanica defoliation confirm the importance of herbivory in temperate seagrass meadows. Mar. Ecol. Prog. Ser. 340, 63-71. doi: 10.3354/meps340063

Quinn, P. K., and Bates, T. S. (2011). The case against climate regulation via oceanic phytoplankton sulphur emissions. Nature 480, 51-56. doi: $10.1038 /$ nature 10580

Rhoades, D. F. (1979). "Evolution of plant chemical defense against herbivores," in Herbivores: Their Interactions With Secondary Plant Metabolites, eds G. A. Rosenthal and D. H. Janzen (New York, NY: Academic Press), 3-54.

Richir, J., Abadie, A., Binard, M., Biondo, R., Borges, A., Cimiterra, N., et al. (2015). STARECAPMED (STAtion of Reference and rEsearch on change of local and global anthropogenic pressures on Mediterranean ecosystems drifts) - Année 2014. Calvi: Rapport de recherches, STARESO.

Rix, L. N., Burdett, H. L., and Kamenos, N. A. (2012). Irradiance-mediated dimethylsulphoniopropionate (DMSP) responses of red coralline algae. Estuar. Coast. Shelf Sci. 96, 268-272. doi: 10.1016/j.ecss.2011.11.022

Roca, G., Alcoverro, T., Krause-Jensen, D., Balsby, T. J. S., van Katwijk, M. M., Marbà, N., et al. (2016). Response of seagrass indicators to shifts in environmental stressors: A global review and management synthesis. Ecol. Indic. 63, 310-323. doi: 10.1016/j.ecolind.2015.12.007

Romero, J., Martínez-Crego, B., Alcoverro, T., and Pérez, M. (2007). A multivariate index based on the seagrass Posidonia oceanica (POMI) to assess ecological status of coastal waters under the water framework directive (WFD). Mar. Pollut. Bull. 55, 196-204. doi: 10.1016/j.marpolbul.2006.08.032

RStudio Team. (2016). RStudio: Integrated Development for R. RStudio, Inc., Boston, MA. Available online at: http://www.rstudio.com/.
Saha, M., Rempt, M., Gebser, B., Grueneberg, J., Pohnert, G., and Weinberger, F. (2012). Dimethylsulphopropionate (DMSP) and proline from the surface of the brown alga Fucus vesiculosus inhibit bacterial attachment. Biofouling 28, 593-604. doi: 10.1080/08927014.2012.698615

Schober, P., Boer, C., and Schwarte, L. A. (2018). Correlation coefficients: Appropriate use and interpretation. Anesth. Analg. 126, 1763-1768. doi: 10.1213/ANE.0000000000002864

Schultz, J. C., Appel, H. M., Ferrieri, A. P., and Arnold, T. M. (2013). Flexible resource allocation during plant defense responses. Front. Plant Sci. 4:324. doi: 10.3389/fpls.2013.00324

Silva, J., Sharon, Y., Santos, R., and Beer, S. (2009). Measuring seagrass photosynthesis: methods and applications. Aquat. Biol. 7, 127-141. doi: $10.3354 / \mathrm{ab} 00173$

Simó, R., Hatton, A. D., Malin, G., and Liss, P. S. (1998). Particulate dimethyl sulphoxide in seawater: production by microplankton. Mar. Ecol. Prog. Ser. 167, 291-296. doi: 10.3354/meps167291

Simó, R., and Vila-Costa, M. (2006). Ubiquity of algal dimethylsulfoxide in the surface ocean: geographic and temporal distribution patterns. Mar. Chem. 100, 136-146. doi: 10.1016/j.marchem.2005.11.006

Slezak, D., and Herndl, G. J. (2003). Effects of ultraviolet and visible radiation on the cellular concentrations of dimethylsulfoniopropionate (DMSP) in Emiliania huxleyi (strain L). Mar. Ecol. Prog. Ser. 246, 61-71. doi: 10.3354/meps 246061

Steele, L., Darnell, K. M., Cebrián, J., and Sanchez-Lizaso, J. L. (2014). Sarpa salpa herbivory on shallow reaches of Posidonia oceanica beds. Anim. Biodivers. Conserv. 37, 49-57. Available online at: http://abc.museucienciesjournals. cat/volume-37-1-2014-abc/sarpa-salpa-herbivory-on-shallow-reaches-ofposidonia-oceanica-beds- $2 /$ ?lang=en

Stefels, J. (2000). Physiological aspects of the production and conversion of DMSP in marine algae and higher plants. J. Sea Res. 43, 183-197. doi: 10.1016/S1385-1101(00)00030-7

Stefels, J., Steinke, M., Turner, S., Malin, G., and Belviso, S. (2007). "Environmental constraints on the production and removal of the climatically active gas dimethylsulphide (DMS) and implications for ecosystem modelling," in Phaeocystis, Major Link in the Biogeochemical Cycling of ClimateRelevant Elements, eds M. A. van Leeuwe, J. Stefels, S. Belviso, C. Lancelot, P. G. Verity, W. W. C. Gieskes (Dordrecht: Springer), 245-275. doi: 10.1007/978-1-4020-6214-8_18

Sunda, W., Kieber, D. J., Kiene, R. P., and Huntsman, S. (2002). An antioxydant function for DMSP and DMS in marine algae. Lett. Nat. 418, 317-320. doi: $10.1038 /$ nature00851

Sundareshwar, P. V., Morris, J. T., Koepfler, E. K., and Fornwalt, B. (2003). Phosphorus limitation of coastal ecosystem processes. Science 299, 563-565. doi: 10.1126/science. 1079100

Tomas, F., Alvarez-Cascos, D., Turon, X., and Romero, J. (2006). Differential element assimilation by sea urchins Paracentrotus lividus in seagrass beds: implications for trophic interactions. Mar. Ecol. Prog. Ser. 306, 125-131. doi: $10.3354 /$ meps 306125

Toms, J. D., and Lesperance, M. L. (2003). Piecewise regression: a tool for identifying ecological thresolds. Ecology 84, 2034-2041. doi: 10.1890/02-0472

Traer, K. (1979). "The consumption of Posidonia oceanica Delile by Echinoids at the Isle of Ischia," in Proceedings of the European Colloquium on Echinoderms, ed. M. Jangoux (Brussels).

Van Alstyne, K. L. (2008). "Ecological and physiological roles of dimethylsulfoniopropionate and its products in marine macroalgae," in Algal Chemical Ecology, ed. C. D. Amsler (Berlin; Heidelberg: Springer-Verlag), 173-194. doi: 10.1007/978-3-540-74181-7_8

Van Alstyne, K. L., and Houser, L. T. (2003). Dimethylsulfide release during macroinvertebrate grazing and its role as an activated chemical defense. Mar. Ecol. Prog. Ser. 250, 175-181. doi: 10.3354/meps 250175

Van Alstyne, K. L., and Puglisi, M. P. (2007). DMSP in marine macroalgae and macroinvertebrates: distribution, function, and ecological impacts. Aquat. Sci. 69, 394-402. doi: 10.1007/s00027-007-0888-Z

Van Alstyne, K. L., Wolfe, G. V., Freidenburg, T. L., Neill, A., and Hicken, C. E. (2001). Activated defense systems in marine macroalgae: evidence for an ecological role for DMSP cleavage. Mar. Ecol. Prog. Ser. 213, 53-65. doi: $10.3354 /$ meps 213053 
Van Diggelen, J., Rozema, J., Dickson, D. M. J., and Broekman, R. (1986). Beta-3-dimethylsulphonioproprionate, proline and quaternary ammonium coumpounds in Spartina anglica in relation to sodium chloride, nitrogen and sulphur. New Phytol. 103, 573-586. doi: 10.1111/j.1469-8137.1986.tb02894.x

Vassallo, P., Paoli, C., Rovere, A., Montefalcone, M., Morri, C., and Bianchi, C. N. (2013). The value of the seagrass Posidonia oceanica: a natural capital assessment. Mar. Pollut. Bull. 75, 157-167. doi: 10.1016/j.marpolbul.2013.07.044

Vergés, A., Becerro, M. A., Alcoverro, T., and Romero, J. (2007). Experimental evidence of chemical deterrence against multiple herbivores in the seagrass Posidonia oceanica. Mar. Ecol. Prog. Ser. 343, 107-114. doi: 10.3354/meps06885

Wittmann, K., Mazzella, L., and Fresi, E. (1981). Age specific patterns of leaf growth: their determination and importance for epiphytic colonization in Posidonia oceanica (L.) Delile. Rapp. Comm. Int. Mer. Mediter. 27, 189-192.

Wittmann, K. J. (1984). Temporal and morphological variations of growth in a natural stand of Posidonia oceanica (L.) Delile. PSZNI Mar. Ecol. 5, 301-316. doi: 10.1111/j.1439-0485.1984.tb00128.x

Wittmann, K. J., and Ott, J. A. (1982). Effects of cropping on growth in the Mediterranean seagrass Posidonia oceanica (L.) Delile. PSZNI Mar. Ecol. 3, 151-159. doi: 10.1111/j.1439-0485.1982.tb00380.x

Zhang, L., Kuniyoshi, I., Hirai, M., and Shoda, M. (1991). Oxidation of dimethyl sulfide by Pseudomonas acidovorans DMR-11 isolated from peat biofilter. Biotechnol. Lett. 13, 223-228. doi: 10.1007/BF01025822

Zheng, Y., Bu, N. S., Long, X. E., Sun, J., He, C. Q., Liu, X. Y., et al. (2017). Sulfate reducer and sulfur oxidizer respond differentially to the invasion of
Spartina alterniflora in estuarine salt marsh of China. Ecol. Eng. 99, 182-190. doi: 10.1016/j.ecoleng.2016.11.031

Conflict of Interest: AA is at present employed by company Seaviews.

The remaining authors declare that the research was conducted in the absence of any commercial or financial relationships that could be construed as a potential conflict of interest.

The reviewer, MS, is currently co-organizing a Research Topic with three of the authors, JR, SG, and AB, and confirms the absence of any other collaboration.

Citation: Richir J, Champenois W, Engels G, Abadie A, Gobert S, Lepoint G, Silva J, Santos R, Sirjacobs D and Borges AV (2020) A 15-Month Survey of Dimethylsulfoniopropionate and Dimethylsulfoxide Content in Posidonia oceanica. Front. Ecol. Evol. 7:510. doi: 10.3389/fevo.2019.00510

Copyright (C) 2020 Richir, Champenois, Engels, Abadie, Gobert, Lepoint, Silva, Santos, Sirjacobs and Borges. This is an open-access article distributed under the terms of the Creative Commons Attribution License (CC BY). The use, distribution or reproduction in other forums is permitted, provided the original author(s) and the copyright owner(s) are credited and that the original publication in this journal is cited, in accordance with accepted academic practice. No use, distribution or reproduction is permitted which does not comply with these terms. 


\section{OPEN ACCESS}

Edited by:

Peter Convey,

British Antarctic Survey (BAS),

United Kingdom

Reviewed by:

Paolo Vassallo,

University of Genoa, Italy

Neeraj Kumar

Meerut College, India

*Correspondence:

Arnaud Abadie

arnaudabadie@aol.fr

Specialty section:

This article was submitted to Biogeography and Macroecology,

a section of the journal

Frontiers in Ecology and Evolution

Received: 21 November 2018 Accepted: 09 May 2019

Published: 31 May 2019

Citation:

Abadie A, Richir J, Lejeune P, Leduc M

and Gobert S (2019) Structural

Changes of Seagrass Seascapes Driven by Natural and Anthropogenic Factors: A Multidisciplinary Approach

Front. Ecol. Evol. 7:190

doi: 10.3389/fevo.2019.00190

\section{Structural Changes of Seagrass Seascapes Driven by Natural and Anthropogenic Factors: A Multidisciplinary Approach}

\author{
Arnaud Abadie ${ }^{1,2 *}$, Jonathan Richir ${ }^{1,3}$, Pierre Lejeune ${ }^{4}$, Michèle Leduc ${ }^{4}$ and \\ Sylvie Gobert ${ }^{1,4}$ \\ ${ }^{1}$ Laboratory of Oceanology, Interfacultary Center for Marine Research (MARE) Centre, University of Liege, Liège, Belgium, \\ ${ }^{2}$ Seaviews, La Ciotat, France, ${ }^{3}$ Chemical Oceanography Unit, Institut de Physique, Université de Liège, Liège, Belgium, \\ ${ }^{4}$ STARESO, Calvi, France
}

Seascape ecology has been widely applied to marine habitats, including seagrass meadows, through various approaches all over the world for the past 30 years. However, these methods mainly study seagrass meadows on a single spatial scale and monitor a single driver of heterogeneity. Additionally, few assess the seascape's structural evolution. This creates gaps between the scientific data provided and those required by environmental managers and stakeholders in charge of seagrass meadow conservation. To meet their expectations, in this paper we developed a new multidisciplinary approach based on the coupling of mapping techniques, particle flux, and biometric investigations in a Mediterranean Bay, the Calvi Bay (Corsica, France), to assess the structural changes of Posidonia oceanica (L.) Delile meadows subject to disturbances. We focused our investigations on the structural characteristics, the spatial dynamics, and the particle fluxes of natural sand areas generated by bottom currents and dead matte patches which ensued from anchoring damages at 10, 15, and $20 \mathrm{~m}$ depth. Natural sand patches and anchoring patches differed in size, the first the largest. They also displayed different erosion-colonization dynamics. Natural sand patches were eroded at a mean speed of $12 \mathrm{~cm} \cdot \mathrm{a}^{-1}$ and colonized at a rate of $7 \mathrm{~cm} \cdot \mathrm{a}^{-1}$. Anchoring patches showed a mean erosion speed of $3.5 \mathrm{~cm} \cdot \mathrm{a}^{-1}$ and a colonization rate of $6.5 \mathrm{~cm} \cdot \mathrm{a}^{-1}$. Regarding particle fluxes, continuous meadow, and natural patch sedimentation and resuspension rates were $3.7 \mathrm{gDw} \cdot \mathrm{m}^{-2} \cdot \mathrm{d}^{-1}$ and $4.1 \mathrm{gDw} \cdot \mathrm{m}^{-2} \cdot \mathrm{d}^{-1}$ in average, respectively. In contrast, anchoring patches at $20 \mathrm{~m}$ depth acted as sediment traps (112.60 gDw. $\mathrm{m}^{-2} \cdot \mathrm{d}^{-1}$ in winter) and showed a higher particle resuspension rate. Our results highlighted the dichotomous dynamics of seagrass seascapes influenced by natural and anthropogenic factors. Thus, the smallest anchoring patch will take about 27 years to be recolonized while the biggest requires 60 years to be covered by the plant. With an upscaling approach, together with the newest mapping tools of marine habitats, we suggest a new method to study the evolution of seagrass meadows at a large spatial scale.

Keywords: seascape, seagrasses, dynamics, anthropogenic impacts, management, conservation 


\section{INTRODUCTION}

Over the past century, landscape ecology has been widely used to tackle environmental issues through the study of habitats' spatial heterogeneity and its effect on species distribution (Pickett and Cadenasso, 1995). A landscape can be defined as a shifting arrangement of biotic structures and the resulting mosaic of patches within a matrix connecting them (Forman et al., 1986; Robbins and Bell, 1994). Landscape ecology consists in the study of the structure, i.e., the spatial assembling of patches within the matrix; the function, i.e., the distribution of organisms within the landscape; and the evolution, i.e., the changes over time of both the structure and the function (Turner, 1989). Patch dynamics is commonly used in landscape ecology for the management of natural and anthropic ecosystems (Pittman et al., 2011; Jackson et al., 2017), although for marine habitats no formal landscape approach was developed until the 1990s (Bell and Hicks, 1991; Robbins and Bell, 1994). This recent field of study was named "seascape ecology," with reference to the application of landscape ecology concepts to the marine environment (Pittman, 2017).

Because of the ecosystemic and economical services they provide, the strong research interest they create, and the need to provide management tools, seagrass meadows were among the first marine habitats to be studied with a seascape approach (Bell et al., 2006). The seagrass Posidonia oceanica (L.) Delile endemic to the Mediterranean Sea plays major roles at the scale of the whole basin. For that reason, this seagrass is one of the most studied species with a seascape approach (Abadie et al., 2018b). Posidonia oceanica builds extensive beds with complex three-dimensional structures. These seagrass beds are under the influence of natural and anthropogenic factors leading to both spatial and temporal heterogeneity (Boudouresque et al., 2009). The definition of a $P$. oceanica seascape will vary according to the spatial scale considered and the seafloor matrix (e.g., sand, rock, seagrass) in which habitat patches are embedded (Pagès et al., 2014). In the present study, a P. oceanica seascape is defined according to Abadie et al. (2015) as the set of the different habitats (i.e., types of patch) of natural and anthropogenic origin included in a meadow matrix.

Natural factors such as erosive bottom currents and extreme seasonal wave events shape the $P$. oceanica seascape by generating sand patches within the meadow matrix (Figure 1A) and restraining the development and colonization of the plant at shallow depths (Gobert et al., 2016; Vacchi et al., 2017). Natural patches derived from bottom currents present a structural duality with an eroded vertical matte edge opposed to a colonized one (Abadie et al., 2017). In addition, the particle flux within the canopy drives the meadow's vertical growth and results in the elevation of the matte, i.e., a complex of dead/living rhizomes, roots, and sediments (Boudouresque and Jeudy De Grissac, 1983).

Anthropogenic impacts are more diverse and may affect the seascape structure with contrasted dynamics given their origin (Giakoumi et al., 2015). Mechanical impacts such as anchoring (Figure 1B), trawling, explosions, and costal urban development lead to the immediate disappearance of the seagrass and the creation of dead matte patches (Meinesz and Lefèvre, 1983; Francour et al., 1999; Kiparissis et al., 2011). Other human activities that persist over time such as fish farming, sewage outfalls, and dredging may also create dead matte patches within the $P$. oceanica matrix through over-sedimentation, organic matter overload, and light availability reduction. These persisting processes take months or even years to affect the meadows in contrast to the previous (Pergent-Martini et al., 1995; Holmer et al., 2008; Boudouresque et al., 2009).

According to the various dynamics of patches composing the $P$. oceanica seascape, the study of its changes requires a better understanding of processes involved at various spatial and temporal scales (Wedding et al., 2011). This information is needed when studying $P$. oceanica meadow changes for management or conservation purposes (Montefalcone et al., 2013). Nowadays, this knowledge is missing which restrains the

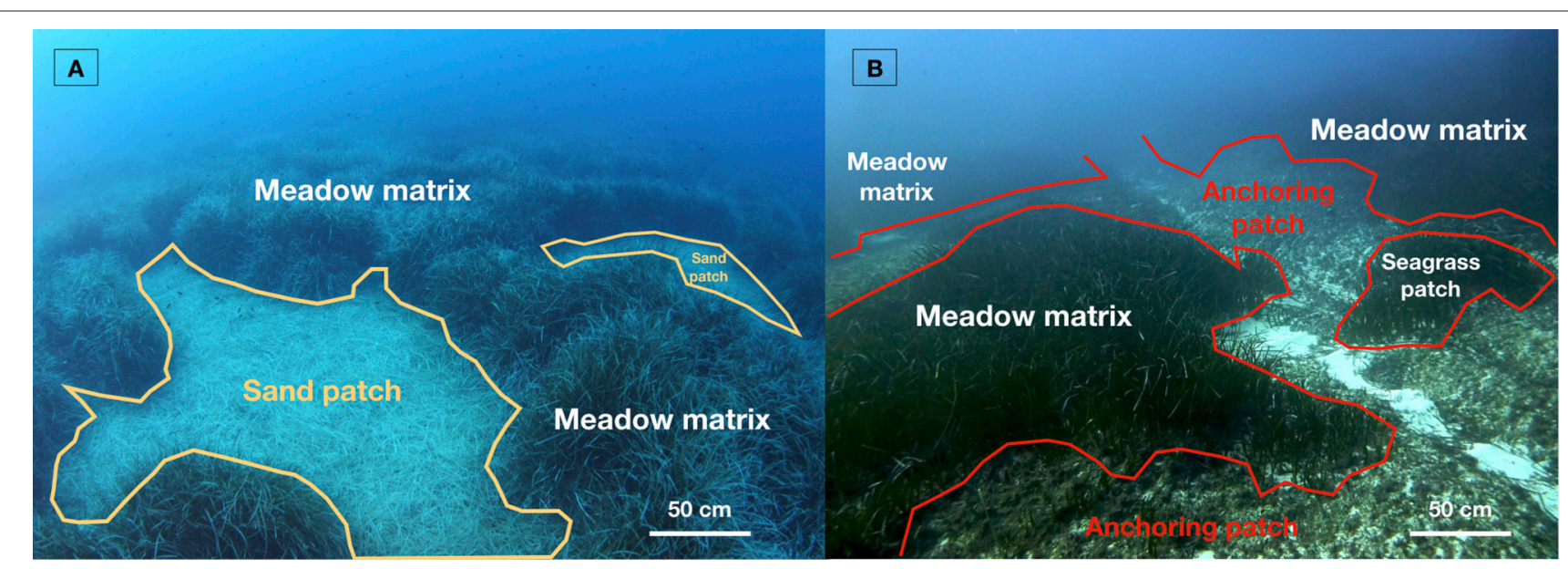

FIGURE 1 | Two contrasted P. oceanica seascapes in Calvi Bay at $20 \mathrm{~m}$ depth (Corsica, France): (A) a natural seascape made of sand patches generated by water movements; (B) a seascape impacted by intensive anchoring leading to dead matte patches. Photos: A. Abadie. 
use of practical seascape ecology as a standard tool for the study of seagrass meadows' evolution for decision makers and stakeholders. European directives, such as the Water Framework Directive (WFD) and the Marine Strategy Framework Directive (MSFD), aim at evaluating the ecological status of key marine ecosystems such as P. oceanica meadows (Gobert et al., 2009; Personnic et al., 2014). Consequently, the development of a seascape ecology approach specific to seagrass meadows is required. By studying the link between the structure of seagrass habitats, the distribution of its inhabiting organisms and changes occurring over time for the whole system, seascape ecology is a promising approach to addressing the management obligation ensuing from these directives (Abadie et al., 2018b).

To respond to this lack of knowledge for Mediterranean seascape management, an extensive research effort was performed at various temporal (seasonal to pluriannual) and spatial scales (several $\mathrm{m}^{2}$ to $\mathrm{km}^{2}$ ) in Calvi Bay (Corsica, France) to study natural and anthropogenic patch dynamics.

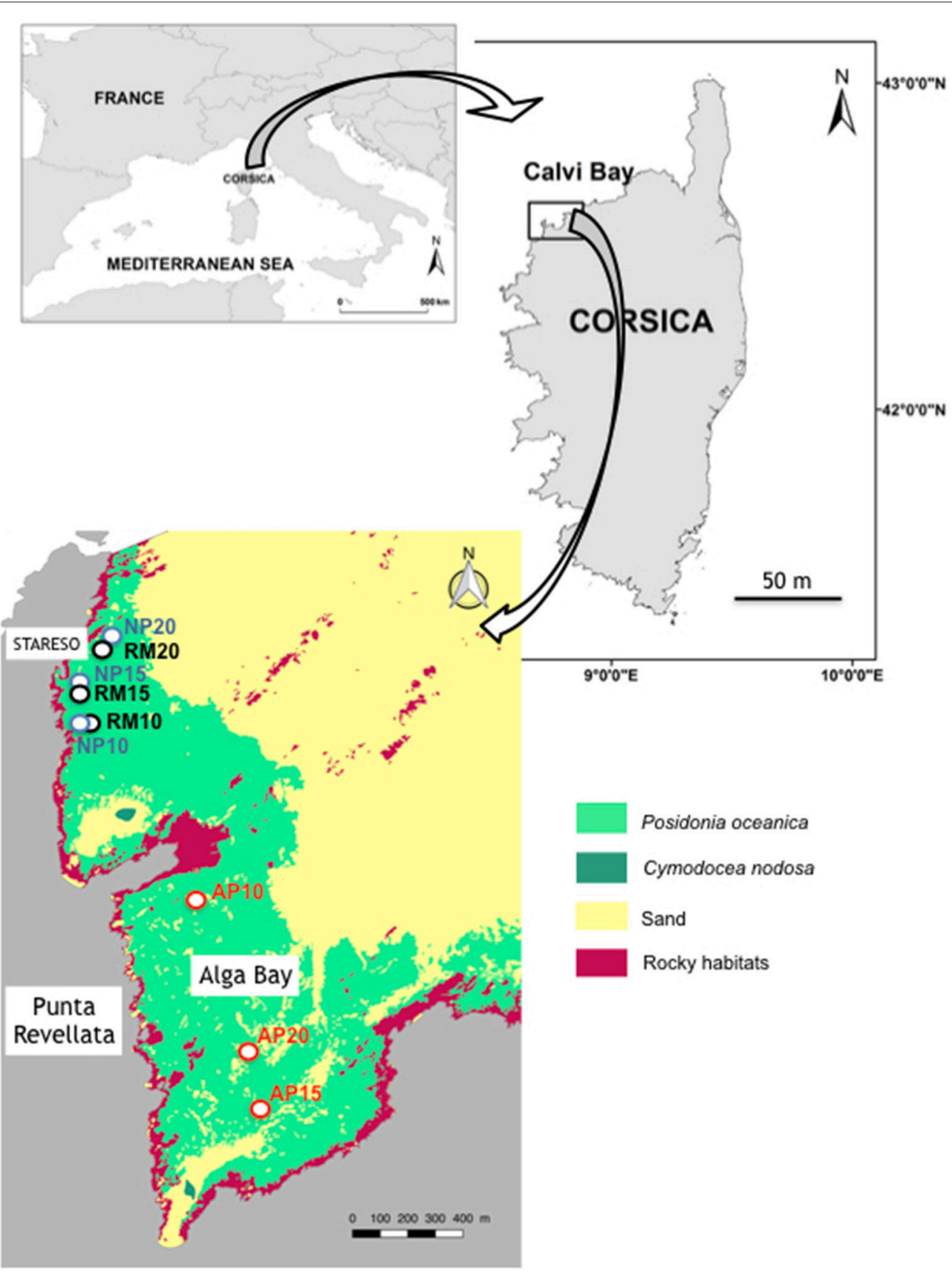

FIGURE 2 | Location of study sites in the Calvi Bay. RM, reference meadow; NP, natural patch; AP, anchoring patch. Ten, fifteen, and twenty numbers are depths. Mapping data of marine habitat are from Abadie (2012). 
First, a cartographic analysis of $P$. oceanica seascapes was performed at a large spatial scale using side scan sonar images allowing to classify patches according to their origin (Abadie et al., 2015). A second study focused on the characterization of the structure of meadows impacted by intensive anchoring and chemical dynamics within sediments of the resulting dead matte patches (Abadie et al., 2016). A third work presented results of long term investigation of the structural dynamics of sand patches resulting from water movement (Gobert et al., 2016). The most recent work compared sediment chemistry of natural sand patches at various depths and the resulting structural edge effect on the surrounding meadow (Abadie et al., 2017).
In this context, this work aimed to answer a fundamental question in the field of seagrass seascape ecology: do natural and anthropogenic patches within a meadow matrix show the same dynamics? More precisely, specific objectives of the present study were: (1) to provide a quantitative description of natural and anthropogenic anchoring patches' dynamics through a multidisciplinary approach and the acquisition of original results; (2) to merge these new findings with observations from previous studies on $P$. oceanica seascapes conducted in Calvi Bay in order to draw a general picture of $P$. oceanica seascapes' dynamics; (3) to bring new insights for seascape management for $P$. oceanica meadows and other seagrass ecosystems by

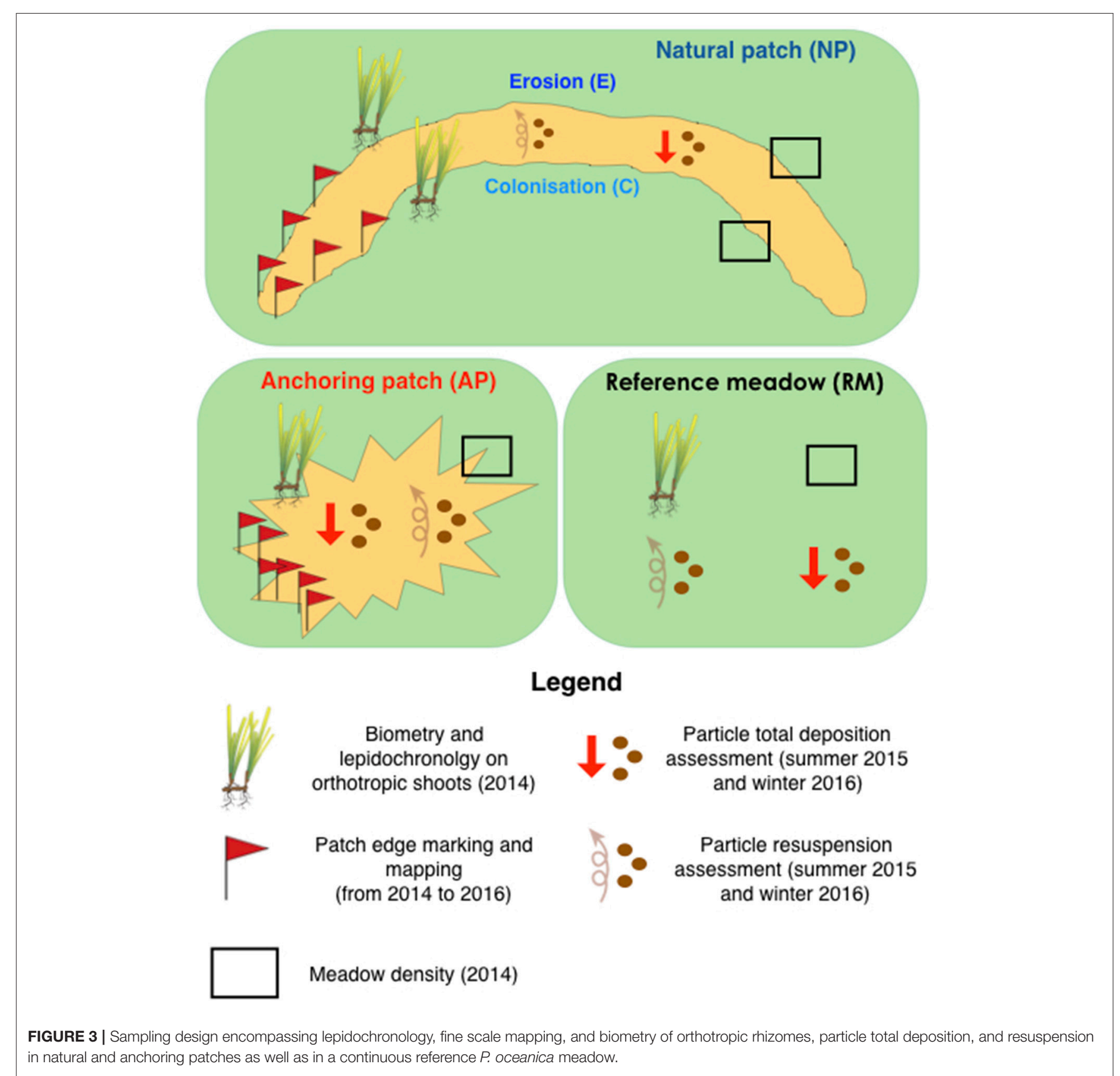


suggesting an approach for large spatial scale investigations of their structural evolution.

\section{MATERIALS AND METHODS}

\section{Sampling Design and Study Sites}

The sampling design was based on the comparison of (1) the characteristics of natural sand patches generated by water movements (both eroded and colonized sides are considered), (2) anthropogenic patches generated by anchoring, and (3) a continuous reference meadow with no human impact (Figure 2). The multidisciplinary approach (1) encompassed the growth rate and biometry of orthotropic rhizomes at the edge of the surrounding meadow, (2) the particle total deposition and resuspension inside patches as well as in the reference meadow, and (3) the spatial evolution of each patch. In order to take into account the influence of light and water movement reduction with increasing depth, this sampling design was repeated simultaneously at 10,15 , and $20 \mathrm{~m}$ depth.

Study sites were located in the Calvi Bay (Corsica, France), nearby the research station STARESO (Figure 3). Natural patches (NP) with their eroded ('E) and colonized ('C) edges (respectively, NPE and NPC), and the continuous reference P. oceanica meadow (RM) are located in the western part of the Bay near the extremity of the Punta Revellata (Figure 2). Eroded edges take the shape of a vertical wall of matte while colonized sides show plagiotropic rhizomes on bare sediments as described by Gobert et al. (2016). An intensive research effort has been performed on the P. oceanica meadows of this area since the 1970s where no mechanical anthropogenic impact has ever been observed (Michel et al., 2012). Anchoring patches (AP) are located in the smaller Alga sub-Bay at the basis of the Punta Revellata (Figure 2). An intensive anchoring pressure of leisure boats of various sizes, i.e., from 5 to $90 \mathrm{~m}$ long, has been reported for several decades in the Alga Bay. The origin of these anchoring patches was attested to through the observation of mechanical impacts along their edges corresponding to the abrasion resulting from anchor removal. Study sites nearby the STARESO research station and in the Alga Bay are the same than those studied by Abadie et al. $(2016,2017)$.

\section{Patch Marking and Mapping}

Six patches (two at each depth) were mapped using the method of Gobert et al. (2016) to monitor their surface evolution between 2014 and 2016 (Figure 3). Patch borders were marked out with labeled pegs anchored $50 \mathrm{~cm}$ deep in the sediments. A fine scale map was then obtained using triangulation measurements between pegs, i.e., by measuring the distance and orientation of each peg from the other. Each year, the distance between each peg and the nearest meadow border was measured and then reconstructed in a GIS software (QGis 3).

\section{Biometry, Rhizome Growth, and Meadow Density}

Twenty orthotropic $P$. oceanica shoots were sampled in winter 2014 in each station (RM, NPE, NPC, AP) at each depth (10, 15, and $20 \mathrm{~m}$; Figure 2) for a total of 240 shoots. Leaf surface was measured using the method of Giraud (1979). Rhizome growth and the number of new scales per year were measured using lepidochronology (Pergent et al., 1989). This method reconstructs the yearly chronological cycle of leaves' development through the measurement of their scale thickness. Ten replicates of the meadow density were randomly performed at each station using $25 \times 40 \mathrm{~cm}$ quadrats using the method of (Giraud, 1977).

\section{Particle Flux}

The particle flux, i.e., total deposition and resuspension, was investigated using the particle traps developed by Gacia et al.
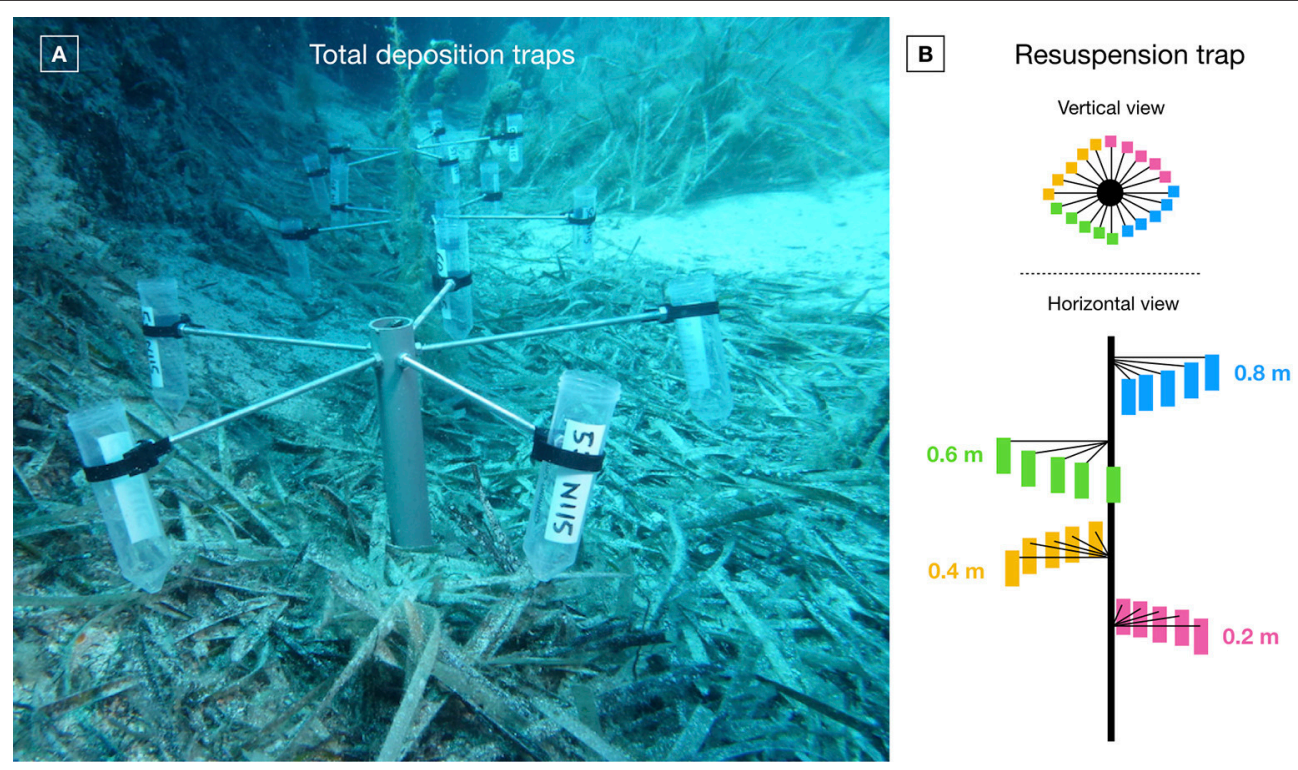

FIGURE 4 | (A) Total deposition traps in a natural patch (photo: A. Abadie); (B) Schematic vertical and horizontal views of a resuspension trap. 

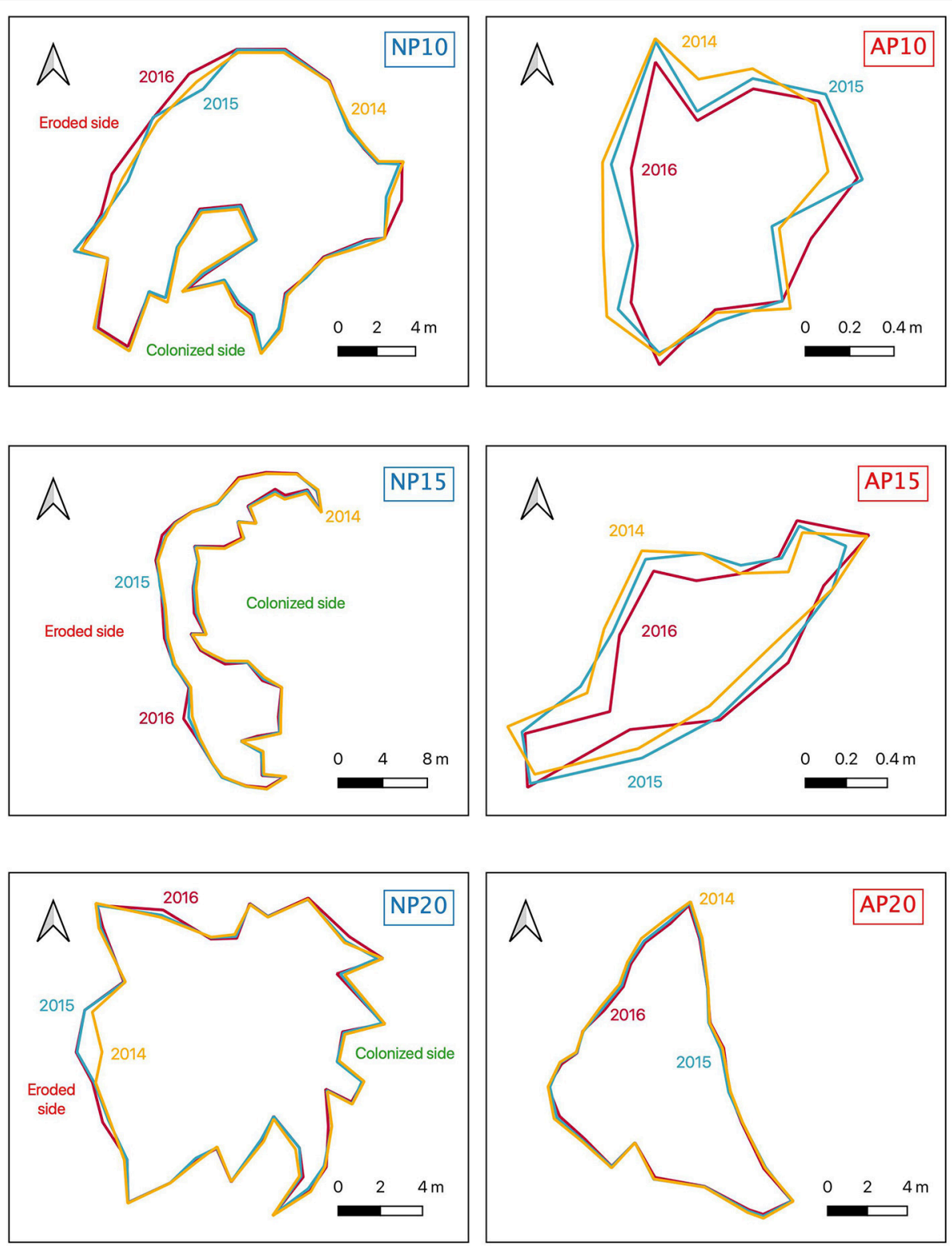

FIGURE 5 | Maps of the borders of natural (NP10, NP15, NP20) and anchoring patches (AP10, AP15, AP20) in 2014 (yellow), 2015 (blue), and 2016 (red). The position of the eroded and the natural sides are indicated for natural patches.

(1999). Traps were deployed and retrieved using SCUBA. Total deposition traps took the shape of PVC stands supporting centrifugation tubes with an aspect ratio of the opening around 3, each stand encompassing five tubes (Figure 4A). They were deployed $20 \mathrm{~cm}$ above the substrate. Particle resuspension traps were PVC ropes with four tube levels starting at $20 \mathrm{~cm}$ from the substrate and separate from each other by $20 \mathrm{~cm}$ (i.e., at $0.2,0.4,0.6$, and $0.8 \mathrm{~m}$ high). Each tube level was composed of five tubes, for a total of 20 tubes (Figure 4B). Tube levels were placed in a spiral fashion in order to avoid masking by upper ones (Figure 4B). Three total deposition traps $(n=15$ tubes) and one resuspension traps ( $n=20$ tubes) were deployed during 8 days at each depth in natural (NP) and anchoring patches (AP) and in the continuous reference meadow (RM). After retrieval, the content of particle traps was immediately filtered in STARESO's laboratory using pre-weighted GF/F filters with diameter of $25 \mathrm{~mm}$. Filters and their particle content were dried at $60^{\circ} \mathrm{C}$ during 4 days before being weighted again using a Mettler AJ100 scales with $0.0001 \mathrm{~g}$ precision. Results were expressed in $\mathrm{g}_{\mathrm{DW}} \cdot \mathrm{m}^{-2} \cdot \mathrm{d}^{-1}$ taking into account the $0.000573 \mathrm{~m}^{2}$ opening area of the tubes and the 8 days of underwater deployment.

\section{Statistical Analyses}

Statistical analyses were performed under the R 3.5.1 software (R Development Core Team, 2018) using the FactoMineR package. 
TABLE 1 | Evolution of natural and anthropogenic patch area $\left(\mathrm{m}^{2}\right)$ and edge length $(\mathrm{m})$ between 2014 and 2016.

\begin{tabular}{|c|c|c|c|c|c|c|}
\hline \multirow[t]{2}{*}{ Patch } & \multicolumn{3}{|c|}{ Area $\left(m^{2}\right)$} & \multicolumn{3}{|c|}{ Edge length (m) } \\
\hline & 2014 & 2015 & 2016 & 2014 & 2015 & 2016 \\
\hline NP10 & 138.5 & 133.8 & 140.1 & 69.4 & 70.4 & 69.1 \\
\hline NP15 & 143.9 & 142.7 & 141.7 & 97.3 & 98.2 & 98.9 \\
\hline NP20 & 136.8 & 136.8 & 138.9 & 67.1 & 67.0 & 68.5 \\
\hline AP10 & 1.0 & 0.9 & 0.8 & 4.1 & 4.4 & 4.0 \\
\hline AP15 & 0.8 & 0.9 & 0.8 & 4.8 & 4.5 & 4.8 \\
\hline AP20 & 90.6 & 87.7 & 86.0 & 45.2 & 44.6 & 44.2 \\
\hline
\end{tabular}

The normality of leaf surface, meadow density, rhizome growth, and scale number residual distribution were tested by ShapiroWilk statistic. Differences between stations (NPE vs. NPC vs. AP vs. RM) were tested for each depth $(10,15$, and $20 \mathrm{~m})$ with an ANOVA, after checking for homoscedasticity using the Fisher test. The Kruskal-Wallis test was performed when ANOVA assumptions were not met. ANOVAs and KruskalWallis tests were followed by post-hoc Tuckeys' or Dunns' multiple comparison test of means, respectively. The same statistical approach was applied to total deposition data.

\section{RESULTS}

Natural patches showed similar areas ranging between 136.8 and $143.9 \mathrm{~m}^{2}$ (Table 1; Figure 4) but had disparities in their total edge length varying between 67.1 to $97.3 \mathrm{~m}$ at a depth of 20 and $15 \mathrm{~m}$, respectively (Table 1). Anchoring patches showed a strong dimorphism both in terms of area [1.0 and $0.8 \mathrm{~m}^{2}$ at 10 and $15 \mathrm{~m}$ depth, respectively, but $90.6 \mathrm{~m}^{2}$ at $20 \mathrm{~m}$ depth; Figure 4)] and total edge length ( 4.1 and $4.8 \mathrm{~m}$ at 10 and $15 \mathrm{~m}$ depth, respectively, and 45.2 at $20 \mathrm{~m}$ depth; Table $\mathbf{1}$ ).

Although natural patches showed a clear dichotomous morphology between erosion and colonization (i.e., two continuous edges), edges of anchoring patches were an alternation of colonization and erosion without any distinct pattern (Figure 5). The percentage of the edge colonized among natural patches (NP) varied from $57.1 \%$ at $20 \mathrm{~m}$ depth to $77.3 \%$ at $10 \mathrm{~m}$ depth (Figure 6). Erosion speed (ranging from 10.5 to $15.6 \mathrm{~cm} \cdot \mathrm{a}^{-1}$ ) exceeded colonization speed (ranging from 6.5 to $8.4 \mathrm{~cm} \cdot \mathrm{a}^{-1}$ ) at all depths (Figure 6). A different pattern was

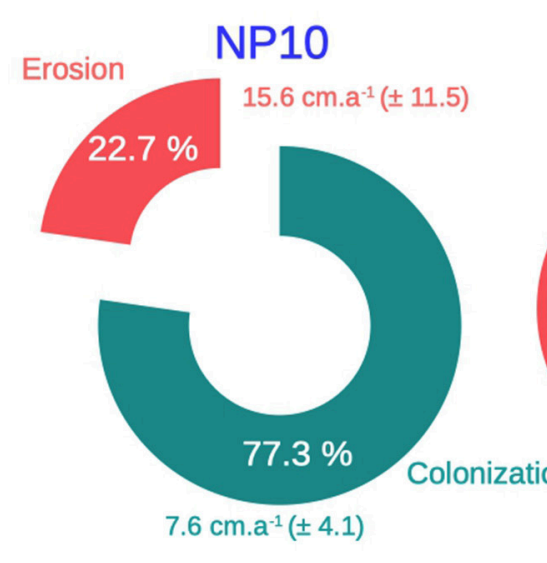

AP10

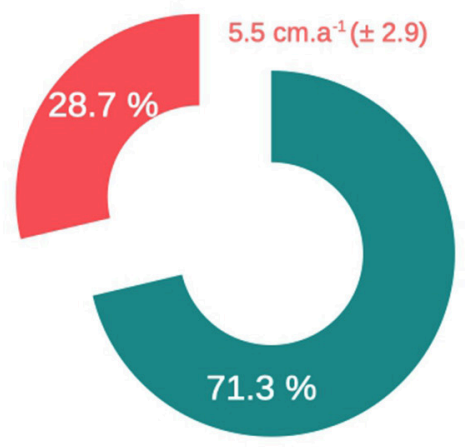

$4.7 \mathrm{~cm} \cdot \mathrm{a}^{-1}( \pm 2.9)$

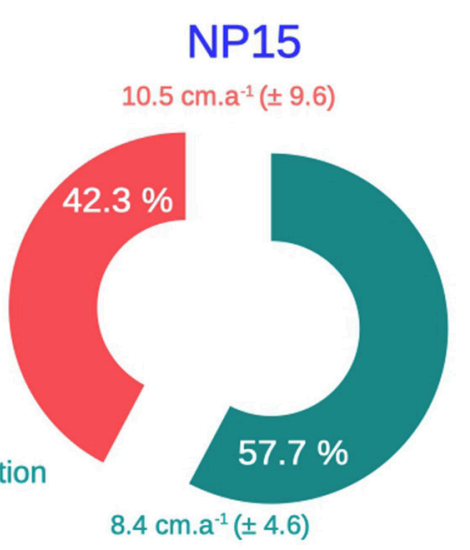

AP15

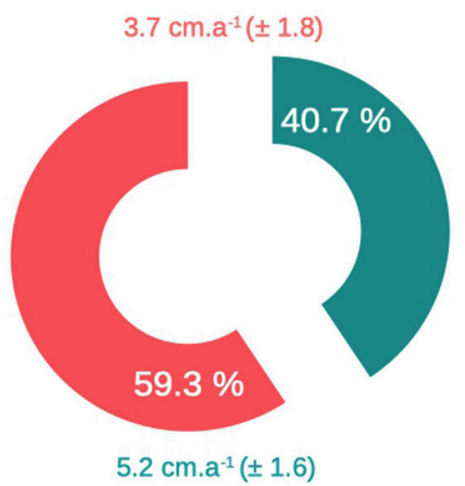

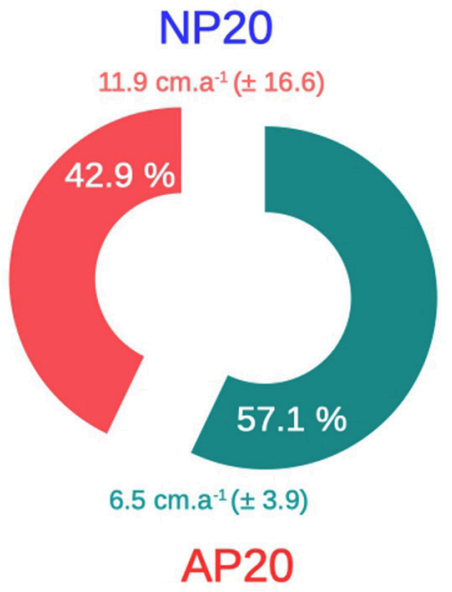

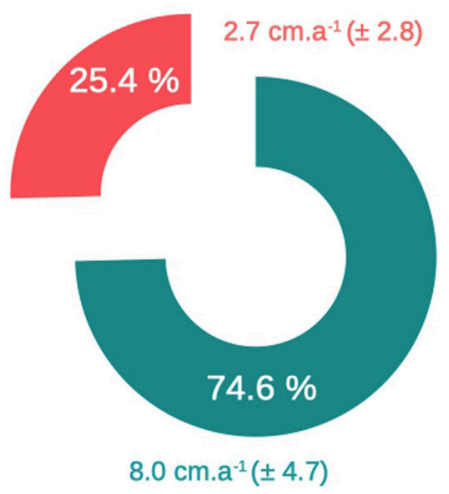

FIGURE 6 | Mean erosion (red) and colonization (green) in cm. $\mathrm{a}^{-1}$ over the edge of natural (NP) and anchoring (AP) patches at 10,15 , and $20 \mathrm{~m}$ depth between 2014 and 2016. Mean erosion and colonization speeds are expressed \pm their standard deviation. Percentages represent the edge proportion of erosion and colonization over the whole patch perimeter. 

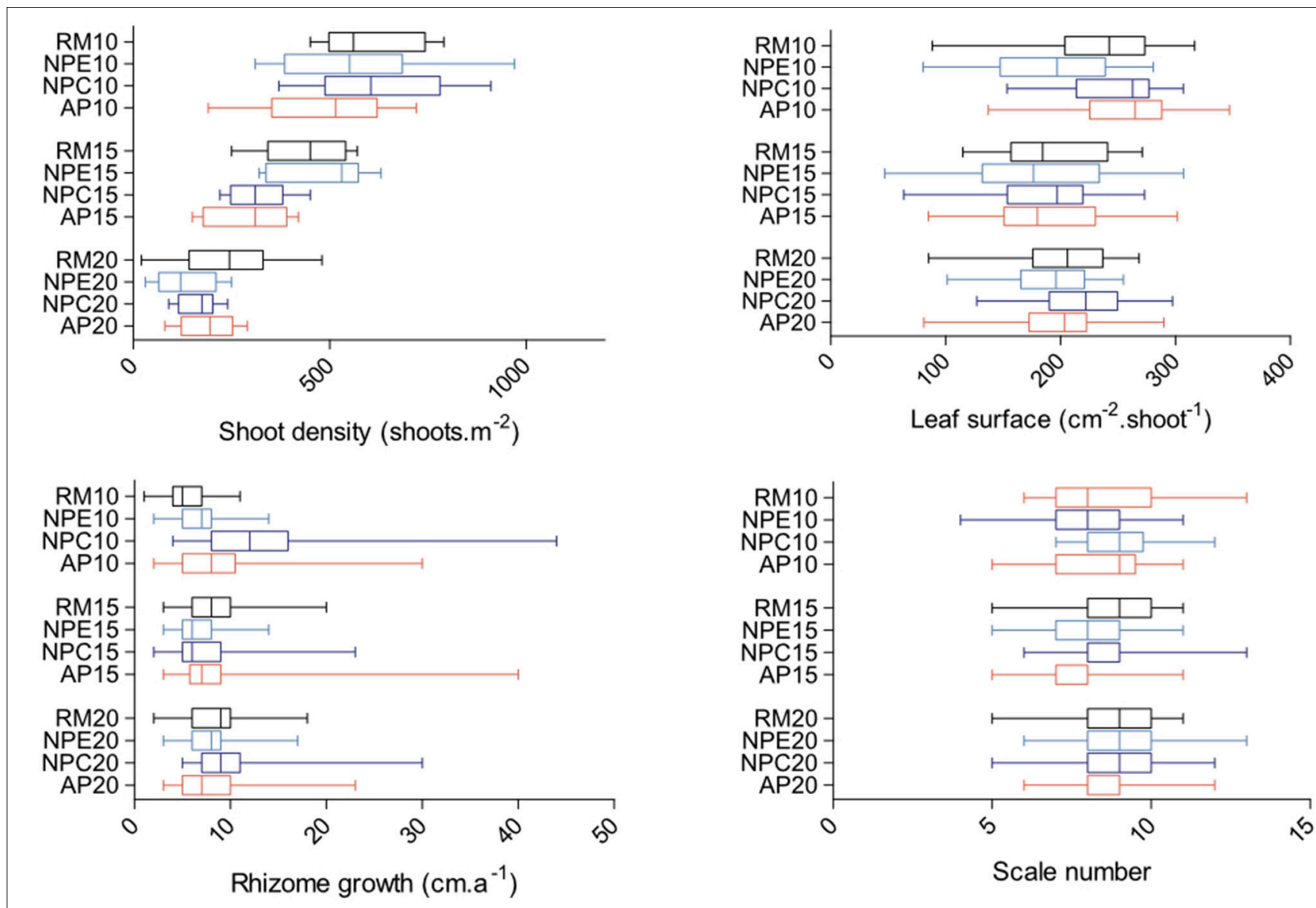

FIGURE 7 | Boxplots of leaf surface $\left(\mathrm{cm}^{-2}\right.$.shoot $\left.{ }^{-1}\right)$, shoot density (shoots. $\mathrm{m}^{-2}$ ), rhizome growth $\left(\mathrm{cm} . \mathrm{a}^{-1}\right)$, and leaf scale number per year (scales) for each of the 12 monitored stations (RM, reference meadow, black; NPE, natural patch erosion, clear blue; NPC, natural patch colonization, dark blue; AP, anchoring patch, red) at either 10, 15, or $20 \mathrm{~m}$ depth. Double bars represent minimum and maximum values.

observed for anchoring patches (AP) with contrasted percentage of erosion: $28.7 \%$ at $10 \mathrm{~m}$ depth, $59.3 \%$ at $15 \mathrm{~m}$ depth, and $25.4 \%$ at $20 \mathrm{~m}$ depth, respectively (Figure 6). Erosion speed was similar to colonization speed at $10 \mathrm{~m}$ depth (AP10, 5.5 an,d $4.7 \mathrm{~cm} . \mathrm{a}^{-1}$, respectively; Figure 6). In contrast, at 15 and $20 \mathrm{~m}$ depth, colonization speed $\left(5.2 \mathrm{~cm} \cdot \mathrm{a}^{-1}\right.$ at $15 \mathrm{~m}$ depth and $8.0 \mathrm{~cm} \cdot \mathrm{a}^{-1}$ at $20 \mathrm{~m}$ depth) speed exceeded erosion $\left(3.7 \mathrm{~cm} \cdot \mathrm{a}^{-1}\right.$ at $15 \mathrm{~m}$ depth and $2.7 \mathrm{~cm} \cdot \mathrm{a}^{-1}$ at $20 \mathrm{~m}$ depth; Figure 6).

The maximum mean leaf surface was measured at $10 \mathrm{~m}$ depth at AP10 (254.5 $\mathrm{cm}^{2} \cdot$.shoot ${ }^{-1}$; Figure 7). Significant differences were found between stations (ANOVA: $F=4.856$; $p<0.0001$; $d f=11)$. NPE10 mean leaf surface was smaller than AP10 and NPC10 ones (Figure 7). Mean shoot density showed a pick value at $10 \mathrm{~m}$ depth at NPC10 (630 shoots.m ${ }^{-2}$; Figure 7). Significant differences were found between stations (ANOVA: $F=19.5 ; p<0.0001 ; d f=11)$. Fifteen meter depth station NPE15 mean shoot density was higher than AP15 one (Figure 7). Rhizome growth followed a different pattern with both lowest (5.55 mm.a ${ }^{-1}$, RM10) and highest (13.65 mm.a ${ }^{-1}$, NPC10) mean values recorded at $10 \mathrm{~m}$ depth, all stations considered (Figure 7). Significant differences were found between stations (KruskalWallis test $=182.9 ; p<0.0001)$. Post-hoc Dunn's tests highlighted strong disparities between most stations at $10 \mathrm{~m}$ depth and between RM15 and NPE15 at $15 \mathrm{~m}$ depth (Figure 7). Finally, the maximum mean leaf scale number produced per year was recorded at station NPE20 (9.3 scales.a ${ }^{-1}$; Figure 7). Like for the other three parameters, significant differences were found between stations (Kruskal-Wallis test $=100.0 ; p<0.0001$ ). These differences were observed at $15 \mathrm{~m}$ depth between stations RM15 and AP15 and between stations NPC15 and AP15 (Figure 7).

The maximum mean total deposition is observed at station AP20 both in summer 2015 and winter 2016 with 6.38 and 112.60 gDw. $\mathrm{m}^{-2} \cdot \mathrm{d}^{-1}$, respectively (Figure 8). Significant differences were found between stations both in summer 2015 (KruskalWallis test $=56.9 ; p<0.0001$ ) and in winter 2016 (KruskalWallis test $=120.7 ; p<0.0001)$. In summer, post-hoc Dunn's tests revealed differences between station RM15 and the two other $15 \mathrm{~m}$ depth stations, and between $20 \mathrm{~m}$ depth stations RM20 and AP20 (Figure 8). Although mean total particle deposition at 10 and $15 \mathrm{~m}$ depth are of the same order in summer 2015 and winter 2016 (ranging from 2.44 to $8.51 \mathrm{~g} D \mathrm{w} \cdot \mathrm{m}^{-2} \cdot \mathrm{d}^{-1}$ ), far higher values were measured at $20 \mathrm{~m}$ depth in winter 2016 compared to summer 2015 with values ranging from 24.80 to 112.60 gDW. $\mathrm{m}^{-2} \cdot \mathrm{d}^{-1}$ (Figure 8). Among the three stations RM20, NP20, 


\section{Summer 2015}

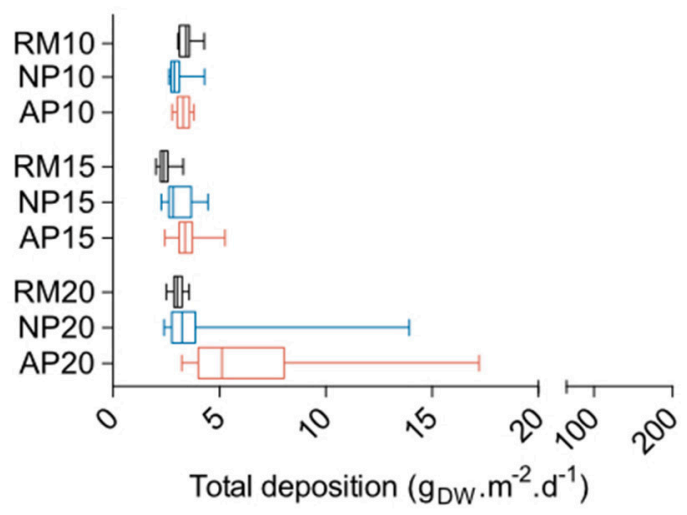

Winter 2016

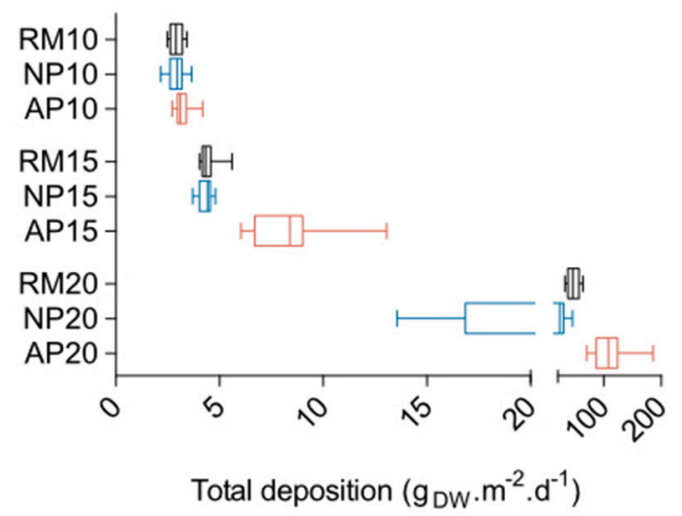

FIGURE 8 | Boxplots of total particle deposition within natural (NP, blue) and anchoring patches (AP, red) and in continuous reference meadows (RM, black) at 10, 15, and $20 \mathrm{~m}$ depth in summer 2015 and winter 2016. Double bars represent minimum and maximum values.

and AP20, AP20 mean total deposition in winter 2016 was significantly higher (Kruskal-Wallis test $=32.55 p<0.0001$ ).

A decrease of the vertical particle flux, or resuspension captured by traps was observed for all stations from 0.2 to $0.8 \mathrm{~m}$ above the seafloor (Figure 9). In summer 2015 at 10 and $15 \mathrm{~m}$ depth, the mean weight of trapped particles in the water column $\left(0.8 \mathrm{~m}\right.$, ranging from 1.77 to $2.54 \mathrm{~g}$ Dw. $\left.\mathrm{m}^{-2} \cdot \mathrm{d}^{-1}\right)$ was similar to the one closest to the sea bottom $(0.2 \mathrm{~m}$, ranging from 2.31 to $3.37 \mathrm{gDW} \cdot \mathrm{m}^{-2} \cdot \mathrm{d}^{-1}$; Figure 9). Resuspension at $0.2 \mathrm{~m}$ above the sea bottom showed the same disparities than for total deposition (Figures 8, 9). At $20 \mathrm{~m}$ depth stations in summer 2015, a higher mean weight of trapped particles were measured at all sampling heights. At station AP20 in particular, mean values ranged from $3.06 \mathrm{gDw} \cdot \mathrm{m}^{-2} \cdot \mathrm{d}^{-1} 0.8 \mathrm{~m}$ above the seafloor to 4.63 $\mathrm{g}_{\mathrm{DW}} \cdot \mathrm{m}^{-2} \cdot \mathrm{d}^{-1} 0.2 \mathrm{~m}$ above (Figure 9). In winter 2016, higher amounts of particles were trapped in the $0.8 \mathrm{~m}$ water column height above the seafloor, these amounts further increasing with the depth. The mean weight of particles was similar between the three stations at $10 \mathrm{~m}$ depth (Figure 9). At 15 and $20 \mathrm{~m}$ depth, stations AP15 and AP20 showed much higher amount of particles in the water column compared to RM and NP stations especially as we got closer to the sea bottom, with mean values ranging, respectively, from 4.12 to $8.82 \mathrm{gDw} \cdot \mathrm{m}^{-2} \cdot \mathrm{d}^{-1}$ and from 50.78 to $155.44 \mathrm{gDW} \cdot \mathrm{m}^{-2} \cdot \mathrm{d}^{-1}$ (Figure 9).

\section{DISCUSSION}

The aim of the present study was to answer a fundamental question in the field of seagrass seascape ecology: do natural and anthropogenic patches within a meadow matrix show the same dynamics? We have addressed this conservation issue through a multidisciplinary approach coupling spatial investigations, biometric analysis, and a particle flux evaluation. From field and laboratory measurements, it is clear that natural and anthropogenic patches (here anchoring patches) show contrasted structural dynamics. But how does this assertion provide new insights in the field of seagrass conservation and management?
To discuss this aspect of seagrass seascape ecology, we will consider together results from the present study and findings of previous researches conducted in the Calvi Bay on P. oceanica seascapes (Abadie et al., 2015, 2016, 2017; Gobert et al., 2016). Through an upscaling approach, we will conclude by suggesting a large spatial use of these data through extensive mapping.

\section{Colonization vs. Erosion: A Balanced Process?}

Prior to any consideration about the colonization and erosion dynamics, it is worth noting that natural sand patches and anchoring dead matte patches are not similar in terms of shape and area (Pasqualini et al., 1999; Boudouresque et al., 2012; Abadie et al., 2015). In the present study, we did not find in the Calvi Bay anchoring patches matching the size of natural ones at 10 and $15 \mathrm{~m}$ depth (Figure 4). But these observations do not imply that large anchoring patches do not exist elsewhere along the Mediterranean coast at these depths. The study of Ganteaume et al. (2005) in Port-Cros (France) at $9 \mathrm{~m}$ depth supports this assertion, although no distinctions were made by these authors among intermatte-i.e., patch-types.

Due to these disparities in size and shape, a relative approach was chosen to study the duality between the erosion and the colonization processes occurring at their edge. The natural patch at $10 \mathrm{~m}$ depth showed a higher proportion of colonized than eroded edge. In contrast, patches at 15 and $20 \mathrm{~m}$ depth showed balanced proportions of both edge types (Figure 6). This finding may seem unlikely since patches at $10 \mathrm{~m}$ depth are more exposed to water movements generated by waves and extreme storm events (Vacchi et al., 2012). This is counterbalanced by the erosion speed which exceeded the colonization one at all depths. While light availability at $20 \mathrm{~m}$ depth reduces $P$. oceanica capacity to colonize raw substrates (Marba and Duarte, 1998; Di Maida et al., 2013), light and water movement conditions at 10 and $15 \mathrm{~m}$ depth are optimal for the plant development (Elkalay et al., 2003) thus leading to higher colonization rates at the latter depths. This proportional balance between eroded and colonized edges 


\section{Summer 2015}

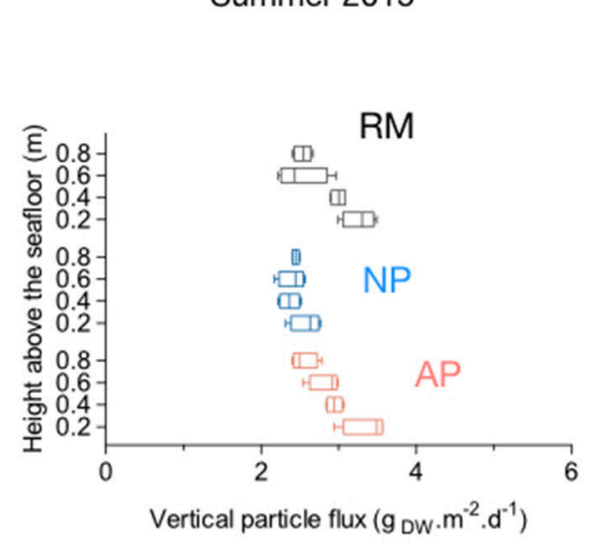

\section{Winter 2016}

$10 \mathrm{~m}$

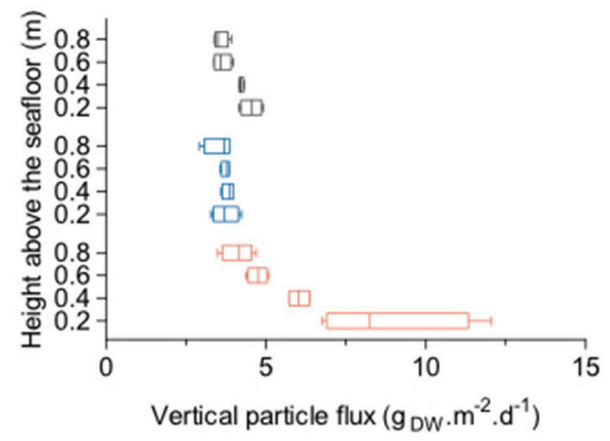

$15 \mathrm{~m}$

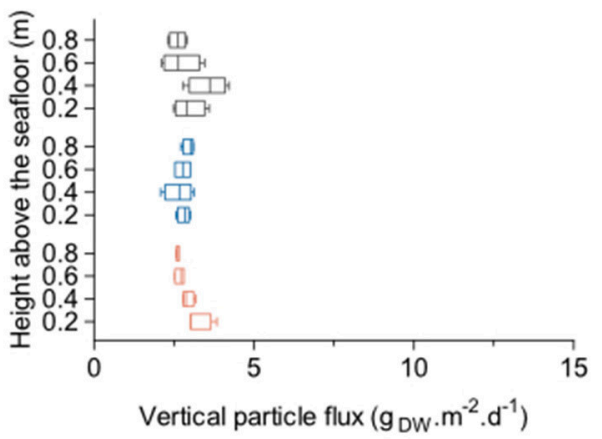

$20 \mathrm{~m}$
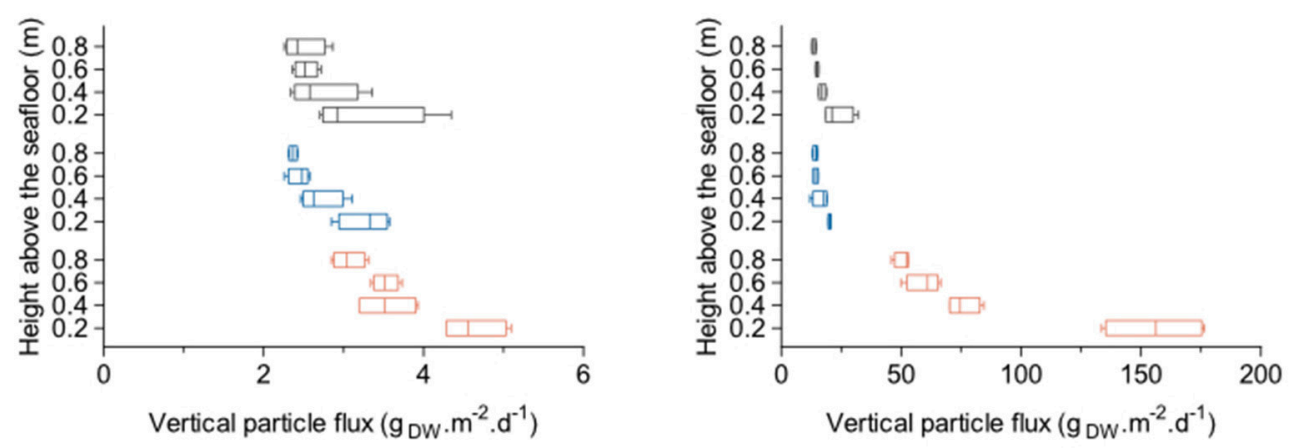

FIGURE 9 | Boxplots of vertical particle fluxes (resuspension) within natural (NP) and anchoring patches (AP) and in continuous reference meadows (RM) at 10, 15, and $20 \mathrm{~m}$ depth in summer 2015 and winter 2016. Double bars represent minimum and maximum values.

at $20 \mathrm{~m}$ depth coupled with a higher erosion speed results in the creation of large patches with an "ovoid" shape (Abadie et al., 2015). At $15 \mathrm{~m}$ depth, the higher colonization speed creates narrow corridors (Boudouresque et al., 1980; Gobert et al., 2016). These observations support the theory of Abadie et al. (2015) that described a succession of natural patches with various shapes from the seaward limit of the meadow to the landward according to water movement intensity and light availability.

Contrary to natural patches, anchoring patches showed a more erratic pattern of their proportions of colonized and eroded edges along the 10-20 m depth bathymetric gradient. However, when looking at their surface dynamics, we observed that colonization rate exceeded erosion, except for the patch at $10 \mathrm{~m}$ depth. These findings on the favorable dynamics of recolonization are contrary to Abadie et al. (2016) theory on patch extension due to $\mathrm{H}_{2} \mathrm{~S}$ chemical damages in anchoring dead matte patches. Indeed, these authors measured high $\mathrm{H}_{2} \mathrm{~S}$ concentrations at $10 \mathrm{~cm}$ depth within the dead matte of anchoring patches theoretically unfavorable to any efficient recolonization by the seagrass. In addition, the colonization process at patch edges involving plagiotropic rhizomes with few $\mathrm{cm}$ long roots (Gobert et al., 2016). So although anchoring patches are recolonized, the very slow growth 
rate of the plant (Boudouresque et al., 1983; Marba and Duarte, 1998) moderates any recovery optimism. Thereby, according to the proportion of colonized edges and colonization speed rate by plagiotropic shoots, it would take about 27 years for the 0.83 $\mathrm{m}^{2}$ anchoring patch at $15 \mathrm{~m}$ depth to be fully recolonized by $P$. oceanica (erosion excluded). For the largest $90 \mathrm{~m}^{2}$ anchoring patch investigated at $20 \mathrm{~m}$ depth, it would take about 60 years for the plant to recolonize the area. These time estimates are much longer that what would be expected from recolonization rates measured in the present study Moreover, they do not take into account the persistent anchoring pressure that delays meadow recovery. Part of the explanation could rely on the influence of $P$. oceanica morphology on the structural dynamic of patch edges.

\section{Influence of $P$. Oceanica Morphology on the Structural Dynamic of Patch Edges}

The structural dynamics and recolonization rates of both natural and anchoring patches rely certainly on the morphology of plants growing at their colonization edges. According to our data it is, however, hard to highlight any specific morphological traits of the meadow at the edge of patches explaining those dynamics. Leaf surface and meadow shoot density were similar among patch edges, and differences were observed between patch edges and the continuous reference meadows regarding rhizome growth rate and the number of new leaves. More specifically, rhizome growth was higher at the colonized edge of the natural patch at $10 \mathrm{~m}$ depth (Figure 7). High vertical growth of orthotropic rhizomes suggests high sedimentation rates (Boudouresque and Jeudy De Grissac, 1983; Alcoverro et al., 1995). High vertical growth ensures the formation of stronger matte providing better protection against water movements and extreme wave events (Vacchi et al., 2017) and therefore reducing the proportion of edge eroded. In a previous study, Abadie et al. (2017) reported that chemical and morphologic characteristics of natural patch edges in the Calvi Bay at different depths showed clear disparities: hydrodynamism is the main driver of patch dynamics through erosion which leads to changes in sediment biochemistry and the plant biological adaptations for colonization.

A contrasted statement was made by Abadie et al. (2016) regarding anchoring. These authors showed that anchoring pressure did not clearly affect $P$. oceanica meadow morphology at $10 \mathrm{~m}$ depth but had a direct mechanical action at 15 and $20 \mathrm{~m}$ depth by generating dead matte areas. Similar observations in the present study confirmed their statement. Few morphological adaptations of the plant foliar structure were observed except regarding the number of leaves produced over time that was lower at 15 and $20 \mathrm{~m}$ depth at the colonization edge of anchoring patches. These few differences could indicate a relocation of internal resources from leaf production to rhizome horizontal growth (Lepoint et al., 2004; Almela et al., 2008) as revealed by the higher colonization rate.

\section{Particle Flux Within Anchoring Patches}

At this stage of the discussion, it is obvious that the main drivers of the dynamics of natural and anchoring patches are the hydrodynamism and the mechanical damages caused by anchors respectively. As "gaps" within continuous meadows, patches modify the particle flux over the whole $P$. oceanica seascape. Indeed, continuous meadows are known to efficiently trap suspended particles within the canopy (Dauby et al., 1995; Terrados and Duarte, 2000), while unvegetated areas show higher resuspension rates (Gacia et al., 1999). But what about small unvegetated areas within $P$. oceanica meadows, i.e., natural and anchoring patches within the meadow matrix?

Our results showed that the reference continuous meadow reduced particle resuspension thanks to the leaf canopy. Similarly to large unvegetated areas, natural patches showed high resuspension rates of particles (Gacia and Duarte, 2001). Anchoring patches also act as sediment traps but in a different way. This difference was especially observed in winter at 15 and $20 \mathrm{~m}$ depth for patches AP15 and AP20 that showed morphological particularities. AP15 had a roughly circular shape forming a cauldron-like hole inside the matte. Such an ideal aspect ratio easily trapped suspended particles. In contrast, AP20 was a vast area of dead matte with little relief favoring suspended particle retention. From these structural differences, we can assume that superficial dead matte, recently created by anchoring, composed of dead roots and rhizomes and not yet fully filed with sediments, may continue to trap suspended particles from the water column until filling.

The recolonization process of anchoring patches suggests that the higher particle deposition rates observed act as a positive feedback (Maxwell et al., 2017) by providing an organic matterrich substrate. On the contrary, the high hydrogen sulfide concentrations measured by Abadie et al. (2016) at the very same stations reveal an additional negative feedback. The apparent resilience of $P$. oceanica meadows to anchoring damages in this area may derive from the overall good biological and physical conditions in Alga Bay (e.g., low algal cover, good water quality, stable climate, trophic interactions) (Unsworth et al., 2015).

\section{Upscaling for Management Purpose}

One of the main interests of stakeholders managing coastal areas colonized by $P$. oceanica meadows is to detect hotspots of anthropogenic impacts and to quantify abnormal regression of these meadows. Since the purpose of seascape ecology is to deal with large spatial scales (hectares to hundreds of $\mathrm{km}^{2}$ ), small scale studies of patch dynamics such as the present work must be upscaled to become useful managing tools. Previous works have shown that acoustic imagery using side scan sonars allow to detect and map depth limits of seagrass meadows (Pasqualini et al., 1998; Montefalcone et al., 2013) and to identify natural and anthropogenic patches (Pasqualini et al., 1999; Leriche et al., 2006). From a study of Abadie et al. (2015), it is now possible to detect, classify, and discriminate natural and anthropogenic patches along the Corsican coast from side sonar images. However, although side scan sonars provides high resolution images, their positioning precision is, at best, at several meters (Brissette and Clarke, 1999).

Due to the slow growth of $P$. oceanica and the centimetric annual evolution of patches revealed in the present study, it is obvious that a metric positioning accuracy is not sufficient 
to properly investigate the spatial evolution of $P$. oceanica seascapes. The solution of this issue relies on the use of another acoustic sensor able to provide acoustic imagery at large spatial scale as well as a centimetric positioning precision: the multibeam echo sounder (Le Bas and Huvenne, 2009). Moreover, new algorithms are currently under development to use multibeam echo sounder bathymetric data to detect seagrass meadows (Abadie et al., 2018a).

\section{CONCLUSION}

This study highlighted the dichotomous spatial evolution of natural and anchoring patches within the P. oceanica seascape and their disparities in terms of particle trapping, together leading to contrasted dynamics. Such punctual observations, when upscaled to the whole seascape through large-scale mapping, could bring new insight into the evolution of seagrass meadows.

High precision large spatial scale mapping through pluriannual surveys will provide managers and stakeholders with maps highlighting hotspots of seagrass meadow cover which is increasing or decreasing. However, to this day, precise information (metric to centimetric) on large-scale distribution of marine organisms is widely missing, especially for benthic key species like seagrasses. The development of new underwater mapping techniques such as the multibeam echo sounder will

\section{REFERENCES}

Abadie, A. (2012). Evolution des herbiers à Posidonia oceanica (L.) Delile dans la Baie de Calvi (Corse, France) et Influence de Lancrage dans la Baie de l'Alga Marseille: Aix-Marseille University.

Abadie, A., Borges, A. V., Champenois, W., and Gobert, S. (2017). Natural patches in Posidonia oceanica meadows: the seasonal biogeochemical pore water characteristics of two edge types. Mar. Biol. 164:166. doi: 10.1007/s00227-017-3199-5

Abadie, A., Gobert, S., Bonacorsi, M., Lejeune, P., Pergent, G., and PergentMartini, C. (2015). Marine space ecology and seagrasses. Does patch type matter in Posidonia oceanica seascapes? Ecol. Indic. 57, 435-446. doi: 10.1016/j.ecolind.2015.05.020

Abadie, A., Lejeune, P., Pergent, G., and Gobert, S. (2016). From mechanical to chemical impact of anchoring in seagrasses: the premises of anthropogenic patch generation in Posidonia oceanica meadows. Mar. Pollut. Bull. 109, 61-71. doi: 10.1016/j.marpolbul.2016.06.022

Abadie, A., Marty, P., and Viala, C. (2018a). "BATCLAS index: a new method to identify and map with high resolution natural and artificial underwater structures on marine wind turbine sites." in Wind Energy and Wildlife Seminar, 3rd (Artigues-prés-Bordeaux), 120-127.

Abadie, A., Pace, M., Gobert, S., and Borg, J. A. (2018b). Seascape ecology in Posidonia oceanica seagrass meadows: linking structure and ecological processes for management. Ecol. Indic. 87, 1-13. doi: 10.1016/j.ecolind.2017.12.029

Alcoverro, T., Duarte, C. M., and Romero, J. (1995). Annual growth dynamics of Posidonia oceanica - Contribution of large-scale versus local factors to seasonality. Mar. Ecol. Prog. Ser. 120, 203-210.

Almela, E. D., Marbà, N., Álvarez, E., Santiago, R., Martínez, R., and Duarte, C. M. (2008). Patch dynamics of the Mediterranean seagrass Posidonia oceanica: implications for recolonisation process. Aquat. Bot. 89, 397-403. doi: 10.1016/j.aquabot.2008.04.012

Bell, S. S., Fonseca, M. S., and Stafford, N. B. (2006). "Seagrass ecology: new contributions from a landscape perspective," in Seagrasses: Biology, Ecology, and Conservation, eds A. W. D. Larkum, R. J. Orth, and C. M. Duarte (Dordrecht: Springer), 625-645. doi: 10.1007/978-1-4020-2983-7_26 soon fill this lack of precise information. Finally, from a wider viewpoint, as the coastal fringe is a continuum of the terrestrial coastal environment, the fusion of land and underwater maps will bring about new insights to the comprehension of their interconnection (e.g., mangroves to seagrass meadows) and will be a powerful tool for large-scale management and conservation.

\section{AUTHOR CONTRIBUTIONS}

AA was responsible for the write-up of introduction, methods results, and discussion. AA, JR, and ML carried out the experiment and data collection. SG and PL supervised and advised AA on experimental design and write-up. SG and JR edited and added text to manuscript throughout.

\section{FUNDING}

This research work was conducted in the framework, of the STARE-CAPMED (STAtion of Reference and rEsearch on Change of local and global Anthropogenic Pressures on Mediterranean Ecosystems Drifts) program funded by the Territorial Collectivity of Corsica and by The French Water Agency (PACA-Corsica). The first author acknowledges a Ph.D. grant (2013/0470) of the French ANRT (Association Nationale Recherche Technologie).

Bell, S. S., and Hicks, G. R. F. (1991). Marine landscapes and faunal recruitment: a field test with seagrasses and copepods. Mar. Ecol. Prog. Ser. 73, 61-68.

Boudouresque, C. F., Bernard, G., Bonhomme, P., Charbonnel, E., Diviacco, G., Meinesz, A., et al. (2012). Protection and Conservation of Posidonia oceanica Meadows. Tunis: RAMOGE pub.

Boudouresque, C. F., Bernard, G., Pergent, G., Shili, A., and Verlaque, M. (2009). Regression of Mediterranean seagrasses caused by natural processes and anthropogenic disturbances and stress: a critical review. Bot. Mar. 52, 395-418. doi: 10.1515/BOT.2009.057

Boudouresque, C. F., and Jeudy De Grissac, A. (1983). L'herbier à Posidonia oceanica en Méditerranée: les interactions entre la plante et le sédiment. J. Rech. Océanogr. 8, 99-122.

Boudouresque, C. F., Jeudy De Grissac, A., and Meinesz, A. (1983). "Relations entre la sédimentation et l'allongement des rhizomes orthotropes de Posidonia oceanica dans la baie d'Elbu (Corse)," in International Workshop on Posidonia oceanica Beds, eds C. F. Boudouresque, A. jeudy De Grissac, and J. Olivier (Marseille: G.I.S. Posidonie), 185-191.

Boudouresque, C. F., Thommeret, J., and Thommeret, Y. (1980). "Sur la découverte d'un bioconcrétionnement fossile intercalé dans l'herbier à Posidonia oceanica de la baie de Calvi (Corse)," in Journées d'Etude de Systématique et Biogéographie Méditerranéenne (Cagliari: CIESM pub.), 139-142.

Brissette, M., and Clarke, J. E. (1999). Side scan versus multibeam echo sounder object detection: Comparative analysis. Int. Hydrogr. Rev., 76, 21-34.

Dauby, P., Bale, A. J., Bloomer, N., Canon, C., Ling, R. D., Norro, A., et al. (1995). Particle fluxes over a Mediterranean seagrass bed: a one year case study. Mar. Ecol. Prog. Ser. 126, 233-246. doi: 10.3354/ meps 126233

Di Maida, G., Tomasello, A., Sciandra, M., Pirrotta, M., Milazzo, M., and Calvo, S. (2013). Effect of different substrata on rhizome growth, leaf biometry and shoot density of Posidonia oceanica. Mar. Environ. Res. 87-88, 96-102. doi: 10.1016/j.marenvres.2013.04.001

Elkalay, K., Frangoulis, C., Skliris, N., Goffart, A., Gobert, S., Lepoint, G., et al. (2003). A model of the seasonal dynamics of biomass and production of the seagrass Posidonia oceanica in the Bay of Calvi (Northwestern Mediterranean). Ecol. Modell. 167, 1-18. doi: 10.1016/S0304-3800(03) 00074-7 
Forman, R. T. T., Godron, M., and Sons, J. W. (1986). Landscape Ecology. New York, NY: John Wiley.

Francour, P., Ganteaume, A., and Poulain, M. (1999). Effects of boat anchoring in Posidonia oceanica seagrass beds in the Port-Cros National Park (NorthWestern Mediterranean Sea). Aquat. Conserv. Mar. Freshw. Ecosyst. 9, 391-400.

Gacia, E., and Duarte, C. M. (2001). Sediment retention by a Mediterranean Posidonia oceanica meadow: the balance between deposition and resuspension. Estuar. Coast. Shelf Sci. 52, 505-514. doi: 10.1006/ecss.2000.0753

Gacia, E., Granata, T. C., and Duarte, C. M. (1999). An approach to measurement of particle flux and sediment retention within seagrass (Posidonia oceanica) meadows. Aquat. Bot. 65, 255-268. doi: 10.1016/S0304-3770(99)00044-3

Ganteaume, A., Bonhomme, P., Bernard, G., Poulain, M., and Boudouresque, C. F. (2005). Impact de l'ancrage des bateaux de plaisance sur la prairie à Posidonia oceanica dans le Parc national de Port-Cros (Méditerranée nord-occidentale). Sci. Rep. Port Cros Natl. Park. 21, 147-162.

Giakoumi, S., Halpern, B. S., Michel, L. N., Gobert, S., Sini, M., Boudouresque, C. F., et al. (2015). Towards a framework for assessment and management of cumulative human impacts on marine food webs. Conserv. Biol. 29, 1228-1234. doi: $10.1111 /$ cobi. 12468

Giraud, G. (1977). Essai de classement des herbiers de Posidonia oceanica (Linné) Delile. Bot. Mar. 20, 487-491.

Giraud, G. (1979). Sur une méthode de mesure et de comptage des structures foliaires de Posidonia oceanica (Linnaeus) Delile. Bull. Museum d'Histoire Nat. Marseille 39, 33-39.

Gobert, S., Lepoint, G., Pelaprat, C., Remy, F., Lejeune, P., Richir, J., et al. (2016). Temporal evolution of sand corridors in a Posidonia oceanica seascape: a 15-year study. Mediterr. Mar. Sci. 17, 777-784. doi: 10.12681/mms.1816

Gobert, S., Sartoretto, S., Rico-Raimondino, V., Andral, B., Chery, A., Lejeune, P., et al. (2009). Assessment of the ecological status of Mediterranean French coastal waters as required by the Water Framework Directive using the Posidonia oceanica rapid easy index: PREI. Mar. Pollut. Bull. 58, 1727-1733. doi: 10.1016/j.marpolbul.2009.06.012

Holmer, M., Argyrou, M., Dalsgaard, T., Danovaro, R., Diaz-Almela, E., Duarte, C. M., et al. (2008). Effects of fish farm waste on Posidonia oceanica meadows: Synthesis and provision of monitoring and management tools. Mar. Pollut. Bull. 56, 1618-1629. doi: 10.1016/j.marpolbul.2008.05.020

Jackson, E. L., Santos-Corujo, R. O., and Pittman, S. J. (2017). "Seascape patch dynamics," in Seascape Ecology, ed S. J. Pittman (Hoboken, NJ: John Wiley and Sons), 153-188.

Kiparissis, S., Fakiris, E., Papatheodorou, G., Geraga, M., Kornaros, M., Kapareliotis, A., et al. (2011). Illegal trawling and induced invasive algal spread as collaborative factors in a Posidonia oceanica meadow degradation. Biol. Invas. 13, 669-678. doi: 10.1007/s10530-010-9858-9

Le Bas, T. P., and Huvenne, V. A. I. (2009). Acquisition and processing of backscatter data for habitat mapping-comparison of multibeam and sidescan systems. Appl. Acoust. 70, 1248-1257. doi: 10.1016/j.apacoust.2008.07.010

Lepoint, G., Vangeluwe, D., Eisinger, M., Paster, M., van Treeck, P., Bouquegneau, J.-M., et al. (2004). Nitrogen dynamics in Posidonia oceanica cuttings: implications for transplantation experiments. Mar. Pollut. Bull. 48, 465-470. doi: 10.1016/j.marpolbul.2003.08.023

Leriche, A., Pasqualini, V., Boudouresque, C. F., Bernard, G., Bonhomme, P., Clabaut, P., et al. (2006). Spatial, temporal and structural variations of a Posidonia oceanica seagrass meadow facing human activities. Aquat. Bot. 84, 287-293. doi: 10.1016/j.aquabot.2005.10.001

Marba, N., and Duarte, C. M. (1998). Rhizome elongation and seagrass clonal growth. Mar. Ecol. Prog. Ser. 174, 269-280. doi: 10.3354/ meps174269

Maxwell, P. S., Eklöf, J. S., van Katwijk, M. M., O’brien, K. R., de la Torre-Castro, M., Boström, C., et al. (2017). The fundamental role of ecological feedback mechanisms for the adaptive management of seagrass ecosystems-a review. Biol. Rev. 92, 1521-1538. doi: 10.1111/brv.12294

Meinesz, A., and Lefèvre, J. R. (1983). "Régénération d'un herbier à Posidonia oceanica quarante années après sa destruction par une bombe dans la rade de Villefranche (Alpes-Maritimes)," in International Workshop on Posidonia oceanica Beds, eds C. F. Boudouresque, A. Jeudy De Grissac, and J. Olivier (Marseille: G.I.S. Posidonie), 39-44.

Michel, L., Abadie, A., Biondo, R., Borges, A., Collignon, A., Champenois, W., et al. (2012). STARE-CAPMED-Rapport D'activité 2012. STARESO.
Montefalcone, M., Rovere, A., Parravicini, V., Albertelli, G., Morri, C., and Bianchi, C. N. (2013). Evaluating change in seagrass meadows: a timeframed comparison of Side Scan Sonar maps. Aquat. Bot. 104, 204-212. doi: 10.1016/j.aquabot.2011.05.009

Pagès, J. F., Gera, A., Romero, J., and Alcoverro, T. (2014). Matrix composition and patch edges influence plant-herbivore interactions in marine landscapes. Funct. Ecol. 28, 1440-1448. doi: 10.1111/1365-2435.12286

Pasqualini, V., Pergent-Martini, C., Clabaut, P., and Pergent, G. (1998). Mapping of Posidonia oceanica using aerial photographs and side scan sonar : application off the Island of Corsica (France). Estuar. Coast. Shelf Sci. 47, 359-367.

Pasqualini, V., Pergent-Martini, C., and Pergent, G. (1999). Environmental impact identification along the Corsican coast (Mediterranean sea) using image processing. Aquat. Bot. 65, 311-320. http://dx.doi.org/10.1016/S03043770(99)00048-0

Pergent, G., Boudouresque, C. F., Crouzet, A., and Meinesz, A. (1989). Cyclic changes along Posidonia oceanica rhizomes (Lepidochronology) - present state and perspectives. Mar. Ecol. Pubbl. Stn. Zool. Napoli 10, 221-230.

Pergent-Martini, C., Pasqualini, V., and Pergent, G. (1995). Monitoring of the Posidonia oceanica meadow in proximity of the sea outfall from the sewage treatment plant at Marseille (Mediterranean, France). EARSeL Adv. Remote Sens. 4, 128-134.

Personnic, S., Boudouresque, C. F., Astruch, P., Ballesteros, E., Blouet, S., BellanSantini, D., et al. (2014). An ecosystem-based approach to assess the status of a mediterranean ecosystem, the Posidonia oceanica seagrass meadow. PLoS ONE 9:e98994. doi: 10.1371/journal.pone.0098994

Pickett, S. T. A., and Cadenasso, M. L. (1995). Landscape ecology: spatial heterogeneity in ecological systems. Science 269, 331-334. doi: $10.1126 /$ science.269.5222.331

Pittman, S. J. (2017). "Introducing seascape ecology," in Seascape Ecology, ed S. J. Pittman (Hoboken, NJ: John Wiley and Sons), 3-25.

Pittman, S. J., Kneib, R. T., and Simenstad, C. A. (2011). Practicing coastal seascape ecology. Mar. Ecol. Prog. Ser. 427, 187-190. doi: 10.3354/meps 09139

R Development Core Team (2018). R: A Language and Environment for Statistical Computing. Vienna, Austria: R Foundation for Statistical Computing.

Robbins, B. D., and Bell, S. S. (1994). Seagrass landscapes: a terrestrial approach to the marine subtidal environment. Trends Ecol. Evol. 9, 301-304. doi: 10.1016/0169-5347(94)90041-8

Terrados, J., and Duarte, C. M. (2000). Experimental evidence of reduced particle resuspension within a seagrass (Posidonia oceanica L.) meadow. J. Exp. Mar. Bio. Ecol. 243, 45-53. doi: 10.1016/S0022-0981(99)00110-0

Turner, M. G. (1989). Landscape ecology: the effect of pattern on process. Annu. Rev. Ecol. Evol. Syst. 20, 171-197.

Unsworth, R. K. F., Collier, C. J., Waycott, M., Mckenzie, L. J., and CullenUnsworth, L. C. (2015). A framework for the resilience of seagrass ecosystems. Mar. Pollut. Bull. 100, 34-46. doi: 10.1016/j.marpolbul.2015.08.016

Vacchi, M., De Falco, G., Simeone, S., Montefalcone, M., Morri, C., Ferrari, M., and Bianchi, C. N. (2017). Biogeomorphology of the Mediterranean Posidonia oceanica seagrass meadows. Earth Surf. Process. Landf., 42, 42-54.

Vacchi, M., Montefalcone, M., Bianchi, C. N., Morri, C., and Ferrari, M. (2012). Hydrodynamic constraints to the seaward development of Posidonia oceanica meadows. Estuar. Coast. Shelf Sci. 97, 58-65. doi: 10.1016/j.ecss.2011.11.024

Wedding, L. M., Lepczyk, C. A., Pittman, S. J., Friedlander, A. M., and Jorgensen, S. (2011). Quantifying seascape structure: extending terrestrial spatial pattern metrics to the marine realm. Mar. Ecol. Prog. Ser. 427, 219-232. doi: 10.3354/meps09119

Conflict of Interest Statement: The authors declare that the research was conducted in the absence of any commercial or financial relationships that could be construed as a potential conflict of interest.

Copyright (๑) 2019 Abadie, Richir, Lejeune, Leduc and Gobert. This is an open-access article distributed under the terms of the Creative Commons Attribution License (CC $B Y)$. The use, distribution or reproduction in other forums is permitted, provided the original author(s) and the copyright owner(s) are credited and that the original publication in this journal is cited, in accordance with accepted academic practice. No use, distribution or reproduction is permitted which does not comply with these terms. 


\section{OPEN ACCESS}

Edited by:

Alberto Vieira Borges,

University of Liège, Belgium

Reviewed by:

Sebastiaan van de Velde, University of California, Riverside,

United States

Tania M. Costa

São Paulo State University, Brazil

Alex Clare Goudie Thomson University of Technology Sydney,

Australia

*Correspondence:

Michael N. Githaiga

njoroge.michael04@gmail.com

Specialty section:

This article was submitted to Conservation,

a section of the journal

Frontiers in Ecology and Evolution

Received: 05 November 2018

Accepted: 18 February 2019

Published: 15 March 2019

Citation:

Githaiga MN, Frouws AM, Kairo JG and Huxham M (2019) Seagrass Removal Leads to Rapid Changes in

Fauna and Loss of Carbon.

Front. Ecol. Evol. 7:62.

doi: 10.3389/fevo.2019.00062

\section{Seagrass Removal Leads to Rapid Changes in Fauna and Loss of Carbon}

\author{
Michael N. Githaiga ${ }^{1 *}$, Anna M. Frouws ${ }^{2,3}$, James G. Kairo ${ }^{4}$ and Mark Huxham ${ }^{2}$ \\ ${ }^{1}$ Department of Biological Sciences, University of Embu, Embu, Kenya, ${ }^{2}$ School of Applied Sciences, Edinburgh Napier \\ University, Edinburgh, United Kingdom, ${ }^{3}$ Centre for Marine Ecosystem Research, Edith Cowan University, Perth, WA, \\ Australia, ${ }^{4}$ Kenya Marine and Fisheries Research Institute, Mombasa, Kenya
}

Seagrass habitats are important natural carbon sinks, with an average of $\sim 14 \mathrm{~kg} \mathrm{C}$ $\mathrm{m}^{-2}$ buried in their sediments. The fate of this carbon following seagrass removal or damage has major environmental implications but is poorly understood. Using a removal experiment lasting 18 months at Gazi Bay, Kenya, we investigated the impacts of seagrass loss on sediment topography, hydrodynamics, faunal community structure and carbon dynamics. Sediment pins were used to monitor surface elevation. The effects of seagrass removal on water velocity was investigated using Plaster of Paris dissolution. Sediment carbon concentration was measured at the surface and down to $50 \mathrm{~cm}$. Rates of litter decay at three depths in harvested and control treatments were measured using litter bags. Drop samples, cores, and visual counts of faunal mounds and burrows were used to monitor the impact of seagrass removal on the epifaunal and infaunal communities. Whilst control plots showed sediment elevation, harvested plots were eroded $\left(7.6 \pm 0.4\right.$ and $-15.8 \pm 0.5 \mathrm{~mm} \mathrm{yr}^{-1}$ respectively, mean $\pm 95 \%$ $\mathrm{Cl})$. Carbon concentration in the surface sediments was significantly reduced with a mean carbon loss of $2.21 \mathrm{Mg} \mathrm{C}$ ha $^{-1}$ in the top $5 \mathrm{~cm}$. Because sediment was lost from harvested plots, with a mean difference in elevation of $3 \mathrm{~cm}$, an additional carbon loss of up to $2.54 \mathrm{Mg} \mathrm{C} \mathrm{ha}^{-1}$ may have occurred over the 18 months. Seagrass removal had rapid and dramatic impacts on infauna and epifauna. There was a loss of diversity in harvested plots and a shift toward larger bodied, bioturbating species, with a significant increase in mounds and burrows. Buried seagrass litter decomposed significantly faster in the harvested compared with the control plots. Loss of seagrass therefore led to rapid changes in sediment dynamics and chemistry driven in part by significant alterations in the faunal community.

Keywords: macrofaunal communities, seagrass removal, surface elevation, carbon, bioturbation

\section{INTRODUCTION}

Seagrass beds are critical marine habitats with a wide global distribution. Their dense canopies and organically enriched sediment are habitat and refuge for a large community of resident and transient fauna including commercially important fish species, crustaceans and molluscs (Howard et al., 2014). Seagrass meadows can influence hydrodynamics by reducing current velocity, dissipating wave energy and stabilizing the sediment, leading to local sediment accretion 
(Potouroglou et al., 2017) and contributing to the protection of whole shorelines as well as facilitating the health of other ecosystems (Guannel et al., 2016). In common with the other "blue carbon" habitats (mangroves and tidal marshes), seagrasses are increasingly recognized as making an important contribution to climate change mitigation because of their ability to sequester carbon in the sediment (Duarte et al., 2005; Mcleod et al., 2011; Githaiga et al., 2017b; Huxham et al., 2018).

Seagrasses are estimated to have the greatest spatial extent of the three blue carbon ecosystems (ranging between 164,000 and $500,000 \mathrm{~km}^{2}$, with a best approximation of 177,000 $\mathrm{km}^{-2}$; Green and Short, 2003). However, they also probably suffer the fastest rates of destruction; indeed one estimate of $7 \%$ area lost $\mathrm{yr}^{-1}$ may be the worst trend for any global habitat (Waycott et al., 2009). Whilst natural events, including outbreaks of disease and eruptions of grazing urchins, can result in significant local seagrass decline (Short and WyllieEcheverria, 1996; Herkül and Kotta, 2009), the major drivers of seagrass loss are anthropogenic: eutrophication, land erosion (leading to enhanced sedimentation), mechanical damage due to dredging, seining, boat mooring, and anchoring (Short and Wyllie-Echeverria, 1996; Orth et al., 2006). The loss of seagrass implies the removal or diminution of the ecosystem services they provide, but much uncertainty remains over how quickly this might happen. In particular, the impacts of seagrass loss on carbon sequestration remains poorly understood. In their study of the global impacts and costs of carbon (C) emissions from the degradation of blue carbon habitats, Pendleton et al. (2012) assumed that between 25 and $100 \%$ of $\mathrm{C}$ in the top meter of sediment or soil is oxidized following habitat destruction. This large range, and the concomitant uncertainty in climate change impacts, underlines the need for further research on the temporal dynamics of sediment $\mathrm{C}$ following habitat loss.

One approach to the understanding of sediment and $\mathrm{C}$ dynamics following habitat destruction is to compare intact and damaged sites. Macreadie et al. (2015) provide an example from Australia, where seismic testing in the 1960s damaged a series of Posidonia australis beds, leading to a loss of $72 \%$ of sediment C. Such "natural experiments" have the advantages of temporal and spatial scale, but do not allow the controlled understanding of causal drivers that a manipulative experiment permits. There are few experimental studies that explore the impacts of seagrass loss on C; the two most relevant (Macreadie et al., 2014; Dahl et al., 2016) found no C losses following small scale disturbances, which is in contrast to the findings of the natural experiment in Macreadie et al. (2015). This suggests that disturbance may need to be large scale (in time and/or space) before an effect is found, or that there are site-specific factors not yet understood. The present study complements this recent work, using artificial removal of seagrass canopy cover in harvested plots and comparisons with intact controls to explore the impacts of seagrass canopy removal on surface elevation, sediment dynamics and $\mathrm{C}$ storage, with a novel focus on the role of fauna in mediating any changes. We test the null hypotheses that removal of intertidal seagrass has no effects on sediment C concentration, surface elevation, hydrodynamics and faunal community composition.

\section{MATERIALS AND METHODS}

\section{Study Site}

This study was carried out at Gazi Bay $\left(4^{\circ} 25^{\prime} \mathrm{S}\right.$, and $39^{\circ} 30^{\prime} \mathrm{E}$ ), in Kwale County, Kenya, in an intertidal area between the western and the eastern creeks (Figure 1). There are 12 seagrass species recognized in the bay, 6 of which are dominant: Cymodocea rotundata Ascherson, Cymodocea serrulata (R. Braun) Aschers. \& Magnus, Enhalus acoroides (L.f.) Royle, Syringodium isoetifolium (Aschers.) Dandy, Thalassodendron ciliatum (Forssk.) den Hartog, and Thalassia hemprichii (Enhrenberg) Aschers. These occur either as monospecific stands or mixed with other seagrass species with their coverage extending from low intertidal to 7 or $8 \mathrm{~m}$ depth below chart datum (Harcourt et al., 2018). The other six species are: Halodule uninervis (Forssk.) Aschers., Halodule wrightii (Aschers.), Halophila minor (Zoll.) den Hartog, Halophila ovalis (Braun) Hooker, Halophila stipulacea (Forssk.) Aschers, and Zostera capensis (Setch). Macroalgae are also abundant in the seagrass meadows; these include: Caulerpa spp., Cystoseira trinoids, Dictyota spp., Gracilaria cortica, Gracilaria saloicornia, Halimeda spp., Hyponea cornata, Sargassum spp., Turinaria decudrens, Ulva partusa, and Ulva reticulate (Coppejans et al., 1992). The intertidal and shallow subtidal areas are further characterized by obvious mounds, typically $10-20 \mathrm{~cm}$ high above the sediment, produced by a large population of Callianassa $s p p$. burrowing shrimp. The current study was confined to areas of monospecific stands of Thalassia hemprichii and Enhalus acoroides since these seagrass species are most abundant in the accessible intertidal regions. These stands have mean $( \pm 95 \% \mathrm{CI})$ shoot densities of $996 \pm 94$ and $248 \pm 28 \mathrm{~m}^{-2}$ for T. hemprichii and E. acoroides, respectively (Githaiga et al., 2017b).

Eight $3 \times 2 \mathrm{~m}$ plots were delineated using $2.5 \mathrm{~cm}$ diameter, $60 \mathrm{~cm}$ long PVC pipes pushed $50 \mathrm{~cm}$ into the sediment at each corner. Plots were placed in monospecific stands of E. acoroides and T. hemprichii (four each), at a minimum distance of $30 \mathrm{~m}$ apart, and four were each randomly assigned to removal and control treatments. The harvested treatment involved clipping, and removing, all the seagrass within the plots down to the sediment surface level (Figure 2). A timber platform, resting on supports outside the plots, was used every time during clipping, and when collecting samples and data, to avoid disturbing the sediment and belowground seagrass biomass. Any regrowth of shoots was clipped every 30 days within the 18-month duration of the experiment.

\section{Sediment $\mathbf{C}_{\text {org }}$ Density}

Measurements of carbon density in the harvested and control treatments were made 18 months after the experimental initiation. Five shallow $(5 \mathrm{~cm}$ depth by $2.7 \mathrm{~cm}$ diameter, using plastic pipe) and two deep (50 cm depth by $5 \mathrm{~cm}$ diameter, using a Russian peat corer) cores were taken per plot, for surface and deeper sediment analysis. Deep cores were sliced into $5 \mathrm{~cm}$ subsections and all samples were oven dried for $72 \mathrm{~h}$ at $60^{\circ} \mathrm{C}$ to obtain a constant weight. Dry Bulk density (DBD) (the dry weight of sediment per unit volume) was calculated for each sample as follows: $\mathrm{DBD}\left(\mathrm{g} / \mathrm{cm}^{3}\right)=$ Dry weight/Original volume of the 


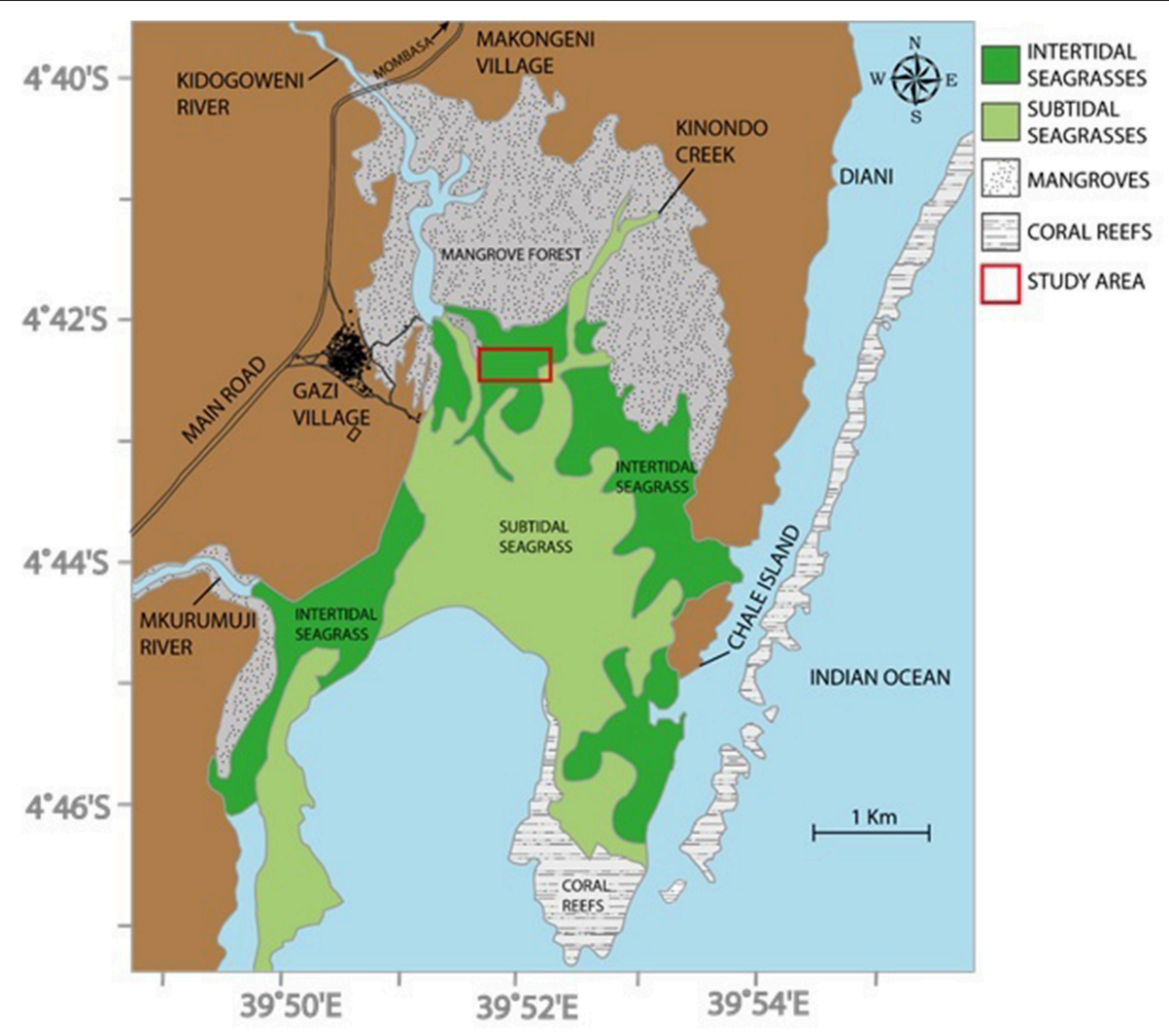

FIGURE 1 | Seagrass experimental area, Gazi Bay, Kenya (after Troch et al., 2001; Bouillon et al., 2007).

sediment. Organic matter was measured in each sample by Loss On Ignition (LOI), using a muffle furnace at $450^{\circ} \mathrm{C}$ for $6 \mathrm{~h}$. The weight loss was used to calculate the \% LOI and hence the organic matter (OM) and the organic carbon density; \% LOI = [(Initial dry weight-Weight remaining after ignition)/Initial dry weight] $\times 100) . \mathrm{C}_{\text {org }}$ values were derived using the relations: $\%$ LOI $<$ $0.2: \% \mathrm{C}_{\text {org }}=0.40 * \%$ LOI-0.21; $\%$ LOI $>0.2: \% \mathrm{C}_{\text {org }}=0.43 * \%$ LOI-0.33 taken from the Blue Carbon Manual (IPCC, 2013; Howard et al., 2014). The data from the five surface cores and the equivalent depth for the deep cores were combined, given $n=7$ per plot for surface samples and $n=2$ per plot for deeper samples.

\section{Litter Decomposition}

Prior to the start of the experiment, seagrass leaves of E. acoroides and T. hemprichii were harvested from areas adjacent to the experimental plots, washed and dried in the oven for $48 \mathrm{~h}$ at $80^{\circ} \mathrm{C}$ to a constant weight. Three grams of dried litter from each species was placed in $5 \mathrm{~cm}$ by $3 \mathrm{~cm}$ nylon bags of $1 \mathrm{~mm}^{2}$ mesh size and sealed. In each plot, at the start of the experiment, four litter depths $5 \mathrm{~cm}, 10 \mathrm{~cm}$, and $15 \mathrm{~cm}$ giving a total of 12 bags in each plot. One bag from each depth profile was retrieved every 15 days at spring tides and taken to the laboratory where they were washed over a $1 \mathrm{~mm}$ sieve to remove sediments. The resulting litter after washing was oven dried at $80^{\circ} \mathrm{C}$ for $48 \mathrm{~h}$ to obtain the dry weight. The decay rates along the depth profiles were then calculated and compared. Dried seagrass leaves do not reflect the chemical complexity of sedimentary organic C, with its mix of sources, ages and susceptibility to mineralisation. Hence the litter bags were used to provide a simple measure of possible changes between treatments in biogeochemical processes that manifest in decay rates (such as oxygen availability) rather than simulations of ambient, unaltered sedimentary processes.

\section{Surface Elevation Pins}

Surface Elevation Pin arrays (SEPs) were established within each plot. Six $1 \mathrm{~m}$ long, $5 \mathrm{~mm}$ diameter stainless steel rods were hammered to the bedrock at a spacing of $1 \times 2 \mathrm{~m}$. A spirit level was used to ensure that the rods were inserted vertically, and a hack saw was used to cut the tops of the rods leaving a projection of $20 \mathrm{~cm}$ above the sediment surface. Measurements of surface elevation change were taken monthly during low spring tides. The height of the projection of each steel rod above the sediment surface was recorded after lowering a thin, plastic horizontal disc ( $<1 \mathrm{~mm}$ thick and diameter $40 \mathrm{~mm}$ ) with a central hole over the top and down to the sediment surface to avoid taking measurements affected by local scouring immediately adjacent to the pin.

\section{Speed of Water Movement}

The effect of seagrass removal on the speed of water movement was measured indirectly by use of plaster of Paris "clod cards" (gypsum blocks) following Jokiell and Janice (1993). 


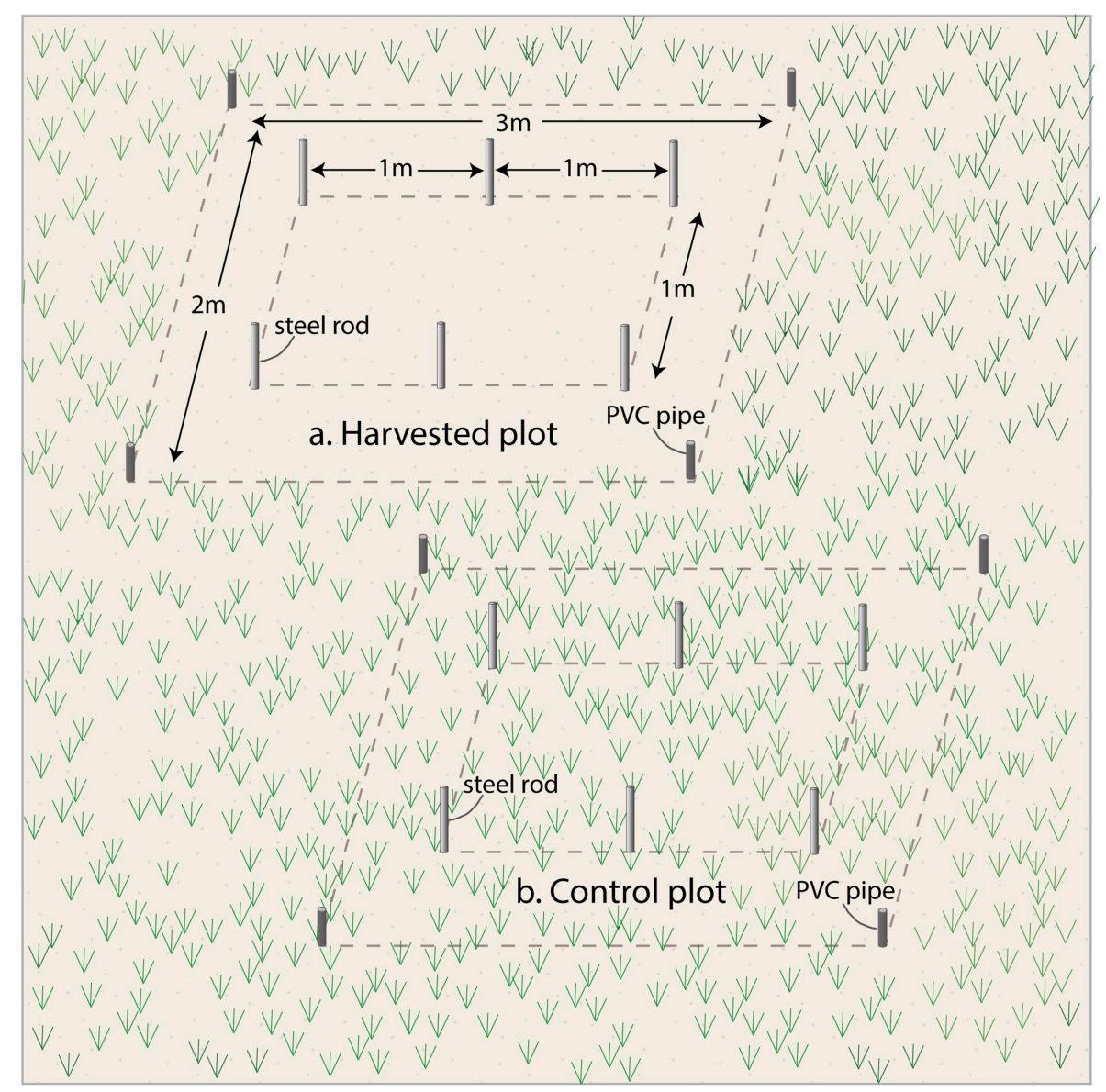

FIGURE 2 | Layout of the (A) Seagrass harvested and (B) control plots.

Measurements were taken 5 times in different spring tides in the months of February, March, August and December of 2015 and June of 2016. The clods were prepared by mixing $100 \mathrm{ml}$ of fresh water with $80 \mathrm{~g}$ plaster of Paris powder manufactured by Hobby Craft Trading limited, Dorset UK, poured in ice cube trays $(4 \times$ $2 \times 1.5 \mathrm{~cm}$ per cube) and dried to form the clod cubes. They were then sanded at the bottom to attain a uniform weight of $12.5 \pm 1.5 \mathrm{~g}$ within a batch. Each of the plaster cubes was glued to a plastic plate measuring $3 \times 8 \mathrm{~cm}$ with silicone cement (No Nonsense Ltd.BA 228RT) and the combined weights recorded. Four plaster clod cards facing the four cardinal directions were fixed to straight poles at heights of 0,15 , and at $80 \mathrm{~cm}$ from the sediment surface and one pole placed at the center of each of the 8 plots (Figures 3,4). They remained in the field for $24 \mathrm{~h}$ after which they were removed and taken to the laboratory for oven drying at $40^{\circ} \mathrm{C}$ for 48 hours and dry weight was recorded.

\section{Infaunal and Epifaunal Communities}

Two cores $(10.5 \mathrm{~cm}$ diameter by $10 \mathrm{~cm}$ depth) were randomly collected per plot at 1 month after the start of the experiment, and three cores per plot at 13 months after the start of the experiment. Cores were gently washed over a $500 \mu \mathrm{m}$ mesh sieve to collect infauna and seagrass biomass. To study epifauna communities, two drop box samples were randomly taken per plot at 13 months after the start of the experiment (Figure 4). A bottomless square metal box $(50 \times 50 \times 50 \mathrm{~cm})$ was rapidly pushed into the sediment at low tide $(<50 \mathrm{~cm}$ depth). Fauna present within the box was collected with a $500 \mu \mathrm{m}$ mesh sieve. Sieving stopped when two consecutive sieves were retrieved without fauna present. Fauna from cores and drop box samples was fixed in $10 \%$ formalin between 2 and 7 days before being washed and stored in 70\% ethanol (Bowden et al., 2001; Berkenbusch et al., 2007). Organisms were identified to family level when feasible using a Leica Stereo Zoom S6E microscope with $40 \times$ magnification. Identification was performed using a variety of guides and webpages and occasional expert advice (Day, 1967; Smith and Heemstra, 1999; Hayward and Ryland, 2000; NgocHo, 2003; Campbell, 2007; Sida and WIOMSA, 2011; Odido et al., 2015; WoRMS Editorial Board, 2015). Fauna were also assigned to functional groups (FG). The numbers of visible burrows and mounds in the sediment in all the plots were counted in each of nine successive months, starting 156 days after the start of the experiment, as an indicator of bioturbating activity. Counts only included burrows with a diameter $>0.5 \mathrm{~cm}$ and the seagrass in 
the control plots carefully pushed aside if necessary, to facilitate accurate counting of burrows.

\section{Data Analyses}

When appropriate the assumptions of normality and homogeneity of variances were checked by inspecting residuals, and where necessary the data were $\log 10$ or square root transformed to improve statistical fit. Repeated measures ANOVA, with treatment and time factors, was used to compare surface elevation between the harvested and control treatments. Carbon density between treatments was compared using separate nested ANOVAs for surface (top $5 \mathrm{~cm}$ ) and whole core profiles. Rates of litter decay at each depth and within each plot were calculated by fitting exponential curves to derive

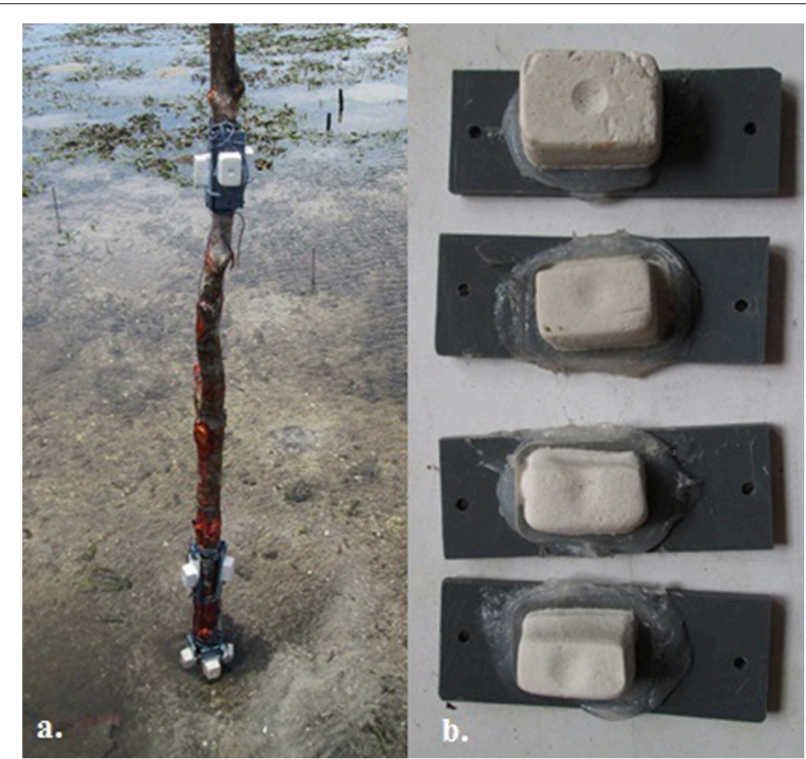

FIGURE 3 | Plaster of Paris clods for the current speed monitoring. (a) Clod cards mounted to a stick in field (b) Clod card drying after removal from the field, showing clear differences in dissolution. decay constants $(k)$ for each plot $\times$ depth combination. These were used as replicates in a two-way ANOVA with depth and treatment as factors. The effects of the factors treatment (harvested vs. control), height and time on the percentage weight loss of gypsum clods over a $24 \mathrm{~h}$ period, repeated 5 times, were examined using repeated measures ANOVA. Abundance and taxon counts of fauna were compared between removal and control treatments at 1 and 13 months. Differences in key functional groups between treatments were explored by examining the percentage contributions of each group to total abundance in treatments, and visible evidence of bioturbation (burrows and mounds) was compared between treatments using repeated measures ANOVA. Statistical analyses were performed using Minitab 17 and SPSS 23 software.

\section{RESULTS}

\section{$C_{\text {org }}$ Density}

The $\mathrm{C}_{\text {org }}$ density differed significantly between treatments in the surface sediment (top $5 \mathrm{~cm}$ ) after 18 months [nested ANOVA, $\left.\mathrm{F}_{(1,6)}=9.98, p=0.02\right]$. The mean $( \pm 95 \% \mathrm{CI}) \mathrm{C}$ densities in the top $5 \mathrm{~cm}$ of sediment were $0.0085( \pm 0.0027)$ and 0.004 $( \pm 0.0005) \mathrm{gC} / \mathrm{cm}^{3}$, translating to a mean difference between treatments of $2.21 \mathrm{Mg} \mathrm{C} \mathrm{ha}{ }^{-1}$ in the top $5 \mathrm{~cm}$. However, this difference was limited to the surface, with no significant differences found over the whole depth profiles.

\section{Litter Decay at Three Depths}

The seagrass litter showed exponential decay throughout the 2-month period of monitoring across all the depths in all cases (Figure 5). Significantly faster litter decay rates were recorded in harvested compared to control plots $\left[F_{(1,2)}=22.50, p=0.042\right]$ while depth did not have significant effects on litter decay rates (Supplementary Material).

\section{Surface Elevation}

Harvested plots showed a trend of sediment loss over the course of the experiment, compared with periods of stability and accretion in controls (Figure 6). Clear differences between

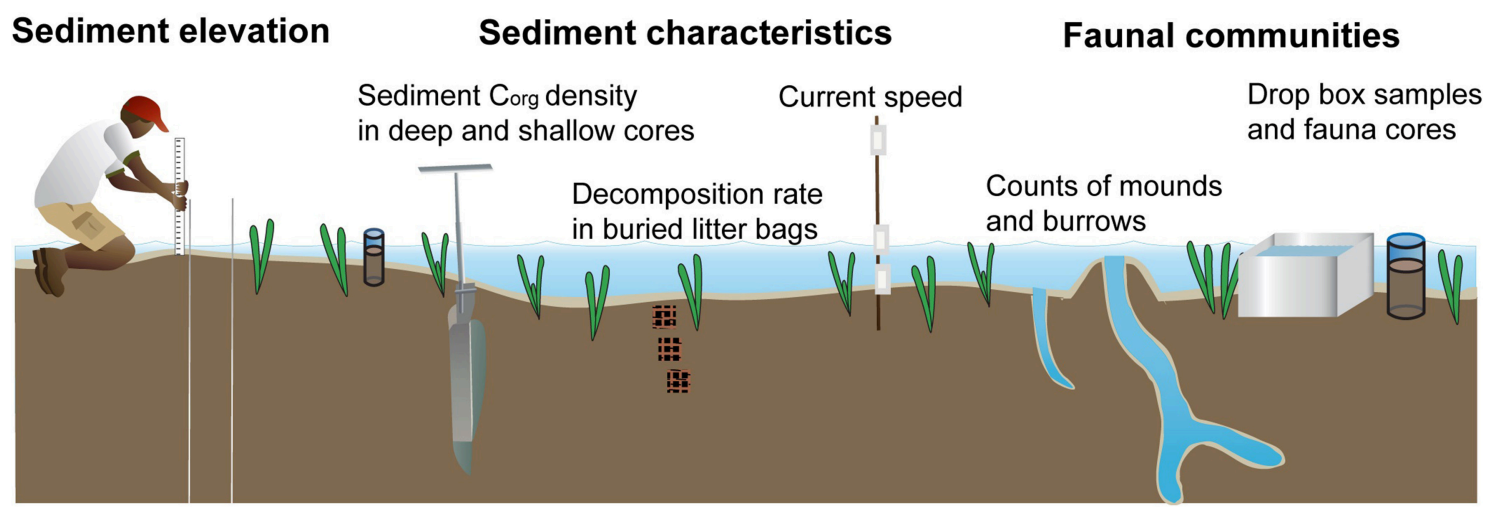

FIGURE 4 | Combined layout of the experimental set up (Images adjusted from: ian.umces.edu/symbols). 

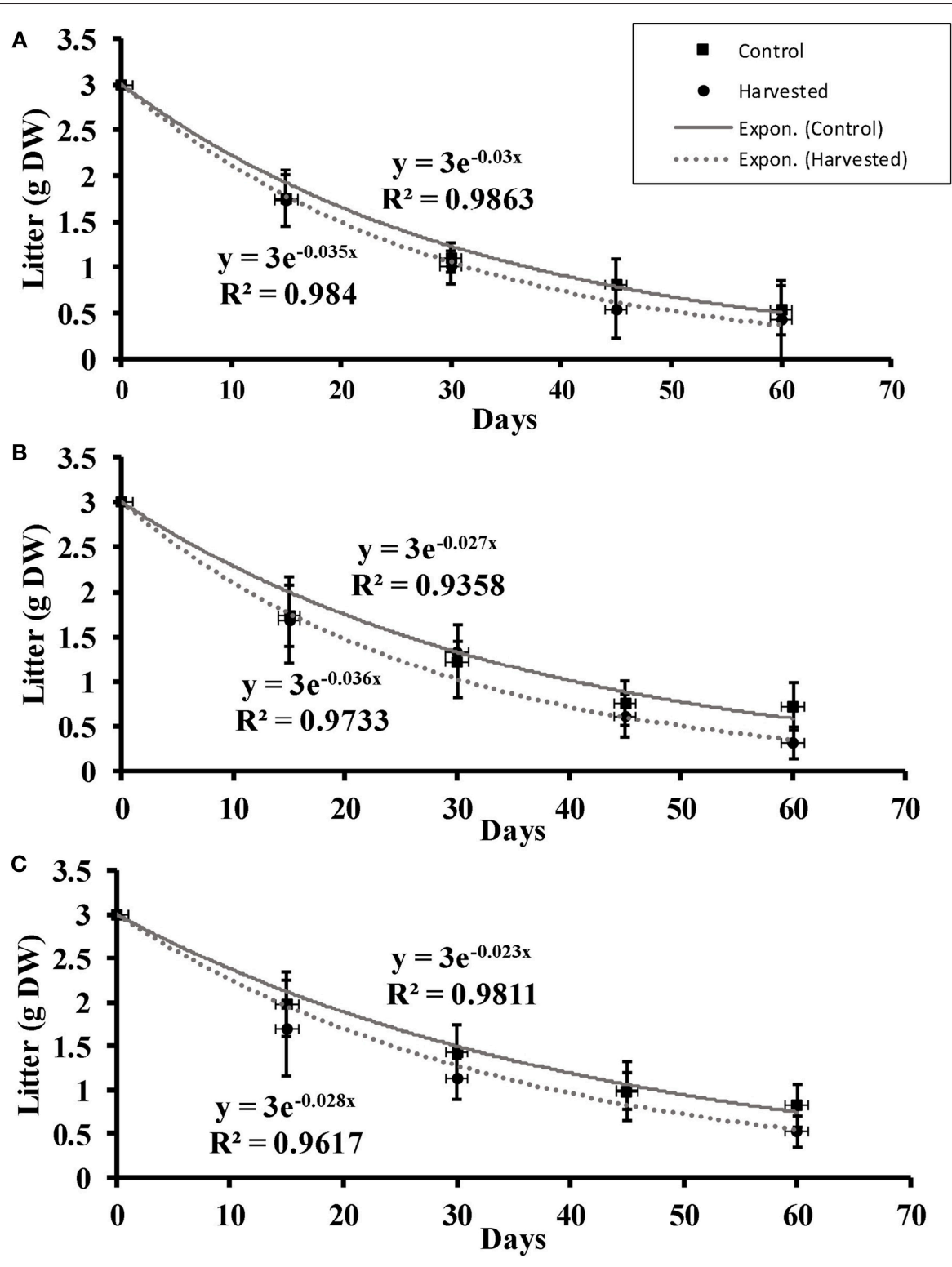

FIGURE 5 | Litter decomposition (mean $\pm 95 \%$ Cl) over a two-month period at (A) $5 \mathrm{~cm}$, (B) $10 \mathrm{~cm}$, and (C) $15 \mathrm{~cm}$ depths in the harvested and control plots.

treatments appeared 8 months from the start of the experiment (Figure 7), perhaps implying a loss of belowground, as well as aboveground, biomass was important; roots and rhizomes persisted for many months before beginning to die off. The mean ( $\pm 95 \% \mathrm{CI}$ ) sediment elevation over the eighteenmonth period in the control treatment was $7.6 \pm 0.4 \mathrm{~mm}$ $\mathrm{yr}^{-1}$ compared with $-15.8 \pm 0.5 \mathrm{~mm} \mathrm{yr}^{-1}$ in harvested plots. There was a significant interaction effect between treatment and time in the repeated measure ANOVA on sediment elevation change $\left[F_{(17,102)}=3.59, p<0.01\right.$; Figure 6]; the non-overlapping confidence intervals show significant differences at multiple individual time points (Supplementary Material).

\section{Speed of Water Movement}

The percentage weight loss of clod cards $\left(\frac{\text { Weight loss after } 24 \text { hrs exposure }}{\text { Original weight }} \times 100\right)$ was used as an indicator for current speed, with a higher percentage weight loss indicating a larger current speed. Clod cards placed close to the sediment in the seagrass removal plots lost more weight than those in the controls within the 24-h exposure period, suggesting higher current speed in the harvested plots. Weight loss was higher at 15 and $80 \mathrm{~cm}$ above the sediment surface, with little differences here between treatments (Supplementary Material). Hence there was a significant interaction effect between height and treatment $\left[F_{(2,12)}=6.102, p=0.015\right.$; Figure 7$]$. 


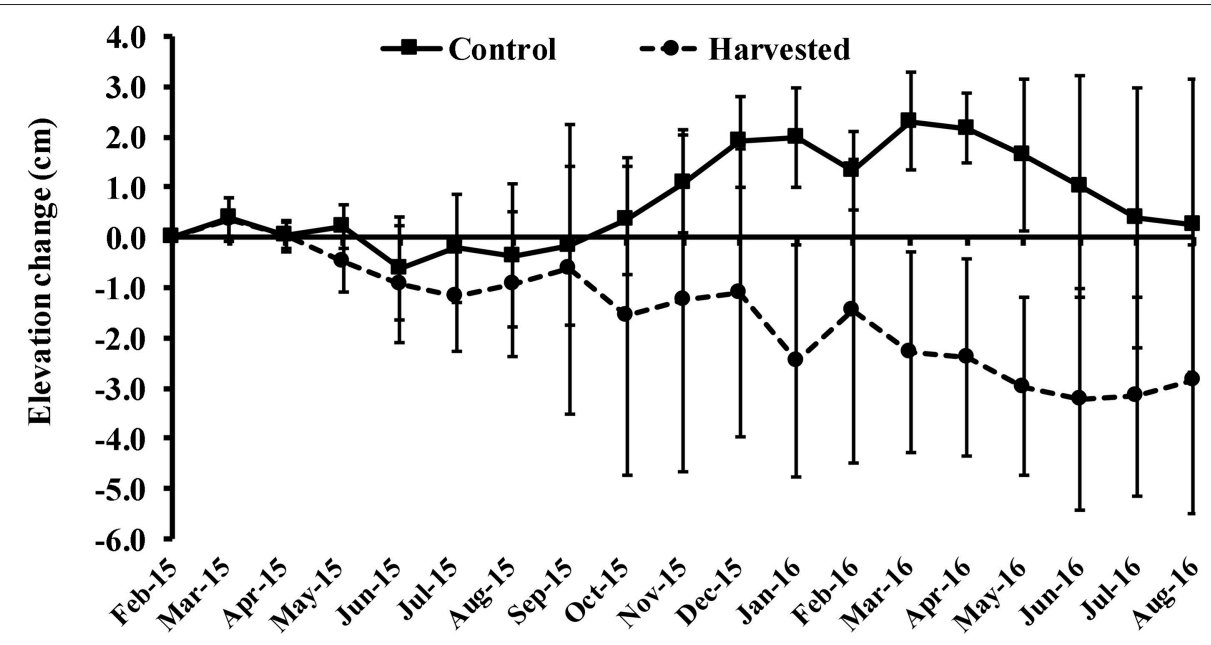

Month

FIGURE 6 | Mean surface elevation change $( \pm 95 \% \mathrm{Cl})$ in the seagrass beds of Gazi Bay relative to the initial height of each pin in February 2015.

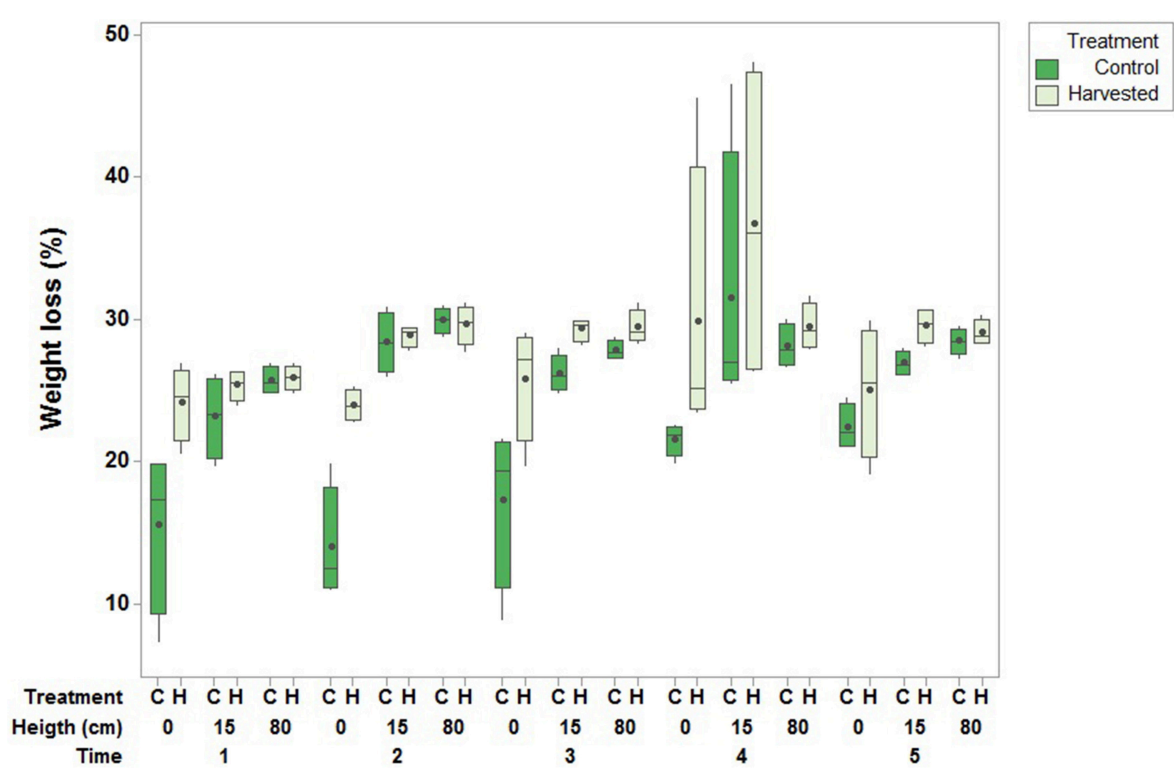

FIGURE 7 | Effect of seagrass removal treatment on \% loss of gypsum clod cards (central lines are medians, boxes interquartile ranges and the dots are means) over a 24-h exposure period. Boxplots are based on one measurement per plot ( $N=4$ per treatment) with three heights (0, 15 , and $80 \mathrm{~cm}$ from the sediment) and five measurement times [February (1), March (2), August (3) and December (4) 2015 and June 2016 (5)].

\section{Infaunal and Epifaunal Communities}

A total of 33,092 organisms were processed at the two sampling moments in 2015 and 2016, with almost 27,000 from control and around 6,000 individuals from harvested plots. There was a total of 57 taxa, 52 from control, and 38 from harvested plots. Across all the samples the crustacean taxa of Amphipoda and Ostracoda and the Polychaete families Orbiniidae/Paraoniidae (grouped together for convenience within this study) were most abundant. Control plots were dominated by small crustaceans with a high abundance of Amphipoda, Apseudomorpha, and Ostracoda while harvested plots were also dominated by Amphipoda but the polychaete families of Orbiniidae/Paraonidae and Cirratulidae were the second and third most abundant taxa. When comparing treatments, the polychaetes Cirratulidae and Lumbrineridae/Oenonidae and the Leptocardii (lancelet) stand out in their higher abundance in harvested than control plots.

There was a larger average biomass of fauna in control [2.240 $( \pm 1.854(95 \% \mathrm{CI})) \mathrm{g} / \mathrm{m}^{2}$ dry weight] compared with harvested plots [0.684 ( $\pm 1.862(95 \% \mathrm{CI})) \mathrm{g} / \mathrm{m}^{2}$ dry weight]. Crustacea formed the heaviest taxon when biomass for both treatments was 
combined. The taxa with the largest contribution to biomass in control plots were Chordata, dominated by Scorpaenidae and Apogonidae, and Mollusca. Within harvested plots Crustacea formed the largest contribution in biomass, especially due to the biomass of Decapoda in harvested plots which surpassed the Decapoda biomass in control plots.

One month after the start of the experiment the abundance of infauna in harvested plots was only $\sim$ one quarter that of controls (Figure 8), suggesting a rapid loss of fauna that persisted to 13 months. Taxon richness was also reduced in the harvested plots, with mean $[ \pm$ standard error (SE)] taxon counts for control and harvested treatments of $36( \pm 2)$ and $28( \pm 3)$, and $47( \pm 2)$, and $28( \pm 1)$, respectively, for 1 and 13 months.

The collected taxa were grouped based on their body type [soft, rigid (exoskeleton), vertebrate, calcified (mollusc)], body size (1: $<1 \mathrm{~mm}, 2: 1-5 \mathrm{~mm}, 3:>5 \mathrm{~mm}$ ), diet (predator, deposit feeder/scavenger, suspension or filter feeder, grazer, mixed feeding methods) and interaction with the sediment (sediment surface (reside at the sediment surface or in the top few $\mathrm{cm}$ ), tube building, mobile (mobile between sediment layers), pelagic, attached to substrate or flora or commensal). Eight functional groups (FG) were created based on the distribution of fauna over these categories: (1) Large molluscs, (2) Small crustaceans, (3) Small polychaetes and other worms, (4) Large polychaetes at the sediment surface, (5) Large crustaceans at the sediment surface, (6) Large burrowing and tube dwelling polychaetes, (7) Pelagic fish, and (8) Large burrowing crustaceans (Supplementary Material).

As well as impacting total abundance and taxon richness, seagrass removal caused a large change in the proportional importance of different functional groups (FG). Large molluscs and small crustaceans and worms were particularly vulnerable to seagrass removal (1-3 in Figure 9). Simultaneously large burrowing and tube dwelling polychaetes, large burrowing crustaceans and pelagic fish were groups that increased in proportional importance in removal plots (6-8 in Figure 9), indicating a shift toward larger, bioturbating fauna as a result of seagrass disturbance.

Evidence of bioturbating activity at the surface of the plots, in the form of burrows and mounds, was monitored from day 156 to 397 of the experiment, following the results of cores and drop samples which suggested a potential difference in abundance of bioturbating fauna between treatments. There were clear and consistent differences, with higher numbers of mounds and burrows in the harvested treatment (Figure 10). Repeated measures ANOVA showed significant effects of treatment $\left[F_{(1,6)}\right.$ $=20,872, p=0.004]$ and time on the number of mounds, and a significant interaction $\left[F_{(8.48)}=4.452, p<0.001\right]$ between time and treatment for burrow counts, caused by the low count of burrows in the removal treatment at day 367 (Figure 10) following a storm event in the bay causing extensive resuspension of sediment.

\section{DISCUSSION}

We found significant differences in $\mathrm{C}_{\text {org }}$ in the surface sediment between harvested and control plots, although these differences did not extend to the full sediment profile. Hence our results lend support to those of Macreadie et al. (2015), in their comparisons of historical sites of disturbance, in suggesting carbon losses following seagrass removal. They do not concur with the experiments reported in Macreadie et al. (2014) and Dahl et al. (2016); in contrast to these studies, we found significant losses of $\mathrm{C}_{\text {org }}$ despite the relatively small temporal and spatial scales of our work.

These changes in $\mathrm{C}$ concentration and the vulnerability of sequestered $\mathrm{C}$ that they imply arise from a combination of physical and biological factors. Seagrass is very effective in damping waves, slowing currents and trapping sediment. As a result, seagrass contributes to coastal protection and to the healthy functioning of contiguous ecosystems, such as mangroves (Guannel et al., 2016) and acts synergistically with other blue carbon habitats to sequester more $\mathrm{C}$ together than any of these ecosystems are likely to trap on their own (Huxham et al., 2018). Over a period of 500 days, the sediment surface within intertidal seagrass plots (dominated by E. acoroides and T. hemprichii) at Gazi showed elevation rates of $25 \mathrm{~mm} \mathrm{yr}^{-1}$, compared with erosion of $34 \mathrm{~mm} \mathrm{yr}^{-1}$ in adjacent un-vegetated control plots (Potouroglou et al., 2017). The present results, this time using an experimental rather than survey approach, complement these findings in showing a similar ability of the intertidal seagrass to trap and stabilize sediment.

The significant differences in gypsum dissolution recorded at the sediment surface suggest that impacts on water movement are a causal mechanism for this enhanced sediment trapping. Many other studies have demonstrated that even low or sparse canopy seagrass beds are capable of attenuating wave energy (e.g., Christianen et al., 2013; Potouroglou et al., 2017), and here we show these effects can be significant, even at spatial scales of only $6 \mathrm{~m}^{2}$ in patches surrounded by lush seagrass. Hence the bottomup, physical effects of these foundation species on hydrodynamics partly explain the vulnerability of sediment $\mathrm{C}_{\text {org }}$ following seagrass removal. However, the large and rapid changes we show in faunal communities following seagrass removal suggest an important role for top-down biological processes as well.

The presence and density of fauna, especially large bioturbators, can be used as an indicator and predictor of the functional status of benthic environments (Eyre, 2011). Faunal impacts on $\mathrm{C}$ storage have been documented in many blue carbon habitats, including seagrass (Papaspyrou et al., 2004; Thomson, 2018). Herbivory can have direct impacts on cover and production through consumption, for example green turtles (Heithaus et al., 2014) and urchins (Rose et al., 1999) can remove most aboveground biomass. However, indirect effects may be at least as important, although they are harder to document. Bioturbators can have dramatic impacts on $\mathrm{C}$ storage and even on ecosystem persistence, especially when trophic control by predators is relaxed (Atwood et al., 2015). For example, salt marsh at Cape Cod, USA is retreating rapidly because of enhanced burrowing by the crab Sesarma reticulatum, which has been released from predator control by overfishing (Coverdale et al., 2014). Callianassid shrimp in Indonesia have burrows extending down to a meter below the surface and can cause sediment turnover of $3.4 \mathrm{~kg} \mathrm{~m}^{-2}$ day $^{-1}$. Their activities 


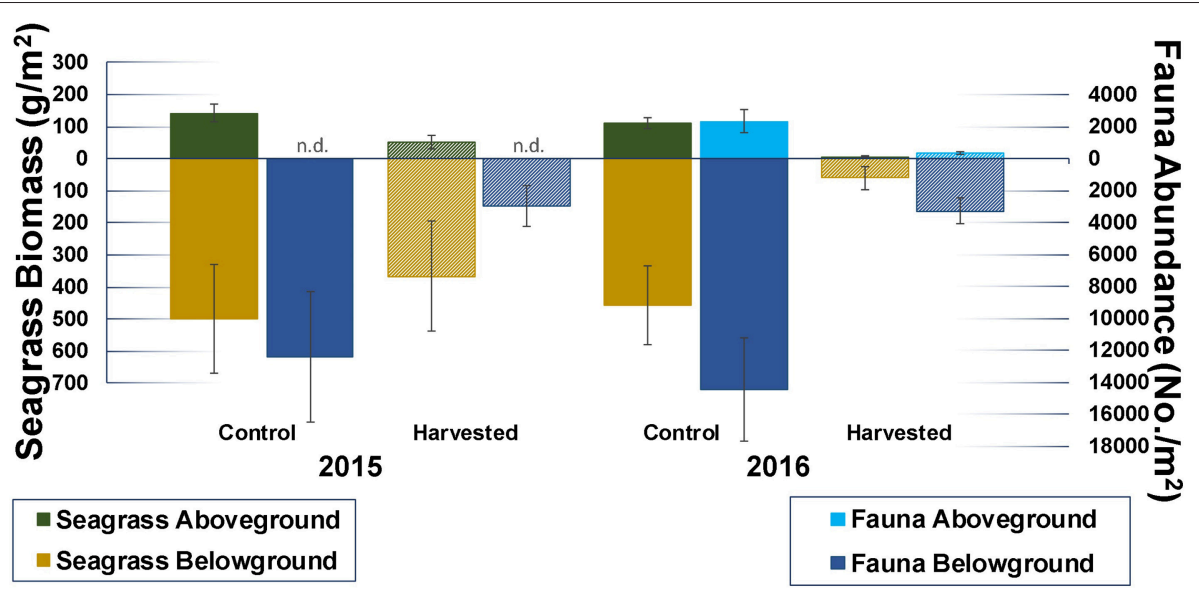

FIGURE 8 | Mean ( \pm SE) faunal abundance in control and harvested plots one and 13 months after the start of the experiment (2015 and 2016 , respectively). Aboveground fauna was sampled using drop samples (2016 only), belowground fauna and seagrass biomass were sampled using cores. Seagrass aboveground biomass contains shoots, belowground biomass roots and rhizomes. Harvested plots appear in a raster pattern.

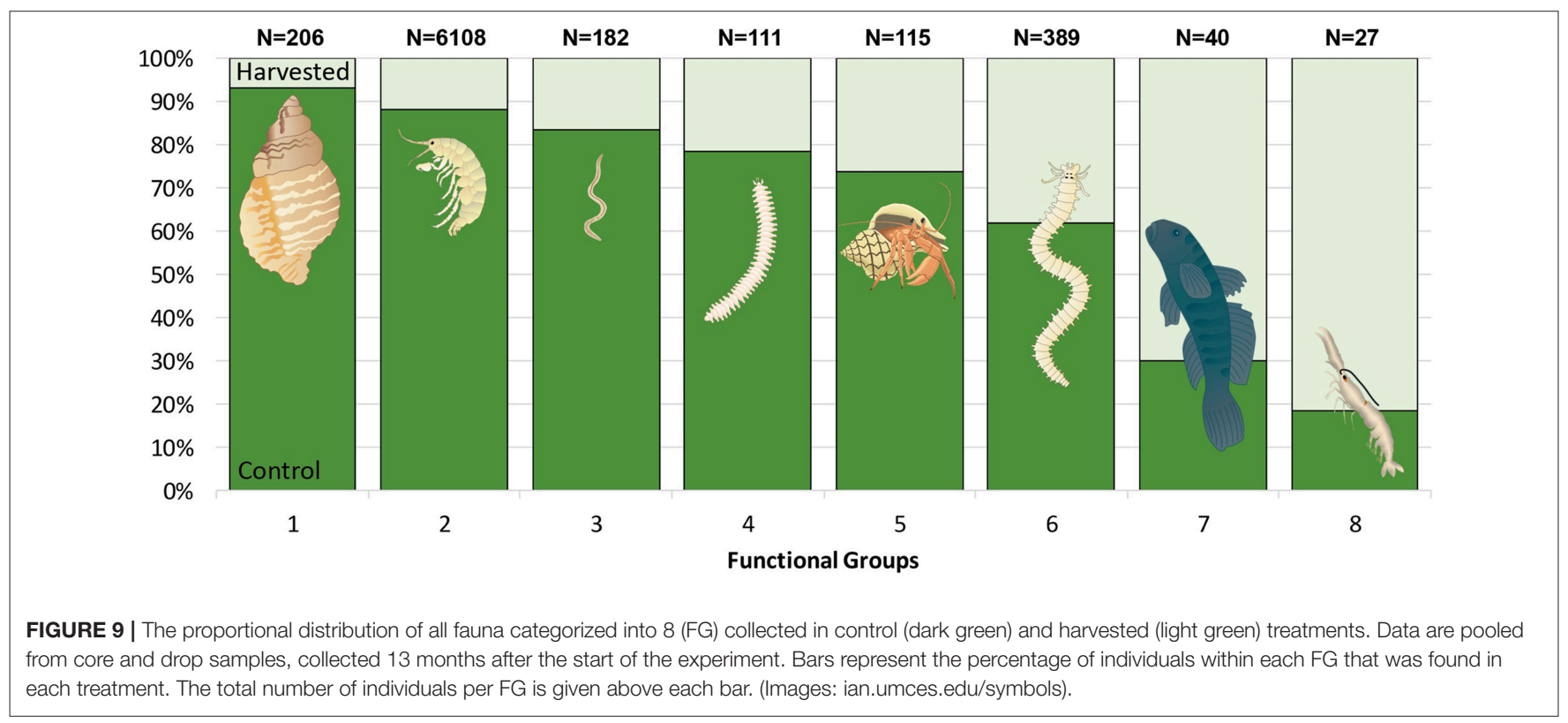

may determine the spatial extent of seagrass beds (Kneer et al., 2013). The seascape at our experimental site is characterized by a trough and hummock appearance, in which un-vegetated areas with shrimp mounds are found outside of shallow depressions full of seagrass. This distribution could originate from the small tidal pools remaining in the depressions during low tide, which can protect seagrass against desiccation (Curran and Martin, 2003; Kneer et al., 2013). The significantly enhanced number of mounds and burrows in removal plots suggests that shrimp were able to colonize when seagrass was removed, and their vigorous bioturbation would have contributed to the exposure, loss and oxidation of buried carbon. Although seagrass roots release oxygen during the day, this creates an oxic microzone around the rhizosphere of only several hundred micrometers in diameter in otherwise typically anoxic sediment (Sand-Jensen et al., 2005; Brodersen et al., 2015). In these anoxic conditions, bioturbation by callianassid shrimp can provide a substantial input of oxygen into the sediment, particularly through processes of bio-irrigation, which is predominantly used in biogeochemical processes and microbial respiration (Webb and Eyre, 2004). The remineralization processes promoted by callianassid burrowing activity can result in a 2 to 5 times increase in $\mathrm{CO}_{2}$ emission (Thomson, 2018). Whilst callianassid shrimp are the most obvious bioturbators, seagrass removal resulted in a general shift in community structure toward larger bodied, more active taxa; perhaps as the physical barriers of dense seagrass canopy and rhizomes were removed, facilitating predation, or as the sediment chemistry changed, permitting 

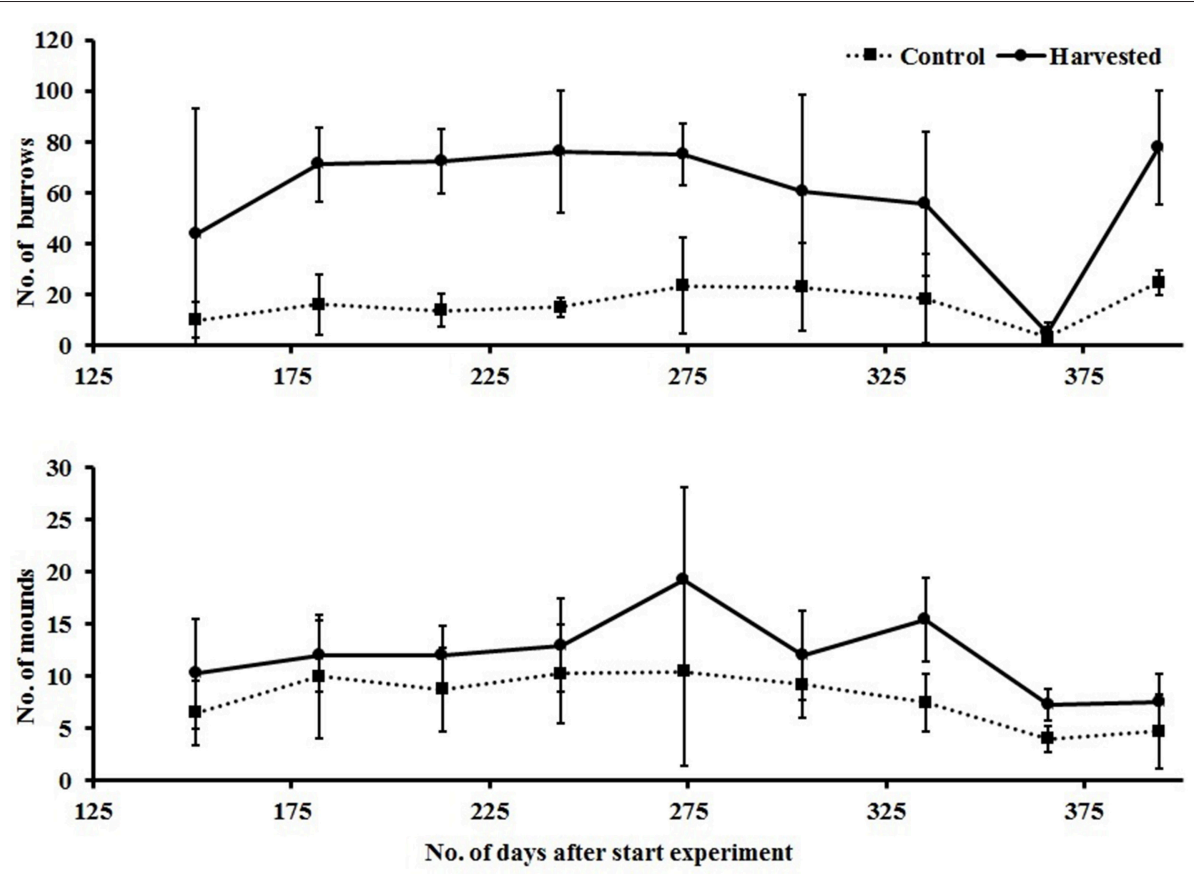

FIGURE 10 | Mean ( $\pm 95 \% \mathrm{Cl})$ counts of burrows (top) and mounds (bottom) visible in plots, recorded as evidence of bioturbation by large bodied epi and infauna.

higher sedimentary oxygen levels. Patches dominated by seagrass or by shrimp and other bioturbators may represent different stable states in the seascape mosaic here. Clear differences in the characteristics (including $\mathrm{C}$ density) of sediment taken from seagrass and bioturbator patches, which extend to $50 \mathrm{~cm}$ depth, suggest these small scale structures are surprisingly persistent (Githaiga et al., 2017b), and that there is mutual inhibition between seagrass and shrimp, hence relatively small-scale disturbances, such as those imposed experimentally here, may result in long-term shifts in community composition and biogeochemical state, driven by a switch in the dominance of functional groups.

Evidence for changes in sediment chemistry as a result of seagrass removal comes from the significantly enhanced rate of decomposition we found in the harvested plots, which was consistent down to $15 \mathrm{~cm}$ depth, below the level we detected changes in $\mathrm{C}_{\text {org }}$. Seagrass sediments are characterized by low levels of oxygen and slow rates of organic decomposition, a key feature contributing to their ability to sequester C. Seventy years after the date of disturbances in their study, Macreadie et al. (2015) found clearly distinct microbial communities in sediment where seagrass had been lost compared with intact control areas; the former was characterized by a higher abundance of aerobic heterotrophs, the latter by sulfate reducing and anaerobic bacteria. Although litter decomposition rates do not provide a direct measure of microbial densities, they can be used as an indirect measure of microbial activity. The rapid (first 60 days) emergence of differences in decay rates between seagrass and removal treatments here suggests that changes in microbial communities might be very fast, particularly when mediated as here by macrofaunal shifts.

We recorded a mean reduction in $\mathrm{C}_{\text {org }}$ density in the top $5 \mathrm{~cm}$ of sediment equivalent to a loss of $2.21 \mathrm{Mg} \mathrm{C} \mathrm{ha}^{-1}$ After 18 months there was also a mean difference in elevation of $3 \mathrm{~cm}$ between treatments. Because $\mathrm{C}_{\text {org }}$ density does not differ with depth in control plots [that is, there was no effect of depth on $\mathrm{C}_{\mathrm{org}}$ density down $50 \mathrm{~cm}$ cores taken here or in Githaiga et al. (2017a)], this difference does not arise from comparing surface sediment in controls with sediment that was previously buried in harvested plots. Measuring only surface $\mathrm{C}_{\text {org }}$ density underestimates the total impact of seagrass removal on $\mathrm{C}$ loss, since it does not include the aboveground biomass or the sediment that was lost from harvested plots. We do not know the fate of the $\mathrm{C}$ found in the sediment that was lost; it could simply move elsewhere, or it could be oxidized. This is true for most studies of coastal sediment carbon. Indeed, there is a lively debate about the multiple uncertainties involved in estimating $\mathrm{C}$ stocks and flows in seagrasses at local and global levels. If $\mathrm{C}$ (especially allochthonous C) trapped in seagrass sediment would be stored elsewhere, for example in coastal basin sediments, were it not intercepted by seagrass then estimates of total sequestration by seagrass beds are exaggerated (Johannessen and Macdonald, 2016). Taking the mean $C$ densities for our control plots as representative, another $2.54 \mathrm{Mg} \mathrm{C} \mathrm{ha}^{-1}$ could have been lost within the 18 months of this study if all the $\mathrm{C}$ contained in this eroded sediment was oxidized.

Seagrass is a globally threatened habitat. Across the Kenyan coast, total coverage of seagrass is declining at $1.59 \% \mathrm{yr}^{-1}$, and in Gazi losses are faster at $1.68 \% \mathrm{yr}^{-1}$; decline here 
is likely to be caused mostly by small-scale but persistent damage from fishing activities (Harcourt et al., 2018). There are many reasons for concern about these losses, since they may undermine the livelihoods of local fishers, enhance erosion and diminish the natural beauty of these coasts. In addition, as demonstrated here, seagrass removal may lead to the loss of stored $\mathrm{C}$ and future sequestration potential, and faunal changes can act to speed up this process and perhaps prevent or slow seagrass recovery.

\section{ETHICS STATEMENT}

Permit for this study was issued by the National Commission for Science, Technology \& Innovation (NACOSTI): Permit no NACOSTI/P/14/2443/769 on 17th February 2014. We took the necessary care ensuring minimum effects on the plant and animal life during the study.

\section{AUTHOR CONTRIBUTIONS}

MG conceived and developed the sampling design, collected analyzed the data, wrote the manuscript, prepared figures, tables, submitted the manuscript, and reviewed the manuscript. AF Conceived and designed the sampling work, was involved in data collection, data analysis, drawing of figures, writing and reviewing the draft manuscript before submission. JK Conceived and designed the sampling work, provided the technical support and reviewed the manuscript. $\mathrm{MH}$ Conceived and designed

\section{REFERENCES}

Atwood, T. B., Connolly, R. M., Ritchie, E. G., Lovelock, C. E., Heithaus, M. R., Hays, G. C., et al. (2015). Predators help protect carbon stocks in blue carbon ecosystems. Nat. Clim. Chang. 5, 1038-45. doi: 10.1038/nclimate2763

Berkenbusch, K., Rowden, A. A., and Myers, T. E. (2007). Interactions between seagrasses and burrowing ghost shrimps and their influence on infaunal assemblages. J. Exp. Mar. Bio. Ecol. 341, 70-84. doi: 10.1016/j.jembe.2006.10.026

Bouillon, S., Dehairs, F., and Velimirov, B. (2007). Dynamics of organic and inorganic carbon across contiguous mangrove and seagrass systems (Gazi Bay, Kenya). J. Geophy. Res. 112, 1-14. doi: 10.1029/2006JG000325

Bowden, D. A., Rowden, A. A., and Attrill, M. J. (2001). Effect of patch size and in-patch location on the infaunal macroinvertebrate assemblages of Zostera marina seagrass beds. J. Exp. Mar. Bio. Ecol. 259, 133-54. doi: 10.1016/S0022-0981(01)00236-2

Brodersen, K. E., Nielsen, D. A., Ralph, P. J., and Kühl, M. (2015). Oxic microshield and local $\mathrm{pH}$ enhancement protects Zostera muelleri from sediment derived hydrogen sulphide. New Phytol. 205, 1264-76. doi: 10.1111/nph. 13124

Campbell, A. (2007). Seashores and Shallow Seas of Britain and Europe. London: Bounty Books.

Christianen, M. J., van Belzen, J., Herman, P. M., van Katwijk, M. M., Lamers, L. P., van Leent, P. J., et al. (2013). Low-canopy seagrass beds still provide important coastal protection services. PLOS ONE 8:e62413. doi: 10.1371/journal.pone.0062413

Coppejans, E. H., Beeckman, H., and De Witt, M. (1992). The seagrass and associated macroalgae vegetation of Gazi Bay (Kenya). Hydrobiologia 247, 59-75. doi: 10.1007/BF00008205

Coverdale, T. C., Brisson, C. P., Young, E. W., Yin, S. F., Donnelly, J. P., and Bertness, M. D. (2014). Indirect human impacts reverse centuries the sampling work, was involved in data analysis, led on raising and administering the funds, was involved in writing, provided the guidance and reviewed the draft manuscript before submission.

\section{ACKNOWLEDGMENTS}

This article is based on work that was part of the Coastal Ecosystem Services in East Africa (CESEA) NE/L001535/1 research project and was funded with support from the Ecosystem Services for Poverty Alleviation (ESPA) programme. The ESPA programme is funded by the Department for International Development (DFID), the Economic and Social Research Council (ESRC) and the Natural Environment Research Council (NERC) through collaboration by Edinburgh Napier University, Kenya Marine and Fisheries Research Institute and the University of Embu. Additional support, particularly for Ankje Frouws (AF), came from the British Council Newton Fund, grant no. 275670159. We would like to thank the KMFRI, Gazi station team: Laitani Suleiman, Tom Peter Kisiengo and Derrick Omollo for their assistance both in the field and in the laboratory, and Donna Ridland for assistance with taxonomy.

\section{SUPPLEMENTARY MATERIAL}

The Supplementary Material for this article can be found online at: https://www.frontiersin.org/articles/10.3389/fevo. 2019.00062/full\#supplementary-material

of carbon sequestration and salt marsh accretion. PLoS ONE 9:e93296. doi: 10.1371/journal.pone.0093296

Curran, H. A., and Martin, A. J. (2003). Complex decapod burrows and ecological relationships in modern and Pleistocene intertidal carbonate environments, San Salvador Island, Bahamas. Palaeogeogr. Palaeoclimatol. Palaeoecol. 192, 229-245. doi: 10.1016/S0031-0182(02)00687-9

Dahl, M., Deyanova, D., Lyimo, L. D., Näslund, J., Samuelsson, G. S., Mtolera, M. S. P., et al. (2016). Effects of shading and simulated grazing on carbon sequestration in a tropical seagrass meadow. J. Ecol. 104, 654-664. doi: $10.1111 / 1365-2745.12564$

Day, J. H. (1967). A monograph of the polychaeta of Southern Africa. J. Mar. Bio. 48:836. doi: 10.1017/S0025315400019299

Duarte, C. M., Middelburg, J. J., and Caraco, N. (2005). Major role of marine vegetation on the oceanic carbon cycle. Biogeosciences 2, 1-8. doi: 10.5194/bg-2-1-2005

Eyre, B. D and Maher, D. (2011). Mapping ecosystem processes and function across shallow seascapes. Cont. Shelf. Res. 31, 162-72. doi: 10.1016/j.csr.2010.01.013

Githaiga, M. N., Kairo, J. G., Gilpin, L., and Huxham, M. (2017a). The Role of Seagrass Meadows in Gazi Bay, Kenya as Carbon Sinks. Ph.D thesis, Edinburgh Napier University, Edinburgh.

Githaiga, M. N., Kairo, J. G., Gilpin, L., and Huxham, M. (2017b). Carbon storage in the seagrass meadows of Gazi Bay, Kenya. PLoS ONE 12:e0177001. doi: 10.1371/journal.pone.0177001

Green, E. P., and Short, F. T. (2003). World Atlas of Seagrasses. Berkeley, CA: University of California Press.

Guannel, G., Arkema, K., Ruggiero, P., and Verutes, G. (2016). The power of three: coral reefs, seagrasses and mangroves protect coastal regions and increase their resilience. PLoS ONE 11:e0158094. doi: 10.1371/journal.pone.0158094

Harcourt, W., Briers, R., and Huxham, M. (2018). The thin(ning) green line? Investigating changes in Kenya's seagrass coverage. Biol. Lett. 14, doi: $10.1098 /$ rsbl.2018.0227 
Hayward, P. J., and Ryland, J. S. (eds.). (2000). Handbook of the Marine Fauna of North-West Europe. New York, NY: Oxford University Press.

Heithaus, M. R., Alcoverro, T., Arthur, R., Burkholder, D. A., Coates, K. A., Christianen, M. J. A., et al. (2014). Seagrasses in the age of sea turtle conservation and shark overfishing. Front Mar Sci. 1:28. doi: 10.3389/fmars.2014.00028

Herkül, K., and Kotta, J. (2009). Effects of eelgrass (Zostera marina) canopy removal and sediment addition on sediment characteristics and benthic communities in the Northern Baltic Sea. Mar Ecol 30, 74-82. doi: 10.1111/j.1439-0485.2009.00307.x

Howard, J., Hoyt, S., Isensee, K., Telszewski, M., and Pidgeon, E. (2014). "Coastal Blue Carbon:Methods for assessing carbon stocks and emmission factors in mangroves, tidal salt marshes and seagrasses," in Conservation International (Arlington, VA: Conservation International, Intergovernmental Oceanographic Commission of UNESCO, International Union for Conservation of Nature).

Huxham, M., Whitlock, D., Githaiga, M., and Dencer-Brown, A. (2018). Carbon in the coastal seascape : how interactions between mangrove forests, seagrass meadows and tidal marshes influence carbon storage. Curr. For. Rep. 4, 101-110. doi: 10.1007/s40725-018-0077-4

IPCC (2013). Supplement to the 2006 IPCC Guidelines for National Greenhouse Gas Inventories: Wetlands. eds T. Hiraishi, T. Krug, K. Tanabe, N. Srivastava, J. Baasansuren, M. Fukuda, and T. G. Troxler (IPCC).

Johannessen, S. C., and Macdonald, R. W. (2016). Geoengineering with seagrasses: is credit due where credit is given? Environ. Res. Lett. 11. doi: $10.1088 / 1748-9326 / 11 / 11 / 113001$

Jokiell, P. L., and Janice, I. (1993). Water motion on coral reefs : evaluation of the' clod card' technique. Mar. Ecol. Prog. Ser. 93, 175-81.

Kneer, D., Asmus, H., and Jompa, J. (2013). Journal of experimental marine biology and ecology do burrowing callianassid shrimp control the lower boundary of tropical seagrass beds? J. Exp. Mar. Bio. Ecol. 446, 262-72. doi: 10.1016/j.jembe.2013.05.023

Macreadie, P. I., Trevathan-Tackett, S. M., Skilbeck, C. G., Sanderman, J., Curlevski, N., Jacobsen, G., et al. (2015). Losses and recovery of organic carbon from a seagrass ecosystem following disturbance. Proc. Biol. Sci. 282. doi: 10.1098/rspb.2015.1537

Macreadie, P. I., York, P. H., Sherman, C. D. H., Keough, M. J., Ross, D. J., Ricart, A, M., et al. (2014). No detectable impact of small-scale disturbances on 'blue carbon' within seagrass beds. Mar. Biol. 161, 2939-2944. doi: 10.1007/s00227-014-2558-8

Mcleod, E., Chmura, G. L., Bouillon, S., Salm, R., Björk, M., Duarte, C. M., et al. (2011). A blueprint for blue carbon: toward an improved understanding of the role of vegetated coastal habitats in sequestering $\mathrm{CO}_{2}$. Front. Ecol. Environ. 9, 552-560. doi: 10.1890/110004

Ngoc-Ho, N. (2003). European and Mediterranean thalassinidea (Crustacea, decapoda). Zoosystema 25, 439-555.

Odido, M., Appeltans, W., BelHassen, M., Mussai, P., Nsiangango, S. E., Vandepitte, L., et al. (2015). African Register of Marine Species Muraenesocidae Kaup, 1859. Available online at: http://www.marinespecies.org/afremas\%20/ aphia.php? $\mathrm{p}=$ taxdetails\&id $=125430$

Orth, R. J., Carruthers, T. J. B., Dennison, W. C., Duarte, C. M., Fourqurean, J. W., Heck, K. L. Jr., et al. (2006). A global crisis for seagrass ecosystems. Bioscience 56, 987-997. doi: 10.1641/0006-3568(2006)56[987:AGCFSE]2.0.CO;2
Papaspyrou, S., Thessalou-Legaki, M., and Kristensen, E. (2004). Impact of Pestarella tyrrhena on benthic metabolism in sediment microcosms enriched with seagrass and macroalgal detritus. Mar. Ecol. Prog. Ser. 281, 165-79. doi: $10.3354 /$ meps 281165

Pendleton, L., Donato, D. C., Murray, B. C., Crooks, S., Jenkins, W. A., Sifleet, S., et al. (2012). Estimating global "blue carbon" emissions from conversion and degradation of vegetated coastal ecosystems. PLOS ONE 7:e43542. doi: 10.1371/journal.pone.0043542

Potouroglou, M., Bull, J. C., Krauss, K. W., Kennedy, H. A., Fusi, M., Daffonchio, D., et al. (2017). Measuring the role of seagrasses in regulating sediment surface elevation. Sci. Rep. 7:11917. doi: 10.1038/s41598-017-12354-y

Rose, C., Sharp, W C., Kenworth, W. J., Hunt, J. H., Lyons, W., Prager, E. J., et al. (1999). Overgrazing of a large seagrass bed by the sea urchin Lytechinus variegatus in Outer Florida Bay. Mar. Ecol. Prog. Ser. 190, 211-22. doi: 10.3354/meps190211

Sand-Jensen, K., Pedersen, O., Binzer, T., and Borum, J. (2005). Contrasting oxygen dynamics in the freshwater isoetid Lobelia dortmanna and the marine seagrass Zostera marina. Ann. Bot. 96, 613-623. doi: 10.1093/aob/mci214

Short, F. T., and Wyllie-Echeverria, S. (1996). Natural and humaninduced disturbance of seagrasses. Environ. Conserv. 23, 17-27. doi: $10.1017 /$ S0376892900038212

Sida and WIOMSA. (2011). A Field Guide to the Seashores of Eastern Africa and the Western Indian Ocean Islands, ed M. D Richmond (Norwich: Sida), 155.

Smith, M. M., and Heemstra, P. C. (1999). Smith's Sea Fishes. Southern Africa: Southern Book Publishers.

Thomson, A. C. G. (2018). Bioturbator-stimulated loss of seagrass sediment carbon stocks. Limnol. Oceanogr. 64, 1-15. doi: 10.1002/lno.11044

Troch, M. D., Gurdebeke, S., Fiers, F., and Vincx, M. (2001). Zonation and structuring factors of meiofauna communities in a tropical seagrass bed (Gazi Bay, Kenya). J. Sea Res. 45, 45-61. doi: 10.1016/S1385-1101(00) 00055-1

Waycott, M., Duarte, C. M., Carruthers, T., Orth, R. J., Dennison, W. C., Olyarnik, S., et al. (2009). Accelerating loss of seagrasses across the globe threatens coastal ecosystems. Proc. Natl. Acad. Sci. USA. 106, 12377-12381. doi: 10.1073/pnas.0905620106

Webb, A. P., and Eyre, B. D. (2004). Effect of natural populations of burrowing thalassinidean shrimp on sediment irrigation, benthic metabolism, nutrient fluxes and denitrification. Mar. Ecol. Prog. Ser. 268, 205-220. doi: $10.3354 /$ meps 268205

WoRMS Editorial Board (2015). World Register of Marine Species. Available online at: http://www.marinespecies.org at VLIZ.

Conflict of Interest Statement: The authors declare that the research was conducted in the absence of any commercial or financial relationships that could be construed as a potential conflict of interest.

Copyright $\odot 2019$ Githaiga, Frouws, Kairo and Huxham. This is an open-access article distributed under the terms of the Creative Commons Attribution License (CC $B Y)$. The use, distribution or reproduction in other forums is permitted, provided the original author(s) and the copyright owner(s) are credited and that the original publication in this journal is cited, in accordance with accepted academic practice. No use, distribution or reproduction is permitted which does not comply with these terms. 


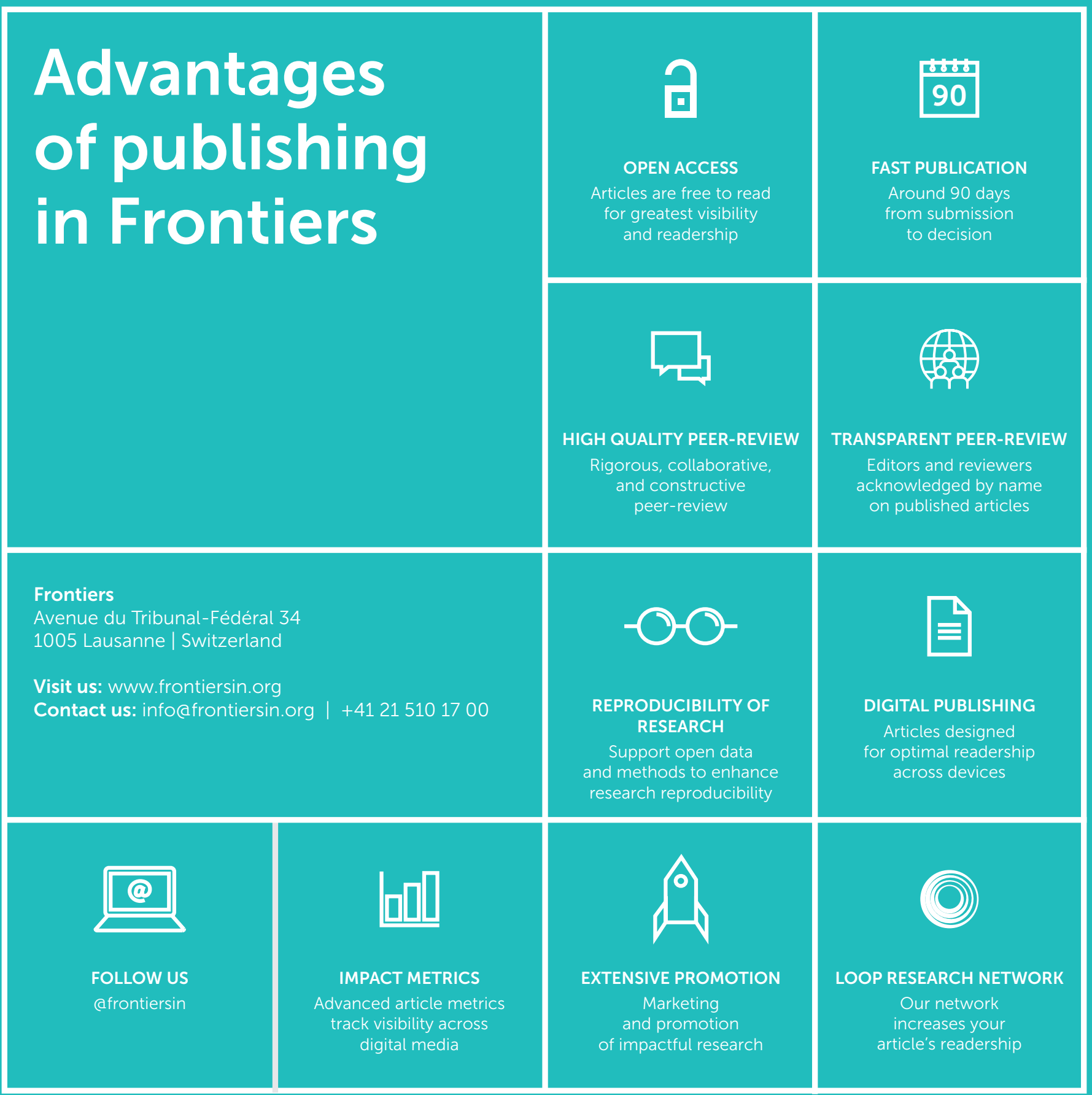

